\title{
Mental capital : the economic significance of mental health
}

Citation for published version (APA):

Weehuizen, R. M. (2008). Mental capital : the economic significance of mental health. [Doctoral Thesis, Maastricht University]. Datawyse / Universitaire Pers Maastricht. https://doi.org/10.26481/dis.20080627rw

Document status and date:

Published: 01/01/2008

DOI:

10.26481/dis.20080627rw

Document Version:

Publisher's PDF, also known as Version of record

\section{Please check the document version of this publication:}

- A submitted manuscript is the version of the article upon submission and before peer-review. There can be important differences between the submitted version and the official published version of record.

People interested in the research are advised to contact the author for the final version of the publication, or visit the DOI to the publisher's website.

- The final author version and the galley proof are versions of the publication after peer review.

- The final published version features the final layout of the paper including the volume, issue and page numbers.

Link to publication

\footnotetext{
General rights rights.

- You may freely distribute the URL identifying the publication in the public portal. please follow below link for the End User Agreement:

www.umlib.nl/taverne-license

Take down policy

If you believe that this document breaches copyright please contact us at:

repository@maastrichtuniversity.nl

providing details and we will investigate your claim.
}

Copyright and moral rights for the publications made accessible in the public portal are retained by the authors and/or other copyright owners and it is a condition of accessing publications that users recognise and abide by the legal requirements associated with these

- Users may download and print one copy of any publication from the public portal for the purpose of private study or research.

- You may not further distribute the material or use it for any profit-making activity or commercial gain

If the publication is distributed under the terms of Article $25 \mathrm{fa}$ of the Dutch Copyright Act, indicated by the "Taverne" license above, 


\section{Mental Capital The economic significance of mental health}


(C) 2008 Rifka Weehuizen

All rights reserved.

Published by Universitaire Pers Maastricht ISBN 9789052787343

Printed in the Netherlands by Datawyse Maastricht 


\title{
Mental Capital The economic significance of mental health
}

\author{
PROEFSCHRIFT \\ ter verkriiging van de graad van doctor \\ aan de Universiteit Maastricht, \\ op gezag van de Rector Magnificus, Prof. mr. G.P.M.F. Mols, \\ volgens het besluit van het College van Decanen \\ in het openbaar te verdedigen op vrijdag 27 juni 2008 om 12.00 uur \\ door
}

Rifka Maria Weehuizen

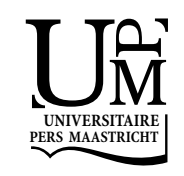




\section{Promotor}

Prof. dr. L. Soete

\section{Beoordelingscommissie}

Prof. dr. L. Borghans (voorzitter)

Prof. dr. C. de Neubourg

Prof. dr. N. De Vries 
"The density of settlement of economists over the whole empires of economic science is very uneven, with a few areas of modest size holding the bulk of the population. [...] The [Economic] Heartland is more overpopulated than ever, while rich lands in other parts of the empire go untilled."

Jobn Maynard Keynes (1936), The General Theory, Preface.

"The less then we trouble ourselves with scholastic inquiries as to whether a certain consideration comes within the scope of economics, the better. If the matter is important let us take account of it as far as we can."

Alfred Marshall (1890) Principles of Economics, Bk.I,Ch.II, par.35. 



\section{Contents}

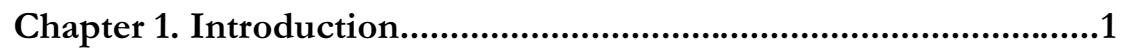

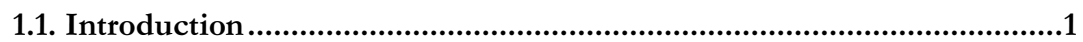

1.1.1. The Donner report........................................................................................

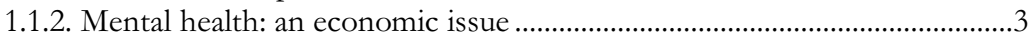

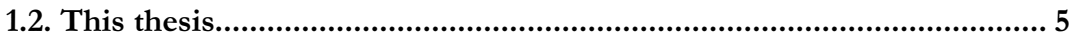

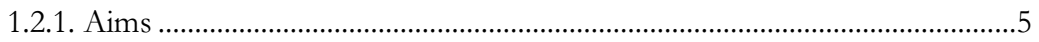

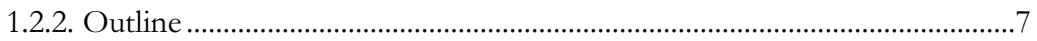

Chapter 2. The changed nature of work............................................ 9

2.1. Introduction................................................................................. 9

2.2. The changing labour market ..........................................................11

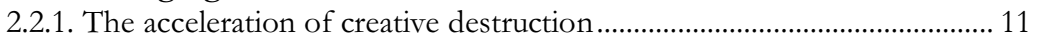

2.2.2. Increased job insecurity, turnover and unemployment .............................. 13

2.2.3. The psychological costs of unemployment................................................ 17

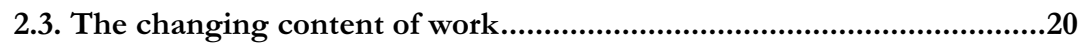

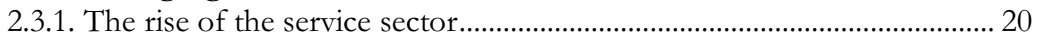

2.3.2. The increase of non-routine work .......................................................... 23

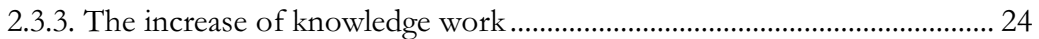

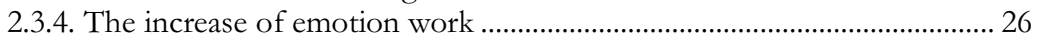

2.4. The changing organisation of work..................................................29

2.4.1. Organizational change ................................................................................. 29

2.4.2. Flexibilisation and 'psychological transaction costs' .................................... 30

2.4.3. The changing management of work ........................................................... 34

2.4.4. The changing psychological contract .......................................................... 40

2.4.5. Institutionalized change................................................................................... 41

2.5. The intensification of work and non-work ............................................46

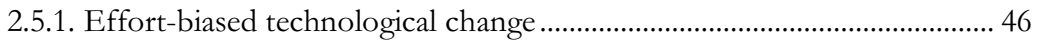

2.5.2. The intensification of work.......................................................................... 47

2.5.3. The intensification of consumption............................................................ 52

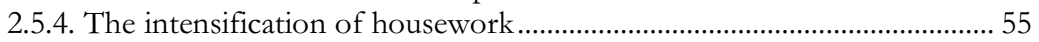

2.5.5. Polarisation of effort levels .................................................................... 58

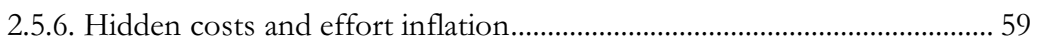

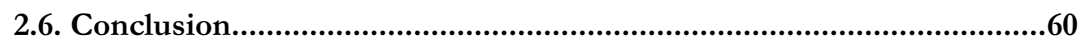

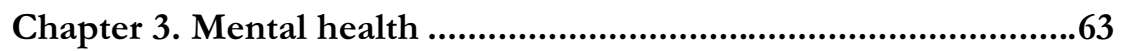

3.1. Introduction................................................................................63

3.2. Mental health: definitions and considerations ..................................64

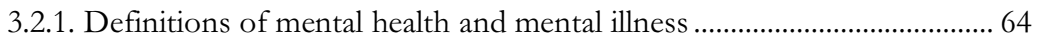

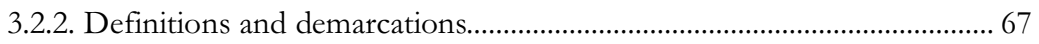

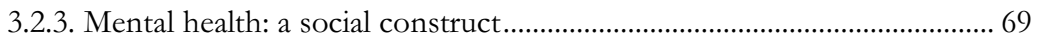

3.2.4. Interpreting the figures on mental health ..................................................... 72

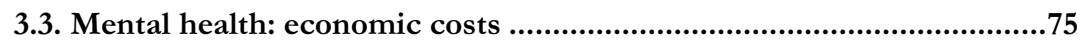

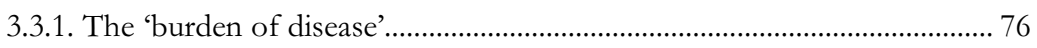

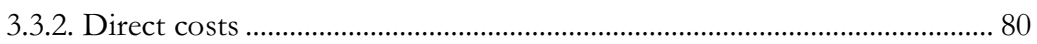

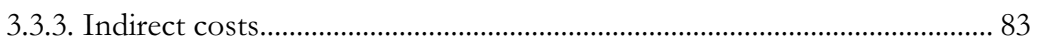




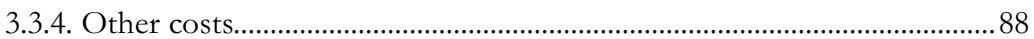

3.3.5. Costs of work-related stress ............................................................... 91

3.3.6. Increasing (costs of) mental health problems? ........................................... 95

3.3.7. Assessing the evidence .................................................................................. 99

3.4. Mental health: its role in production.................................................102

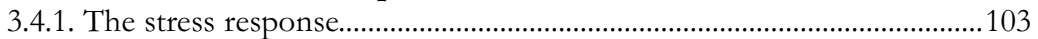

3.4.2. Mental health as output: the production of stress .....................................104

3.4.3. Mental health as input: stress and production............................................108

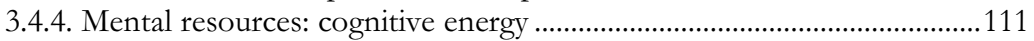

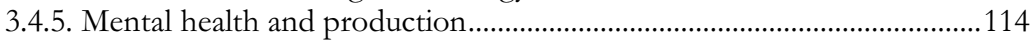

3.5. The productive aspect of mental health: agency ................................117

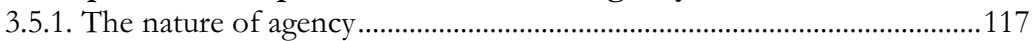

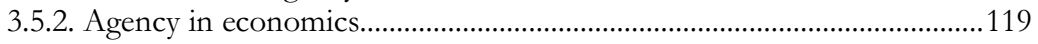

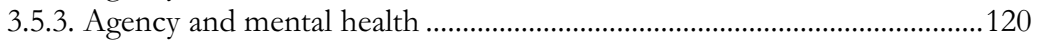

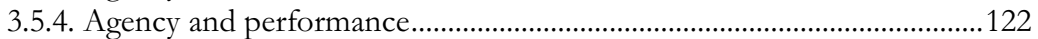

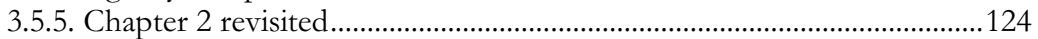

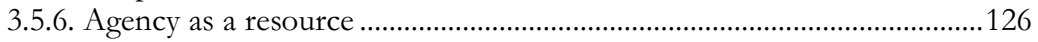

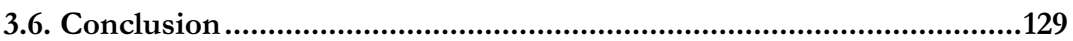

Chapter 4. Mental Capital ............................................................131

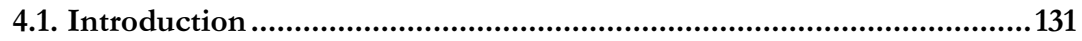

4.2. Mental capital? ..........................................................................132

4.2.1. Mental capital as a durable produced means of production......................132

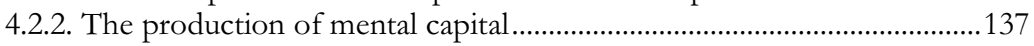

4.2.3. Investment in and returns of mental capital............................................. 140

4.3. The use of the capital concept ..........................................................144

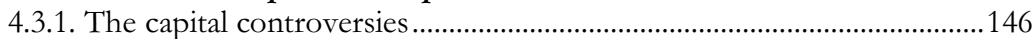

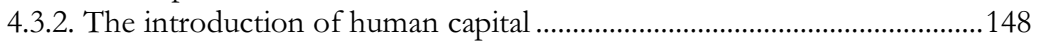

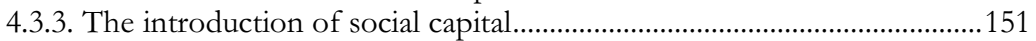

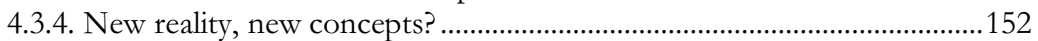

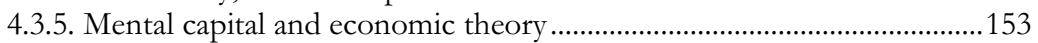

4.4. Mental capital and economic growth theory.....................................154

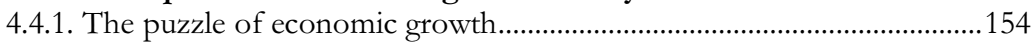

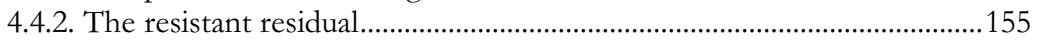

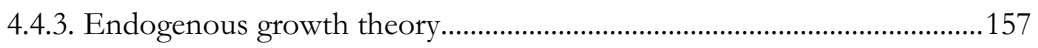

4.5. Mental capital and human capital theory...........................................158

4.5.1. The narrowing of the human capital concept...............................................159

4.5.2. Mental capital and human capital formation ............................................... 161

4.5.3. Mental capital and human capital use ......................................................... 162

4.5.4. Some new explanations of old phenomena using mental capital............164

4.6. Mental capital and bounded rationality ............................................167

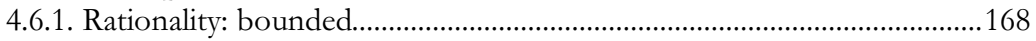

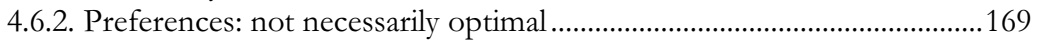

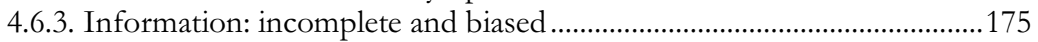

4.6.4. Calculation: satisficing rather than maximizing........................................177

4.6.5. Decision and execution: weakness of will .................................................... 181

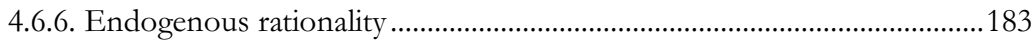

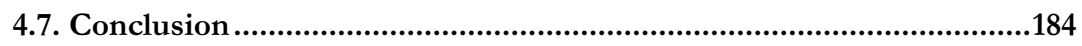


Chapter 5. A model of mental capital and technological change 187

5.1.Introduction........................................................................................... 187

5.2. Variables and relationships................................................................. 187

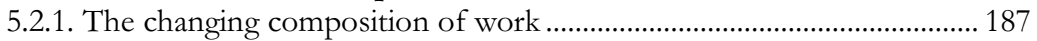

5.2.2. The intensification of work and mental effort.......................................... 189

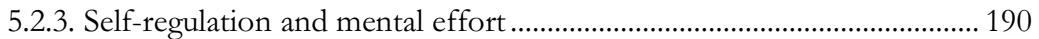

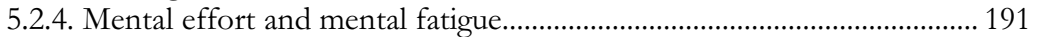

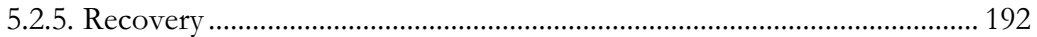

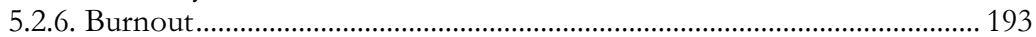

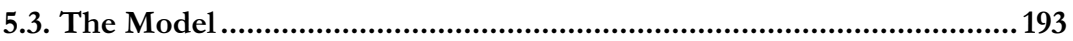

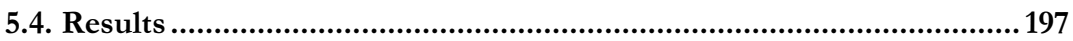

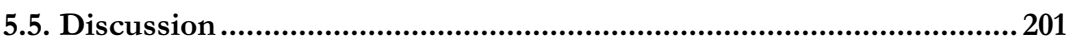

5.5.1. The rate of technological substitution.......................................................... 201

5.5.2. Decision latitude of the worker................................................................... 202

5.5.3. Mental capital............................................................................................ 203

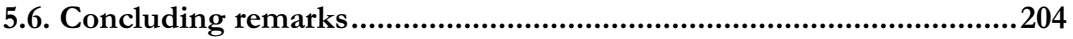

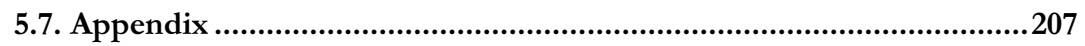

Chapter 6. A model of mental capital spillovers..........................209

6.1. Introduction..........................................................................................209

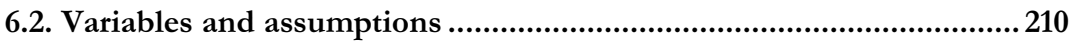

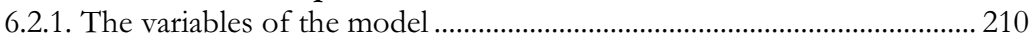

6.2.2. Innovation, flow of stress and level of stress............................................ 211

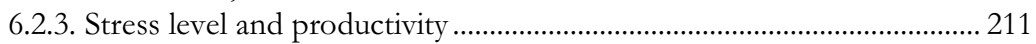

6.2.4. Stress level and coping............................................................................... 212

6.2.5. Stress level, spillover and responsiveness ................................................. 212

6.2.6. Stress level, buffering and responsiveness................................................ 220

6.2.7. Overview: streamlining the variety of effects and pathways.................... 221

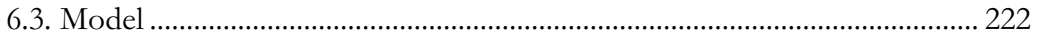

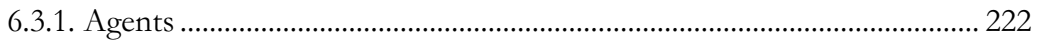

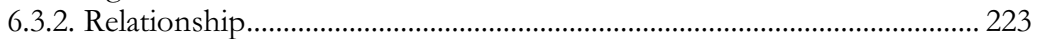

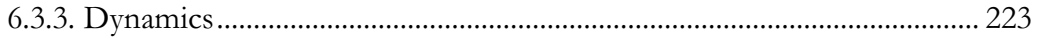

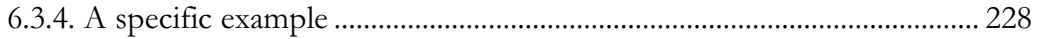

6.3.5. Implications for productivity and economic growth ............................... 230

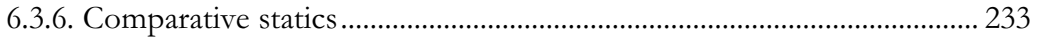

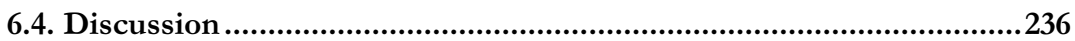

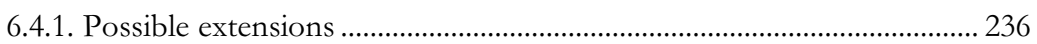

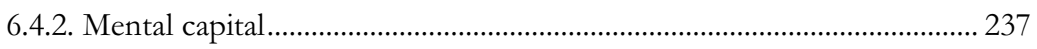

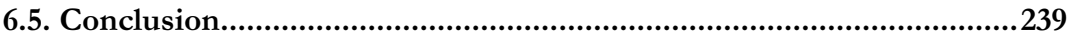

Chapter 7. Conclusion..................................................................... 241

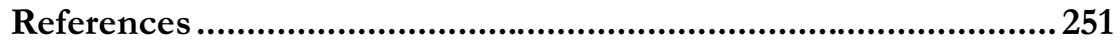

Nederlandse samenvatting .........................................................293

Acknowledgements.......................................................................295

About the Author ......................................................................297 



\section{List of Figures}

1.1. Suicide rates and labour productivity over time in Ireland. ............................................. 5

2.1. Health effects of job insecurity and unemployment, UK 1994. ................................... 16

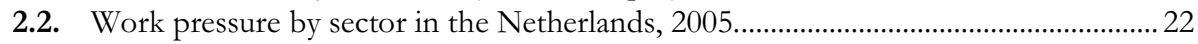

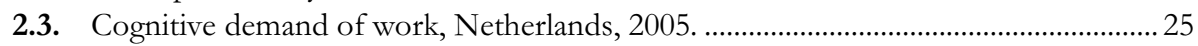

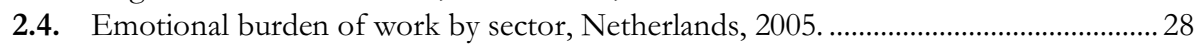

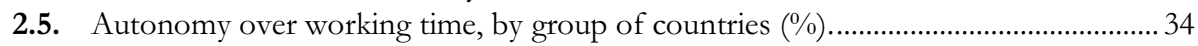

2.6. Percentage of workers in EU indicating having to working at very high speed.......... 48

2.7. Percentage of workers in EU indicating having to work to tight deadlines.................. 49

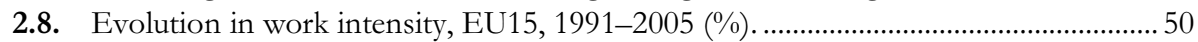

2.9. GDP as percent of EU average, and life satisfaction: Ireland, 1980-2003................... 54

2.10. Hours spent caring for children and adults per week, by country group and

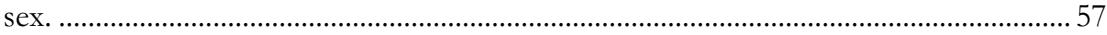

2.11. Hours spent on housework per week, by country group and sex.................................. 58

3.1. Continuum of depressive symptoms in the population................................................... 68

3.2. The relative influence of biological and environmental determinants of mental health problems.

3.3. Different types of deviation and their relations to mental illness................................... 71

3.4. Burden of diseases world-wide, measured in disability life adjusted years ................... 77

3.5. Proportion of incapacitated per illness, the Netherlands, 2001. ........................................ 78

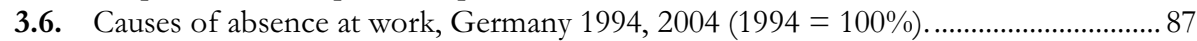

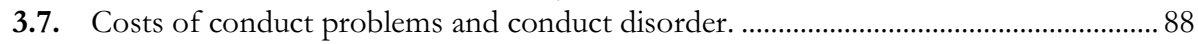

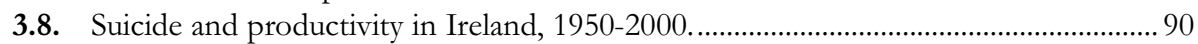

3.9. Health effects of work on the labour force (EU-15), 1995 and 2000. ......................... 92

3.10. The correlation between job stress of persons and health care costs of these persons, in a period of five years...................................................................................... 94

3.11. Annual prevalence of anxiety disorders in primacy care in the Netherlands in

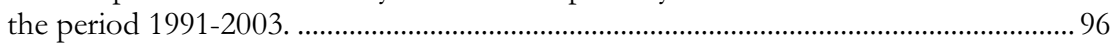

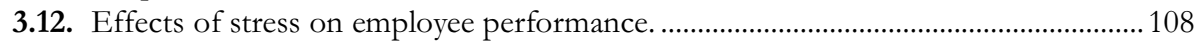

3.13. Yerkes-Dodson relationship between stress and performance..................................... 110

3.14. Schematic representation of the effects of stress and mental health on

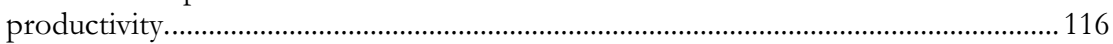

4.1. Effects of Depression on Experienced Utility............................................................. 181

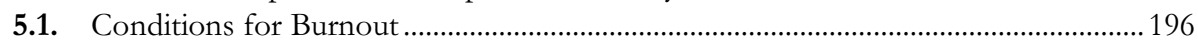

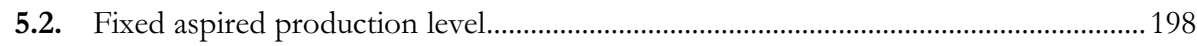

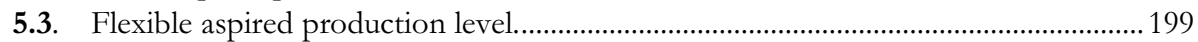

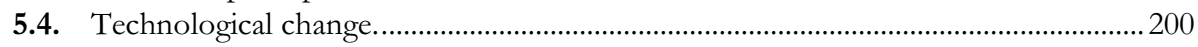

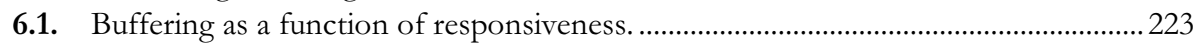

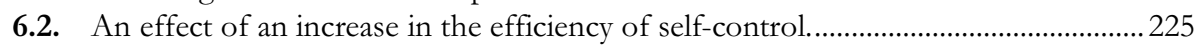

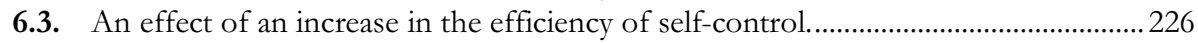

6.4. Dyadic buffering as a function of the relationship intensity........................................22

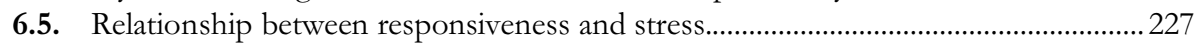

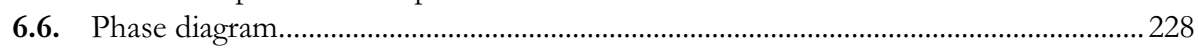

6.7. Effect of external stress in the presence of a social relationship.................................229

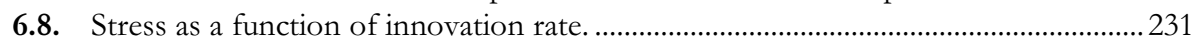

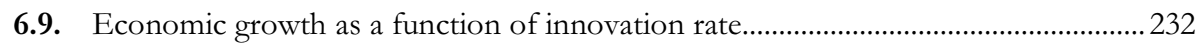





\section{Chapter 1. Introduction}

\subsection{Introduction ${ }^{1}$}

In today's innovation-driven, knowledge-intensive economy, people increasingly work with their heads rather than with their hands. In the past, physical health was crucial for performance at the job; today, it is mental health. Consequently, the mental health of the labour force has become an important economic factor, more than in the past. At the same time though, exactly the mental health of the labour force seems to be under increasing pressure in today's economy. Alarming reports abound about increasing work-related stress, burnout, depression and mental health problems, and the enormous costs associated with them, in terms of reduced productivity, increased absenteeism and work disability, reduced human capital investment, and increased health care costs. So while mental health has become more important to the economy, is also under more pressure from the economy - to some extent two sides of the same coin. Mental health is becoming more valuable and more scarce - qualities that are at the core of what economics is about.

However, in spite of the obvious, growing economic importance of mental health, economic science has not found a real place for this factor in its theory and analyses. Though there is ample knowledge about the effects of economic developments (such as the emergence of the service economy, the changed nature of work, increased flexibilization and innovation) on mental health, and vice versa, of the effects of (lack of) mental health on central economic concerns such as productivity, innovation and growth, this knowledge is only very partially exploited by economists. This is not only intellectually a bit disappointing but also socially slightly alarming, because the evidence suggests that some of the notions put forward by economists may be a factor in creating an economy which affects negatively affects the mental health of its agents. For example, economists tend to argue for a more flexible labour market to increase the mobility of labour; this tends to lead to job insecurity, and psychological research shows this leads to less commitment, less mutual investment, and less trust between employer and employee, which has a negative effect on productivity. Or, economists tend to argue for more innovation, the engine of economic growth; but psychological research shows that high rates of change tend to be stressful too employees and this tends to negatively affect productivity, which may cancel out the positive productivity effects of innovation, at least to some extent.

Mental health is much more than just a form of health. In its most basic sense, it is a condition for the validity of what may be the central assumption of economics: rationality. Mental health by definition affects the ability of economic actors to be rational.

\footnotetext{
1 Parts of this thesis have been published in earlier versions. Chapter 1 is partly based on the research in Weehuizen (2003), a position paper for the Dutch Ministry of Economic Affairs, which was published in the strategic series of the Ministry. Chapters 2 and 3 are to some extent based on two chapters of Weehuizen (2006), a report for the Dutch Consultative Committee of Sector Councils for research (COS) and its member council, the Advisory Council for Health Research (RGO). The model of chapter 5 is based on the model in Straathof and Weehuizen (2005). The analysis presented in chapter 4 and the model developed in chapter 6 have not been published in any earlier form.
} 
Consequently, an increase in mental health problems further removes economic reality from the economic ideal: a state of optimal utility for all. There may thus be a special responsibility of economists to make sure that economics helps to protect mental health rather than damage it. This thesis hopes to help addressing this challenge, by providing more insight on the economic significance of mental health. Presenting and integrating knowledge from a large variety of disciplinary sources, it proposes to see mental health as a form of capital. While aware of the vulnerability of such a proposal, the thesis finds the capital concept useful for capturing a range of economically relevant characteristics of mental health.

\subsubsection{The Donner report}

The idea for this thesis was born out of a few intriguing sentences in an important Dutch policy report in 2001. Just like many other countries in Europe, the Netherlands suffered of a stubborn 'epidemic' of work disability due to mental health problems. ${ }^{2}$ This particular type of work disability had become so prevalent in the Netherlands in the nineties (accounting for more than one third of all work disability), that it was considered one of the main policy challenges of the time. Many studies were done to investigate the causes of the problem, and most concluded that the main cause was institutional; the Dutch law for work disability (the "WAO") had created incentives which were at best ineffective, and at worst counterproductive. The work disability arrangement effectively functioned as an 'institutional trap': it was easy to get in, and very hard to get out.

To some extent the "WAO" (the Dutch law on work disability) was consciously used by firms as a convenient way to reorganise their organisations and get rid of their least productive employees. Instead of firing employees who did not fit after a re-organisation, or who were unproductive for some reason, they could be categorised as work-disabled. Neither workers nor unions protested very hard against this practice, since work disability benefits were higher and more attractive than unemployment benefits. Often there were psychological problems involved (if only because of the psychological consequences of a reorganisation and the notion of being superfluous), and it was relatively easy to use the system. It was assumed that in particular the category of work disability caused by psychological problems would respond favourably (shrink) to changes in the system.

As a consequence of this perspective on the problem, new rules, stricter criteria and activating incentives were developed and implemented. The new rules provided employers with a huge financial disincentive to have sick or work disabled employees (having to pay their wages for two years), making them more motivated to prevent (work-related) disability and more creative in finding solutions for fixing unfavorable person-job fits. As to employees, they faced a less attractive financial disability arrangement and got both more help and more pressure to accept work fitting with their specific work disability. The emphasis shifted from work disability to work ability.

\footnotetext{
2 For a more elaborate analysis of the problem of work disability due to psychological reasons in the Netherlands including detailed references, see Weehuizen (2003).
} 
It was expected that the new rules would especially work out well in the area of work stress. To some extent, 'endogenizing' the costs of work-stress by making employers responsible for paying wages for sick employees indeed inspired many employers to keep better track of the stress levels and mental health of their employees, and to intervene in an early phase before employees really started to spiral down. However, the institutional changes had some unintended consequences. A less than desirable effect was increased 'front door selection': employers more actively starting to select on psychological features of an employee, and becoming more reluctant to offer permanent contracts. Moreover, to some extent institutional reforms led to a shift of the problem rather than diminishing it; part of the people with damaged mental resilience who in the past would have entered work disability, now often ended up into unemployment. Changing the rules was successful in that it did significantly reduce the number of people formally work disabled. However, against expectations, there was no disproportionately high reduction of the proportion of work disability due to psychological problems; this remained unchanged at about 30 percent.

Was there perhaps more than meets the eye to the work disability problem? Perhaps the institutional setting of the Netherlands was not (only) causing the high rate of work disability due to psychological causes, but (also) signaling a deeper development in the economy. In an attempt to get at the bottom of the stubborn problem of disability, a commission was instituted in the Netherlands, consisting of a large number of experts, policy-makers and representatives of employers and employees: the "Commissie Donner" (named after its chair). In the final report of this Commission (2001), the focus was largely on the need for redesign of institutions, which were seen as the main culprit. However, the report also included a few intriguing paragraphs about other possible causes of psychologically-based work disability: $:^{3}$

\begin{abstract}
"The developments of the demand for WAO benefits and of the composition of the WAO-populations are not autonomous. They must be placed against the background of the substantial social and economic changes that have taken place in the past decades. For example, the structure of the economy, the production and the work organisation changed considerably. These changes are directly and indirectly influencing the demand for work disability arrangements. The continuous reorganisations in work organisations for example, which is accompanied with insecurity and mismanagement of human resources form an independent source of illness and work disability.” (p. 29).
\end{abstract}

"The fact that [characteristics of] the work situation, including psychological and other not immediately obvious deficiencies, increasingly form the cause of work disability, can very well (also) be explained by the transformation of the economy in the past thirty years, in which physical and industrial work was largely replaced by immaterial service activity and knowledge work. It cannot be excluded that the development of the volume of work disability (WAO) indicates a deterioration of the work climate, due to sharpened productivity demands, higher time pressure and higher pace if work. That these changes result in increasing work disability in the Netherlands could then be explained by the fact that the Dutch law enables this more. [...] If it would turn out that the development of the volume is a consequence of growing risks and health

\footnotetext{
${ }^{3}$ Commissie Donner (2001) Working on work ability (translated from Dutch).
} 
problems, related to the current way of producing and organising, than that would be the cause, and perhaps also the problem.” (p.47).

The report did not elaborate on these remarks, although they signal a number of complex and fascinating questions about the productive basis of our economy.

\subsubsection{Mental health: an economic issue}

This thesis addresses the issue of the economic role of mental health. This is major economic issue, concerning millions of people and billions of euros a year. Over the past decade, the major economic impact of mental health problems have become increasingly clear and recognized. An important step in this recognition was the landmark study commissioned by the World Health Organization, The Global Burden of Disease (1996). This report showed, unexpectedly, that depression had become the second leading illness in terms of burden of disease, being more costly to society than many other much more salient illnesses. Follow-up reports such as the World Health Report of 2001 supported the prediction that in 2020, depression will rank highest in terms of lost productivity, disability and costs.

Mental health is an important economic issue, as some numbers will illustrate. ${ }^{4}$ Mental health problems costs the EU an estimated 3-4 percent of GDP, mainly through lost productivity. The cost of depression alone to the US economy in 2000 was estimated to be $\$ 83.1$ billion; of this $\$ 51.5$ billion (62 percent) were workplace costs (absenteeism and low productivity). The cost of depression in Europe is similarly high: $€ 118$ billion per year in 2004. About 28 percent of the labour force in the EU-15 (more than 40 billion workers) report having to deal with serious work stress, making stress the number one negative health effect of work. About 20 percent reports chronic fatigue due to pressure at work. In 2000, the ILO estimated that the costs of work-related stress amount to 1-3.5 percent of GDP.

Many resources are spent on repairing and improving mental health. Antidepressants have mushroomed from a modest market in the 1980s into a $\$ 15$ billion industry in 2004, having annual growth rates of up to 24 percent. The self-help market in the U.S. was worth $\$ 9.6$ billion in $2005 ; 11.4 \%$ yearly growth is expected through 2010 , to a value of $\$ 13.9$ billion. Many billions are spent on stress management and counselling programs by the privatesector, the prevalence of these programs in the US growing from 27 percent in 1985 to 48 percent in 1999. While Europe shows a lag in these practices, it is catching up rapidly.

There is a growing recognition that mental health is an economic asset, and that damaging this asset should be compensated for. Illustrative is that in 2001 the first ever British case in which an employer admitted liability for causing stress resulted in $f, 67,000$ compensation to an employee; later that year a primary school teacher received a record compensation payment of $£ 254,000$, having retired from her job after a nervous breakdown due to excessive job stress. In the Netherlands a similar trend can be detected; in 2002, a woman received $€ 80.000$ from her employer for the damage caused by high stress in her job due to structural overwork; in 2004 a court ruled that an employer had to pay $€ 70,000$ to an

\footnotetext{
${ }^{4}$ All these figures including the sources can be found in more detail in section 3.3.
} 
employee to compensate for the damage due to high job stress and resulting burnout. Many more cases have been settled out of court or are still in preparation

Mental health problems lead to a loss of productive power in the economy. The most dramatic example of this suicide; a life long worth of (potential) human capital is taken from the economy. Though suicide is a complex phenomenon, there is some indication that it not only an economic loss, but also a loss related to the economy, or rather, to economic change. As a striking example, Figure 1 shows the growth of productivity and male suicide in Ireland, between 1950 and 2000. The suicide rate in Ireland has grown by 400\% in only three decades, exactly in the same period when the economy became more dynamic and productivity also increased by about $400 \%$. Up to $90 \%$ of suicides are related to mental health problems. Figures such as this need careful interpretation; but the almost perfect correlation between suicide rates and productivity cannot help but make one wonder about how this dynamic period of growth of the economy might be related to the mental health of its members. Economic growth may have a shadow side that needs closer examination; and this examination may provide new insights in the nature of growth itself.

\section{Suicide and productivity in Ireland}

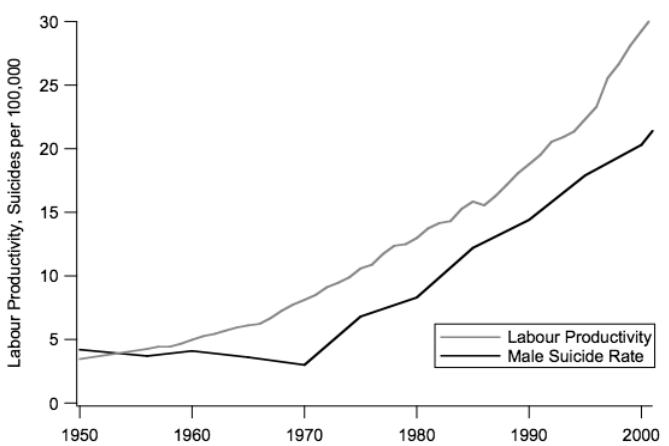

Figure 1. Suicide rates and labour productivity over time in Ireland. Source Groningen Growth and Development Centre Total Economy Database; WHO Mental Health Division (2005); graph created by R. Cowan.

\subsection{This thesis}

\subsubsection{Aims}

Facts such as mentioned above raise many questions about the economic dimension of mental health, and about the mental health dimension of the economy. In spite of the clear economic significance of mental health, to date economic theory has not had much to say about it. Mental health is by and large assumed to be a part of health in general, which in turn is a part of human capital - thus theoretically mental health is as a subset of a subset of human capital, not attracting particularly much attention. Research in behavioral economics, while recognizing the importance of psychological mechanisms for understanding economic behavior, generally does not include mental health in its analysis. In order to become a real 
topic for economic research, mental health must be conceptualised in a way that makes it accessible to economists, in terms of existing research topics and existing economic methodology. Conceptual work is needed to capture and organise the empirical facts about the relationship between mental health and economic variables such as productivity, growth and utility. This thesis aims to contribute to this conceptual work, by examining the role of mental health in the economy, and by characterising mental health in a way that it can become a meaningful part of economic analysis.

Mental health has impact on both consumption and production. In terms of consumption, mental health problems effectively diminish (experienced) utility; it is hard to enjoy your nice car and your fancy TV-set when you are depressed. If GDP growth would be 'corrected' for the loss of actual experienced utility due to mental health problems, the resulting utility growth curve for the past decades might look quite a bit less impressive. ${ }^{5}$ In addition, mental health affects production. Lack of mental health is (increasingly) associated with reduced productivity, work disability, and reduced investment in, and use and maintenance of, human and social capital. On the other hand, due to structural changes in the economy and in the nature of work particularly, good mental health is (increasingly) associated with the opposite: higher productivity, and more investment in, and use and maintenance of human and social capital.

This thesis will focus on the productive dimension of mental health. It will be argued that mental health is (indicative of) a largely unrecognized production factor, which is of increasing importance due to changes in the nature of the economy. The widespread, increasing attention for mental health problems in the last two decades may be related to the awareness of their increasing economic consequences. A particular mental health problem now has more economic consequences than exactly the same mental health problem in the pas. A century ago, the larger part of the labour force was working in relatively simple manual jobs in industry or agriculture; now the larger part is working in knowledge intensive, emotion-intensive service jobs. Whereas a factory-worker with depressed feelings can still "turn the screws" on the assembly line, his productivity still largely intact, this is much less the case for knowledge workers doing cognitive work and service workers doing socialemotional work.

Mental health problems may or may not have increased, but their economic impact surely has. The productive role of mental health has become more important, and this thesis will provide more insight into this productive role, and how it might be conceptualized as a production factor, and eventually as a form of capital. The thesis will sketch a number of implications of the increased economic significance of 'mental capital', and will present two formal applications to illustrate how inclusion of this factor into economic analysis can provide important new understanding in the area of productivity and growth.

This thesis proposes a way to incorporate the factor of mental health and its productive psychological correlates into economic theory. On the one hand, it is important to do justice to the complex nature of this variable, and thus to not simplify its nature and dynamics too much when translating it into an economic concept. On the other hand, the use of a concept

\footnotetext{
${ }^{5}$ Analogous to correcting price-indices for changes in quality.
} 
depends not only on its ability to adequately reflect a complex phenomenon, but also on its explanatory power, its practical applicability in the analysis of actual economic problems. This means that there is an inevitable trade-off, which is classic for science: the trade-off between specificity and generality; between correspondence with reality (in this case, its fit with empirical findings in psychology) and applicability (in this case, its ability to connect to existing economic theory and concepts). The challenge is to find the right balance, to design a 'bridging' concept that both psychologists and economists can live with, and that enables and stimulates fruitful exchange between the two disciplines. The thesis will present a way to do this by proposing a concept that may succeed in this balancing act.

\subsubsection{Outline}

Chapter 2 describes how the nature of work has changed due to creative destruction and technological and organisational innovation. It is shown that work by and large has become more demanding of mental health, and that mental health has become more crucial for performance, given the mentally demanding nature of work. The chapter connects literature from a range of disciplines, including sociology, psychology, organisation science, business studies and labour economics.

Chapter 3 describes the nature of mental health. In order to understand how mental health functions as a production factor, we need to know more about its determinants, effects and dynamics. It is shown that mental health is to some extent an 'output' of the economic process, more specifically of work; work can improve mental health through variables such as job satisfaction, and it can reduce mental health through variables such as work-related stress. In addition, mental heath can be seen as an 'input' of the economic process, through its effect on performance at the job, but also more indirectly through its effect on, for example, human capital formation. In order to provide a generalized relationship between mental health and productivity, the stress mechanism is taken as the main pathway of this relationship. The chapter ends by suggesting that it is not mental health in itself, but an important correlate of mental health, namely (self-)agency, that is the real productive factor at stake. Mental health can be seen as a proxy for this factor, just as education can be seen as a proxy for knowledge and skills. The chapter builds its argument on a large body of literature in psychology, theoretical, experimental and observational.

Chapter 4 discusses how the economic function of mental health, or rather agency, can be expressed in terms of economic theory. Given what chapter 2 and 3 have shown us about the role and function of mental health in the production process, it is proposed to conceptualise the factor that is indicated by mental health as a form of capital. The advantages and disadvantages of doing this are discussed from a theoretical and a pragmatic point of view. One issue addressed here is the relationship between mental capital and human capital. It will be argued that they are complements, in the same way that the literature has argued that human and physical capital are complements. In addition, mental capital will be related to growth accounting and bounded rationality; the added value of including this factor in the existing analyses is illustrated. 
The proof of the pudding is in the eating. Thus, chapters 5 and 6 present formal models of different processes involving labour and (elements of) mental capital, to show that this factor can, usefully and without too many problems, be included into standard economic applications, and to show that including it has clear added value, in terms of providing new insight into old issues.

Chapter 5 examines changes in productivity of an individual worker when the rate of innovation is increased, leading to an intensification of work. More innovation should lead to more productivity (almost by definition), but when mental capital variables and dynamics are added in the model, it becomes clear that this is not necessarily true. Innovation changes the ratio of routine to nonroutine labour, making work mentally more demanding. The model addresses the connection between mental effort, recovery, and burnout, illustrating pathways from one to the other, and mechanisms by which employees (and employers) can deal with preventing the (structural) productivity loss related to burnout.

In chapter 6, a formal model is developed concerning mental capital 'spill-overs' between people. People increase the mental health of other people by providing stress-reducing social support, but at the same time they can function as a source of stress. Overall stress levels determine the nature and size of the spill-overs (in terms of stress) from one person to another. As the rate of innovation goes up, the rate of change within a job increases, and stress rises. Because of spill-overs between two agents in a relationship, above a certain rate of innovation, stress levels rise to such an extent that the positive productivity effects of innovation are countered by the negative effects of the induced stress. In this model we observe multiple equilibria, and the interpersonal interaction leads to hysteresis, making it the more important not to pass the threshold level of innovation.

Finally, in chapter 7 some conclusions are drawn about implications and further theoretical development and applications, thereby stressing the need for true interdisciplinary cooperation. 


\section{Chapter 2. The changed nature of work}

\subsection{Introduction}

This chapter will show that the nature of work has changed in terms of content, organization, management and intensity, and that this has psychological consequences. Obviously, the developments in the world of work are complex and multifaceted rather than simple and straightforward. Many jobs require higher skills, but many other jobs are becoming de-skilled. Many workers become more autonomous but many others find themselves more closely observed through sophisticated monitoring systems. More flexibility is good for some workers who are enabled to better coordinate their work and life, but not good for others who find it hard to deal with the accompanying insecurity and who have difficulties planning and managing their own time. More autonomy seems desirable, but the accompanying responsibility can be stressful and the necessary self-management is effortful. As always, there are two sides to each coin. This chapter presents a discussion of the main trends, as they are more or less agreed on by research in the area of work.

The chapter describes, evaluates and interprets these main trends in the world of work, and reflects on the psychological consequences of these changes. The chapter will show that, by and large, jobs have become psychologically more demanding. In order to perform well on the job, workers in the more dynamic labour market of today's innovation-based economy need a higher level of cognitive, social and emotional skills, and need to be able to cope with change on a structural basis. Good mental health is an essential condition for this; it determines the extent to which we can use our skills effectively and productively.

The reverse is also true. We need good mental health for work, but we also need good work for mental health. The review in this chapter suggests that work affects mental health more than in the past - for better and worse. Because of its characteristics and it organization, work has a psychological impact on workers which it did not have before; or at least, not to the same extent. It is visible in its positive guise, in the research on job satisfaction and job engagement, showing that jobs have more potential to provide psychologically valuable elements such as intrinsic motivation, self-esteem, possibilities for self-development and personal growth, and a sense of meaning. But it is even more visible in its negative guise, in the ample research on the negative psychological effects of work, such as work stress and burnout, and resulting mental health problems such as depression and anxiety.

The chapter will argue that due to the changed nature of work, work affects mental health more than in the past, and mental health affects work more than in the past. In other words, work has become more important as a determinant of mental health, while mental health has become more important as a determinant of (performance at) work. Consequently, mental health is increasingly turning into a critical economic asset, both at the individual and the collective level.

In order to support this argument, an extensive overview of literature will be presented, and findings from different disciplines will be combined, contrasted or complemented. A typical 
example for the style of argument is to first present research showing that certain job characteristics are more stressful and associated with more mental health problems than others, next to present research showing that the number of jobs with these types of job characteristics have increased, and then to combine these findings to argue that, on average, work has become more demanding of mental health.

This chapter will focus on what is often referred to as 'high-end' or 'enriched' jobs. ${ }^{1}$ While both enriched and impoverished jobs may lead to stress and mental health problems, this is not (as) true the other way around: stress and mental health problems have more consequences for enriched jobs than for impoverished jobs, due to the more important function of cognitive, social and emotional skills which critically depend on mental health. Performance on these jobs depends more, and in a more complex way on mental health, and the job risks of high-end jobs in terms of mental health are less obvious, more complex, and less understood.

In many ways, work has become more interesting, less (physically) burdening, less repetitive and with a greater potential to be satisfying and meaningful. However, in as many ways, work is presenting new risks and unexpected trade-offs. The research used in this chapter is mostly dealing with the negative rather than the positive psychological consequences of the changed economy. One reason is that there simply is much more empirical evidence on the negative effects of (characteristics of) work. Another reason is that in order to understand the function of some factor, sometimes you can best (or even only) observe features of how this factor works by looking at what happens when it is not there. In addition, while it may be interesting to stimulate the potential positive effects of work on mental health, it is more urgent to understand how to prevent negative effects, in order to reduce real, and, according to the research, widespread, partly hidden suffering of workers. Moreover, from an economic perspective, more insight in the negative mental health effects of work may prove to be crucial for a better understanding the determinants of productivity and thereby of many of the core topics of economics, such as economic growth. Because it is not fully clear to what extent positive effects on mental health improve performance, but it is quite clear how much negative effects on mental health damage performance.

The chapter will start to describe the core process driving changes in the nature of work: the process of creative destruction - a powerful economic 'engine' fuelled by technological development, competition, and the quest for increased efficiency. This process of creative destruction has changed work in fundamental ways. The current chapter will discuss how work has changed, in terms of the changing labour market (2.2), and the changing content (2.3), organisation (2.4), and intensity (2.5) of work, each time discussing what research has to say about the psychological prerequisites and consequences of these changes. Although the focus is on work, there will be some attention for work-related changes in the non-work sphere, because changes in the sphere of work affect the area of non-work and that in turn affects the area of work.

\footnotetext{
${ }^{1}$ The term 'high-end' usually refers to skill-levels (high) and wages (high), while 'enriched' is an indication that the work is non-routine and rich in content in terms of complexity, variation and autonomy. 'Low-end' or 'impoverished' jobs are characterized by low skill levels, low wages, and by a high degree of standardization and routine work.
} 


\subsection{The changing labour market}

\subsubsection{The acceleration of creative destruction}

The economy can be understood as a system in which the main rationale is an eternal quest for increasing efficiency, for achieving the optimal allocation of scarce means over alternative ends and thereby maximizing overall utility. This process is driven by competition and profit motives, but also by a more basic desire that seems to be built in (perhaps evolutionary): to do more with less.

There are different ways in which an economy can become more efficient: increasing (global) division of labour and specialization lead to economies of scale and scope, technological and organizational innovation lead to more resourceful use of resources. Innovation is generally aimed at creating new products and services thus finding new ways of creating added value (product innovation) and at improving production processes finding new ways of achieving better cost-benefit ratios of production (process innovation). Process innovation generally leads to substitution of human labour by technology, and/or increasing labour productivity by increasing the efficiency of the use of human capital. Globalization (in combination with competition) often leads to relocation of jobs to low-wage countries or to countries with other competitive advantages. ${ }^{2}$ Together these forces fuel a process of creative destruction, in which existing jobs are steadily reduced while at the same time new jobs created. While quantitatively this may not lead to any major differences in terms of numbers of jobs in the longer term, qualitatively this leads to major changes, in terms of job content, job organization and job requirements. The number of jobs may be the same, but the jobs themselves are definitely not.

This process of creative destruction has accelerated over the last decades, due to a number of positive feedback mechanisms. A first mechanism is related to the prices of the substitutable production factors technology and labour. The extent to which and rate at which technology replaces human labour depends among other things on the relative price of technology and labour (wages). In the course of the past century, the price of labour has been rising steadily ${ }^{3}$, while the price of technology, in terms of its productive potential, has been decreasing rapidly, especially in the last few decades. ${ }^{4}$ Thus, whereas human labour has

\footnotetext{
2 Technology has a key role in this. Globalisation is to an important extent enabled by (and to some extent driven by) technological development, especially the development of transport technology and ICT. The same is true for increased competition: it is related to globalisation (which is enabled by technology) which increases the number of potential competitors, due to the increase of transparency of supply and demand on markets all over the world.

${ }^{3}$ The price of labour is increasing because of a number of developments. The average amount of education has increased dramatically in the past century. This adds to the cost of labour, since more resources are needed to invest in human capital, both before and during being employed in a job, and this has to be earned back in some way in the form of higher wages. Also, advanced economies need advanced public sectors to accommodate them, to provide the complex legal, social and physical infrastructure needed to support and enable these economies. Having a public sector is costly, and a growing public sector generally means an increase of taxes. Taxes are generally connected to income, and this increases wages.

4 This is partly a decrease in the price of a certain technology, or an increase of the quality and potential applications of a certain technology. For example the price of personal computers has not fallen dramatically
} 
become more expensive, new technology has become relatively less expensive. Obviously, the price of labour and the price of technology are not independent. The more expensive human labour becomes, the more interesting it is to develop technology for substitution of human workers. Labour needs to offer a better cost-benefit ratio than its potential technological substitutes, and as long as wages are not decreased, the main way of doing this is by increasing human capital per person. This increases the price of labour, since human capital is costly. This in turn makes it again more attractive to replace (increasingly expensive) labour by (increasingly inexpensive) technology, which gives further stimulus to technological development and lowers its relative price. Hence, the price of labour is to some extent a driver for technological development, and vice versa, technological development is to some extent a driver of the price of labour - a positive feedback loop. This is to some extent a self-propelling mechanism. ${ }^{5}$

A second feedback loop can be found in the nature of technological development itself. New technologies contribute to the development and diffusion of information and knowledge, and through this, to the further development of new technology. One cause of this is the increased codification of knowledge by technology (Cowan et al. 2000); codified knowledge can easily be digitalized after which it can be accessed, copied and transported without additional cost. Information and communication technology (ICT) has dramatically increased the speed and efficiency of information and communication processing, and thereby the availability of and access to knowledge. In addition, people (and thus their knowledge) have become more mobile, as transport technology increased the options for affordable transport. As a consequence, knowledge flows have increased dramatically, and with them the diffusion of knowledge and innovation (Castells 1996). The development of ICT is both a cause and a consequence in this process. ICT speeds up the development, diffusion and application of new knowledge, it speeds up the development and diffusion of new technology, including the development and diffusion of itself (Castells 1996). In addition, ICT has contributed to more transparency, less transaction costs and increased global competition, thereby increasing the need to pursue innovation and thus technological development, again including its own development (Freeman and Soete 1997).

The result of the various positive feedback loops is the acceleration of creative destruction and of economic and social change. ${ }^{6}$ An important area of change is the increasingly dynamic labour market, characterized by growing (perceived) job insecurity, job turnover, and more frequent (spells of) unemployment.

\footnotetext{
but rather the quality, speed and applications of PCs have increased dramatically while the price remained the same or dropped.

${ }^{5}$ E.g. See Arrow et al. (1961); Garud and Kumuraswamy (1995), Dewan and Min (1997).

${ }^{6}$ The Social Readjustment Scale (Holmes and Rahe 1967) is used for measuring stress related to 'life events' (e.g. marriage, divorce, death of a spouse, birth of a child, loss of job), and which indicates the degree of change a person experiences over a period of time in Life Change Units (LCU). Miller and Rahe (1997), when reviewing and re-adjusting found that when comparing the average life change intensity scores across 30 years, a $45 \%$ increase in mean values was seen; this indicates that the average amount of change of a person has increased.
} 


\subsubsection{Increased job insecurity, turnover and unemployment}

The increasingly dynamic economy is characterized by more frequent reorganization, downsizing and mergers, ${ }^{7}$ and these are accompanied by a growth in contingent employment, such as temporary jobs, part-time jobs and contract performance-based jobs (e.g. Burchell et al. 1999; Quinlan et al. 2001). This in turn has resulted in growing job insecurity, both actual and perceived. ${ }^{8}$ Job insecurity fluctuates with fluctuations in the labour market and the economy, but research shows that there is a structural underlying trend of increasing job insecurity. ' Job insecurity involves much more than just the fear of losing a job; it also relates to the fear of losing valuable job characteristics, and job prospects. Thus, innovation and reorganization without laying off employees can still cause considerable feelings of job insecurity. ${ }^{10}$ Feelings of job insecurity can be very intense, stressful and damaging to well-being, and are associated with negative mental health effects. ${ }^{11}$ Some research suggests that job insecurity is more stressful than unemployment. ${ }^{12}$

\footnotetext{
7 Downsizing can be necessary to reduce slack and improve performance so that a company can survive. However, Kets de Vries and Balasz (1997) point out that in practice it not seldom has the character of a "quick fix" leading only to temporary improvements, as surviving employees have to work harder to do the same work with less workers, and become overworked and demoralised, afraid to be next. Burchell et al. (1999) show evidence that corporate restructuring and downsizing have led to the erosion of internal labour markets, reducing incentives to invest in longer term and/or collective firm goals.

${ }_{8}$ Burchell et al. (2002) present an overview of empirical evidence indicating a structural increase in job insecurity. Based on representative survey data in a number of industrialised countries, Green (2003, 2007) finds evidence that insecurity increased in the 1970 s and 1980 s, but that the perceived rising insecurity during the 1990s was a middle-class phenomenon based in part on the experience of professional workers and on the finance industry. Thus job insecurity in one sector may spill over to another sector in the form of perceived job insecurity, even though that other sector does not have real change in job security. In terms of psychological consequences what matters is the perception of job insecurity rather than actual job insecurity; it is the perception that leads to feelings of insecurity, which in turn lead to stress its consequences.

9 Smith's (2000) review shows widespread agreement in the research literature that career stability is on the decline, supported by empirical evidence in terms of figures on turn-over and unemployment rates and on types of contracts and promotion chances.

${ }^{10}$ Burchell et all (1999) found that many employees were only moderately worried about actually losing their job, but were very concerned about the loss of valued job features, such as control over the pace of work and opportunities for promotion. These fears were particularly noticeable in organisations where senior management tried to eliminate existing job demarcations and to flatten managerial hierarchies. Making organisations 'flatter' reduces the opportunities to provide (a feeling of) advancement and status for aspiring employees, which is experienced as a form of job insecurity.

${ }^{11}$ Research suggests a clear causal link between job insecurity and reduced psychological well-being in the form of anxiety, depression and stress (e.g. Dekker and Schaufeli, 1995; Kim et al. 2006). Hellgren and Sverke (2003) show in a longitudinal study that the cross-lagged effect of job insecurity on mental health problems was significant whereas the reversed effects of mental health complaints on subsequent insecurity were not. Wichert et al. (2000) reviewing the psychology literature on the costs and consequences of job insecurity, conclude that job insecurity, even in the midst of general prosperity, can lead to a deterioration in physical and mental health. Nolan et al. (2000), presenting a review of empirical research findings on the effect of job insecurity on mental health, find that prolonged job experience of job insecurity leads to increasingly impaired psychological well-being. Ferrie et al. (1998) examining the effects of a major organisational change find that compared with controls, employees experienced significant deterioration in self-rated health, including minor psychiatric morbidity. Ferrie et al. (2002) find that loss of job security has adverse effects on self reported health and minor psychiatric morbidity, which were not completely reversed by removal of the threat and which tend to increase with chronic exposure to the stressor. Longitudinal studies such as Frese (1985), Ferrie et al. (1995), Roskies et al. (1993) and Hellgren et al. (1999) clearly indicate that the causality is from job insecurity to health problems rather than the other way around.
} 
In addition, this has economic effects. Job insecurity might increase productivity because it makes workers work harder in order to keep their job; ${ }^{13}$ however research findings suggest that the overall effects of job insecurity on productivity are often the opposite. ${ }^{14}$ Especially when workers are highly involved in their jobs, job insecurity appears to be detrimental for their productivity. ${ }^{15}$

Increased creative destruction leads to an increase of job turnover, often with an intermittent period of unemployment. In economic theory, unemployment is considered costly to the extent that human capital remains unused for a period of time, to the extent that it may lose its some of its value due to firm-specificity of human capital and due to inactivity of human capital during unemployment (loss of skills and knowledge). ${ }^{16}$ In addition, costs such as friction costs, transaction costs and search costs are recognized in economics, but there is little awareness in economics of the psychological costs of unemployment, in terms of stress and resulting physical and mental health problems and their long-term economic consequences such as temporary and structural loss of productivity. ${ }^{17}$ It is recognized that

12 The reason that job insecurity is such a negative factor is the experience of uncertainty and ambiguity it causes, which can have paralysing effects on the coping process; thus stress cannot be reduced by coping but remains present. Dekker and Schaufeli (1995) find that certainty of loosing a job is less stressful than having a job but fearing to loose it, not know whether it indeed will happen and not knowing what best to do. Jacobson (1987) points out that in contrast to unemployment, job insecurity is of minimal social visibility. This means that unless there is strong evidence of imminent job loss, the affected employee is expected to continue working as usual. The insecure worker therefore has no special status and no opportunity to express dissatisfaction or seek help and this can add to the experienced stress.

13 Nolan et al. (2000) distinguish two ways in which job insecurity might affect the performance of an individual employee: (1) a direct effect, an employee working harder to maximise the chance of retaining employment, or conversely working less hard, because of lack of future perspective at this employer; (2) an indirect effect, as job insecurity causes stress or dissatisfaction, which in turn affects productivity.

14 Sverke et al. (2002) in a meta-analytical review of research on this topic find that job insecurity has detrimental consequences for employees' job attitudes, organizational attitudes and health. Probst (2005) finds that job insecurity is related to lower job satisfaction and higher turnover intentions and work withdrawal behaviours. Conventional wisdom often assumes that security breeds complacency, however empirical research does not support this assumption. The review of Burchell et al. (1999) shows that the relationship between job insecurity and self-reported motivation levels is generally a negative rather than a positive one. Analysis based on a longitudinal panel survey revealed that people do not adjust to job insecurity; on the contrary, physical and mental well-being continue to deteriorate the longer employees remain in a state of insecurity. Most of the empirical research reviewed by Nolan et al. (2000) suggests a negative relationship between job insecurity and performance, mediated through factors such as decreased motivation, morale, confidence and loyalty, and increased stress, scepticism, anger and bitterness.

15 Probst (2000) finds that employees who were highly invested in their jobs were most adversely affected by job insecurity; they reported more negative job attitudes, more health problems, and a higher level of psychological distress than their less involved counterparts when they perceived their jobs to be threatened.

${ }^{16}$ In case an unemployed person goes through additional schooling of some sort during the unemployment period, loss of skills is less or not present, and new skills may be acquired.

${ }^{17}$ E.g. Murphy and Athanasou (1999) examining sixteen longitudinal studies find that that unemployment negatively affects people's mental well-being. Unemployed individuals report greater psychological distress, lower self-esteem, and higher levels of depression (Waters and Moore, 2002; Winefield et al. 1993). Although there is some reverse causality (being depressed or being prone to depression increases the probability of loosing a job and being unemployed), research shows that involuntary unemployment precipitates elevated levels of depression, suggesting a clear causal relationship (e.g. Kessler et al. 1989). These negative effects can last over time to the extent of being structural; it is found that on average, individuals that became unemployed did not completely return to their former levels of life satisfaction, even after they became re-employed, and 
unemployment leaves economic 'scars' (Ruhm 1991) in terms of income loss in future employment, an effect that persists over a long-term period. However, becoming unemployed does much more than merely reduce your income; unemployment is found to lead to loss of self-esteem and self-efficacy and to mental health problems, which in turn leads to reduced labour market chances. ${ }^{18}$ Thus, there is evidence for 'psychological scarring' due to unemployment, similar to (and in fact one of the causes of) Ruhm's income scarring. ${ }^{19}$

Flexibilization of the labour market increases the chance to become unemployed, but it also increases the chance to find employment again. However, as was argued above, the experience of becoming and being unemployed is stressful ${ }^{20}$ and often has psychological effects such as loss of self-confidence and self-esteem, which negatively affects search effort and the chance to become re-employed. ${ }^{21}$ In addition, flexibilization leads to a structurally higher average of job insecurity. Research suggests that job insecurity may have more negative effects on mental health than not having a job (see Figure 1). On the other hand, it is important realize that employment is not necessarily good for people. Research shows that having a job generally improves mental health; however it depends on the characteristics of a job whether being employed in that job is beneficial to mental health. ${ }^{22}$

that the psychological effects of a next period of unemployment are not diminishing (i.e. people do not get used to becoming unemployed) (Lucas et al. 2004).

18 These psychological costs represent a loss of utility in themselves, but also because psychological costs in turn often lead to economic costs. Positive self-concept, consisting of higher self-esteem, generalized selfefficacy, perceived control, and emotional stability is related to higher search intensity over longer periods of time, which in turn is related to the probability of finding a job. E.g. McKee-Ryan et al, 2005 find that individuals experience increased anxiety and decreased mental health while unemployed; Wanberg et al. (2005) found that core self-evaluation is related to persistence in job search; Judge et al. (1999) find that positive selfevaluation is associated with higher levels of coping and adjustment in a variety of stressful life situations, including unemployment. Turner (1995) finds that current unemployment effects among the previously unemployed are strongest in low unemployment areas, particularly among individuals with a college-level education; this could suggest that financial strain, the more salient stressor for people in lower socioeconomic statuses, may leave fewer traces over time than damage to sense of self, which may primarily characterize higher status victims of job loss.

19 E.g., According to set-point theories of subjective well-being, people react to events but then return to baseline levels of happiness and satisfaction over time. Lucas et al. (2004), examining reaction and adaptation to unemployment in a 15 -year longitudinal study, found that individuals reacted strongly to unemployment and then shifted back toward their baseline levels of life satisfaction; however, on average, individuals did not completely return to their former levels of satisfaction, even after they became re-employed. Furthermore, contrary to expectations from adaptation theories, people who had experienced unemployment in the past did not react any less negatively to a new bout of unemployment. These results suggest that although life satisfaction is moderately stable over time, life events such as unemployment can have a strong influence on long-term levels of subjective well-being.

${ }^{20}$ Research using the Social Readjustment Scale (see footnote 6) confirmed that major life events - including both loss of a job and starting a new job - act as stressors, almost regardless of whether they are positive or negative (e.g. Miller and Rahe 1997).

${ }^{21}$ E.g., Wanberg et al. (2005) found that core self-evaluation is related to persistence in job search;

22 For example, it has been found that job satisfaction is an important moderating variable for the mental health effects of employment; jobs in which workers have high job satisfaction enhanced personal growth, selfesteem and mental health, but jobs low on job satisfaction are detrimental to mental health and can be as bad or worse than being unemployed (e,g, Winefield 2002). 
There is evidence that the distribution of job insecurity and unemployment is becoming more skewed, due to polarization of the labour market. Increasingly the labour market seems to have the character a two-tiered system of employment (Beck, 2000; Green 2007). On the one hand there are the core workers in enriched jobs, receiving good pay, benefits, opportunities for training, increasing their skills and value to the organisation, having a considerable degree of job security. On the other hand there are the peripheral, contingent workers who typically earn lower wages, receive no benefits, work in low skill jobs with few training opportunities, and face significant job instability and insecurity. ${ }^{23}$

\section{Health effects of job insecurity and unemployment in the UK, 1994 \\ (Securely employed at 100) \\ Source: Burchell et al. (1999)}

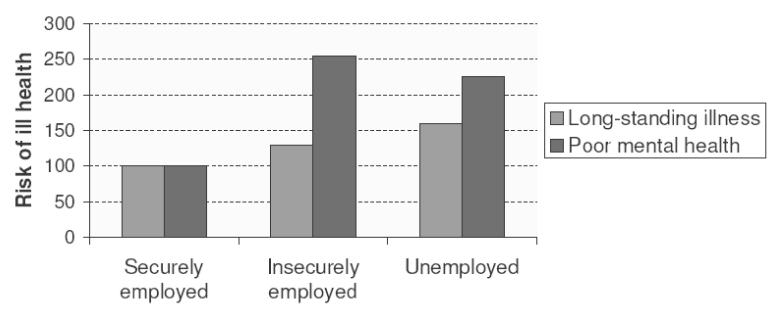

Figure 1. Health effects of job insecurity and unemployment, UK 1994. Source: Burchell et al. 1999).

Gallie (2005) in an empirical study in the EU-15 countries over the period 1996-2001 finds a strong and consistent association between current job insecurity and the work pressure people experienced. ${ }^{24}$ Winefield (1995) presents a review of the literature on the psychological cost of unemployment. Unemployment and mental health problems are clearly negatively correlated. An important issue is whether mental health problems cause unemployment (the 'selection hypothesis'), or that unemployment causes mental health problems (the 'exposure hypothesis'). Research finds evidence for both selection and exposure, indicating dual causality, which can lead to spiral and cascading effects. ${ }^{25}$

\footnotetext{
${ }^{23}$ Smith's (2000) review shows that bifurcation of skill, payment and status leads to resistance and conflict in organizations between permanent and contingent employees, resulting in considerable productivity losses. In addition, research shows that employees in precarious jobs are less motivated to invest in the organization and are less inclined to engage in 'organizational citizenship behaviour' (OCB); job insecurity leads to breaches in the 'psychological contract' between employee and employer, which leads to reduction of productivity (Conway and Briner 2005).

${ }^{24}$ Gallie (2005) found little evidence that past unemployment or temporary work were related to work pressure, but a strong and consistent association between current job insecurity and the work pressure people experienced This finding may be related to the more inclusive social security systems in the EU-15, which softens unemployment 'scarring' in terms of lasting effects on income, skills and labour market position. 'Flexicurity', the proposed new paradigm for social security systems in Europe, aims to provide basic security in combination with activating labour market policies, aimed at preventing de-skilling and polarization, making past unemployment less dramatic than for example in the U.S.

25 A number of longitudinal studies have been carried out designed to identify selection and exposure effects. The evidence suggests that in a time of tight labour markets the unemployed have mental health problems that contributed to their 'unemployability' (supporting the selection hypothesis); while many of the unemployed
} 


\subsubsection{The psychological costs of unemployment}

The relation between unemployment and mental health has been studied since the 1930s. ${ }^{26}$ Unemployment has negative psychological consequences; being unemployed is typically associated with lowered levels of psychological well-being (e.g. Murphy and Athanasou, 1999). Creed and Klisch (2005), reviewing the literature on this, find that when unemployed individuals are compared with those who are employed, the unemployed individuals report greater psychological distress, lower self-esteem, and higher levels of depression (also: Waters and Moore, 2002). Longitudinal studies suggest that unemployment is largely causally related to a decline in well-being and not that poor well-being is associated with less healthy people's drifting into unemployment (e.g. Winefield et al. 1993). Goldsmith et a. (1996b) find clear evidence that having recently completed a spell of joblessness, due either to unemployment or time spent out of the labour force, damages an individual's perception of self-worth. Exposure to bouts of both forms of joblessness also significantly harms self-esteem, and the effect of such exposure persists. A decompositional analysis suggests that joblessness damages self-esteem by generating feelings of depression.

To better understand the psychological costs of job insecurity and (spells of) unemployment, it is necessary to understand the psychological function of work. A review of the literature distinguishes four types of work values: intrinsic (personal growth, autonomy, interest, and creativity), extrinsic (pay and security), social (contact with people and contribution to society) and power (prestige, authority, influence) (Schwartz 1999). Work fulfils important psychological needs, it is (increasingly) an important source of social relations, personal development, self-esteem and a sense of meaningfulness. Because many other social structures (such as the church, the neighbourhood, the extended family, the nation) have diminished in importance, work has become a more dominant source of these deep-seated social and psychological needs of people. In order to better understand the psychological cost of job insecurity and unemployment (even when short-term), we briefly review the major theories in this area. ${ }^{27}$

Deprivation Theory (Jahoda 1981) posits that work represents our strongest tie to reality. The theory distinguishes between the manifest benefits of employment (e.g. earning a living) and its assumed latent benefits that serve to maintain links with reality. She identifies five latent benefits: (1) time structure, (2) social contacts, (3) external goals, (4) status and identity and (5) enforced activity. Jahoda believes that even bad jobs are preferable to unemployment, "even unpleasant ties to reality are preferable to their absence [...] leisure activities [...] are fine in themselves as a complement to employment, but they are not functional alternatives to work" (Jahoda 1981, p. 189). ${ }^{28}$

individuals in a period when jobs are scarce (recession) develop mental health problems because of being unemployed rather than the other way around (supporting the exposure hypothesis). Important mediating factors between unemployment and mental health include lack of self-confidence, self-blame, stress, isolation, lack of control and resignation (e.g. Hammarström and Janlert, 1997)

${ }^{26}$ E.g. Eisenberg and Lazarsfield (1938), Brenner (1973), Catalano and Dooley (1983).

${ }^{27}$ See Morrow et al. 2002; Goldsmith et al. (1996b) for a partially overlapping overview.

28 The belief that a bad job is better than no job has not been supported by the research evidence; research shows that inadequate employment can be just as psychologically damaging as unemployment (e.g. Dooley and Prause (2004) Some researchers have attempted to measure access to the five latent benefits of employment 
Life-span Developmental theory (Erikson 1959, 1982) proposes that there are eight stages in life, each of which has a certain central conflict that needs to be resolved for healthy psychological development. The stage of adolescence and young adulthood is associated with the establishment of identity, and an important provider of identity is work: having a job, a profession, an occupation. Some researchers have reported evidence suggesting that youth unemployment slows down healthy psychosocial development, because it prevents the development of a stable identity (e.g. Gurney 1980). One implication of this is that tackling youth unemployment should be a priority in the fight against unemployment, in order to prevent long-lasting psychological effects, which in turn have economic consequences.

Agency Restriction Theory (Fryer and Payne 1984; Fryer 1986) assumes that people are agents who strive to assert themselves, initiate and influence events, and are intrinsically motivated. In short, agency theory assumes that people are fundamentally proactive and independent, whereas deprivation theory assumes them to be fundamentally reactive and dependent. ${ }^{29}$ According to Agency Restriction theory, the negative consequences of unemployment arise because they inhibit the exercise of personal agency. Many people work for the manifest benefit of employment (e.g. money) without regard to its so-called latent benefits. The restrictions imposed by economic deprivation due to unemployment make it difficult for people to create, plan and realise a satisfying life. In other words, unemployment has negative mental health effects simply because it is associated with poverty and thus represents severe practical limitations to the dreams, wants and needs of people, which makes them anxious and depressed.

Warr's (1987) Vitamin Model assumes that nine features of the environment ${ }^{30}$ affect mental health in an analogous manner to the way vitamins affect physical health. Work is an important and perhaps even the main provider of these "vitamins." One implication of this would be a 'vitamin prescription' with some of these elements for unemployed, in order to keep their mental health in good condition.

Relative Deprivation theory (Crosby 1976, Walker and Pettigrew 1984) argues that, in relation to employment status, relative deprivation may be defined as a perceived discrepancy between

identified by Jahoda and have claimed that access to these features (which can be realised through work but also through leisure activities) is the real variable correlated with psychological well-being (e.g. Evans and Haworth 1991).

${ }^{29}$ Fryer and others developed this theory partly in critique of Jahoda's theory, pointing out that the five supposed latent benefits of employment are all too often costs rather than benefits, such as the "arbitrary time structure without regard for human needs; autocratic supervision; activity for unclear or devalued purposes; a resented identity; the vacuous nature of imposed activities" (Fryer 1986, pp 12-13).

30 These nine 'work vitamins' are: (1) opportunity for control, (2) opportunity for skill use, (3) externally generated goals, (4) variety, (5) environmental clarity, (6) availability of money, (7) physical security, (8) opportunity for interpersonal contact, and (9) valued social position. Some of the environmental features are assumed to resemble vitamins $\mathrm{A}$ and $\mathrm{D}$ in that very high levels not merely cease to be beneficial, but are actually harmful (AD is a convenient abbreviation for 'additional decrement') Others are assumed to resemble vitamins $\mathrm{C}$ and $\mathrm{E}$, in that very high levels, while ceasing to be beneficial, are not actually harmful (CE is a convenient abbreviation for 'constant effect'). Warr (1987) suggests that three of the environmental features availability of money, physical security and valued social position - may reasonably be regarded as falling within the CE category, whereas the remaining six are regarded as falling within the AD category. 
an individual's actual status and the status that he/she expects and feels entitled to. In other words, the psychological costs a person incurs because of being unemployed or having a bad job are related to the expectations of this person. One implication of this is the importance of management of expectations and perceptions of both employed and unemployed people.

Thus, the psychological impact of unemployment can be understood by looking at the psychological function of employment, but in addition it depends on a number of characteristics of unemployment itself: how dramatic the fall in income is, to what extent a person can find other meaningful, social activities during unemployment. One fact that matters is the duration of unemployment. Stages theory (Eisenberg and Lazarsfeld 1938) argues that the psychological response to unemployment could be described in terms of stages, in which (1) a person first experiences shock triggering activity (to find a job), then (2) experiences frustration, pessimism, anxiety and stress (when he does not manage to find a job) and finally (3) becomes fatalistic and adapts himself to his state of unemployment with a broken attitude and feelings of powerlessness and resignation. One implication of this theory is that it is important to prevent people from going into stage 2 and further, meaning that time matters (the longer a person is unemployed the more he gets locked into negative thought patterns, reducing his chance for finding employment) - hence, a psychological argument for economic intervention.

These are the main theories that can be used to explain the psychological benefits of employment and the psychological costs of unemployment. From a pure economic perspective, unemployment is a neutral phenomenon for the individual, as long as it does not affect skills and expected wages are constant over the longer term. However, unemployment has substantial psychological costs and the theories described above indicate the nature and pervasiveness of these costs. ${ }^{31}$ If a more dynamic labour market leads to more people experiencing more spells of unemployment, the psychological costs of this should be taken into account when evaluating the benefits of a more dynamic labour market. This is important from an economic perspective. Not only do these psychological costs imply a huge, real loss of utility, but also they can structurally affect performance and lead to a loss of future productivity and chronic unemployment, as will be explained in more detail in chapter 3.

The theories above suggest that the psychological costs of unemployment can be reduced if the psychological functions normally provided by work are provided to the unemployed. Thus, if a dynamic labour market is seen as desirable or inevitable, the challenge is to minimize its psychological costs, and for this a good understanding of the psychological function of work is crucial. In addition, these theories suggest that not all work will automatically fulfil the psychological functions indicated. In order to maximize the psychological benefits of employment, the characteristics of work matter, as the next sections will show.

\footnotetext{
31 It is important to realise that many of our ideas about work and non-work are culture-bound (Hofstede 1980), thus culture affects the psychological costs and benefits of (un)employment. In some cultures the domain of 'paid work' or 'gainful employment' is more clearly demarcated than in others; having a job is highly valued, and having a (certain type of) job has an relatively large impact on individual identity and status. Loosing a job and not having a job are consequently experienced as more catastrophic.
} 


\subsection{The changing content of work}

The process of creative destruction described in section 2.2.1 has by and large had a positive net result: welfare has increased in terms of output of products and services (as measured by GDP) and unemployment rates have not structurally increased. However, as discussed above, there is a reality behind this that did change: the labour market has become more dynamic, and this is accompanied by an increase of job insecurity and job turnover. These have psychological effects that can be seen as costs, in terms of reduced well-being, life satisfaction and mental health. The evidence presented above suggests that these costs are not trivial, that they are unevenly distributed, and that they have a cascading dynamics. ${ }^{32}$

Furthermore, even though quantitatively not much may have changed in terms of jobs, qualitatively it has. Job creation may even out job destruction in the longer term, but the new jobs are different jobs than in the past. The nature of work has changed, and in this section, we will discuss the changing content of work and its psychological consequences.

\subsubsection{The rise of the service sector}

The shift from an agricultural to an industrial and then to a service economy is a well-known and well-documented phenomenon. ${ }^{33}$ Currently, employment in modern economies consists for almost $80 \%$ of jobs in the service sector. Not only are most jobs located in the service sector, but also many jobs located in agriculture and industry have a service character (e.g., the job of a secretary working in the agriculture sector has the characteristics of service work).

An important reason for the shift to the service sector is the difference in productivity growth of services compared to manufacturing and agriculture. Introduction of technology results in much higher productivity gains in production of goods than in production of services. ${ }^{34}$ Baumol (1967) proposed that economic activities can be classified into two groups: those, typically manufacturing, where it is possible cumulatively to increase output per labour hour, and activities typically in the service sector which by their nature allow only limited and occasional productivity increases. The latter are subject to increasing production costs relative to the former: Baumol's cost disease. In the service sector, consisting of labour-intensive sectors that rely heavily on human (inter)action (such as health care or education) there is much less productivity growth over time than in manufacturing. ${ }^{35}$ Due to

\footnotetext{
${ }^{32}$ In chapter 3, the more precise nature of these costs will be discussed.

${ }^{33}$ E.g. Fuchs (1968, 1982); OECD (2000); Schettkat and Yocarini (2005).

34 The rate of technical substitution between capital and labour is lower; the extent to which capital (e.g. machines) and labour can be substituted for one another at the same level of output is different for services than for manufacturing.

35 "The basic source of differentiation resides in the role played by labor in the activity. In some cases labor is primarily an instrument - an incidental requisite for the attainment of the final product, while in other fields of endeavor, for all practical purposes the labor is itself the end product" (Baumol 1967, p.216). It is hard to increase the efficiency and productivity of such labour. Baumol gives as the most extreme example of the latter the example of live performance: "A half hour horn quintet calls for the expenditure of 24 man hours in its performance, and any attempt to increase productivity here is likely to be viewed with concern by critics and audience alike" (Baumol 1967, p.216).
} 
the difference in productivity growth, as demand for both goods and services rises, labour is shifting from in the production of goods to the production of services. ${ }^{36}$

The service sector is a broad category, covering an extremely diverse set of economic and organizational activities. Within the service sector, certain types of jobs have become more prevalent. Below the most important growth sectors within the service sector are briefly discussed: the transaction sector, the knowledge sector and the personal care sector. ${ }^{37}$

An important sub-sector of the service economy that has grown substantially is the transaction sector. The economy of today is a complex, global system, characterised by an unprecedented degree of division of labour and specialisation. Whereas transformation costs (the costs of production) have gone down enormously in the past century, transaction costs (the costs related to transactions) ${ }^{38}$ have gone up (North 1991). The growth of the number of transactions (and of their costs) has resulted in the growth of the sector that specialises in handling transactions and everything needed for it, such as trade companies, brokers, lawyers, financial services, but also and importantly, public services, the legal system, and the government. $^{39}$

Another sub-sector that has grown considerably in relative size, in terms of employment, is the knowledge sector, both in the public and the private sector. There has been a strong growth of knowledge intensive service firms, ${ }^{40}$ and of organizations involved in R\&D and education. ${ }^{41}$

Yet another sub-sector of the service sector that has grown considerably in the past decades is the personal care sector, which includes health care. A major reason for this growth is demographic: as life expectancy increases, the population is ageing and so is the need for

\footnotetext{
${ }^{36}$ Baumol (1967) on this: "These observations suggest something about the likely shape of our economy in the future. Our model tells us that manufactures are likely to continue to decline in relative cost and, unless the income elasticity of demand for manufactured goods is very large, they may absorb an ever-smaller proportion of the labour force [...] (p. 421). Thus, Baumol argues, "an ever increasing proportion of the labor force must be channelled into these activities" (p.420), resulting in a growth of the absolute and relative number of people working in the service sector.

37 Similarly but slightly different, Miles (1993) suggests subdividing the service sector into physical services, human or person-centred services and information services.

38 Transaction costs refer to the costs incurred in enabling an economic exchange, such as information search costs, and the costs of searching information (about prices, quality), contracting, monitoring and enforcing (Williamson 1981).

${ }^{39}$ Wallis and North (1986) estimated that in the U.S. the transaction sector grew fairly steadily from about $25 \%$ of GNP in 1870 to $47-55 \%$ in 1970 . Total transaction employment was estimated to have increased strongly over time, from about $17 \%$ in 1910 to about $39 \%$ in 1970 . Though information and communication technology has substituted human workers in the transaction sector substantially, the transaction sector has continued to grow in the 1980s and 1990s.

40 These are firms that produce and sell services of which the core value consists of particular knowledge, for example consultancy, accounting. For a list of knowledge intensive services, see Windrum and Tomlinson 1999), who find that the combined contribution of KIS firms to national added value has risen from 29.5 to $37.5 \%$ in the Netherlands, from 22.1 to $34.7 \%(+12.6 \%)$ in the UK and from 24 to $36 \%(+12 \%)$ in Germany.

${ }^{41}$ An important reason for the growth of the research and education sector is the increasing awareness in the past decades of the economic value of knowledge and innovation, and the increasing need of the modern economy for workers with high levels of knowledge and skills. From an economic perspective, education is the production of human capital of the (future) labour force (Becker 1962), and education is a growth industry.
} 
care. Economic development increased both public and private expenditure on personal and health care, and employment in this sector has risen substantially. ${ }^{42}$ In addition, due to the increased female labour participation, personal care work that used to be in the unpaid informal sector (such as child care and care for the elderly), now has become outsourced to the formal paid sector, showing up as ain increase in personal care work.

Research shows that the types of jobs that have grown most in terms of employment generally also are the types of jobs that are most related to stress (see Figure 2). ${ }^{43}$

\section{Work Pressure in the Netherlands, 2005}

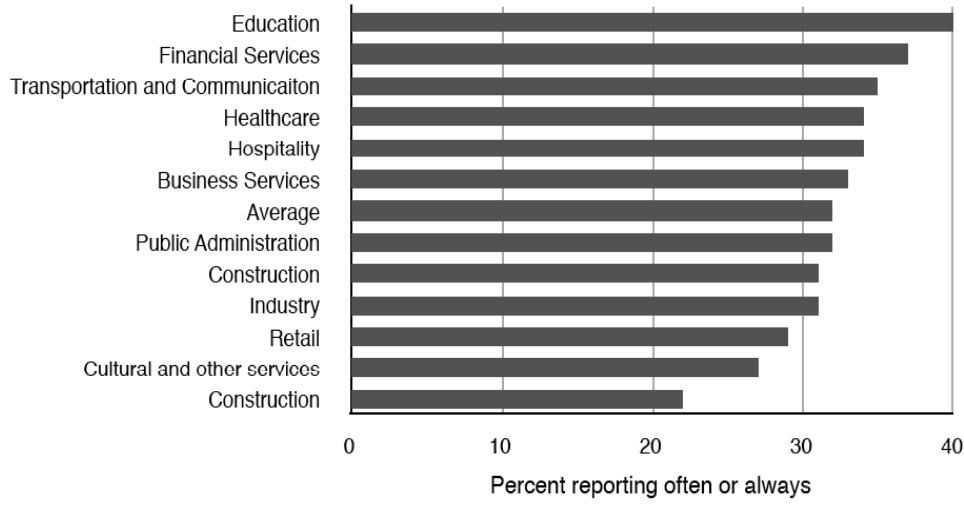

Figure 2. Work pressure by sector in the Netherlands, 2005. Source: TNO Quality of Life, Smulders (2006).

Jobs in important growing sub-sectors of the service sector, such as the transaction sector, the (health) care sector and the education sector typically require substantial cognitive, social and psychological skills. ${ }^{44}$ As will be described in chapter 3, mental health is an important determinant of the extent to which people can make effective use of these skills.

${ }^{42}$ For example, in the US health care spending has gone up from 6 to 14 percent of GDP (Fuchs 1996). Government healthcare expenditures have been growing much more rapidly than GDP in OECD countries. For example, between 1970 and 2002 these expenditures grew 2.3 times faster than GDP in the U.S., 2.0 times faster than GDP in Germany, and 1.4 times faster than GDP in Japan (Hagist and Kotlikoff 2005).

43 E.g. Cranwell-Ward (1987) found that in organizations within the service industry that are technologyintensive and dynamic, stress levels of employees are substantially higher. In an attempt to compare stress levels of different occupations, Cooper et al. (1988) devised a stress league table and ranked over 100 jobs according to their degrees of stress; sales, retailing and management jobs were identified as "over average" occupations in terms of stress. Broadbridge (2002) finds that jobs in retailing have become more stressful due to the increased rate of change, due to changes in technology, in the market (changing customer needs, internationalisation, concentration, increased competition) and the organisation (down-sizing, sub-contracting, centralisation of decision making, polarisation of workforce). Parent-Thirion et al. (2007) find that the levels of psychological strain are highest in the sectors education, health and public administration.

44 One indication that these skills have become more economically important is the wage premium connected to these skills. For example, Dickerson and Green (2004) show that between 1997 and 2001 there was a growth in Britain in the utilisation of computing skills, literacy, numeracy, technical know-how, high-level communication skills, planning skills, client communication skills, horizontal communication skills, problemsolving and checking skills. Computer skills and high-level communication skills carried the clearest positive wage premium. 


\subsubsection{The increase of non-routine work}

The process of creative destruction through technological substitution and innovation follows a logic of specialisation and division of labour between man and machine: machines do what machines can do cheaper and/or better, while human workers do what human workers can do better. With machines and humans each being put to work according to their 'competitive advantages' in production processes, the jobs of human workers increasingly consist of work that is considered typically 'human': ${ }^{45}$ non-routine knowledge work and interpersonal tasks. Routine tasks are increasingly being performed by technology, freeing but at the same time also obliging employees to take on more varied and challenging tasks.

Evidence by Autor et al. (2003) for the U.S. and Spitz (2004) for West Germany suggests that computerization has caused a significant shift in the job composition from routine to non-routine tasks. ${ }^{46}$ This is in line with the hypothesis that computer technology is complementary to workers with relatively high analytical and interactive abilities (e.g. Acemoglu 1998). It is also in line with the finding that the employment share of workers doing routine tasks like administrative work and machine operating has dramatically declined over the last decades in favour of managing and professional tasks (e.g., Bresnahan, 1999).

A consequence of the shift to non-routine work in jobs is that employees' skills are becoming obsolete more quickly, increasing the need for continuing schooling and training. In general, the more skills the better; not only technical change but also organizational change is 'skill-biased', increasing productivity and wages of higher-skilled more than of lower-skilled. ${ }^{47}$ Non-routine tasks require a wider spectrum of abilities like analytical skills, adaptability to new environments, management skills, the ability to communicate with coworkers (and other social skills) than routine tasks. ${ }^{48}$. Other research also points to the increasing importance of social and psychological skills due to the shift to non-routine

45 Obviously, what is considered 'typically human' is to some extent related to the state of technological progress; e.g. the advances in speech recognition, optical abilities and artificial intelligence of computers shift the notion of which tasks are typically and exclusively human.

${ }^{46}$ Spitz (2004) finds that between 1979 and 1998/99 the share of analytical and interactive tasks have increased even for low-educated workers from 7.6 to 21.4 percent. For medium-educated and high-educated workers, the change has been from 12.8 to 40.2 percent and from 35.6 to 73 percent, respectively.

${ }^{47}$ E.g. the empirical study of Caroli and Van Reenen (2001) finds not only skill-biased technical change but also skill-biased organizational change. Organizational change reduces the demand for unskilled workers and leads to greater productivity increases in establishments with larger initial skill endowments. Technical change is also complementary with human capital, but the effects of organizational change is not simply due to its correlation with technological change but has an independent role.

48 E.g. Borghans et al. (2006) show that technological and organizational changes have increased the importance of "people skills" in the workplace. Egger and Grossman (2005) argue that the cognitive, social and psychological abilities to perform non-routine tasks effectively are typically unobservable for empirical researchers, and are only partially related to formal education levels, thus providing a natural ingredient for the residual wage inequality, which cannot be explained by other factors such as education. In line with this, Gould (2002) provides evidence on a surge of the demand for general skills like analytical and social abilities within all broad occupations, along with rising residual wage inequality. Also see Lindbeck and Snower (2000). 
work. ${ }^{49}$ Thus it can be expected that mental health, an important determinant of the extent to which these skills can effectively be applied, has become more important for performance in these jobs.

\subsubsection{The increase of knowledge work}

It is generally agreed that modern economies can be characterized as knowledge economies; and knowledge and knowledge work have come to centre-stage in debates on economic performance (Nonaka and Takeuchi 1995). Power and Snellman (2004) define the knowledge economy as an economy in which the core economic activity consists of the development, processing and application of knowledge, which gets embodied in people, materialized in products, and used in services. Depending on the definition of knowledge, each economy is to some extent a knowledge economy; but the term knowledge economy is reserved for those economies which explicitly produce knowledge for economic application, and which have large knowledge sectors aimed at only that, such as research organizations and R\&D departments of firms.

Knowledge economies are characterized by a high, accelerated pace of technological and scientific advance and by a similarly high rate of obsolescence of knowledge (Power and Snellman 2004). The key components of a knowledge economy include a greater reliance on intangibles than on tangible resources, on intellectual capabilities rather than on physical inputs or natural resources; combined with active and explicit efforts to achieve improvements through integrating new knowledge in every stage of the production process, from the R\&D lab to the factory floor to the interface with customers. These changes are reflected in the increasing relative share of the gross domestic product that is attributable to "intangible" capital (Abramovitz and David 1996).

There has been a good deal of debate in the economics field over whether particular industries are especially knowledge-intensive, and much effort has gone into analysing how much these sectors contribute to growth in productivity. However, the growth in the number of jobs that are knowledge-intensive is not confined only to specific sectors that are commonly singled out, such as the high-tech sector (Power and Snellman 2004). Information and communication technology has increased the amount of information processing in a wide range of jobs, and have lead to an increase of the average amount of knowledge used in jobs.

Knowledge work is not a specific occupation, job or sector, but rather a type of activity that is part of all jobs in different degrees. With economic development, the component of knowledge work in jobs has increased substantially. The increase in knowledge work has led to an increase in three kinds of skills: cognitive, social-psychological, and regulatory. In jobs containing a large component of knowledge work, information processing is often the core of the work. This means that the skills needed to do so, cognitive skills, are of increased

\footnotetext{
49 E.g. Spitz (2004) finds that between 1979 and 1998/99 the share of analytical and interactive tasks has increased even for low-educated workers from 7.6 to 21.4 percent. For medium-educated and high-educated workers, the change has been from 12.8 to 40.2 percent and from 35.6 to 73 percent, respectively.
} 
economic importance, as is underlined for example by the increased wage premium on these skills. ${ }^{50}$

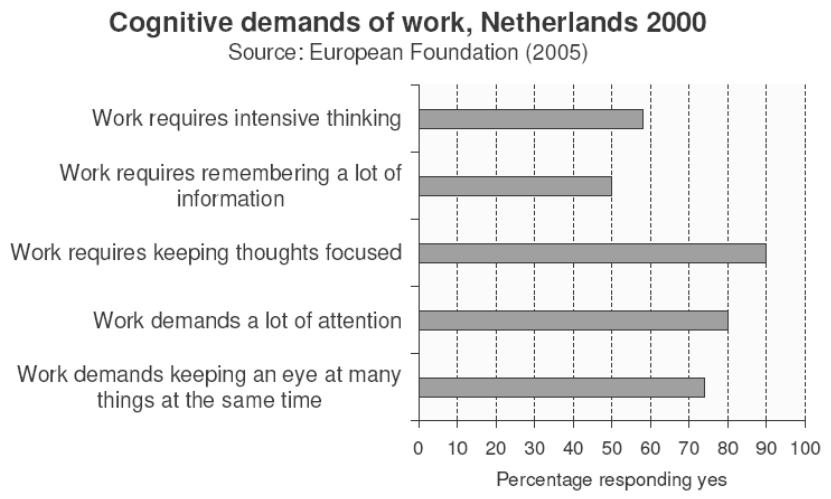

Figure 3. Cognitive demand of work, Netherlands, 2000 Source: European Foundation (2005).

Furthermore, social-psychological skills have become more important. ${ }^{51}$ Nonaka and Takeuchi (1995) argue that the productivity of knowledge work depends on the extent to which transfer of existing knowledge takes place; underutilised knowledge is a large hidden cost in organizations. The most valuable knowledge is embedded in people; because it is so difficult to transfer outside the immediate context of an organization, it has becomes a major competitive advantage. Since this type of knowledge is embedded in persons, and since transfer of knowledge is essential, interpersonal communication has become more important (Sveiby and Simons 2002). Emotional intelligence is crucial for effective knowledge sharing (e.g. Van Rooy and Viswesvaran 2004).

Thirdly, knowledge work requires more regulatory skills. The knowledge worker generally knows more than his manager about the particular task or topic he or she works on. ${ }^{52}$ Rather

\footnotetext{
50 Pryor and Schaffer (1999) show that the returns to cognitive-related ability have risen, due to technologyinduced relative demand shifts. Tyler et al. (2000), testing the labour market signaling hypothesis for the General Educational Development (GED) equivalency credential, find substantial earnings returns to cognitive skills for most high school dropouts. Murnane et al. (1995), using data from two longitudinal surveys of American high school seniors, show that basic cognitive skills had a larger impact on wages for 24-year-old men and women in 1986 than in 1978. For women, the increase in the return to cognitive skills between 1978 and 1986 even seems to account for all of the increase in the wage premium associated with post-secondary education. Murnane et al (2000) find that cognitive skills are important determinants of subsequent earnings, and that the effect of cognitive skills is modest.

51 E.g. Dickerson and Green (2004), using a method for measuring job skills derived from survey data on detailed work activities, show that between 1997 and 2001 there was a growth in Britain not only in the utilisation of computing skills, literacy, numeracy and technical know-how, but also in high-level communication skills, planning skills, client communication skills, horizontal communication skills, problemsolving and checking skills. Computer skills and high-level communication skills carry positive wage premia, both in cross-section hedonic wage equations and through a within-cohorts change analysis

52 E.g. Syed (1998) shows that the complexity of the environment of knowledge workers has increased, and is characterized by more change, more uncertainty and more information that needs to be processed; therefore
} 
than direct supervision and monitoring, knowledge workers are generally managed through indirect management strategies: activation of the self-directing capabilities of workers, increasing their intrinsic motivation so they work hard also without monitoring, and increasing goal alignment between the goals of the organisation and the individual worker. ${ }^{53}$ This means that knowledge workers need to be good at managing themselves.

Jobs with more cognitive demands are often experienced as more satisfying, because workers tend to be content-driven and interested in their work. ${ }^{54}$ Because of the importance of cognitive, social-psychological and regulatory skills for knowledge work, mental health problems affect performance in jobs with high levels of knowledge work more than jobs with lower levels of knowledge work. For example, being depressed is associated with of loss of concentration, reduced cognitive performance, tendency of social isolation and loss of intrinsic motivation. ${ }^{55}$ Conversely, jobs with high levels of knowledge work can affect mental health more than jobs with lower levels of knowledge work, because of the characteristics of knowledge work in terms of job requirements such as self-regulation, self-management, selfmotivation. Research suggests that the characteristics of knowledge work increase the risk of job stress and conflict at work (e.g. Scarbrough, 1999). In addition, knowledge work provides more possibilities for finding intrinsic utility, identification and self-actualisation of workers, but it thereby also provides more possibilities for disappointment and feelings of personal failure.

\subsubsection{The increase of emotion work}

Increasingly, people are interacting with other people as the core of their jobs - providing services, sharing knowledge, communicating, to cooperating (Dollard and Winefield 2002). Workers more and more have to be "people people" (Borghans et al. 2006) with good social and emotional skills. ${ }^{56}$ Consequently there is an increase in emotion work in many jobs. Interpersonal interaction always activates emotions and requires effortful emotion

\footnotetext{
time and attention have become the scarcest resources in such an environment and the ability to allocate these dynamically and optimally has become the more important.

${ }^{53}$ Changes in management practices will be discussed into more detail in section 2.4.3.

${ }^{54}$ E.g. European Foundation (2006) shows differences in "satisfaction with work" especially in the category "very satisfied", which is indicated by $32 \%$ of workers working in a job with high cognitive demands as compared to $13 \%$ of workers in a job with low cognitive demands; and in the category "not at all satisfied", respectively $2 \%$ in cognitively demanding jobs and $10 \%$ in jobs with low cognitive demands.

${ }^{55}$ For more on symptoms of mental health problems, see the Diagnostic Statistical Manual, DSM-IV, APA (1994).

${ }^{56}$ Fuchs (1968), one of the first to describe the emergence of the service economy, already observed that the work in services is generally more "personalised," and that more personal skills are needed and exercised than in the increasingly automated goods industries.
} 
regulation. ${ }^{57}$ Emotions, or rather the ability to control emotions and put them to use for economic purposes consequently becomes more important for economic success. ${ }^{58}$

Morris and Feldman (1996) define emotional labour as the "effort, planning, and control needed to express organisationally desired emotions during interpersonal transactions." Goffman (1959) showed that in every social interaction people follow rules about appropriate emotional expression, so-called 'display rules'. According to Ekman (1982), display rules are norms and standards of behaviour indicating which emotions are appropriate in a given situation, and how these emotions should be publicly expressed. The term "emotion work" (Hochschild 1983) refers to the regulation of emotions as a clear requirement of the job, during work-related interpersonal interactions, between employees and clients, between colleagues, and between workers and managers. Many employees are required to express appropriate emotions as a job requirement controlling both their emotions and the display of their emotions, and managing other people's emotions. ${ }^{59}$ This requires substantial psychological and social skills; it requires "emotional intelligence" (Goleman, 1995).

Emotional labour not only requires more "people skills", but also a different way of organising work. Generally, part of the value of a service that is high in emotion work is created during the interaction with customers. Whether and to what extent an employee puts in emotional work is largely outside of the direct control of the manager. However it is not out of the manager's indirect control. In the service sector, human resource management generally aim very explicitly at selecting employees with social and emotional skills. In addition, managers often employ a number of techniques of goal alignment. Like in the case of knowledge work, this is partly achieved by building on and creating intrinsic motivation through increasing the identification of employees with their profession and with their organisation, and through internalisation of the goals and values of the organisation, through a thorough process of socialisation. ${ }^{60}$

Often more emotion work is experienced in terms of higher work pressure; to some extent workers explicitly recognize it as emotional burden. E.g., Hooftman and Houtman (2008) in an empirical study on working conditions in the Netherlands, find that exposure to emotionally demanding work was reported by $7 \%-8.5 \%$ of workers, with big sectoral differences, emotionally demanding work is common in the healthcare sector, at $20.2 \%$ and lowest in agriculture and building, around $3 \%$. Thus, the proportion of emotion work is

\footnotetext{
57 Muraven and Baumeister (2000) put forward that social interaction is always characterized by emotions which need to be controlled. Before, during and after interacting with others, people adjust their moods and emotions to meet the anticipated demands of the situation. People are generally motivated to make a favourable impression on others across a wide variety of social situations (Dunn et al. 2007), thus more social interaction evokes more emotions and greater need for effortful emotion regulation.

58 The concept of "emotional labour" was introduced by Hochschild (1983), building among others on Goffman (1959). For a review on the literature on emotion work, see Zapf (2002).

${ }^{59}$ Examples are flight attendants who are required to be always friendly, even toward annoying customers and regardless of their real feelings; nurses or teachers who have to show empathy towards patients or children, and bank employees or sales persons who have to signal expertise and trustworthiness by their general demeanour which should always be controlled (Hochschild 1983).

${ }^{60}$ More on new forms of management is provided in section 2.4.3.
} 
higher in the growth sectors of the economy (see Figure 4). Due to sectoral shifts, the average amount of emotion work per capita of the labour force is going up.

\section{Emotional demands from work in the Netherlands, 2005}

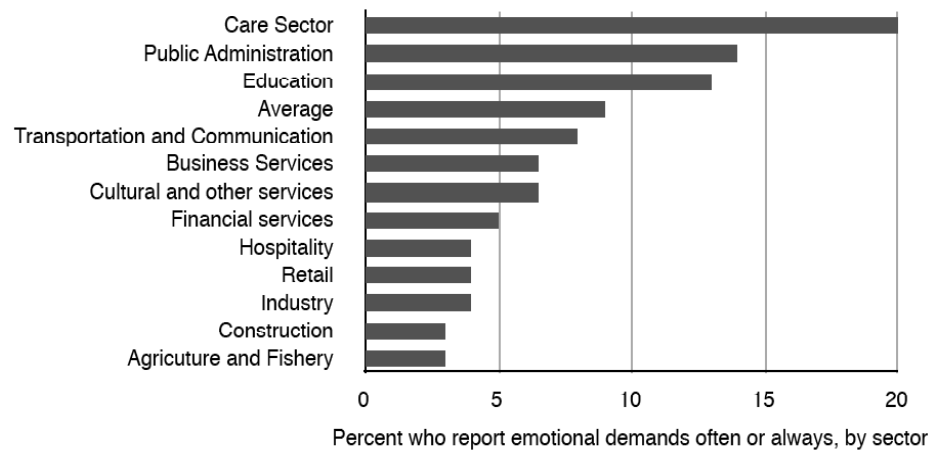

Figure 4. Emotional burden of work by sector, Netherlands, 2005. Source: TNO Quality of Life, Smulders (2006).

Jobs with high levels of emotion work carry psychological risks, such as over-identification and difficulties to establish and maintain borders between work and non-work. Showing emotions not felt at that moment can lead to emotional dissonance and alienation of one's feelings, which can in turn cause psychological problems due to chronic emotional dissonance. ${ }^{61}$ Structural emotional dissonance is stressful, and research has found it to be related significantly to burnout (Zapf 2002).

Burnout $^{62}$ was first investigated in the helping professions (e.g., Maslach 1982), in which work generally is emotionally demanding and associated with high levels of personal, emotional involvement. It is found that burnout is common in these professions, indicating that employees are no longer able to adequately manage their emotions when interacting with clients. In more recent research, it was found that jobs without direct client contact but requiring much interaction with colleagues were also associated with increased risk of burnout (e.g. Maslach et al. 2001).

The research on emotion work shows that it has both positive and negative implications in terms of job satisfaction and job stress (Zapf 2002), and can be viewed as a 'magnifying factor'. Higher levels of emotion work increase the chance of high job satisfaction, but also

\footnotetext{
${ }^{61}$ Emotional dissonance occurs when an employee is required to express emotions which are not genuinely felt in the particular situation; it requires effortful emotion regulation, an increasing job demand. Hochschild (1983) described various psychological consequences of emotion work and posited that emotion work can be seen a special far-reaching form of human exploitation, harnessing the workers' emotions and personalities to make profit.

${ }^{62}$ The three main characteristics of the burnout syndrome commonly occur among individuals who do 'people work': emotional exhaustion, reduced personal accomplishment and depersonalisation. Lack of personal accomplishment refers to the tendency to evaluate one's own work negatively, accompanied by feelings of inefficiency and poor professional self-esteem. Depersonalisation refers to personal detachment (Schaufeli and Enzmann, 1998).
} 
of job stress and work-related mental health problems. Personal characteristics, job characteristics and organizational characteristics together determine the mental health effect of emotion work - for better and worse.

\subsection{The changing organisation of work}

Not only the content of work has changed, but also the organization of work. This section briefly sketches why and in which ways the organization of work has changed, and then discusses the psychological consequences of these changes.

\subsubsection{Organizational change}

Technological development enables, and to some extent requires new forms of organisation, in order to fully realise the potential benefits of new technology. ${ }^{63}$ In the artisan economy before the Industrial Revolution, craftsmen produced products on demand, used generalpurpose tools and technology with constant returns to scale. The degree of customisation was high and independent of the extent of the market. The lack of standardisation limited the division of labour and skilled craftsmen performed most of the intermediate production steps themselves.

By contrast, the mass production economy that emerged with the Industrial Revolution used large-scale, dedicated special-purpose equipment to produce identical items at low marginal costs. Production could now realise increasing returns to scale, and realising 'economies of scale' became the dominant strategy, since the unsaturated markets absorbed whatever was produced, especially as markets were further developed and matured through the use of marketing and advertisement. Workers were generally low-skilled, easily replaceable and relatively cheap; thus, labour was generally organised around the relatively immobile and expensive machines. The standardisation of product markets made the output mix predictable (initiating the mass production era), allowing companies to assign workers to narrowly defined tasks in an extreme division of labour. ${ }^{64}$

In the 1960s, saturated markets could no longer be expanded by mere quantity, and added value had to be found in upgrading and diversifying quality. Economies of scale had to be combined with economies of scope through customisation. This required different ways of

\footnotetext{
${ }^{63}$ Authors such as Mobius (2000) and Mitchell (2005) give an overview of this development from a strictly economic perspective, and provide formal models showing the basic mechanisms and dynamics of this development.

${ }^{64}$ This is generally referred to as 'taylorisation' or 'fordism', a design of work processes characterised by sharp division of labour and standardisation of tasks, where workers performed a narrow set of tasks according to detailed job descriptions. As Taylor himself put it in his theory of 'scientific management': "All possible brainwork should be removed from the shop and centred in the planning or laying-out department. [...] Under our system a worker is told just what he is to do and how he is to do it. Any 'improvement' he makes upon the orders given to him is fatal to his success." (Taylor, 1911, p.21) This gave labour to some extent the character of a commodity which is less context- and person-dependent and can be bought and sold more easily thus making the labour market more into a real market and enabling the capitalist mode of production (Braverman 1974).
} 
organising work, resembling in many ways the 'artisan economy' of earlier periods: broader job descriptions, more team work, flatter hierarchies, more multi-tasking, more direct contact with customers and overall more flexibility. In order to deal with product proliferation, customization and the greater uncertainty about the composition of product demand production firms started to implement innovative flexible production systems. The main goal of these new systems was to increase flexibility of production, to thereby decrease the costs of increased variety (Smith 1997. Mobius 2000, Mitchell 2005).

The large immobile machines in factory were increasingly automated, reducing the need for labour in that part of the production process. The emerging dominant technology (ICT) grew rapidly better and less expensive, and smaller and compact. Technology increasingly is therefore organised around the increasingly high-skilled, relatively expensive workers rather than the other way around. Mobius and Schoenle (2006) explain these trends in the organization of work through a model showing capital-skill substitutability during industrialization and capital skill complementarity in the maturing industrial economy.

\subsubsection{Flexibilisation and 'psychological transaction costs'}

An important development in the area of work is flexibilisation. Two main types of flexibility can be distinguished. External or numerical flexibility matches labour inputs to output fluctuations. Firms often accomplish this by shifting their organizational structure, reducing or downsizing the number of permanent and full-time workers while relying more on contingent subcontracted and temporary help. Internal or job flexibility matches employee skills to changing task requirements, workload, work organization. ${ }^{65}$

External flexibility, flexibilisation of the labour market (e.g. easy hiring and firing), in theory should optimally accommodate and 'smooth' the mechanism of creative destruction, allowing easy re-absorption of workers in other parts of the economy. However, the labour market only partially acts like a real market. ${ }^{66}$ Aspects such as rigidities of location, mismatch between supply and demand of skills, firm-specific human capital, incomplete contracts make the labour market a special case, and social and psychological aspects play a major role in this market, a role which is not recognized sufficiently in economics. ${ }^{67}$

\footnotetext{
65 Wilthagen (2006) proposes the following four-way classification of flexibility: (1) external (numerical) flexibility (e.g. types of employment contracts, employment protection legislation); (2) internal (numerical) flexibility (e.g. working-time arrangements); (3) functional flexibility (e.g. work organisation practices such as task rotation and teamwork) and (4) flexible or variable pay (e.g. profit-sharing schemes). Multi-skilling, broadbanding, changing job classifications, and reengineering represent a few ways that firms implement job flexibility. An important aim of most of these organizational innovations is to increase efficiency and eliminate idle time that workers with narrower skills or job descriptions would have, trying to accomplish more work with fewer workers.

${ }^{66}$ There is an extensive literature on the theoretical and empirical validity of the neoclassical competitive model of labour markets; the labour market is a social institution (e.g. Solow 1990) in which there is imperfect competition requiring inclusion of non-economic factors in explanations of labour market behaviour. For a critique of the assumptions of most currently used labour market models and a proposal to expand the behavioural foundations of labour economics, see Kaufman (2007).

${ }^{67}$ Burchell (1999) finds that job insecurity is damaging to psychological health, marriages and employee motivation, and contributes to 'cycles of disadvantage'. He finds that flows from secure to insecure jobs were more common in the $1980 \mathrm{~s}$ than in the $1970 \mathrm{~s}$ and 1960 s, and that the risk of a transition from a secure job into
} 
It is generally argued that especially in today's globalized markets, inelastic adjustment of wages and employment to economic shocks becomes the binding constraint for productivity and employment growth, and thus external adjustments and high mobility on flexible labour markets are preferred to stable, tenured labour markets. However, empirical evidence does not seem to support this assumption, or perhaps even the opposite (Storm and Naastepad 2007, Dew-Becker and Gordon 2008). ${ }^{68}$

Regulated labour markets are not negatively associated with employment and labour market participation, and are positively associated with higher labour productivity. An important reason for the relationship between non-flexible labour markets and productivity lies in the impact of labour market regulation on worker motivation and worker effort. Storm and Naastepad (2007) identify a number of ways of explaining this: efficiency wage theories, ${ }^{69}$ firm-specific human capital ${ }^{70}$ and tacit knowledge and trust. ${ }^{71}$

This thesis adds an explanation to the possibly detrimental effects of external flexibility on productivity and labour market participation: the psychological effects of this type of flexibility. External flexibility, numerical flexibility through flexible labour market, often translates into high levels of job insecurity for both high-skilled and low-skilled workers. Especially low-skilled workers have few opportunities to acquire new skills in flexible labour markets, and face marginalisation in the periphery of the labour market consisting of temporary workers (Smith 1997). Many workers experience the increased dynamism of the economy as heightened uncertainty and as a source of stress, as was discussed in 2.2.2 and 2.2.3. While transaction costs are recognized and discussed in economic theory, there is only very little awareness of what could perhaps be called 'psychological transaction costs' to employees. These are not taken into account, in spite of compelling evidence in

an insecure job is much greater for those in less advantaged jobs, which is a sign of polarisation. For an extensive account on prevalence and consequences of job insecurity, see Burchell et al. (2001).

${ }^{68}$ For example, Dew-Backer and Gordon (2008) find that protective labour markets have a positive effect on productivity growth and employment and does not have a negative effect on labour market participation. Econometric research by Baccaro and Rei (2005) find that flexibilization of the labour market by making firing more easy is associated with higher unemployment rather than less. Faggio and Nickell (2007) find that deregulated labour markets are not necessary for realizing high labour market participation. Storm and Naastepad (2007) present empirical evidence for a cross-section of 20 OECD countries (1984-1997) that relatively rigid (i.e. regulated and co-ordinated) labour markets promote long-run labour productivity growth. They find that less flexibility leads to investment in increasing labour productivity in for example labour-saving technology and education of employees, due to higher labour costs.

${ }^{69}$ (Non-economic) efficiency-wage theories suggest that, because firms and workers operate under a fairness constraint, a higher real wage rate will positively affect labour productivity by raising workers' commitment (Akerlof 1982). (Economic) efficiency wage theories argue that labour productivity depends positively on worker remuneration: the higher the wage, the higher will be the effort by workers due to a higher cost of job loss (Gordon 1994).

${ }^{70}$ Firm-specific human capital theories posit that workers receive (on-the-job) training and thus acquire firmspecific human capital (which is not available on the external market). To retain them and avoid costly labour turnover, firms share returns and offer job security, but delay transferring the wage gains from increased productivity by means of a seniority system of compensation (Auer et al. 2005). In order to get employers and employees into this win-win situation, labour market regulation is beneficial, and deregulation and external flexibility can be detrimental.

71 Theories on tacit knowledge and trust suggest that employment security will promote the willingness of workers to share their (tacit) knowledge with colleague workers, and will stimulate them to innovate, since they do not have to worry that process innovations will result in layoffs (Agell 1999). 
psychological research that these costs are existing and large, and that they influence labour market decisions in important ways. The uncertainty related to external flexibility and the spells of unemployment that inevitably accompany this type of flexibility leads stress, mental health problems and to erosion of self-efficacy, which in turn negatively affects productivity and labour market participation; the underlying mechanisms and the empirical evidence for this effect will be presented in chapter 3 .

The second type of flexibility is internal or job flexibility. There is a growing belief that organization structures should be flexible, working times should be flexible, and workers should be autonomous and develop new and complementary role orientations. ${ }^{72}$ Smith (1997), reviewing the social science literature on new forms of work organisation finds that to achieve internal flexibility, work arrangements are structurally decentralised, leaving workers in comparatively autonomous positions. Flexible systems aim to strengthen horizontal ties, and to inspire institutionalise involvement, creating opportunities in which workers can interpret information, act on their personal experiential knowledge, make decisions in a timely way, spontaneously innovate in accordance with shifting product and service demands, and maximise their efforts by collaborating with others in offices and on shop floors. Information and communication technology are crucial in this, by enabling more flexibility and flatter hierarchies, ${ }^{73}$ and lead to enriched, higher-skilled jobs. ${ }^{74}$

The evidence on the effect of flexible work practices on workers is mixed. On the one hand, more flexibility in combination with more autonomy can make it easier for workers to "smooth" their busy lives and avoid work-family conflict, leading to higher job satisfaction. ${ }^{75}$ On the other hand, flexibility is found to be associated with negative effects. The expansion of job descriptions and task requirements that accompanies "enriched jobs" creates a set of pressures for workers; e.g. Cooper et al. (2001) shows that jobs have become more fluid, ${ }^{76}$ which has exacerbated role ambiguity and role conflict, resulting in work stress and mental and physical health problems. As traditional job classifications blur, responsibilities of

\footnotetext{
72 Parker et al. (1997) write that the literature suggests "that employees need to embody a broader and more proactive approach to their roles in which they both own, or feel responsible for, work beyond their immediate tasks $[\ldots]$ and recognize the importance of acquiring and using a wide range of skills and knowledge to enable them to contribute at that broader level" (p. 900-901)

73 Specific organisational innovations in this line include quality circles, employee involvement programmes, job enlargement and rotation, self-managing teams, continuous improvement processes, organisational decentralisation, and the promulgation of a new ethos of participation. Just-in-time inventory procedures, outsourcing, and techniques for fine-tuning the size of the work force would institutionalise flexibility more firmly, enabling firms to move swiftly, to cut through excess and minimise waste (Smith 1997).

74 Empirical research shows that there are complementarities in factor demand and productivity regressions among firms' adoption of information technologies, new products and services and innovative forms of work organization. Firms that adopt these innovations tend to use more skilled labor. The effects of IT on labour demand in terms of skills are greater when IT is combined with organizational innovation (Bresnahan et al. 2002).

75 E.g. Lu et al. (2008) found that organizational policies and practices such as work flexibility could alleviate feelings of work interfering with family, further enhancing job satisfaction and organizational commitment; Whittall (2007) reports that employers can reduce absenteeism by applying the so-called 'adjustment latitude principle', tailoring work demands to match the capabilities of employees with health problems.

${ }^{76}$ This trend is continuing, e.g. Holm Christiansen and Ourø Nielsen (2007) find that in the period 2000-2005 the level of 'role clarity' in Denmark has decreased, such that employees experienced their fields of responsibility at work to be less defined.
} 
individual workers can grow without any commensurate increases in rewards. One of the consequences of flexibility and broader role orientations is role ambiguity. Lack of clarity about job roles and about criteria of adequate performance can lead to role overload and role conflict. ${ }^{77}$ This in turn has been associated with job dissatisfaction, anxiety, and employee turnover (e.g., Bolino and Turnley 2005). The increased role ambiguity, role overload and role conflict also may explain the high rate of conflict with co-workers and managers, which is in turn a major sources of stress, work-related mental health problems and absenteeism. The conclusion must be that flexibility has different forms and features, some desirable and others less so, depending also on the perspective one takes, the employee's or the employer's.

The precise extent of the implementation of flexible work practices is not clear. Smith (1997) suggests that the wish to introducing more flexibility is pervasive but the actual presence of this in practice may be much less so. It seems that flexible work practices are increasing, but some more than others, and they are unevenly developed across occupational, organisational, and industrial settings. ${ }^{78}$ Also, the spread of (elements of) flexible work practices differs per country (for example, 0 ). The increase of flexible work practices may partially have been the result of a sector-bias, the increase of the service sector in which such work practices are more present in the first place may have been an important determinant of the overall shift in organisational practices in the economy.

External flexibility is most commonly found in "low-end" jobs, low-skilled and low-paid, but increasingly also in "high end" jobs, though in quite a different way through increased selfemployment by high-skilled workers. Internal flexibility through new flexible practices is most commonly found in "high-end jobs," with highly skilled workers, in firms that are knowledge intensive, which compete in international product markets, emphasise quality, and have relatively highly skilled workers. In the more idealised accounts of work flexibility, organizational structures are flattened and trimmed and designed around the core processes of the organisation, and high-skilled, continually learning, empowered and engaged workers, aided by entrepreneurial managers and use their knowledge and skills to continuously improve the way they produce goods or serve people (Smith 1997). For people in high-end jobs, internal flexibility is often seen as a desirable feature, since it means more opportunities to find better, more interesting and better-paid work. ${ }^{79}$ The mixed results in the literature on

\footnotetext{
77 Role stressors consist of role ambiguity, role overload and role conflict. Role ambiguity is uncertainty, stemming from the lack of availability of information for adequate role performance or task completion. Role overload is the conflict of priorities resulting from expectations that a person performs a wide variety of tasks which are impossible to complete within the given time limits. Role conflict is psychological conflict experienced by an individual (focal person) as a result of conflicting pressures exerted by role senders. See for example Jex et al. (2003).

78 An analysis of fifteen years of the five-yearly survey on working conditions in the EU (European Foundation, 2006) suggests that some flexible work practices spread more easily than others; for example flexible works schedules in terms of working time are only slowly increasing, about two thirds of workers still have fixed work schedules. Country studies such as Holm Christiansen and Ourø Nielsen (2007) on Denmark found that the vast majority of workers continue to perform work during normal daytime working hours; temporary employment has not increased; working from home has increased only slightly, suggesting that most workers still have clear outlines of their job in terms of time.

79 E.g. Birindelli and Rustichelli (2007) find that both managers and employee representatives tend to report higher job satisfaction as an outcome of the introduction of flexible working times (a specific form of internal
} 
whether flexibility is a positive of negative job feature, suggests that is depends on the type of flexibility and on the ability of the worker to deal with the responsibility and selfmanagement that accompanies flexibility. Flexible work practices can be demanding of workers, it can lead to increased "psychological transaction costs", in terms of the increased number of "internal transactions" (choices, decisions) going on inside of the head of employees having to plan and organize their own work. ${ }^{80}$ This is related to the new type of management strategies that accompany flexible work practices within the organization, which will be discussed next.

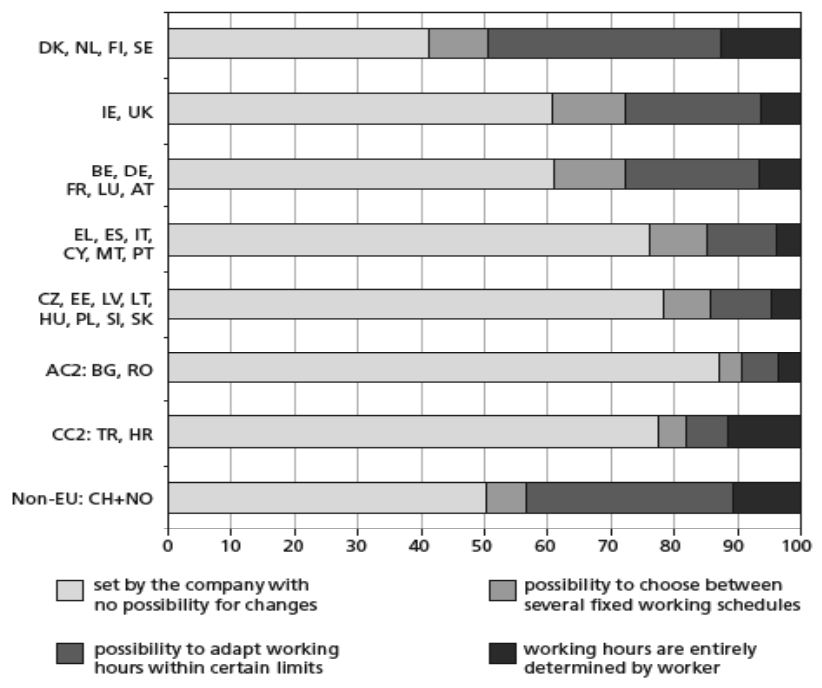

Figure 5. Autonomy over working time, by group of countries (\%). Source: Parent-Thirion et al. (2005).

\subsubsection{The changing management of work}

A core problem in the labour market is contract incompleteness, due to imperfect and asymmetric information - conditions that lead to a host of contracting problems now popular in the modern research literature, such as principle-agent problems and moral hazard (Kaufman 2007). These problems were well-recognized by earlier generations of institutional economists. Commons (1919: 22-3) states, for example, "the labor contract is not automatic and is not enforceable according to specifications. It is a new contract every day and every hour.... The laborer is bargaining while he is working." (Commons 1919, cited in Kaufman 2007).

The challenge from an economic perspective is to maximize worker effort while minimizing the costs related to this, such as contracting costs and monitoring and managing costs. As Kaufman (1999) observes, in economics, work is in principle a source of disutility (on the

flexibility); it helps to reduce in paid overtime hours, it lowers absenteeism, and leads to higher job satisfaction, mainly because of better adaptation of working hours to workload (these positive effects are conditional, only valid in certain types of jobs and organizations).

${ }^{80}$ In chapter 3 the underlying issue of limited cognitive resources will be discussed. 
margin), thus workers in principle have an incentive to minimize it; to call in sick, work at minimum speed, and loaf whenever possible. To prevent this, firms hire supervisors and managers to monitor employees and set up elaborate disciplinary procedures to provide deterrents and punishments. Since a decade or two, it is widely argued in the management literature that a cheaper and more effective method exists to elicit employee work effort and dedication. That is to make the work interesting and self-managed, such as through individual autonomy, team work and job enlargement/job enrichment. ${ }^{81}$ When these practices are implemented, it is argued, work becomes much more intrinsically satisfying and workers become more internally motivated to work hard and attend regularly. As a result, firms no longer need as many supervisors and punitive disciplinary systems, and employee productivity reaches higher levels than can be obtained through manipulation of external rewards and punishments (Kaufman, 1999).

Rather than seeing the worker as a possible source of disturbance of the production process and trying to suppress creative thoughts and initiative as much as possible, as in the times of Taylor (1911), the worker is seen as a source of knowledge, experience and creativity that should be tapped. Direct control of the labour process is no longer seen as necessarily the most effective way to realize organizational goals. It is found to be more effective (in terms of generating effort, productivity, problem-solving) to increase worker autonomy so that they can exercise a degree of discretion in applying their knowledge and ingenuity to the determination and distribution of work tasks, often as part of teams (Sewell 1998).

New work practices imply greater involvement of workers in decision-making and discretionary efforts at work; they change the nature of workers' tasks, becoming less standardised but more demanding in terms of problem-solving efforts by the workers (Birindelli et al. 2007). Self-managing individuals are responsible for determining approaches to task execution as well as for monitoring and managing their own behaviours (Manz and Sims, 1980). In self-managing situations, many of the functions traditionally reserved for managers become the responsibility of subordinates, including monitoring performance, taking corrective action, and seeking necessary guidance or resources (Manz and Sims, 1987). An important related trend is to institute self-managing work teams, in which employees manage themselves and each other via peer pressure.

Self-management ${ }^{82}$ by employees is generally especially effective in dynamic environments because it is more adaptive, faster, and more direct. Research suggests that there are systemic

\footnotetext{
${ }^{81}$ Empirical evidence such as fifteen years of working conditions survey research (European Foundation 2006) shows that the levels of autonomy at work in the EU are relatively high; around two thirds of employees are able to choose or change the order of tasks, speed and methods of work (in the case of the self-employed, almost 90\%). Most European workers are responsible for assessing the quality of their work themselves $(73 \%)$ and solving unforeseen problems on their own (81\%). Also, for a majority of Europeans, work involves learning new things $(70 \%)$. The increase of autonomy over the past decades has slowed down and in the last 10 years, the high levels of autonomy seem to be slightly decreasing (European Foundation 2006).

82 Self-management can be viewed as a set of behavioural and cognitive strategies that assist individuals in structuring their environment (at work or elsewhere), establishing self-motivation, and facilitating behaviours appropriate for attaining performance standards (Manz, 1986). Self-management refers to all the processes needed for effective goal setting and goal getting. It involves the learning and orchestration of cognitive processes for acquiring skills, self-monitoring progress, and providing self-reinforcement (Gist and Mitchell 1992).
} 
links between the way work is organised in a firm and its capacity to innovate; organisations giving more discretion to workers (more autonomy) are better able to innovate (e.g. Lorenz and Valeyre 2006; Arundel et al. 2006). Increased self-management is particularly effective in jobs with high levels of knowledge work and emotion work. In service jobs, interpersonal interaction generally is at the core of jobs, and this is generally difficult to fully and precisely script and monitor, making it more effective to let the worker self-manage and self-monitor. In knowledge work, typically a knowledge worker knows more about his own field of expertise than his manager. In jobs with a lot of emotion work, the worker is generally better informed about his own positive and negative emotions as he is experiencing them himself, and thus about the need to manage them. The shift towards self-management and autonomy of employees is from this perspective not surprising.

Self-management allows continuous "micro-management." Research suggests that selfmanagement, building on employee commitment rather than on control-oriented approaches to management generally leads to better performance of workers, to some extent depending on the nature and context of work (e.g. Uhl-Bien and Graen, 1998; Frayne and Geringer 2000; Latham and Frayne 1989). Self-management is potentially much more effective for an organisation, as long as the employee directs his self-management towards achieving organisational goals. This requires a firm belief on the individual's part that he or she wants to set and commit to the goals of self-management (Stewart et al. 1996). ${ }^{83}$

Under-engaged employees represent an economic cost, as a vast reserve of untapped 'employee performance potential'. ${ }^{84}$ In management literature, the theme of 'unleashing' the 'hidden value' of human potential in organisations has gained enormous popularity (O'Reilly and Pfeffer 2000). Empirical research suggests that flexible practices, autonomy and participative decision-making indeed can amplify workers' performance (e.g. Smith 1997). However, these higher levels of autonomy and participation are more constraining than they seem at first sight. In return for their limited increase in freedom, workers can now be held responsible for outcomes that were once the near-exclusive responsibility of supervisors and managers, and thus have to face the uncertainty and stress that comes with responsibility and accountability. Autonomy is often considered a positive feature of jobs, but it implies additional work: people have to be able to assess their own problems, set their own goals, self-monitor their progress and interpret their situation.

Even corporate workers employed on a permanent, secure basis are increasingly expected to act like subcontracted workers (Smith, 1997). Employers expect employees (especially in

\footnotetext{
${ }^{83}$ This is a solution to the principal-agent problem. There is asymmetry of information between the principal and the agent, and there is divergence between the interest of the principal and of the agent. The solution to the information problem is to largely decentralise management of work to the level of the worker. The solution to the problem of diverging interests is to reduce this divergence. In order to make the agent act in the interest of the principal, management techniques are applied involving goal alignment of agent and principal, identification of the employee with the organisation and the goals of the organisation, through means of selection of new employees with certain personality traits and certain drive, and through intense socialisation processes in which the goals of the organization are imprinted in the individual employee.

${ }^{84}$ Work engagement is positively affecting performance via its effects on variables such as organizational commitment, self-efficacy, time and effort spent on work; e.g. Harter et al. (2002), Hakanen et al. (2006); Salanova et al. (2005), Schaufeli and Bakker (2004).
} 
high-end jobs) to think of themselves as entrepreneurs within the organization, and almost as self-employed. They are expected to continually ask themselves how and where they can add more value to their work organisation, and how they can change themselves to be more fit for their current or potential future task. Workers have to continuously pro-actively invest in and exploit their own human capital, and have internalized the need to do so, in the form of practices such as life-long-learning. The deeper personal and interpersonal engagement in the planning and execution of work means an increase of emotion work and the psychological risks that come with this.

It appears that employees increasingly come to see themselves as products, which they have to exploit, perpetually marketing themselves to the market place. In this new workplace, the ability to manage and sell oneself takes on new meaning. The employee increasingly sees himself as a "personal company" (run by himself); Drucker (1998) for example points to the need for each knowledge worker in the new economy to think and behave like a chief executive officer; Peters (1997) writes about a 'brand called you'; and Cappelli (1999) points to the need for employees to brand and market themselves as products.

Empirical studies show that the new work practices such as more autonomy are widespread. ${ }^{85}$ The outcomes of the new management strategies are ambiguous for workers. It is often argued that more control over work helps workers to deal with job demands, resulting in less work pressure and stress (the demand-control model from Karasek, 1979). However, the literature on self-management suggests that more control can also be a demand in itself. ${ }^{86}$ Increased autonomy shifts responsibilities from supervisors to workers and results in practice not in more freedom but in more intensive and demanding work. Some researchers even speak of practises such as empowerment, autonomy and involvement as a "wolf in sheep's clothing" that managers can use to exploit and control labour in new

85 E.g. Greenan et al. (2005), reviewing empirical studies on new work practices find that these are quite widespread in the EU-15; for example, workers' autonomy involved $60-70 \%$ of all workers, complex tasks concerned around $60 \%$ of all workers; teamwork and task rotation involved slightly more than $50 \%$ and $40 \%$ of all workers, respectively. Flexible work practices are quite common across the EU-15 and their adoption took place mostly in the 1980s and early 1990s. Evidence of Gallie (2005) suggests that this trend has been slowing down; in 1996-2001, job control did not significantly increase in the EU-15 and the complexity of work (e.g. solving unforeseen problems, complex tasks, learning) seemed to even decrease between 1995 and 2000 in the EU-15. Greenan et al. point out that in many countries there was an increase in complexity but this increase can be explained fully by sectoral and occupational shifts; thus more people work in sectors and occupations that have complex work, but the work itself has not become more complex. Another issue to consider is evolved expectations about how much complexity a job normally has (desensitization). The measurement and comparison of working conditions between countries and over time needs careful interpretation, however all the authors in the area seem to agree on the basic trends, and merely disagree on when, how long and how much.

${ }^{86}$ E.g. Gallie (2005), studying in the EU-15 countries over the period 1996-2001, shows that higher levels of job control have a strong association with higher levels of work pressure even when other factors (including occupational class position) had been taken into account. In addition, Gallie finds that rising skills have negative effects on work pressure. Sluiter et al. (2001) find that job control did not contribute significantly to explaining the variance in health complaints and need for recovery; more job control did not reduce health complaints or need for recovery. Empirical evidence for the impact of job control on variables such as work pressure and work intensity is inconclusive, indicating that it concerns a complex relationship in which factors such as the individual characteristics of employees, job characteristics, and history (e.g. accumulation of work stress) play a role. 
ways (Power and Snellman 2004). These strategies are in fact decentralizing not only decision power but also responsibility, uncertainty and risk. In this way, the dynamism of the economy is less absorbed and buffered by organizations than in the past, but rather passed on to lower levels of the organization, exposing workers at the individual level to new forms of stress. Critics of the new work practices therefore argue that many changes are cosmetic and often serve as a means of concealing traditional control and authority relations (e.g. Barker 1993, Harrison 1994).

Smith (1997) argues that, though autonomy, involvement and empowerment are at the core of the new model of work, in fact workers are compelled to engage in the organisational mechanisms by which they are achieved by means of a multifaceted, invisible, decentred system of control. Decentred control systems incorporate and reproduce particular hierarchical features of traditional control systems, but their features have taken new forms. They insert mechanisms for monitoring and evaluating into all the pores of the organisational hierarchy: in new technological systems that keep track of workers' performances, in new ways of organising the work flow that bring workers to the foreground of the attention (scrutiny) of co-workers and supervisors, in work groups that heighten the degree to which individuals monitor themselves and each other, or in measures for incorporating the subjective interpretations of customers as a source of data for evaluating workers. Interesting in this respect is Kahn's (1990) conceptualization of engagement at work as "the harnessing of organizational members' selves to their work roles” (Kahn 1990, p. 694).

Many of the organisational innovations aimed at less hierarchy and more autonomy in fact represent a new, decentralised, less visible but not less dominant system of control. Monitoring, evaluating, and disciplinary action move down the hierarchy from the hands of supervisors and diffuses into the hands of teams, co-workers and of the worker himself. In effect, autonomous teams and autonomous workers are taking on the responsibility from management for rationalizing and intensifying their own work activities; in disciplining themselves, they are unwittingly intensifying their own work practices (Sewell 1998). Individual autonomy is held in line by intensified monitoring of the self, continual supervision and disciplining by work peers, shifting of responsibility for production goals onto the shoulders of workers, by concealing managerial power from team participants. In these ways, power potentially resides in all locations, emerging at different times and being exercised by different actors: supervisors, co-workers, and even customers. ${ }^{87}$

Sennett (1998) points out that dismantling the old bureaucratic order in firms has not meant

\footnotetext{
${ }^{87}$ Smith (1997) in her extensive review describes how there are many compensatory systems of control that accompany autonomy and participation. For example, in sales and service settings in which employers and managers strive to maximise flexibility and competitiveness, architectural and spatial arrangements allow customers to watch every aspect of workers' movements and behaviour, leaving nothing invisible. Customer surveys evaluate, monitor, and discipline workers, thus extending the nexus of control into all sets of interactions in the workplace; and 'mystery shoppers', individuals paid to use the firm's services anonymously, evaluate the performance of workers without the knowledge of the latter. Cultural programs are deployed strategically to amplify normative commitments to constant change and pressure, to encourage self-monitoring and heightened involvement in shaping how corporate goals are achieved, and to position workers to continually self-reflect, improve, and innovate.
} 
less organizational structure but rather organizational structure that is less clear. He describes how flexible organizations are continuously implementing new structures, work processes, and products, through such practices as downsizing, reengineering, and delayering of the management structure so that the present becomes discontinuous from the past. Teambased work practices are supported by power arrangements that are fluid and, thus, difficult to discern, and even more difficult to challenge. Managers of flexible organizations set challenging goals for multitasked teams, but with no clear direction for accomplishing these goals and tasks - employees have to autonomously figure this out, self-managing themselves in the right direction. Sennett observes that instead of designing and managing systems for carrying out work, managers become more like accountants who track progress but offer little in the way of supporting structure or even responsibility for such assistance. Seniority counts for little in an organization pursuing creative destruction of its ways of operating; younger workers are preferred by flexible organizations not only because they tend to be a cheaper source of labour but because they are more readily submissive to change of any sort (Sennet 1998).

Sennet (1998) observes that the responsibility that used to be part of the manager's role now has been diffused to the team and the market. Managers assert that practices like downsizing are not their decision but, rather, are due to an external market they cannot control. The 'buffering' function of organizations and managers, dealing with the uncertainties and complexities of the external environment, has become eroded, and employees feel the full force of insecurity of anonymous economic forces. The organizational practices developed to deal with this dynamic, innovative, competitive economy are in fact themselves also an important source of the emergence of such an economy.

Control strategies are increasingly based on the creation of shared meaning, which obviates the need for the principles of hierarchy and explicit rule-governed procedure (Sewell 1998). This is an ideational form of control, as it establishes conformity through the creation of a unitary set of organizational values. Those who share these values can deduce from general statements an almost limitless number of rules and targets to guide their own behaviour under changing conditions. Even with nominally increased autonomy and decentralized decision making, in reality, discretion is highly circumscribed by the expectations of behaviour built into organizational values. Externally determined rules are open to wider scrutiny and processes of appeal, unlike self-imposed discipline (Sewell 1998) ${ }^{88}$ Ezzamel and Willmott (1998) argue that is necessary "to reengineer employee identities and promote a corporate vision that inspires psychic change" for new management approaches such as teamwork to work, and suggest that these new approaches could be seen as forms of "instrumental humanism."

Thus, the literature (often based on in-depth case-studies) strongly suggests that the shift in management practices towards more autonomy, participation and involvement may in fact represent a form of job intensification and a delegating of uncertainty downward (including

\footnotetext{
${ }^{88}$ Sewell (1998) describes how new forms of (indirect) control have come to the forefront, no longer explicit through rules, but implicit through internalised norms and values ("ideational control") and through informal group pressure ("concertive control"). Weber's "iron cage" of rationality is not loosened but tightened, be it in less visible and more complex ways (Barker 1993).
} 
the accompanying stress) to the level of the individual worker. ${ }^{89}$ The new type of management practices may in reality be a sophisticated form of "hyper-Fordism, obscured behind participatory language" (Power and Snellman 2004, p. 211). It seems that the psychological "buffer function" of organisations, absorbing risk and uncertainty for the worker, is disappearing; there is a redistribution of risk away from organisations and from the state towards the individual Beck (2000).

\subsubsection{The changing psychological contract}

Due to the inevitable incompleteness of contracts, work effort is variable and at any wage level the marginal product can take a large range of values depending on the effort employees exert (Kaufman 2007). In jobs with high levels of knowledge work and emotion work, effort is even less contractible, more so than in normal jobs. The incomplete formal labour contracts are complemented by implicit 'psychological contract'. Psychological contracts are defined as beliefs about the reciprocal obligations and rewards that make up the employment exchange; they are sets of beliefs about what both employee and employer are entitled to receive and obligated to give in exchange for the other party's contribution (Rousseau, 1995). Because of the increase in knowledge work and emotion work as part of jobs, informal, implicit, unwritten psychological contracts have gained importance.

Robinson and Morrison (1995) show that psychological contracts are especially important for what is called 'organisational citizenship behaviour' (OCB $)^{90}$ and thus increase amount of effort employees put into their work and improve organisational functioning (Turnley et al. 2003). Employees experience the employment relationship to some extent as a gift relationship (Akerlof 1982), as a social exchange, and decide on their effort levels based on their perception of fairness of the social exchange relation. Violation of a psychological contract involves a strong emotional experience or feelings of betrayal and deeper psychological distress, resulting in anger, resentment, a sense of injustice and harm (Rousseau, 1995). This leads to a wide array of negative outcomes, including reduced job satisfaction, reduced trust in the organisation, increased cynicism about organisational life in general, reduced effort levels, and increased intent to quit (Turnley et al., 2003)

In the past decades, the psychological employment contract between firms and workers has altered (for a review of the literature on this, see Sullivan 1999). Under the old contract, workers exchanged loyalty for job security; under the new contract, workers exchange performance for continuous learning and increasing their individual marketability (Arthur and Rousseau, 1996). Especially in 'high-end jobs', workers have what is called in the

\footnotetext{
${ }^{89}$ For empirical evidence, see for example Green (2002); investigating empirical data from Britain in the 1990s, Green finds that technological and organizational changes are an important source of work intensification, in particular the use of high-commitment human resource policies.

${ }_{90}$ Organisational citizenship behaviour (OCB) has been defined as employee behaviour that is extra-role, that promotes organisational effectiveness, and that is not formally recognised by an organisation's reward system (Organ, 1988). OCB includes such actions as adhering to informal rules designed to maintain order, demonstrating above average work attendance, and not taking extended work breaks. OCB can also be personally focused on helping specific individuals include such actions as assisting others who have been absent, helping colleagues who have heavy workloads, and taking a personal interest in the well-being of other employees.
} 
literature a "boundaryless career", with characteristics such as: portable skills, knowledge, and abilities across multiple firms; personal identification with meaningful work; on-the-job action learning; the development of multiple networks and peer learning relationships; and individual responsibility for career management. This changing psychological deal can have negative consequences resulting either in disengaged, cynical, less productive workers (who find neither job security and trust from the old deal, nor self-actualization and meaning supposedly part of the new deal), or highly individual self-interested workers who only invest in their own career rather than in the well-being others and of the organization (e.g. Cartwright and Holmes 2006).

In many ways, high-end jobs seem to be ideal, in that the worker in principle is autonomous and empowered. The old dichotomy of capital and labour seems to vanish, with the labourer in control of his own means of production, being the owner of the most important form of capital in today's economy: his own human capital. However, the management of one's own human capital turns out to be not so easy. It requires high levels of mental resiliency and self-efficacy, to choose direction where none is given; to set limits where there are none, in terms of work time, work-load and work-effort; to make decisions and be responsible for their consequences; to deal with uncertainty and ambiguity, to be an entrepreneur, accumulating and exploiting one's own human capital optimally, to "run your own show" all the time, adjusting the repertoire constantly to remain valuable and on top of things. Empirical research shows that instability and insecurity have become widespread in the labour force (e.g. NIOSH 1999; Platt et al. 1999)

Thus, the organization and management of work has become more 'psychologized', it builds more on psychological mechanisms such as psychological contracts, and aims at engagement and autonomy, effectively putting employees to work to manage themselves and each other. Employees become more psychologically involved with their work, and more easily psychologically damaged when things go wrong at work, when they are unable to fulfil the task of self-management, or when psychological contracts are violated. The variability of effort input by employees thus gains a wider bandwidth and a more complex dynamics. This thesis points to one specific reason for this: the psychological effects of problems at work affect the mental health of workers, and this affects both the amount of effort that employees put in and the extent to which this effort is used productively, rationally; since, as will become clear in chapter 3, mental health affects both energy levels (through factors such as motivation) and rationality. First, a more in-depth look is taken at the psychological consequences of structurally increased, institutionalized levels of change, in the next section.

\subsubsection{Institutionalized change}

The flexible labour market and the new ways of organising and managing can be understood as the emergence of more dynamic economic structure, in which change is institutionalized, built in into the very institutions of the labour market and jobs. The institutionalization of change requires employees to deal with change on a continual basis (e.g., Dollard and Winefield 2002). Change in organisations is a complex phenomenon; it takes the form of a constant challenge of routines, habits and negotiated balances of power between employers and employees and between employees among each other. An overview of research by 
Collins (1998) shows that especially when experienced as imposed change (including selfimposed) and at higher levels, it can be a source of distress, anxiety, worry, depression, decreased job satisfaction, decreased organisational commitment, resistance to change, deterioration in organisational morale, reduced job performance, increased turnover and absenteeism. Platt et al. (1999), conducting a detailed literature review of research on the relationship between change at work and the impact on health, find that workplace reorganisation, redundancy, new technology and features of the modern work environment are likely to be associated with deficits in physical and/or psychological health among a wide range of employees. Workers of organisations that have downsized and restructured to improve flexibility and competitiveness are found to suffer more from mental health problems (Chang 2000).

As the size, frequency and speed of change that employees in average experience goes up, the wage premium on adaptive coping skills increases. One way to detect this premium on adaptive skills empirically is by looking at the differences in wage structure in industries with fast and less fast technological change, such as Bartel and Lichtenberg (1987, 1991). ${ }^{91}$ Another way is to link up existing empirical research findings; for example, coping skills are positively related to self-efficacy and internal locus of control (Bandura 1986; Smith 1989), and these variables in turn have been found to be positively related to higher wages and success on the labour market (e.g. Goldsmith et al. 1996a, 2000). ${ }^{92}$

Turbulent competitive environments, technological sophistication, and flexible organising give rise to greater novelty and complexity in work; consequently, there is an expanding interest in information processing by firms and individuals in the face of change, novelty and complexity (Fiol 1994, Louis and Sutton 1991). Sims and Gioia (1986) show that people process information differently in novel versus routine situations: novel situations require 'discontinuous information processing'. Starbuck and Milliken (1988) find that strategic failings often result from over-reliance on automatic processing; information has to be actively sought and carefully processed to make a quality decision when there is little experience on which to rely. Thus more dynamic and flexible working conditions increase the need for effortful information processing.

\footnotetext{
${ }_{91}$ Bartel and Lichtenberg $(1987,1991)$ find that industries with a high rate of technical change pay relatively higher wages to workers of given age and education. They explain this by introducing the notion that new technology creates a demand for learning, that learning is a function of employee ability and effort, and that increases in wages are required to elicit increases in ability and effort. The wages of highly educated workers relative to those of less educated workers are highest in technologically advanced industries which is consistent with the notion that educated workers are better learners, thus implying that education signals the presence not only of cognitive skills and willingness to put in effort, but also of adaptive skills (Bartel and Lichtenberg 1987, 1991).

92 Bandura (1986) has reviewed a large body of empirical evidence showing that perceived self-efficacy (beliefs in one's capabilities to execute required behaviours) facilitates adaptive behaviour and helps to mediate constructive behaviour change. Coping skills are positively related to self-efficacy and an internal "locus of control" of a person (e.g. Smith 1989). Goldsmith et al. (2000) find that people with an internal locus of control are both better at dealing with change and earn higher wages. Goldsmith et al. (1999) review the empirical work on the link between locus of control and wages in which locus of control is assumed to be an exogenous variable; Goldsmith et al. (2000) suggests that the locus of control is to some extent endogenous, efficiency wages can increase the internal locus of control.
} 
Rousseau (1997) describes how changes in the organisation of work present higher demands to the cognitive abilities of people, the new ways of organizing work (horizontal, flexible, multi-tasking, unclear evolving work roles) require much more information processing, information which is becoming more discontinuous and multi-phased. In routine situations such as sustained performance in a stable situation over time, controlled processes allow reliance on automatic processes using established mental models and routines. Change, such as in the case of innovation, requires rethinking of established routines and establishing new consensus about what the organization and its employees are about and how they should proceed, which is effortful both in cognitive and emotional terms (Fiol 1994, Sims and Gioia 1986). The extent to which an organisation can successfully innovate, and deal with change more in general, depends on its absorptive capacity, which in turn depends on the ability of employees to deal with change, both in a cognitive and emotional sense (Fiol 1996)

Important in this respect is the role of "mental models". Mental models establish an understanding of how things fit together; they articulate what is important and unimportant depending on underlying values, shared interests, and common understandings (Kiesler and Sproull, 1982). As Hill and Levenhagen (1995) describe, organizational mental models constitute the frameworks of organizational rationalities and belief systems on which interpretations, policies and procedures are based. These models form the foundations for initiating and organizing subsequent actions. Mental models allow individuals to predict and control their environments, and re the basis of a selection process by implicit or explicit choice. Individuals and organizations will be successful to the extent to which their models are accurate and fitting for the given situation (Barr et al. 1992). Mental models organize and reduce the complexity of reality, but exactly that useful feature limits their accuracy and precision. A mental model that fits the environment today may not be adequate for tomorrow's environment (Barr et al., 1992). In a dynamic environment, individuals and organizations will find themselves more often in situations where "certain experiences cannot be interpreted within the current belief system", necessitating effortful creation of new mental models (Levenhagen and Hill 1995).

The institutionalization of flexibility has psychological consequences at a deeper level, as Sennett (1998) convincingly shows. Sennett describes a 'brave new world' of short-lived relationships and flexible work styles. In this world, employees are conceptualised as either being part of a transient workforce to be drawn on or discarded as required by circumstances and the logic of efficiency, or as autonomous entrepreneurs in charge of their own (career) destiny, who trade their skill and expertise in flexible labour markets. Sennett points out the costs of flexibility and the toll it can take on our energy, our relationships, and our very characters. The psychological consequences of flexibility are quite fundamental according to Sennett: it affects our very personality. The normal sources of identity and existential clarity and security (who am I, where do I belong, what am I about, etc.) are being eroded. People change jobs more frequently, move locations many times in their lives, are far away from friends and family, have to constantly let go of old circles of social contacts and build up new contacts, are 'footloose' and prevent their children from developing 'roots' because of the temporary character of any setting. The flip side of freedom is confusion, uncertainty and stress. Sennett argues that in a flexible world, people increasingly lack a continuous self-narrative, their own personal story that has a structured beginning, middle and end. Instead, with every change to a new job or a new organisation, the individual must 
start all over again. According to Sennett this leads to feelings of emptiness and meaninglessness, and to a "corrosion of character," of the basic sense of self.

A clear, coherent sense of identity $^{93}$ is needed to deal successfully with changing environments, ${ }^{94}$ but exactly that may be in danger of erosion. Identity has an important psychological function (Pulkkinen and Rönkä 1994). As was observed before, each person has a set of mental models or schemata allowing him to select, interpret, process and act on information in a coherent way. Identity provides the most important mental model of all: a model of the self. Without this source of coherence, people have problems to access and use behavioural scripts and routines to make use of. Lack of coherent identity leads to increased mental effort in terms of the hundreds of daily micro-decisions about what to do and what not. A clear sense of identity may be challenged by new circumstances, and an effortful new process of exploration may be needed for renewed identity achievement, which is associated with increased stress, fatigue, and mental health problems (Pulkkinen and Rönkä 1994). Unstable identity formation has a negative influence on the performance and careers of people (Blustein et al. 1989).

Granovetter $(1973,1983)$ argues that modern institutional networks are marked by "the strength of weak ties", by which he partly means that fleeting forms of association have become more useful to people than long-term connections, and partly that strong social ties like loyalty have ceased to be compelling. These weak ties are embodied in for example teamwork, in which the team moves from task to task and the personnel of the team changes in the process. Strong ties grow from long association, and on a willingness to make commitments to others. However, detachment and superficial co-operation are better armour for dealing with current realities than behaviour based on values of loyalty and service; 'entanglement' in longer-term commitments must be avoided, things must be kept open (Sennett 1998). The flexible life leads to an erosion of strong social ties and deep trust according to Sennett. Such social bonds take time to develop; but the short time frame of modern institutions limits the ripening of deep-rooted trust. This leads to a weakening of perceived and actual social support systems, which is associated with higher vulnerability to stress and higher chances of mental health problems.

Giddens (1991) also signals that in a society that has become global and flexible, identity has become a question, a problem even, rather than a given. Giddens takes fro example the growth of the self-help literature as a symptom of this: questions that people did not even think of in the past have now become a major pre-occupation. He describes how globalisation and technological change have led to the emergence of the 'post-traditional society', in which traditions no longer give answers to the basic questions of life, and these answers need to be found by each individual for himself. It seems that in psychological terms, there is a considerable price to be paid for meritocracy, with its increased social

\footnotetext{
93 Identity can be defined as a clearly delineated self-definition comprising the goals, values, and beliefs to which the person is unequivocally committed (Waterman 1982).

${ }^{94}$ Literature reviews and empirical findings show the importance of a coherent identity for dealing with change; e.g. Archer (1989) finds that psychological functioning and adaptive capacities are associated with a clear sense of identity also called "identity achievement" (as opposed to "identity diffusion"); Blustein et al. (1989) find that individuals who have attained a coherent ego identity also tend to report exploratory activity; Fowers and Davidov (2006) find that character strength is needed for openness to new experiences.
} 
mobility and flexibility and its emphasis on achievement rather than background, habit and tradition.

Uncertainty and insecurity in a person's context lead to loss of identity and psychological stress, with negative consequences for mental health. Durkheim (1951) already famously theorised about the connection between suicide and loss of roots and identity due to urbanisation, arguing that identity is a psychological life necessity. Also, Fromm (1942) showed how lack of stability, predictability and roots can lead to psychopathology. Fromm argued that "freedom from the traditional bonds of medieval society, though giving the individual a new feeling of independence, at the same time made him feel alone and isolated, filled him with doubt and anxiety, and drove him into new submission and into a compulsive and irrational activity" (Fromm 1942: 89). Giddens (1991) argues that this problem of individualization eroding the roots of identity is generally resolved through commitment to a certain form of lifestyle, plus the vesting of trust in a given series of abstract systems. Yet this basis for identity is contestable (why this lifestyle and not another?) and vulnerable and can disintegrate under pressure. This puts 'ontological security' at risk, which is the basis for mental health and psychological functioning. ${ }^{95}$

The insecurity inherent in a dynamic employment profile and its negative psychological consequences can in principle be balanced by an activating but inclusive social security system: a system that provides a basic feeling of safety, so individual workers feel confident to take risks, embracing change rather than fighting it. ${ }^{96}$ It is often overlooked that social security systems have an important (though complex) psychological function. The International Labour Organization observed about this psychological dimension in 2006: "Social security is by no means a marginal need of people [...] Feeling secure is strongly related to the trust people have in other people, in their community, in their society and in its institutions." (ILO 2006, p. 9). "Some believe that too much security, particularly income security, undermines people's incentives to engage more in economic activities and to be inventive and productive. But the truth is likely to be exactly the opposite: the less secure we feel, the more averse we are to take risks. Studies reveal that poor people are risk-averse. Rational risk-averse individuals will only take a risk if the potential loss is relatively small compared to their wealth. The poor are usually not eager to risk even small amounts as this threatens their very survival. Wealth provides security, and more can be risked. For many people, social security substitutes wealth. Those who have no access to relevant protection mechanisms against numerous social risks will avoid taking any additional economic risks, as they have to focus on protecting themselves." (ILO 2006, p.12). Research shows that income redistribution through a social security system generally is good for economic

\footnotetext{
95 Giddens (1991) argues that the plethora of available information is reduced via routinised attitudes which exclude, or reinterpret, potentially disturbing knowledge that does not fit in existing mental models and that therefore causes feelings of dissonance. Such closure might be regarded as prejudice, the refusal to entertain views and ideas divergent from those an individual already holds; but in fact, avoidance of dissonance forms part of the protective psychological cocoon which helps maintain 'ontological security' the basis of mental health (Giddens 1991). Thus prejudices can be seen as psychological defence systems signalling ontological insecurity.

${ }^{96}$ Interesting here is the analytical approach towards social security based on the social management of risks of De Neubourg and Weigand (2000). It redefines social policy as public interventions to assist individuals and households to cope with their risks, in a dynamic rather than static framework.
} 
growth, ${ }^{97}$ one explanation of this lies in its social and psychological effects on behaviour.

It is important not to generalize too much when speaking about trends in the labour market and in working conditions, and to avoid giving he impression that there is a clear, uniform picture. Empirical evidence shows a number of trends such as an increase in temporary work, shift work and part-time work, and deteriorating job satisfaction and skill mismatches in most countries of the EU-15, but there is great variation in the patterns of these variables in different countries (Birindelli et al. 2007). This shows that it concerns complex relationships and that specifics of the economy of a country and its social institutions matter a lot. Interesting in this respect is the concept of 'flexicurity.' It aims at enhancing, simultaneously, the flexibility and security dimensions of the labour market, by exploring complementarities/synergies between different policies and institutions (Wilthagen and Tros 2003). Combining flexibility and security in an attempt to overcome the seemingly inevitable trade-off between the two lies at the basis of much recent labour market policy in Europe (Bekker et al. 2008). ${ }^{98}$ Psychological elements are important ingredients in tackling this tradeoff.

\subsection{The intensification of work and non-work}

Work has changed not only in content and organisation, but also in intensity. Technology is used not only to substitute relatively expensive human labour, but also to complement human labour in order to "make the most out of it" - literally. Empirical research shows that both upskilled and deskilled work are subject to a continuous process of intensification. There is increasing evidence suggesting that the increase in labour productivity is related not only to increased efficiency due to technological and organisational innovation, but also to increased effort levels of workers, which can be obtained because of these innovations. This comes at a cost; intensification of work leads to increased job stress and increased mental health problems. In addition, there is evidence of intensification of non-work activities, which also contribute to stress. This section will discuss these trends.

\subsubsection{Effort-biased technological change}

It has become an economic cliché to observe that globalisation and technological development have increased competition; and thereby the need to increase efficiency and productivity and to cut costs, through innovation, re-organisation and downsizing. However, the implications of this (perception of an) economic 'arms race' in terms of work are still not fully understood. As Dollard and Winefield (2002) observe, under pressure of economic

\footnotetext{
${ }^{97}$ E.g. a World Bank publication on poverty reduction strategies: "Others have suggested that greater equity comes at the expense of lower growth and that there is a trade off between growth and equity [...]. A large number of recent empirical studies $[\ldots]$ have found that there is not necessarily such a trade off and that equity in its various dimensions is growth enhancing" (Kingman 2002), sections 12.2.4 and 12.2.5).

98 The emergence of the concept of flexicurity may fit into a broader, changing perspective on the regulation and the role of institutions. Wilthagen and Tros (2003) observe that as of the first half of the 1990s, institutional and regulatory settings in the labour market are no longer seen as mere economic barriers. Rather, certain settings and forms of (re)regulation are considered conducive to economic performance. Social policy is increasingly being described as a 'production factor' (e.g. Auer 2001, Esping-Andersen and Regini, 2000).
} 
rationalisation, workforce numbers in organisations have been reduced, but the amount of work to be done often has not.

Ideally, less people do more because technology takes over some tasks and because of smarter ways of working. Though that may be true to some extent, reality shows an even simpler explanation: less people often do more simply because they put in more effort. This is associated with greater work pressure. An important source of increased work pressure is the introduction of new technology, especially computerisation, aimed at making work processes more efficient. Computerised technology generates efficiency gains, for example through optimal timing for ordering and delivering inputs, through the quick identification and solution of problems in production of goods and services, and through accurate stock or customer handling. Every step of the process is optimized and there is no 'wasted time' anymore. Moreover, thanks to information and communication technology such as email, cell phones and Internet, workers can often take work home and do it anywhere anytime. There is then only one bottleneck left: the employee himself and the effort he is willing and able to put in.

Green and McIntosh (2001) characterise this speed up of work as a process of 'effort-biased technological change' in which the relative productivity of high effort workers is enhanced. High-effort workers have a high elasticity in their supply of effort, they will simply speed up with the process, in contrast to workers with a low elasticity of effort-supply, that will more or less stay at their set-point level. It is therefore economically more interesting to develop and implement technology that increases the effort of the high effort workers: their marginal propensity to 'consume' work is higher, they respond more strongly to increased possibilities to put in effort. Technology increases the productivity of high effort workers more than of less high effort workers. One consequence may be that the best workers are disproportionately burdened. These are generally the people that experience a relatively high degree of intrinsic utility in their work; which is often the case in jobs with a relatively high degree of knowledge work and/or emotion work. Also, there may be a polarization of norms with regard to effort, due to the relationship between norm-formation, interaction and behaviour; corresponding norms reinforce interaction within a (low-effort or higheffort) group and reinforce engagement in norm-consistent behaviour (e.g. Verkooijen et al. 2007)..$^{99}$

\subsubsection{The intensification of work}

Green and McIntosh (2001) found that across many European countries, the 1990s have witnessed an intensification of labour effort. This means that on average more work has to be done in less time, at a higher pace (Figure 6) and with tighter deadlines (Figure 7), resulting in higher average effort levels of workers when at work. They also found that high effort levels are associated with the demands of new technology, high levels of competitive pressure, low levels of worker protection, the level of wage inequality, the frequency of computer use, and changes in the organisation of work. Green and McIntosh observe that

\footnotetext{
${ }_{99}$ On the impact of social norms on labour market behaviour and how agents 'infect' each other norms, see e.g. De Neubourg and Vendrik (1994).
} 
this intensification can have undesirable outcomes: physical exhaustion and mental stress. Increased work effort generates greater output, but presumably effort intensification is not an indefinitely sustainable source of growth.

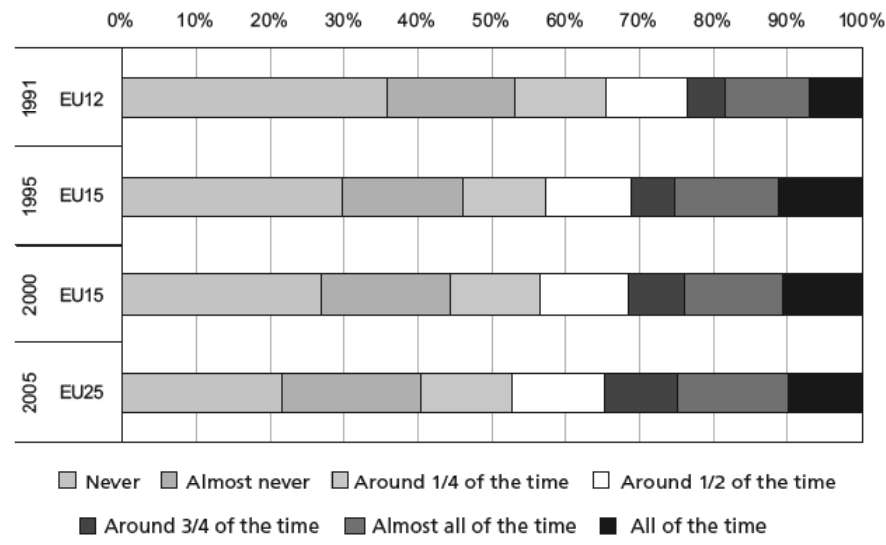

Figure 6. Percentage of workers in EU indicating having to working at very high speed. Source: European Foundation (2006).

An analysis of fifteen years of the five-yearly European Working Conditions Survey (EU-15 and later EU-27) finds: "One of the most consistent findings of the EWCS is the relative intensification of the pace of work over the last 15 years. An increasing proportion of EU workers report working at a very high speed or to tight deadlines. [...] It is important to note the substantial reduction in the proportion of people reporting never working at very high speed (from $36 \%$ to $21 \%$ ) and never working to tight deadlines (from $31 \%$ to $19 \%$ )" (European Foundation 2006, p. 4). This concerns factors such as the speed of work, having tight deadlines, and interruptions at work. ${ }^{100}$ This intensification varies per country, ${ }^{101}$ and is mainly market-driven: the pace of work is more and more dependent on the direct demands of customers and clients (European Foundation 2006; Gallie 2005). Parent-Thirion et al. (2007) find that workers whose pace of work is determined by direct demands from people report higher levels of negative psychological health outcomes.

\footnotetext{
${ }^{100}$ Having frequent interruptions at work is generally seen as a determinant of stress. Around one third of EU workers experience interruptions in their work often or very often; interruptions at work are much more prevalent in service sectors than in manufacturing, construction or transport and communications, and are more prevalent among workers in the higher occupational; those using information technologies and those with a higher degree of autonomy at work report more frequent interruptions (European Foundation 2006).

101 There is considerable variation between countries: while the intensity index for the EU27 as measured in 2005 is $43 \%$, it ranges from more than $50 \%$ in Austria, Cyprus, Denmark, Finland, Greece, Slovenia and Sweden to less than $35 \%$ in Bulgaria, Latvia, Lithuania and Poland (Parent-Thirion et al. 2007).
} 


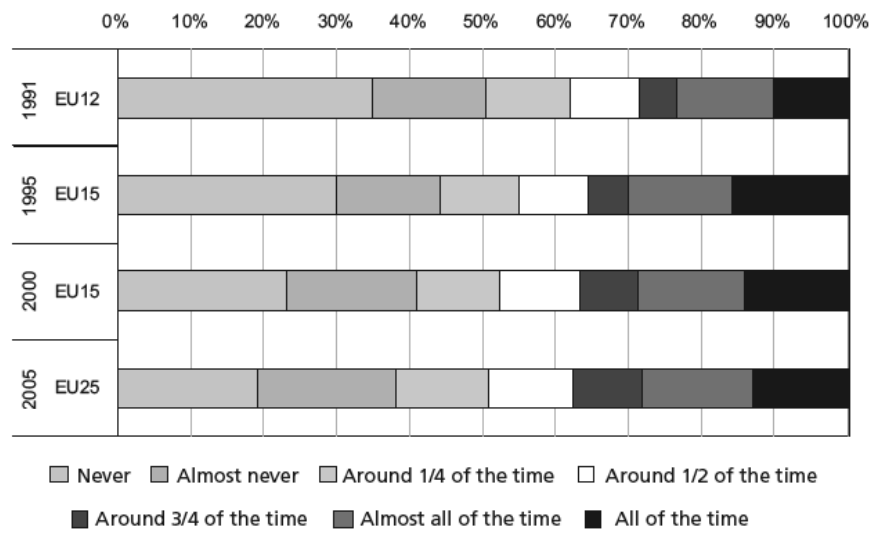

Figure 7. Percentage of workers in EU indicating having to work to tight deadlines. Source: European Foundation (2006).

Technology, in particular using IT, is associated with more complex tasks, an indication of work intensity. E.g. Parent-Thirion et al. (2007) find that complex tasks and learning new things are much more frequent in jobs using information technology; complex tasks can be often found in utilities, financial services and real estate. Learning new things is most reported in utilities, financial services, education and health. Gallie (2005) finds that new technologies have been a factor in creating relatively high levels of work pressure and work stress; those using new technology were likely to be under significantly greater pressure at work, even when a wide range of other factors were controlled. Since the proportion of employees using new technology increased, this can be a cause of increasing work pressure. ${ }^{102}$

The size and increase of work intensification varies per country (Figure 8). Furthermore, the increase of intensification of work seems to be unevenly distributed, some groups experiencing it more than others. For example, Gallie (2005) finds that high skill levels, job control, job insecurity and use of new technology are positively related to work pressure (EU-15 countries, 1996-2001). The widely accepted model of work stress (Karasek 1979) holds that more job control and more skills increase the control of workers to deal with demands at work, thus will reduce work stress; findings such as Gallie (2005) show that there is a more complex underlying reality, and is compatible with the argument that job control necessitates effortful self-management and can actually add to work pressure (as discussed in 2.4.3). Although work pressure at a whole did not increase according to the study, the evidence suggests that the distribution of work pressure may have become more uneven.

\footnotetext{
102 The percentage of people regularly using computers at work has increased significantly, from $31 \%$ to $47 \%$ in 15 years; however, a substantial proportion of the workforce never uses computers at work (44\% overall) (European Foundation 2006). Gallie (2005) does not find an overall increase in work pressure in the EU-15 in 1996-2001, but substantial and relatively stable differences in work pressure between countries, which to a considerable extent reflect compositional differences with respect to the main determinants and correlates of work pressure, such as the use of information technology.
} 


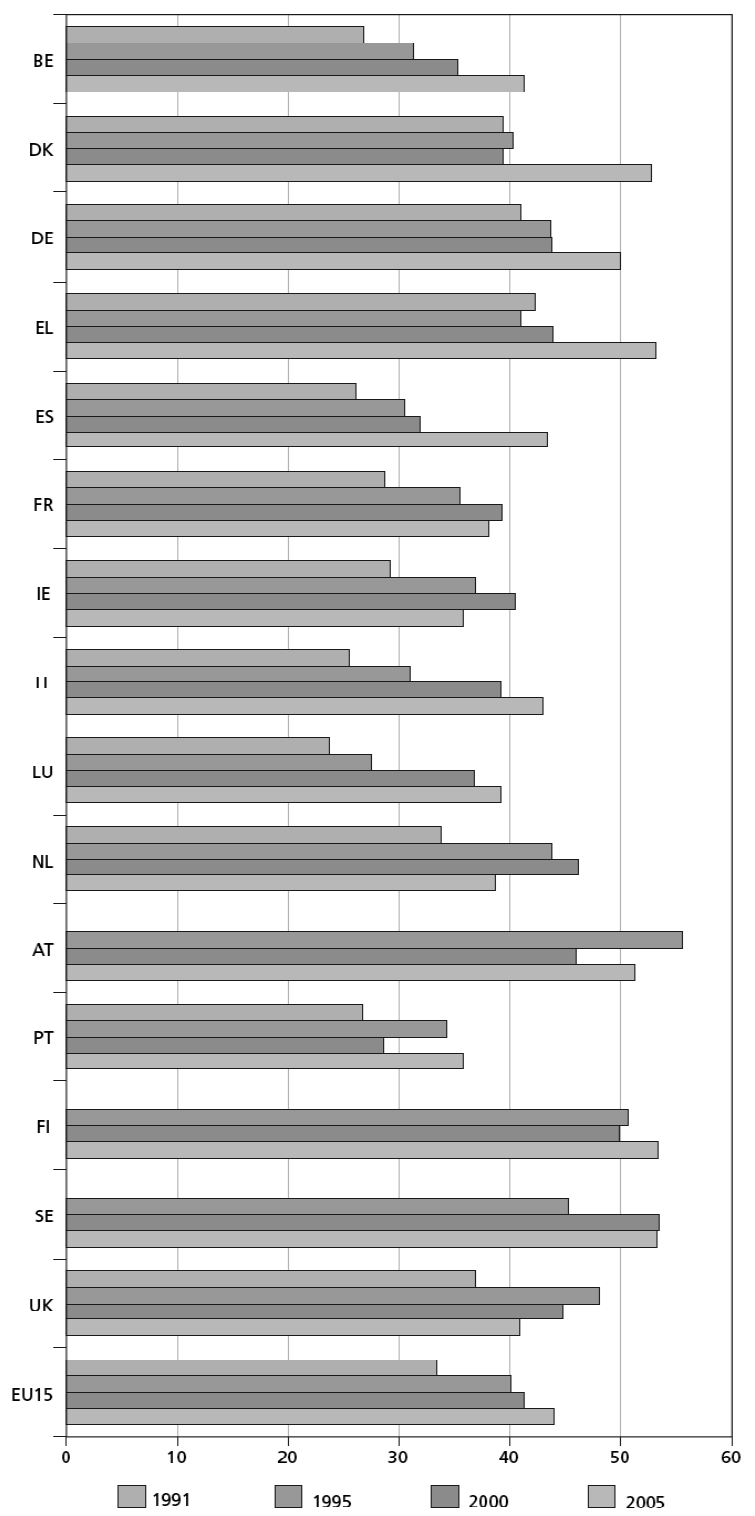

Figure 8. Evolution in work intensity, EU15, 1991-2005 (\%).Note: Austria, Finland and Sweden, being outside the EU in 1991, were not included in that year's survey. Data for 1991 cover EU-12 only. Source: Parent-Thirion et al. (2007).

Empirical evidence suggests that there is polarization in the number of working hours, a group of workers working longer and harder and other groups of workers working less hours (European Foundation 2007). An economic explanation for this is rising wage inequality could be responsible for the increased number of hours worked by those at the 
top (Bell and Freeman 2001). The explanation is that if the wage distribution becomes wider, the financial gains to be made in absolute terms from moving up this distribution are greater, and so individuals work longer hours in an attempt to further their careers and move up the pay ladder. The same argument can be applied to work effort, and Green and McIntosh (2001) find that effort is indeed increasing the most where wage inequality has significantly widened. The result is a situation in which, within a certain part of the economy, everyone works hard in order to rise, but because all are doing it, no one rises; an "effort arms race" in certain "ponds". 103

The extent to which an employee is willing to put in effort is a desirable feature for employers because it is highly correlated with productivity, but it not always easily observable. Selecting and rewarding indicators of willingness to put in effort, such as making long hours, can lead to suboptimal outcomes. ${ }^{104}$ In addition, high levels of effort can become institutionalized as a social norm in certain groups, thus reinforcing low or high effort levels, further feeding polarization of effort intensification. To what extent the effort is effectively productive is not always clear, effort intensification may have decreasing marginal returns in terms of productivity.

In the last century, the average workweek has gone down from about 60 to less than 40 hours in most developed countries. Though this may seem to indicate that people work less than in the past, it is important to look at the reality behind the average work-week. To some extent the average working hours have gone down due to the increase of part time work, related to the increase of female labour participation. This means that household work, formerly a full-time though unpaid job, now is combined with part-time work, which indicates much higher real working hours (paid and unpaid) for women, and to the extent that household tasks are shared with men, also for men. Furthermore, especially knowledge workers tend to take work home, and the informal, non-overtime hours in the evenings and weekends should be taken into account when discussing trends in working hours. No less important than working hours is how much work is being done during these hours, in other words, productivity per hour, which to some extent can be seen as an indicator of work intensity. Innovation is aimed at doing more work in less time, thus squeezing out 'passive' and 'relaxed' jobs (e.g. Dollard and Winefield 2002). The result of the rationalization, flexibilization and compression of production is in principle a constant stream of work for employees, at a higher level of activity and with fewer periods of stoppage and 'wasted' time. Whether this time was really wasted, is subject of discussion. The spare time within the

103 This is a reference to Frank's (1985) 'Choosing the right pond'; the human quest for status can take many forms, having an intense job and putting in much effort can be a means of gathering status, and due to reference effects this may spiral upwards.

${ }^{104}$ In Akerlof 's (1976) 'rat race' model, in which output sharing rule of payment can lead to an "overwork" equilibrium, workers working at a speed higher than optimum. Building on this, Landers et al. (1996) argue that long working hours emerge as a screening device for individuals with a low disutility of work. Employers want to identify, select and promote workers with a propensity to work very hard; employees start to work towards looking good in terms of indicators of working hard such as making long hours. The result can be inefficient long work hours. Souza-Posa and Ziegler (2003) finds a similar result. Since firms cannot observe workers' true productivity, they use long working hours as a mechanism to sort productive workers. The model of SouzaPosa and Ziegler predicts that workers with a high productivity will tend to work inefficient long hours; they find confirmation for this in an empirical analysis: high-productivity workers are more likely to experience hours constraints in the form of overemployment than low-productivity workers. 
production process, the breaks in the workflow, can also be seen as important 'recovery time'. 105

Over the past 25 years, productivity has increased dramatically. It is generally assumed that this comes from technological substitution and more efficient ways of working. He scarce research on effort intensification however suggests that the increasingly favourable inputoutput ratio may to some extent be misguiding; it may be that workers put in more effort per hour worked, which effectively means an increase of input, not in terms of ours worked but in terms of effort.

Information and communication technology is a time-saver enabling workers to do more in less time, but at the same it creates work and it increases the time people spend working. Computers, phones, blackberries have to be produced, fixed and maintained, computer skills have to be learned, software has to be developed, work processes have to be restructured to integrate new technology; all this gives rise to a growing sector of ICT manufacturers, ICT specialists, computer education, and change management consultants. The costs of all this, in terms of time and money, have to be taken into account in order to get an idea of the real money and time-saving effect of technology. Information and communication technology enables workers to work outside of office hours and outside of the office, at home, at night, in the weekends. This is saving them time such as the time needed to go to the office to work. But in terms of time, the more important effect is perhaps not that time can be used more, but that more time can be used. Finally, the increased information and communication possibilities may create work rather than reduce it; ${ }^{106}$ emails and voicemails are left easily, one interaction leads to another interaction, and if the protective 'friction' of transaction costs that used to inhibit interactions largely disappears due to ICT, the number of interactions can spiral up (e.g. Schuff et al. 2006).

The intensification of work has costs in terms of mental health; it is found to increase stress and resulting psychological problems, including depression, burnout, anxiety, psychosomatic complaints and cardiovascular problems (e.g. Teuchman, Totterdell and Parker 1999).

\subsubsection{The intensification of consumption}

Schor (1998) signals and describes a process of 'intensification of consumption': people are spending more and more. Given the tremendous increases in productivity and the enormous output growth, due to rapid technological change and innovation, this is not a surprising trend: somebody has to consume all these goods and services otherwise the economy would stop growing. It is the other side of the economic coin. Research shows an intensification of work and increasing work-related stress, and, much less in the picture but not to be underestimated, of increasing consumption-related stress (Duhachek 2005).

\footnotetext{
105 E.g. Sonnentag and Zijlstra (2006); Sonnentag and Natter (2004)

${ }^{106}$ E.g. About 25\% of executives at large companies (a group scoring high in terms of effort intensification) indicate that their communications (voice mail, e-mail, and meetings) seem to be creating more work than they solve; nearly $40 \%$ spend a half to a full day per week on communications that are not valuable (BusinessWeek, 2005, based on a McKinsey survey of 7,800 executives).
} 
Schor (1998) investigated the underlying causes for the intensification of consumption, and found that people these days choose different "reference groups" than in the past. ${ }^{107}$ Reference groups used to be mainly composed of people near us in the social hierarchy. But people now are more likely to take the top 20 percent of the income distribution as an aspirational target. This has created a strong "aspiration gap" - the gap between what one has and can afford, and what one aspires to (see also Frank 1985). This leads to an upward spiral of consumption, which Schor calls the 'new consumerism'. Schor argues that the anxiety many people feel about their financial future is paralysing; it makes people feel out of control. Many people do not feel as if they are spending a lot. Rather, many feel they are just making it, barely able to stay even. This feeling is not restricted to families of limited income. Research shows that this is a generalised feeling, existing at all levels of income. ${ }^{108}$

Easterlin (2005) finds that mainstream economists' inference that in the pecuniary domain "more is better," based on revealed preference theory, is wrong. An increase in income, and thus in the goods at one's disposal, does not bring with it a lasting increase in well-being, because of the negative effect on utility of hedonic adaptation and social comparison. The utility anticipated ex ante from an increase in consumption turns out ex post to be less than expected, as one adapts to the new level of living, and as the living levels of others improve correspondingly. A better theory of well-being builds on the evidence that adaptation and social comparison affect utility more in pecuniary than non-pecuniary domains. The failure of individuals to anticipate that these influences disproportionately undermine utility in the pecuniary domain leads to an excessive allocation of time to pecuniary goals at the expense of non-pecuniary goals, such as family life and health, and reduces well-being. This implies there is a positive feedback leading to intensification of consumption.

Exemplary is the case of Ireland, in which there was rapid economic growth increasing the purchasing power of the population, but nevertheless the average level of happiness of people has not changed (see Figure 9).

\footnotetext{
107 'Reference group' refers to those people (real and fictitious) against whom we consciously and semiconsciously measure our own consumption levels. They help form our aspirations and the degree to which we are satisfied with what we have (Schor 1998).

108 Twenty-seven percent of all households making more than $\$ 100,000$ a year say they cannot afford to buy everything they really need. Nearly 20 percent say they "spend nearly all their income on the basic necessities of life." In the \$50,000-100,000 range, 39 percent and one-third feel this way, respectively. Overall, half the population of the richest country in the world say they cannot afford everything they really need (Schor 1998).
} 


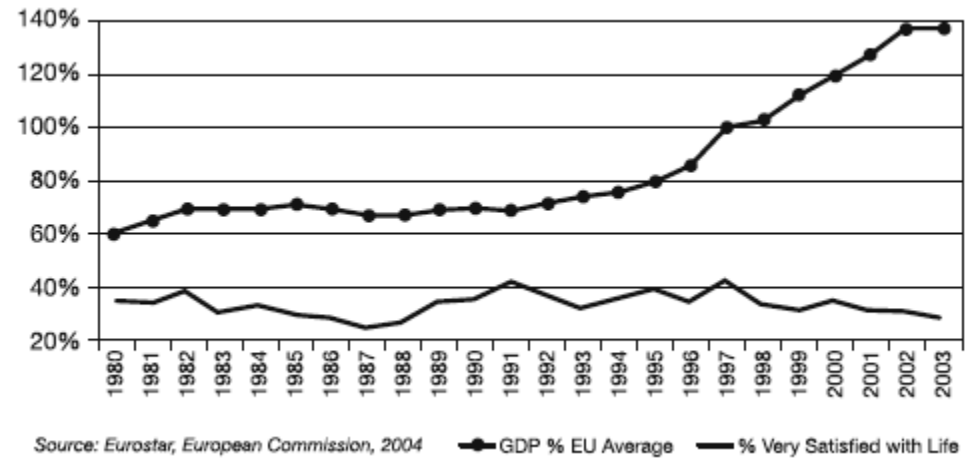

Figure 9. GDP as percent of EU average, and life satisfaction: Ireland, 1980-2003. Source: Eurostat, 2004.

Using consumption to express social identity is not a new phenomenon, but the scale of it is. Veblen (1899) identified and described in the $19^{\text {th }}$ century the phenomenon of 'conspicuous consumption' by the rich, expressing and increasing their social status by their spending. By the 1920s, productivity and output were growing rapidly due to technological progress, and more and more people had entered the comfortable middle classes and begun to enjoy substantial discretionary spending. This mass prosperity eventually engendered a new socioeconomic phenomenon - a mass keeping-up process that led to convergence among consumers' acquisition goals and purchasing patterns. The advent of mass production in the 1920s made possible an outpouring of identical consumer goods that nearly everybody wanted, accompanied by declining prices, so that they became within reach for many. By the 1950s, the era of mass consumption was a fact. People looked to their own neighbourhoods for their spending cues, and the neighbours grew more and more alike in what they had. Like compared with like and strove to become even more alike. This phenomenon was called 'keeping up with the Joneses' (Duesenberry, 1949). ${ }^{109}$

Americans (and to some extent people of other cultures influence by American culture) began engaging in more upward comparison. Schor (1998) proposes that an important cause is the increase of productivity and the accelerating pace of product innovation, both related to technological change and changing markets. In addition, information and communication technology changed the image of who the relevant 'Joneses' were. To gain broader distribution for the plethora of new products, manufacturers have gone to lifestyle marketing, targeting their pitches of upscale items at rich and non-rich alike. Beginning in the 1970s, the death of the 'belonging' process that had driven much competitive consumption was declared. The establishment of an individual identity - rather than staying current with the Joneses - was becoming the main driving force. The new trend was to

${ }^{109}$ In addition to Schor, a number of economists have emphasised these social and comparative processes in their classic accounts of consumer culture, among them, John Kenneth Galbraith, Fred Hirsch, Tibor Scitovsky, Richard Easterlin, Amartya Sen, and Robert Frank. Among the most important of their messages is that consumer satisfaction, and dissatisfaction, depend less on what a person has in an absolute sense than on socially formed aspirations and expectation; indeed, the very term 'standard of living' suggests the point: the standard is a social norm (Schor 1998). 
consume in a personal style, with products that signalled your individuality, your personal sense of taste and distinction.

Schor (1998) describes that throughout the 1980s and 1990s, most middle-class Americans were acquiring at a greater rate than any previous generation of the middle class. At a minimum, the average person's spending increased 30 percent between 1979 and 1995 . At a maximum, calculated by taking into account a possible bias in the consumer price index, the increase was more than twice that, or about 70 percent. Yet, by the mid-nineties, America was decidedly anxious. Many households felt pessimistic, deprived, or stuck, apparently more concerned with what they could not afford than with what they already had. Definitions of the 'good life' and even of 'the necessities of life' continued to expand, even as people worried about how they could pay for them. ${ }^{110}$

Giddens (1991) observes a more fundamental psychological consequence of the intensification of consumption. Because of the diminishing influence of traditions establishing the identity of people, the identity of a person is no longer a given but has to be actively shaped. Giddens observes that increasingly the "project of the self" becomes translated into one of the possession of desired goods and the pursuit of artificially framed styles of life. ${ }^{111}$ The consumption of ever-novel goods becomes in some part a substitute for the genuine development of self; appearance replaces essence as the visible signs of successful consumption come actually to outweigh the use-values of the goods and services in question themselves. ${ }^{112}$ Zygmunt Bauman (in an interview with Rojek, 2004) argues that individual needs of personal autonomy, self-definition, authentic life or personal perfection are to some extent translated into the need to possess, and consume, market-offered goods. The market feeds on the unhappiness it generates: the fears, anxieties and the sufferings of personal inadequacy it induces release the consumer behaviour indispensable to its continuation (Bauman 1998). Though to some this may seem a unjustified, overly pessimistic interpretations of the effect of the capitalist system on the psychology and identity of people, it is to some extent supported by empirical research on stress-related consumption and consumer stress, and by research in the vein of the 'economics of happiness' (Lane 2000).

\subsubsection{The intensification of housework.}

The intensification of work is taking place not only in paid jobs, but also in unpaid but hugely important 'jobs' in the household, at home. There has been a dramatic increase in the participation of women in the labour force. Traditionally women were doing work in the

\footnotetext{
${ }^{110}$ Schor (1998) shows that the pressures for upscale consumption, and the work schedules that go along with it, created millions of exhausted, stressed-out people who started wondering if the cycle of work and spend was really worth it. There is a small but growing group of what Schor calls 'down shifters' (which can be found at all income levels), reducing their hours of work and, in the process, earning and spending less money.

111 Giddens (1991) suggests that there is an increasing 'commodification' of the self, and points out that even the project of the self as such has become heavily commodified. Not just lifestyles, but self-actualisation is packaged and distributed according to market criteria. Self-help books stand in a precarious position with regard to the commodified production of self-actualisation. In some ways such works break away from standardised, packaged consumption. Yet in so far as they become marketed as pre-packaged theorems about how to 'get on' in life, they become caught up in the very processes they nominally oppose.

112 Christopher Lasch describes this vividly in The Culture of Narcissism (1979).
} 
household. In many ways a household is like a business: it takes in raw materials and sends out processed products (Becker and Tomes, 1986). The most important thing that housework produces is people in a certain state; people who are fed, rested, clothed and able to go out every day to work (Cowan 1983). In addition, households produce the future labour force (children) and build up present and future human capital (education and health).

Due to household technology such as washing machines, freezers and vacuum cleaners, part of the tasks of housewives were substituted by technology and the productivity of housewives increased, enabling women to also work outside of the house. However, a substantial part of the household work cannot be out-sourced. In practice the household still represents a considerable workload, especially in combination with raising children. Raising children has become more labour-intensive, because standards and expectations for what children need have gone up, possibly due to higher expected returns ${ }^{113}$ or to evolutionary pressure for 'K-selection'. ${ }^{114}$ Women still take most of the care tasks (Figure 10). Off-job demands stemming from household and care responsibilities have increased due to increasing female labour participation and the growth of dual-earning families, contributing to increasing work-family conflict (e.g. Hammer et al. 2005) and the compression of tasks in time (Hochschild 1997). ${ }^{115}$

\footnotetext{
113 Becker (1992) suggests that parents invest more in children in terms of time, effort and money (e.g. education) because they want to raise the human capital of their children to get more return on this later when they may have to depend on the children in old age.

${ }^{114}$ In biology, two main strategies of reproduction are distinguished, K-selection (few offspring) and r-selection (many offspring) (MacArthur and Wilson 1967). Which strategy is favoured by evolution depends on a variety of circumstances. Animals with few offspring can devote more resources to the nurturing and protection of each individual offspring, thus reducing the need for many offspring. On the other hand, animals with many offspring may devote fewer resources to each individual offspring; for these types of animals it is common for many offspring to die soon after birth, but normally enough individuals survive to maintain the population. In stable or predictable environments K-selection predominates, as the ability to compete successfully for limited resources is crucial, and populations of $\mathrm{K}$-selected organisms typically are very constant and close to the maximum that the environment can bear. Traits that are thought to be characteristic of K-selection include: large body size, long life expectancy, and the production of fewer offspring that require extensive parental care until they mature.

115 This needs some qualification; it is more complex than simply adding up effortful work and non-work tasks. For example, Sonnentag and Zijlstra (2006) find that time spent on household and childcare activities was not related to need for recovery. This suggests that one cannot simply add work-related and other domestic demands in order to assess the total impact of these demands. Apparently there are qualitative differences between these various demands. Spending time on household and child care may have a beneficial effect on recovery, because it may help to switch off from job-related demands and can be highly rewarding (Sonnentag and Zijlstra 2006).
} 


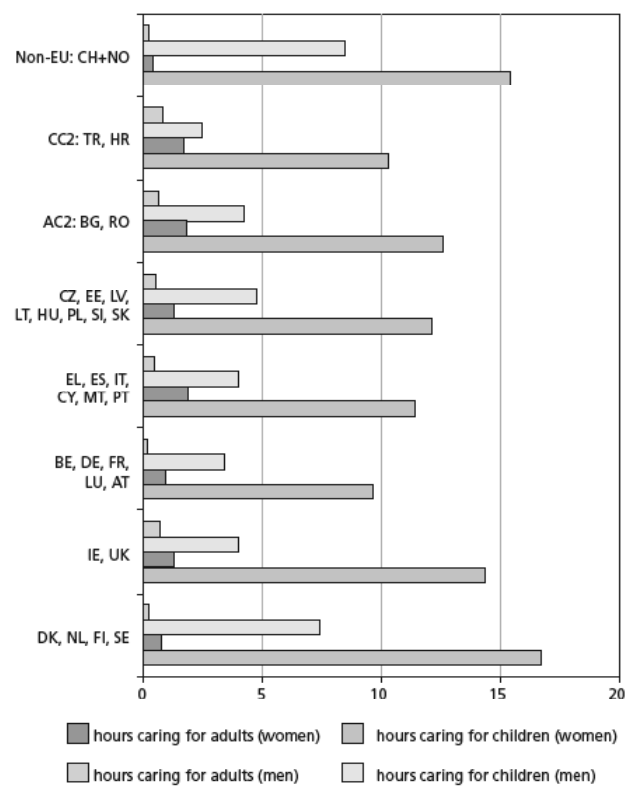

Figure 10. Hours spent caring for children and adults per week, by country group and sex. Source: Parent-Thirion et al. (2006).

Empirical research has shown that work-family conflict is negatively related to desirable outcomes such as family-related satisfaction and performance, emotional well-being/ general life satisfaction, job attitudes and job performance, and is positively related to undesirable outcomes, such as distress/burnout, intentions to quit work absenteeism alcohol abuse depression decreased psychological health. ${ }^{116}$ Role pressures from conflicting work and family demands are among the variables linked to poor mental health. For example, Frone (2000) found that employees who experienced high levels of work-to-family or family-towork conflict were much more likely to report a clinically significant mental health problem compared with employees who experienced low levels of either source of conflict; the evidence suggests causality from work-family conflict via stress to mental health problems (e.g. Frone et al. 1997), though it can be expected that there is also some reverse causality.

The intensification of household work is felt disproportionally by women (Hochschild 2001) (see Figure 11). ${ }^{117}$ Empirical research shows that it is especially women that face a double

\footnotetext{
${ }^{116}$ For a review, see Allen, et al. (2000).

${ }^{117}$ Hochschild (2001) shows that, just as there is a wage gap between men and women in the workplace, there is a 'leisure gap' between them at home. When both partners work it generally still is the woman that does most of the household tasks, thus effectively having two jobs: a 'first shift' at the office and a 'second shift at home. Hochschild paints a portrait of couples as time thieves, children as emotional bill-collectors, spouses as efficiency experts, parents who feel like helpful mothers and fathers mainly to their colleagues at work, and women who - like generations of men before them - flee the pressures of home for the relief of work. Hochschild points out how after the first shift at work and the second at home, comes the third, and hardest, shift: repairing the damage created by the first two.
} 
load of work, increasingly doing paid work but still doing the larger part of unpaid work. ${ }^{118}$ The intensification of non-work adds not only stress of too many demands, but also guilt, which is stressful in its own right. Badly-performed household, child or spousal tasks (due to over-employment at work) tend to be causes of stress, feelings of guilt, inadequacy and anger, and to increased conflict in families and problems with children due to lack of sufficient attention (Hochschild 1997).

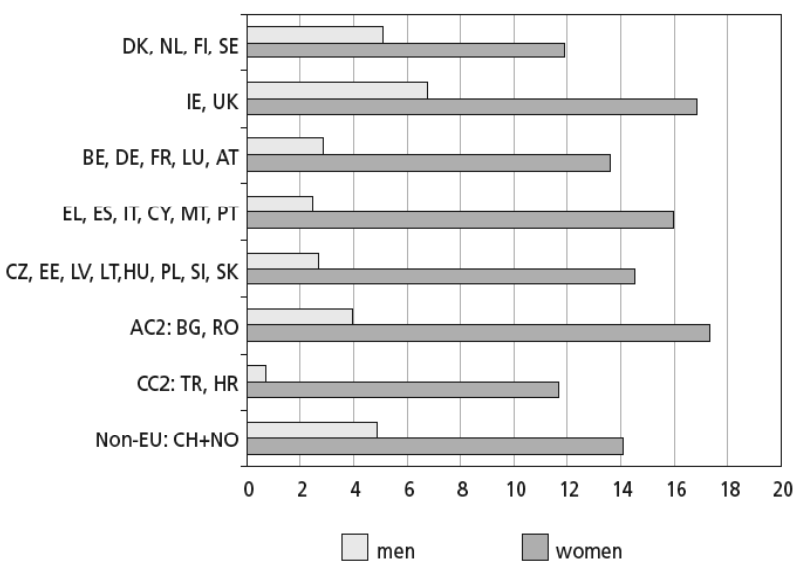

Figure 11. Hours spent on housework per week, by country group and sex. Source: Parent-Thirion et al. (2006).

\subsubsection{Polarisation of effort levels}

Dollard and Winefield (2002), reviewing empirical research on changes in employment, find that there is more over-employment, more under-employment and more frequent unemployment in the labour force. In line with this, Beck (2000) observes an increasing polarisation of the labour market in terms of working hours and effort. At one pole, there is a group of full-time workers facing demands for steadily increasing hours of work and work intensity (but with access to retirement). At the other pole are those who are unemployed or in insecure, often part-time, employment. One interpretation of the data is that the polarisation of the labour market present at any point in time reflects an underlying polarisation of the population as a whole. An alternative interpretation involves a life-cycle view, in which people move from the periphery to the core labour force and perhaps back again.

Both interpretations imply a serious misallocation of work and leisure. On the first view, some individuals or households have too little leisure throughout their working lives to enjoy the relatively large incomes they earn, while others have involuntary leisure and inadequate

\footnotetext{
118 E.g. the European Working Conditions Survey (Parent-Thirion et al. 2005) shows: "On average, the unpaid work-paid work ratio is $150 \%$ for female part-time workers whereas it stands at $33 \%$ for male part-time workers." (p.27) "The findings show [...] that even women working part time work more hours in total than men working full time, taking into account other tasks related to caring, household duties, etc. (p.92)
} 
consumption. On the second view, the misallocation occurs within the lifecycle, with people being massively overworked during their child-raising years, then facing decades of idleness.

Smith (1997) describes how an increase of contingent work may lead to effortintensification. In principle, core workers benefit from the increase of contingent labour, because they are buffered by a peripheral work force brought in to absorb fluctuations in work cycles but specifically excluded from participating in the core of organisation. Contingent workers are not trained in new production methods, nor are they authorised to participate in self-managed groups or quality circles. In contrast, by and large they are assigned to the least skilled, most easily filled jobs, and they are monitored by their permanent counterparts. They are typically excluded from the company events and rituals that are organised socially to glue together the new participative agenda. However, temporary workers often work hard, in order to keep their jobs as long a possible and to increase their chances for permanent work. Smith suggests that the presence of a large and growing contingent work force serves to signals to permanent workers what can happen if one should refuse or limit one's efforts. The presence of scores of contingent workers seeking full-time and permanent jobs may increase the effort-levels of permanent workers. The result is an imbalance: large proportions of the work force are either under-employed or over-employed, and an overall intensification of work for both the temporary and the permanent workers.

\subsubsection{Hidden costs and effort inflation}

To understand how it is possible to have 'hidden costs' due to the limitations of the economic conceptual toolset, it may be enlightening to look at the discussion on 'disguised unemployment', as was set out by Joan Robinson in 1936. "An economy consisting of selfsupporting families each working their own land must always enjoy full employment, since each individual is free to work as long as he considers the real reward he obtains a sufficient inducement for his efforts. In any economy in which there is specialisation and exchange the principle of effective demand comes into play, and unemployment may occur" (Robinson 1936, p.225).

Robinson points out that the level of unemployment and increases or decreases in this level depend on the definition of unemployment. "It has always been felt that the definition of "employment" was arbitrary, and that a man when he is shaving himself, or a woman when she is scrubbing her own floor, is "producing utilities" just as much as when he is mining coal or she is serving at a counter" (p.236). She proposes that the real phenomenon at stake is workers going from work with higher productivity to work with lower productivity, and depending on the institutional system of a country the work with lower productivity is part of the paid labour market and either labeled employment or unemployment." She thus point out that there is 'disguised unemployment': [A] decline in demand for the product of the general run of industries leads to a diversion of labour from occupations in which productivity is higher to others where it is lower. The cause of this diversion, a decline in effective demand, is exactly the same as the cause of unemployment in the ordinary sense, and it is natural to describe the adoption of inferior occupations by dismissed workers as disguised unemployment. (p. 226). Robinson then observes: "The analysis of disguised 
unemployment makes it clear that while everyone is occupied for twenty-four hours a day, so that the total amount of occupation can never be increased, yet employment can be said to increase when part of a man's time is transferred from an occupation in which its productivity is lower to one where it is higher." (p. 226).

In a similar way as the difference between being occupied (work in broad sense of the word) and being employed (paid work), there is a difference between production inputs and production costs. Workers put in time, effort and resources into the production of goods and services that input into production, but of this only the input measured is taken into account as costs. Thus, in theory input can go up while costs stay the same. If due to an innovation output goes up in terms of measurable products and services sold at the market while the costs stay the same, productivity may seem to increase and production may seem more efficient. However, if in reality costs (as measured, quantified inputs) remain the same or go down, nevertheless overall input (both measured and non-measured) may increase because not all inputs are taken into account as costs. In that case the efficiency - in terms of the ratio of real input and real output - may in fact not increase due to the innovation (and in theory may even decrease). We propose to call the situation that labour input increases while labour costs remain the same or decrease "effort inflation".

\subsection{Conclusion}

This chapter presented an overview of changes in the nature and organization of work, and of what is known about the psychological consequence of these changes. The research which was reviewed supports the claim that work on average has important effects on mental health, more (and more complex) than in the past due to changed job characteristics; and vice versa, that mental health has important effects on work, via its effects on important job requirements such as flexibility, self-management, adaptability and on cognitive, social and emotional skills, again more so than in the pas, due to changed job requirements.

The chapter showed that the changes in the economy and in particular in the nature and organization of work have resulted in an increased importance of cognitive, social and emotional skills, and of mental resilience, self-efficacy and personal stability, as employees have to compensate for the decreased day-to-day "micro" stability of the external environment by continuously (re)creating of internal stability. If they fail to do so, they suffer from stress, and over time their mental health is affected. This while precisely mental health is a crucial determinant of the skills and characteristics mentioned above, and thereby of the performance and productivity of employees. To name only one possible, important economic implication of this is, that while technological and organisational innovation may raise productivity, through their effects on mental health they also may reduce productivity.

The evidence available pointed to negative rather than positive effects of work on mental health. The changed nature of work may also have positive effects on mental health (e.g. job satisfaction, personal growth, self-esteem). It is not really clear whether the changes in the nature of work have more negative than positive psychological effects. The distribution of good and bad effects in the population of workers often is uneven, and at the individual level the effects may not outweigh each other. It seems that the bandwidth of psychological 
effects has increased, but it is hard to tell what exactly the net effect is. What matters most for this thesis is the fact that there $i s$ an (increased) effect of work on mental health and vice versa. The focus in this thesis is on negative mental health effects, because these are most clearly described in research, and the role of mental health in economic processes can to some extent be better understood by looking at the economic consequences of lack of mental health.

The evidence presented suggests that work can somehow "use up" the mental health of workers in the productive process. To put it schematically: a worker with a certain mental health status enters a job, experiences substantial job stress, and ends up with a lower mental health status - hence some how mental health has been depleted during production. This chapter has shown that this happens often, and more so in the type of jobs that are becoming more prevalent in the economy.

The large body of research showing "depletion" of mental health due to work is the basis on which this thesis makes a more general claim: that mental health can be seen as a resource in the production process. As is the case with productive resources, more of this resource means higher productivity, less of this resource means less productivity. However, it is unclear what the nature of this resource is and how it plays a role in the economic production process. In the next chapter, a next step is taken in clarifying the economic role of mental health. 



\section{Chapter 3. Mental health}

\subsection{Introduction}

Chapter 2 presented research findings about the changes in the content, organization, management and intensity of work, and their psychological consequences. In order to really understand the economic function of mental health and how it might be changing, we need to go beyond this. We need to understand the actual pathways underlying the relations found. Only then we can arrive at useful statements about the economic function of mental health.

The evidence in chapter 2 is interpreted as a sign that mental health (or some close correlate of it) in some way functions as an input factor in the production processes of today's economy. It seems that for jobs with certain characteristics more of this yet undefined input is needed than for other jobs; that some persons possess more of this input than others; that this input can diminish under the influence of stress; and that it can structurally be destroyed due to mental health problems. In addition, it was observed not only that mental health has (more) effects on work, but also that work has (more) mental health effects. Therefore it was concluded that mental health can be seen as some sort of (unintended) output. Mental health states change under the influence of job characteristics, and thus mental health states can be seen being 'produced' to some extent as a (side)product of production processes at work.

This chapter starts with a discussion of the nature of mental health and mental illness (3.2); it will become clear that these are not so easy to define, because mental health is more than just a medically defined phenomenon. It is important to address the issue of definitions at some length, in order to be able to interpret research results on, for example, the prevalence and costs of mental health problems in the right way.

Next, an overview is given of what is known of the prevalence of mental health problems and the costs associated with them (section 3.3), in order to show that it is in no way a marginal phenomenon but rather an economic factor of major importance. The facts and figures presented will, with qualification and careful interpretation, show that mental health problems are very costly, both in terms of direct costs (e.g. health care) and indirect costs (e.g. loss of productivity), and that they seem to be increasing. It is unclear whether there is a real increase for mental health problems in themselves (most of the observed increase is attributed to better recognition and less stigma), it is clear that there is an increase of the costs related to mental health problems. Partly this is again increased recognition of these costs and growing insight of the detrimental effects of mental health problems in all spheres of life, but partly it is a real increase in costliness; mental health problems affect performance at the job more because of the increased cognitive and psychosocial requirements of jobs (as described in chapter 2). In addition section 3.3 will show that there is evidence of an increase in work-related stress and the costs related to this, including the costs of mental health problems caused or triggered by this stress. 
Next, a closer look is taken at the more precise economic role of mental health. Most of us will recognize that work can make a person happy or depressed, if only from our own experiences. Apparently, at work not only certain products or services are produced, but also certain mental health states. However, how are mental health states 'produced' during work? In section 3.4, we will look at how mental health can be an output of environmental factors, such as job conditions, by discussing the main mechanism at stake here, the stress response. A second conclusion of the discussion in chapter 2 was that mental health has more effects on (performance at) work than in the past, and thus functions as an input to the work process. In section 3.4, the underlying mechanism determining the effects of mental health on productivity is identified. Mental health determines the extent to which an employee can deal productively with stress; this is one of the main pathways through which mental health affects performance at work. By discussing the relationship between stress and performance and the different factors determining this relationship, more insight is gained about how mental health functions as an input, affecting core economic variables such as productivity.

After having established that mental health in some way functions as an input and output of the production processes in an economy, the next question is what exactly in mental health has productive value. Is it really mental health that affects the relationship between stress and performance? If so, then why do some mental disorders affect economic functionality so much more than others? And how is this related to other factors that affect performance, such as human capital? By looking at the way in which functionality is compromised by mental health problems, it is possible to identify more precisely the productive component of mental health (section 3.5). The research presented in this section suggests that it is not mental health itself, but its productive correlate 'agency', which accounts for the productive effects associated with mental health. Agency, the ability of a person to act rationally on his own behalf and in his own interest, is an important construct in psychological theory, and is found to crucially moderate the relationship between stress and performance.

Finally, in section 3.6, we will take stock of what the findings of this chapter tell us about the economic function of mental health and how we could conceptualize it.

\subsection{Mental health: definitions and considerations}

In this section, the definitions of mental health and mental illness are discussed as a medical construct (3.2.1) and as a social construct (3.2.3). Based on this, the widely observed increase of mental health problems is assessed (3.2.4).

\subsubsection{Definitions of mental health and mental illness}

The definitions of mental health and mental illness are not clear-cut, as a short overview of definitions used in some recent seminal science-based policy reports on this topic shows. 
The Surgeon General ${ }^{1}$ (1999), in an elaborate report on mental health, defined mental health as follows: "Mental health is a state of successful performance of mental function, resulting in productive activities, fulfilling relationships with other people, and the ability to adapt to change and to cope with adversity. Mental health is indispensable to personal well-being, family and interpersonal relationships, and contribution to community or society." (p.4) "Mental illness is the term that refers collectively to all diagnosable mental disorders. Mental disorders are health conditions that are characterized by alterations in thinking, mood, or behavior (or some combination thereof) associated with distress and/or impaired functioning" (p.5). The report of the Surgeon General points out that mental health and mental illness form a continuum, and that the mental health problems that do not cross the threshold of the diagnosis of mental disorder are nevertheless very important because they represent tremendous loss of functionality and well-being. Also, they can easily develop into fill-fledged mental illness. The report uses the term "mental health problems" for "signs and symptoms of insufficient intensity or duration to meet the criteria for any mental disorder" (p.5). ${ }^{2}$

In the World Health Report 2001, Mental health. New understanding new hope, the WHO (2001a) writes about mental disorder: "Mental and behavioural disorders are understood as clinically significant conditions characterized by alterations in thinking, mood (emotions) or behaviour associated with personal distress and/or impaired functioning" (p.21). The WHO (2001b) describes mental health as: "a state of well-being in which the individual realizes his or her abilities, can cope with the normal stresses of life, can work productively and fruitfully, and is able to make a contribution to his or her community" (p.1). ${ }^{3}$

The EC report The State of Mental Health in the European Union (EC 2004) observes that mental health has a positive as well as a negative dimension: "The positive dimension refers to the concepts of well-being and ability to cope in the face of adversity. This encompasses various dimensions including: self-esteem, internal locus of control or mastery, optimism, and sense of coherence, to mention the most frequently measured. The negative dimension relates to the presence of symptoms defined as psychological distress as well as to mental disorders. These mental disorders are defined through recognised classifications such as the International Classification of Disease (ICD10) or the Diagnostic Statistical Manual Version IV (DSM IV)" (EU 2004, p.4)

\footnotetext{
1 The Surgeon General of the United States is the nation's leading spokesman on matters of public health, appointed by the President of the United States for a 4-year term of office.

2 The report of the Surgeon General pointed out that there is no clear-cut difference between mental health and physical health. "Instead of dividing physical from mental health, the more appropriate and neutral distinction is between "mental" and "somatic" health. [...] Mental health refers to the successful performance of mental functions in terms of thought, mood, and behavior. Mental disorders are those health conditions in which alterations in mental functions are paramount. Somatic conditions are those in which alterations in nonmental functions predominate" (Surgeon General 1999, p.6).

${ }^{3}$ In the World Health Report 2001 (WHO 2001a) the WHO stresses that the definition of mental health is not clear-cut: "Mental health has been defined variously by scholars from different cultures. Concepts of mental health include subjective well-being, perceived self-efficacy, autonomy, competence, intergenerational dependence, and self-actualization of one's intellectual and emotional potential, among others. From a crosscultural perspective, it is nearly impossible to define mental health comprehensively. It is, however, generally agreed that mental health is broader than a lack of mental disorders" (p.5).
} 
The EU Green Paper Improving the mental health of the population: Towards a strategy on mental health for the European Union (EC 2005) follows the WHO definition of mental health and mental ill health, and emphasizes that mental illness is broader than just medically recognized disorders: "Mental ill health includes mental health problems and strain, impaired functioning associated with distress, symptoms, and diagnosable mental disorders, such as depression" (p.4).

The terms 'mental health' and 'mental illness' indicate that it concerns a state of being which is seen primarily as a medical phenomenon. Psychology and psychiatry have developed detailed diagnostic systems with criteria for diagnosing mental disorders. ${ }^{4}$ While mental disorders can now be diagnosed reliably and accurately, ${ }^{5}$ the diagnostic systems in use are not as complete and 'hard' as it seems at first sight. For example, in the earlier versions of the DSM, some mental disorders were included that now are no longer there, while in later versions there are disorders that were never there before. What is considered mentally healthy or mentally ill changes over time, and is different in different cultures (WHO 2001a). People who heard voices in the air were considered to be saints in contact with god or witches in contact with the devil, while nowadays they would probably be labelled schizophrenic. Sometimes a mental disorder gets dismissed from the diagnostic system, as in the case of homosexuality, which was officially listed as a mental disorder in DSM for a long time. ${ }^{6}$ Sometimes a mental health disorder is added, such as Post-Traumatic Stress Syndrome (PTSD), which is recognized as a disorder since $1980{ }^{7}$ And sometimes, a mental health problem is increasingly diagnosed although it is not (yet) included in DSM, as in the case of burnout. ${ }^{8}$

\footnotetext{
4 The most used comprehensive system for classifying and diagnosing mental health problems is the fourth edition of the Diagnostic and Statistical Manual of Mental Disorders, known as DSM-IV, designed by the American Psychiatric Association (APA). Another important, more general diagnostic system (covering all existing illness, both somatic and mental) is the International Statistical Classification of Diseases and Related Health Problems (10th Revision) designed by the World Health Organization, known as the ICD-10; chapter V (F) gives a detailed classification of mental disorders.

${ }^{5}$ Diagnostic criteria for disorders have been standardized internationally. Concordance between two experts in the diagnosis of mental disorders averages 0.7 to 0.9 . These figures are in the same range as those for physical disorders such as diabetes mellitus, hypertension or coronary artery disease (WHO 2001a, p.22). In addition to these two main diagnostic systems, many specific scales have been developed for measuring specific symptoms of specific conditions, such as the Beck Depression Inventory.

${ }^{6}$ The classifying in the DSM-II of homosexuality as a mental disorder was largely removed in 1973, and finally completely removed in 1986. Currently it is generally considered as a preference that falls within the range of preferences that are considered 'normal'.

7 Post-Traumatic Stress Syndrome (PTSD) consists of a distinct set of patterns following a highly traumatic event, such as intrusive recollection, avoidant behavior and flat affect, over a certain minimal period of time and with a certain minimum severity. Since its inclusion in the DSM-II in 1980, the diagnosis of PTSD has increased rapidly. For a set of symptoms to become recognized as a distinct syndrome is an important step; Marshall et al. (1999) point out that a new diagnosis can greatly influence scientific research, access to resources, and treatment selection in clinical practice.

8 The symptoms labeled as burnout consist of three distinct but loosely coupled dimensions: emotional exhaustion (feelings of being emotionally overextended and exhausted), depersonalization (the development of negative, uncaring, cynical attitudes towards others), and negative personal accomplishment (loss of feelings of self-competence) (Maslach 1982; Maslach, et al. 2001). Though it presents a distinct set of symptoms and has a distinct etiology, prognosis and treatment options, to this point it is not included in DSM.
} 
Rosenberg (2006) points out that since the late 19th century, we have created and expanded disease categories to include an ever-broader variety of emotional pain, idiosyncrasy, and culturally unsettling behaviours. "Psychiatry has been the residuary legatee of these developments, developments that have always been contested at the ever-shifting boundary between disease and deviance, feeling and symptom, the random and the determined, the stigmatized and the value-free. Even in our era of reductionist hopes, psychopharmaceutical practice, and corporate strategies, the legitimacy of many putative disease categories will remain contested" (Rosenberg 2006, p.407).

At the core of mental illness is the notion of deviance, different from normal. Pilgrim and Rogers (1999) describe different notions of normality and abnormality that psychologists and psychiatrists use. The statistical notion of normality simply says that frequently occurring behaviours in a population are normal behaviours - so behaviour that does not occur frequently is therefore not normal. 'Normality' refers to certain 'norms' (the words share the same linguistic origin). In the statistical notion these norms are determined simply by frequency, in a 'normal distribution' over the population. Where exactly the 'tails' of frequency distributions are drawn (distinguishing what is considered still normal and what not), and how much deviation is tolerated within the range of the label 'normal', depends to an important extent on context, time, and culture.

\subsubsection{Definitions and demarcations}

In this thesis, 'mental disorders' refers to diagnosable health conditions that are characterized by alterations in thinking, mood, or behaviour (or some combination thereof) associated with distress and/or impaired functioning. 'Mental health problems' is used to refer to all signs and symptoms of mental illness that cause functional problems but that are of insufficient intensity or duration to meet the criteria for a full-fledged mental disorder. Mental health problems are less serious and debilitating than mental disorder, but the prevalence of mental health problems is much higher.

The reports of the WHO, the Surgeon General and the EU all stress that there is no clear line separating mental health from mental illness, but rather that there is a continuum of (combinations of) symptoms which as of some point of severity is labeled as a disorder.

Figure 1 shows a continuum for the mood disorder depression, taken from the World Health Report (WHO 2001a). The continuum goes from normal mood changes (feeling down once in a while) to dysthymia (feeling down often) to major depression (being clinically depressed). Similar continua can be drawn for other mental health problems such as anxiety disorder. 


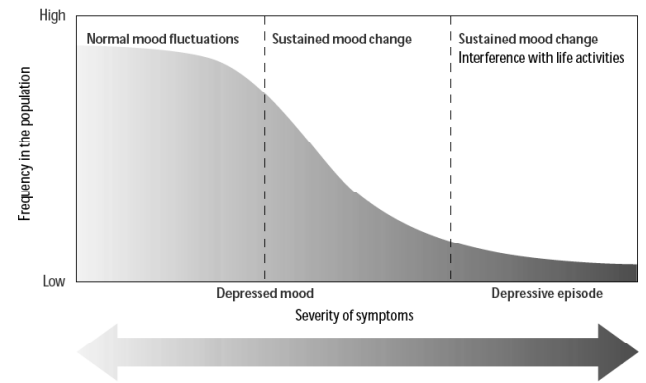

Figure 1. Continuum of depressive symptoms in the population. Source: Figure 1.3, World Health Report 2001 (WHO 2001a).

For this thesis, the 'medium' mental health problems are of most interest (the middle area in the figure), because the studies and reports discussed above suggest that problems in this category seem to be increasing in frequency, and that the impact of this type of problems in terms of cost is increasing. ${ }^{9}$ In addition, people in this category often still work, though with reduced productivity or even negative productivity, ${ }^{10}$ and the economic function of mental health (the topic of investigation of this thesis) can be better understood by looking at people that are still economically functioning to some extent.

Mental illness (like any illness) is the result of a combination of factors biological, environmental (social) and personal (psychological) factors. ${ }^{11}$ Mental illness can be seen as a range of disorders varying in the degree of importance of biological and social determinants, as put forward (in highly schematized form) in the figure below.

\footnotetext{
${ }^{9}$ E.g. Schaufeli and Kompier (2001) find that: "A closer inspection of the mental health problems causing work disability in the Netherlands revealed that the majority - approximately $80 \%$ - do not suffer from major psychopathology such as psychosis, neurosis or personality disorder, but from adjustment disorder. [...] Following the International Classification of Diseases (ICD-10), these cases are labelled as 'situation dependent or exogenous reaction' and include predominantly chronic job stress and burnout” (p.16).

${ }^{10}$ The term 'negative productivity' refers to the situation in which an input factor reduces rather than increases output. This is the case for example when an employee brings down morale, or takes the wrong decisions especially when it concerns a manager since managers tend to have a large effect on the productivity of the employees.

11 This insight is the basis of the 'biopsychosocial model of disease', put forward by Engel (Engel, 1977). Both the reports on mental health of the Surgeon General (1999) and of the WHO (World Health Report 2001) use the biopsychosocial model as a framework for clarifying the different factors that together determine mental illness. In Marmot and Wilkinson (1999) an overview of evidence-based findings is presented, linking social factors such as social-economic status (SES), social support, employment to physical and mental health outcomes.
} 


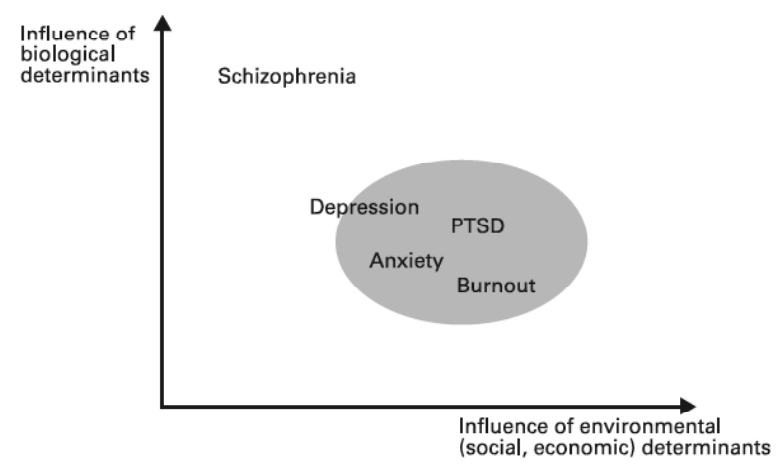

Figure 2. The relative influence of biological and environmental determinants of mental health problems. The grey area indicates the main area of interest for this thesis.

One of the aims of this thesis is to provide more understanding of the influence of the economy on mental health; consequently mental health problems for which social determinants play a relatively more important role are the more relevant here.

Following the widely accepted biopsychosocial model of disease, mental illness is the result of the interplay of biological, psychological and social risk factors. An increase of mental illness is not likely to be caused by a sudden change in the frequency of certain genetic makeup associated with mental illness. Social factors can change more easily, more dramatically and in a much shorter timeframe; thus an increase in prevalence and incidence of mental illness would more likely to be related to a change in social risk factors rather than biological factors. As to the psychological factor, a person can use different coping strategies and can actively change his environment. However, exactly this ability can be destroyed by stress and mental health problems, as will become clear later in this chapter. The interaction of biological, social and psychological factors tend to lead to low steady states of mental health from which it is difficult to get out. This is one of the reasons why mental illness such as depression tends to be characterized by relapse and chronicity once it has developed, and why prevention and early recognition is so important.

\subsubsection{Mental health: a social construct}

In order to interpret the research on mental health, more understanding of the socially constructed nature of mental health and illness is necessary. As the term itself implies, mental health is associated with health and illness, and therefore seems to refer principally to a medical condition. However, this is only a partial and in fact a relatively recent interpretation of the symptoms now associated with mental illness. For many centuries, deviating perceptions, thoughts and behaviour were accounted for by supernatural explanations (God, the devil). As of the $17^{\text {th }}$ century, these explanations were increasingly replaced by medical notions, beginning with rather crude ideas such as 'phrenology' (the idea that the shape of the skull explained symptoms of mental illness) to highly advanced and sophisticated neuroscientific explanations (Pilgrim and Rogers, 2005). Over the past few 
centuries, madness has become 'medicalised' and subject to scientific investigation, in the growing fields of psychiatry, psychology and more recently neuroscience. Deviant mental functioning was put in the framework of health and disease; a person was no longer (supernaturally) possessed or (morally) bad, but (medically) sick.

In the course of the twentieth century however, criticism of the increasingly medical view on mental and behavioural phenomena grew. One of the most outspoken critics was Thomas Szasz. In The Myth of Mental Illness (1961) and The Manufacture of Madness (1970), Szasz argue that mental illness is largely an invention of psychiatrists for reasons of professional advancement, and endorsed by society because it sanctions easy solutions for problematic people. Over the centuries, Szasz alleges, medical men and their supporters have been involved in a self-serving manufacture of madness, by affixing psychiatric labels to people who are odd, socially undesirable, or in other ways different and challenging. Mental illness can be created by suggesting symptoms to patients. After labelling someone as having a certain mental illness, the patient starts to have symptoms he had never had before.

Another famous critic was Michel Foucault, writing the History of Madness (1961). Foucault (1961, translated edition 2006) gives an account of the history of madness, thereby severely criticizing modern psychiatry. Until then, the medical treatment of madness was generally seen as an enlightened liberation of the mad from the ignorance and brutality of preceding ages. But according to Foucault, the new idea that the mad were merely sick, mentally ill, and in need of medical treatment was necessarily a clear improvement. He argued that the alleged scientific neutrality of modern medical treatments of insanity are in fact covers for controlling challenges to a conventional bourgeois morality. Foucault did not argue against the existence of medical factors contributing to madness; he acknowledged that clearly there are physiological factors involved. However, he wanted to show that the final definition of mental illness is as much social as it is medical.

Today it is generally recognized that mental illness is at least to some extent a medical phenomenon. Increasingly, science finds physiological correlates of mental illness, such as the concentration (or lack) of certain neurochemicals or certain patterns in the structure of the brain. However, the fact that mental illness is associated with a degree of chemical imbalance does not necessarily mean that a chemical imbalance is the cause of mental illness. It could equally be merely an expression of mental illness, the causes (and possibly the solutions) being located elsewhere.

Mental illness is not just any form of deviance, but focuses on forms of deviance that are considered problematic by either the deviant person himself or by his social environment, or both. What is considered to be a problem depends on the norms of the social environment and of the person who has to function in this environment. In addition there is a third factor that is taken into account when judging whether deviance is a problem or merely variation: functionality. Someone can suffer from symptoms that are considered deviant in medical terms and social terms (for example agoraphobia ${ }^{12}$ or narcissistic personality disorder ${ }^{13}$ ) and

12 Agoraphobia is a strong consistent fear of open spaces, often preventing a person from going out of the house (APA 1994). 
be considered deviant in socio-cultural terms (for example be labelled as weird or egomaniac) but still be functional (socio-economic criteria), depending on the requirements of his socio-economic environment. A person can be quite normal according to both medical and socio-cultural criteria, but nevertheless be not functional, being unemployed or being unable to function in the job contexts that are available. In fact, some available job contexts may even require a person to be deviant in socio-cultural and even medical terms, in order to be successful. To some extent, what is labelled 'mental illness' may in fact be economic dysfunctionality. If a job context is 'crazy', suffering from burnout in response may in fact be a quite 'normal' way to respond.

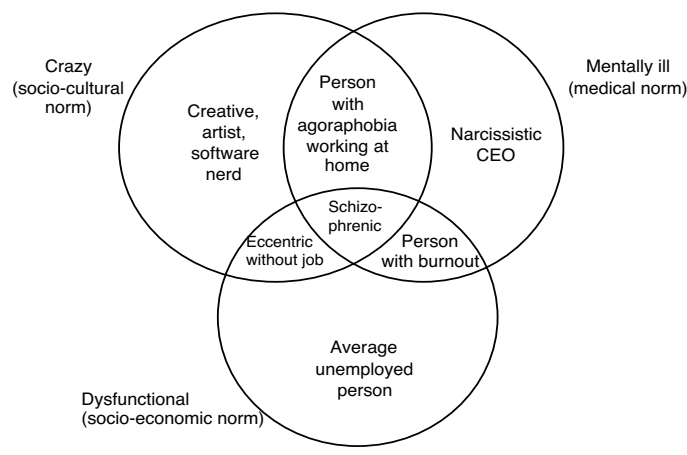

Figure 3. Different types of deviation and their relations to mental illness.

Concerns about increasing speed and complexity of life and growing socio-economic demands on mental health are not new (see for example Breedveld and Van den Broek, 2002). For example, at the end of the $19^{\text {th }}$ century, industrialization was taking its full effect and there was rapid societal change; this was associated with psychological problems, which were attributed to societal change. Schuster (2003) describes how in the 1870 s, there was a growing group of people of seemingly healthy men and women, usually living in cities, who experienced physical pain, emotional distress, and profound exhaustion. Schuster observes that to explain this condition, leading American neurologists George Beard and S. Weir Mitchell "combined the European science of nervous energy with a conservative suspicion of the social changes taking place in late-century America" (p. 2327). ${ }^{14}$ The result was neurasthenia, a culturally oriented diagnosis that attributed mental and physical symptoms to the lack of nervous energy brought on by the stresses of modern society. ${ }^{15}$ For Beard and

13 Narcissism is a personality disorder characterized by feelings of grandiosity, self-importance, of being superior and entitled to special treatment, in combination with a lack of affect (the ability to experience feelings) and empathy (the ability to understand and relate to other people's feelings) (APA 1994).

14 The titles of their work are illustrative: Beard wrote the seminal American Nervousness. Its causes and consequences (1881) and Mitchell Wear and Tear, or Hints for the Overworked (1887).

${ }^{15}$ Schuster (2003) describes: "According to Mitchell, two sorts of persons were particularly at risk of overtaxing their supply of nervous energy: ultracompetitive businessmen and socially active women. Mitchell thought both of these groups were unique but unfortunate products of a modernizing America. During the nation's dramatic transformation into a modern society, families migrated from the countryside to the city, men left traditional jobs as tradesmen and farmers to join the growing ranks of businessmen and office workers, women went from being mothers and daughters to also being university students and physicians, and technological 
Mitchell, neurasthenic patients were casualties of modern society whose bodies and minds could not keep up with the seemingly accelerated lifestyles of men and women in the latter part of the 19th century (Schuster 2003; Wessely and Hotopf 2001).

There is a certain parallel with today's policy reports and this thesis suggesting that the 'epidemics' of burnout, depression and anxiety are related to changes in society, such as globalisation, new technology, flexible work practices. The difference is that today there are high quality epidemiological studies based on unprecedented amount of data. Perhaps even more important, today there is a large, clearly defined and tested body of research about the precise mechanisms through which factors in the environment (such as rapid economic and social change) can cause stress, which in turn can cause mental illness. ${ }^{16}$

\subsubsection{Interpreting the figures on mental health}

In the next section, 3.3, the prevalence and impact of mental health problems is discussed, based on a broad array of empirical studies. The figures presented will show that the economic impact of mental health problems is substantial and intricate, involving billions and billions of euros, thus deserving more attention from economic science. However, it is important to read and interpret these facts and figures with care, and with a clear understanding of different explanations for the findings about high and seemingly increasing prevalence of mental health problems.

It is not easy to establish the extent to which there has been a real increase of mental health problems in recent years. However, more and better epidemiological studies show at the least that mental health problems are more widespread than was recognized for a long time - regardless of whether they actually are increasing. Also they show that the costs of mental health problems are surprisingly high, much higher than was generally thought, and that these costs have increased. This is only partially because of the increase of mental health care costs. What research suggests is that the same mental health problem now is more costly, due to its larger effect on performance at work - because work is, as described in chapter 2 , more mental in nature, requiring cognitive and emotional skills.

This thesis attributes the observed increase in mental health problems to some extent to the nature of work taking its toll in terms of the mental health of workers, and the rest of this

developments such as telegraphs, telephones, and railroads became increasingly common parts of everyday life. As a diagnosis, neurasthenia commanded an intuitive legitimacy because it incorporated the anxieties that arose from these changes into the way people thought of their health. [...] In many cases, diagnoses of neurasthenia attached themselves to traditional ideals, such as the restorative virtues of farming vis-à-vis the fast-paced stress of modern business or the Victorian belief in women's disposition for motherhood rather than scholarship. [...] Today, the illness stands as a reminder of the interaction between medicine and culture and helps illustrate how health care both influences and is influenced by developments in the rest of society." (p.2327). Wessely and Hotopf (2001) draw an analogy with the concerns of medical and social authorities at the end of the 19th century. "Numerous commentators drew attention to an apparent epidemic of both neurasthenia and mental illness. This epidemic was partly blamed on changing patterns of work and education, such as the increasing demands made by the spread of mass education and the introduction of new business techniques and practices. But these concerns gradually receded, with editorialists concluding that the relation between these conditions and unwelcome features of modern life was more spurious than real, and that "we had become more tender in our ills"." (p. 976)

16 The basic features of the mechanisms uncovered in this body of research will be described in section 3.4 . 
chapter will explain how that may be. However, there are other causes of and explanations for the observed increase of mental health problems, which are briefly described below. It is impossible to clearly isolate the effects of the different potential causes of the increase in reported mental health problems. All of the factors summed up below play a role. However, this thesis will provide enough empirical research in chapter 2 and 3 to plausibly claim that the changed mode of economic production is a real and substantial factor contributing to the observed increase in reported mental health problems.

Measurement: the increase of mental health problems represents to some extent an increase in of measurement of these problems, due to the increasing interest in understanding them and dealing with them, related to the ideals of the Enlightenment which gave rise to the expansion of scientific investigation of an growing number of phenomena. In the past there may have been as much mental illness, but it simply was not measured.

De-stigmatization: the social stigma attached to mental health problems is disappearing, making it easier for people with mental health problems to talk about it and look for treatment. This raises the figures.

Relative importance: as other types of health problems in the rich countries became less prevalent due to the progress in medical science, the relative importance of mental health problems increased. This brings them more to the forefront. This is an argument along the lines of Maslow's (1954) pyramid of needs: since basic needs such as food and physical security are fulfilled for the bulk of the population in developed countries, socialpsychological needs become more important and get more attention.

Demographic change: mental health problems are found to be more prevalent in older people, thus demographic change towards an aging society will have as a side-effect an increase the number of mental health problems. ${ }^{17}$

The income and price elasticity of demand: the demand for mental health care has a high income elasticity (Frank and McGuire, 1999). The increase in use of mental health care does not necessarily mean an increase of mental health problems. The presence of a growing mental health care sector in combination with lower relative financial thresholds for access increases utilization of mental health care. Ellis and McGuire (1986) point out that the price elasticity of mental health care is higher than of other health care, and that there has been expansion of insurance coverage of mental health care leading to increased use of health care both in numbers of users and in use per person.

Medicalization: over the past decades there is a trend of (re)labelling thoughts, feelings and behaviour that do not correspond sufficiently with the requirements of the social environment as medical conditions (Dworkin 2001). This phenomenon is called 'medicalization'. Partly it is a matter of inflation of medical language: somebody who is very

\footnotetext{
${ }^{17}$ Nguyen and Zonderman (2006) reviewing the literature on age and depression conclude that the evidence on increased depression in elderly people is inconclusive, and that current literature seems to suggest that age by itself is not a risk factor for depression, after adjusting for age-related risk factors, including physical health, material resources, and social factors (Rothermund and Brändtstädter, 2003).
} 
busy is "stressed", and somebody who feels a bit down is "depressed". Partly it also has to do with re-labelling. For example, a child with a lot of energy and with little concentration these days is not a difficult child but a child suffering of ADHD. Or, a person who is very shy is not very shy anymore but has social phobia. ${ }^{18}$

Psychologization: broadly speaking, people have two means for expressing distress: somatization and psychologization. People that feel stressed can experience this in the form of headaches, stomach ache or backache, and they can experience it as feeling down, becoming anxious. In the Western world psychologization of stress is more common, while in the rest of the world somatization is the norm (Kilhstrom and Kihlstrom 1999). This can be expected to contribute to an increase in the reporting of mental health problems and the use of mental health care.

Economic interests: the mental health care sector is a sector in which individuals and organisations earn money. These have an economic interest to emphasize the size and seriousness of mental health problems and to 'develop' their market by increasing awareness of potential 'customers' of their needs with regard to their mental health (Szaz, 1970).

Higher ambitions: the rapid developments in the neurosciences have led to a growing understanding of mental health problems and increased treatment options. This leads to igher ambitions not only of medical doctors but also of policymakers, as the many policy reports of the past decade illustrate. After having satisfied many of the material needs of the population, policy-makers find a new policy-challenge in the area of mental health, diminishing its negative impact and increasing its presumed correlate, happiness.

Psychological imperialism: Medicalization and psychologization are related to the phenomenon of 'psychological imperialism': the broadening of the categories of mental illness, by describing and understanding issues outside of the direct domain of psychology in psychological terms. This tendency was already observed by Münsterberg (1899), in the very beginning of psychology a science. ${ }^{19}$

Individualization: Globalization, urbanization and individualization have left people more and more 'disembedded' and consequently more isolated (Giddens 1991). The diversity and mobility of populations have increased, and many people live away from their families and relatives and do not know their neighbours. Social support is an important factor determining the risk of developing mental health problems. According to Lane (2000), the

18 Dworkin (2001) argues that this is a sign of a growing phenomenon in society: the medicalization of unhappiness.

${ }^{19}$ Hugo Münsterberg, president of the American Psychological Association at the turn of the $19^{\text {th }}$ century, observed in his President's Address in 1898 (published in 1899): "My address deals with the limits of psychology. I know quite well that such a choice easily suggests the suspicion of heresy; whoever asks eagerly for the limits of a science appears to the first glance in a hostile attitude towards it. To emphasize its limiting boundaries means to restrain its rights and to lessen its freedom. It seems, indeed, almost an anti-psychological undertaking for any one to say to this young science, which is so, full of the spirit of enterprise: Keep within the bounds of your domain. [...] Psychology, it seems to me, encouraged by its quick triumphs over its oldfashioned metaphysical rival, today moves instinctively towards an expansionistic policy. A psychological imperialism which dictates laws to the whole world of inner experience seems often to be the goal." Münsterberg (1999). 
sources of social support are diminishing. Mental health problems that were generally solved with the informal help of a local social support system of family, friends and neighbours, now show up in formal mental health care. One could argue that formal mental health care to some extent replaces the gap in social support that has been eroded by modern times. ${ }^{20}$

(Post)modernization: Globalisation absence of a clear perspective and a stable identity may lead to feelings of uncertainty, loss of meaning and even nihilism (Sennett 1998). ${ }^{21}$ This may affect mental health in terms of existential doubts and lack of purpose, leading to anxiety and depressions. These collective feelings are likely to be expressed in the form of individual mental health problems.

\subsection{Mental health: economic costs}

This thesis proposes that work-related stress and mental health problems have increased as a result of changes in the nature of work. The arguments and empirical evidence for this have been presented in chapter 2 .

In addition, this thesis proposes that mental health has become more important for performance at work. The extent to which certain mental health problems are in effect problematic depends partly on what is required of the individual with these mental health problems. If requirements change, the same level of mental illness may become more problematic, become more salient, and lead to more costs. For example, one of the symptoms of depression is social withdrawal. If a person works on the land in agriculture this will be less problematic in economic terms than when a person works in a service job in which social interaction is at the core of the job.

If this is the case, it should be reflected in the numbers on the productivity costs (costs due to lost productivity) of mental illness; these should be higher even if the prevalence mental illness would have remained the same. In addition, it should to some extent be seen in increases in the expenditure on improving mental health, on mental health care but also on expenditure on products and services to improve subclinical mental health problems, which are not serious enough to make it into mental health care but nevertheless have profound

\footnotetext{
${ }^{20}$ Information and communication technology have to some extent increased connectedness by the possibility of a 'global village' (McLuhan 1964), in which people are connected with their social network(s) wherever they are through Internet, email, cell phone (Castells 1996). However compared to the past these are voluntary connections that can be dissolved without many social implications, and therefore remain relatively 'weak ties' (Granovetter 1983).

${ }^{21}$ Sennett (1998) argues that the constant flux of today's economy takes away the possibility to develop social and psychological roots needed to form a stable personality and character. Giddens (1991) argues that in the post-traditional order of today, self-identity is not inherited or static; rather, it becomes a reflexive project - an endeavour that we continuously have to work on. Giddens (1991) writes that a person's identity depends on "the capacity to keep a particular narrative going", for which the person has to "continually integrate events which occur in the external world, and sort them into the ongoing 'story' about the self' (p54). People are increasingly free to choose what they want to do and who they want to be; but increased choice can be both liberating and troubling, in form of increased pressure to analyse the available choices and minimise risks of which people are increasingly aware, and the emotional stress accompanying this.
} 
costly disabling effects. In the next section, different types of costs will be presented showing that indeed this particular pattern of cost increases is found.

Chapter 2 has shown how the characteristics of work in today's economy put a premium on good mental health, and can lead to loss of mental health. Based on this, it is argued that mental health should be seen as an important production factor in the economy - which would explain the premium on it, and the apparent depletion of it. Due to the intangibility of mental health, it is not easy to estimate how much mental health contributes to the production process. This section on costs aims to give an idea about the economic importance of mental health as by giving some indication of the costs related to the absence of this factor. This section will show that it concerns substantial costs which are rising; we are surely not dealing with a marginal economic phenomenon.

First, an overview is given of the unexpectedly high burden of mental illness, in terms of prevalence and disabling impact (3.3.1). Next, the different types of costs related to mental health problems are described: the direct costs of expenditure on mental health care and other ways to improve mental health (3.3.2); the indirect costs deriving from lost productivity due to reduced productivity at the job, absenteeism, work disability, and mortality (3.3.3); and the costs related specifically to work-related mental stress and workrelated mental health problems (3.3.5). Finally, evidence on the increase of mental health problems is assessed (3.3.6).

\subsubsection{The 'burden of disease'}

Up till the 1990s, the size and impact of mental health problems was not really recognized, nor did they figure prominently in the public debate. ${ }^{22}$ This changed in the 1990 s, due to a number of eye-opening studies. Most notably in 1996, the milestone report The Global Burden of Disease was published, the result of a study by the Harvard School of Public Health commissioned by the World Health Organization and the World Bank (Murray and Lopez 1996). This influential report, aimed at estimating and comparing the costs associated with different illnesses, quite unexpectedly identified mental disorders as being in the top of leading causes of disability and economic burden worldwide: $12 \%$ of all Disability Adjusted Life Years (DALYs) worldwide (in 1996) and no less than 23\% of all DALYs in developed countries. ${ }^{23}$

\footnotetext{
22 E.g. "The burden of mental illness on health and productivity in the United States and throughout the world has long been profoundly underestimated." Report of the Surgeon General (1999) (p. 4). "WHO is making a simple statement: mental health - neglected for far too long - is crucial to the overall well-being of individuals, societies and countries and must be universally regarded in a new light", World Health Report 2001 (WHO 2001a, p.ix).

${ }^{23}$ The burden of disease is calculated in DALYs (Disability Adjusted Life Years), which allows comparison of the relative burden of disease across many different disease conditions. The disability component of this measure is weighted for severity of the disability, in which 0.00 is totally healthy and 1.00 is basically dead. Mental illness turns out to be highly disabling. For example, severe major depression (weight category 0.650.80 ) is considered roughly equivalent in burden to blindness or paraplegia (paralysis from the waist down), whereas severe schizophrenia during active psychosis is equal in disability burden to quadriplegia (paralysis from the shoulders down, weight category 0.80-1.00) (Stouthard et al. 1997). The larger part of depression is mild (category 0.10-0.15) comparable to for example grade 2 osteoarthritis, or moderate (category 0.30-0.40) comparable to severe asthma and deafness. In developed countries such as the US and in Europe, mental
} 
The most prevalent mental illness, depression, was found to be the second leading cause of disability worldwide, and the fourth cause of the global burden of disease (the overall costs associated with disease). This implies that the overall consequences of depression are more disabling and more costly than the overall consequences of road traffic accidents, cancer, malaria or tuberculosis. It was projected that within the few decades, depression would have the dubious distinction of becoming the second cause of the global disease burden.

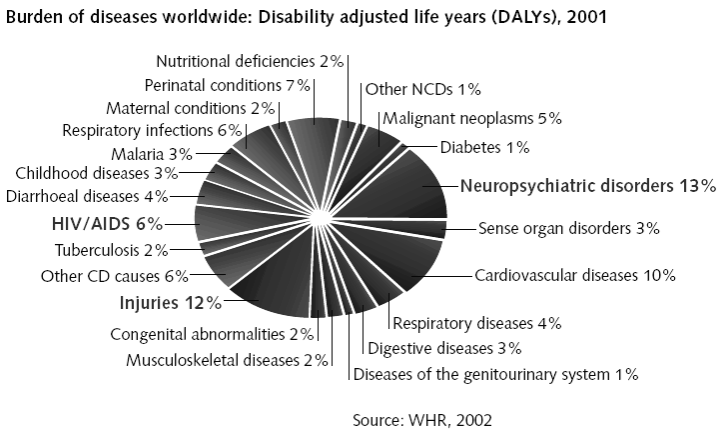

Figure 4. Burden of diseases world-wide, measured in disability life adjusted years (DALYs), 2001. Neuropsychiatric disorders account for about $13 \%$ of all burden of disease; this category includes mental illnesses with a large biological causal component such as dementia and schizophrenia. However the largest sub categories are depressive disorder and anxiety disorder which have important social determinants. The costs related to these mental illnesses are high because they affect people in their working age and because once they have developed they tend to have a chronic course. Source: WHO, World Health Report 2002 (WHO 2002a).

The 'Burden of Disease' report brought to the forefront that mental illness is serious, widespread and very costly, and it put mental health high on policy-agendas, both national and international. This was reflected in a growing number of policy reports about the topic. In the United States, the annual Surgeon General's Report of 1999 had mental health as its theme, highlighting not only the high prevalence and burden of mental health problems, but also the increased possibilities to actually do something about it, given the new developments in neurosciences; it concluded that there may be more problems than we thought, but also more solutions. The World Health Organization (WHO) dedicated the World Health Report of 2001 to the subject (WHO 2001a), increased its research and awareness raising efforts, and published a number of additional studies on mental health over the past years. ${ }^{24}$ The International Labour Organization (ILO) published several reports

disorders cause more share of DALYs than in developing countries, because in many development countries people suffer from illnesses that are mostly no longer present in the developed world, such as malaria and tuberculosis, or are more contained such as HIV. However, depression also ranked in the top ten of leading causes of DALYs in developing countries.

24 Such as: WHO (2002b) Nations for Mental Health. Final Report, and WHO (2002c) Mental Health Global Action Programme MHGAP. In addition WHO started a huge data-collection project called 'ATLAS' in which data on prevalence of mental disorder, spending on mental health care and much more is collected for almost all countries of the world. 
about mental health in relation to work. ${ }^{25}$ In Europe, a series of studies, reports, meetings, conferences, declarations and resolutions of the European Commission, the European Parliament and the European Economic and Social Committee put mental health visibly and clearly on the European agenda as a key topic for policy. ${ }^{26}$ Also the costly consequences of work-related stress received growing attention of researchers and policy-makers at the international ${ }^{27}$ and national level. ${ }^{28}$

There are considerable differences in the burden of disease of different regions of the world. Whereas worldwide mental health disorders were estimated to account for $12 \%$ of all DALYs (Disability Adjusted Life Years) and 31\% of all YLDs (Years Lived with Disability), in Europe and the Americas this was much higher: respectively $20 \%$ and $23 \%$ of all DALYs and $43 \%$ (both) of all YLDs (WHO 2001a). Factors explaining this such as income elasticity and the relative decrease of other illnesses have been described in section 3.2.4. Of relevance here is that there is relatively much mental illness in high-income countries, and that mental illness appears to be relatively disabling in these countries compared to other illnesses that are typically highly prevalent in high income countries. For example, in The Netherlands in 2001 six of all people suffering from a chronic illness, mental health problems were most likely to be an obstacle for people to work or to find a job; eight out of ten were incapacitated (CBS 2003; Figure 5).

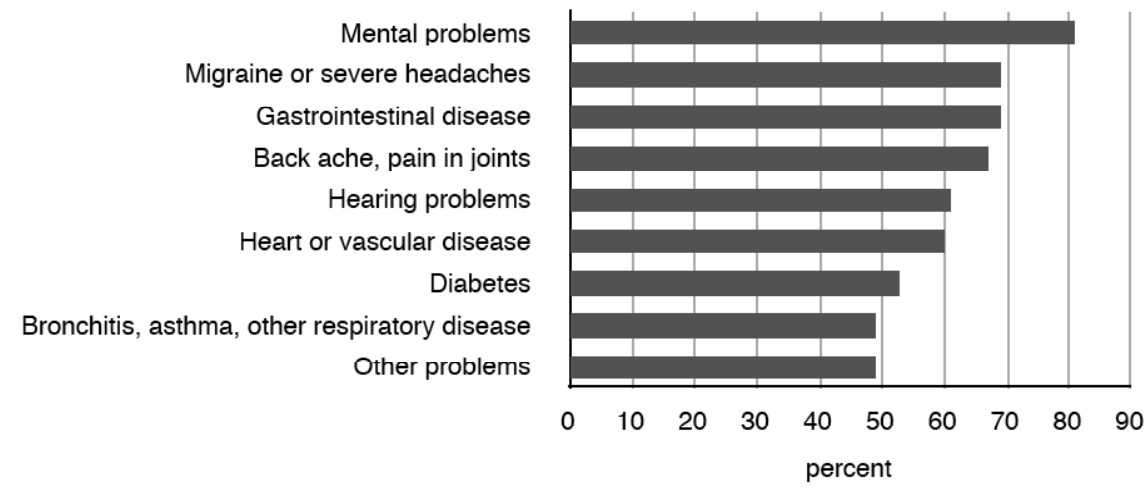

Figure 5. Proportion of incapacitated per illness, the Netherlands, 2001. Source: CBS 2003.

25 E.g. ILO Report Mental Health and Work. Impact, Issues and Good Practices (Harnois and Gabriel, 2000); ILO Report Mental Health in the Work Place (Gabriel and Liimatainen, 2000).

${ }^{26}$ E.g. The State of Mental Health in the European Union (EC 2004); Green paper on Improving the mental health of the population: Towards a strategy on mental health for the European Union (EC 2005). In 1995, a European Network on Mental Health Policy was established. Several Ministerial Conferences took place (Madelin 2005): in October 1999 the European Conference on Promotion of Mental Health and Social Inclusion (Lavikainen et al. 2001), in October 2001 on the theme of Coping with Stress and Depression-related problems in Europe and in March 2003 on Mental Health and Stigma.

${ }^{27}$ E.g. Guidance on Work-related Stress. Spice of life or kiss of death (EC 2002) and Mental Health and Work. Impact, Issues and Good Practices. (ILO, 2000).

28 See Weehuizen (2005) for an overview of reports by various national governments, policy agencies and NGOs. 
Sobocki et al. (2006), in a study on the cost of depression in Europe, find that in 28 countries with a population of 466 million, at least 21 million were affected by depression. The total annual cost of depression in Europe was estimated at Euro 118 billion in 2004, which corresponds to a cost of Euro 253 per inhabitant. Direct costs alone totalled dollar 42 billion, comprised of outpatient care (Euro 22 billion), drug cost (Euro 9 billion) and hospitalization (Euro 10 billion). Indirect costs due to morbidity and mortality were estimated at Euro 76 billion. This makes depression the most costly brain disorder in Europe, accounting for $33 \%$ of the total cost. The cost of depression corresponds to $1 \%$ of the total economy of Europe (GDP). Greenberg et al. (2003) estimate the costs of depression in the U.S. to be 83.1 billion dollars in 2000. Of this, 26.1 billion dollars (31\%) were direct medical costs, 5.4 billion dollars $(7 \%)$ were suicide-related mortality costs, and 51.5 billion dollars $(62 \%)$ were workplace costs. Hu (2006) reviewing all internationally published cost-of-illness studies on the costs of mental illness, finds that the studies reviewed indicate great variation in cost estimates even for the same mental disorder during the same time period within a country. These wide variations may be due to differences in disorder classification, definition of cost categories, sample populations, data sources, and discounting rate. $\mathrm{Hu}$ observes that, given the limitations of the cost of illness studies reviewed, one should be careful in interpreting and using these estimated results. One thing however was very clear in all studies, the empirical results from the reviewed studies indicate that the negative economic consequences of mental illness far exceed the direct costs of treatment; given the effectiveness of mental health treatments, this makes treatment of mental illness an important economic issue.

The increasing number of cost-of-illness studies show that mental health problems are more prevalent, more disabling and more costly then was generally assumed. Whether they are increasing is a complex questions which will be addressed in section 3.3.6. In order to get a better grasp of the economic dimension of mental health, a sketch is given of the nature and size of costs related to mental health problems. The total costs of mental health problems can be divided into two categories of costs: direct and indirect costs. ${ }^{29}$ Direct costs refer to costs associated with the use of health-care resources. ${ }^{30}$ Indirect costs are defined as the value of the output that is lost because people with a certain illness, disease or disorder are impaired in their ability to work productively. ${ }^{31}$ Typical cost items in this category are costs

\footnotetext{
${ }^{29}$ E.g. Greenberg et al., 1999; Rice Kelman and Miller (1992); Rice and Miller, 1998; Miller and Magruder (1999).

30 Andlin-Sobocki et al. (2005) describe different types of direct costs. Direct healthcare costs are costs for goods and services used in the prevention, diagnosis, treatment and rehabilitation of the illness, disease or disorder in question, e.g. costs for medical visits, hospitalization and pharmaceuticals. Direct non-medical costs include all other resource use related to a disease, for example transportation, social services, adaptations of accommodations etc. Sometimes it can be difficult to decide if a specific cost item, for example informal care, should be included as healthcare cost or non-medical costs. From a societal perspective, it does not matter as long as it is included in the analysis (Andlin-Sobocki et al., 2005).

31 There are two main valuation methods for productivity costs: the friction method and the human capital approach. In cost of illness studies based on the human-capital approach, indirect costs are estimated as the lost gross income during the time of absence from work. According to the friction cost method, indirect costs for long-term absence, disability and mortality mainly only occur during the time it takes to replace a worker, i.e. the friction period, due to diminishing returns to labour, internal labour reserves within firms, and the fact that sick employees can sometimes make up for lost work when they return to work. For a discussion on this, see Johannesson and Karlsson (1997)
} 
of loss of production due to reduced productivity at work, absenteeism, work disability and early retirement. The loss of productivity due to mental health problems is generally valued using gross earnings lost or some proportion of the gross earnings if an individual is unable to work at full capacity. The indirect costs tend to be much larger than the direct costs. ${ }^{32}$ The overview of the costs and their cascading nature will give more insight into the central position of mental health in a person's economic functioning.

\subsubsection{Direct costs}

The 'production', 'repair' and 'maintenance' of mental health involves an economic sector of increasing size and importance. Although mental disorders are estimated to account for $12 \%$ of the global burden of disease, yet the mental health budgets of the majority of countries constitute less than $1 \%$ of their total health expenditures - a huge 'treatment gap' (WHO 2001a). In developed economies such as in Europe and the US, the relative and absolute expenditure on mental health care is higher. Low direct costs often reflect lack of treatment and will be accompanied by high indirect costs (Chisholm et al. 2000). The relationship between disease burden and disease spending is disproportionate, and the finding of substantial under-treatment suggests that the optimal expenditure of mental health care is generally much higher (WHO 2001a, p.3), in spite of the risk of adverse selection effects.

To give some notion of the size of public expenditure on mental health care in high-income countries, the figures for the Netherlands are given. According to the Dutch Central Bureau of Statistics, public mental health care expenditure increased from 2.2 billion in 2000 to 4.18 billion euro in 2006 , about $6.4 \%$ of overall health expenditure. ${ }^{33}$

Given the high (economic) burden associated with mental illness, estimated to be $20 \%$ of all DALY's in European countries such as the Netherlands, the percentage spent on mental health care compared to overall health care is rather low. ${ }^{34}$ Overall public expenditure on health care was about $12.4 \%$ of GDP in 2006 , thus public spending on mental health care

\footnotetext{
32 E.g. Hu (2004) finds that of the total cost of depression in Australia for 1997-98 (US $\$ 1.8$ billion), $22 \%$ are direct costs, 78\% indirect, and in Taiwan for 1994 (US\$1.4 billion) he finds 25\% direct costs, 75\%indirect costs. Sobocki et al. (2007) find that the cost of depression increased from a total of 1.7 billion euros in 1997 to 3.5 billion euros in 2005, mainly due to the significant increase in indirect costs due to sick leave and early retirement during the past decade; in 2005, indirect costs were estimated at 3 billion euros ( $86 \%$ of total costs). Micro-level research on the impact of depression and other mental health problems on functionality suggests that the actual indirect costs are more pervasive and larger than is generally assumed in cost-of-illness studies.

33 The increase in public spending on mental health care is generally determined by budget maxima; the real 'demand' for mental health care may substantially higher (Slobbe et al. 2006). Health care finance is a complex topic; the numbers given here are meant to be illustrative for the size of expenditure. For interpretation beyond that, a more precise overview of methods of category definitions, measurement and calculation would be needed.

${ }^{34}$ In 2003 , the cost of health care for depression was 660 million euro in the Netherlands, about $1.1 \%$ of total costs of health care (Slobbe et al. 2006). This while the 'burden of disease' related to depression alone is estimated to be responsible for more than $11 \%$ of all Disability Adjusted Life Years (DALYs) (Polder et al. 2002). The health care costs due to anxiety disorders in the Netherlands in 2003 was 275,2 million, about $0.5 \%$ of total health care; the real health care costs related to anxiety discords are thought to be much higher (Slobbe et al. 2006).
} 
was about $0.8 \%$ of GDP, but the costs associated with mental health problems are estimated to be up to $4 \%$ of GDP or more (Rice et al. 1990) or more. ${ }^{35}$

Mental health problems not only lead to high costs in terms of mental health care, but also in terms of physical (somatic) health care. It is well-documented that individuals with high levels of distress and with mental health problems have a substantially greater somatic health care utilization than individuals without (Gurmankin Levy et al. 2007). People with mental health problems often wander through the physical health care system with somatic complaints, which are actually expressions of hidden mental problems. ${ }^{36}$ E.g. Berndt et al. (2000) find that employees with mental disorders accounted for 15 percent of the employee population, but accounted for 31 percent of all employees' total medical spending during the period of the research study. People with a diagnosis of depression have about twice the health care costs of people without the diagnosis (Kathol et al., 2005). Research shows that stress alters immune system functioning, increases susceptibility to cold viruses, and increases healing time for wounds (Halpern 2005). Increased health risks are associated not only with clinical depression but also with levels of depressive symptoms in the normal range (e.g. Frasure-Smith et al., 1995). A review of 91 studies found that in the presence of active behavioral health treatment, patients with diagnosed mental health disorders reduced their overall medical costs by $17 \%$, whereas controls who did not get behavioural health care increased costs an average of $12.3 \%$ (Chiles, Lambert and Hatch, 1999). Thus, part of the cots due to physical health care should be put on the account of mental health problems.

An important growth market giving some additional indication of the prevalence and costs related to mental health problems is the pharmaceutical sector. Antidepressants have mushroomed from a modest market in the 1980 s into a $\$ 15$ billion $^{37}$ industry in 2004; the

\footnotetext{
35 Research strongly suggests that spending more on mental health care would decrease the overall costs resulting from mental health problems. E.g. Kessler and Frank (1997) observe: "[T]he losses in our study seem substantial in comparison with the estimated costs of treatment. [...] The increase in the expected unconditional income of a person with major depression resulting from successful treatment [estimated cost of $\$ 920$ ] are estimated to be $\$ 2,098$ for women and $\$ 4,679$ for men” (p.75). Accumulated over time this involves substantial gains (in this study, productivity is assumed to be reflected in the wage level).

36 Gurmankin Levy et al. (2007) describe the different ways in which psychological distress and mental health problems ca lead to increased use of physical health care. Somatization is highly prevalent in primary care where $20-30 \%$ of patients fulfill criteria for somatoform disorders and even more patients may present medically unexplained symptoms of shorter duration (Fink et al. 1999). Costs for treatment of patients with somatization disorders are ninefold that of an average person (Smith et al. 1986). The major part of treatment costs are due to (largely ineffective) medical investigations (91\%) and not to psychiatric or psychotherapeutic treatment (which would be effective) (Rost, et al. 1994).

${ }^{37}$ Global sales of anti-depressants in 2004 were estimated to be 15 billion; the United States (71\%) account for most of the global sales of antidepressants, though Europe $(19 \%)$ and Japan (5\%) seem to be catching up (Research and Market, 2005). As to numbers for Canada, Hemels et al. (2002) find that in Canada between 1981 and 2000, total prescriptions for antidepressants increased from 3.2 to 14.5 million. The number of prescriptions expanded by $238 \%$, with an increased cost of 2.7 billion dollars. Total expenditures for antidepressants increased exponentially, from 31.4 million dollars in 1981 to 543.4 million dollars in 2000. Cost per prescription increased linearly from 9.85 dollars in 1981 to 37.44 dollars in 2000. Utilization and costs of pharmacotherapy for depression have increased above the inflation rate (Hemels et al., 2002). The number of prescriptions for antidepressants in the Netherlands increased from 2.9 million in 1997 to 5.5 million in 2004 (the larger part of this is made up by repeated prescriptions); in the second half of 2004, about 760,000 people got antidepressant medication at the pharmacy (Wieren et al. 2007).
} 
market for antidepressants has been growing rapidly, in 1998 even by 24 percent, and is expected to keep growing. ${ }^{38}$ The increase of prescription of medication is related to their effectiveness and availability, and might to some extent be related to the need or preference for a 'quick fix' (Dworkin 2001). ${ }^{39}$

Another sector growing rapidly is the so-called 'self-help industry', which can be seen as indicating something about the presence of subclinical (less serious) mental health problems, and the apparently growing need people feel to increase their self-understanding and mental resilience. Some numbers about this market in the United States can illustrate this (the trend in Europe is similar, with some delay and some moderation). In 2005, the self-improvement market $^{40}$ in the U.S. was worth $\$ 9.6$ Billion (Marketdata 2005). The market grew more than $24 \%$ between 2003 and 2005; $11.4 \%$ yearly growth is expected through 2010 , to a value of $\$ 13.9$ billion. $^{41}$ An estimated $42 \%$ percent of American adults used alternative therapies for mental health problems in 1997, compared to 34\% in 1990 (Eisenberg et al., 1998). In the United States in 1999 an estimated 7.5 million individuals were taking the herbal supplement St. John's Wort to combat depression and 10.8 million used Ginkgo bilboa to enhance memory. Worldwide sales of St. John's Wort in 1998 were estimated to be $\$ 570$ million and US sales to be $\$ 210$ million; St. John's Wort sales are estimated to be growing at approximately $50-90 \%$ per year in the last few years, compared with an approximate $20 \%$ growth rate for the SSRIs (antidepressants such as Prozac and Zoloft) (Nangia et al. 2000). An estimated 5\% of American adults attended a self-help group in the past year (Eisenberg et al., 1998). The nature of self-help products and services indicates that it is more than just consumption to satisfy needs at the higher levels of Maslow's pyramid. Part of the self-help industry aims to address real problems that would remain under the surface otherwise due to lack of awareness and reluctance to go to professional mental health care. Another part of the self-help industry aimed at increasing features such as self-knowledge, personal effectiveness and mental resilience aims at increasing the ability of people to deal with normal demands posed by daily life in (post)modern society - which could be interpreted as indicating that daily life is psychologically more demanding than in the past.

\footnotetext{
38 Goode (2002) observes that the depression therapy market is one of the largest pharmaceutical markets in the world; several antidepressants have achieved blockbuster status. Although the market for antidepressants continues to grow, the rate of growth has slowed, in part because of generics competition.

39 Dworkin (2001) points out that physicians are faced with more demands and less budget and time per patient, especially in 'managed care' constructions. At the same time they are confronted with increasing psychological and psychosomatic complaints from patients. Many doctors take the path of least resistance by prescribing medication whenever a patient is feeling 'blue'. Insurance companies save money when depressed patients receive medication rather than (much more expensive) counselling.

40 The market for self-improvement includes self-help books, CDs, audiocassettes, motivational speakers, videos, public seminars, workshops, holistic institutes, personal coaching.

${ }^{41}$ Self-improvement shows represented $48 \%$ of all infomercials, at $\$ 1.29$ billion dollars a year (Market Data, 2005) A steady diet of self-help books appears at the estimated rate of 2,000 per year and they routinely occupy prominent places on the best-seller lists (Rosen, 1993). In 2005, $\$ 693$ million worth of self-improvement books were sold; the market is forecast to grow 8.3\%/year (Marketdata 2005). An estimated 40,000 people in the U.S. work as life coach or work coach and this $\$ 2.4$ billion market is growing $18 \%$ per year (Marketdata 2005).
} 
Not only governments and individuals, but also firms increasingly spend money on mental health related services; ${ }^{42}$ they send their employees to courses to increase their socialpsychological skills and personal effectiveness, and spend large amounts of money on elaborate psychological selection procedures, in order to get the right psychological personenvironment fit. Because of increasing recognition of the effect that stress may have on the organization (e.g., worker health and productivity), the popularity of worksite stress management programs in has grown significantly over the past 20 years (Nigam, et al. 2003). National surveys conducted in the United States in 1985, 1992, and 1999 found that the prevalence of stress management and counselling programs (among private-sector worksites employing 50 or more workers) was $27 \%, 37 \%$, and $48 \%$, respectively. ${ }^{43}$

This brief, illustrative overview of research findings on direct costs related to mental health problems shows that these direct costs are high and increasing. The increase appears to be especially related to relatively less serious, subclinical mental health problems, which may indicate that this category has grown, and/or that medium mental health problems are considered more problematic than in the past (and thus more money is spent on dealing with it). Chapter 2 has presented evidence that a number of factors that are known to be causally related to stress and to minor and major mental health problems have increased, strongly suggesting that there may be an actual increase. It also presented evidence that good mental health is more important in order to be productive in the type of jobs that are increasingly dominant in the labour market (working with head and heart rather than with hands). This suggests that the relative economic vale of good mental health has increased, and increased spending on mental health fits with this observation.

Thus, the increased expenditure on mental health does not merely have the character of consumption (direct utility of feeling better), but is also and increasingly related to production: it also increases the productive abilities of persons, especially in modern economies. Individuals, businesses and governments are clearly more and more aware of the productive value of mental health, and explicitly and consciously spend money to increase it.

\subsubsection{Indirect costs}

The main source of indirect costs is the extent to which mental health problems affect the quality and availability of the labour force. They are associated with reduced productivity ${ }^{44}$ (including 'presenteeism'), ${ }^{45}$ increased absenteeism, ${ }^{46}$ work disability, ${ }^{47}$ (long term)

\footnotetext{
42 Harvard economist Ronald Kessler, specialized in cost of mental illness studies, observes: "There is an entire burgeoning area of literature that looks at the impact of medical conditions on role performance. Depression is one of the most costly conditions in the workplace, and the majority of dollars for health care comes from employers. They are very interested in knowing what they are getting for their dollar. Where once mental health was likely to be the first thing cut, today a lot of forward thinking employers are seeing the value of high-quality mental health care." (Moran 2004, p.9).

${ }^{43}$ Nigam, et al. 2003; Van der Klink, et al. (2001).

${ }^{44}$ E.g. Ettner et al. (1997) describe the symptoms of depression that interfere with work performance; for example, inability to concentrate, low energy and easy fatigability, exaggerated self-doubts, indecisiveness and disturbed sleep.

45 'Presenteeism' refers to the phenomenon of showing up at work while being not productive, or even counterproductive. E.g. Kessler and Frank (1997) observe that persons with a psychiatric disorder generally
} 
unemployment, ${ }^{48}$ and reduced investment in and return on human capital. ${ }^{49}$ Mental health problems affect productivity in a variety of ways through their effects on skill acquisition, absenteeism, reduced cognitive and social functioning. Especially in high-income countries, which are crucially building on the quality and effective use of human capital, the costs associated with mental health problems and the resulting loss of functionality are large, and increasing. ${ }^{50}$

In this section, different types of indirect costs are presented and discussed. The aim is not only to show the enormous size of these indirect costs but also to given an idea of the central complex role of mental health with regards to productivity. The evidence presented suggests that mental health not only directly affects economic outcomes (e.g., depression leading to less productivity due to its symptoms such as reduced energy, social withdrawal, reduced ability to focus) but also indirectly, as both mediating (e.g. unemployment in the past affecting the probability of employment today via its effect on mental health) and moderating variable (e.g. mental health influencing the extent to which education results in higher income in later life).

There are different approaches to dealing with the indirect cost of illness. One option is to estimate how much production has not occurred due to illness, using the wages of sick people in the period of their sickness as a proxy for this lost production. ${ }^{51}$ However illness has more indirect costs than only lost production. The Panel on Cost Effectiveness in

have lower productivity on the job as a result of impaired concentration, reduced cognitive abilities, or absenteeism, even when controlling for early life events such as schooling. Also see footnote 35 .

46 E.g., Hooftman and Houtman (2008) in an empirical study on the Netherlands, find that about $6 \%$ of absenteeism (all causes) is related to psychological problems and symptoms of burnout. As to absenteeism specifically due to work-related illnesses, this category of absenteeism tends to result in longer, more costly spells of absence. When employees indicate that the absenteeism is work related this is usually due to work pressure: about $35 \%$ of workers. As to longer spells of work-related absence ( $>13$ weeks), the most prevalent reason is psychological health problems, about $25 \%$ of workers.

${ }^{47}$ E.g. in the Netherlands, work disability due to psychological problems is still the largest category of work disability (35\% in 2006), in spite of stricter regulation and much effort put into prevention (Hooftman and Houtman 2008).

48 E.g. Kessler and Frank (1997) find that mental illness lowers employment rates by 11 percent or more. Mayer et al. (1991), using a fixed effects model, show that the risk of deterioration of mental health is greater among the unemployed and vice versa, generating long-term effects leading to withdrawal from the labour market and greater dependency on social welfare programs. Mental disorder may affect employment rates directly, through involuntary unemployment and indirectly, poor productivity translating into lower labor force participation rates through the offered wage rate. Workers with major depression were over 27 times more likely to experience work loss due to emotional problems than respondents with no disorders (Kouzis and Eaton, 1994). See chapter 2 for a more detailed discussion of research on mental health and unemployment.

${ }^{49}$ E.g. Bartel and Taubman (1986) find that psychiatric disorders reduce educational attainment and lead to teenage pregnancy, early marriage, and marital instability.

${ }^{50}$ E.g. the Word Health Report 2001 of the WHO shows that the burden of mental illness makes up $20 \%$ of all DALYs and $43 \%$ of all YLDs in Europe - a much higher percentage than in less developed economies.

${ }^{51}$ Brouwer and Koopmanschap (2005) describe different approaches for valuing indirect non-medical costs of illness. Traditionally, the human capital method was used for measuring productivity costs: lost production is measured using gross income on the individual level over the period of illness. However, if the unemployment rate in an economy is higher than the frictional unemployment, then it will often be possible to replace a person (after a while). The friction cost method distinguishes between a friction period, in which productivity loss occurs and a further period where a sick worker has been replaced. 
Health and Medicine ${ }^{52}$ proposed a broader definition of costs: "costs associated with lost or impaired ability to work or to engage in leisure activities due to morbidity and lost economic productivity due to death.” (Gold et al. 1996, p. 181). This definition allows for productivity costs to occur while working but being less productive. In addition, it gives room to costs in the area of non-work, by including the lost or impaired ability to engage in leisure activities. A broad approach to costs includes estimates of loss of quality of life of persons with mental health problems, and loss of productivity and quality of life of others (e.g. spouses, children). In this thesis, the loss of quality of life and the ability to engage in and enjoy leisure activities is left out of the discussion. However, the 'spill overs' of productivity loss to other people is taken into account, most prominently in a dyadic model in chapter 6 .

The indirect costs of mental health problems are estimated to be much higher than the direct costs. Greenberg et al. (1993) estimate that the annual costs of depression in the United States in 1990 total approximately $\$ 43.7$ billion; of this, $\$ 12.4$ billion (28\%) is attributable to direct costs, $\$ 7.5$ billion $(17 \%)$ comprises mortality costs, and $\$ 23.8$ billion $(55 \%)$ is derived from productivity costs. A subsequent study reported a cost burden of $\$ 52.9$ billion using revised prevalence data and a refined workplace cost estimation approach (Greenberg et al. 1996). Greenberg et al. (2003) estimate the cost of depression to the US economy in 2000 to be $\$ 83.1$ billion; of this $\$ 26.1$ billion (31 percent) were direct medical costs, $\$ 5.4$ billion (7 percent) were suicide-related mortality costs, and $\$ 51.5$ billion (62 percent) were workplace costs (absenteeism and low productivity). Frank and Gertler (1991) find that the presence of mental distress reduces earnings by approximately $21 \%$ to $33 \%{ }^{53}$ A study on the total cost of mental health disorders in the U.S. estimated these costs to be 148 billion dollars per year in the US, about $2.5 \%$ of GDP (Rice et al. 1990).

Adler et al. (2006) find that the productivity cost of depression alone in the U.S. amounts to $\$ 44-\$ 51$ billion dollars annually. Stewart et al. (2003) find that $81 \%$ of lost productivity costs due to depression are explained by reduced performance while at work. They find that depressed employees cost employers in the U.S. an estimated $\$ 44$ billion per year in lost productivity (not including costs associated with short- and long-term disability). Berndt et al. (2000) find that workers with depression had a 37 percent higher absentee record. Broadhead et al. (1990) found that, compared with asymptomatic individuals, persons with major depression had a 4.78 times greater risk of disability. Persons with minor depression

\footnotetext{
52 This panel, also called the "Washington panel" consisted a group of 13 non-government scientists and scholars with expertise in cost effectiveness analysis convened by the United States Public Health Service in 1993. The panel was charged with assessing the current state of science in their subject and providing recommendations for the conduct of studies in order to improve their quality and comparability.

53 Bartel and Taubman (1979) found that recent diagnoses of mental disorders were associated with a significant and large reduction in earnings relative to individuals with no mental disorders. They report roughly a 24\% reduction in 1973 earnings attributed to the presence of a psychiatric diagnosis made between 1968 and 1973. The size of the estimated effects on earnings underscores the disabling nature of mental disorders (Frank and Gertler 1991). Bartel and Taubman (1986), using a more differentiated definition of mental disorder, indicated that recent diagnoses (1-5 years) of psychosis were linked to a $37 \%$ reduction in earnings compared to unimpaired individuals (an earlier diagnosis reduced earnings by $27 \%$ ). Recent neuroses were found to reduce earnings by $13 \%$. Other mental disorders had an estimated effect of $24 \%$ reduction in earnings, when they were recent. Benham and Benham (1981) found an estimated impact of psychoses on reduction of earnings of 27 to $35 \%$. Neurosis however had a positive impact on earnings equal to about $23 \%$ over individuals with no such disorder.
} 
had a 1.55 times greater risk of disability days and days lost from work. Because of its prevalence, individuals with minor depression were associated with $51 \%$ more disability days than persons with major depression. Badura et al. (2004) find that absenteeism due to psychological problems is growing even when overall absenteeism is decreasing. ${ }^{54}$ Other mental health disorders carry comparable costs; for example, the annual costs of anxiety disorders in the United States for the year 1990 were estimated to be approximately $\$ 40$ billion (Greenberg et al. 1999).

Greenberg et al. (1996) estimated the economic burden of depression to be $\$ 52.9$ billion in 1990 , with over $60 \%$ of the reported costs resulting from increased absenteeism and presenteeism among depressed workers. Stewart et al. (2003) find that in the period 20012002 , US workers with depression cost employers an estimated $\$ 44$ billion per year in lost productive time (LPT), an excess of $\$ 31$ billion per year compared with peers without depression. ${ }^{55}$ Hamilton et al (1997) estimate that people suffering from anxiety have a 16.5 percent lower labour-force participation rate than that of non-sufferers. Kessler et al. (2006) find that bipolar disorder costs twice as much in lost productivity as major depressive disorder. Each U.S. worker with bipolar disorder averaged 65.5 lost workdays in a year, compared to 27.2 for major depression. Even though major depression is more than six times as prevalent, bipolar disorder costs the U.S. workplace nearly half as much. Poor functioning while at work accounted for more lost days than absenteeism. Although only about 1 percent of workers have bipolar disorder in a year, compared to 6.4 percent with major depression, the researchers projected that bipolar disorder accounts for 96.2 million lost workdays and $\$ 14.1$ billion in lost salary-equivalent productivity, compared to 225 million workdays and $\$ 36.6$ billion for major depression annually in the United States. While job performance improved as depression symptoms waned, "clinically improved" depressed patients still performed substantially worse than healthy controls on mental, interpersonal, time management, output and physical tasks (Kessler et al. 2006).

In European countries, comparable costs are found (comparable when taking differences in population into account). Mental ill health costs the EU an estimated 3\%-4\% of GDP, mainly through lost productivity. ${ }^{56}$ Mental disorders are a leading cause of early retirement and disability pensions. ${ }^{57}$ Thomas and Morris (2003) estimate the costs of depression in the UK in 2000 at over $£ 9$ billion, including direct treatment costs of $£, 370$ million; the number

\footnotetext{
54 The 'Fehlzeiten' Report of 2003 (Badura et al. 2004) shows that absenteeism in Germany fell to its lowest level for the past 30 years, dropping to $3.6 \%$, the lowest level since the introduction of continued payment of remuneration in $1974 .{ }^{54}$ At the same time however, a significant increase in psychological illnesses is reported. Since 1994, the cases of reported psychological illnesses increased by $74.4 \%$, and the number of sick days resulting from these illnesses rose by $36.7 \%$. An increase of absenteeism due to psychological problems in spite of an overall decrease of absenteeism could suggest less stigma attached to reporting psychological problems; given the evidence presented in chapter 2 it is plausible that it also reflects an increase in actual work-related mental health problems.

55 This estimate does not include labor costs associated with short- and long-term disability. Stewart et al. (2003) conclude that a majority of the LPT costs that employers face from employee depression is invisible and explained by reduced performance while at work. Use of treatments for depression appears to be relatively low, indicating cost-effective opportunities for improving depression-related outcomes in the US workforce.

${ }^{56}$ Estimation by ILO. http://agency.osha.eu.int/publications/newsletter/8/en/index_23.htm

57 Mental Health Economics European Network, project co-funded from Community Health Promotion Programme (1997-2002), http: //www.mentalhealth-econ.org.
} 
of working days lost yearly in the UK due to depression in 2000 was estimated to be 109.7 million.

In the Netherlands, the indirect costs (lost productivity) due to mental health problems is found to be at least six times the cost of the direct costs (Trimbos 2001). Bijl and Ravelli (2000) estimate that the costs of care for depression in the Netherlands are 388 million euro a year (in this the economic value of the care provided by family and friends is included). When including the costs of lost productivity the costs of depression in the Netherlands is estimated to be 2.1 billion a year, for the age group 18-65 years; when younger and older groups are included, in particular the costs of care are much higher (Bijl and Ravelli 2000). Psychological problems are a major cause of absenteeism, and in many countries this category of absenteeism has increased substantially in the $1990 \mathrm{~s} .{ }^{58}$ In Germany for example this category it almost doubled (see Figure 6). The costs of absenteeism due to mental health problems are estimated to be 7.5 billion euro, about $2 \%$ of GDP of the Netherlands; most of these costs are paid by employers. Gründemann en Van Vuuren (1997) estimated that sickness absence and work incapacity constitute huge benefit costs amounting in total to $\$ 25$ billion in 1995 , corresponding to approximately $8 \%$ of the Dutch GDP.

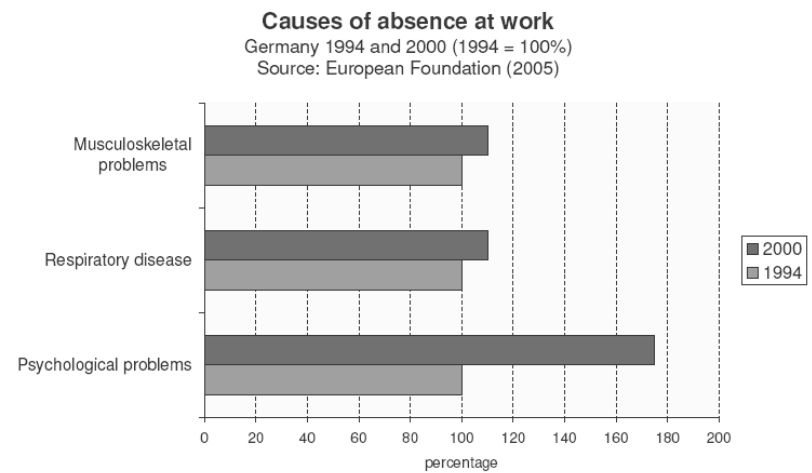

Figure 6. Causes of absence at work, Germany 1994, 2004 (1994 = 100\%). Source: European Foundation (2005).

The costs of reduced productivity, absenteeism and work disability has been related to job characteristics. For example it is found that job insecurity leads to less productivity and more absenteeism and the evidence suggests that mental health is both a mediating and moderating variable in this relationship; Smit and Bijl (2000) estimated the costs of lost productivity due to job insecurity via its effects on mental health to be about 1.1 billion euro a year, about $0,25 \%$ of GDP. In the Netherlands, about 700 thousand workers suffered from burn-out due to work-related stress in 2004, about 10 percent of the employed labour force of approximately 7 million people (CBS 2004). About one third of all work disability is

\footnotetext{
58 Absenteeism figures can be quite variable and fluctuating; for example, in the Netherlands it increased in the 1970 s to $10 \%$ and then decreased in the period $1980-1997$ to $4.6 \%$; in 2005 the percentage was $4.5 \%$ (SCP 2007). However, the share of psychological problems as cause of absenteeism remained the same over time, accounting for one third of all absenteeism, suggesting that the decrease of absenteeism was not in particular related to a relatively large decrease of the particular category of absence due to psychological problems.
} 
related to psychological problems in 1998, and still in 2006. The rather drastic reform of the work disability arrangements in the mean time has lead to a reduction of the overall number people in work disability benefits, but not to the expected disproportional reduction of work disability due to psychological problems. ${ }^{59}$

\subsubsection{Other costs}

In addition to productivity costs there are yet other costs. For example, mental illness has been related to crime rates; people with mental health problems are found to commit more and more serious crimes than people without. For example Rouse (1995) estimated that $34 \%$ of the total costs of mental illness come from loss of productivity, $26 \%$ of the costs were due to somatic health consequences of mental disorders, and 22 percent of the costs were due to crime. Conduct and behavioural disorders in childhood incur costs for the social, educational as well as criminal and justice systems as Figure 7 shows (Scott, Knapp, Henderson and Maughan, 2001). Fazel and Danesh (2006), reviewing 62 surveys on mental disorder in prisoners, find that prisoners have about two- to four-fold excesses of mental illness, and about a ten-fold excess of personality disorders. It is not clear to what extent these mental health problems are causes, consequences, or both, of imprisonment. It is plausible to expect that this is the tip of the iceberg and that a larger part of the other people in prison suffers from sub-clinical mental health problems. If mental health has become a more important requirement for functioning in jobs on average, the proportion of prisoners with mental health problems can to some extent be interpreted as a symptom of exclusion from the job market - their mental health problems are more of a disability than in the past.

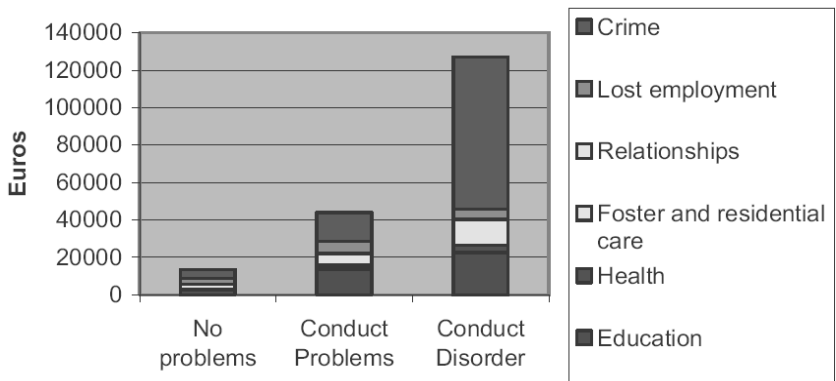

Figure 7. Costs of conduct problems and conduct disorder. Source: Scott et al. (2001). Costs converted into Euro-values by David McDaid, Mental Health Economics European Network.

\footnotetext{
${ }^{59}$ In 2004, regulations regarding work disability benefits have been amended; it has become much more costly for employers to have employees that are sick and unable to work, giving them an incentive to prevent work disability, and the entry criteria for entry into work disability have become stricter, shifting the focus from work disability to work ability (looking at what an employee can do, rather than what he cannot do). Hooftman and Houtman (2008) find that despite a total reduction in disability inflow due to the new regulations, the relative share of psychological and cardiovascular disorders has increased; work disability due to psychological problems is with 35\% (in 2006) still the most prevalent category (it was expected that this rather diffuse category would shrink more easily than other categories due to the new regulation).
} 
The consequences of mental health disorders are not only serious and disabling, they can in addition be deadly, since mental illness strongly increases the risk of suicide. This is a enormous productivity cost, since suicide takes away many years of productive work. The European region has one of the highest suicide rates in the world; Currently, in the EU, some 58,000 citizens die from suicide every year, more than the annual deaths from road traffic accidents, homicide, or HIV/AIDS (WHO (2001a, p. 11).

Over the past 30 years, for the 39 countries for which complete data is available for the period 1970-96, the suicide rates seem to have remained quite stable, but the aggregate rates hide important differences regarding the sexes, age groups, geography and longer time trends. ${ }^{60}$ Suicide rates in Europe range from 3.6 per 100,000 population in Greece to 44 per 100,000 population in Lithuania, the highest in the world. ${ }^{61}$ Suicide rates in Europe between 1980 and 2003 show a mixed picture in terms of increase and decrease. ${ }^{62}$

Not only from a human perspective but also from an economic perspective this is a tremendous economic loss: human capital in which much was invested (food, housing, education) which can no longer be of use in the economy. About $60 \%$ of all suicide can be attributed to depression (Greenberg et al. 1993) ${ }^{63}$ thus a larger part of the costs related to suicide can be put on the account of mental health problems. The amount of estimated lost lifetime earnings due to depression-induced suicide in 1990 was calculated at $\$ 7.5$ billion, or $17 \%$ of the total cost of depression (Greenberg et al. 2003). Of the $\$ 83.1$ billion spent in 2000 on the treatment of depression and related expenses, $\$ 5.4$ billion (7 percent) were suicide-related mortality costs (Greenberg et al. 2003)

The World health Report 2001 observes that it is difficult to find a common explanation for this diverse variation of (changes in) suicide rates. Socioeconomic change (in any direction) is often suggested as a factor contributing to an increase in suicide rates. ${ }^{64}$ Ireland could be

${ }^{60}$ WHO (2005). Many factors influence suicide rates; for example, secularization of society is associated with higher suicide rates. However, the number of 'deaths with unclear cause' (a category often used to include suicide in countries where religion morally prohibits suicide) did not nearly diminish in the period 1950-1995 to an extent that it could explain the increase of suicide, suggesting that the increase in suicide is not a substitution or labelling effect in the data.

${ }^{61}$ Eurostat, data for 2002.

62 Rihmer (2007) describes changing suicide rates in Europe. Between 1980 and 2003, in Western and Central Europe, out of the 13 countries with high baseline suicide rates (20 or more) in 1980/1981, 10 countries (Denmark, Hungary, Austria, Switzerland, Estonia, Slovenia, Latvia, Finland, Czech Republic and Belgium) showed decrease (in average: $26.9 \%$, range: 6-57\%), and 3 countries (Lithuania, Russian Federation, Ukraine) showed increase (in average: $15.7 \%$, range: $10-25 \%$ ). Out of the 16 countries with low baseline suicide rates (less than 20) 9 countries (Sweden, Germany, U.K., Norway, Greece, Slovakia, Netherlands, France and Italy) showed decrease (in average 15.2\%, range: 7-31\%), and 7 countries (Ireland, Spain, Romania, Poland, Portugal, Iceland and Bulgaria) showed increase (in average 49.1\%, range: 3-10\%).

${ }^{63}$ E.g. Chen and Dilsaver (1996) find that the lifetime rate of suicide attempts in people with major depression is $15.9 \%$.

64 The relation between economic change and suicide was famously discussed by Durkheim, in his seminal sociological study Suicide (1897). Durkheim proposed that a high rate of economic change in society and the associated level of social disintegration and normative flux leads to higher levels of suicide, more precisely, of 'anomic suicide'. Anomie is a condition characterized by (1) a weakening or absence of clear standards and shared values in society, and/or (2) a growing discrepancy between dominant (new) norms and values and everyday reality, resulting in feelings of alienation and purposelessness. The absence of a solid frame of reference for people about what matters and what is important leads to confusion and existential inner conflict, 
interpreted as a striking example of this; in Ireland the male suicide rate increased by $400 \%{ }^{65}$ in the same period that economic growth per capita increased $800 \%$ (and GDP per hour worked $1000 \%$ ). Figure 8 show that the suicide rate tracks labour productivity very well, suggesting that there may be a causal relationship with the underlying factor determining labour productivity, the nature of work.

\section{Suicide and productivity in Ireland}

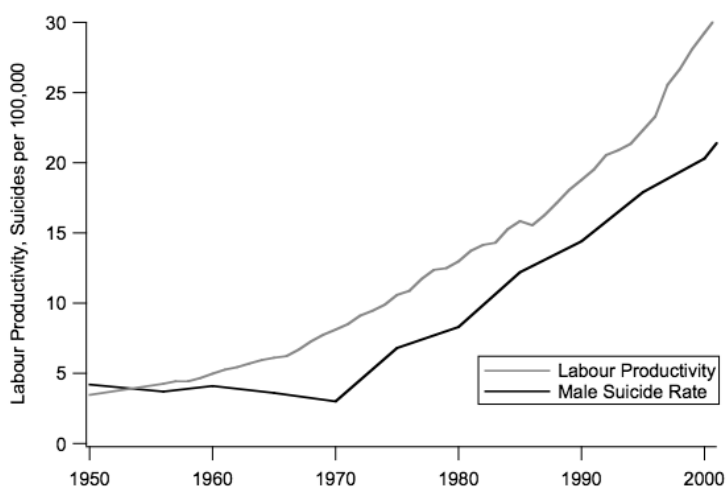

Figure 8. Suicide and productivity in Ireland, 1950-2000. (Productivity is GDP per hour worked.) Sources: Groningen Growth and Development Centre Total Economy Database (2006); WHO Mental Disease Division (2005).

Interpretation of what (changes in) suicide rates may indicate is difficult, and the precise explanation for variations in suicide rates must always be considered in the local context. ${ }^{66}$ However, it is by no means far-fetched to causally connect death to work characteristics via its effect on mental health; for example in Japan there is a widely recognized form of "suicide" directly related to work, which has a name of its own, "karoshi' (Nishiyama and Johnson 1997); and suicide caused by work has been officially recognized by the Japan Occupational Safety and Health Resource Center (JOSHRC) as well as court decisions about compensations. $^{67}$

Agerbo et al. (2007) investigated the association between occupation and suicide, using population registers, which contain information about the entire Danish population. Higher suicide rates were associated with lower overall job status; most differences in suicide risk

which can result in suicide. Durkheim believed that anomie is common when the surrounding society has undergone significant economic changes, whether for better or for worse.

65 Suicide in Ireland, A National report (Irish Department of Public Health, 2001).

66 The World Health Report 2001 observes that a relationship between rapid socio-economic change and suicide has been documented in research, but at the same time increases in suicide rates have also been observed in periods of socioeconomic stability, while stable suicide rates have been seen during periods of major socioeconomic changes. Nevertheless, these aggregate figures may hide important differences across some population segments. For instance, a flat evolution of suicide rates may hide an increase in men's rates statistically compensated for by a decrease in women's rates; and male suicide is related to other socioeconomic variables than female suicide.

${ }^{67}$ See the documentation of the Japan Occupational Safety and Health Resource Center (JOSHRC) on this at http://www.jca.apc.org/joshrc/english/15-1.html 
between occupations were accounted for by differences in income and employment status. Two exceptions were the medical and nursing professions, which suffered the highest suicide rates of all 55 occupations examined; these sectors are known to have a high psychosocial work burden ('emotion work', as discussed in chapter 2), and may have easier access to means for suicide. ${ }^{68}$ Research has connected suicide risk specifically to psychosocial burden of work, by isolating and controlling for different variables. A 2005 study of TNO reported that the number of work-related suicides related to psychosocial work burden in the Netherlands is 200 per year, about $0.3 \%$ of the labour force (Blatter et al. 2005). The total number of deaths due to psychosocial work burden is estimated to be 660 workers; this is composed of suicide, stress-related cardiovascular disease and accidents. ${ }^{69}$

\subsubsection{Costs of work-related stress}

In order to get some notion of the costs that can be specifically related to work-related mental health problems, some numbers on work-related stress and its associated costs are reviewed. Work-related stress is an important cause of mental health problems. ${ }^{70}$ High job demands have consistently been associated with psychological distress and depression; though it is important to note that much research in this field has suffered from methodological shortcomings (cf. Reichenberg and MacCabe 2007). ${ }^{71}$ However, the relationship between stress and mental health problems is well-established at the micro level, and much is known about the physiological mechanisms through which stress leads to mental disorder, ${ }^{72}$ and a number of carefully controlled prospective studies clearly conform this relationship. ${ }^{73}$

\footnotetext{
${ }^{68}$ Increased risk of suicide among medical professionals has been quite consistently reported (Schernhammer, 2005). In the study by Agerbo et al (2007), suicide by medicines in doctors was increased around 13 times, suggesting that easy access to drugs, combined with expertise in pharmacology, may explain some of the excess. However, even when deaths by medicines were excluded, suicide rates in doctors and nurses were still comparable to those in unskilled occupations, suggesting that additional factors may be operating.

${ }^{69}$ These figures are based on databases from 2003 and 2004, and a justified estimate of the extent of workrelatedness of the problems (Blatter et al. 2005).

70 This is well-established in research; for examples of this type of research, see Munce et al. (2006) who find in a controlled large epidemiological Canadian sample that high overall work stress is a strong predictor for depression, almost doubling the risk of depression. Also see Mausner-Dorsch and Eaton (2000), Tsutsumi et al. (2001).

${ }^{71}$ For example, confounding by for example socioeconomic status has not always been adequately controlled. Individuals vary markedly in their propensity to report psychological distress, leading to spurious associations between self-reported job stress and psychiatric symptoms, especially in cross-sectional studies. It is often difficult to exclude reverse causality: for example, individuals with mental health problems might be less adept at avoiding stressful working environments than healthy individuals (Reichenberg and MacCabe 2007).

72 In section 3.4 the underlying relationship between stress and mental health and stress and performance will be described in detail.

${ }^{73}$ For example Melchior et al. (2007) documented an association between work stress and rates of depression and anxiety in young adults. Crucially, they capitalized on the prospective study design, demonstrating that working in high-demand jobs (i.e. jobs with excessive workload, or extreme time pressures) was associated with the onset of new depression and anxiety in individuals without any pre-employment history of psychiatric disorders. Overall, around $45 \%$ of new cases of depression and anxiety in the cohort were attributable to high job demands.
} 
In high-income countries, job stress and the mental health problems resulting from it is considered an important social and economic problem. Studies such as EU (1999), NIOSH (1999), ILO (2000), European Foundation (2001), Harnois and Gabriel (2000) and GOHNET (2001) suggest that there is an increase of work-related psychosocial risk factors such as work-related stress. ${ }^{74}$ The Labour force Survey of the European Foundation (Paoli and Merllie 2001) shows that about 28\% of the labour force in the EU-15 (more than 40 billion workers) report having to deal with serious work stress, making stress the number one health effect of work. About 20-22\% reports chronic fatigue due to pressure at work(see Figure 9). Job stress has been found to be causally related to other disabling work-related problems such as backache (e,g, Niemi et al. 1997; Lundberg et al. 1999) and headache (Labbé et al. 1997).

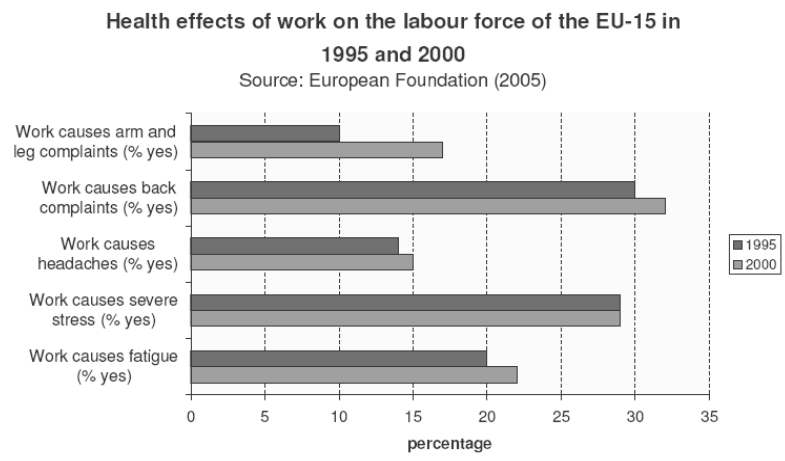

Figure 9. Health effects of work on the labour force (EU-15), 1995 and 2000. Source: European Foundation (2005)

Mental health problems due to job stress affect many workers. For example, the Dutch Central Bureau for Statistics (CBS) reported that one in ten workers in the Netherlands had been downcast or depressed for at least two weeks in succession in 2002, and one in eight experienced feelings of strong anxiety; the more pressure at work, the more prevalent and serious these symptoms (CBS 2004). ${ }^{75}$ About $22 \%$ of the labour force indicates to be mentally fatigued; about 1 in 10 workers is fatigued to the extent that the diagnosis of burnout is appropriate.

\footnotetext{
74 There is some evidence suggesting that in recent years the increase of work-related stress is leveling of (but not decreasing). For example, Jones et al. (2006) analyzing the Labour Force Survey in the UK found that the estimated prevalence rate of stress and related (mainly heart) conditions has doubled during the 1990s, the increase leveling off since 1998/99 remaining stable till 2004. This is probably not related to an increase in the propensity to report work-related complaints, since the prevalence rate of another common work-related problem, musculoskeletal disorders, decreased and the rate of 2004 was less than the level in 1995 and 1990.

75 Correlations between variables such as self-reported stress and self-reported depressive feelings have to be interpreted with care. To some extent there may be reversed causality (workers feeling depressed performing less well and thus experiencing more pressure at work) and to some extent there may be confounding factors such as personality (workers who are prone to report feeling down may also more easily report pressure at work). However, the subjectivity of self-reported data is not a major problem in the case of stress, since stress is to an important extent a subjective phenomenon, and self-reports have been found to correspond quite accurately with more objective measures such as reports by others and levels of stress hormones such as cortisol (e.g. Lundberg and Hellstrom 2002).
} 
To get some notion of what the costs of high stress could be at the level of the individual, it is illustrative to look at court-ruled or pre-court-settled compensations paid by employers to employees. In the UK for example, in 1999 an employee got $f 47,000$ in compensation for stress; in 2001 the first ever British case in which an employer admitted liability for causing stress resulted to $£ 67,000$ compensation to an employee; later that year a primary school teacher received a record compensation payment of $£ 254,000$, having retired from her job after a nervous breakdown due to excessive job stress (Chaudhuri, 2001). In the Netherlands a similar trend can be detected; in 2002, a woman got 80.000 euros from her employer for the damage caused by high stress in her job due to structural overwork; in 2004 a court ruled that an employer had to pay 70.000 euros to an employee to compensate for the damage due to high job stress and resulting burnout, many more cases have been settled or are still in preparation (FNV, October 2004).

At the level of society, ILO (2000) estimated that the costs of work-related stress amount to $1-3.5 \%$ of GDP. Other estimates are much higher; for example Cooper et al. (1996) estimated that stress-related illness and absenteeism costs the United Kingdom the equivalent of $10 \%$ of GDP. Stephens and Joubert (2001) estimated that work-related stress in Canada contributed $\$ 14.4$ billion to the burden of mental disorders in 1998. Hoel et al. (2001) estimated the cost of work-related stress in the $15 \mathrm{EU}$ Member States to be on average about $4 \%$ of GDP in aggregate, not taking indirect costs into account. Rice et al. (1990) found indirect costs of work stress to be at least twice the direct costs of care.

It is estimated that about half of absenteeism is related to work stress, due to too high workloads and conflicts at work (European Foundation 2005). Employees may experience a range of physical, psychological, and behavioral consequences as a result of job stress (Quick et al. 1997), and organizations may in turn be affected by low production quality and quantity, internal conflicts, lack of cooperation, high turnover, and costs associated with sick leave and worker disability (Schabracq, et al. 2003). Between $50 \%$ and $60 \%$ of absenteeism, and about one-fourth to one third of work disability in the EU has been related to workrelated stress and its resulting mental health consequences (Kessler et al. 1999). Jones, et al. (2006) estimated that 12.8 million working days (full-day equivalent) were lost in 2004/05 in the UK through stress, depression or anxiety caused or made worse by work. ${ }^{76}$

Job stress has a host of indirect costs; for example it has been related to higher levels of physical health problems and use of physical and mental health care (Figure 10).

\footnotetext{
${ }^{76}$ Occupations carrying above average prevalence rates of self-reported work-related stress, depression or anxiety included: teaching and research professionals $(3.0 \%)$, health and social welfare associate professionals $(2.0 \%)$ and corporate managers $(1.7 \%)$; these occupational groups together accounted for around a third of the prevalent cases (Jones et al. 2006).
} 


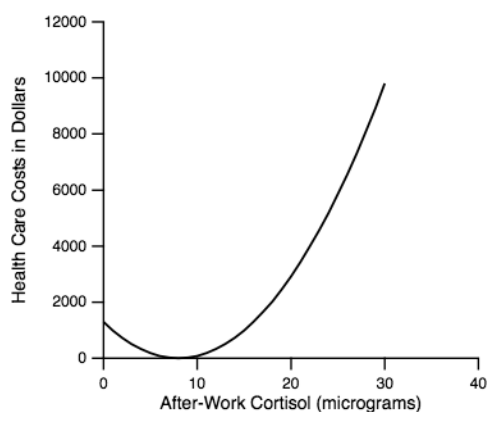

Figure 10. The correlation between job stress of persons (measured in terms of the level of the stress hormone cortisol) and health care costs of these persons, in a period of five years. Source: Figure 3 in Ganster et al. (2001)

Stress is related to the psychosocial burden of work. A TNO report of 2005 investigated absenteeism and work disability specifically resulting from psychosocial work burden (Blatter et al. 2005). ${ }^{77}$ In this report, the yearly absenteeism due to psychosocial work burden is estimated to be $2-4 \%$ of the labour force. ${ }^{78}$ The costs of the consequences of psychosocial workload are estimated to be 4 billion euros yearly (based on data from 2003 and 2004); ${ }^{79}$ this is almost $1 \%$ of the gross national product of the Netherlands. Almost half of this is related to work disability benefits. The share of work disability benefits due to work-related psychological problems is $14 \%$. The total of work disability due to psychological problems is about one third of all disability; thus, about half of this concerns psychological problems that are directly caused by work. The TNO report states that the problems related to psychosocial work burden are not expected to diminish in the coming years, though the costs related to it may, due to changes in regulation for work disability in the Netherlands. ${ }^{80}$

\footnotetext{
77 The extent to which psychological problems causing absenteeism and/or work disability is work-related is determined by a weighted method. Self-reports of employees indicate that about $75 \%$ is work-related. This high percentage is used to determine the work-related psychosocial burden, in terms of absenteeism and disability, but only certain specific sub-diagnoses are taken into account of which there is a high probability that they are work-related. In which case $75 \%$ is a credible percentage. For the cost-calculation of work-related costs due to psychological problems all diagnoses are included, but for this calculation an lower percentage of work-relatedness is used, of 25\% (Blatter et al. 2005).

${ }^{78}$ Long-term absenteeism (longer than 13 weeks) due to work-related psychological problems is estimated to be $0.17-0.75 \%$. The share of absenteeism caused by work-related psychological problems of the total absenteeism is estimated to be 3.6-6.3\%. This share is increasing substantially when it concerns longer-term absenteeism, meaning that psychosocial problems are especially responsible for longer-term absenteeism.

${ }^{79}$ These figures are based on databases from 2003 and 2004, and a justified estimate of the extent of workrelatedness of the problems. Four types of costs are included: diminished productivity ('presenteeism'), absenteeism, work disability and medical costs (Blatter et al. 2005).

80 The reform of the work disability arrangement in the Netherlands includes more stringent criteria of entering work disability and more attention for what an employee can do rather to what he or she cannot do. An important element is that employers have to pay longer for employees that are sick due to psychosocial work burden, making it more attractive to actively solve and prevent the problem rather than passively let an employee slide into work disability. Also the own responsibility of employees is emphasized more, among other things through legal obligation to cooperate in finding a solution for example by accepting less demanding work. E.g. Houtman (2007).
} 


\subsubsection{Increasing (costs of) mental health problems?}

Research studies and policy reports are inclined to claim that mental disorders such as depression are not just highly prevalent but in addition are increasing. For example, the World Health Report 2001 predicted that depression would rise to become second highest of all (mental and somatic) illness in terms of causing DALYs, and subsequent World Health Reports indeed show an increase in the absolute and relative prevalence and burden of depression. Explanations for the increase lie in the area of demographic developments (older people are more prone to depression) and to a relative shift due to decreasing costs of other illnesses.

High prevalence estimates in previous psychiatric epidemiological surveys have been a source of concern because of the distinguishing value of diagnoses; about half of the population has some sort of mental disorder at some point in life, and every year a quarter has a disorder. ${ }^{81}$ However, as Kessler et al. (2005a) observes, even mild mental health problems are associated with substantial levels of impairment, and it is difficult to make a principled argument for narrowing the diagnostic criteria to raise the threshold for clinical significance.

While research is quite clear about the high prevalence of and high costs related to mental health problems costs, there is much less clarity about a possible increase in prevalence and costs. For example, in the case of the Netherlands, Meertens et al. 2003 found that in the Netherlands the rate of depression has not increased in the period 1975-1996 (based on a small annual questionnaire as part of a larger survey); and the prevalence of 'negative feelings' (measured by the Affect balance Scale of the Dutch Central Bureau of Statistics) remained more or less the same in the period 1989-2000, around $12.4 \%$. The number of patients diagnosed with depression registered at primary care in the Netherlands has doubled in the period 1994-2004; the number of newly diagnosed patients also doubled (Schoemaker et al. 2005). Schoemaker et al. observe that this increase can mostly be explained by better recognition by primary care doctors and less stigma for asking for help among patients. Though there is only limited data available, the data that exists suggests that the number of people with anxiety disorders in the Netherlands has almost tripled in the period 1991-2003 (see Figure 11). Schoemaker and Poos (2005) attribute this largely to an increase in recognition and a decrease in stigma. Based on demographic developments alone an increase of $4.7 \%$ in anxiety disorders can be expected between 2005-2025 in the Netherlands.

\footnotetext{
${ }^{81}$ E.g. Kessler et al. (2005a) finds the following lifetime prevalence estimates in the U.S.: anxiety disorders, $28.8 \%$; mood disorders, 20.8\%; impulse-control disorders, 24.8\%; substance use disorders, $14.6 \%$; any disorder, $46.4 \%$; the estimated lifetime risk of any disorder at age 75 years is $50.8 \%$. They conclude that about half of Americans will meet the criteria for a DSM-IV disorder sometime in their life, with first onset usually in childhood or adolescence.
} 


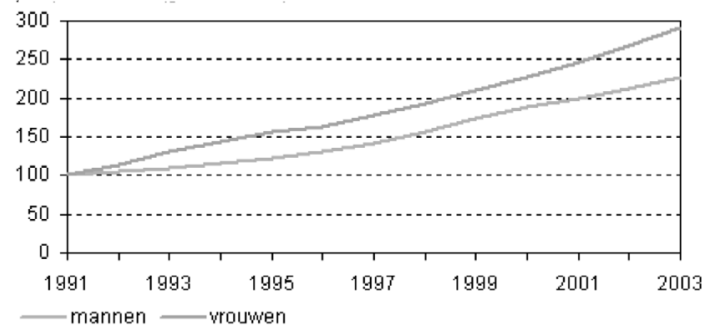

Figure 11. Annual prevalence of anxiety disorders in primacy care in the Netherlands in the period 1991-2003, standardized on the population of 1990 and indexed $(1991=100)$. Source: Schoemaker and Poos (2005).

For the U.S., Kessler et al. (2005b) find that the prevalence of mental disorders did not change in the period 1999-2003 (29.4 percent between 1990 and 1992 and 30.5 percent between 2001 and 2003), but the rate of treatment increased. Among patients with a disorder, 20.3 percent received treatment between 1990 and 1992 and 32.9 percent received treatment between 2001 and 2003. Overall, 12.2 percent of the population 18 to 54 years of age received treatment for emotional disorders between 1990 and 1992 and 20.1 percent between 2001 and 2003. Kessler et al. (2005b) conclude that despite an increase in the rate of treatment, most patients with a mental disorder did not receive treatment.

Thus, the number of diagnosed mental health problems has increased quite dramatically in the past few decades; however, as observed in 3.2.4, it is difficult to determine to what extent there is a real increase in mental health problems such as depression, and to what extent it is due to better recognition and registration, and reduced stigma making it easier for people to ask for help. ${ }^{82}$ Most researchers attribute most of the increase in mental health problems to more visibility of these problems not to an actual increase of these problems; to what extent subclinical mental health problems have increased is not clear. The challenge of isolating the influence of different factors on prevalence rates and costs in order to interpret data correctly is a major issue in epidemiological and cost-of-illness research, as the discussion of Kessler et al. (2005b) on methodological artefacts shows. ${ }^{83}$ There is a

\footnotetext{
${ }^{82}$ E.g. The number of patients diagnosed with depression registered at primary care in the Netherlands has doubled in the period 1994-2004; the number of newly diagnosed patients also doubled (Schoemaker et al. 2005). Schoemaker et al. observe that this increase can mostly be explained by better recognition by primary care doctors and less stigma for asking for help among patients. For the U.S., Kessler et al. (2005b) find that the prevalence of mental disorders did not change in the period 1999-2003 (29.4 percent between 1990 and 1992 and 30.5 percent between 2001 and 2003), but the rate of treatment increased. Among patients with a disorder, 20.3 percent received treatment between 1990 and 1992 and 32.9 percent received treatment between 2001 and 2003. Overall, 12.2 percent of the population 18 to 54 years of age received treatment for emotional disorders between 1990 and 1992 and 20.1 percent between 2001 and 2003. Kessler et al. (2005b) conclude that despite an increase in the rate of treatment, most patients with a mental disorder did not receive treatment.

${ }^{83}$ Kessler et al. (2005b) observe that a key issue in assessing the societal burden of mental disorders is whether the evidence of increasing prevalence is real or a methodological artefact. Their research results show that mental disorders are highly prevalent, that lifetime prevalence is, if anything, underestimated. They find an increase in prevalence of mental disorder and in onset at younger ages. Kessler et al. argue that the increase partly to be a real increase. They give a number of reasons to argue that the observed cohort effect in their study is at least partly due to substantive rather than methodological factors. No evidence was found for the
} 
perception of increase among lay persons, ${ }^{84}$ but again this could be related to more knowledge, less stigma and more awareness.

Studies and reports on the burden of disease focus on clinical mental illness, thus on mental health problems that are serious enough to pass the threshold of being labelled a recognized mental disorder. As was put forward in section 3.2.2, mental health and mental illness form a continuum, and the diagnosed cases of mental health problems that make it into the statistics should be seen as the 'tip of the iceberg' (also). Below the clinical surface, the big bulk of subclinical mental health problems looms. It can be expected that the bigger the tip, the bigger the underlying iceberg. These subclinical problems are costly, because they concern a much larger group, they seriously affect productivity through affecting energy, motivation and quality of decisions (see 3.4.3) and they often remain untreated, ${ }^{85}$ while treatment tends to have relatively large positive effects in this group. ${ }^{86}$ Greenberg et al. (1993b) find that because depression often is not properly recognized and begins to affect many people at a relatively early age, it exacts costs over a longer period of time and in a more subtle manner than other major illnesses, ${ }^{87}$ and find that it imposes a particularly heavy burden on employers in the form of higher workplace costs.

While it is unclear whether mental health problems are really increasing, it is less unclear that the costs related to mental health problems are increasing. ${ }^{88}$ Still, the question of increasing

convergence among cohorts with increasing age that would be expected if methodological factors were responsible for intercohort variation in prevalence estimates. In addition, Kessler et al. (2005b) used a nonresponse survey, weighting to correct for nonresponse bias and a special age-at-onset probing strategy to reduce recall bias to minimize the effects of methodological factors on the results. Nonetheless, residual effects of methodological factors are likely, based on the fact that longitudinal studies show that mental disorders are associated with early mortality and the fact that resolved mental disorders reported in baseline interviews often are not reported in follow-up interviews. To the extent that these biases are at work, the high prevalence found in the younger cohorts might also apply to older cohorts. This means that the observed increase is partly the result of underrecognition of mental illness in the past rather than 'overrecognition' in the present.

${ }^{84} \mathrm{Mehl}$ (2006) investigated the accuracy of lay assessments by peers in detecting depression. On the one hand, peers have more access to observations of depressive symptoms, since they see potential patients in everyday life. On the other hand, depressive symptoms are often interpreted as personality traits by lay observers, which makes recognition less accurate. Mehl (2006) finds that peers showed little accuracy at determining other persons' levels of depressive symptoms, but quite accurate among moderately and severely depressed persons.

${ }^{85}$ Less serious mental health problems may be responsible for larger costs than serious mental disorder. E.g. see Broadhead et al. (1990): "Because of its prevalence, individuals with minor depression were associated with $51 \%$ more disability days in the community than persons with major depression. This group was also at increased risk of having a concomitant anxiety disorder or developing major depression within 1 year. We conclude that the threshold for identifying clinically significant depression may need to be reevaluated to include persons with fewer symptoms but measurable morbidity. Only by changing our nosology can the societal impact of depression be adequately addressed." (p.2524).

${ }^{86}$ E.g. Berndt et al. (1998) find that patients with the least severity of baseline depression have the greatest work improvement after treatment, suggesting again that medium level mental health problems are economically most interesting. Greenberg et al. (1993) urge to include individuals who suffer from only some of the symptoms of this illness because this category is very costly due to high prevalence and on-the-job productivity losses; in addition they point out the importance of including costs of depressive symptoms to the production of household services (influencing the productivity of spouse and future productivity of children.

${ }^{87}$ Greenberg et al. (1993b) compare depression with major illnesses such as coronary heart disease, cancer, and AIDS by highlighting salient characteristics of each illness. Their comparative illness framework considers the costs, prevalence, distribution of sufferers, mortality, recognition, and treatability of each disease. 88 
costs is not a simple one. The cost-of-illness studies by Greenberg et al. (1993a, 2003) provide a good illustration of the trends and considerations in this area. Greenberg et al. (2003) investigate the cost of illness in 2000 as compared to the cost of illness in 1990 (which was investigated by Greenberg et al. 1993a). Greenberg et al. (2003) observe that the economic burden of depression is driven by a number of factors, including its prevalence rate (i.e., how widespread the disorder is in society), its treatment rate (i.e., the extent to which the illness is addressed in the medical sector), and its debilitating nature (i.e., how impairing the condition is among sufferers). Changes in any of these factors are likely to affect the estimated burden of illness. Depression has been shown to substantially limit activities of daily living at work, home, and school, and to result in adverse social outcomes that may be irreversible, including reduced educational attainment, increased likelihood of teenage parenting, and marital instability. All of these characteristics influence not only the magnitude but also the distribution of costs (e.g. among direct treatment and workplace costs). ${ }^{89}$

Greenberg et al. (2003) show that the treatment rate of depression increased by over $50 \%$, and the economic burden of depression rose by $7 \%$, going from $\$ 77.4$ billion in 1990 (inflation-adjusted dollars) to $\$ 83.1$ billion in 2000 . Of the 2000 total, $\$ 26.1$ billion (31\%) were direct medical costs, $\$ 5.4$ billion $(7 \%)$ were suicide-related mortality costs, and $\$ 51.5$ billion $(62 \%)$ were workplace costs. The increase in the direct treatment costs of depression was less than proportional, from $\$ 19.9$ billion in 1990 to $\$ 26.1$ billion in 2000 (as compared to an increase from 43.7 billion to 83.1 billion in overall costs) which is related to less expensive forms of treatment. ${ }^{90} \mathrm{~A}$ higher rate of depression treatment probably has contributed to the stable workplace costs associated with this illness, which did not substantially increase. Greenberg et al. (2003) interpret this as being the result of counteracting effects. With the improvement in macroeconomic conditions in the form of a lower unemployment rate and a larger labour force, many more depressed people were employed in 2000 compared with a decade earlier, which probably had beneficial impacts on workplace costs. However, even as treatment for depression was available to an increased number of workers, tending to lower workplace costs, the robust economy drew into the labour force many more individuals dealing with this psychiatric disorder, which tended to

\footnotetext{
${ }^{89}$ During the time frame of investigation of Greenberg et al. (2003), not only were there many changes in the epidemiologic profile of depression, but the macroeconomic context in which the cost comparison was made also changed significantly, from a period of recession starting in mid-1990 to one of long-term economic expansion that continued until early 2001. The business cycle impact on cost-of-illness estimates can manifest through a number of pathways including, most prominently, its effect on the employment rate of depressed people and, therefore, access to health care coverage, as well as the possibility of a prevalence rate reduction from an economic upswing. The analysis of Greenberg et al (2003) works through the implications of these changes in the disease- and treatment-specific characteristics of depression, as well as changes in general business conditions to develop a comparably estimated burden of illness assessment.

${ }^{90}$ Greenberg et al (2003) show that the annual direct cost per treated patient decreased substantially over time, from approximately $\$ 4100$ in 1990 to $\$ 3300$ in 2000, a reduction of $18.7 \%$, as a result of more effective treatment and a shift toward less costly forms of treatment such as the use of antidepressants. Patients treated for depression were 4.8 times more likely to receive an antidepressant in the late 1990s compared with a decade earlier (Greenberg et al. 2003). Lower direct costs per treated case in this context seem to imply greater value obtained for only slightly greater expenditures. Greenberg et al. (2003) observe that, from a resource utilization perspective, there is a tension between making outreach to treat depression sufferers and the typically lesser quality of care provided as that occurs.
} 
raise workplace costs. Unbundling these counteracting effects shows that an increased treatment rate resulted in a $7 \%$ decrease in workplace costs, from $\$ 51.9$ billion to $\$ 48.2$ billion, while a higher employment rate increased workplace costs by $6 \%$, from $\$ 48.2$ billion to $\$ 51.5$ billion. Although these effects tended to offset one another, with the large increase in the number of depressed workers overall workplace costs per depressed employee declined by $10.1 \%$ between 1990 and 2000, from approximately $\$ 5000$ to $\$ 4500$. This could to some extent be related to the lower wages of the additionally employed workers with depression bringing down the average wages of the group of workers with depression, and due to using the human capital method in which productivity costs are given by wages this could translate into lower costs.

Greenberg et al (2003) conclude that the economic burden of depression remained relatively stable between 1990 and 2000, despite a dramatic increase in the proportion of depression sufferers who received treatment. They suggests that, if there had not been such an increase in treatment rates, the rate of depression would have been much higher - indicating an increase counterbalanced by increased depression with a net results that is stable.

Experts agree that is hard to be conclusive on the issue of whether mental health problems are on the rise. Longitudinal trends are hard to pick up because attitudes about mental illness have changed over time and it is hard if not impossible to control for that. Any growth rate observed could merely reflect that people are more able and willing to talk about their feelings now than in times past, when there was little awareness and when such conditions carried a heavy stigma. Cross-national trends are difficult to discern because of the varied ways mental health data are collected in different countries and the difference in awareness and cultural differences in communicating about mental health problems (Schmidt 2007; Hu 2006).

\subsubsection{Assessing the evidence}

This thesis claims that mental health is of great economic importance, and that this economic importance is growing. An over view of the costs associated with lack of mental health shows that these are large and that the part of these costs that is work-related is growing.

In section 3.3.1 it was shown that mental health problems are widespread and costly, especially because of their effects on productivity. This was in particular so in high-income countries where the burden of mental illness is much higher $(20-23 \%$ as opposed to a global average of $12 \%$ ) than in developing countries, and is increasing. This does not necessarily mean that countries with advanced economies have more mental health problems. Clearly, it is related to the relative contribution of other illnesses. However, even if that would be the only phenomenon underlying the numbers, then still it can be argued that mental health is especially important in high-income countries; it is a bottleneck to economic growth, if only because other illnesses are less of a bottleneck. The high relative burden of disease does not necessarily mean that mental health is more crucial for economic performance due to the nature of work in advanced economies; however, the numbers do not conflict with such a 
claim, and in combination with the empirical evidence presented in chapter 2 this claim can be called plausible.

In section 3.3.2, it was shown that the direct costs of mental health problems have increased; the expenditure on improving mental health, such as mental health care but also the rapidly growing self-help industry. Although this expenditure has important characteristics of consumption (improving mental health because that provides direct utility to people) it also and increasingly has characteristics of production - the expenditure appears increasingly to be consciously and explicitly aimed at improving mental health in order to become more productive. The increasing expenditure on mental health improvement can be seen as a sign of increasing awareness of the importance of good mental health. In addition it could indicate an increase of mental health problems, but this is hard to prove (or disprove) given the many factors that determine the increased reporting of mental health problems. The numbers suggest an increase of mental health problems, if only because of the fact that the big increase of treatment of mental disorder apparently did not lead to a decrease. Since research shows that treatment of mental health problems is often effective, it must be concluded that increased treatment has reduced mental health problems. Thus, even if the rate of mental health has not increased but has remained the same, then there must have been an increase of mental health problems, which was cancelled out by an increase in treatment.

In section 3.3.3, it was shown that the productivity costs related to mental health problems have increased. In fact, they have increased more than the direct costs (health care), and they have increased in spite of increased treatment (one would expect that treatment, since it reduces symptoms of mental health problems, would lead to less productivity costs). This is consistent with the claim that the costliness of mental health problems has increased, due to the larger productivity effects of mental health problems, which in turn is due to the changed characteristics of work.

Section 3.3.4 pointed out additional other costs of mental health problems (costs related to crime and suicide); to the extent that mental health problems are triggered or aggravated by job characteristics, the costs deriving from them should be attributed to work and thus can be seen as (unintended) production costs.

Section 3.3.5 showed that workers in developed countries report high levels of work stress, a known cause/trigger of mental health problems; and it showed that high costs are associated with high stress levels. The fact that increasingly courts of justice rule that stress and stressrelated illnesses such as burnout are a direct consequence of work, and the high amounts of money that have to be paid by employers to employees with stress, suggest that stress and its consequences should perhaps be seen as an (unintended) cost of production. This psychological production cost is partly paid for by the employee through loss of wellbeing, reduced performance, reduced income and career chances, and through an increased chance of unemployment and work disability. In welfare states such as the Netherlands, this production cost is partly paid by public money, through arrangements such as work disability benefits. Thirdly, this production costs is paid for by the party who controls the production process and who gets the profits from production, the employer; and increasingly so, in countries such as the Netherlands. The recognition of the role of the employer in taking care 
of the maintenance of his worker's mental health and in preventing mental health problems is institutionalized in the new Dutch regulation for sickness and work disability. ${ }^{91}$

Clearly, (work-related) mental health problems are highly prevalent and highly costly. It is less clear whether (work-related) mental health problems and their costs are on the rise. Section 3.3.6 indicated that research shows a mixed picture; some evidence suggests the prevalence and costs have remained the same, other evidence suggests an increase. Epidemiological and cost-of-illness research is inconclusive, but it is noteworthy that in spite of increased efforts in the area of prevention, treatment and self-help, there is if anything no decrease. This could be interpreted as a sign of an underlying increase counterbalanced by interventions, leading to a net result of no observed increase.

Regardless of whether mental health problems have increase, it is clear that the costs related to mental health problems have increased, more specifically the indirect costs of the effects of mental health problems in terms of reduced performance at the job and reduced employability,

This is in line with chapter 2 which presented evidence that mental health has become more important for adequate performance at work, due to the increased importance of cognitive, social and emotional skills. If mental health is more important for performance, then absence of mental health will be more detrimental to performance. Thus in countries with advanced knowledge economies, the same level of mental health problems would be more problematic and more costly than in the past. Though the empirical studies in the current section have to be interpreted with care and comparison between countries is tricky, they do clearly show that the indirect costs related to mental health problems are high in countries with knowledge-intensive service economies such as Europe and the US, concerning up to several percentage points of GDP; that alone is enough to justify a closer investigation of the economic role of mental health.

For this thesis, the important issue is not whether there is an increase in mental health problems per se, but whether mental health problems are more than before related to the psychosocial demands of work; because then mental health problems can be seen a 'production cost'. Chapter 2 provided ample evidence for this. It showed that the job characteristics that are empirically found to be related with job stress and work-related mental health problems have increased in prevalence, which by reason of logic suggests that job stress and work-related mental health problems also will have increased. Research suggests that this is a real trend, which is by no means diminishing. ${ }^{92}$ To some extent this is a 'frictional' issue, due to a skill mismatch. Psychological job requirements change more rapidly than the skills of workers to fulfil these psychological requirements. Over time, workers are learning to better deal with the new job characteristics and organizations are

91 Through a system of financial and legal checks-and-balances including the mutual obligation of both employer an employee to offer and accept work that the employee can still do given his condition, in principle a social optimum can be achieved. Also see footnote 80

92 E.g. in a 2007 report from the European Agency for Safety and Health at Work (OSHA), titled Expert forecast on emerging psychosocial risks related to occupational safety and bealth (Brun and Milczarek 2007), key experts from a number of European countries agree that the psychosocial risk factors as indicated in chapter 2 have increased and will continue to increase. 
learning how to prevent stress, which will counterbalance this trend. However, the structurally high levels of reported and actual job stress, ${ }^{93}$ as described in section 3.3.5, suggests that the gap between what jobs require and what workers can handle is widening, and can become structural.

There are two reasons why this gap may become structural. First, just like there are physical limits to doing physical labour in the past, likewise there are mental limits to deal with the mental labour in today's work settings. Analysis of the characteristics of people in work disability and unemployment indicate that for a growing part of the labour force these limits may have been reached, excluding them from participation on the labour market. Many of the unemployed and work disabled are not able to deal with the demands of today's jobs; the supply of the type of job contexts in which they would be able to work is diminishing. Secondly, there is substantial path dependency: the workers that cannot handle the psychological requirements of their jobs will develop mental health problems, which in turn will make these workers even less able to deal with their job, which then again increases their mental health problems. As the next section will show, the mental health of a worker is an endogenous variable, via its main mediating variable: stress.

\subsection{Mental health: its role in production}

Work can cause work-related stress, and this in turn can cause or trigger mental health problems. Thus, a mental health state can be viewed as a (largely unintended) 'output' of the production process. In this section, we will look at how mental health states can be 'produced' by factors in the environment, by looking at what stress is, how stress can lead to mental health problems (3.4.1), and how work can lead to stress (3.4.2).

Workers with good mental health are generally more productive than workers with bad mental health. ${ }^{94}$ This suggests that mental health can to some extent bee seen as an input to the production process. In this section we discuss in what way mental health acts as a (largely unrecognized) 'input' in the production process (3.4.3 and 3.4.4).

\footnotetext{
${ }^{93}$ See footnote 75 about the close relationship between reported and actual job stress.

94 This needs some qualification. As was explained in 3.2.2, mental health and mental illness can best be understood as two ends of a continuum of adequate cognitive, emotional and behavioural functioning (whereby what is 'adequate' is to some extent socially determined). For some professions, certain deviations in thoughts, feelings and behaviour may actually be good for performance. Psychological studies indicate that highly creative people share an elevated risk of serious mental illness. For certain individuals, such ailments may actually contribute to their achievements; but often the same condition eventually ruins their inventiveness and their lives. As Levine (2005) explains, mental illness does not make a person creative, but individuals endowed with artistic vision and particular skills can, at times, transform the loosening of linkages which accompanies mental illness into inspired creative associations. However, these novel associations can be difficult to harness for the individual. Numerous empirical findings show that people it psychological problems are generally less productive than people without, so it is justified to say that there is a positive relationship between mental health and productivity.
} 


\subsubsection{The stress response}

The main pathway through which environmental factors (such as working conditions) can affect mental health is the stress mechanism. When an organism perceives a potential threat or opportunity, a mechanism in his system is activated to respond. The repertoire of responses is rather limited; the main options are 'fight' or 'flight.' 95 The 'flight or fight response', also called the 'acute stress response' was first described by Cannon (e.g. Cannon 1915). According to Cannon, this response is hard-wired into our brains and represents a "genetic wisdom" designed to protect us from bodily harm. When we experience a certain level of stress - whether from internal worry or external circumstances - the 'fight or flight' response is activated, and a set of physiological reactions is triggered, involving among others the cardiovascular system, the respiratory system, and the immune system. This ensures that we become physically and psychologically prepared for some sort of action to deal with the perceived threat or opportunity. For clear, real dangers to our physical survival, the fight or flight response is of great value and very functional. However, most threats today are not physical in nature; they consist for example of missing a deadline, rush hour traffic, or having an argument with a superior or spouse. These (non-physical) threats of modern times nevertheless trigger the activation of our (physical) fight or flight system. But in most cases today, fight or flight is not a real option and even counterproductive. Therefore it is very important to control this response and channel it into more productive directions. As we will see in section 3.5, the ability to regulate is essential for successful performance, and thus for core economic factors such as productivity.

One of the first theories in the area of stress which is still dominant is Selye's General Adaptation Syndrome (Selye 1936). The optimal situation for a human body is to be in a state of 'homeostasis', which is a state of metabolic equilibrium in which the core processes needed to keep the body in good shape are optimized. However, man lives in a dynamic environment that poses continuous challenges, in terms of opportunities and threats. Changes in the environment require adaptation (fight, flight, or other actions), and the stress response is the trigger for that adaptation process. Selye's theory maintains that a certain amount of stress (arousal) is considered good, whereas too much stress can result in pathology, as persons can no longer achieve homeostasis. Currently the term 'allostasis' is often used, indicating the ability to maintain homeostasis in the face of change (dynamic equilibrium).

Psychosocial stress can be conceptualized as incongruence between the abilities and needs of a person and the environment (Storch et al. 2007). At the individual level, psychosocial stress is the result of a cognitive appraisal of what is at stake and what can be done about it (Lazarus, 2005; Lazarus and Folkman, 1984). Stress depends on the anticipation of something harmful or challenging in the future, and thus stress requires an interpretation by the person about the significance of the situation. The process of appraising which circumstances are harmful and which are benign is crucial to the production of stress reactions. Lazarus (1963) pointed to the importance of 'cognitive appraisal', which implies that the same stimulus can be threatening or not, depending upon the interpretation the

\footnotetext{
95 This pair of basic responses is reminiscent of a pair that is better known in economics: Hirschman's 'voice'
} and 'exit' (Hirschman 1972). 
person makes concerning its future personal significance. The threat is not simply an attribute of the stimulus; rather it depends for its threat value on this appraisal, which in turns depends on the personal interpretation, which depends on aspects such as the personality structure, past experiences and social cues. In addition it depends on the mental health status of a person, for example a person suffering from depression may perceive stimuli more negatively and thus suffer more stress. ${ }^{96}$

In the biological response to psychosocial stress, the hypothalamus-pituitary-adrenal (HPA) axis plays a central role and has been examined extensively. The activation of the HPA axis in response to stress and its effects on cardiovascular, immune, and metabolic as well as emotional, behavior, and cognitive processes helps to maintain equilibrium during and after stress; however, extensive and/or long-standing release of HPA axis hormones has been shown to have detrimental effects on mental health (Storch et al. 2007). When the level of stress is high and there is no opportunity to reduce it through taking some sort of action, a non-used reservoir of stress hormones is built up in the body. If not properly metabolized over time, this can lead to disorders of a number of bodily systems, including - crucially the brain itself. The very capacity to regulate the stress response itself, largely located in the brain, can get affected, and this may result in structurally high levels of 'allostatic load' (e.g. McEwen, 1998), resulting in the 'production' of mental health problems and mental illness. Thus, stress is related to mental health both as cause and as consequence. An important source of stress is work, the next section shows how stress is 'produced' at work.

\subsubsection{Mental health as output: the production of stress}

In the section above, it was briefly described how stress can lead to mental health problems. But how does work lead to stress? There is an extensive body of empirical research on job stress and its determinants. ${ }^{97}$ In this section, the main theories derived from extensive empirical research are presented, representing 'condensed empirical evidence'.

Work stress research generally focuses on links between taxing aspects of the work environment (stressors), the perceptions and appraisals of them, and the resulting manifestations of strain including physiological, psychological and behavioural changes (Baker 1985). Work stress theories attempt to describe, explain and predict when work stress will occur. A range of different theories has been proposed, each having a different emphasis and leading to different implications for intervention.

One of the best-known models for work stress is the Demand-Control Model. In this model it is assumed that work stress primarily arises from the structural or organizational aspects of the work environment (Karasek 1979): "strain results from the joint effects of the demands of the work situation (stressors) and environmental moderators of stress, particularly the range of decision-making freedom (control) available to the worker facing those demands." Faced with high levels of demands and a lack of control over decision-making and skill

\footnotetext{
${ }^{96}$ Distorted information processing is a core characteristic in DSM-IV for most mental illnesses (APA 1994).

97 A review of a large number of studies on stress ad mental health by D'Amato and Zijlstra (2003) shows a clear association between measures of work-stress and mental well-being, with a variety of factors may moderate the stress-strain pathway or relationship (e.g. intervening variables, socio-demographics factors).
} 
utilization, the associated arousal (stress) cannot be channelled into an effective coping response. ${ }^{98}$ Unresolved strain may in turn accumulate and, as it builds up, can result in anxiety, depression, psychosomatic complaints and cardiovascular disease. High job demands in combination with poor or lacking job resources preclude actual goal accomplishment, which is likely to cause failure and frustration. In its turn this may lead to withdrawal from work, and reduced motivation or commitment. Reducing commitment can be an important self-protection mechanism that may prevent exhaustion.

According to the demand-control model, workers such as those in machine-paced jobs, assemblers and service-based cooks and waiters experience the highest levels of stress because they are in jobs high in demands and low in control. High-end professionals on the other hand such as lawyers, university professors, consultants or account managers are more commonly in jobs combining high levels of demands but also high levels of autonomy. Presumably high status workers have the opportunity to regulate high levels of demands through frequent opportunities to use control, and mobilize resources (Karasek and Theorell 1990). However, low control work (such as routine labour) can be less stressful than high control work. Planning, regulating, (self-)managing, decision-making, autonomy - in other words, high control - is in itself demanding, and can result in stress. ${ }^{99}$ As chapter 2 showed, autonomy in itself can be highly stressful. Often the autonomy is only partially real, in the sense of effective freedom. Often it represents a shift of problems and uncertainty from the level of management to the level of individual workers, increasing regulation requirements. ${ }^{100}$

A second, related model, the Job Demands-Resources model (Demerouti et al. 2001), is based on the assumption that the characteristics of working environments can be always classified in two general categories: job demands and job resources. This makes this model into an overarching model that may be applied to various occupational settings, irrespective of the particular demands and resources involved. Job demands refer to those physical, psychological, social, or organizational aspects of the job that require sustained physical and/or psychological (cognitive and emotional) effort and are therefore associated with certain physiological and/or psychological costs. Examples are a high work pressure, role overload, poor environmental conditions and problems related to reorganization. Job

\footnotetext{
${ }_{98}^{9}$ The relationship between stress and performance is discussed in detail in section 3.4.

${ }^{99}$ The stress dynamics related to non-routine jobs is formalizes as part of the model in chapter 5 .

100 The term regulation stands for the internal cognitive processes of goal and plan development, the transformation of goals and plans into actions, monitoring, and feedback processing. Regulation requirements, in particular job complexity, are related to properties of the hierarchical-sequential organisation of action and comprise the complexity of decisions, the number and connectedness of goals and sub-goals, and the extent of conscious vs. automatic regulation processes. Accordingly, a problem-solving kind of task is considered to be high in regulation requirements, whereas loading and printing a document may be considered as a routine task that can be carried our using scripts or action schemata stored in memory and adapted for the particular situation, keeping regulation requirements low. Regulation requirements (complexity) and regulation possibilities (control) can have positive effects in terms of personality enhancement, because they address important psychological needs (to feel competent, to learn, to be challenged, to have control). In contrast, regulation problems (too much external regulation, or too little) generally make working difficult, unpleasant and stressful (Zapf 2002). The importance of regulation requirements and its relation to mental health will be explained in more detail in section 3.5 .
} 
resources refer to those physical, psychological, social, or organizational aspects of the job that help a person to deal with present and future demands. ${ }^{101}$

A third model, the Effort-Reward Imbalance Model (Siegrist 1996) emphasizes the social framework of the job, for example the social status of a job. Workers expend effort at work and expect rewards as part of a social exchange process. The work role provides a crucial link between self-regulatory functions such as self-efficacy and self-esteem and a social structure within which to access opportunities for fulfilment and recognition (the importance of self-regulatory functions will be further discussed in section 3.5). When a worker puts in an effort at work that does not seem to be adequately rewarded, strain results (this is related to what was discussed about violation of the 'psychological contract' in chapter 2). Similarly, when workers experience a threat to their job security, an imbalance results that can lead to strain. Effort/reward imbalance and over-commitment are found to be important in explaining adverse mental and physical health effects

A fourth model, the Person-Environment Fit Model (French, Rogers and Cobb 1974) emphasizes not only the importance of the characteristics of the situation or environment and the characteristics of the person, but in particular the match or 'fit' between them. The same situation or environment can be fine for one person but highly stressful for another, and vice versa; what counts is the fit. When misfit is present, strains such as job dissatisfaction, anxiety, depression and absenteeism can occur. When discussing the relationship between stress and performance in section 3.5, we will see that this relationship is different for different persons but also for different tasks, and matching these is one of the main ways of optimizing performance.

In a fifth model, Cognitive Phenomenological Theory, stress is defined in this approach as a relationship between the person and the environment that is appraised as taxing or exceeding resources, and endangers well-being (Lazarus and Folkman 1984). Appraisal of stress is necessary. If a situation is perceived as stressful and important, then the worker mobilizes different coping strategies either to modify the person-environment relationship (that is, problem-focused coping) or to attempt to regulate resulting emotional distress (that is, emotion-focused coping). The situation is then reappraised and the process repeated. If the situation is resolved, coping ceases. If it is unresolved then psychological and physiological strain persist resulting in longer-term negative effects on health and wellbeing (Lazarus and Folkman 1984). ${ }^{102}$ The theory cannot generalize about which specific aspects of the work environment would be stressful because due to the appraisal process, different individuals might see the environment in different ways (Baker 1985). This is important, because one of the determinants of appraisal is mental health; changed mental health status can change appraisal and through that pathway increase the production of stress (even

\footnotetext{
101 'Job resources' are aspects (of a person and a work situation) which (1) are functional in achieving work goals; (2) reduce job demands and the associated physiological and psychological costs; (3) stimulate personal growth and development. Resources may be located at the level of the organization at large (e.g., pay, career opportunities, job security), at the interpersonal level (e.g., supervisor and co-worker support, team climate), at the level of the organization of work (e.g., role clarity, participation in decision-making), and at the task level (e.g., performance feedback, skill variety, task significance, task identity, autonomy) (Demerouti et al. 2001).

102 These coping dynamics are formalized as part of the model presented in chapter 6.
} 
though the actual situation itself has not changed), which in turn can lead to further mental health problems.

A sixth model is the stress generation model of Hammen (1991). Hammen described stress generation as the process by which depressed people contribute to the occurrence of stress in their lives and thereby contribute to their experience of depression. That is, depressed people, in part, cause their own stressful experiences, which then lead to further depression. Although the stress generation model was originally designed to explain a process characteristic of unipolar depression, it has recently been shown to occur in samples with only mild or moderate levels of depressive symptomatology (e.g., Pothoff, Holahan, and Joiner, 1995).

A seventh model, consisting of a set of contagion theories, posits that stress and its effects can increase through inter-agent interaction effects. There is evidence for burnout 'contagion' to others in the organization. Through various mechanisms (Hatfield et al. 1994), stress and burnout can 'spill over' from one member to other members of work groups (e.g. Bakker and Schaufeli, 2000; Westman and Etzion 1999) especially if the stressed person is a manager (Sy et al. 2005); in addition, stress spills over between home and work and vice versa (e.g. Westman and Etzion 1995; Rook et al. 1991). ${ }^{103}$

With this review of theories about how work-related stress and mental health problems are 'produced' during work, we can look at chapter 2 with new eyes. The changes in the nature of work can be characterized as increased psychological demands on workers. The changes in the organization of work, such as increased flexibility and autonomy, could be seen as an increase of control, which would even out the increased demands and prevent production of stress. However, control itself also takes up personal resources, in terms of effort, and the means for more control are in themselves quite demanding. The self-regulatory functionality of a worker can be reduced when there is an effort-reward imbalance, which will lead to accumulating stress and from there to mental health problems. Whether increasing demands produce stress depends on the individual worker and his ability to increase his control with more marginal benefit than marginal cost. Even if stress is produced, it depends on the individual worker whether this has negative consequences in terms of his performance, as we will see in 3.4. The insight that (subjective) appraisal plays an important role in how demands and control are perceived and thus the extent to which stress is produced, makes clear how mental health problems are not only the result of work stress but can also cause work stress, by changing (distorting) the appraisal process itself. The different work-stress theories thus help to understand why and through which pathways the changes in the nature of work have contributed to an 'production' of stress and mental health problems, and to see how mental health status is a (largely unintended) output of work.

103 The 'contagion' dynamics of stress and mental health problems forms the core of the formal model in chapter 6 of this thesis. 


\subsubsection{Mental health as input: stress and production}

An important pathway through which mental health affects performance (and thereby production) is through its effect on a person's ability to deal with stress. Therefore we will look in more detail at the relationships between stress, performance and mental health. As was discussed in 3.3.1, stress is a necessary phenomenon to activate a person so that he deals with the challenges or opportunities he encounters. Stress is a crucial response of the mechanism to increase chances of survival. However, at the same time it is clear that stress often has negative aspects on performance. This is illustrated by Figure 12, showing the negative effects of stress on performance.

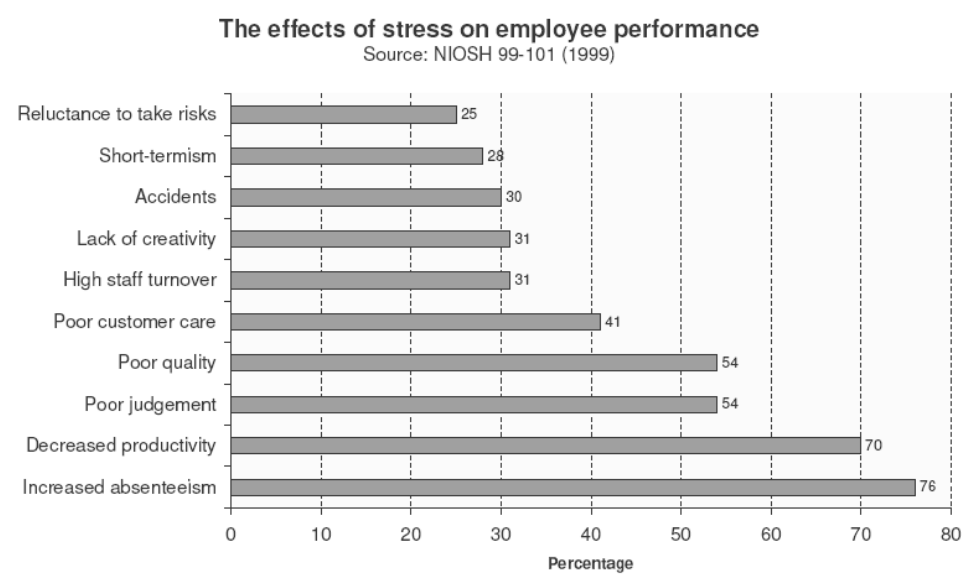

Figure 12. Effects of stress on employee performance. Source: NIOSH (1999)

According to the literature (e.g. Schrabacq et al. 2003), stress can have a variety of negative work-related outcomes. Some outcomes are quantifiable, such as absenteeism and labour turnover. Some outcomes are less quantifiable, such as the people who physically turn up for work but are unable to contribute fully because of their stress-related problems. Stress may result in irrational thinking and rigidity of views, faulty decision-making, communication breakdowns, interpersonal conflict, general time wasting and avoidance of responsibilities or tasks, and job dissatisfaction (Schrabacq et al. 2003).

Although researchers have been exploring the relation between stress and job performance for nearly a century, there remains controversy about how this relation is best characterized. Muse et al. (2003), in a review of 52 empirical studies about the relation between stress and performance, distinguish three primary theories on the relation: negative linear, positive linear, and the inverted-U. ${ }^{104}$ The inverted-U theory has an intuitive appeal, and although the

104 The negative linear theory is based on the premise that stress at any level consumes an individual's time, energy, and attention, taking away from the task at hand and consequently inhibiting performance. Thus, this theory states that stress is detrimental to performance and increasing levels of stress are increasingly detrimental. In direct opposition to the negative linear theory, the positive linear theory is based on the belief that stress and anxiety present challenges to the individual, which, in turn, improve performance; more stress leads to more performance. Muse et al. (2003) point out that the inverted-U theory of the stress-performance 
empirical research findings do not unequivocally support the inverted $U$ theory, Muse et al. conclude it is a plausible and useful theory. ${ }^{105}$ Obviously the relationship between stressors and performance is a complicated one, and it is highly schematic to depict this relationship as an inverted $\mathrm{U}$ or any other simple relationship. Different stressors have different effects on differents aspects of performances (e.g. see Mendl 1999). Just as it is not possible to convert everything of value into money, similarly we cannot translate everything that affects performance into (some degree of) stress. However, for this thesis in economics, depicting stress as a variable with which all effects on performance can be described in a similar 'psychological currency,' is useful, and precise enough.

The U-shaped/curvilinear relationship between job stress and performance can be originally traced to the early work of Yerkes and Dodson (1908), and, at present is probably the most popular one in terms of management/organizational textbooks. In learning experiments with mice, Yerkes and Dodson found that moderate arousal increases functional adaptation while high levels of arousal leads to dysfunctional behaviour. ${ }^{106}$ The 'Yerkes-Dodson law' suggests that the relationship between stress (arousal) and performance has the shape of an inverted U. Teigen (1994) describes the historical reinterpretation and reformulation of the Yerkes-Dodson law from 1908 to the present; it was used to depict the relationship between different variables, such as punishment and memory, and arousal and coping. ${ }^{107}$ In this

relation represents a merger of the negative (stress is bad) and positive linear theories (stress is good) by suggesting that increasing stress is good to a point, beyond which it becomes bad. Consistent with the positive linear theory, the inverted- $U$ suggests that some stress is necessary to motivate optimal job performance and is, therefore, functional. At levels above the level needed to motivate optimal performance, the inverted-U is consistent with the negative linear; increasing levels of stress are dysfunctional with regard to job performance. 105 Muse et al. (2003) review the empirical research on the relationship between stress and performance between 1975-2000 and in first instance find that the negative linear theory is best supported. However, closer inspection of the research reviewed shows a number of problems in the design of most studies, which lead to a bias in favor of finding a negative relation between stress and performance. Muse et al. discuss these problems in some detail. In the different research studies stress is defined differently in a crucial way; it matters whether stress is defined as arousal due to a stimulus requiring adaptation, or as a response to a stimulus when adaptation is not sufficient. Furthermore, research often is focused on high stress situations, and there is very little research on the understressed condition thus the first part of the inverted $U$ may not show up in the research results, research has over-sampling on the high stress side of the inverted-U stress continuum. Also, the theory about the negative effect of stress is in some research reflected in the research design which may connect stress and negative consequences together already in the process of data collection. Muse et al. (2003) find that all but one of the studies in our review were found to have at least one of these problems, and conclude that the inverted $\mathrm{U}$ hypothesis about the relation between stress and performance is plausible.

106 The original Yerkes-Dodson law from 1908 concerned the relationship between stimulus strength and habit formation. Yerkes and Dodson found that mice were learning a certain task quicker if they were given a higher stimulus (electric shock), but only up to a certain point; as the intensity of the stimulus would go up beyond that point mice learned the task less quick, implying an optimal level of stimulation. They also found that the optimal level of stimulation was for a more difficult task was at a lower level than for a less difficult task.

107 The Yerkes-Dodson law has been empirically substantiated in many different settings and seems to be a general mechanism in the animal world between variables indicating arousal of some kind on the one hand and performance of some kind on the other. There is a debate in psychology what exactly the Y-D law refers too, because in the course of time the law has been broadened to include not only stimulus intensity but arousal and stress in general. Teigen (1994) describes the historical reinterpretation and reformulation of the YerkesDodson law from 1908 to the present. In its original form, the law was intended to describe the relation between stimulus strength and habit-formation for tasks varying in discrimination difficultness. But later generations of investigations have rendered it variously as the effects of punishment, reward, motivation, drive, arousal, anxiety, tension or stress upon learning performance, problem-solving, coping or memory; while the 
thesis, in line with this "conceptual stretching" of the Y-D law over the past century, its basic curvilinear shape is used to portray the relation between the variables of stress and performance (productivity), to connect to the terminology that is familiar to economics

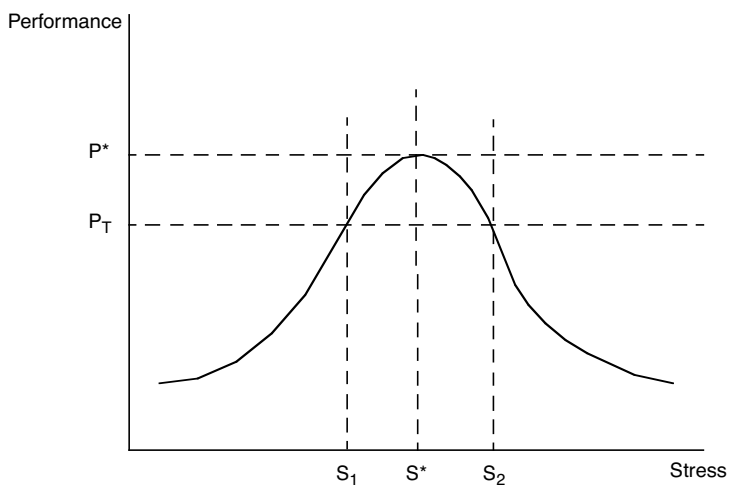

Figure 13. Yerkes-Dodson relationship between stress and performance. Based on Yerkes and Dodson (1908).

The relationship between stress and performance shows a Y-D inverted U. A particular curve with particular shape and position represents a specific person-job (or person-task) combination. Every task has a target level of performance, called here $\mathrm{P}_{\mathrm{T}}$. In the figure, the agent can perform satisfactorily, or better, if his stress or arousal level lies between $S_{1}$ and $S_{2}$. But as we have seen in 3.4, stress is the result of the (perceived) discrepancy between demand and control, in other words between what needs to be done and what a person is able to do. If a person's stress level lies below $S_{1}$ or above $S_{2}$, there will be a discrepancy between required and actual performance, which creates extra stress. This leads to a higher stress level S. If the person is under-stressed, this increases performance, bringing it to a satisfactory level. However, if our agent is over-stressed, an increase in arousal increases the discrepancy between demand and control, increasing stress levels yet further, and a vicious cycle emerges. A shift from inside to outside the "safe zone" ( $\mathrm{S}_{1}$ to $\left.\mathrm{S}_{2}\right)$, can be caused by several types of changes. Stress external to the task, such as difficulties at home, changes to the general environment, such as increased innovation, or increasing the target performance level $\mathrm{P}_{\mathrm{T}}$.

The advantage of choosing the relationship between stress and performance as the key relationship for describing the role of mental health as input factor is that stress is a generic

task variable has been commonly referred to as difficulty complexity or novelty, when it is not omitted altogether. Teigen discusses how the various reformulations reflect conceptual changes and new developments in the areas of learning, motivation and emotion. The plasticity of the law reflects to some extent the vagueness of basic psychological concepts in these areas. In addition however, it reflects that the Yerkes-Dodson curve expresses a basic relationship to be observed between a variety of psychological variables which are distinct but closely related and which behave according to the same general pattern. Accordingly, some authors seem to take the variety of interpretations as evidence of the robustness and generality of the law rather than as a sign of historical and conceptual confusion. 
variable; it is the result of a perceived discrepancy between what is and what should be, between perceived demands and perceived control. Thus it is no longer necessary to specify what exactly the demands are and what the ability to control; a variety of job contexts and personal characteristics can be lead back to this relatively simple schema. The inverted U based on the Y-D law is a person-situation representation. If the demands in a certain job are high, the height of expected performance $(\mathrm{P})$ is higher compared to a job in which the demands are not so high. Whether a person can deal with this level of $\mathrm{P}$ depends on the shape and height of his inverted $\mathrm{U}$.

At which stress level $\mathrm{S}^{*}$ the optimal level of performance lies, differs per person; some persons perform best at high stress levels, while others do better with moderate stress. The extent to which performance increases or decreases with increasing stress levels depends on the slope of the curve at different points, in other words on the shape of the curve. Some people are quite robust and have a long, stretched out curve, meaning that already at low stress levels they perform well, and at high stress levels they continue to perform well. Other people have a more narrow or compressed curve; they need considerable stress to at all get going, then in a short time reach their maximum performance, but when stress levels increase further, their performance equally fast drops.

At which exact value performance level $\mathrm{P}^{*}$ lies also differs per person, and depends on a person's human capital. Note that the extent to which a person's human capital is transformed into actual performance is variable, and depends on stress level S, and on the shape and position of the curve. To have the right education for a job is therefore not enough to ensure good performance, whether a person manages to make most of his human capital depends on stress levels of the job and his own stress-performance profile. Whereas the person with the compressed YD-curve may at optimum performance perform better than the person with a stretched out curve, overall performance of a person with a stretched out curve may nevertheless be better, depending on the profile of the job and the job conditions. ${ }^{108}$ In addition to personal characteristics, task difficulty and task novelty determine the shape and position of the inverted U. In order to gain more understanding of how stress is related to performance and how this relationship might be expressed in economic terms, the next section discusses a cognitive energy perspective on performance.

\subsubsection{Mental resources: cognitive energy}

In information processing and decision-making, human make use of a scarce resource. In Kahneman's (1973) study on attention and effort the notion of 'cognitive energy' was proposed. Experimental research showed that there was a limited factor in the brain which was required to activate and monitor information processing structures, thereby determining the speed and quality of cognitive performance. The provision and allocation of the limited

\footnotetext{
108 One could argue here that stress is endogenous at the personal level, since a person himself can reduce stress for example by better time management. That is indeed what will be put forward into more detail later in this chapter; the degree to which a person manages to manage himself (which is called 'self-agency') determines how stressed a person gets when confronted with high demands. An important endogenous aspect in this is that once a person is stressed, his performance will be worse and worse, also his performance on managing himself. With his loss of self-agency, stress will increase even more, triggering a downward spiral.
} 
cognitive energy resources is determined by arousal, which is a measure of importance of a certain task, and thus a regulator of cognitive effort. Kahneman's idea of a limited reservoir of mental energy states that the more arousal, the more energy is mobilized to deal with tasks, and the higher the capacity for processing information. ${ }^{109}$ A limited and rapidly consumed cognitive energy pool will set the limits of task performance ${ }^{110}$ and which constrain coping ability. ${ }^{111}$ Kahneman (1973) proposes that actors have a pool of limited cognitive energy which is consumed by cognitive processes. Some activities are more demanding and therefore require more mental effort than others. Effort describes how demanding the processing of a particular input is. Some tasks might be relatively automatic in that they make few demands in terms of mental effort, despite the fact they may have a high information load. ${ }^{112}$ Attention has been identified as an appropriate measure of the effort or energy level devoted by the central nervous system to perform cognitive processing. Attentional load is considered an indicator of the "resources" (Navon, 1984) or the "effort" (Kahneman, 1973) demanded by a task; the key idea behind this is the idea of "mental energy". When attention is focused on one task, additional resources are allocated to it, leading to a decrement in the resources available to the non-prioritised other task. Performance on the secondary task then reflects the attentional resources allocated to the primary task.

Cognitive effort and cognitive scarcity have been the focus of numerous studies in psychology (e.g., Simon 1982), and to some extent in economics (e.g., Conlisk 1996:

\footnotetext{
109 Kahneman (1973) argues that all mental processes gather their resources from a common energy source, using an analogy with electricity: "The concept of a limited capacity has a precise meaning. The generator can only supply a certain amount of power. When the demands exceed that amount, the addition of one more toaster or air conditioner to the circuit no longer results in a corresponding increase of electrical output" (Kahneman, 1973, pg. 15). "A capacity theory of performance provides an alternative to theories which explain man's limitations by assuming the existence of structural bottlenecks: limitations due to the structure of the brain. Instead of such bottlenecks, a capacity theory assumes that there is a general limit on man's ability to perform mental work. It also assumes that this limited capacity can be allocated among concurrent activities.

110 Research suggests that this has a biological basis; for example Pribram and McGuinness' (1975) neuropsychological model of attention control identifies two basal-located energetic mechanisms, relating to input (arousal) and output (activation) processing stages, supervised by an effort mechanism associated with allocation of limited energy resources.

${ }^{111}$ Coping is an important subcategory of goal-directed behavior, which is a central element of agency. Changes in the environment requires a response from the individual, who has to invest extra effort in mental problem solving and decision making and in increased behavioral output associated with pursuing goals in the light or change or alternatively changing goals. Coping is based on a process of resource management, the goal of which is to optimize benefits gained from the costs invested in demanding situations. The research of Schonpflug (1986) suggests that both structural and resource limitations elements play a role, the structural dimension may be determining the efficiency and effectiveness of cognitive processes and through that moderate the real scarcity, a limited amount of cognitive energy

112 There are a number of similar theories all based on the idea of mental capacity as some sort of a scarce resource. For example, Easterbrook (1959) observed that in problem-solving tasks there are relevant and irrelevant cues. With increased arousal fewer cues are processed, thereby excluding irrelevant ones. But as arousal increases further, also cues relevant for the task in question get lost. Humphreys and Revelle (1984) showed that arousal increases attention and persistence, but reduces the efficiency of information processing (e.g. retrieving information from memory). All theories in this vein predict that optimal arousal will vary from task to task. For instance, high levels of arousal will be more detrimental for tasks requiring a wide range of peripheral cues (Easterbrook 1959), or for tasks relying heavily upon retrieval from memory (Humphreys and Revelle 1984).
} 
Herrnstein and Prelec 1991), in particular via the economic work of Simon and Kahneman as basis of notions such as bounded rationality which has become part of the core of economics. ${ }^{113} \mathrm{~A}$ consistent finding is that humans have limited cognitive resources and allocate them judiciously. Cognitive effort or thinking has been seen as costly and humans have been described as "cognitive misers" (Fiske and Taylor 1984, p. 12) expending only the effort necessary to make a satisfactory rather than optimal, decision. As environments require more cognitive effort to process information fully, decision-makers often switch to decision strategies or heuristics that are easier to implement but these heuristics frequently result in less accurate decisions, biased responses, and preference reversals (Kahneman 1973).

Engaging in activities that demand continual conscious control consumes limited energy resources, over time resulting in performance degradation and greater fatigue; while automatic control (reflexes, routines) does not seem to use these resources or at least much less (Bargh, Chen and Burrows, 1996). Routines are literally 'mindsavers' (Sinclair-Desgagné andSoubeyran, 2000). In chapter 2 it was shown that the proportion of routine tasks in jobs has on average decreased, especially in the high-end jobs, whereas the proportion of nonroutine tasks has increased. In addition, chapter 2 pointed at the evidence of an intensification of work, meaning that more tasks and/or more complex tasks need to be done in less time. Together this implies that more cognitive energy is needed in average jobs, making this energy a more scarce resource. ${ }^{114}$ An optimal dynamic allocation of this increasingly scarce resource (in light of the growing demand) thus becomes more important.

Kahneman's energy theory can be directly connected to a variety of empirical studies of work. Green and Gallie (2002), as one example, find that compared to less skilled jobs, higher skilled jobs engender with greater levels of arousal among workers. They find that those who have experienced an increase in the skills required in their job are more likely to report a rise in their level of stress, than those whose skills are stationary or falling. Part of the reason why higher skilled jobs are associated with greater levels of anxiety and selfreported stress is that higher skilled jobs also involve significantly more mentally demanding work which uses limited cognitive energy. Acquiring more skills to do a particular job is not sufficient, in addition a worker has to gain more cognitive energy which can to some extent be achieved by spending less of it on non-productive activities such as worrying or conflicts with colleagues or boss, or taking on too much work. Again, it boils down to a need for

\footnotetext{
${ }^{113}$ It is noteworthy that both Simon and Kahneman, the two psychologists who have won the Nobel Prize for Economics (respectively in 1978 and 2002) were working on cognitive limitations in decision-making and the consequent different forms of cognitive economizing such as stereotypes, routines, heuristics, bounded rationality.

114 Even when participants have high motivation for performing a task, with attendant energizing effect (Wright and Brehm, 1989), cognitive energy limitations delimit performance of cognitive tasks requiring conscious control. From an energy perspective, it is better to have as many processes automatized as possible in order to have our cognitive resources available for new threats or opportunities. However, that is precisely what is harder to do in many jobs; chapter 2 showed that it is harder to establish routines in jobs since routine tasks are mechanized and automatized over time, and thus more scarce cognitive resources are needed to deal with everyday working life. The total available processing capacities may be increased or decreased by other factors, such as expertise. The more expertise, the higher the capacity for processing complex information from the environment, and the better performance. However, to acquire more skills and expertise is in itself effortful and uses (scarce) cognitive energy.
} 
better self-management. Increased work effort will have a substantial detrimental impact on well-being if a person does not have enough agency to allocate and direct his limited cognitive energy effectively.

Baumeister et al (1998) shows that cognitive resources diminish with use, evoking a resource energy notion. Because information processing is costly, Tversky and Kahneman (1974) posited that people seek cognitive means that obviate the need for further, costly processing. The notion of efficient use of cognitive resources that are otherwise required for ongoing cognitive tasks has also been used to explain the automaticity of much of human behaviour. In this regard, much social behaviour that in the past was found to be functional has become automatic - to some extent regardless of whether they are still functional. Otherwise, all of the cognitive energy that went into the original decisions would have to be revisited in each instance, which would have ongoing cognitive resource costs.

\subsubsection{Mental health and production}

When investigating the more precise nature of the role of mental health in the production process in this chapter, first the key relationships at stake have been identified and described: the relationship between stress, mental health and production (performance) and the relationship between production (work), stress and mental health. Work acts on mental health via work stress, caused by a discrepancy between demand and control in a person-job configuration. Mental health acts on performance at work via its effect on the ability of a person to perform at a certain stress level.

A key step was to consciously abstract from the many different characteristics that jobs and persons may have, and lead these back to one variable, the 'currency' into which other variables can be expressed: stress. The advantage of doing this is that it enables us to talk about a range of different types of jobs in a general sense by discussing them in terms of stress, just as an economist can talk about a wide range of things in terms of money. In addition, all personal characteristics of a worker can be lead back to one variable: the extent to which his performance is affected by stress. We no longer need to know what exactly made him stressed and whether other persons would be as stressed as he is in the same situation; we can simply describe him in terms of his stress-performance profile. This analytical step is important to be able to connect to economic theory in a meaningful way; for that we need a few general variables and relationships rather than very many specific variables and relationships.

Next, some of the underlying mechanisms explaining the inverted $U$ shape of the stressperformance relationship have been discussed, in particular the notion of scarce cognitive resources. The discussion of research on this in the sections above showed that mental health seems to affect the level of cognitive resources; for example depression leads to concentration problems and mental fatigue, which are forms of reduced cognitive resources. In addition mental health seems to affects the allocation of these scarce resources; for example, a person with depressive symptoms will spend most of his cognitive resources on 
negative unproductive thoughts rather than on productive activities, and a person with symptoms of anxiety disorder will direct much of it to worrying incessantly. ${ }^{115}$

Research is clear on te negative impact of mental health problems such as depression on performance. ${ }^{116}$ Typically research in psychology studies a specific mental health problem and its effects on specific aspects of performance. Though it is impossible to generalize these effects, most researcher seem to agree than an important effect of most mental health problems is a diminished ability to deal perform under stress, and a heightened propensity to experience environmental factors (persons, circumstances, events) as stressors. This is why this thesis has chosen to take the relationship mental health - stress resiliency - performance as the basic relationship to depict the economic significance of between mental health.

Harkness et al. (2006) observe that stress research shows that after each recurrent depressive episode, the ability to handle stress goes further down which increases the risk for subsequent depression. The stress sensitization (or "kindling") hypothesis (Post 1992) proposes that individuals become sensitized to the life events that precipitate depression, and to the depressive episodes themselves, such that less stress is required to precipitate recurrences of depression than was required to precipitate the first onset. ${ }^{117}$ Sensitisation is a process of reorganisation of neural circuitry in which an organism strengthens its defensive reflexes and responds more vigourously to a variety of previously neutral stimuli after exposure to a potentially threatening or noxious stimulus (Stam 2007). If the stress response is repeated or sustained for long periods of time without removing the source of the stress, or if the stressful experience is so overwhelming that it overtaxes homeostatic mechanisms, this 'allostatic overload' may precipitate disease (McEwen, 2004). Stam (2007) presents an overview of research literature showing empirical (neurochemical) evidence of stress sensitisation, including evidence for a sensitised feedback regulation of the HPA axis which is involved in the regulation of the stress response itself. An important consequence is that stress leads to mental health problems, and mental health problems lead to decreased ability to deal productively with stress - a positive feedback loop with important consequences for productivity of stressed workers.

Job demands that are more complex and less routine require more cognitive resources, and since these resources are limited this requires a better allocation and use of these cognitive resources, which in itself uses cognitive resources. Since jobs require more and better use of scarce cognitive resources, and since mental health problems reduce cognitive resources themselves and the optimal allocation of them, it can be argued that on average jobs in the present economy have become more critically dependent on mental health.

\footnotetext{
${ }^{115}$ For the precise patterns of symptoms of different mental illnesses such as the ones mentioned here, see DSM-IV. We will go more into detail about the impact of mental health on the rational allocation of resources including ones own mental resources in chapter 4 , when discussing bounded rationality.

${ }^{116}$ E.g. Adler et al. (2006) in a study on the effects of depression on job performance find that the group of test persons with depression had significantly greater deficits in managing mental-interpersonal, time, and output tasks, compared to a group of test subjects with rheumatoid arthritis and a healthy control group.

117 This theory explains for example why the risk of recurrence increases with each successive episode and why the course of depression involves increasingly shorter well intervals between episodes over time (Solomon et al., 2000).
} 
In the figure below, the effect of stress and of mental health on productivity is depicted. The level of stress determines the extent to which optimal performance is achieved; too little or too much means suboptimal performance ("stress effect" in the figure). It is important to keep in mind that since high stress levels are costly, it is not sound to say that it does not matter at which side of the inverted $U$ one is (pre-optimum or post-optimum) although this may seem the case from the perspective of immediate output. To be post-optimum means costs in terms of (mental) health problems which will have negative effects on potential productivity later in time by making the inverted U shrink and shift to the left ("mental health effect" in the figure).

The inverted-U curve is a static depiction in which "too much" and "too little" stress have the same effects on performance. However, given the cost in mental resources of stress, excess stress will move the curve over time, shifting it to he left and making is lower and narrower as mental health and thus the capacity toe respond productively to stress is eroded. A move from normal to high stress level will in the short run make performance fall from $\mathrm{P}_{0}$ to $\mathrm{P}_{1}$, and in the long run it will shift the curve to the left and change its shape, so that performance falls further, to $\mathrm{P}_{2}$.

Mental Capital, Stress and Productivity

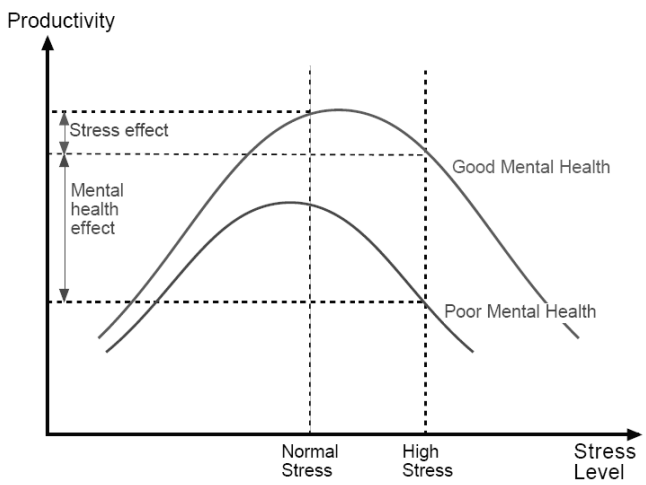

Figure 14. Schematic representation of the effects of stress and mental health on productivity.

It has become clear that mental health has an effect on the relationship between stress and performance via its effect on the level and use of cognitive energy, the extent to which a person can self-control and self-manage. ${ }^{118}$ It is thus not mental health itself that has the effect, but a variable that is crucially affected by mental health. In the next section we will take a closer look at the nature of this variable.

\footnotetext{
118 As was remarked before, in economics the prefix "self" often indicates that something goes by itself, and thus requires no effort. This is not what is meant here; here the "self" prefix refers to the object of the verb: managing oneself, keeping oneself in control. This is not an effortless but rather an effortful activity.
} 


\subsection{The productive aspect of mental health: agency}

Different mental health problems have different effects on performance. As was put forward in the introduction of this chapter, it may not be mental health itself, but some aspect or close correlate of it that is responsible for the observed effects of mental health problems on performance. In this section, we discuss a close correlate of mental health which has appeared as the mediating variable between mental health and performance: agency. This is called a mediating variable because empirical literature shows strong correlations between mental health and agency on the one hand, and between agency and performance on the other hand, as will become clear in the discussion below. Agency as a theoretical concept helps to conceptually organize the many effects of mental health problems on performance. We are interested in the effects of mental health only as far as they affect economic performance. By focusing on agency (which is determined by mental health) rather than at mental health itself, the complexity of the relationship under scrutiny becomes more manageable.

\subsubsection{The nature of agency}

'Agency' stands for the state of being an agent, the degree of "actorship" that a person has, the degree of acting capability. The main psychological theory on agency is Bandura's social cognitive theory (e.g. Bandura 1986). To be an agent is to intentionally make things happen by one's actions. Agency enables people to play an active part in their self-development, adaptation, and self-renewal with changing times (Bandura 2001). Bandura argues that agency is the most important aspect that distinguishes humans from other species. Human adaptation and survival depend on the power of forethought to override immediate reaction. Other species are heavily innately programmed for stereotypic survival in a particular habitat. But humans are not just reactive products of selection pressures, they are players in the evolution process, actively creating new types of environments rather than merely adapting to them. The reason that people are able to do this is thought to lie in the presence of specialized neurophysiological systems in the brain, that enable specific types of information processing such as reflection about one's own thought processes, motivation and action, and forethought, the ability to think prospectively about possible futures and possible outcomes of different combinations of actions and how to judge these outcomes. In acting as agents for themselves, people monitor their actions and enlist cognitive guides and self-incentives to produce desired personal changes. They are just as much agents influencing themselves as they are agents influencing their environment, according to Bandura.

The most important determinant of personal agency is a person's beliefs about his or her capabilities to exercise control over events that affect his life. Beliefs about self-efficacy function as an important set of proximate determinants of human motivation, affect and action. They operate on action through motivational, cognitive and affective intervening processes. People's perceptions of their efficacy influence the types of anticipatory scenarios they construct and reiterate. Those who have a high sense of efficacy visualize success scenarios that provide positive guides for performance. Those who judge themselves as inefficacious are more inclined to visualize failure scenarios that undermine performance by dwelling on how things will go wrong. Empirical research shows that this is a powerful 
effect: cognitive simulations in which individuals visualize themselves executing activities skillfully enhance subsequent performance quite dramatically, and vice versa (see Bandura 1995 for an overview of research on these aspects). A high sense of efficacy fosters cognitive constructions of effective actions, and this in turn further strengthens self-perceptions of efficacy. Self-efficacy or agency refers to the ability to perform the actions an agent deems desirable, but also the ability of an agent to recognize what actually is desirable for him.

People's beliefs in their capabilities affect how much stress and depression they experience in threatening or taxing situations, as well as their level of motivation (Bandura 1989). Emotionally taxing factors such as stress and depression affect action both directly and indirectly by altering the nature and course of thinking. Threat is not a fixed property of situational events. Rather, threat is a relational property concerning the match between perceived coping capabilities and potentially aversive aspects of the environment. ${ }^{119}$

Perceived coping inefficacy is accompanied by high levels of subjective distress, and physiological arousal (e.g. autonomic arousal, plasma catecholamine secretion; Bandura et al. 1985). People who believe they can exercise control over potential threats do not conjure up apprehensive cognitions and, therefore, are not perturbed by them. But those who believe they cannot manage potential threats experience high levels of stress and anxiety arousal. They tend to dwell on their coping deficiencies and view many aspects of their environment as fraught with danger. Through such inefficacious thought they distress themselves and constrain and impair their level of functioning. Perceived self-efficacy in thought control is a key factor in the regulation of cognitively generated arousal. It is not the frequency of aversive cognitions but the inability to turn them off that is the major source of distress.

The functionalities associated with agency predominantly seem to reside in the frontal lobe of the brain. ${ }^{120}$ This is the main area where conscious, non-automatic, non-routine control tasks are being performed. Conscious control consumes limited energy resources, over time resulting in performance decrements and greater fatigue, while automatic control does not seem to use these resources (Bargh et al. 1996).

As we have seen in chapter 2, the proportion of routine tasks in jobs has on average decreased especially in the high-end jobs, whereas the proportion of non-routine tasks has increased. This means that more cognitive energy is needed, which becomes a more scarce resource. Agency is crucial both for optimal allocation of increasingly scarce resources (due to the growing amount of novel, non-routine tasks) and for investment in skills by allocating time and effort to it in order to increase the supply of the scarce cognitive energy and the

\footnotetext{
119 Also see the demands-control model in chapter 2.

${ }^{120}$ Research suggests that the frontal lobes are the site of a specialized "executive" mechanism or mechanisms, one of whose functions is to organize domain-specific processes elsewhere in the brain in such a way as to override habitual but currently inappropriate configurations or to establish new configurations. A dramatic example of this is the "utilization behavior" occasionally observed in some frontal lobe patients (Shallice 1994). These patients are unable to inhibit the performance of complete action patterns characteristically associated with everyday objects. In these cases, the person seems, either permanently or transiently, to have lost endogenous control over his or her behavior; behavior is instead pathologically dominated by the power of stimuli to evoke task-sets associated with them - that is, it is exogenously controlled (thus low or no agency).
} 
efficiency of its use. However, agency is a form of conscious control, and thus uses cognitive energy itself, which complicates the dynamics involved.

\subsubsection{Agency in economics}

In economics, (self-)agency is assumed, and it is such a basic assumption that it is left almost completely implicit. However, reality shows that economic actors often only partially manage to act on their own behalf. Different people have different degrees of agency, and for any single individual the degree of agency fluctuates over time. While economics does not problematize or even mention self-agency, it is a major topic of research in other disciplines, especially in social psychology.

Economists treat economic actors in terms of what Bandura (1986) calls 'mechanical agency'. The self is some sort of internal instrumentality through which external influences operate mechanistically on action, but it does not itself have any motivative, self-reflective, self-reactive, creative or self-directive properties. In this view, internal events are mainly products of external ones. People are not intentional cognizers with a capacity to influence their own motivation and action; rather they are neurophysiological computational machines. This notion of what an agent is or does fails to explain the demonstrable explanatory and predictive power of self-referent factors. In contrast to economics, social cognitive theory subscribes to a model of emergent interactive agency (Bandura 1986). Persons are neither autonomous agents nor simply mechanical conveyors of animating environmental influences. Rather they make causal contribution to their own motivation and action within a system of triadic reciprocal causation. Any account of the determinants of human action must, therefore, include self-generated influences as a contributing factor (Wood and Bandura 1989). ${ }^{121}$

In economics, agency explicitly appears in what is called 'principal-agent theory', which is concerned with the problem of motivating one party (with certain goals and certain risk attitude) to act on behalf of another (with different goals and different risk profile). ${ }^{122}$ Agency theory of this form is used not only in economics but also in a number of other disciplines such as sociology and political science. Even in the domain of behavioral economics, studying different forms of bounded rationality, the assumption of (self-)agency is not really questioned. Economic actors are assumed to continuously act on their own behalf, even if they are not always so good at it in terms of the rationality of their actions; and moreover, this self-agency is assumed to have no cost.

\footnotetext{
${ }^{121}$ Bandura developed a conceptual model of triadic reciprocal causation of behaviour, which was extensively empirically tested. In analyzing the operation of human agency in this interactional causal structure, cognitive, vicarious, self-reflective, and self-regulatory processes play a central role.

122 The principal-agent problem arises when a principal compensates an agent for performing certain acts which are useful to the principal (for example, the employer) and costly to the agent (the employee), and where there are elements of the performance which are costly to observe, due to information asymmetry, uncertainty and risk. The solution is to ensure the provision of appropriate incentives so that agents act in the way principals wish them to, to obtain goal-alignment. The difficulty of doing this in practice is reflected in a multitude of (costly) reward and compensation mechanisms ('carrots') and supervisory schemes ('sticks'). See for example Eisenhardt (1989) for an overview of the economic version of agency theory.
} 


\subsubsection{Agency and mental bealth}

Research shows that mental health problems and mental illness can be understood as a form of diminished agency, in particular an essential component of agency which psychological research distinguishes, self-efficacy. ${ }^{123}$ It depends on the type of mental health problem to what extent agency is reduced. Specifically, depression has been related to reduced agency (and vice versa). ${ }^{124}$ Similar relationships have been found for other highly prevalent and costly disorders, such as anxiety and obsessive-compulsive disorder. ${ }^{125}$

Some forms of mental illness have less impact on performance than others. For example, narcissistic personality disorder, especially when subclinical, is often related to high rather than low economic performance, the narcissist working hard to create assets (wealth, power, status) to support his over-inflated but fragile self. ${ }^{126}$ Narcissism is found to be related to high levels of agency. ${ }^{127}$ Thus a mental health problem which is characterized by high agency (such as narcissism) has much less influence on productivity than a mental health problem characterized by low agency (such as depression). This supports the argument of this section that the economic dimension of mental health is best captured by looking at its productive correlate, agency; mental health affects productivity through its effect on agency.

Many theories of self-regulation are based on a negative feedback control model. In such models, reduction of discrepancy (between a desired state and an actual state of the world) functions as a motivator and regulator of action. Perceived discrepancy between performance and an internal standard triggers action to reduce the incongruity. Human self-

\footnotetext{
123 "Among the mechanisms of human agency, none is more central or pervasive than people's beliefs in their efficacy to regulate their own functioning and to exercise control over events that affect their lives. Perceived self-efficacy refers to beliefs in one's capabilities to produce given attainments. A sense of personal efficacy is the foundation of human agency. Unless people believe they can produce desired effects by their actions, they have little incentive to act or to persevere in the face of difficulties." (Bandura et al. 1999, p. 258)

124 One the first to conceptualize mental illness in terms of reduced agency was Beck (1967), who showed that depression both results from and results in systematic cognitive distortions in individuals' perceptions of their world, their future, and themselves. In that same vein, Rehm (1977) proposed that depression occurs as the result of dysfunctions in self-monitoring, self-evaluation, or self-reinforcement. The causality goes in both directions; depressive rumination impairs ability to initiate and sustain adaptive acitivities, and it further diminishes perceptions of personal efficacy which leads to additional negative ruminations (e.g. Kavanagh and Bower 1985; Wei et al. 2005). The occurrence, duration and recurrence of depressive episodes is found to be strongly related to perceived self-inefficacy to exercise control over ruminative thought (Kavanagh and Wilson 1989). The link between depression, self-efficay and agency has been amply empirically substantiated (e.g. Bruch 2002; Barton and Morley 1999; Holahan et al. 2005; Fritz 2000; Saragova et al. 2002).

${ }^{125}$ E.g. Feltz (1982); Ozer and Bandura (1990); Williams et al. (1989).

126 Sekdikides et al. (2004) review a long list of research findings on narcssism with relation to functionality. Narcissism is characterized by a self-centered, self-aggrandizing, dominant, and manipulative interpersonal orientation. Narcissism is inversely related to agreeableness, empathy, gratitude, affiliation, and need for intimacy, whereas it is positively related to competitiveness, exploitativeness, Machiavellianism, anger, hostility, and cynical mistrust of others. Narcissists have emotional highs and lows, their self-esteem is unstable and highly dependent on their social interactions; they tend to react angrily and aggressively to threatening feedback.

127 While subclinical narcissism is generally reasonably functional, in clinical narcissism the high levels of agency ('unmitigated agency') become dysfunctional (Helgeson and Fritz 1999).
} 
motivation relies on discrepancy production (goal setting) as well as on discrepancy reduction (goal achievement). ${ }^{128}$

In acting as agents over their environments, people draw on their knowledge and skills to produce desired results. In acting as agents over themselves, people monitor their actions and enlist cognitive guides and self-incentives to produce desired personal changes. They are just as much agents influencing themselves as they are influencing their environment (Bandura 1989). The same is true for meta-cognitive activity. In their everyday transactions, people act on their thoughts and later analyze how well their thoughts have served them in managing events. People are active managers of their own thoughts, and it matters how good they are at this. The extent to which a person can reflect on and regulate their thoughts successfully indicates the degree of agency he or she possesses.

The functions associated with agency appear to be physically located in a very specific part of the brain. As Levine (2005) describes, neuroscientists maintain that the frontal lobes mediate a collection of high-level cognitive processes that enable us to control and direct lower-level processes. The role of executive function in human behavior is to coordinate the many brain activities needed to set goals, make plans to attain these goals, organize steps to carry out those plans, and ensure that the desired outcomes are achieved. This capacity can be likened to that of a company's chief executive officer (Levine 2005). The brain's CEO, working from the frontal lobes, sequences and prioritizes the many steps that must be performed, generating a plan to accomplish goals and coming up with new tactics when circumstances change.

Levine (2005) points out that, because the frontal lobes interact with multiple brain systems, executive brain functions are highly sensitive to mental illness, psychiatric disorders, brain damage and substance abuse. Because demands for executive functions are greatest in unstructured, novel situations, patients with executive difficulties often appear normal when taking routine psychological and neurological tests. Executive dysfunction is therefore often not diagnosed, even in people who are seriously disabled by it. Psychologists are not in full agreement, but most acknowledge that multiple executive functions are mediated by the frontal lobe.

The following are among the abilities residing in the frontal lobe (Levine 2005):

- Abstract thinking

- Attention shifting

- Information manipulation

- Planning and foresight

- Monitoring and error correction

- Decision making

- Inhibition

- Social functioning

\footnotetext{
128 Bandura and Cervone (1983) show that people initially motivate themselves through proactive control by setting themselves valued challenging standards that create a state of disequilibrium and then mobilizing their effort on the basis of an estimation of what it would take to accomplish them. After people attain the standard they have been pursuing, those who have a strong sense of efficacy generally set a higher standard for themselves, creating new discrepancies.
} 
Given the differential effects of mental health status on agency, what can we say about the extent to which mental health status can be used as a proxy for agency? It can be argued that the mental health problems that are recognized and diagnosed most are those that affect agency most, resulting in a bias in the data of mental health problems towards those that affect agency substantially. This has to do with the fact that what is considered mentally ill is to some extent a social construct, and as long as a person functions well economically (for example has a job, shows up at work and completes assignments), the institutional system for signaling and addressing mental health problems is not activated. For example, a mental disorders such as narcissism is notorious for underreporting, because generally the patient is working hard (in order to gain power and social status to support the fragile self) and does not recognize that he or she is suffering from a disorder, given the nature of the illness (extreme self-centeredness). In that case, problems such as dysfunctional relationships less well-being are only a problem at the individual level, not at the social level, and given the attribution bias of narcissistic people it will generally not be addressed. Recognition, diagnosis and treatment are thus much less present in the figures of mental health problems and disorders, even though the prevalence may be as high as depressive disorder. ${ }^{129}$ However, such a bias is not problematic for the purpose of this thesis. From an economic perspective we are not interested so much in the degree of illness, but rather in the effects of it on agency and thus on economic performance. The most prevalent and most reported mental disorders such as depression are associated with strongly reduced agency, so mental health status seems a good proxy for agency - at least as good as education is as a proxy for human capital.

\subsubsection{Agency and performance}

The relationship of agency and its key constituents (such as self-efficacy, self-esteem, mental health) with performance, is well-supported by research.

The relationship of (lack of) mental health to performance has been discussed extensively in the first part of this chapter. A number of studies show the relationship of self-efficacy with performance. E.g. Bandura (1986) shows that self-efficacy affects one's choice of settings and activities, skill acquisition, effort expenditure, and the initiation and persistence of coping efforts in the face of obstacles. Those with moderate to high self-efficacy tend to engage more frequently in task-related activities and persist longer in coping efforts; this leads to more mastery experiences, which in turn enhance self-efficacy. Those with low selfefficacy tend to engage in fewer coping efforts; they give up more easily under adversity and evidence less mastery, which in turn reinforces their low self-efficacy (Bandura, 1986). Researchers in the slipstream of Bandura have found similar effects. E.g. Gist (1987) investigates the usefulness of self-efficacy as a conceptual construct to explain and predict individual and organizational performance. Reviewing the research literature, Gist finds that many studies have reported high correlations between self-efficacy and subsequent task performance, often via pathways such as motivation, quality of decision-making, risk taking, effort expenditure. In studies where efficacy perceptions have been altered by various

129 Often diagnosis of these types of disorder is only made in the case of co-morbidity, when narcissism is present in combination with another disorder such as dysthymia (minor depression). 
treatments, the resulting efficacy perceptions predict subsequent performance, although enactive mastery (accomplishing something for example a challenging target at work) yields the greatest increases. Gist and Mitchell (1992) find that self-efficacy is associated with better work-related performance, better learning and more adaptability. Hill et al. (1987) show empirically that self- efficacy (both general and domain specific, i.e. with respect to technology) is an important factor in diffusion and adoption of new technology.

There are a number of studies showing important effects of selfesteem on performance (and vice versa). E.g. Duffy et al. (2000) observe that research has demonstrated that relationship conflict is consistently and negatively related to the performance and satisfaction of individuals and groups in organizations, and show that self-esteem is an important moderating variable in this; individuals with high and low self esteem differ substantially in their reactions to situational cues such as negative feedback, conflict and interpersonal relationships, and through this, self-esteem can make or break performance. Pierce et al. (1993) observe that it has been empirically demonstrated that role-related influences such as conflict, overload, and ambiguity can have an impact on the affective and behavioural responses of organization members, and that an individual's ability, adaptability, and selfesteem influence those reactions. In a series of moderated hierarchical regression analyses, they find that individuals with low self-esteem are more reactive than their counterparts with high self-esteem, they are more susceptible to adverse role conditions, such as role conflict, ambiguity, and overload, and a poor work environment and poor supervisory support.

Agency has been directly linked, both conceptually and empirically, to self-regulation, and diverse lines of research have documented the prominent role that self-regulatory mechanisms play in the performance of people (Bandura 2001). An important pathways through which agency is found to affect performance is its effect on coping abilities and coping effort, in other words on control (as in the demand-control model). High levels of agency leads to less steep rise of stress levels in situations of high demands, and to higher performance all over, in particular also at high levels of stress. These effects are thought to be the consequence of the regulation capacity that is the main constituent of agency. ${ }^{130}$

Agency is positively correlated with the development and effective use of skills (and through this with performance). A skill is not a fixed property that one does or does not have within one's behavioral repertoire. Rather, skill involves a generative capability in which cognitive, social, and behavioral skills must be organized and effectively orchestrated to serve a host of purposes. There is a marked difference between possessing knowledge and skills and being able to use them well under difficult circumstances. People with the same skills may perform poorly, adequately, or outstandingly depending on fluctuations of non-ability influences. There is an important variable which consists of the ability of orchestration of preexisting skills (Sternberg and Kolligian, 1990; Bandura 1996).

\footnotetext{
130 There is psychological evidence that there are decreasing returns to increases in agency; more agency is not automatically better, especially at (very) high levels of agency. There is for example a trade-off between individual and social ways of coping (Knoblich and Sebanz 2005). At a certain point individual-focused coping diminishes social coping to an extent that it outweighs the benefits of agency.
} 
If we accept the economic importance of mental health, and if we accept that agency is the main variable through which mental health has its economic effects, then we are obliged to consider the dynamics of agency in economic analyses, since these will influence the dynamics of performance and productivity and all the economic variables that depend on these.

\subsubsection{Chapter 2 revisited}

We can now reformulate the findings of chapter 2 in by putting them in terms of Figure 13: stress levels, task performance, task difficulty, target level of performance, and shifts in the shape and position of the inverted $\mathrm{U}$. This will help to better understand the effects of changes in the world of work on stress and performance, and it will illustrate the use of the general model of Figure 13, which we reproduce here for convenience.

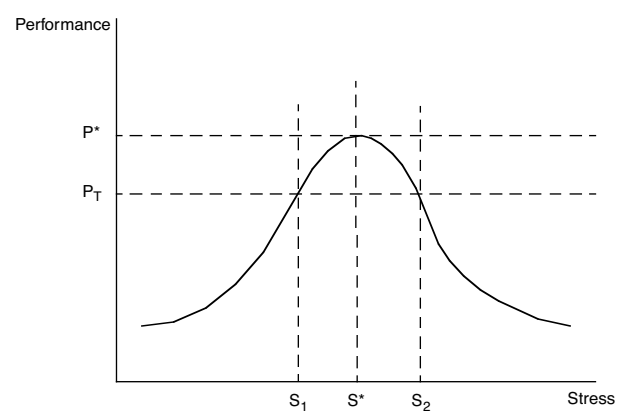

In chapter 2, it was found that jobs and job markets have become more flexible, increased innovation and creative destruction requiring more adaptation of workers, who have to change employer, job content and job location regularly and thus have less possibility to build up routines (2.2). In enriched jobs, work is on average increasingly complex and effortful, both in cognitive terms (more knowledge work) and in social-emotional terms (more emotion work) (2.3). Workers in enriched jobs are increasingly required to be flexible and autonomous, adding the effortful task of continuous adaptation and self-regulation (2.4). In addition, there is an effort intensification of work, there are more tasks to do and these tasks are more mentally effortful (2.5).

If job content remains the same (so the YD curve remains the same) but job circumstances become temporarily more stressful (for example due to a reorganisation), a shift in stress level can push a person from $\mathrm{S}^{*}$ to $\mathrm{S}_{2}$ so over the top of his inverted $\mathrm{U}$, thus reducing his performance $\mathrm{P}$ to below the required target level $\mathrm{P}_{\mathrm{T}}$. This means he can no longer fulfil his normal job requirements, which will cause further stress and a further drop in performance.

If job content changes, the YD-curve changes. In terms of the relationship between stress and performance, all else constant (same person, same circumstances), a more complex and/or non-routine task has a more compressed YD-curve of which the optimum performance $\mathrm{P}^{*}$ is located at lower values of stress. The compression implies that the 
tolerable variation in stress (roughly $\mathrm{S}_{2}-\mathrm{S}_{1}$ ) is smaller. This means that if the environment is as stressful as it always was, and the person also remains unchanged, a change in the content of conditions of work involving an increase of complex and/or non-routine tasks, shifts this person's curve to the left, whereby $\mathrm{S}_{2}$, the maximum stress level associated with acceptable performance, may end up at the left of actual stress level S. The result is that performance goes down, and with desired or required performance remaining at the same level, the worker will experience a performance gap, causing stress. And since he is already now beyond the "safe zone", he experiences a further drop in performance, and so on. We can now see how a gradual change in the content and conditions of work change the relationship between stress and performance and can lead to a structural increase in work-related stress.

The intensification of work due to effort-biased change can be understood as an increase in the required performance level $\mathrm{P}_{\mathrm{T}}$. If work becomes so intensified that the required $\mathrm{P}_{\mathrm{T}}$ becomes bigger than the $\mathrm{P}$ of an individual at a current stress level, the individual will not be able to meet the performance standards, which will make him stressed, thus increasing $\mathrm{S}$, and, depending on exactly why he is under-performing, may further reduce his performance P.

More flexibility, autonomy and worker-involvement are typically seen as increasing a worker's control over his own work. According to demand-control theories this should lead to less discrepancy and thus less stress. A possible way to characterise this in terms of Figure 3.3 is that the curve becomes flatter (not lower, but more stretched out), having better performance at every level of stress. This can be seen as a benefit to new work structures. However, chapter 2 also showed evidence that the increase in control is demanding in itself. We found in the current chapter that self-regulation is effortful and consumes cognitive energy, to speak in terms of Kahneman (1973). The inverted $U$ is a person-task configuration, meaning that its exact shape depends on both the nature of work (difficult or simple) and the nature of the person (stress-sensitive or stress-resistant). Increasing complexity of work changes the task, making the inverted $U$ more compressed horizontally (narrower). Increasing control changes the worker making he inverted $U$ stretched out horizontally, but because exercising control itself takes away cognitive resources, the inverted $U$ becomes compressed vertically (less high). More autonomy can be seen as adding an extra task to the worker's workload, an effortful task that has to be executed all the time: the management of the self. If the target level of performance $\mathrm{P}_{\mathrm{T}}$ stays the same while the inverted $U$ becomes compressed vertically (thus lower levels of performance at the same stress levels), a worker will more easily enter the area close to the top of his inverted $U$ and the risk of 'tipping over' the top increases, the worker enters the high stress level area of performance. If he does not manage to keep up $\mathrm{P}_{\mathrm{T}}$ from that position, he risks spiralling down.

Finally, since the Y-D curve portrays a worker-job combination, changes in the worker will also change the shape and/or location of the curve. For example, a stress management course could raise the level of the curve for the individual (increasing the level of $\mathrm{P}^{*}$ ) and make it more stretched out (increasing the distance between $S_{1}$ and $S_{2}$ ). Alternatively, ongoing trouble at home could shift the entire curve to the left, as cognitive resources are being used to manage stress in another environment leaving less available for the work domain. The discussion of chapter 2 in terms of the YD-model shows that some relatively 
simple formalism can be used to describe, order and conceptually organize many of the changes we observe in today's workplace.

In addition, thinking in terms of the Y-D curve helps to understand a phenomenon such as effort intensification. Extracting more effort from workers is an important way to increase profits, especially in labour-intensive sectors such as many parts of the service sector. If mechanizing and automatizing is not possible, productivity growth suffers, and this "Baumol's disease" is typical for the service industry. Thus other ways of increasing productivity or at least increasing output have to be found. Organizational changes such as decentralization, increased autonomy, flexibilization, involvement and engagement result in an increase of self-management of the worker, and at the same time an increase in the (psychological) pressure to perform. By increasing pressure, performance will go up according to the Y-D curve - thus more output and more profit for the firm. ${ }^{131}$ However, this is not necessarily an increase in productivity but rather an increase in effort. Moreover, it is a risky way of increasing output and profit. A worker who works close to the top of his YD curve can easily get pushed over this top, for example when there temporarily is more work due to more demand or sickness of colleagues. Because of the positive feedback that characterizes the level of agency, this can be the beginning of a downward spiral, and the firm will end up with less productivity, less output and less profit rather than more.

Since it is not easy for a firm to get rid of people that no longer contribute at a high enough level due to legal regulation and due to the costs associated with the loss of firm-specific human capital and hiring new people, the question is whether from a profit perspective the effort intensification is worth it in the end. A fluid labour force replacing burnt-out workers with new ones could be a solution, but job turnover has well-known costs for the firm so this strategy is dubious at best.

\subsubsection{Agency as a resource}

Hobfoll (2002) points out that psychological research has increasingly turned to an examination of the impact of people's resources on their stress resistance and well-being. Although the focus on resilience that resource models incorporate is not new, the dominance of deficit and pathology models is becoming more balanced by attention to the link between people's resources and their resilience (Seligman and Csikszentmihalyi, 2000). This has broad implications not only for psychology as a field but for the potential contribution of psychology to public debate and public policy, because - as Hobfoll points out - with rapid technological, social demographic, and global-political change occurring, there is a natural vying for resources.

\footnotetext{
${ }^{131}$ E.g. Bowles and Gintis view effort intensification in this way: "Peak-level performance by workers benefits the capitalist rather than the worker. Actual labor productivity will normally fall short of the maximum possible with the available labor power However, the value of the (average) product of labor will normally exceed the value of labor power (the wage), giving rise to profits. Profits on a given stock of money capital are thus maximized by exploiting the labor power of each worker to the fullest, that is, by getting as much labor as possible out of each worker" (Bowles and Gintis 1975).
} 
A number of major theoretical perspectives that focus on psychosocial resources define resources as follows: resources are those entities that either are centrally valued in their own right (e.g., self-esteem, close attachments, health, and inner peace) or act as a means to obtain centrally valued ends (e.g., money, social support, and credit). ${ }^{132}$

Resource-based views of human adaptation, coping, and well-being saw their germination to a large extent in the outgrowth of World War II, as researchers tried to understand why some men experienced combat-induced psychopathology, whereas others were resilient. The resource-based notion of well-being versus breakdown was further developed by Caplan (1974). He pointed to two key resources, one an aspect of self and one an aspect of the social environment, namely sense of mastery and social support. This interplay between social resources and the resilient self became a main theme in later research, driven by observations such as that mortality rates are affected by having close friends and relatives, being a church member, and taking part in informal and formal groups. At about the same time, the combination of high stress and a lack of psychosocial resources was related to higher psychological risks.

A number of resource theories have been developed, which differ in focus, but overlap in several ways. Key resources are those that might be viewed as management resources, that is, resources that serve to permit a person to deploy effectively his or her other assets to achieve his or her goals. Those who possess high levels of self-efficacy, for example, might be more capable of selecting, altering, and implementing their other resources to meet stressful demands.

The most widely studied resources in psychology today are aspects related to control. In the realm of stress, these have been most commonly studied under the rubric of internal control (Seligman, 1975) and self-efficacy (Bandura, 1997). Control-related constructs typically relate to perceived and not objective control, and they relate to the self as the agent of control.

Self-efficacy is an important pillar of agency. It has been linked in prospective studies with robust stress resistance in the face of everything from minor hassles to major tragedies (Bandura, 1997). Closely related, perhaps in its genesis at least, is 'dispositional optimism'. It was found that people with dispositional optimism tend to experience more favourable wellbeing overall and better stress resistance. A closely related trait is self-esteem. People high in self-esteem are less likely to interpret life's difficulties as a mark of their own lowered selfworth. Self-esteem, like self-efficacy and optimism, has been found to be related to wellbeing and better stress resistance. ${ }^{133}$ Another key resource that has been studied is the degree of goal pursuit. In general, those who stick to their goals have more favourable coping outcomes (Seligman, 1975). This trait is adaptive, however, and "learned helplessness" has been studied quite extensively, by Seligman (1975) among others. The positive end of this

\footnotetext{
132 To avoid a definition of resources that is either circular or all-encompassing, only those constructs that are held as resources for a wide range of people are considered. Thus, for example, although self-efficacy is not a resource for all persons or for any person in all situations, it has been found to be a resource for most people in a broad array of situations, at least in Western societies. Bandura (1997).

133 Possession of these traits is likely to be correlated, since efficacious people are likely to learn that they can control the environment, which will lead to self-esteem and optimism.
} 
continuum, tenacity in goal pursuit (as opposed to helplessness), has been less well studied, even though it appears to have important potential.

Some theories consider resource constructs with multiple components. Antonovsky (1979) developed the theory of sense of coherence, comprising three components: (a) the sense that one can usually predict one's future, (b) the ability to derive meaning from important aspects of one's life, and (c) and the sense that powerful forces tend to serve one's benefit. This is closely related to the definition of agency. Kobasa (1979) looked at personality hardiness, constituted as (a) a sense of control over life's vicissitudes, (b) a sense that stressors represent challenges rather than threats, and (c) a sense of commitment to life tasks - again closely related to the definition of agency. Good evidence was found for hardiness being related to better psychological well-being, the ability to more effectively withstand everyday and midlevel stressors, and better physical health.

Mental health disorders tend to affect key resources such as social support, self-control and self-efficacy. For example, one of the common symptoms of depression is social withdrawal and social isolation, which will diminish the use of social support and over time the social support system itself. Another common symptom of depression is low self-efficacy, the feeling that you are worthless; and extreme fatigue, which undermines the motivation to use any available resources. Other mental health problems are related to disturbed impulse control and distorted cognitions, which again will get in the way of applying resources when needed, and will add to resource loss and failure to build up resources. Mental health is crucial for the creation, maintenance and use of the resources that are needed cope with stressful situations and thereby to maintain mental health. Mental illness in turn will diminish the very resources that are needed to prevent and fight mental illness. This leads to negative stress spirals.

When the key resources are diminishing, as in the case of mental health problems which compromise rationality in different ways, resources will be put to work at the wrong places (for example someone overestimating his resources in a manic phase) or not at all (for example someone who underestimates his resources because of low self-esteem, or simply cannot motivate himself to activate and use them due to depression). This means that the demands are either not dealt with or dealt with in a way that the net result is a loss of resources. On the other hand, resources and mental health can strengthen each other in an upward spiral. Resources are linked to other resources. Hence, there is a general tendency for enrichment of resources among those who possess a solid resource reservoir. This principle has been noted by a number of researchers who have examined how resources cotravel in "resource caravans" (Hobfoll (2002).

People are adaptive; they will use what resources they have to solve life's difficulties and obtain their goals (Seligman and Csikszentmihalyi, 2000). This drive in itself can be seen as a 'resource' that determines the effective use and hence the value of all other resources. Mental disorders such as depression attack and compromise the factor making up the core of the resource-models: the ability and drive to build, maintain and use resources.

Crucial for building, maintaining and using resources is the ability of self-management, and that in turn is determined by the ability of self-control. Self-control is the exertion of control 
over the self by the self. That is, self-control occurs when a person attempts to change the way he or she would otherwise think, feel, or behave. Muraven and Baumeister et al. (2000) give a brief overview of the literature on self-control. Self-control behaviours are designed to maximize the long-term best interests of the individual. People exert self-control when they follow rules or inhibit immediate desires to delay gratification. Without self-control, the person would fail to delay gratification or would respond automatically. Self-control involves overriding or inhibiting competing urges, behaviours, or desires. Automatic processes are efficient and rigid, whereas controlled ones are costly (in terms of effortful consumption of resources) and flexible (Bargh et al. 1996).

The exact nature of the personal resource needed to overcome the strength of the preexisting patterns is unclear. Research suggests that the resource is limited and partially consumed in the process of self-control. A finite number of behaviours may be controlled, and there is an after-effect associated with self-control as the available amount of the resource is reduced. The resource needed for self-control is a limited, consumable strength (Muraven, Tice and Baumeister 1998), which can be depleted ${ }^{134}$ but which can also be built up (Muraven, Baumeister and Tice (1999). Directing one's self-control efforts toward one goal diminishes the resources available for self-control in any other sphere (e.g. Kahneman 1973). Tasks that require more self-control are more affected by depletion than tasks that require less self-control. Self-control strength is expended in the process of self-control. The decrease in self-control strength is presumably not permanent. However if people are unable to replenish their strength, they may become chronically impaired at self-control. There are substantial individual differences in the basic capacity for self-control. Frequent exercise of self-control followed by the opportunity for full rest and replenishment may gradually increase the individual's total strength for self-control; Muraven and Baumeister (2000) compare self-control to a 'mental muscle'.

\subsection{Conclusion}

In this chapter a critical step is taken for this thesis: mental health is connected to production and thereby has entered the economic realm. The chapter described the nature of mental health as a medical and social construct (3.2). It was shown that mental health problems are highly prevalent and have a high, growing economic impact. It provided a notion of the high economic value of mental health by giving an overview of the different types of costs related to the lack of mental health (3.3). Next, it discussed the more precise nature of the role of mental health as an economic factor (3.4). It was shown that mental health is both an input to and an output of production, via the mediating variable of stress. Work can lead to stress, which can lead to mental health problems (mental health as output of work); mental health problems lead to reduced productivity, which implies that good mental health leads to more productivity (mental health as input to work). Not mental health but its close proxy, (self-) agency, was shown to be the production factor (3.5). In economics, (self-)agency is assumed, actors are implicitly assumed to be acting on their own behalf. However in this chapter it has become clear that agency is a scarce resource, which differs between people and changes over time, and that it to some extent is an endogenous

\footnotetext{
134 Baumeister et al. (1998) and Baumeister et al. (2000) and call this 'ego-depletion.'
} 
variable in economic processes, through the effect of work on mental health, which either strengthens agency or erodes it.

In this chapter it has become clear that mental health, an indicator of and condition for agency, is an important economic factor, deserving more sophisticated place in economic theory and in economic analyses. In the next chapter it is proposed how this could be done. 


\section{Chapter 4. Mental Capital}

\subsection{Introduction}

In chapter 2, we found that in the current economy, on average work has changed in a way that (1) mental health status affects performance on the job more than in the past, and (2) jobs affect mental health status more than in the past. Certain job characteristics are found to be associated with more stress and mental health problems; and jobs with (more of) these characteristics have increased in number and importance. The conclusion of chapter 2 was that mental health has become an important economic factor, more so than in the past; and thus that we urgently need to know more about the economic role of mental health.

In chapter 3 we investigated the nature of mental health, to understand how mental health is affected by (conditions of) work, and how (performance at) work is affected by mental health. We found that mental health can be seen as an (largely unintended) output of a production process, via the stress mechanism: a job can lead to job stress, which in turn can cause or trigger mental health problems. In addition, we showed that mental health can be seen as a (largely unrecognized) input to a production process, via its effect on performance under stress (inverted-U): workers with mental health problems are less productive and their productivity is affected more by stress. Further investigation showed that the effect of mental health on performance is mediated by the effect of mental health on a person's selfagency. Cognitions, emotions and behaviour have to be evaluated, directed and controlled in order to be effective and lead to optimal performance. Agency indicates the ability to selfregulate, and it determines the extent to which a person's scarce mental resources are utilized in an efficient and effective way. With this, it determines the extent to which a person's potential maximum level of performance (given his human capital) can be realized, in terms of actual level of performance. This in turn determines productivity and adaptive capacity (crucial for creative destruction and innovation), and through this economic growth.

Given its impact on productivity, it was argued that agency has the character of a resource in the economic production process. But what kind of resource is it? While we have discussed the essential elements and dynamics of agency in relation to productivity, we have not yet managed to really embed agency and its main measurable proxy, mental health, into economic theory, in such a way that economists can actually include it in their analyses.

In this chapter we take a closer look at the economically relevant properties of agency. We find that is has all the characteristics that are generally identified with capital, and propose to thus conceptualize it that way: as 'mental capital' (4.2). We will discuss what is gained conceptually by doing this, and address the main potential objections against it, by placing it in the context of the discussion on the concept of capital in general (4.3). In this discussion it will become clear why mental capital is a useful concept and why it should not simply be folded into the concept of human capital. In order to illustrate its added value, we will explain how the concept of mental capital relates to important branches of economic theory: 
growth theory (4.4), human capital theory (4.5) and bounded rationality (4.6). Finally, some conclusions are drawn about the usefulness of the concept of mental capital (4.7)

\subsection{Mental capital?}

Capital is an important concept in economic theory. Though widely used, its use is not unproblematic, as we will see in section 4.3 when discussing the 'capital controversies'. First we look at the characteristics that currently are associated with capital and capital goods in economic theory. Capital is generally understood to refer to a means of production, which is produced (man-made) and is used to produce itself, which can be increased at a cost (investment), yielding benefits over time (returns).

In this section we will discuss to what extent agency, the productive correlate of mental health, has these characteristics, and thus to what extent we could speak of 'mental capital'. We will find the characteristics of agency match closely with those of capital, and that the concept of capital is analytically useful for organizing and integrating the empirical observations presented in chapters 2 and 3 .

\subsubsection{Mental capital as a durable produced means of production}

The term "capital" is generally used to refer to the existing stock of goods which are used in the production of other goods or services and which have themselves been produced by previous human activities. In other words capital refers to 'produced means of production.' In this section we will discuss to what extent our main variable, agency, can be seen as a means of production. This is done by addressing four key characteristics of traditional capital goods.

First, a capital good is a production factor, which can imply both that it changes in the quantity employed will change the level of production directly, but also that it may change the productivity of other factors of production. Second, capital goods are produced means of production, they are man-made. Third, capital goods are durable and can be used many times. As a means of production capital is used in the production process, but it is not used up during the process. Capital goods are not transformed during production, contrary to, for example, a resource such as iron which in production is transformed into, for example, pins. Capital goods do not lose their identity during production; the machine used to transform iron into pins is used in the production process but is still a pin-producing machine after the process has completed.

Agency as a means of production (1)

Chapter 2 presented empirical evidence that mental health is positively related to productivity, income and employment status. This suggested some sort of productive role for mental health. Next, empirical evidence showed that stress and mental health problems were on average more prevalent in jobs that require more self-regulatory ability: workers have to plan and manage their work, allocate their resources, and self-regulate and self- 
motivate $^{1}$ at a much higher level. ${ }^{2}$ The more they are able to do this, the more productive they are. On the other hand, if they are not able to do this due to stress and mental health problems, not only are they less productive as a 'first order effect', but also their mental health is (further) affected as a second order effect; so not only their actual productivity but also their potential productivity is reduced. It appears that for many jobs at least, changes in a worker's degree of agency (and recall that diminished agency is a common feature of reduced mental health) changes that worker's output. Agency has the character of a production factor.

Unlike a simple material input, capital, as a means of production, has the property of (potentially at least) affecting the productivity of other inputs. Agency shares this feature as well. In particular, improved agency will increase the productivity of labour directly, and increase the productivity of capital, through better decision-making, for example. ${ }^{3}$ How these processes work is elaborated here.

In chapter 3, we expressed the effect of mental health on performance at different level of stress, as captured by the Yerkes-Dodson law. ${ }^{4}$ Above a certain level of stress, performance tends to go down. Research such as Kahneman (1973) suggests that the explanation lies in the fact that any agent has only a limited amount of mental resources. Thus what matters for performance is both the available quantity of this resource, and the efficiency and effectiveness with which it is put to work. The latter seems to be the more important factor; having a lot of mental energy but using it wastefully or applying it in the wrong way or for the wrong goals will not help our performance but rather harm it. The capacity of a brain seems to be determined by the quality of its internal structure and organization, ${ }^{5}$ similarly to the capacity of a computer chip. The concept of (self)agency refers to the self-regulatory ability of a person, his ability to set meaningful goals, and to orchestrate his external and internal resources (thoughts, feelings, behaviour) to achieve these goals, and it thus reflects

\footnotetext{
${ }^{1}$ As was observed in chapter 3, the prefix 'self does not suggest activities that happen by themselves (so without effort). Rather, 'self' refers to the object of the work, so the management and motivation of the agent by the agent. This is the way the prefix is used in psychology; this intrapersonal dimension is a major theme in that discipline.

${ }^{2}$ In principle, this could mean that we are dealing with a selective sample, that people choosing these types of jobs are also more prone to becoming stressed and developing mental health problems. However, there is no empirical evidence pointing in this direction; on the contrary evidence seems to suggest that there is a selective sample in the opposite direction. One of the requirements for most of the types of jobs at stake is a high education level. A higher education level not only indicates intelligence, knowledge and skills, but also a high degree of self-regulatory ability. Especially at the university level education becomes much less structured and students that successfully deal with that can thus be seen as relatively strong in self-management, selfmotivation and self-regulation.

${ }^{3}$ Here were are taking a vision of agency as a separate production input. This need not be the case: it can in principle be incorporated into the labour input, by re-defining labour in terms of efficiency units, as is often done to incorporate human capital (often education) into the analysis.

4 This was an important step toward the abstraction of the elaborate detailed body of research on the relationship between mental health and performance. The advantage of choosing this as the key relationship is that stress is a generic variable, and the inverted $U$ of stress and performance, based on the Y-D law, can be used to describe a wide variety of situations and persons in a general way.

5 The structure and organization of the brain is extremely complicated, and will be a puzzle for many neuroscientists for many years to come. For the purpose of this thesis, all we can do is to make plausible that the structure and the organization of the brain matters for performance similarly to a means of production, and can be affected by stress and mental illness or other forms of brain damage (somewhat similarly to a breakdown of a machine due to overuse, lack of maintenance, or other causes).
} 
the efficiency and effectiveness of a person in allocating his mental resources. Due to the changes described in chapter 2, optimal allocation of mental resources over competing tasks or activities has become more demanding (since more complex tasks are competing for them); additional capacity has to come from a better internal organization of the brain, which is reflected in a higher degree of agency.

The main productive effect of agency thus lies in its effect on the efficiency and effectiveness of production processes that rely heavily on the mental activities. As was argued in chapter 2 , in a knowledge-based service economy, work increasingly consists of complex cognitive, social and psychological tasks. Human knowledge and human skills are the main resources from which value is created; they are transformed into goods and services by human workers, and the main tool they use for this is the brain. The quality of the structure of the brain, used as a means of production, is therefore crucial for productivity in the knowledge service economy. In this respect the brain can be compared to a highly sophisticated machine. ${ }^{6}$ Similarly to a machine used for the transformation of iron into pins, the brain is used for the transformation of knowledge and skills into knowledge products and services. A better machine increases the productivity of working with material resources, and a better brain increases the productivity of working with intangible resources (knowledge, ideas, emotions). As the demands on the brain as means of production are growing, the impact of loss of quality of the brain increases - which is one of the reasons for the increased attention for mental health problems from an economic perspective.

The notion of the brain as a tool, the performance of which can be improved, is not uncommon in psychology. For example, Macrae et al. (1994) argue that the development of physical tools, such as ploughs or printing presses, has been paralleled by the development of cognitive 'tools' or sophisticated routine strategies of inference and evaluation (that permit a sufficiently effective analysis of the (more complex and demanding) environment to be accomplished in an efficient fashion. The benefit of such 'cognitive toolbox' (as Macrae et al. call it) presumably lies in the fact that they make more efficient use of limited cognitive resources, so that these are freed up for the performance of other necessary or desirable mental activities. Routines, stereotypes, scripts and schemata are examples of mental resource saving tools; they are thought to reside in the brain as pre-fab cue-activated structures. ${ }^{8}$ With only finite cognitive resources available, actors need to derive economical

\footnotetext{
${ }^{6}$ Adam Smith made a somewhat similar comparison centuries ago: "A man educated at the expense of much labour and time to any of these employments which require extraordinary dexterity and skill, may be compared to an expensive machine." Quoted in: Smith (1776) B.I, Ch.10, "Of Wages and Profit in the Different Employments of Labour and Stock," paragraph I.10.9

${ }^{7}$ Macrae et al. (1994) remark that human adaptation to the challenging and complex environment often takes the form of developing tools that facilitate the execution of mundane but necessary tasks, leaving more time and energy available for other, more complex or rewarding activities, and point out that these tools are not only material tools such as machines but also cognitive 'tools' such as routines, stereotypes.

${ }^{8}$ There is much research in psychology showing that the efficiency of the brain has a neurological basis. To further illustrate how the brain can be seen as a 'tool' for information processing and decision-making, the example of hemispheric specialization can be useful. Hemispheric specialization and intercommunication is an important determinant of the capacity and efficiency of the brain (Friedman and Polson, 1981). Belger and Banich (1998) found that increasing complexity at the perceptual level and even more at the decision level increases the advantage afforded by interhemispheric processing. Conversely, the absence of a mechanism for distributing load results in poor performance and decrements in overall attentional capabilities at higher levels of task complexity, as observed with split-brain patients (Belger and Banich 1998).
} 
strategies for the allocation of these resources to the tasks encountered in everyday interaction (Gilbert and Hixon 1991). Agency determines their capacity for doing this. It reflects the internal organization of the brain, our main means of production, our main capital. The increasing interest of economists in the internal workings of the brain shows its economic relevancy.

In the discussion on the nature of capital (of which more in 4.3 below), some authors proposed to see capital as a 'fund' of value, feeding a 'flow' of productive services over time. ${ }^{10}$ Like traditional capital goods, agency functions as a fund of productive value generating a flow of productive services (interpretations, decisions, computations, motivations) over time. It is worth pointing out that agency is a means of production that is individual by nature; I cannot take someone else's brain and use his agency to do my information processing and to take my decisions. However, I can use his agency by contracting him to deliver mental capital services to me, thereby using his agency as a means of production for my goals.

\section{Agency is produced (2)}

Why not simply say that the brain itself is the means of production, rather than agency? The reason for this is twofold. First, in the case of a machine, it would be wrong to say that the physical material that the machine is made of is the means of production. What matters is how the material is put together, how it is organized; that is what makes it a tool, a means of production. Exactly the same amount of physical materials (iron, plastic, silicon and whatever more a machine is made of but not organized in the form of the machine would not be a means of production; a worker could do nothing with it. Similarly, it is not the brain tissue itself that is the means of production, but rather the way it is structured and organized. The essence of capital is that it is a produced means of production, and it is the produced part that makes it capital. This is why it is proposed to take the intangible part of the brain, its agency structure, as the key feature when discussing the brain as a means of production,

To an important extent the organization of the brain is genetic. But within these genetic constraints there can still exist a wide variety of structures and ways of functioning. This (physiological and chemical) structure is changed through experience and more directly through drugs or brain damage. Changes can be temporary (such as fatigue or mood) or more durable (such as some mental health problems). These changes can be side effects of other actions, driven in many cases just by daily life, but they can also be deliberate. It is learned, and taught, especially as a child, but even as adults deliberate efforts to change our levels of agency, either through training of some sort or through direct chemical intervention, are common. It may seem somewhat crass to consider that this is all about

\footnotetext{
${ }_{9}$ Increasingly, economists are becoming interested in the internal economy of the brain. E.g. Ainslie (1992), puzzled by the phenomenon of hyperbolic discounting, introduced the term "picoeconomics" (micro-microeconomics) to describe the research on internal processes.

${ }^{10}$ For example Walras (1874) divided between the stock of capital and the flows of "services" of capital (i.e. the income flows arising from that stock). Capital, he argued, was not "used up" in the production process, but rather provided "services" and it was these services that entered the production process. Clark (1893) proposed that capital is an entity of value that can be embodied in all kinds of objects (including men), and compares it to a waterfall: "A waterfall consists in particles of water [...] The water moves, the fall stays where it is $[. .$.$] capital$ goods are, like particles of water, vanishing elements. True capital is like the fall.” (p.308).
} 
making more productive workers, but indeed that is often the effect (and to some extent at least, it is actually the stated aim of much of the training we receive). Thus agency is produced.

Agency is durable (3)

Capital goods such as machines are characterized by durability, they still exist after being used in production and they do not lose their identity in the process. They can get worn out with use, and may break down during production; but maintenance can diminish or cancel out this depreciation, and capital goods that have broken down can be repaired. To what extent are these features found in the case of agency?

Agency is relatively stable over time, though it does diminish after periods of active use of it (such as a working day), depending on the level of stress and the resulting accumulated fatigue; regular maintenance is needed, which predominantly takes place when the mind does not have to work. ${ }^{11}$ If maintenance is not sufficiently possible, for example if stress levels are high, fatigue is increasing, and there is not enough opportunity to recover, over time the brain may get physiologically affected. ${ }^{12}$ Often maintenance and repair of the agencyfunction takes place at home in the family, or, if more serious repair is needed in the mental health care sector.

So, while the degree of agency may fluctuate to some extent, it is not transformed into something else during the production process; in principle, the systems in which agency resides such as the frontal lobe of the brain remain intact, just as a machine remains intact during use. However, stress and mental health problems may decrease the performance of the brain, just as overuse and parts breaking down may decrease the performance of a machine. Thus, agency, residing in certain structures of the brain, is durable. In principle, with sufficient maintenance, it will not diminish or be 'used up' during use. It is still there the next day, ready to be used to deal with new tasks and challenges.

Summarizing, the empirical evidence presented in chapter 2 and 3 has been brought together in this section to show that agency:

- functions as a production factor determining the efficiency an effectiveness of the process of (mental) production;

- provides productive services (thoughts, decisions, motivation, action) over time;

- is produced, and used in its own production.

- is durable - it is in principle not transformed itself during the production process and is not loosing its identity over time;

\footnotetext{
${ }^{11}$ Research has found that sleep has a crucial function in structuring and repair-like processes taking place in the brain (e.g. Hamilton et al. 2007; Drosopoulos et al. 2007) and lack of sleep is associated with mental health problems such as depression (Cukrowicz et al. 2006). Physical activity such as sports has been found to favorably change the balance of neurochemicals and is associated with improvement in mental health (Biddle et al. 2000).

${ }^{12}$ Long term exposure to stress hormones is found to be related to shrinking brain tissue, reduction of the number of axons and the number of their connections, and a changed neurochemical balance (Sapolsky et al, 1986; Lupien et al. 2005).
} 
Agency does seem to display the central feature of economic capital. Treating agency or mental health as a form of capital invites the possibility of intervention to change its availability as a productive factor, and the intensity of its use in production. Private investment, by individuals and firms may be profit or utility maximizing strategies. Policymakers may make similar considerations regarding social welfare. Certainly, policy often has these sorts of goals as regards physical capital (through tax incentives and interest rate policy), particularly when there are fears of under-investment, so similar concerns may arise in the case of mental capital. In the next two sections we address the feasibility of treating agency in this way, by exploring the nature of its production and the way investment and return operate.

\subsubsection{The production of mental capital}

In this section we discuss how and where is agency produced. The potential level of agency of a person is to some extent given by nature (genetic), but it needs to be actively developed, and is thus largely man-made. Important elements of agency such as mental resilience and self-efficacy are the product of formal and informal 'production processes', which continue all through a person's life. Here we will discuss the most important 'production sites' of (elements of) agency: the family, school, work, and the mental health care sector. Agency is a composite factor which is generally investigated by studying its constituent elements such as self-efficacy and mental health. To get more insight into the production of agency, we will refer to research on the production of its main elements.

A major producer of elements of agency and of mental health (for better or worse) is the family. ${ }^{13}$ Many studies look at the effect of family situation on mental health status. Empirical research shows that the proverbial 'bad childhood' is rightly associated with different kinds of mental health problems. ${ }^{14}$ Empirical research has investigated a number of characteristics of family life and their effects on the mental health of family members, ${ }^{15}$

\footnotetext{
13 The notion that the family is a major producer of health (e.g. Grossman, 2003) and of human capital (Becker 1989) has been around for some time. Some economists, such as Marshall (1959) thereby underlined the psychological component of this, stating that among the "cost of production of efficient men", the costs involved of families "to make their homes happy, to bring up their children vigorous in body and mind, truthful, cleanly, gentle and brave" should be included (p.469).

14 Prospective longitudinal research has shown substantial continuity of youth depression into adulthood, with impaired functioning in work, social, and family life, and markedly elevated risk of adult suicide attempts and completed suicide (see, e.g., Costello et al., 2002; Weissman et al., 1999). Research for risk factors in the development of mental health problems at an early age has found a numerous risk factors, ranging from the presence of prenatal negative maternal life events (e.g. Gutteling et al. 2000) to different types of parenting (e.g. Magaro and Weisz 2000). Retrospective studies using reports of depressed adult psychiatric patients and depressed nonpatients depict certain characteristics of family processes in the past and/or present. Depressed adults recall, less affection and tolerance and greater rejection (Coyne and Downey, 1991), and parent's use of control techniques such as derision, negative evaluation, and love withdrawal (Crook and Raskin 1981; Mezulis et al. 2006). A review of the research literature on the relationship between childhood experiences and depression in adulthood can be found in Bemporad and Romano (1993); A review of the research on the relationship between early environment characteristics and anxiety in adulthood can be found in Chorpita and Barlow (1998).

15 E.g. Strazdins et al. (1997), reviewing literature on the psychological role of the family, point out that in family settings family members do emotional work, in order to create and maintain "mental hygiene" which keeps family members emotionally healthy. Emotional work involves caring for, and understanding, other family members' emotional needs, as well as monitoring and maintaining the quality of interpersonal interactions within the family. In families, women often take primary responsibility for emotional support,
} 
especially from parents to children, ${ }^{16}$ including the effect of parental mental health problems $^{17}$ and abuse; ${ }^{18}$ but also between siblings ${ }^{19}$ and spouses - the effects of marital dissatisfaction, ${ }^{20}$ divorce ${ }^{21}$ and social support ${ }^{22}$ - and between friends and colleagues. ${ }^{23}$ Other studies directly look at the relationship between family characteristics and core elements of agency itself, ${ }^{24}$ such as the important feature of emotion regulation. ${ }^{25}$

Next to family and friends, education is also an important producer of agency and its constituent elements such as mental health and self-efficacy. The level and quality of

nurturing, setting limits, establishing routines, and organizing their children, particularly when children are young. Mental hygiene is an important factor for helping to prevent mental health problems (Strazdin et al. (1997). Providing 'mental hygiene' is effortful, it is a clear example of 'production' of mental health by the family.

16 E.g. Serbin and Stack (1998), introducing a special journal issue on intergenerational social-psychological risks, find that there is an intergenerational continuity (of varying magnitudes) in terms of cognitive, social and emotional development (including mental health problems); parenting practices are found to be the main gateway for transfer of a variety of characteristics between generations.

${ }^{17}$ For an overview of the research findings on the adverse effects of parental depression on child psychological functioning see Cummings, Davies and Campbell (2000).

${ }^{18}$ E.g. Reckling and Buirski (1996) give an overview of the effects of abuse on children: difficulty identifying and acknowledging their affect; increased aggression and rage; increased dysthymia, depression and anxiety, lack of empathy, lower performance on cognitive tasks. Reckling and Buirski show that these effects can be understood more fully as derailments in self-development and the capacity to regulate affect.

${ }^{19}$ E.g. Kramer and Bank (2005) in a special issue reviewing research on siblings find that research clearly shows that sibling relationships serve as important contexts for psychological development, social-emotional skills, behavioural regulation and relational functioning.

${ }^{20}$ Research involving diverse methods and samples demonstrates that depressive symptoms covary reliably with marital dysfunction and that longitudinal links between these variables exist in both directions (Davila et al. 2003). Marital dissatisfaction is found to contribute to the onset of depression, and depression is found to contribute to marital dissatisfaction, through behaviors that interfere with interpersonal relationships or through the generation of increased stress (Davila et al. 1997). For a review of literature on this topic, see Beach (2001).

21 The rate of divorce has grown substantially in the past decades, currently divorce rates in developed countries are up to $50 \%$ (Hetherington et al. 1998) Marital dissolution is marked by depression and periods of disequilibrium and emotional numbness, the restabilization process usually takes from 2 to 5 years (Kaslow 2001). For children, parents' divorce can have long-term adverse mental health consequences in terms of emotion regulation and self-esteem, important correlates of agency (Hetherington et al. 1998).

22 Research shows that the presence of a supportive marital relationship decreases vulnerability depression, whereas the absence increases vulnerability; the spouse is found to be perhaps the most important contemporary producer of an adult's mental health, for better or worse (DeLongis et al. 2004).

23 Social support in the form of family, friends and colleagues produces effects on mental health and selfesteem; and it has been found to act as a moderator or buffer of the stressor-strain relationship (Beehr 2003).

${ }^{24}$ E.g. Sroufe (1991) finds that the operation of the family system is important in determining the ego-resiliency of adolescents. Ego-resiliency is an important correlate and building block of agency; it refers to the ability of a person to flexibly respond to the demands of internal need states and external environmental constraints. The ego-resilient person is characterized by resourcefulness, having an ability to maintain an integrated performance when under stress, being able to process two or more competing stimuli, and having the capacity to become less or more controlled under varying conditions (Sroufe 1991).

25 Emotional self-regulation refers to the ability to initiate behavioral and emotional changes during emotionally charged situations in order to meet goals and manage arousal and predicts current and later adjustment (Denham, 1998). In early childhood, persistence during challenges, frustration tolerance, and compliance with caregiver demands are hallmarks of successful emotional self-regulation (Eisenberg et al., 2001). Parenting and sibling interaction is found to have crucial influence on developing agency in toddlerhood, the phase when a child develops more mobile, willful, and unsafe behavior, and at the same time lacks the skill to regulate emotions or to consider his or her own safety or the needs of others (e.g. Gardner et al. 2007). 
education is found to be positively related to mental health and self-efficacy. ${ }^{26}$ To some extent this is a selection/screening effect, but to some extent agency proxies are also actually produced during education rather than merely signalled by education level.

In later life, one of the most important 'production sites' of mental health and agency is work. In chapter 2 and 3 it was discussed how working conditions can erode or improve mental health and important elements of agency such as self-esteem and self-efficacy. Work provides the environment in which most adults spend most time in per day, so it is a major provider of (positive and negative) experiences. It was therefore argued in chapter 3 that work not only produces goods or services that it is intended to produce, but that it also produces mental health effects, as a side-product, for better or worse. ${ }^{27}$ Gaining work experience, learning to deal with more complex tasks and with higher stress levels is a sign of increasing agency. Agency is thus the result of labour and increases the productivity of later labour. ${ }^{28}$ In addition, the current HRM practices are explicitly targeted at increasing agency of workers, for example through courses to increase personal effectiveness, and management and leadership training.

Another production facility is the mental health care sector. Mental health care is generally given to people who are lacking mental health, suggesting some sort of repair function rather than a production function. However, since a person enters the sector with a certain mental health status and in principle leaves it with a much higher mental health status, one can plausibly say that mental health and thereby agency has been produced. ${ }^{29}$ Furthermore there is the 'self-help industry', which has impressive growth rates, and is of increasing importance to people as a source of self-insight, self-efficacy and self-esteem - important elements of agency. $^{30}$

\footnotetext{
${ }^{26}$ E.g. Bear et al. (2003) observe that schools have an important role as one of the key mechanisms by which children come to perceive themselves as the cause, source, or agent of their own behavior, and act accordingly; e.g. Hoge et al. (1990) find that school experiences are causally related to mental health and self-esteem.

27 Adam Smith (1776) already observed that production processes produce also mental states, and given the working conditions of his time in factories, he was mainly concerned with the adverse mental effects associated with division of labour: "The man whose whole life is spent in performing a few simple operations [...] has no occasion to exert his understanding [...]. His nature loses therefore the habit of such exertion and generally becomes as stupid and ignorant as it is possible for a human creature to become [...] incapable of relishing or bearing a part in any rational conversation.[...] The uniformity of his stationary life naturally corrupts the courage of his mind"'(p.734-735).

28 As chapter 2 and 3 showed, work experiences can also diminish agency when it concerns negative experiences which reduce self-esteem and self-efficacy, leading to insecure, demotivated and depressed employees with a low level of agency.

${ }^{29}$ There is a substantial body of empirical evidence showing that mental health care treatments often (but not always) improves mental health status and thus is 'producing' mental health (e.g. Westen and Morrison 2001). For example, treatments with demonstrated benefits in reducing symptoms and improving functioning have been developed for mental problems such as anxiety disorders (e.g. Beidel et al. 2000), attention deficit disorders (e.g. Jensen and Cooper, 2002), and depression (e.g. Clarke et al. 1999). The evidence on the effectiveness of treatment is mixed because different treatments are more or less effective for different disorders; the growing body of studies on effectiveness improve evidence-based therapy and thus the all-over effectiveness of mental health care.

${ }^{30}$ See the discussion on the self-help industry in section 3.3.2.
} 
Agency is being produced as a result of learning experiences of an individual, based on his experiences with the world ${ }^{31}$ and what these experiences tell him about himself and his abilities. Especially in the beginning of life, the agency of a person is actively produced with the help of the agency of others, such as parents and teachers, shaping and guiding a child towards sufficient agency to become a stand-alone person (in other words, towards adulthood which should indicate a minimum level of agency). The basic production process of agency takes place inside the head of the person, through organizing information about the self, using information about successes and failures as feedback to further develop a sense of how to think, feel and act optimally, and practicing to self-regulated thoughts, feelings and behaviour. In this process of reflection (partly conscious, partly not), a person uses his existing agency to get more insight and control over himself; thus using agency to create more agency. ${ }^{32}$ Like traditional capital goods, agency is used to produce itself, showing that the analogy with capital goods further helps to develop an economic perspective on mental health and agency.

Summarizing, agency, its constituting elements such self-esteem, self-efficacy and mental health, can be seen as 'produced goods', and are used in their own 'production'. With this it fulfils yet another important characteristic of capital.

\subsubsection{Investment in and returns of mental capital}

Capital is income not consumed for the sake of (more) future income. This points to yet another important characteristic of capital. Capital is a stock of value, which can be increased (both quantitatively and qualitatively) at a cost, resulting in a stream of benefits (productive services) later in time. Future revenue gives current cost the character of an investment. Capital can be increased by means of investment, and this investment has returns over time in terms of additional revenues. In this section we look at these aspects more carefully, in order to further assess the appropriateness of the mental capital concept.

Agency can be increased, at a cost: for example, the costs of mental health care, ${ }^{33}$ the (opportunity) costs of parental attention, or the costs of training and human resource management for employees. ${ }^{34}$ Furthermore, increased agency has clear pay-offs, ${ }^{35}$ both for

\footnotetext{
${ }^{31}$ For an overview of research on other aspects of society that appers to have an effect on agency formation and mental health (e.g. immigration, the new media), see Kaslow (2001).

${ }^{32}$ Life reflection is a fundamental social-cognitive process of self-understanding that emerges during the first two decades of life and continues to occur throughout the remaining life span (e.g. Habermas and Bluck, 2000). Staudinger (2001) in a review of research on this topic shows that life reflection leads to the accumulation of self-insight and personality growth, needed for personality continuity in times of change; this is correlated with agency, self-insight being an important condition for self-efficacy.

33 There are many studies on the cost-effectiveness of mental health care, usually performed to compare the improvement on certain scales of mental illness of different types of therapy (e.g. see Barrett et al, 2005; Gold et al. 1996); the effectiveness of therapy can be used to estimate the costs and (wider) benefits (including productivity benefits) and thus to estimate ROI.

${ }^{34}$ E.g. Gist and Mitchell (1992) reviewing empirical studies find that self-efficacy can be enhanced by training in the areas of self-management and behavioral modelling, and that when self-efficacy is enhanced, performance improves.

${ }^{35}$ For an overview of research on the relationship between constituent elements of agency (self-efficacy, selfesteem, mental health) and performance, see section 3.4. To have an idea of the size of pay-offs, see section 3.3
} 
the individual and for his environment (work, home); ${ }^{36}$ it has been found to lead to better performance, higher productivity, better decision-making, higher income, less absenteeism, and less chance to be unemployed or work disabled. ${ }^{37}$

Research in psychology predominantly looks at the consequences of lack of mental health and the accompanying lack of agency. The costs of improving mental health problems can be seen as the investment, and the various costs resulting from mental health problems as a proxy for the return of this investment. ${ }^{38}$

Due to the feedback loops ${ }^{39}$ and spillovers ${ }^{40}$ of mental capital, loss of mental capital tends to trigger a cascading, downward spiral, while increase of mental capital tends to have a cascading upward spiralling effect. This makes mental capital an interesting object for investment. ${ }^{41}$ In spite of the substantial pay-offs of spending on agency-enhancing factors such as mental health and self-efficacy, there appears to be significant underinvestment, at the level of public spending, spending by firms, and spending by individuals. ${ }^{42}$

on costs related to lack of mental health, taking mental health as a proxy for agency. Let it be noted that given the definition of mental health in section 3.2, a person with low self-esteem has reduced mental health.

${ }^{36}$ Clearly, increasing agency and its correlate mental health has also an important consumption character, since mental health and the ability to know what you want and to do what you want are goods with high intrinsic utility. However, we focus here on the production effects of investment in agency and mental health. The fact that a factor such as mental health has both consumption and production value can make the questions of public vs. private funding more difficult, but it is in that respect in principle similar to education.

${ }^{37}$ See chapters 2 and 3 for elaborate empirical evidence on this.

38 As illustration, a schematic example is given here. If a depressed individual unable to work receives mental health care worth 1200 euros, after which he is able to work again a year sooner than a depressed individual who receives no treatment, the benefits of this are the amount of a year's worth of his salary, or alternatively, a year of disability benefits if this person would have entered a work disability arrangement otherwise. If work disability benefits amount to 1000 euros a month, the cost of mental health care would have a return of 12,000 euros, thus a ROI of $1000 \%$.

${ }^{39}$ The main feedback loop referred to here is described in some detail in chapter 3: high levels of stress affect the fontal lobe systems and the HPA axis, which in turn affects the ability to deal with stress effectively, thereby further increasing stress levels, feeding a downward spiral. Conversely, increasing mental health and agency will trigger an upward spiral, making it an interesting object for investment.

${ }^{40}$ Empirical evidence shows that stress, moods, mental health problems and other mental capital relevant variables spill over from one domain to the other and from one person to the other; the empirical evidence for these spill-over effects is discussed extensively in chapter 6 .

${ }^{41}$ The idea of mental health being an object of investment can increasingly be found in research. For example, Halpern (2005), who was president of the American Psychological Association (APA) in 2004, in her presidential address: "Reducing stress is a good business practice." (p. 406); "These findings convert "soft" psychological data into return-on-investment dollars." (p. 407). Blount et al. (2007) observe that the more broadly we account for the impact of behavioural health services in primary care, the greater the identified savings are, but the more difficult it is to document these savings rigorously. Improved occupational functioning is one of the most immediate results of improvement from depression through treatment. Depression is associated with an average of 4 to 5 lost work days per month in addition to any days lost to accompanying medical conditions. Underfunctioning ("presenteeism") as a result of depression can equal the same loss in productivity as 2.3 days absent per month (Wang et al., 2004). The monthly cost to an employer of an employee with depression is over $\$ 550$, substantially greater than the monthly cost of evidence-based treatment. Patients with severe depression who improved reduced their disability days by $36 \%$, and patients with moderate depression who improved reduced their disability days by $72 \%$ (Korff, et al. 1992). The estimated annual cost to employers in lost productive time of employees suffering from depression was estimated to be $\$ 44$ billion per year in 2001-2002, 31 billion more than employees without depression (Stewart et al. 2003). For the purpose of illustration, assuming that treatment could reduce the depression-related lost productive time by $50 \%$, this would result in a 'return on investment' of about 15 billion a year.

42 Research consistently finds significant underinvestment in mental health and mental resilience. For example, the World Health Report 2001 estimated that in European countries, 45-70\% of people with mental health 
Public expenditure on mental health in many European countries is disproportionately low compared to overall expenditure on health care, given high prevalence and high costs associated with mental health problems. ${ }^{43}$

Secondly. firms also tend to underinvest, though this seems to be getting less. Firms are increasingly spending more on better human resource management upgrading the psychological skills of employees and especially of managers, who have to optimize working conditions also from a psychological perspective. The increasing recognition of psychological factors as an item for investment in business can be illustrated by the increase of popular books with titles such as Emotional capital: Maximizing the Intangible Assets and the Heart of Brand and Business success (2000), ${ }^{44}$ Emotional Capitalists. The New Leaders (2005), ${ }^{45}$ Unleashing Intellectual Capital (2000), ${ }^{46}$ and Psychological Capital: Developing the Human Competitive Edge (2006). ${ }^{47}$

In line with this, there is increasing early recognition of (work-related) mental health problems and increased early intervention to prevent downward spirals of employees, going from increased absenteeism towards work disability. In countries such as the Netherlands, the legal framework give firms are strong incentives to pay more attention to the mental

problems are not in treatment (WHO 2001a). An important reason is that there is significant market failure: mental health problems affect the rationality of people reducing their ability to act as rational consumers of products and services that would fulfil their need for mental health. This implies an important role for governments, similarly to the role the state has in other areas with market failure, such as requiring citizens to save for their pension and to have a health insurance.

${ }^{43}$ E.g. Mental health problems account for nearly $20 \%$ of all health problems in Europe; however of 28 countries, only 4 countries allocating more than $10 \%$ of their health budgets to mental health (Frank and McGuire 1999).

44 Illustrative excerpt from Emotional Capital: "[P]eople assets can only be harnessed by managing both intellectual capital (your peoples' knowledge) and emotional capital (the feelings and beliefs that motivate people to take positive action). Knowledge management is moving up the agenda in many companies. Yet organizational knowledge is meaningless if your people are unmotivated, apprehensive or uncommitted. How many companies have paid the price of an alienated workforce with problems like poor customer service, labour disputes and low productivity - all hallmarks of low emotional capital? Emotional capital can be managed as a tangible asset and a direct contributor to the balance sheet (back cover) (Thomson, 2000).

45 From Emotional Capitalists: "[A]nyone who is genuinely motivated can develop their emotional intelligence and boost their stocks of emotional capital" (p.16). "Emotional independence expressed as self-reliance and self-belief is indispensable to becoming an emotional capitalist and building emotional capital in your personal lief and business" (p.26) (Newman 2005).

${ }^{46}$ From Unleashing Intellectual Capital: "[O] rganizations in the Knowledge Age need a new management model for generating, capturing and leveraging intellectual assets in order to stay competitive" (p.5) "Machines need to be monitored, controlled and maintained by external sources. [...] People and organizations, however, are living systems, not machines. Living systems have the innate capacity to self-assemble, self-sustain, change constantly, reproduce, learn and self-organize" (p.7). "People are not simply a means of production, They are biological systems constantly seeking to fulfil their needs and aspirations. [...] Even from an economic perspective, people in companies are not assets, but investors, similar to shareholders. Shareholders invest their money in an institution, whereas members of a firm invest their time, energy and intellect" (p.8) (Ehin 2000)

${ }^{47}$ Excerpt from Psychological Capital: "How can organizations and individuals ready themselves to achieve distinct competitive advantages? [...] We call for the investment and development of psychological capital. [...] [M] ore important but to often slighted in this war, we would argue, is finding innovative ways of capitalizing on and developing human, social and especially the psychological capacities of human resources for sustained competitive advantage. [...] Simply concentrating and accumulating more of the traditional resources once considered vital for organizational success have proven insufficient for attaining sustainable sources of competitive advantage. [...] We propose that such advantage can be gained through investing, leveraging, developing and managing psychological capital" (p.7) (Luthans et al. 2006) 
health of employees and to prevent work stress and work-related psychological problems. It is difficult and expensive to fire employees, and firms are legally obliged to pay at least $70 \%$ of the wages of sick employees for a period of two years; this inspires employees to work on prevention and early recognition and solution of problems. ${ }^{48}$

Thirdly, there is underinvestment at the level of the individual. If anyone, it is the individual himself who would profit from increasing his mental capital. It would help him to become more productive thus gaining a better position in the labour market a higher income, less chance to lose a job. In addition, it will help him to enjoy the fruits of his work more, in terms of real 'experienced utility' (Kahneman 2000). After all, if a person is stressed or depressed (thus low on mental capital), his new car, house or gadget will make him much less happy, effectively meaning a loss of utility. Nevertheless, individuals do not always actively built up more mental health and more agency; even worse, they often let their mental capital slip away, in stressful jobs, worries, loss of self-esteem, burnout and depression.

One of the reasons for this underinvestment is the occurrence of serious flaws in the market for mental health care and related markets such as the self-help industry. Frank and McGuire (1999) show that mental health economics is like health economics only more so: uncertainty and variations in treatments are greater; the assumption of patient self-interested behaviour is more dubious; there is more risk of moral hazard and adverse selection; market failures are more serious, and the social consequences and external costs of mental illness are "formidable" (Frank and McGuire 1999).

Mental health problems lead to diminished rationality and reduced agency capacity of people; they are less capable to act on their own behalf and in their own best interest, and this leads to increased market failure. Mental illness reduces an individual's ability to function in a consumer role vis-à-vis for example mental health care services, and interferes with the maintenance and creation of social networks (family and friends), weakening the connection with others who might serve as caregivers or 'substitute decision-makers' by taking over the failing agency function of the person with mental health problems. This leads to a suboptimal amount of spending on improvement of mental health, and calls for an active role of the government. By increasing the supply of mental health care and services for strengthening the agency of a person such as psychotherapy or a 'life coach', and making these services easily accessible and affordable, more people that need help would receive help, often in an earlier phase so that more serious problems can be prevented.

\footnotetext{
48 See for more details on the Dutch law in this area: http://www.werkennaarvermogen.nl/. When mental health problems are the result of work stress, the practice of requiring the employer to carry the costs of employees with mental health problems is effective, since it is a way of endogenizing costs of production. However, mental health problems of employees can also originate in the non-work sphere, and the employer is nevertheless responsible. On the one hand, endogenizing mental health costs results in improvement of working conditions and psychological sustainability. On the other hand it leads to "front-door selection" (Schaufeli and Kompier 2001); employees get screened more intensively psychologically before being hired, with the help of psychological tests and assessment centres. This latter strategy can lead to exclusion of people with less mental capital on the labour market, which is undesirable since exclusion can lead to further erosion of their mental capital.
} 
However, as always there is a scarcity of financial means and there are many other worthy destinations for public money, so the question of how much should be spent on dealing with mental health problems is important. This question is not easy to answer. The demand for mental health has a high price elasticity, making it difficult to identify the 'real' demand. ${ }^{49}$ The result of increasing demand by increasing awareness of mental health problems and the possibilities for solution, in combination with offering more and more easily accessible supply can also be suboptimal; due to the high price elasticity and the important subjective dimension of mental health problems, part of mental health care would be used by people that may not really need it. It may not be possible to ever find out the optimal level of expenditure or construct an optimal meeting of supply and demand. However, Frank and McGuire (1999) suggest that underconsumption may in the end be more costly than overconsumption. Early recognition and intervention is generally much more effective than later treatment, and saves the direct and indirect costs associated with more serious problems. Introducing cost-sharing for example could result in an initial decrease of health care consumption, but a delayed, much higher increase in consumption and therefore costs later in time, because medical problems will be diagnosed in a later stage when is it harder and more expensive to treat them. ${ }^{50}$

In this section 4.2, we have explored to what extent the characteristics of agency correspond with the characteristics generally associated with capital and capital goods. We have found that there is a good match: agency is a produced means of production, which is durable, which is used in the production of (own or other people's) agency, which can be invested in with substantial returns over time. It herewith satisfies all the important characteristics of capital, justifying the term 'mental capital'. In the next section, we will look more into depth at the discussion about the nature of capital and address possible objections to the concept of 'mental capital'.

\subsection{The use of the capital concept}

The aim of this thesis is to get more grasp on the economic dimension of mental health, because it is increasingly clear how important this dimension is in a knowledge economy where most people work with their head. In 4.2, it was shown that agency - a composite variable containing a number of factors that determine the efficiency and effectiveness of the brain - fulfils all the criteria of what is thought of as 'capital' in economic theory. To view agency as a form of capital has analytical value, it helps to organize a broad and heterogeneous body of research spread out over different disciplines, and it puts an important psychological variable into an 'economic coat' that fits well, increasing the chance that this variable can enter the economic arena in a meaningful way.

\footnotetext{
${ }^{49}$ Ringel et al. (2002) based on a review find price elasticity estimates for mental health care between 2.66 and 4 times those estimated for general ambulatory health care.

${ }^{50}$ Frank and McGuire (1999) show that investment in mental health eliminates costs associated with low levels of mental health. Mental disorders correlate substantially with other costly problems: unemployment, crime, violence and homelessness (also see chapter 2). Many of these problems have consequences for others as well as the person with the illness, which means that decentralized market-decision-making will tend to undervalue effective treatments for mental illnesses. For this reason government has historically taken a large role in provision and regulations of some forms of mental health care (Frank and McGuire 1999).
} 
While there is strong empirical evidence supporting the plausibility of each step towards fitting agency on to the conceptual mould of capital in 4.2, the idea of 'mental capital' will raise a number of objections and questions. In this section the five main questions and objections will be addressed.

First, the concept of capital appears to have been developed for a quite clear-cut type of goods, such as machines, whose price and output are clear and measurable, and of which the cost-benefit ratio and return on investment can be calculated. In the case of mental capital this is different. Although psychology has developed sophisticated tests and scales to measure (changes in) (elements of) agency, it is not so easy to link investment (for example in the form of better parenting or of mental health care) to increases in mental capital, nor is it clear-cut what exactly the returns are from investment in mental capital; the intangible character of this production factor and the many elements that influence it makes it hard to be precise. Does that make the concept of mental capital less useful, and perhaps even appropriate, given what seems to be the original intention of the concept?

Second, the capital concept has been broadened already in the past decades; will further broadening of the concept of capital make it lose its analytical value?

Third, the idea is that the concept of mental capital will help to enrich economics with insights of psychology that have economic relevance and should be taken into account in some way. But does that really work? How does mental capital relate to existing economic research which incorporates psychological elements, such as behavioural economics and especially bounded rationality?

Fourth, mental capital seems in several ways quite closely related to human capital; so why not simply fold it into the concept of human capital?

Fifth, the proof of the pudding is in the eating: what do research and policy gain from the concept of mental capital?

We will deal with these questions in the following way. First (4.3.1), we will show that the concept of capital is not at all as clear-cut as it may seem. By discussing the 'capital controversies' that raged in economics in the last century, it will become clear that even the most traditional concept of capital (physical goods such as machines and buildings) is problematic with regard to definition, valuation and measurement of returns. Nonetheless the concept of capital is widely used for physical capital goods, and has proven itself useful. Difficulties regarding definition and measurement are thus not sufficient as reason to reject the concept of mental capital.

Next (4.3.2), we will discuss the further broadening of the concept of capital in the past, most notably the introduction of the concept of human capital and social capital. We will briefly discuss the reasons for their introduction, their reception, the criticism and their usefulness. The point of doing this is (1) to show that also with regard these capital concepts there were and are many conceptual difficulties, but they nevertheless have become widely and fruitfully used, and (2) to show that their introduction was a response to changes in 
economic reality, necessitating new concepts to capture these. By discussing how in the past two capital concepts were successful in capturing new or increasingly important aspects of reality, the case for the use of a capital concept reflecting mental resilience and agency will become stronger.

After this, we take a closer look at how mental capital is related to four important branches in economics: growth theory (4.4), human capital (4.5), and bounded rationality (4.6). This will serve to show how the concept of mental capital connects to and adds an important new dimension to what already is being done in these branches of economics.

\subsubsection{The capital controversies}

The definition and measurement of capital are among the most fiercely ${ }^{51}$ and passionately ${ }^{52}$ debated topics in economics.

There have been three great 'capital controversies' in the twentieth century. The first capital controversy took place at the end of the $19^{\text {th }}$ and beginning of the $20^{\text {th }}$ century. The controversy can be related to fundamental changes in the economy, which created the need to rethink the concept of capital and what it stood for. The Industrial Revolution had brought to the forefront a production factor (machines) that did not yet have a clear place in theory: it was not land, neither was it labour, nor was it (financial) capital in the traditional sense of the word. ${ }^{53}$ The Industrial Revolution had transformed the economy beyond

\footnotetext{
51 Bliss (1975): "When economists reach agreement on the theory of capital they will shortly reach agreement on everything else. Happily, for those who enjoy a diversity of views and beliefs, there is very little danger of this outcome. Indeed, there is at present not even agreement as to what the subject is about." The discussion about capital has been going on for more than a century. Some citations to illustrate follow here. Fisher (1896) wrote: "Of economic conceptions few are more fundamental and none more obscure than capital," and adding that "the long and unsatisfactory controversies over the relation of capital to wages, production and interest, have been accompanied by controversies equally long and unsatisfactory over the meaning of capital itself." (p.509). Patten (1889) observes that "almost every writer on economic subjects uses the word "capital" in a new sense, or at least gives it a definition differing from all others. So varied a use of he term cannot but make the whole subject ambiguous and perplexing" (p.188). Fisher characterized the discussion of capital as "a vain search for some criterion of classifying wealth into capital and income" and a "fruitless chase"(p.520), and only "occasionally a ray of light would penetrate these dreary fogs" (p.524). Tuttle (1903): Enough has been said to show that the way is strewn with capital concepts, some broader, some narrower, some emphasizing one characteristics, some another, but no one of them capable of commending general assent" (p.93).

52 For example, Fisher (1896) observes that "The incessant criticism and efforts at reconstruction [of the definition of capital] go on unabated. Almost every year there appears some new attempt to settle the disputed conception, but unfortunately no authoritative result has yet followed these attempts. On the contrary, many of them only served to put more combatants in the field and furnish more matte to the dispute." (p.511). BohmBawerk (1907) wrote: "With every respect for the intellectual qualities of my opponent, I must oppose his doctrine with all possible emphasis, in order to defend a solid and natural theory of capital against a mythology of capital (p.282). Hayek (1936) compared the attempt of Knight against a certain concept of investment with a "crusade" (p. 199); he accused Knight of introducing a "pseudo-concept devoid of content and meaning, which threatens to shroud the whole problem in a mist of words" and of "the substitution of a meaningless statement for the solution of a problem" (p. 201). Fisher (1896) observes that "The incessant criticism and efforts at reconstruction [of the definition of capital] go on unabated. Almost every year there appears some new attempt to settle the disputed conception, but unfortunately no authoritative result has yet followed these attempts. On the contrary, many of them only served to put more combatants in the field and furnish more matter to the dispute." (p.511).

53 There was a considerable time lag between changes in economic reality and economic theory detecting these; as Kuhn (1962) shows, this time lag is typical since existing conceptualizations are stretched to include new
} 
recognition, and economic science was struggling to accommodate these changes in its concepts and theory. Since machines were expensive and the purchase of machines required financial capital, machines were generally considered to be a form of capital. However, as a consequence it became less clear what exactly capital was. The issue of this controversy was the question what the term 'capital' referred to: savings (thus financial), a stock of goods (thus material), either all goods present (property) or only the goods that were means of production (capital goods); or, more abstract, value (thus immaterial) embodied in (durable) goods providing (productive and/or consumptive) services. ${ }^{54}$

The second capital controversy took place in the 1930s. ${ }^{55}$ A central issue in this controversy was the validity of the assumption of equilibrium; this assumption lies at the heart of neoclassical economics and many other assumptions are derived from it or built on it among these assumptions about the value and revenue of capital. Among other things, it was argued that equilibrium is not the usual outcome of an economic process and therefore an inadequate assumption on which to base tools for analyzing processes of capital accumulation and growth.

These issues came back in full force in the third capital controversy, which took place from the mid 1950s to the mid 1970s. This controversy is known as the Cambridge capital controversy. ${ }^{56}$ An important issue was the question of how capital contributed to economic growth. In order to find this out, it is necessary to measure capital and to measure increases in capital. However, the measurement of the value of capital was a problem. Capital is heterogeneous and capital goods cannot simply be added up. Therefore the value of heterogeneous capital goods had to be expressed in money value, which then could be added. This would enable comparing capital of one country to capital in another, and if the countries had differential growth rates, the effect of capital of on growth could then be estimated. In addition it would enable figuring out the influence of increasing capital on economic growth within a country by relating the increase of capital in a certain period to the growth rate in that period.

However, how to determine the money value of capital goods? There are basically two ways. One way is to look at the cost of making or buying them and take this as the money value. But is the money value given by book value (historical price) or rather by replacement cost (current price); and what about inflation? In fact, the real value of a machine does not lie in its cost price, but rather in its effects on increasing outputs over time, and its value should be the present discounted value of future profits. In a perfect market this would be reflected in the price, but in a real economy this is not necessarily the case. More fundamentally even, if the increase of capital is related to the growth of output (economic growth), while the value of capital is also defined in terms of its contribution to output, the result is an analytical

observations and disregarding or moulding observations that do not fit, until it has become abundantly clear that they cannot accommodate new observations anymore in a meaningful sufficiently parsimonious way.

54 See for example Fisher (1896), Patten (1889), Clark (1888), Bohm-Bawerk (1891).

55 Among economists such as Knight, Hayek and Kaldor.

56 The Cambridge controversies consisted of a strong disagreement between protagonists associates with Cambridge, England, and Cambridge, Massachusetts. Prominent protagonists were Sraffa, Robinson, Pasinetti and Garegnani in the "English corner", versus Samuelson, Solow, Hahn and Bliss in the "American corner." The battle was fought via first rank journals such as the Quarterly Journal of Economics, the Review of Economic Studies and the Economic Journal (see Coen and Harcourt (2003) for a detailed overview). 
circularity, and any conclusion based on circular assumptions is scientifically suspect or even meaningless, and leads to all kinds of anomalies. ${ }^{57}$ This is what was put forward by economists from Cambridge, England, and which was denied by economists from Cambridge, Massachusetts.

On the one hand, much of the debate was esoteric and mathematical, while on the other hand part of it was ideological. ${ }^{58}$ This combination did not help to arrive at a clear discussion and even less to some sort of consensus. The resolution of the debate, particularly how broad its implications are, is still not agreed upon by economists. Cambridge England pointed out a serious analytical weakness but could not offer an alternative, and Cambridge Massachusetts seems to have chosen to ignore it, although (or because?) it seemed to sweep away the analytical basis of their research.

Cohen and Harcourt (2003) point out that today these issues about anomalies involving the measurement of capital in aggregate production function models are seen as a 'tempest in a teapot', with no real significance.

With the introduction of endogenous growth theories, the problem of circularity became less serious. Contributors to the new theories of endogenous growth and business cycles, taking off in the 1980s, using aggregate production functions, hardly mentioned the issue at all. This seems to be out of convenience rather than out of scientific clarity about the issue. Macroeconomics textbooks discuss 'capital' as if it were a well-defined concept - which it is not, except in a very special one-capital-good world (or under other unrealistically restrictive conditions). The measurement of physical capital and its effect on output remains problematic. Summarizing, it can be concluded that "capital" is a contentious and possibly incoherent concept, but it nevertheless is widely used and widely considered useful.

\subsubsection{The introduction of human capital}

The Industrial Revolution changed the economy; machines needed to be accounted for in economic theory in some way, and the capital concept seemed most fit for this. As the

\footnotetext{
${ }^{57}$ For example, according to neoclassical production theory, an increase in the amount of capital employed should cause a fall in the rate of profit (following diminishing returns). Sraffa instead showed that a change in the rate of profit would change the measured amount of capital, and in highly nonlinear ways: an increase in the rate of profit might initially increase the perceived value of a capital good, but then reverse the effect at still higher rates of profit (a phenomenon called 'reswitching'). The analysis further implies that a more intensive use of a factor of production, including other factors than capital, may be associated with a higher, not lower, price of that factor. According to the Cambridge, England, critics, this analysis is thus a serious challenge, particularly in factor markets, to the neoclassical vision of prices as scarcity indices and the principle of substitution they claim underlies the neoclassical theory of supply and demand. Lavoie (2000) and Gehrke and Lager (2000) point out that the capital controversy brought to light fundamental flaws in neo-classical growth theory (the assumption that heterogeneous capital goods can be added by taking their monetary value, the assumption that the price of capital goods reflects their marginal profit, the assumption that economies tend towards equilibrium), and that many other assumptions, models and analyses which are based on these flaws are thus also flawed.

58 The Cambridge, England economists pointed out that the rate of profit is not a price, and it isn't clear that it is determined in a market. In particular, it, at best, only partially reflects the scarcity of the means of production relative to their demand. While the prices of different types of means of production are indeed prices, the rate of profit can be seen as reflecting all kinds of other factors including the social and economic power that owning the means of production gives this minority to exploit the majority of workers and to receive profit. This gave the controversy an ideological dimension that did not help to resolve the issue.
} 
economy changed further, also the discipline of economics evolved, searching for better explanations of economic phenomena such as (differences in) economic growth. In this process, new factors were taken into account, and the capital concept was expanded further to include factors other then material means of production; most notably human capital and social capital.

In the 1960s, economists got renewed interest in the quality of human labour (e.g. knowledge, skills) rather than merely the quantity. As early as the $18^{\text {th }}$ century it was recognized that the knowledge and skills of human workers had value. ${ }^{59}$ Though some economists thought that in principle it should be included as a form of capital, ${ }^{60}$ many others felt it should not, because it would complicate analysis ${ }^{61}$ and because it seemed morally dubious. ${ }^{62}$ However, in the 1960 s the issue came back, with the work of, among others,

59 Adam Smith (1776) already put forward the question whether "the acquired and useful abilities of all the inhabitants or members of society" are capital, on the ground that "the acquisition of such talents ... always costs a real expense, which is a capital fixed and realized, as it were, in his [the labourer's] person" (vol. I book II, chap.1). However the concept of capital remained limited. As Patten (1889) observes: "since Adam Smith, the labour expended to elevate and educate the labourer himself is denied to be capital. But this is without good reason, and important truths are thus overlooked and neglected. Labour expended beforehand on the labourers will increase the produce of industry just as much as the labour expended in making machines or improving the land. There is no reason why one should be capital and the other not." J.B. Say and John Stuart Mill also argued that the labourer himself is an investment of capital. Walsh (1935) observed that "in all essential respects, the investments made in professional abilities and material capital act in the same way. Within this range the capital theory fittingly applies to men."(p.285).

${ }^{60}$ E.g. Weisbrod (1966): "Capital may exist in intangible form, as well as in the tangible, traditional forms of factories and machines. Intangible capital may be embodied in people - in labour resources. This would constitute a hybrid class of productive resources - a combination of labour and capital which might be called 'human capital'."

${ }^{61}$ Schultz (1961) stated that: " [] t has been all too convenient in marginal productivity analysis to treat labour as if it were a unique bundle of innate abilities that are wholly free of capital." Letting go of this assumption would add a lot of complexity and would reduce the status of work already done.

${ }^{62}$ Schultz (1961) describes some of these moral concerns: "No doubt there are reasons for being wary. Deepseated moral and philosophical issues are ever present. Free men are first and foremost the end to be served by economic endeavour, they are not property or marketable assets.[...] The mere thought of investment in human beings is offensive to some among us. Our values and beliefs inhibit us from looking upon human beings as capital goods, except in slavery, and this we abhor. We are not unaffected by the long struggle to rid society of indentured service and to evolve political and legal institutions to keep men free from bondage. These are achievements we prize highly. Hence, to treat human beings as wealth that can be augmented by investment runs counter to deeply held values. It seems to reduce man once again to a mere material component, to something akin to property. And for man to look upon himself as a capital good, even if it did not impair his freedom, may seem to debase him." However, at the same time some economists defended the use of the term human capital on moral grounds. For example, Von Thunen (1875, in Kiker 1969) argued that the concept of capital applied to man did not degrade him or impair his freedom and dignity, but on the contrary that the failure to apply the concept was especially pernicious, for example in wars; "for here [...] one will sacrifice in a battle a hundred human beings in the prime of their lives without thought in order to save one gun". The reason is that "[...] the purchase of a cannon causes an outlay of public funds, whereas human beings are to be had for nothing by means of a mere conscription decree." Weisbrod (1966): "Some readers may feel that health and education policies are moral issues that should not be subjected to the cold scrutiny of an economist. But surely one need not choose between an economist's view and a philosopher's view of wise public health and education policies. Both are relevant. [...] Returns in the form of enhanced productivity are relevant for wise policy-making. But so are non-economic considerations." Schultz (1961) saw an additional positive effect; with human capital becoming more important, every person now owned his own means of production: "By investing in themselves, people can enlarge the range of choice available to them. It is one way free men can enhance their welfare. [...] Labourers have become capitalists not from a diffusion of the ownership of corporation stocks, as folklore would have it, but from the acquisition of knowledge and skill that have economic values. This knowledge and skill are in great part the product of investment and combined with 
Schultz (1961) and Becker (1962). In this period, two major economic puzzles were combined into one solution. Solow (1956) had found that no less than $88 \%$ of economic growth was residual, in other words, could not be explained by the traditional production factors such as land, labour and physical capital goods (more on this in section 4.4). At the same time, economists were trying to explain the increased expenditure on education. Putting the problem of the residual and the discussion of education expenditure together, it was proposed that the stock of capital may have grown faster than thought, because in fact the increased knowledge and skills of the labour force reflect an increase in a special form of capital embodied in persons: human capital. ${ }^{63}$ This additional increase in capital was held to be (part of) the explanation of the unexplained economic growth. The production factor labour remained what it was, a quantitative measure of input by workers (determining the number of units of work), and the quality of this input was given by the level of human capital (determining the value of production per unit of work). This was not self-evident at the time, and economists shied away from taking human capital into their analyses. ${ }^{64}$

The term 'human capital' had many conceptual difficulties and unclarities. ${ }^{65}$ For example, it was considered a major problem that it is hard to distinguish between investment and consumption when education is concerned since people also value knowledge and skills in themselves. For investment, only that part counts that has economic value, but since it is hard to separate this some economists proposed to measure the investment in human capital by looking at its returns, measured in terms of increased income. ${ }^{66}$ Similarly to the capital controversy about physical capital, this introduces an analytical circularity in terms of the valuation of education in terms of its impact on output.

other human investment predominantly account for the productive superiority of the technically advanced countries."

${ }^{63}$ Schultz (1961): "Although it is obvious that people acquire useful skills and knowledge, it is not obvious that these skills and knowledge are a form of capital, that this capital is in substantial part a product of deliberate investment, that it has grown in Western societies at a much faster rate than conventional (nonhuman) capital, and that its growth may well be the most distinctive feature of the economic system. It has been widely observed that increases in national output have been large compared with the increases of land, man-hours, and physical reproducible capital. Investment in human capital is probably the major explanation for this difference."

${ }^{64}$ Gary Becker about this, in his Nobel lecture in 1993: "Human capital is so uncontroversial nowadays that it may be difficult to appreciate the hostility in the 1950s and 1960s toward the approach that went with the term. The very concept of human capital was alleged to be demeaning because it treated people as machines. To approach schooling as an investment rather than a cultural experience was considered unfeeling and extremely narrow. As a result, I hesitated a long time before deciding to call my book Human Capital (1964) and hedged the risk by using a long subtitle that I no longer remember. Only gradually did economists, let alone others, accept the concept of human capital as a valuable tool in the analysis of various economic and social issues." (Becker 1993). Schultz (1961), at the time: "What economists have not stressed is the simple truth that people invest in themselves and that these investments are very large. Although economists are seldom timid in entering on abstract analysis and are often proud of being impractical, they have not been bold in coming to grips with this form of investment. Whenever they come even close, they proceed gingerly as if they were stepping into deep water."

${ }^{65}$ Schultz (1961) states: "What are human investments? Can they be distinguished from consumption? Is it at all feasible to identify and measure them? What do they contribute to income? Granted that they seem amorphous compared to brick and mortar, and hard to get at compared to the investment accounts of corporations, they assuredly are not a fragment; they are rather like the contents of Pandora's box, full of difficulties and hope."

66 Schultz (1961) states: "For human capital there is an additional problem that is less pressing for physical capital goods: how to distinguish between expenditures for consumption and for investment. This distinction bristles with both conceptual and practical difficulties." 
In spite of the problematic sides of the concept of human capital, it was taken into use in economics in the 1960s to describe a factor that was highly relevant in economics, but which did not yet have a (proper) place in economic theory. The term human capital was useful in capturing this factor. Its acceptance was however not certain in the early years. ${ }^{67}$ It was and still is a troubled concept with analytical difficulties, but it nevertheless inspired fruitful new lines of research, and gave input to successful new policy.

\subsubsection{The introduction of social capital}

In the 1980s and 1990s, there was growing interest in yet other sources of productive value. Historical economic research suggested that differences in economic growth could be explained by differences in the density and quality of social relations in a population. ${ }^{68}$ It was found that social relations, and a more generalized variable, trust, had productive economic value, through reducing transaction costs and positive spill-overs. To capture the influence of social relations on output, again the concept of capital was used: social capital. ${ }^{69}$ The introduction of the concept of social capital led to a growing body of research confirming the importance of relations and more detailed insights for example on the differential impact of strong ties and weak ties. ${ }^{70}$

However, in spite of its success in pointing out the economic importance of social relationships, the use of the concept of social capital was and still is not unproblematic. Its definition is still not clear and agreed upon ${ }^{71}$ some branches of economists find it difficult to accept the concept, ${ }^{72}$ and it suffers from similar problems as physical and human capital,

\footnotetext{
${ }^{67}$ Becker (1962) at the time when human capital still had to prove its usefulness: "This new faith in human capital has reshaped the way governments approach the problem of stimulating growth and productivity." [...] "The next few years should provide much stronger evidence on whether the recent emphasis placed on this concept is just another fad or a development of great and lasting importance."

${ }^{68}$ E.g. Putnam et al. (1993) investigated the success of northern Italy relative to Southern Italy, and attributed it to different social structures, tracing these back to the twelfth century.

${ }^{69}$ There are many definitions of social capital. The sociologist Pierre Bourdieu (1986) described it as follows: "Social capital is an attribute of an individual in a social context. One can acquire social capital through purposeful actions and can transform social capital into conventional economic gains."

70 Economists find the social capital metaphor useful in studies of economic development, transition economies, common resource property use, and education (Sobel 2002). For an example of research on the effects of social capital on economic growth, see Akcomak and Ter Weel (2006).

71 An important source for witnessing the development and problems of the concept of social capital is a voluminous publication of the World Bank, edited by Dasgupta and Serageldin (1999). Sobel (2002) about this large volume: "In the thirteen articles that follow, at least nine contain extended discussion of what social capital means. [...] One would have liked the editors to include a clear definition of the concept in the introduction of the book, and eliminated the need to define social capital repeatedly in the contributions. But this would have been impossible. No one could dispute that social capital is multifaceted. Authors recognize that if they are going to use the term then they must define how they will use it."

72 The World Bank publication starts with two short articles by Kenneth Arrow (Arrow 1999) and Robert Solow (Solow 1999). They argue, in Solow's words, that social capital is "an attempt to gain conviction from a bad analogy." Arrow argues that social capital generally does not require conscious deliberate material sacrifice and thus cannot be seen as a form of capital. Arrow was referring to aspects of social capital that are acquired without calculation or sacrifice. Children learn their first language without calculation; people are born into nobility and ethnicity; and it is a stretch to view social capital derived from childhood friendships as a product of conscious calculation (Sobel 2002).
} 
such as the circularity of its definition. ${ }^{73}$ Also, like human capital social capital has some special features that, in the beginning, economists in found hard to accommodate in their theoretical framework, such as the fact that human and social capital tend to increase with use rather than decrease. ${ }^{74}$ It was argued that it was not clear how social capital exactly contributed to economic growth, even though there still was a large residual to explain. ${ }^{75}$ And last but not least, the term 'capital' suggests that strong social relations are valuable and "good", 76 but that is not necessarily the case; for example gangs in ghettos or the Italian Mafia often have high levels of social capital.

All these elements have led to understandably sceptical reactions concerning the scientific value and justification of the concept of capital. ${ }^{77}$ However, in the case of human capital and social capital, the fruitful research deriving from the introduction of these concepts justifies their existence. ${ }^{78}$ And as we have seen earlier in this section, the most widely accepted form of capital, physical capital, is itself fundamentally problematic but has been accepted after decades of debate. ${ }^{79}$

\subsubsection{New reality, new concepts?}

The introduction and use of human capital and social capital have deepened the insight of economists into the economy, including the insight in the workings of physical capital itself.

\footnotetext{
73 Some authors, e.g. Coleman and Putnam, at times seem to equate the existence of social capital with outcomes obtained using social capital. As Sobel (2002), Portes (1998) and Durlauf (1999) observe, this equations leads to circular arguments: a successful group succeeded because it has social capital, but the evidence that the group has social capital is its success. Authors such as Durlauf (1999) try to reject the use of the concept of mental capital because its definition is too vague to operationalize and it would lack sufficient explanatory power.

${ }^{74}$ E.g. Ostrom (1999) points out that social capital need not depreciate with use the way physical capital does. In important instances, making use of social capital increases the stock of social capital available for future use. ${ }^{75}$ Dasgupta (1999) suggests that social capital influences growth through directly enhancing factor productivity, and discusses the measurement problems of social capital.

76 Sobel (2002) observes that there is a normative element in the social capital literature: "[D]eveloping social capital is good not only because it is associated with good economic performance. It is valuable intrinsically. If extensive use of community ties leads to the same economic performance as, say, strong legal rules, then society would be better off if the outcome came about through social networks."

77 Authors such as Arrow and Solow, not the least, convincingly point out the weaknesses of the analogy between physical capital and social capital. However, authors such as Coleman (1988), Glaeser et al. (2000) and Stiglitz (1999) are a convincing in highlighting the strengths of the analogy. Scholars trying to avoid the term social capital entirely are missing out on having a powerful label for the elements they discuss and investigate in their work.

78 Sobel (2002) argues that the topics gathered under the social capital umbrella are worthy of study, and application of economic principles can provide important insights, thus justifying the use of the term: "A vague keyword is not sufficient reason to condemn a promising line of research" (Sobel 2002). Dasgupta (1999, p.398) concludes: "Social capital is useful insofar as it draws our attention to those particular institutions serving economic life that might otherwise go unnoted."

79 As was mentioned before, in addition to social capital and human capital, a flood of other 'capitals' have been put forward in the last decades: cultural capital (e.g. Bourdieu 1987; Holt 1998), health capital (Grossman 1972), organizational capital (e.g. Gort et al. 1985; Tomer 1987; Brynjolfsson et al. 2002; Bounfour 2007), intellectual capital (e.g. Nahapiet and Goshal 1998; Stewart 1998), emotional capital (Thomson 2000), psychological capital (Luthans et al. 2006), motivational capital (Akerlof and Kranton 2005) can be found in the research literature. However, the use of the term 'capital' often does not signify more than merely the observation that certain factors have economic value, and there are few serious analytical attempts to investigate the value of the capital concept for the elements they refer to; nor is there substantial empirical research that uses these concepts.
} 
Applying the capital concept outside of its original meaning has proved to be fruitful rather than harmful. Concepts are cognitive tools to capture and organize observations of reality. If reality changes, concepts are stretched, and often get changed in the process in order to accommodate the observations of this changing reality. When a change is of a certain order, an explicit discussion about concepts arises. ${ }^{80}$ As this section showed, this has happened several times in the history of economics - changes in the economy demanded changes in the way we think about core elements of economics, including the concept of capital. When appropriate, new capital concepts appeared, and proved their worth over time (or not), by the usefulness of their applications. It is generally acknowledged that in the past decades, the economy has changed quite dramatically, not in the last place because of the rapid development and spread of ICT. In Chapter 2, the changes in the sphere of work were discussed, indicating the importance of mental health (often by pointing at the growing consequences of the lack of it). These changes have created the need for finding a way to capture intangible factors of increasing economic value such as agency, and perhaps the concept of mental capital can do the job here.

What do we learn from these capital controversies? First, it has become clear that even the most traditional concept of capital has serious analytical and conceptual problems, in terms of definition, measurement and effects. Using the concept of capital for physical means of production such as machines has nevertheless proved to be useful for economic research, and has lead to valuable new insights and useful new policy. While lack of clarity of the capital concept generally is not a reason to accept mental capital as a concept, it does imply that difficulty defining mental capital precisely is not a reason a priori to reject it. In economics, unclear concepts have proven useful and durable.

Second, it has become clear that as economic reality changes (for example, the growth of the importance of machines in production due to the Industrial Revolution, the lack of equilibrium during the Great Depression, the lack of convergence in the post-war period, the rise of the knowledge economy and the service economy, the changed nature of work), theory has to follow and accommodate these changes, and sometimes new concepts need to be developed to capture and express the significance of these changes.

\subsubsection{Mental capital and economic theory}

What justifies the introduction of a new concept? First, a concept is useful if it organizes a large body of knowledge in a meaningful way. Second, a concept is useful if it helps to increase our understanding of phenomena in reality and if it inspires new lines of research that can further increase this understanding, resulting in more and better insight and a better basis for intervention through policy-making.

As we have seen in the sections above, the concept of capital is effective in organizing the relevant knowledge that we presently have about the economic aspects of mental health, capturing a large and rather heterogeneous body of knowledge from other disciplines (psychology, psychiatry, neuroscience), integrating this knowledge and bringing out the

${ }^{80}$ For a discussion of this phenomenon, see publications on history and philosophy of science, e.g. Kuhn (1962), Galison (2005). 
economic dimension of this knowledge. Whether the concept is useful for 'importing' this knowledge into economic analyses is a next question.

In this section, we will show how the factors labelled as mental capital are related to four important branches of economic research: growth theory (4.4.1), human capital theory (4.4.2), bounded rationality (4.4.3.) and utility (4.4.4). We will show that it helps to explain issues that are subject of investigation in these particular branches of research, and that it gives rise to ideas for new directions of research for giving better answers to these old questions. In addition, we will discuss how introducing the term mental capital could affect research programming and policy-making (4.4.5).

\subsection{Mental capital and economic growth theory}

Growth accounting is a set of theories used in economics to explain economic growth. The total national income in an economy is explained by various factors, traditionally the total stock of capital (e.g. buildings and machinery) available, the size of the labour force, and the technology available (e.g., production and management techniques). An increase in national income must in this view be explained by an increase in the capital, an increase in the labour force, or an improvement in the technology used. How does mental capital fit into growth theories? A brief discussion about the development of growth theories will help to clarify this.

\subsubsection{The puzzle of economic growth}

Ever since Adam Smith's 'Wealth of Nations', the question of what determines economic growth, and how to explain differences in economic growth between countries and over time, has been in the centre of interest of economics. Since the 1950s, many economists undertook comparative studies of economic growth. Some said that the path to long-term growth was achieved through investment in industry and infrastructure, and in moving further and further into capital-intensive automated production. From this point of view, promoting physical capital accumulation should be a primary long-term aim of government economic policy.

Crucially, Robert Solow (1956) found that in the U.S. in the first half of the $20^{\text {th }}$ century, only $12 \%$ of economic growth could be explained by factor accumulation, leaving $88 \%$ basically unexplained - at least when limiting oneself to only the traditional production factors. ${ }^{81}$ This unexplained part of economic growth is called the "Solow residual" and is

\footnotetext{
${ }^{81}$ Solow was not the first to point out the existence of an unexplained residual. For example, Goode (1959) observed: "It is significant, nevertheless, that the growth of output in advanced economies cannot be fully explained by increased inputs of physical capital and labour. For example, the proportion of increased output attributable to measured increases in the amount of labour and physical capital employed has been estimated at 50 to 60 per cent in the four largest industrial countries (France, Germany, the United Kingdom and the United States) during the forty years prior to World War I and at only about 30 per cent in the United States over the period 1869-78 to 1944-53. Technological advance no doubt contributed greatly to the growth of output. Another consideration is the possibility that the available statistics greatly understate capital formation because they omit human capital" (pp 148-149). Abramovitz (1956) calls attention to the "chronic
} 
thought measure changes in "total factor productivity". This is normally taken as a measure of the value of technological change. Solow defined rising productivity as rising output with constant capital and labour input. This rising output was taken to be the result of changes in the level of technology: the same level of capital goods (in terms of money value) could nevertheless have more impact on labour productivity, because of the (technological) quality of the capital goods.

This suggested that total factor productivity was the long-run determinant of national growth, and that only under-capitalized countries could increase per-capita income substantially by investing in physical capital and infrastructure. Physical capital is needed to increase total factor productivity, but it only had a beneficial effect in combination with a number of other factors such as technology, economic institutions, and human capital. Solow concludes that the equilibrium rate of growth of output per unit of labour input depends almost entirely on the rate of technological progress "in the broadest sense."

\subsubsection{The resistant residual}

Denison (1962) unpacked "technical progress in the broadest sense" into a number of constituents of which various human capital variables and "technological change in the narrow sense" are the most important. Taking the period from 1929 to 1982 and smoothing away the business cycle, he finds that the real output increased at an average rate of 3.1 percent a year. Denison estimated that a quarter of it can be attributed to increased labour input of constant educational level. Another 16 percent (i.e. about $1 / 2$ percent a year) is credited to the increased educational qualifications of the average worker. The growth of capital in the traditional sense of the word (e.g. machines) accounts for 12 percent of the growth of output (almost exactly Solow's 1957 result). Denison imputes 11 percent of total growth to "improved allocation of resources" (e.g. the movement of labour from lowproductivity agriculture to higher productivity industry). Another 11 percent is attributed to "economies of scale". But still, $34 \%$ of recorded growth is left unaccounted for, and so is credited to "the growth of knowledge".

To what extent such seemingly precise percentages as given by Denison are meaningful is a question, ${ }^{82}$ but the exercise helped to get a more sophisticated view regarding possible determinants of economic growth and their relative shares. Solow distinguished only three factors: straight labour, straight capital, and residual "technical change"; Denison decomposes the residual into five components. Of these two categories are especially relevant for this thesis. The first is the "improved allocation of resources". Chapter 2 has shown that personal agency has increased considerably in a highly individualized posttraditional society, and that this is very important for the self-allocating capacity of the labour force. Rather than tradition, talent and motivation determine the choice of work much more than in the past, and in combination with increased flexibility within jobs and on the labour market, this leads to a more optimal allocation of people over jobs, and fits

understatement of investment" because of the omission of expenditures for health, education and training, and research" (pp 12-13).

82 Solow (1987) in his Nobel Prize Lecture about Denison's findings: "One does not have to believe in the accuracy of these numbers; the message they transmit is pretty clear anyway." 
naturally with Denison's “improved allocation of resources”. There is a second, similar, way in which agency can enter, namely allocation within jobs. Efficient allocation involves not only matching people (skills, talent, aptitudes) with jobs having the right characteristics, it also involves allocation of efforts across tasks within jobs. Here the discussion of earlier chapters becomes relevant. Technical changes that demand more intra-job allocation skills will only produce growth when those skills are available. In addition to growth in education, growth in agency in the way described above improves the quality of the labour force, and could, in principle, be part of yet more complete growth accounting. On the other side, though, self-allocating and flexibility are far from effortless: as we saw in chapter 2 it comes at a price of uncertainty, risk, stress and possibly mental health problems. More mental capital means an increase in the self-regulatory powers of workers and thus an increase in the efficiency and effectiveness of their mental effort, so that further improvement of the allocation of human resources is possible, and at a lower (mental) cost.

The second category of interest here is the "growth of knowledge". Generally this is taken to refer to technological progress in the narrow sense of improved machinery or physical capital (Solow 1987), but Solow points out that it should be interpreted more broadly than that. Denison captures some of this broadness by including educational qualifications of the labour force: increases in amounts, and changes in qualities of what people learn in school contribute to growth, and this is measurable in a concrete way. However, especially in the services sector, "social technology" and "social innovation" generally are more important than material technology. Moreover, since workers have to be flexible, adaptive and selfallocating their "mental technology" has become more important: conscious control over one's thoughts, feelings and behaviour; better cognitive, social and emotional skills; more agency. Concerns about education and economic growth today are often directed at the perceived shortage of students taking engineering and science. Doubtless these remain important; however the changes in the nature of work discussed in previous chapters imply that other knowledge is important: for example, self-knowledge. In addition, this means that not only natural sciences but also social and behavioural sciences are important as source of knowledge for innovation.

Two more brief comments about growth accounting may be suggestive of areas deserving further exploration. First, countries with high economic growth rates tend to have a rapid turn-over in technologies as they accumulate capital. It has been suggested that this will tend to make it harder to gain experience with the available technologies, resulting in a smaller Solow residual. The ability of the labour force to adapt will determine the extent to which rapid innovation and technological change will effectively increase labour productivity. Agency is a measure of the degree to which a worker can adapt to new circumstances and can deal with new tasks, flexibility and uncertainty; thus mental capital may be an essential element to get an optimal mix of production factors. A corollary of this discussion relates to the tension between static and dynamic efficiency. Dynamic efficiency is about rapid innovation and change, resulting in high growth rates. Static efficiency is about allocation of resources to achieve a given end. Stability facilitates this process, and rapid changes due to continual innovation make it difficult to achieve, partly because it involves movements of labour from job to job or task to task. Increases in agency, of the sort discussed in Chapter 3 can ease this tension. If workers are better able to self-allocate and regulate, changes due to innovation are less disruptive, and the re-allocation of resources is facilitated. 
Second, Solow residuals are variable. For example mass-produced traded goods seem to have a higher residual than does the service sector. This may create a 'drag' on the overall residual as more effort is moved into services industries precisely because they have low productivity growth (being harder to automate). Material technology matters less in the services industry, and productivity growth in services is thus relatively more dependent on social technology (e.g. organizational innovation, new management techniques) which are notoriously hard to capture quantitatively. This thesis suggests that in addition, productivity growth in the services is dependent on the increased efficiency and effectiveness of the application of cognitive, social and psychological skills at the individual level; and it is agency or mental capital which determines how effectively these can be put to work.

\subsubsection{Endogenous growth theory}

In neoclassical growth models, the long-run rate of growth is exogenously determined, generally by an assumed rate of technological progress and an assumed rate of labour force growth. This does not explain the origin of growth. Endogenous growth theorists such as Romer $(1986,1989)$ see this as an over-simplification. Endogenous growth theory attempts to endogenize the growth rate as a way to explain the non-convergence of rich and poor countries. Several competing models have been developed, but central importance is usually given to the production of new technologies and human capital. Firms and individuals have an incentive to innovate in order to exploit an advantage over their competitors. Some of the knowledge associated with the innovation "spills over" to other economic actors, which increases those actors' ability to innovate. Through this mechanism a virtuous cycle arises.

This thesis proposes that an important factor determining the speed of technological innovation (especially absorption and diffusion) and of the accumulation of human capital are to an important extent determined by the level of agency of workers, since this is what determines their ability to deal with novelty and to be adaptive, flexible, self-regulating and self-allocating. It is argued that the 'absorptive capacity' of a country of new technology and of additional physical and human capital is crucially dependent on the level of agency of the labour force in that country. ${ }^{83}$

This gives a new dimension to questions of economic growth, and the differences in economic growth and economic development between countries, the lack of convergence. For example, it might help explain the 'poverty-security trap' in which a number of developing countries are locked in. ${ }^{84}$ These countries are characterized by poverty and

\footnotetext{
${ }^{83}$ A specific example of research showing that the diffusion and absorption of technology depends on agency (as operationalized by the construct of self-efficacy) is Hill et al. (1987). The extensive discussion of research findings on the importance of agency for productive adaptive behavior especially when dealing with novelty in section 3.5 indicates the importance of agency for innovation.

${ }^{84}$ E.g. Baingana et al. (2005) in a report for the World Bank, observe that poverty is both a cause and a consequence of conflict, and argue that mental health is a critical variabe in this spiral: "A growing body of research and experience $[\ldots]$ has shown that individuals and communities traumatized by conflict and displacement, experience lasting mental health and psychosocial disorders and they do not easily revert to normal once the violence ends. As a result there is increasing recognition that addressing mental health and psychosocial needs in conflict and post-conflict situations is critical for reducing the likelihood of future conflicts and ensuring effective and sustainable reconstruction." (p.1).
} 
violent conflict, two enormous stressors that affect the mental health and the level of agency of the population dramatically. Both poverty and conflict teaches the average person that his fate is not in his own hands, and this reduces the sense of agency of a person. ${ }^{85}$ The world is a place where things happen to them, rather than a place that they control. While people in conflict countries become very good and creative at surviving, the psychological profile that goes well with a survival mode of being does not combine well with a development mode of being. Development means investing; taking risks, having trust and confidence that others will be reliable and that investments and efforts will pay off. People in conflict countries have learned that this is not the case, and their individual agency and collective absorptive capacity will be reduced, diminishing the effectiveness of developmental assistance and hampering economic development and growth.

Increasingly it has become clear that it is the mix of production factors and the nature of their relationship what matters, requiring a much more micro-account about the determinants of economic growth. This thesis suggests that mental capital, the degree of agency of a person is a crucial element of the mix of production factors. The 'absorptive capacity' of a worker (absorbing new knowledge, dealing with change and the accompanying insecurity, adapting to new circumstances) is an essential complement to the other production factors such as technological change and human capital accumulation. It codetermines the extent to which these factors effectively lead to an increase in labour productivity.

\subsection{Mental capital and human capital theory}

As was briefly described in section 4.3.2, in the 1960s economists realized that for economic growth, it is not only the quantity of labour that matters but also the quality. The quantity of labour was given by the classic production factor 'labour', and the quality of labour was captured by 'human capital'.

In this section, we will argue that important elements constituting agency (vigour, adaptive ability, creativity, confidence, self-efficacy, self-esteem) were originally seen as part of human capital but fell overboard over the years as human capital was increasingly quantified and formalized. One reason for this narrowing down was that human capital was too broadly defined to be analytically useful. As long as years of education are easier to measure and compare than, say, mental health status or stress levels, the latter will not make it into economic analyses via the human capital concept, in spite of their economic importance.

The concept of mental capital can help to open promising lines of research, similarly to the human capital concept has done. ${ }^{86}$ To label agency as 'mental capital' rather than folding

\footnotetext{
85 This is related to the phenomenon of 'learned helplessness' by Seligman (1975).

${ }^{86}$ Becker observed this in 1962 when explaining why human capital was so important and should be included in economic theory. He argued that human capital could help to understand economic phenomena that up till then were ignored because they did not fit in existing theoretical frameworks. For example, Becker (1962) discusses the phenomenon of turnover: "In the usual analysis of competitive firms, wages equal marginal product, and since wages and marginal products are assumed to be the same in many firms, no one suffers from turnover. It would not matter whether a firm's labour force always contained the same persons or a
} 
them into human capital is not only an analytical trick. Mental capital is similar to human capital in many respects, but in important respects it behaves quite differently (for example because of the feedback loops discussed in chapter 3) - differently enough to justify keeping separate from human capital.

The next question is then, if we choose not to see mental capital as a part of human capital, is how it relates to human capital. We will argue that mental capital plays an important role in the formation and effective use of human capital. In analogy to the "complementarity hypothesis" (e.g. Griliches 1969, or Layard, 1975), in which human capital is perceived as complementary to physical capital, we will argue that mental capital is complementary to human capital. It determines the formation, optimal allocation and effective use of human capital. A high level of human capital with a low level of mental capital will not have much productive effect, just as a high level of physical capital does not have much effect without the necessary human capital to operate it and thereby realize its productive potential.

Finally, one of the main arguments used for the acceptance of the concept of human capital was that it helped to explain economic phenomena that until then did not have good (if any) explanation. At the end of this section we will show that mental capital can do the same; that it inspires different, useful explanations for the same phenomena that human capital has tried to explain.

\subsubsection{The narrowing of the buman capital concept}

At its inception, human capital was supposed to cover anything tied to human beings that had economic value (Becker 1962). However, this was such a broad and undefined category, that Schultz (1961) even compared it to "the contents of Pandora's box". The broadness and undefinedness of the concept quickly led to an understandable but rather drastic simplification of it in use. Already in the 1960s human capital was effectively reduced to education, which was easy to measure and to translate into (opportunity) costs, and to onthe-job training, for which years employed was generally used as a rather crude proxy.

What got lost on the way during the narrowing of the human capital concept? Schultz (1961) pointed out that health is an important element of human capital and that this is not only determining the quantity of labour but also the quality. ${ }^{87}$ Consequently, Schultz included

rapidly changing group. Any person leaving one firm could do equally well in other firms, and his employer would replace him without any change in profits. In other words, turnover is ignored in traditional theory because it plays no important role within the framework of theory." But obviously turnover is an important and costly problem for firms in reality. Becker argued that human capital, especially when firm-specific, could explain these costs. Human capital as a concept was defended and accepted because it helped to better explain economic phenomena.

${ }^{87}$ Schultz (1961): "Health activities have both quantity and quality implications. Such speculation as economists have engaged in about the effects of improvement in health, has been predominantly in connection with population growth, which is to say with quantity. But surely health measures also enhance the quality of human resources." Also Weisbrod (1966) pointed at the quality aspect of health: "A healthier worker is a more productive worker - absent less from the job and more productive and creative while on it." He referred to the impact of health on happiness and efficiency on the job: "Thus whereas we have traditionally referred to expenditures on health, we now must recognize that a substantial fraction of those expenditures are truly investments - in increased longevity and lifetime labour productivity, as well as in increased human happiness 
elements such as "stamina", vigour" and "vitality" in the description of health as a part of human capital. The human capital concept proposed by Becker in 1962 was also envisioned broadly; including, among other things, "emotional health." importance of "personality" and "persistence," characteristics again associated with agency. However from the beginning the emphasis was on education and on-the-job training, probably because that seemed the more compelling insight at the time given the rapid increase of skill and knowledge requirements due to technological change, and given the extent to which science had captured the general imagination as the key to future prosperity. In the process of developing more quantitative analyses a lot of the content of human capital got lost in attempts to find quantifiable and measurable concepts: years of education and years of work experience are easier to measure and to compare, and thus more attractive for modelling.

It seems that within the concept of human capital, some sort 'residual category' came into existence, which is referred to in a variety of terms such as "economic talent", "persistence", "personality" and "vigour". Excluding them from analysis or measurement is relatively innocuous if they are given and unchanging. However, as chapter 3 has shown, is this is not the case. These factors are elements of agency, and it was shown that agency is to a considerable extent produced. While difficulties of measurement and analytical complexity ensure that there will always be some residual categories, it would be valuable to move beyond the situation in which we rest with some crude measures of education, knowledge and health, since the "residual" aspects, such as talent or persistence are growing in importance.

and decreased suffering. [...] [] t takes no account of either premature deaths of the debilitating effects of illness and accidents for those who remain on the job, but with impaired efficiency."

${ }^{88}$ Becker (1962) states: "One way to invest in human capital is to improve emotional and physical health. In Western countries today earnings are much more closely geared to knowledge than to strength, but in an earlier day, and elsewhere still, strength had a significant influence on earnings. Moreover, emotional health increasingly is considered an important determinant of earnings in all parts of the world. [...] [A]n improvement in working conditions - higher wages, coffee breaks, and so on - might affect morale and productivity." These ideas however never gained much research attention, the research on human capital is almost completely dominated by education and on the job training.

89 When introducing the concept of human capital, Becker and others were aware that conventional measures of ability - intelligence tests or aptitude scores, school grades, and personality tests - while undoubtedly relevant at times, do not reliably measure the talents required to succeed in the economic sphere. The latter require a particular kind of personality, persistence and intelligence (Becker 1962). Later, Becker (1993) again pointed at the importance of factors such as attitude. Becker (1993): "The concept of human capital also covers accumulated work and other habits, even including harmful addictions such as smoking and drug use. Human capital in the form of good work habits or addictions to heavy drinking has major positive or negative effects on productivity in both market and nonmarket sector. [...] It also means that the process of investing or disinvesting in human capital often alters the very nature of a person: training may change a lifestyle from one with perennial unemployment to one with stable and good earnings, or accumulated drinking may destroy a career, health and even the capacity to think straight" (p.392). However, almost no economic research has been done on these aspects of human capital. Perhaps this is related to the strong desire to lead everything back to an explanation involving a rational calculating actor. Becker may not have realized that exactly the assumption of a rational actor is undermined by his own remarks about for example "the capacity to thinking straight." Also, his acknowledgement that "human capital often alters the very nature of a person" implies that his preferences and behavior can change; thus that preferences are not stable and are not exogenous coming from nowhere, but can be changed under the influence of investing in human capital - a factor within the model, not outside. 


\subsubsection{Mental capital and buman capital formation}

What makes a person invest in his human capital? Becker (1962) gives a purely economic explanation: if the person has reason enough to expect good returns from it. This means that people who are less intelligent spend much less time at school investing since education would not have much effect on their human capital, and thus the returns in terms of higher income later would be much too low to justify the investment.

Becker and other human capital theorists do acknowledge that there may be suboptimal decisions and behaviour of economic actors when investing (or not) in their human capital. They mention some elements of 'market failure' in the investment in human capital. For example, there is lack of information about future conditions in which the acquired knowledge and skills may or may not have value, making it harder to make a decision on the basis of expected utility and adding a risk premium..$^{90}$ This uncertainty has increased with the increased creative destruction of the economy.

Nevertheless, the explanation of Becker and colleagues is a limited and not very sophisticated way to describe why and how people make educational choices. In the area of human capital formation, individuals only partially act as rational actors making wellcalculated decisions. ${ }^{91}$ Especially when they are young (as most people are when making important human capital choices) people tend to have limited agency: they have high time discounting and low self-regulation and self-management skills, and are more easily influenced by their social environments thus behave less like an individual rational actor. Theorists such as Schultz (1961) and Weisbrod (1966) pointed out that people tend to underinvest in education, referring to elements such as attitude and poor judgement, and even pleading for counselling of young people to improve their choices in education and reduce the underinvestment. ${ }^{92}$

Educational choices are related to self-perception and self-esteem in important ways. Some students of limited intelligence nevertheless go to university because they have a high level of agency; their parents and their context told them that this is where they belong, and they can envision themselves doing it. By contrast, others who are above average intelligence but growing up with low self-esteem and a low sense of self-efficacy and agency, and cannot envision going to university. These are relatively subtle influences and difficult to document.

\footnotetext{
${ }^{90}$ In addition, Becker and others point out that human capital is a very illiquid asset - it cannot be sold and is rather poor collateral on loans; thus a positive liquidity premium, perhaps a sizable one, would be associated with it.

${ }^{91}$ Eckhaus (1963): "Extension of the assumptions of perfect markets for goods to areas such as education raises the danger of creating an analysis that caricatures reality. The ghost of "economic man" walks again when Becker argues that individual decisions are made by comparison of their productivity with the productivity of investment in education."

92 Weisbrod (1966): "[] mportant choices are made by young people, who may be poor judges of their longterm interests. Dropping out of high school may seem wise to a youth impatient to increase his earnings, but the wisdom of the decision becomes less obvious with the passage of time." Thus he proposes that there is a role for the government, to help youngsters with lower level of agency (and thus high discount rates) make better decisions. Young people generally have less agency since that is something that has to be developed over the course of years, and this is especially the case when they have mental health difficulties such as low selfesteem. Incidentally, Derek Bok points out that Adam Smith made very similar remarks about career choice 200 years ago (Bok, 2003, p.45).
} 
The effects of psychological factors in human capital formation is much clearer in the case of mental health problems; many young people drop out of school due to mental health related factors such as depression and behavioral conduct problems. ${ }^{93}$

Interestingly, Becker (1962) observed that there are ways to improve this suboptimal decision-making regarding human capital formation: "It also means that the process of investing or disinvesting in human capital often alters the very nature of a person: training may change a life-style from one with perennial unemployment to one with stable and good earnings, or accumulated drinking may destroy a career, health and even the capacity to think straight" (Becker 1987). Becker hereby acknowledges the importance of agency in human capital formation; however he assumes that more education is the panacea. He seems to observe "threshold values" of human capital but does not present a satisfying explanation, apart from the idea that more education breeds more education. High levels of education and high levels of agency are not the same thing, as one can observe when highly educated people are stressed, depressed or in other ways in a suboptimal mental state: their productivity drops like a stone.

Since elements that are associated with agency and mental capital determine the formation of human capital, it can be argued that mental capital is one of the conditions for optimal investment in human capital.

\subsubsection{Mental capital and human capital use}

The early human capital theorists were aware that education increases potential productivity, but not necessarily actual productivity. ${ }^{94}$ They acknowledged that what mattered in human capital was the ability to adapt and meet the needs of a changing economy, and to develop and absorb new ideas and practices. Education strengthens the knowledge and skills of the labour force, but is no guarantee of productivity in a dynamic environment where novelty is ubiquitous. This suggests that mental capital is important for the effective use of human capital. In chapter 3 and earlier in this chapter we found that agency is crucial for the optimal allocation of personal resources such as time, effort, or attention. Agency determines the degree to which a person can put his own human capital effectively to work. This is crucial, since human capital only serves its productive function if it is sufficiently controlled and directed.

How can we understand this in economic terms? We will first look at how human capital was positioned vis-à-vis physical capital, because it may help to understand how different forms of capital interact more generally.

\footnotetext{
93 There are differences in educational attainment between nondepressed and depressed (Glied and Pine, 2002, Franko et al. 2005). For example, Kessler et al. (1997) reported higher school dropout rates in adolescents with depression than in nondepressed adolescents. Weissman et al. (1999) found that participants with depression had significantly lower educational achievement, had a lower socioeconomic status, and missed more work because of psychopathology than did their nondepressed counterparts. Franko et al. (2005) note that impairment in this area can be associated with even mild degrees of depression. Depressive symptoms in adolescence, even if only mild, may affect motivation, the ability to concentrate, and the energy level needed to attain educational goals.

94 E.g. Weisbrod (1966): “[Education's] economic value lies primarily in its contribution to individuals" productive potential rather than in its contribution to the economy's success in achieving that potential."
} 
The many attempts to empirically establish the effects of education (and thus of human capital) on growth by including education levels as a form of productive input, by and large failed. Two studies found a way around this. Azariadis and Drazen (1990) treated education not as a continuous but rather as a discrete variable and found threshold effects. Benhabib and Spiegel (1994) looked at the mix of production factors and found that education has an effect on growth when it is treated as complementary to of other production factors. Specifically, technology spills over from leaders to followers, and the rate of flow depends on level of education of the followers. This indicated that human capital had its impact through complementarities with technology and capital intensity. ${ }^{95}$ The implication is that more education alone does not increase economic growth, but that in combination with increases of capital and technology it does. What matters then is the mix of production factors, rather than absolute levels. Interestingly, these ideas are present in Goode (1959) who observed that for technology transfer to be effective, the labour force in the receiving country needed a appropriate level of "absorptive capacity". ${ }^{96}$ Over the past decades, formal and empirical analyses have given evidence of the complementarity between physical capital and human capital.

Similarly to the way human capital is complementary to physical capital, evidence suggests that mental capital is complementary to human capital. ${ }^{97}$ Someone with a high level of human capital (knowledge, skills) but without much mental capital (lack of agency, for example due to stress or mental health problems), will be unable to put those skills to effective use. In the worst case he will even use his human capital for non-productive or counter-productive action, for example by taking the wrong decisions or in conflicts with colleagues or supervisors.

Economists have pointed out that economic growth requires large investments in both physical and human capital, due to their complementarity. This thesis adds to this the need to invest in mental capital, both to increase it and to maintain it. The real bottleneck of the knowledge-based service economy may not knowledge or skills but the ability to use these

95 Veblen, more famous for his work on consumption, also wrote the issue of human capital and complementarity in production.: "A corresponding body of immaterial equipment - knowledge and practice of ways and means - is likewise requisite, under the rule of the same technological exigencies (1908, p. 535). And it is only due to the immaterial capital of workers, that capital goods become a "means of production", since "without this, the goods in question would be simply raw materials, somewhat deranged and impaired through having been given the form which now makes them "capital goods" (1908, p. 537).

${ }^{96}$ Goode (1959): "But there is ample evidence that societies at intermediate stages of development have many problems in adapting to their use the technology and physical capital that are imported or constructed locally with the aid of foreign engineers and contractors. Output is often disappointing, and poor maintenance of plant and equipment is common. Such experience has led to the opinion that many underdeveloped countries do not have the capacity to absorb large amounts of physical capital even when it can be obtained from abroad on favourable terms. The lack of absorptive capacity is often due to inadequate supplies of suitable labour, which reflect past deficiencies of investment in human capital." He was further explicit: "Rapid growth requires large investments in both physical capital and human capital. A properly balanced development program should make provision for both and should attempt to select projects that promise roughly equal rates of return on the two forms of capital."

${ }_{97}$ Veblen (1908), perhaps foreseeing the importance of mental capital, pointed out that all capital is dependent on the "traits of human nature, physical, intellectual and spiritual" (p.543), the "productive powers of labour" including its "nervous energies" (p.544) and argued that what makes the difference is "how the human agent deals with his means of life, not of how the forces of the environment deal with man" (p.542), thereby more or less identifying agency as the main economic variable underlying all other variables. 
more efficiently and effectively. This ability depends on their individual agency, which shows itself in improved and more dynamic self-allocation of the labour force, and self-regulation and self-management of workers, putting their knowledge and skills to work in an optimal way.

We can see this from a slightly different angle. Man is not human capital; he has human capital. This is the essential insight for understanding how agency functions as a means of production: agency is the ability of man to manage his human capital, which is the main resource in the knowledge economy. The idea that (self-) agency is complementary to other forms of capital is not new, ${ }^{98}$ but is rarely made explicit, or included explicitly in economic analyses. The ability to act purposefully with foresight following reason rather than instincts by regulating emotions is a fundamental axiom of modern economics, and lies at the basis of all other forms of capital, since capital represents purposeful accumulation, income and consumption foregone for the sake of later benefits.

\subsubsection{Some new explanations of old phenomena using mental capital}

To show the added value of mental capital to understand economic phenomena, some examples will be given below. These are not formal analyses, but rather descriptions meant to be suggestive of the sorts of explanations that the use of mental capital permits.

A well-known observation is that unemployment increases the probability of future unemployment. This could be because unemployment has a signalling function, indicating lack of the right knowledge and attitude. Human capital theory adds to this the insight that knowledge and skills deteriorate when they are not used, such as during unemployment. Losses in earnings can be cushioned by appropriate payments but these do not keep idleness from taking its toll on human capital. Mental capital adds yet another element, with different implications. Unemployment has a profound negative psychological effect on people, as was described in section 2.3.3. It reduces their sense of self-esteem and self-efficacy, and thereby their agency. The loss of mental capital due to unemployment may be more serious than the loss of knowledge and skills, because with the depletion of mental capital it becomes more and more difficult to make investments to recover from the depletion of human capital. ${ }^{99}$ This means that increased creative destruction in an economy may be good for economic growth, but not for mental capital, and through this effect it will have a negative impact on economic growth. An obvious issue is how these two effects balance, and conditions under which the net effects are positive or negative. One of the policy question this raises is whether a more smooth transition between jobs could reduce the loss of mental capital and to what extent policy for unemployment should be aimed at increasing mental capital. In

\footnotetext{
98 Already in the early days of capital discussions, it was observed that specific personal resources contributed to the accumulation of capital in the traditional sense of the word. As Tuttle (1903) wrote: "It is naturally easier for some men to accumulate capital than for others. It is easier for the man of large productive capacity and large self-control than for the man of small productive capital and small self-control. It is easier, other things remaining the same, for the man of foresight than for the improvident.” (p.61)

${ }^{99}$ E.g. Fryer (2002) shows how the detrimental effects of unemployment on mental health in turn reduces the chance of employment, keeping unemployed in a low level steady state of mental capital.
} 
some European countries we see evidence that policy-makers are beginning to move in this direction, especially for long-term unemployed. ${ }^{100}$

A more theoretical economic issue arises in the distinction between producer goods and consumer goods. Producer goods have productive value and can be increased to get more output, while consumption goods are valued in themselves, providing direct utility. Schultz (1961) pointed at the mixed character of many investments in human capital. In a poor country where the labour force is starving, extra food would be a producer good, while in a rich country extra food would be pure consumption. What does this mean for mental capital? It may seem that mental health, feeling good, in control and even happy, is mostly a consumption good. Feeling good about oneself is important for the well-being of people and thus an admirable goal in itself; and indeed, a century or so ago when many people worked on the land or in manual jobs in factories, it was mainly a consumption good and had little if any added value for productivity. However, whereas (additional) food has become a consumption good in these times of plenty, (additional) mental health seems to have gone the opposite direction: it has become more and more a producer good.

The reason for the shift in the character of mental health from consumption good to production good in modern economies is the change of the production process. Just as physically demanding work requires good nutrition and health care so that labour remains physically fit, mentally demanding work requires good mental health care so that labour remains mentally fit. The traditional means of increasing human capital consist of increasing education and health care; this however will not necessarily help to increase mental capital. Policy aimed at mental capital formation should pay much more attention to mental health care and look at the psychological qualities of parents, teachers and managers. These activities are producing producer goods and thus are increasing economic growth.

A third puzzle that leant itself to explanation by human capital was the empirical findings about earnings. Almost all studies show that age-earnings profiles tend to be steeper among more skilled and educated persons. Becker and colleagues argue that this is due to the investment character of human capital: first you give something up or forego income, and later you get returns. Since observed earnings are gross of returns and net of costs, investment in human capital at younger ages would reduce observed earnings then and raise them at older ages, thus resulting in a steeper age-earnings profile.

The inclusion of mental capital into the analysis suggests another explanation, which may be as compelling. In chapter 3 it was made clear that there is a strong bidirectional positive feedback between perceived self-efficacy and performance, the one increasing the other and vice versa. This leads to efficacy-performance spirals (Lindsley et al. 1995), which can lead to a polarization in income development: those who earn more, will earn even more, and those that earn less will earn less more. This diagnosis would mean that the fact that age-earning profiles become steeper is not just a normal effect of the market that comes with investing in anything, but a form of market failure, a sort of internal Matthew effect operating through

${ }^{100}$ For example, in the Netherlands there is special attention for recognizing and dealing with psychological problems and development of social-emotional skills of long-term unemployed (SZW 2000) and young unemployed people, often drop-outs from school who often become long-term unemployed (e.g. Verberne et al. 2007). 
efficacy and performance. People who initially have a low level of agency will not perform well, which will work as a self-fulfilling prophecy, furthering lowering agency and performance. This is not because they are not able to fulfil the requirements of the task, but because they perceive themselves to be unable. That means that intervention of some kind, increasing their agency, can help to break or soften the spiral and perhaps reverse it, which would mean a tremendous economic gain not only for the individual but also for the economy as a whole.

Another phenomenon thought to be better explained by taking human capital into account concerned personal income distribution. At least since the time of Pigou economists have tried to reconcile the strong skewness in the distribution of earnings and other income with a presumed symmetrical distribution of abilities. Human capital offers an explanation that is not only consistent with economic analysis but actually relies on one of its fundamental tenets, namely, that the amount invested is a function of the expected rate of return. In conjunction with the effect of human capital on earnings this tenet can explain several wellknown properties of earnings distributions.

By definition, the distribution of earnings would be exactly the same as the distribution of ability if everyone invested the same amount in human capital. But different agents clearly invest different amounts in human capital development. As this investment is driven by expected rate of return, high ability agents will invest more. This strong positive correlation between ability and investment will create a skewed distribution of income, even though ability and investment themselves are symmetrically distribution.

Again here mental capital would provide a slightly different account with different consequences. Psychological research has taught us that what matters for actual performance is not actual ability but perceived ability. Of course the two are correlated, but not in a straightforward and static way. People's perceptions about their ability influence their performance, which in turn influences their perceptions again. It is thus even possible that a person starting out with above average abilities nevertheless has low perceived abilities and low performance, due to perception errors (as a result of low self-esteem, depression or other factors) or due to bad luck early in his career. This process will change a single-peaked (and even symmetric) distribution of actual abilities into an extreme distribution of perceived abilities having two peaks. Since performance and so income depends on perceived abilities, it will show a similar shape. This is in concordance with the income distributions in countries such as the US today which show growing polarization. In European countries in spite of more egalitarian wage structures and social institutions, there also is an increasing pattern of polarization (e.g. Esping-Andersen et al. 2002).

This would indicate that the skewed distribution is not just some sort of 'natural economic fact of life' and thus justified or at least inevitable, but rather that there is an intricate form of market failure at the level of information processing. Apparently individuals can have an internal information asymmetry, not knowing their own abilities and worth, and thus not knowing how to estimate their chances and how best to put themselves to work in the market. 
There is a clear endogenous element here, since the ability to know about your abilities is itself an ability. The reason to distinguish this from other abilities (such as the ability to work with a computer, or the ability to take care of a patient) is that it has the character of a 'metaability'. In its strongest form, increasing a person's agency will produce a bigger improvement in performance than investment in skills per se. In a weaker form, skills, or an investment in skills, can be strongly leveraged by investments in agency. This does not mean that everyone should be sent to a self-efficacy course, but it does mean that there is a tricky form of market failure which requires a different type of intervention than arise from analyses such as those of Becker and his colleagues. We return to the issue of market failure in section 4.6, when bounded rationality is being discussed.

\subsection{Mental capital and bounded rationality}

An important branch of economic research which has been growing rapidly the past few decades is behavioural economics. The standard economic actor maximizes his utility according to his preferences, while having complete information and being fully rational. These assumptions were useful for modelling and were thus common for quite a long time, in spite of being obviously unrealistic. It was attractive to make these assumptions, because they circumvent many difficult questions about optimal choice. As of the 1950s criticism arose, most notably in the person of (later) Nobel Laureate Herbert Simon. He pointed out that these assumptions were not only incorrect but also unnecessary, because in fact deviations from the model of economic man are common and systematic, and must be included in economic analyses in order to have any relevance for reality. ${ }^{101}$ This triggered the start of a new branch of economics that has grown substantially especially in the last decades: behavioural economics. The full-fledged recognition of this branch of economics was symbolized by the Nobel Prize of Economics for a psychologist, Daniel Kahneman, in 2002.

Behavioural economists investigate the ways in which economic actors systematically deviate from this model of the economic actor (generally taken together in the term bounded rationality'), and what effect this has on economic phenomena. Mental health problems are defined as cognitive, emotional and behavioural problems (see chapter 3), and by definition signal distorted information processing, diminished rationality and dysfunctional behaviour of an actor. As we saw in chapter 3, mental health problems affect the agency of a person and that in turn affects the quality of his cognitive, emotional and behavioural processes. Since mental capital reflects the degree of agency of an actor, the level of mental capital can be expected to affect the overall degree of bounded rationality of an actor.

In this section, we will briefly discuss the nature of bounded rationality and its different aspects. We will show how the concept of mental capital is related to the research on bounded rationality, and discuss how mental capital can add to the insights from this research by discussing heterogeneity, variability and endogeneity of rationality.

101 Simon et al. (1986): "In a world of limited rationality, economics and the other decision sciences must closely examine the actual limits on rationality in order to make accurate predictions and to provide sound advice on public policy." 


\subsubsection{Rationality: bounded}

Rationality refers to the extent to which thinking or acting is in accordance with the lines of logic and corresponds with what one would think or do if one would reason logically about it. In economics, a decision is called rational if it is in some sense optimal, given a number of conditions about means and ends. Rational choice theory assumes human behaviour to be guided by instrumental reason. Accordingly, individuals always choose what they believe to be the best means to achieve their given ends, and these ends are known to them via their preferences which indicate the relative utility different options would provide. Economic actors are regarded as maximizing utility, which serves as the "currency" to express everything they experience as valuable in. ${ }^{102}$

For a choice to be considered fully rational, a number of conditions have to be present, among which:

- Preferences. There has to be a preference ranking for a set of items which is complete (every item is ranked), transitive, reflexive, and exhibit non-satiation.

- Information. An individual must be aware of all possible choices and must have precise information about exactly what will occur under any choice made ${ }^{103}$

- Calculation. The decision-maker must maximize his utility by perfectly weighing and comparing all of the alternatives, and all comparisons must be consistent with each other and over time.

- Decision and execution. Finally, the rational decision-maker must always choose the item he prefers and execute the behaviour that this choice implies

Unfortunately, as economists know well (but often choose to downplay) there are few if any actors who fulfil all or even any of these criteria in real life. Preferences are often intransitive, information is incomplete and biased, calculation is imprecise and incomplete, and optimal decisions are often not taken but not executed. In other words, actors are boundedly rational and behavioural economists are rapidly expanding our insights on the different aspects of bounded rationality and their consequences. ${ }^{104}$ The mental state of a person and his agency influence the different aspects of bounded rationality. This is very clear from the list of symptoms used in diagnosing mental disorders in the DSM-IV (APA 1994). For example, depression includes diminished ability to think or concentrate, or indecisiveness; anxiety includes difficulty concentrating or mind going blank; paranoia includes preoccupation with unjustified doubts about the loyalty or trustworthiness of friends or associates; posttraumatic stress disorder includes significant social, interpersonal, or work-related problems, for example a feeling of disconnection from other people. We will discuss each of these aspects of a rational choice in the next subsections, each time reflecting on the role of mental capital.

\footnotetext{
102 If the actor is a firm it maximizes profits, but in a general equilibrium setting, firms are owned by utilitymaximizing individuals, and so profit maximization is instrumental to utility maximization.

$103 \mathrm{Or}$, in the case of maximizing expected utility rather than just utility, an individual has a reliable probability distribution describing what will happen under any choice made.

104 Bounded rationality is a complex topic and the brief discussion of it in this thesis only reflects the basics of the issues at stake. The research literature on this is abundant and growing rapidly. Among key authors in this area are Herbert Simon, George Loewenstein, Colin Camerer, Matthew Rabin, Daniel Kahneman, Amos Tversky, Richard Thaler, John Conlisk, James March, George Akerlof, and others.
} 


\subsubsection{Preferences: not necessarily optimal}

Micro-economics text books typically begin by deriving utility functions from preferences. Preferences are taken as given and immutable, and not to be questioned. When the axiom of revealed preference (that if an agent does action $X$ when $Y$ was in the feasible set, then the agent prefers $X$ to $Y$ ) is added, a completely consistent system is created, in which the agent's goal of maximizing utility is equivalent to satisfying (to the extent possible given constraints) his preferences. From this consistent structure at the individual level, it becomes possible to derive the welfare theorems, in which markets produce Pareto optimal outcomes (which is often taken to be a necessary condition for maximizing social welfare).

The notion of revealed preferences is axiomatic and there is some sense in which the axiom is obviously correct. In the absence of coercion, why would a person do $X$ if it was not his preferred option? Even if we can say that the agent "knew $X$ was bad for him" this just means that at the moment of action, he preferred the "bad" to the "good". This circumvents the problematic notions of good and bad, and it permits the economist considerable freedom, while allowing him to avoid difficult normative debates about preferences.

Economists are generally reluctant to be normative about preferences; they are seen as a given and it is not up to an economist to decide whether they are good or bad. One reason for this is that the optimality of markets depends crucially on the notion of revealed preferences. If the preferences that are revealed in the choices of people are not 'rational', in the sense that they do not serve the best interests of the person with these preferences, then economists have to let go of the connection between perfect markets and welfare maximization. A market failure due to boundedly rational preferences is however hard to accept for economists, even for behavioural economists. Economists generally have argued that there may be all kinds of issues with preferences, but that these are by definition not economic issues; economists take preferences as a given and leave it to other disciplines to sort out how they are formed and changed. To the extent that they deal with inconsistencies such as people choosing something that is not maximizing their all-over utility, economists choose to understand this as a negotiation between different selves (now and in the future) with different preferences, in which the future self often looses out (e.g. the research on hyperbolic discounting). ${ }^{105}$

Often people do not know what they (should) want to get most utility; they make mistakes, are misguided by themselves or are not able to prioritize and be consistent. We observe many "revealed preferences" that do not seem to be utility maximizing: the revealed preference of a battered woman to stay with her abusive husband; the revealed preference of a drug addict for drugs, the revealed preference of a workaholic to work more; the revealed preference of a narcissistic manager to focus on external success signals of a firm rather than internal management problems; the revealed preference of a depressed person to stay at home with the curtains closed; the revealed preference of a stressed person to write an angry

\footnotetext{
105 Hyperbolic discounting is the finding that people structurally discount the prospect of future rewards in a curve that is more deeply bowed than a "rational" exponential curve, value seems to be experienced as inversely proportional to delay. Some economists argue that this can be understood as a process of "limited warfare among successive selves", a sort of intertemporal bargaining inside an actor (e.g. Ainslie 1986, 1992a, 1992b, 2000).
} 
email to a colleague starting a cascade of conflict at work; the revealed preference of an anxious person to postpone decisions. To argue a depressed self happens to have a preference for staying inside the house as economists would do is true by definition but does not provide much insight. An interesting aspect of all these examples is that the agents in them could all be described as suffering from diminished mental health, and more specifically, diminished agency. These types of cases are not at all uncommon, ${ }^{106}$ and studying the effect of mental capital on preferences would permit economics to capture phenomena that are obviously strongly connected with welfare, but which must currently be finessed in some (often convoluted) way.

The implication of generalizing beyond these examples is that an increase of stress and mental health problems in the population can be expected to lead to an increase in the distortion of preferences. This has serious consequences, given the central place of preferences in economic theory. It would be worth pushing on the economist's model of preferences and how they are linked to utility. ${ }^{107}$ People often do not know their real preferences (thus all the effort people spend these days to try to "find themselves", to get closer to "who they really are", and so on, often making use of the self-help industry), and the ordering of them, and have problems weighing preferences and being consistent. This is true for average economic actors, and it is even truer for economic actors that are stressed and have mental health problems, in other words that are low on mental capital.

The issue of preferences is difficult in economics, because of the axiom of revealed preferences and all that is built on it. However, relaxing the assumption of revealed preferences does not have to mean that everything will fall apart. Careful reformulation can help to give room to insights that cannot be ignored anymore, while still preserving the basis of so much economic models. While it may be true that it is impossible to identify "real" references as opposed to "false" preferences, psychology does offer tools to do so. For example, there are many tools to give more insight into personality (thus giving inside to the actor about himself), and in addition there are many ways to measure well-being and satisfaction, which can help to give some idea about the (mis)match between "revealed" and "actual" preferences. ${ }^{108}$

\footnotetext{
${ }^{106}$ It is important to stress that we are not talking about some isolated outliers that we can rightfully ignore. As was pointed out in chapter 3, symptoms of mental health problems are located on a continuum; the fact that only at a high level of symptoms a phenomenon is called 'mental illness' should not hide the fact that there is a large part of the population that has sub-clinical levels of symptoms. Also see the discussion at the beginning of section 4.4 .

107 There is a difficulty here in that by assumption agents maximize utility, by definition utility is derived from preferences, and so at that level there is nothing to discuss. We would rather interpret this as a discussion taking place at a more fundamental level, involving some of the basic assumptions and definitions of rationality. If we retain the assumption that an agent's goal is to maximize utility, we must be tentative about the link between preferences (particularly revealed preferences) and utility. If we keep the derivation of utility functions from (revealed) preferences, we must be hesitant about whether the ultimate goal of an agent is utility. Retaining the utility-maximization assumption and examining the link between revealed preference and utility seems likely to be the more fruitful approach.

108 A Gul and Pesendorfer (2005) argue: "What makes individuals happy ('true utility') differs from what they choose. Economic welfare analysis should use true utility rather than the utilities governing choice ('choice utility')."
} 
These issues are slowly attracting more attention, and especially in the past decade economic studies about different types of utility are starting to clarify the complex but economically highly relevant nature of preferences in economic terms. ${ }^{109}$

The degree to which an economic actor has problems with correctly identifying and weighing his preferences depends on the extent to which he has accurate knowledge of himself and of his context, and thus on the quality of information-processing. This is affected by mental health problems. As was shown in chapter 3 , mental health problems lead to a deterioration of cognitive, social and emotional skills. People think less clearly and have more problems finding out what they (should) want. For example somebody who is depressed sees things from a negative perspective and does not undertake activities that would make sense, such as going to school or going to work. He does not have a correct notion of the utility that he would get from that; for a depressed person most things seem not only unattainable but also meaningless if attained; the expected utility is thus very low.

An important factor of preference formation is the social context of a person. People find out about options and about the validity of their preferences by observing and communicating with others their environment. To again take depression as an example, an important symptom of depression is social withdrawal and isolation, which takes away important sources of forming sound preferences and keeping preferences on the right track. The state of a person's mental health affects his or her social interactions and context in both subtle and dramatic ways. The implication is that an increase of stress and mental health problems in the population can be expected to lead to an increase in the distortion of preferences. This needs attention, given the central place of preferences in economic theory.

People's preferences are not immutable but can change with time and circumstance. ${ }^{110}$ They can change for the better - after all, people learn about themselves and their options and can manage to get a better match as time goes by. They can also change for worse, for example if a person loses track of himself and what he wants, which is a common feature of people with mental health problems. To yet again give an extreme example as illustration, people

109 E.g. Kahneman, Wakker and Sarin (1997) discuss the difference between decision utility (the traditional form of utility in economics), experienced utility and remembered utility. There are discrepancies between these, and while instant utility tends to control decisions it is experienced and remembered utility that matter for overall utility maximization. Scitovsky (1976) presented numerous ideas about experienced and predicted utility. His treatment implies that people are not generally able to solve the problem of maximizing experienced utility subject to a budget constraint, at least in part because of their limited understanding and ability to predict their own enjoyment of goods and activities. He argued for example that American consumers tend to overinvest in comforts and to underinvest in pleasures and suggested that members of other cultures achieve greater success in maximizing utility.

110 Increasingly economists are relaxing the assumption of stable preferences to give room for changes, especially economists working on intertemporal choices. Often the term "taste" is used to explain this; tastes can change. Thaler and Shefrin (1981), developing a first systematic, formal treatment of a two-self economic man, have a related but different approach: "Our framework differs from the changing-tastes literature in that we model man as having two sets of preferences that are in conflict at a single point in time. This idea is certainly not new. Adam Smith used a two-self model much like ours in his Theory of Moral Sentiments (1759). More recently Schelling $(1960,1978)$ and Buchanan (1975) have recognized the importance of simultaneous conflict in understanding self-control problems. Outside economics the idea is commonplace." Schelling (1978) uses the term 'egonomics', to refer to the self-management an economic actor needs to do in order to harmonize the different wants of different "selves" over time. The term 'egonomics' is also used more recently by Marcum and Smith (2007) in the title of a popular literature management book highlighting the importance of (handling your) ego for success. 
with suicide wishes usually did not have these wishes in the past; while in rare cases it may be their objective situation which has changed (for example, having a terminal illness), most often it is their preference structure which has changed. The phenomenon of regret gives some idea of how common it in fact is that preferences structures change; the businessman who regrets not having seen his children grow up because he was always working, or the housewife that gave up a career because she thought at the time that this is what she wanted, to be a mother and wife.

Changes in mental health can be the cause of longer-lasting changes in preferences. To an anxious person it may indeed be best to stay at home and never leave the house; this is what will make him feel best and he is thus maximizing his preferences. However, the change in preferences signals a change in the utility function of the person. ${ }^{111}$ The potential utility level that can be realized by maximizing according his new preferences is lower than the potential utility he could have achieved with another, more normal utility function. To really maximize his utility, he should switch to a normal utility function. However, this requires him to undertake action and seek help, and doing that is highly uncomfortable and threatening for an anxious or depressed person, thus representing major disutility. If he would do that, he would not maximize his utility of that particular moment, but forego utility now in the hope of getting more overall utility later. However, he will not do this, since it would require him to be irrational given his current preferences and given his current information on which he bases his expected utility. ${ }^{112}$ In terms of Kahneman et al. (1991), he would suffer disutility to increase his potential maximum utility level, by attempting to switch to another utility function. It is important to note that this is not merely, for example, a downward shift in the utility function due to feeling depressed. It is rather a more fundamental transformation of the utility function itself, since being depressed actually changes a person's preference ordering in ways that reduces the optimized utility level (even in the absence of a downward shift).

This does not imply a claim to cardinality. Cardinality is a problem because economists do not want to compare the utility functions of different persons, for good reasons. Economists feel that they cannot make statements about one person having more utility than another how could they possibly tell, and who are they to decide on that? Also, in economics it is assumed that actors maximize their utility, and if that is the case it seems rather useless to say that one person has more utility than the other, because both will have as much utility as is possible for them anyway; so even if there was a difference in utility levels, as long as they were able to maximize there is not much that can or should be done. Psychologists have less problems with comparing persons in terms of for example their well-being, happiness or life satisfaction. In fact, it is an important topic of their research, and psychologists have developed elaborate, thoroughly tested measurement instruments to get more grip on the qualitative, subjective aspects of life in a way that meaningful comparison of people is

111 A number of authors interested in intertemporal choice (e.g. procrastination, self-control, saving, etc.) have used multiple-self frameworks (a way to indicate different utility functions at different points of time in the same person) to model the gap between short- and long-term preferences (E.g. Thaler and Shefrin (1981); Hoch and Loewenstein (1991), Akerlof (1991); Ainslie (1992); Laibson (1997), O’Donoghue and Rabin (2001). 112 A typical feature of mental health problems is distorted information processing; for example, typical for depression is hopelessness, the depressed person expects that things will never get better; typical for anxiety is fear, the anxious person expects that any change will be for the worse. See the Diagnostic Statistical Manual IV for more of these typical symptoms. 
feasible and legitimate. To compare the well-being of one person over time, such as a person who develops mental health problems and then recovers from them, sophisticated measurement instruments have been developed. ${ }^{113}$ Interpersonal comparison is problematic in economics, but intrapersonal comparison seems less challenging since at least it concerns comparing different states of the same person. ${ }^{114}$ So it does seem reasonable to claim about a single person that utility is being optimized today, while this optimal level is nevertheless lower than yesterday's optimum, which is what happens when an actor develops mental health problems.

The idea that the utility function of a person today can be different from tomorrow is slowly gaining some recognition in economic theory, because behavioral economics has managed to convincingly show that this is the case and that economic modeling is nevertheless still possible. The notion of different utility functions over time can especially be seen in the research on time-inconsistent behavior in intertemporal choices, for example in the case of the optimal amount of saving. ${ }^{115}$

Diminished mental capital indicates that the preferences on which people act are less functional in providing utility than would be the preferences they would act upon if they had a higher level of mental capital. Psychological research gives some clues about the underlying mechanisms for the effect of mental capital on the way preferences change in terms of the actual utility they will yield. In psychology, the observation that people can and often do make mistakes in identifying and ordering their own preferences and selecting their goals is an important object of research. Psychology also is not making normative judgements about preferences, but contrary to economics it does deal with the question of how preferences change and the issue of the implication of (changes in) preferences. Psychologists are for example interested in the extent to which preferences are internally consistent, and the

\footnotetext{
${ }^{113}$ In psychology, a range of measurement tools (scales, inventories) is developed to identify the presence and degree of certain psychological symptoms indicating for example depression, anxiety, distress, or personality disorders. For example, for measuring symptoms of depression, there is the Beck Depression Inventory (BDI); for measuring symptoms of anxiety there is the Depression Anxiety Stress Scales (DASS) (Lovibond and Lovibond, 1995). and the Social Interaction Anxiety Scale (SIAS) (Mattick and Clarke, 1998); for Obsessive Compulsive Disorder (OCD) there is the Yale-Brown Obsessive-Compulsive Inventory (YBOCS) (Goodman et al. 1989). In personality research there is for example the Behavioral Inhibition/Behavioral Activation Scales (BIS/BAS) (Carver and White 1994); the Borderline Personality Inventory (BPI) Chabrol et al., 2004) and the the Narcissistic Personality Inventory (NPI) (Raskin and Hall 1981). There are also (and increasingly) scales developed for positive mental health variables; for example the level of self-esteem can be assessed with the Rosenberg Self-Esteem Scale (RSES) (Rosenberg, 1965).

114 Thaler and Shefrin (1981): "Early selves would like to commit later selves to honor the preferences of those early selves; however, later selves do their best to maximize their own interests. Economists have modeled this situation as an intrapersonal game played among the consumer's temporally situated selves." This leads to interesting and insightful results, but involves greater analytic complexity

115 Akerlof (2002) about this: "For New Classical economics, saving too little or too much, like involuntary unemployment, is an impossibility, a straightforward contradiction of the assumptions of the model. Since saving is the result of individual utility maximization, it must, absent externalities, be just right. Behavioral macroeconomics, in contrast, has developed theoretical tools and empirical strategies to advance understanding of such time-inconsistent behavior." (p.381). [...] A key theoretical innovation permitting systematic analysis of time-inconsistent behavior is the recognition that individuals may maximize a utility function that is divorced from that representing "true welfare." Once this distinction is accepted, "saving too little" becomes a meaningful concept." (p.381). Akerlof points out that it is important "to formalize the distinction between the utility function that describes actual saving behavior and the utility function that measures the welfare resulting from that behavior" (p.382).
} 
extent to which preferences help a person achieve life satisfaction (more or less a synonym for experienced utility in economics).

An example of a model with which these types of questions are studied in a systematic way is the self-concordance model (Sheldon and Elliot, 1999). The self-concordance model is rooted in self-determination theory (SDT) (Deci and Ryan, 1985) and focuses on people's broad personal goal statements. ${ }^{116}$ It deals with the question of how individuals select (and perhaps mis-select) goals in life from among the potentially bewildering array of possibilities (the "tyranny of freedom"; Schwartz, 2000). The self-concordance model explores in detail the longitudinal processes by which initial positive motivation promotes later positive outcomes both in terms of achieving them (productivity, in economic terms) and in terms of enjoying them (utility, in economic terms). ${ }^{117}$ Models such as this enable researchers to study the 'validity' of preferences in a systematic way; a preference and its consequent behaviour that is less self-concordant will provide less utility when utility is maximized according to this preference, and is thus from an economic perspective a 'sub-optimal' preference. ${ }^{118}$

Sheldon and Elliot (1999) investigate the extent of self-concordance by looking at the extent to which a person has access to important integrative capacities during the period of striving to achieve certain goals because of certain preferences. Stress and mental health problems reduce the access to these integrative capacities and thus lead to preferences and choices that score lower on self-concordance. Since self-concordance is an important determinant of changes in mood and life satisfaction and on a number of other outcomes such as productivity and effectiveness, lower level of self-concordance in preferences and choices reduce the utility a person will get from his preferences and choices, and reduce his performance. By keeping the comparison of preferences structures and their potential utility intrapersonal, it is possible to avoid being normative; no judgement is made about the nature of preferences, only in terms of the extent to which they serve the person in acquiring most potential utility given the characteristics of the person.

Mental capital affects the extent to which a person succeeds in identifying, ordering and acting on his own preferences, and through that it affects the utility and productivity of a person's actions. These are central concerns in economics. To an economist it may seem both impossible and wrong to be normative about preferences, but to a psychologist not. Where economics and psychology meet, in behavioural economics, a more sophisticated insight on the nature of preferences is already being incorporated at the micro-micro-level,

\footnotetext{
116 Self-concordance refers to the feeling of ownership that people have (or do not have) regarding their selfinitiated goals. Some people have little feeling of choice in pursuing their goals, despite the fact that they themselves generated them (Sheldon and Elliot, 1999, p. 546). When this is the case, people are unlikely to do well in their goals (Sheldon and Elliot, 1999) or to benefit as much emotionally even if they do succeed at them (Sheldon and Kasser, 1995).

117 For example, Sheldon and Elliot (1999) used path-modelling techniques to show that self-concordant goal pursuit promotes sustained effort over time, which leads to greater progress in goals, which leads to more satisfying daily experiences, which lead finally to changes in global well-being.

118 Other methodologies might also be used to assess how well a person's goals fit that person. For example, researchers have examined matches between participants' goals and their social motives (Brunstein, Schultheiss, and Graessman, 1998), personal resources (Diener and Fujita, 1995), and personality traits (McGregor, McAdams, and Little, 2006) as predictors of positive outcomes.
} 
for example in the form of the acceptance of the effects of 'framing, 119 or the research on procrastination. ${ }^{120}$ What such insights mean when going beyond the level of the individual is not clear and it will take many years to crystallize out; but interesting examples of 'behavioural macroeconomics' (a term introduced by George Akerlof in his 2001 Nobel Lecture) are already developing.

\subsubsection{Information: incomplete and biased}

An important first step in the decision-making process is collecting and evaluating information about the world in order to find out what options there are and in which ways they can be realized. In economics, for a long time it was assumed that actors have complete information. This was not because economists thought this was true, but because it simplified modelling and circumvented difficult issues about heterogeneity of information between actors and over time, the costs related to getting information, and the problem of the interpretation of information.

Since the 1950s, criticism concerning this assumption has been growing, most notably in the person of Herbert Simon. Simon pointed out that information from the environment comes to human actors in a mediated way, via their perception and cognition mechanisms which have limitations and particular features. Information is never complete and even if it was, the limited cognitive abilities of people would prevent them from processing it all. Also, perception and cognition have particular features (e.g. dynamic pattern recognition based on existing structures in the brain) which cancel out the idea of some sort of objective approximation. ${ }^{121}$ Simon pointed out that the simple input-output model of information and decision is in fact highly misleading. Actors select from the information that is available, and this selection is biased, as is the interpretation of the selected information. ${ }^{122}$

Another emerging branch of economics also pointed out that information was incomplete and that this has profound consequences for the decisions of actors and the functioning of markets. Some economists like George Stigler recognized the importance of information but argued that once the real costs of information were taken into account, the standard results of economics would still hold; information was just a transaction cost. This naïe idea about

119 Tversky and Kahneman (1986) about how framing influences preferences: "Alternative descriptions of a decision problem often give rise to different preferences, contrary to the principle of invariance that underlies the rational theory of choice."

${ }^{120}$ E.g. O'Donoghue and Rabin (2001).

121 Simon (1986): “The decision-maker's information about his environment is much less than an approximation to the real environment. The term "approximation" implies that the subjective world of the decision-maker resembles the external environment closely, but lacks, perhaps, some fineness of detail." This is misleading, according to Simon (1986): "in actual fact the perceived word is fantastically different from the "real world". The differences involve both omissions and distortions, and arise in both perception and inferences. The sins of omission in perception are more important than the sins of commission. The decisionmaker's model of the world encompasses only a minute fraction of all the relevant characteristics of the real environment, and his inferences extract only a minute fraction of all the information that is present even in his model."

122 Simon (1986): "Perception is sometimes referred to as a "filter." This term is as misleading as "approximation," and for the same reason: it implies that what comes through is really quite a bit like what is "out there". In fact, the filtering is not merely a passive selection of some part of a presented whole, but an active process involving attention to a very small part of the whole and exclusion, from the outset, of almost all that is not within the scope of attention." 
the role of information was discarded by the work of among others Stiglitz and Akerlof, who studied incomplete and asymmetric information and its effects. The study of incomplete information turned out to be very fruitful in (better) explaining important economic phenomena. Information economics showed that there were patterns in the way information was imperfect, allowing systemization, and by showing the many ways in which information problems affected markets new insights were generated and new, more effective policy could be developed.

Information economics does recognize different levels of information, but only partially addresses the reasons for these differences and not at all the issue of different interpretation of the same information. Behavioural economics looks at information at the micro level, the level of the individual economic actor. It studies the mechanisms of selection and interpretation of information in which existing and emerging 'mental models' JohnsonLaird 1983) play an important role. Behavioural economics has managed to systematize and generalize these to some extent, by categorizing them in a number of biases. These biases are commonly found but are stronger in some persons or groups than in others. Given the important effects of these biases on the quality of decisions and thus on economic core issues such as productivity and the optimality of markets, it is in the interest of economics to increase the understanding of what determines these differences. This makes mental health an important topic.

An important bias in the domain of incomplete information is selective perception and attention. Due to cognitive limitations, people can only be aware of a small amount of all information available, and our mental state influences how much and which information we perceive. According to schema theories (e.g., Bower, 1981) cognitive processing is guided by schemas that largely determine how information is attended to, interpreted, and remembered. Empirical research shows that both the extent to which this selection of information is incomplete in size and the nature of the selection (the content of what is taken in by the brain and what is not) is influenced by mental health. This has been shown in ample research for example in the case of mood, ${ }^{123}$ depression ${ }^{124}$ and anxiety. ${ }^{125}$

The extent to which a decision-maker can make use of information for his decision also depends on his memory function, which determines the availability of information collected in the past which can be retrieved to use for decisions in the present. When people are called on to make a judgment or behavioral decision, they usually do not conduct an

\footnotetext{
${ }^{123}$ E.g. Blaney (1986) reviewing 29 studies on the effect of affective states such as depression on memory, finds extensive support for enhanced encoding and/or retrieval of material the affective valence of which is congruent with ongoing mood (i.e. a person who feels sad and unhappy notices and remembers negative events and situations more than positive ones, while a person who feels good will remark and remember positive things more). This means that mood affects the information that a person uses to base his decisions on; and since a person with a mental health problem such as depression typically feels more sad and unhappy, his information will be biased in that way. Thus mental health can be seen as an indicator for certain informational biases.

${ }^{124}$ E.g. Bradley et al. $(1995,1996)$ show that both non-clinical subjects with high levels of dysphoria (versus controls with low levels of dysphoria) and subjects who met DSM diagnostic criteria for depression (versus normal controls) had more implicit memory of depression-priming information.

125 E.g. Bar-Haim et al. (2007), in a meta-analytic study on attentional bias in people with anxiety problems, find that over 150 studies have established that the attentional system of anxious individuals is distinctively sensitive to and biased in favor of threat-related stimuli in the environment.
} 
exhaustive search of memory for all of the knowledge that might bear on the behavioral decision; rather, they retrieve and use only a small subset of this knowledge that comes to mind most easily. Empirical evidence indicates that mental health problems such as depression influence which subset is chosen, not only is the subset smaller but also less balanced, more negatively biased. ${ }^{126}$

Thus empirical evidence suggests that cognitive biases in the area of incomplete information are stronger and more pervasive in individuals with diminished mental capital (due to stress or mental health problems), and will also be more pervasive in groups with a large proportion of individuals with diminished mental capital (e.g. groups such as long term unemployed with low self-esteem and low sense of self-efficacy and control, or a labour force with high levels of stress and burnout).

Information economics has shown how enormously important information issues are for the functioning of markets. Psychology and behavioural economics have shown that that cognitive limitations and psychological factors influencing the degree and nature of these limitations play a decisive role in determining in what way and to what extent information is incomplete, and how information becomes biased during the process of selection and interpretation. Economic actors act upon their subjective perception of reality, not on "reality" itself (Simon 1955). This is a crucial insight. Given the importance which information economics attaches to the pervasive influence of information on the functioning of markets, and given the effect of mental capital on the selection and degree of bias of information of an actor, mental capital is bound to have an important impact on the functioning of markets through its effect on information.

\subsubsection{Calculation: satisficing rather than maximizing}

According to the standard economic model, an economic actor with identified and ordered preferences and complete information will proceed to calculate his options. In this calculation he will maximize his utility given his preferences and given the information he has about means and ends. However, Simon (1959) and others point out that people have so many preferences and goals, and there are so many options, that the task of weighing, comparing and calculating is in practice insurmountable. In fact, economic actors are typically not maximizing but satisficing; they are not looking for "best" or "most" but for "good enough". This can be the rational thing to do, given the obvious effort-accuracy trade-off. Thinking through and comparing all possible options and their pros and cons would take tremendous time (and thus opportunity costs), and would be paralyzing, harming decision power rather than enhancing it. Consequently, people tend to follow routines and depend on rule-of-thumbs, decisions short-cuts based on what has worked in the past

In dynamic environments with much novelty - such as the current economy, as described in chapter 2 - rules of thumb and common heuristics loose much of their effectiveness: the

\footnotetext{
${ }^{126}$ E.g. Basso and Bornstein (1999) find that persons with depression have memory deficits; Bazin et al. (1994) find that depressed persons have impaired memory on cued recall tasks (in comparison with controls matched for sex, age, and educational level). The research of Massman et al. (1992) show that in depressed persons especially retrieval of newly learned material is impaired.
} 
rationality they represent in stable environments can become counterproductive, and there is more need for active information processing and calculation. In addition, research shows that when tasks are more cognitively complex and more emotionally laden - as is the case in the current economy, due to the increase in knowledge work and emotion work described in chapter 2 - they require more effortful information processing (e.g., Luce et al. 1997). Especially negative emotions tend to take up much cognitive resources. ${ }^{127}$ Thus, the effective use of limited cognitive resources becomes more important in a more dynamic environment with more complex, cognitively and emotionally demanding tasks. In such an environment, mental health problems become more problematic.

More in general, research shows that mental health problems are related to diminished executive performance. ${ }^{128}$ An important aspect is the effect of emotions on the quality of decision-making. ${ }^{129}$ Emotions can be seen as an important form of information (Elster 1998), valuable but costly, because in need effortful regulation and processing. Understanding the influence of emotions on choices is important for understanding economic behaviour. ${ }^{130}$ Agency increases the usefulness of emotions as a source of relevant information, because it is generally associated with higher self-complexity and more balanced self-appraisals. ${ }^{131}$

One reason for the importance of mental capital in determining the quality of rationality of an actor lies in the important role of emotions in decision-making. ${ }^{132}$ Apart from their

\footnotetext{
127 E.g. Lewinsohn and Mano (1993) show that emotional arousal related to negative mood limits the attentional capacity available for decision making; Seibert and Ellis (1991) demonstrated that negative mood states lead to an increased incidence of task-irrelevant thoughts, apparently lowering available cognitive capacity.

${ }^{128}$ E.g. Channon and Green (1999) and Merriam et al., (1999) find that depressive disorder is associated with dysfunction in executive processes and failure to generate or implement adequate performance strategies, whereas relatively automatic processes are thought to remain intact. Degl'Innocenti and Å.H. Bäckman (1998) find that depressed patients were generally slower than control subjects in retrieving relevant information and in altering behaviour appropriately in response to feedback; Weiland-Fiedler et al., 2004) find hat depressed persons have problems with sustained attention.

${ }^{129}$ E.g. Isen (1993) shows that, compared to neutral moods, a positive mood can lead individual decisionmakers to faster and more efficient decision processes, a reduction in contentious strategies, more creative problem solving, and greater cognitive flexibility in categorization tasks. Similarly, Staw and Barsade (1993) show the different effects of positive and negative mood on finding innovative solutions by decision-makers. ${ }^{130}$ Loewenstein (2000) stresses the importance of "visceral factors" (emotions) for economics: "Visceral factors have important, but often underappreciated, consequences for behavior. Moreover, both the determinants of visceral factors and their impact on behavior are not only systematic, but amenable to formal modeling. Economic models that ignore visceral factors approach predictive accuracy only when applied to behavior characterized by low levels of visceral factors. To predict or make sense of viscerally driven behavior, it is necessary to incorporate visceral factors into models of economic behavior."

131 Self-complexity refers to the capacity to differentiate among aspects of the self, such as one's professional self, one's social self, and one's family self. Linville (1985) finds self-complexity to be inversely related to intensity of affective reactions to performance feedback and to daily affective variability, and to function as a cognitive buffer against stress-related illness and depression (Linville 1987). A person who maintains distinctions among various aspects of the self instead of tying all aspects of the person's self-image together is more stable in perception, decision-making and behaviour.

132 Elster (1996): "Emotions are a neglected topic, and the neglect of economists is second to none. I find this surprising. I take it that economics is concerned with the best ways of promoting human satisfaction in a world of scarce resources. [...] [A]ll human satisfactions come in the form of emotional experiences." [...] No economists to my knowledge has considered the emotions in their main role as providers of pleasure, happiness, satisfaction or utility. To put it crudely, economists have totally neglected the most important aspect of their subject matter." Also see Elster (1998). Loewenstein (2000) in a paper on emotions in economics
} 
important impact on utility (as indicators of what has utility for a person and as magnifiers of potential utility), they also plan an important role in decision-making. Emotions can provide information that is not accessible in other ways, and they can aid decision-making in important ways. ${ }^{133}$ Whether emotions are helpful or harmful in the decision-making process depends on the mental health of the decision-making, determining both the appropriateness of the emotion (size, valence) and the ability to interpret and regulate the emotion. Mental health affects emotions and the ability to regulate emotions (agency); and this in turn affects the quality of decision making, through its effects on information (degree of distortion) and processing (degree of rationality).

In expected utility theory, preferences indicate the extent to which a certain choice will result in utility. As we saw above, actors can be mistaken about their own preferences, and mental health status is an indicator of the extent to which they are mistaken. Since the future is uncertain, in addition to preferences the probability of a choice leading to the expected result is taken into account. Here economic actors again show behaviour that is not perfectly rational, overweighing small probabilities of events with large impact, be it bad or good. A common symptom of this is the fact that people have so much insurance and the fact that people buy lottery tickets. Again, when people have mental health problems, this type of bounded rationality increases. ${ }^{134}$

The quality of decisions diminishes if an individual is unable to evaluate fully what the best course of action is or misinterprets the relative costs and benefits (e.g. Vogel, et al. 2006). This evaluation process can be hampered by a number of factors such as anxiety (i.e., the individual wanting to make a quick decision to lessen uncertainty), feeling of self-efficacy (i.e., the individual has a sense of previous failure or success in dealing with this issue), and previous experience (i.e., bad experiences with a specific behavior in the individual in the past while it may be optimal behavior in the present).

An important innovation in expected utility theory was prospect theory (Kahneman and Tversky, 1979). Starting from empirical evidence, this theory describes how individuals evaluate losses and gains given their probabilities. The theory states that different choices are ordered following some heuristic so as to let the evaluation phase be more simple. Prospect

observes that emotions figured prominently in the early theories on utility; however, neoclassical economists expunged the utility construct of its emotional content, which culminated in the development of ordinal utility and the theory of revealed preference (Loewenstein 2000, p. 426).

133 Many pieces of information that we possess are not consciously acknowledged, and the cognitive basis of the emotions includes unconscious knowledge, making emotions into powerful providers of information (Elster 1996). Often what matters is to make some decision rather than any very particular decision. Neurobiological studies show that emotions make an important contribution to rationality by providing a tipping over effect leading to the act of decision-making (for an extensive insightful reading about the function of emotions, see Damasio, 1994 and LeDoux, 1996). Emotions function as an information processing mechanism with their own internal logic, working in conjunction with rational calculation. By restricting the range of options considered (reducing the load on short and long term memory), by focusing on certain variables (certain stimuli receive higher ranking order), and by initiating and terminating the evaluation process (working as a satisficing mechanism), emotions supplement the insufficiencies of reason. Humans' rationality is limited in its information processing capacity, and emotions are in principle helpful tools designed by evolution to make the most of this limited capacity. Mental health problems mess up this important tool.

${ }^{134}$ For example, people with (symptoms of) bipolar disorder that are in a manic phase will tend to overestimate the probability of succeeding in al kinds of plans and schemes and underestimate the probability of negative events, which results in clearly impaired judgement. 
theory posits that individuals evaluate changes in their circumstances according to the gains or losses they entail relative to some reference point. The value function which passes through this point is s-shaped and, as its asymmetry implies, given the same variation in absolute value, there is a bigger impact of losses than of gains (loss aversion). Empirical evidence confirms that individuals place much greater weight on avoiding losses than on incurring gains.

Kahneman and Tversky have demonstrated that many experimental results which are inconsistent with expected utility maximization can be rationalized by prospect theory. For example, downward wage rigidity is a natural implication of prospect theory if the current money wage is taken as a reference point by workers in measuring gains and losses. Other behaviors observed in economics, like the disposition effect or the reversing of risk aversion/risk seeking in case of gains or losses (termed the reflection effect), can be explained with prospect theory.

An important implication of prospect theory is that the way economic agents subjectively frame an outcome or transaction affects the utility they expect or receive. This aspect of prospect theory, in particular, has been widely used in behavioural economics and mental accounting. ${ }^{135}$ Mental health problems change a person's frame of reference; for example a person who is depressed will interpret information in a frame of reference highlighting the negative aspects of it. This will reduce not only his utility but it will aso distort his judgments and affect his performance.

This is depicted in Figure 1 below, showing the typical S-curve characterizing prospect theory. A normal person (with no mental health problems) will mind losses more than gains; he will tend to get more disutility from a loss than utility from a gain of exactly the same size. ${ }^{136}$ This is seen as a sign of bounded rationality, since unless one has very few assets and will not survive without them (making loss so critical), it is in principal not rational. To understand why, suppose a person has a coffee-cup; this cup is taken away, and after this he receives another cup which is in every respect of comparable quality; thus in fact nothing has changed his state, but due to the S-curve of prospect theory a person will nevertheless end up with a net experience of disutility. In the case of an actors with symptoms of depression, this phenomenon is even more present, ${ }^{137}$ thus increasing this bias and reducing rationality, with all the associated economic consequences.

\footnotetext{
${ }^{135}$ Framing and prospect theory has been applied to a diverse range of situations which appear inconsistent with standard economic rationality; the equity premium puzzle, the status quo bias, various gambling and betting puzzles, intertemporal consumption and the endowment effect. The original version of prospect theory gave rise to violations of first-order stochastic dominance. That is, one prospect might be preferred to another even if it yielded a worse outcome with probability one. The editing phase overcame this problem, but at the cost of introducing intransitivity in preferences. A revised version, called cumulative prospect theory overcame this problem by using a probability weighting function derived from Rank-dependent expected utility theory.

136 This is related to two well-known biases in behavioural economics: "loss aversion", the tendency for people strongly to prefer avoiding losses than acquiring gains (Kahneman and Tversky 1979); and the 'endowment effect', people place a higher value on objects they own relative to objects they do not. (Thaler 1980).

137 Research shows that the release of the brain chemical serotonin, which plays a central role in clinical depression, is precisely tuned to various aspects of decision-making and reward-related behavior; the serotonin brain systems that go awry in depression normally play a critical role in supporting healthy and efficient decision-making, for example it leads to increased loss aversion (e.g. Sokol-Hessner et al (2007).
} 


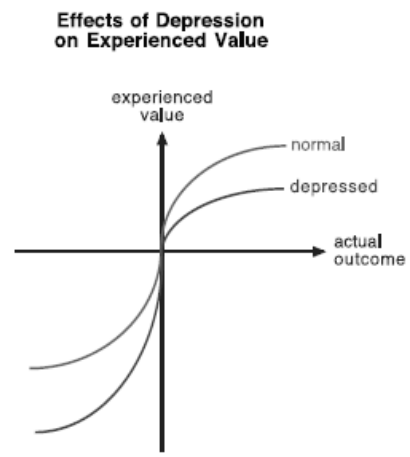

Figure 1. Effects of Depression on Experienced Utility. Inspired by the S-curve of prospect theory (Kahneman and Tversky 1979).

\subsubsection{Decision and execution: weakness of will}

An important step that is often ignored but that is essential for an actor to function effectively is that the actor acts; that after having selected and processed information, calculated options of means and ends while taking preferences into account, he should decide on a course of action, and execute the action. This is less obvious than it may seem; "weakness of will" or "akrasia" is common. ${ }^{138}$ Economic theory traditionally offers little room for this important phenomenon, since it does not fit with the axiom of the rational actor who of course will do what is best to do. ${ }^{139}$ However, even economists acknowledge that there is ample evidence that this is often not the case. ${ }^{140}$

\footnotetext{
138 Akrasia, (from Greek, "lacking command (over oneself)") is a well-known term in philosophy referring to the state of acting against one's better judgment; the inability to carry out an action in accordance with reason or virtue. The question why this should be so has been discussed since Aristotle, observing that people damage their own interests by not acting in a certain way even though they know they should. Stroud and Tappolet (2003): "Among the many practical failures that threaten us, weakness of will or akrasia is often considered to be a paradigm of irrationality." Psychologists are well aware that some people are more able to defer gratification than others, and that the same person can have more weakness of will at one time and context than at another time and context, which indicates that this form of bounded rationality is a dynamic variable. Philosophers such as Davidson (1969) point to the importance of beliefs of actors, arguing that an actor acts against his better judgment because he temporarily believes (or convinces himself) that the inferior action is the better one. Psychologists have done a lot of research on "locus of control" the belief that you have control determines to some extent whether you actually have control.

139 Simon (1986): "The classical theory of perfect rationality leaves no room for regrets, second thoughts, or "weakness of will"." The term is not common usage in economics, for an exception see Zheng (2001). Sen (1993) refers to it in an article on internal inconsistency of choice.

${ }^{140}$ E.g. Laibson et al. (1998): “[E]conomists assume that intentions and actions are aligned. But examples of a systematic gap between intentions and actions abound." (p.92) [...] "People have a systematic tendency to err as judged by their own standards - in the direction of instantaneous gratification." (p.93) Laibson et al. quote a 1997 report on saving and retirement: "The report concludes: "The gaps between people's attitudes, intentions and behavior are troubling and threaten increased insecurity and dissatisfaction for people when they retire. Americans are simply not doing what logic - and their own reasoning - suggests that they should be doing."” (p.93) Laibson et al. conclude: "Such systematic, self-acknowledged error contradicts the standard economic model of the maximizing consumer." (p.93)
} 
Akrasia may be explained in economic terms as the phenomenon of choosing to maximize the "wrong" utility function. As was described in 4.6.2, economists working on intertemporal decision-making find that actors make 'mistakes' in a structural, systematic way. Economists try to attribute the existence of such mistakes to uncertainty and incomplete information, but in addition have put forward the idea that the utility function of an actor at one point of time may be different from his utility function at another point of time, and both of them may be different again from the utility function capturing utility during the period as a whole between these different points in time.

An actor may maximize his utility function of today but thereby fail to maximize his utility function of tomorrow. Ideally actors maximize some sort of cumulative utility function which optimizes the utility function of today and tomorrow while maximizing accumulative life time utility function. Of course uncertainty and incomplete information make it hard to do such calculation for an actor, but the mistakes made while trying this are not random but systematic and thus fit for research. Not only are mistakes systematic, but also (changes in) the degree to which actors make mistakes have systematic patterns; they can be related to changes in mental health. There is empirical evidence that this is the case for, among others, depression, ${ }^{141}$ obsessive compulsive disorder, ${ }^{142}$ and certain personality disorders. ${ }^{143}$

Increasingly (behavioral) economists working on issues such as intertemporal choice try to get more grip on this crucial part of rationality, by introducing 'self-control'. Thaler and Shefrin (1981) characterized self-control as "an internal conflict resembling the principal agent conflict between the owner and manager of a firm." The extent to which the 'principal' within each person can make the person act in his best interest is determined by the level of agency of this person: the ability of self-regulation, self-motivation, self-control. Akerlof (2001) refers to self-control, as a main variable determining the extent to which they succeed to be rational in intertemporal choices. ${ }^{144}$ Interesting is the emerging field of neuroeconomics, using neurosciences and its methods in order to gain more insight in choice processes and in utility. ${ }^{145}$ Findings of behavioral economists and "neuroeconomists"146 support the central thesis of this section: mental capital (agency)

${ }^{141}$ E.g. a typical symptom of depression is inertia and passivity; even normal simple tasks seem impossible to do (APA 1994).

142 E.g., Lawrence et al. (2006) find that inability to decide is a prominent feature of patients with Obsessive Compulsive Disorder.

143 Research shows that impulse control is related to personality traits and personality disorders (in which personality traits are magnified and unbalanced) (e.g. Tice et al. 2001).

144 E.g. Akerlof (2001): "The hyperbolic function captures the difficulty people have in exercising self-control. In contrast to the exponentially declining discount rates that are standard in neoclassical theory, the hyperbolic function assumes that the discount rates used to evaluate tradeoffs between adjacent periods decline as the time horizon lengthens: individuals use high discount rates to evaluate options that require an immediate sacrifice for a future reward and lower discount rates when the same sacrifice is deferred into the future" (p.382). Also see Laibson (1997) and Ainslie (1992).

145 Neuroeconomics studies the mental changes that correlate with and perhaps cause choices. Neuroeconomics extends the approach of behavioral economics by adding observation of the nervous system to the set of explanatory variables. In neuroeconomic experiments, brain scans are used in order to compare the roles of the different brain areas that are involved in economic decision-making. E.g. Camerer, Loewenstein and Prelec (2005) expect a lot of neuroeconomics, arguing that "neuroscience findings raise questions about the usefulness of some of the most common constructs that economists commonly use." (p. 31-32).

146 The emerging field of neuroeconomics is not without its critics. For example, Gul and Pesendorfer (2005) are critical of the wish of neuroeconomics to add to economic insight and make the case for "mindless 
reflects self-control, and thereby indicates the degree to which economic actors are boundedly rational.

One failure in decision-making and execution is to do it too rapidly; impulsivity often leads to low quality decisions and actions. Weakness of will is related to impulsiveness and inhibition, the ability to suppress acting on immediate desires, which has a basis in the brain. ${ }^{147}$ Mental health indicates the extent to which such functions are developed and functional in a person, and thus determines the extent to which an economic actor, after having selected, interpreted and processed information, succeeds in taking the decisions and actions following from this.

\subsubsection{Endogenous rationality}

What can economists learn about bounded rationality by taking into account the insights of mental capital? In the sections above, different aspects of bounded rationality were described and each time it was argued that the aspect of discussion was influenced by the mental health state of an actor. Actors can apparently differ from each other in their degrees of bounded rationality, implying heterogeneity. Some people have much more loss aversion than others, some people are much more influenced by framing effects than others, some people have much more time discounting than others. In addition, one actor can differ in degree of bounded rationality over time, which implies variability. An actor may be perceptive and rational at one point of time, but under the influence of stress or mental health problems he may become closed off and irrational later in time.

This heterogeneity is not random, it is systematic to the extent that the mental health status of a person can give information about the nature and degree of bounded rationality of that person. For example, a person who is depressed will be less happy with possible gains and more unhappy about possible losses, because depression magnifies negative events and diminishes the value of positive events. A depressed person will thus probably be more loss averse than a non-depressed person. A person with anxiety problems will probably overestimate the chance that things will go wrong and underestimate the probability that things will go right and often has low sense of self-efficacy, and this will make an anxious person much more risk averse than a non-anxious person. If you know that the prevalence of people with depressive symptoms in a population (e.g. the employees of a firm) has increased, you can say something about the increased propensity of this firm to innovate; or

economics": "Greater psychological realism is not an appropriate modeling criterion for economics and therapeutic social activism is not its goal. [...] We may be sceptical of neuroscientists' ability to come up with universal, physiologically grounded criteria for measuring happiness. We may also have doubts about the potential effectiveness of neuroeconomists at convincing individuals or society as a whole, to adopt policies that increase "total happiness" by their measure. Our response to the neuroeconomics welfare theory is simpler: such a combination of moral philosophy and activism has never been the goal of economics; grounding this combination in biology is unlikely to make it so."

147 Various lines of evidence suggest that ventromedial and orbitofrontal cortices are critical for adaptive decision making in humans (e.g. Kringelbach and Rolls, 2004). Integrity of the orbitofrontal cortices (OFC) is necessary for learning to make decisions that lead to larger, delayed rewards instead of smaller, immediate rewards (Mobini et al., 2007). Recent neuroimaging results in humans support this account, showing medial OFC activity during selection of an immediate reward (go) and lateral OFC activity when participants suppressed (no-go) this choice in favour of a later delayed reward (McClure et al. 2004). 
if you know that anxiety problems have increased in a group, you can expect less investment in human capital since that requires some optimism and a sense of self-efficacy. The point is, there should be more attention for heterogeneity of bounded rationality, and psychological research on mental health can help to do this in a systematic way so that theorizing and modeling is still feasible.

An example may clarify this. An employer wants to get most output from his employees. Thus he poses demands on them, which raises their stress level and raises their output. Above a certain level of stress, this leads to less efficient information processing, deteriorated self-regulation and less effective decisions and behaviour - thus reducing the quality of all the aspects associated with rational decision-making in economics. This reduces output, leading to a first optimization problem for the employers (how much stress is optimal from the perspective of maximum output). In addition, after a period of stress, the mental health of workers is affected, structurally reducing their capacity for rational behaviour and increasing bounded rationality in its many forms, resulting in a second optimization problem (how long should an employer allow stress on the employee in order to get maximum output).

Thus, the degree of bounded rationality is a variable in the economic process, and (changes in) this variable are to some extent determined within the process. This means that bounded rationality is to some extent endogenous. The discussion in the sections above suggests that there are patterns in the heterogeneity and variability of bounded rationality; a person's mental health state indicates whether he has more or less bounded rationality compared to another actor or compared to himself in the past. Mental health can be measured with tools developed in psychology, so it can be quantified. Given the effects of mental health on incomplete information and bounded rationality, and given the effects of these in turn on for example productivity or the functioning of markets, this opens new avenues for research.

\subsection{Conclusion}

In this chapter, the notion of 'mental capital' was introduced, to capture the economic role of mental health. Given the nature of the economy of today, in which people increasingly work with their heads instead of their hands, merely acknowledging the economic importance of mental health is not enough. In order to understand its role in the economy and in order to make sure that it will be incorporated into economic analyses, it needs to be put into economic terms, and to be connected to existing economic research. This we can do by conceptualizing mental health (or more precisely, its close correlate, agency) as a form of capital. This chapter has shown that the capital concept is well applicable, and that taking mental capital into consideration can add new insight to existing branches of economic research. Including mental capital in economic analysis can lead to a better understanding of core economic issues such as productivity, growth, and choice; and this improved understanding can in turn lead to new, more effective forms of policy.

Up to this point, the analysis has been verbal, based on analysis and synthesis of different branches of empirical and theoretical literature from a number of disciplines. In order for the notion of 'mental capital' to be used in formal economic analyses, it is important to 
develop more specific applications, with a certain degree of formalization. Therefore in the following two chapters, two formal models will be developed in which elements of mental capital play a central role. The purpose of this is illustrative: it is to show that characteristics of mental capital can be incorporated into formal models, and that doing so has added value in terms of new understanding. The models are analytical not empirical models. However, the assumptions, variables and relationships between variables are chosen carefully and are based on the results of extensive empirical research in psychology. The models organize and connect several large bodies of knowledge; they demonstrate complex dynamics, highlight hidden trade-offs, offer new understanding of empirical findings and their relatedness, point out new points of intervention, and give insight in the effect of intervention. 



\section{Chapter 5. A model of mental capital and technological change}

\subsection{Introduction}

Chapter 2 showed that technological and organizational innovation have economic benefits, in terms of more productivity, but also economic costs, because of its effect on the mental health of workers. Mental health was shown to be an increasingly important economic factor, affecting the quantity (absenteeism, work disability) and quality (effectiveness, rationality, creativity, energy, morale) of the labour force. Thus, from the perspective of mental capital, any effects of innovation on mental health are worth investigating and taking into account. Economic research can contribute to this by including mental health related elements in its analysis. In this chapter, an example is given of how this can be done in practice.

Innovation increases productivity, but at he same time, as of a certain level, also can decrease productivity, via its direct and indirect effects on mental health. This means that there is an optimization problem: given the price of technology and the price of labour (which also determines the costs of reduced availability and productivity of labour), and given the role of mental health, what is the best mix of production factors in terms of profit maximization? This is a typical, old economic question, which will be addressed in this chapter in a new way: by adding the dimension of mental capital.

In this chapter a formal economic model will be developed ${ }^{1}$ in which variables uncommon to economics are included: the composition of work, mental effort, mental fatigue, recovery, and burnout. The model links technological change to mental health via its effects on the intensity of work, which in turn affects mental health, and links mental health to output via its effects on productivity. A better understanding of this dynamics is important to preserving both the mental health and the productivity of the workforce. First the variables and their relationships will be described in terms of the empirical literature. Then the model itself is presented, and the outcomes of the model are put into perspective. Finally, in the conclusion, the significance of the model and possible extensions are discussed.

\subsection{Variables and relationships}

\subsubsection{The changing composition of work}

Innovation leads to the creative destruction of jobs and job contents, and thereby to a change in the composition of jobs, in terms of the types of tasks a job comprises. Technology can substitute human labour for routine tasks, but not for nonroutine tasks. As discussed in chapter 2, technological substitution has lead to a shift in the composition of

\footnotetext{
${ }^{1}$ The formal model in this chapter is based on the model developed with Bas Straathof which was published in Soete and Ter Weel (2005). In this chapter, the variables and relationships are grounded more thoroughly and in more detail in the empirical psychological literature, while part of the formal model is left out because it did not add significantly to the message of this chapter.
} 
work. It was argued that technological substitution follows the logic of a division of labour between man and machines, each 'specializing' in their 'competitive advantage'. Machines are put to work on tasks that machines are particularly good at: routine tasks that can be standardized, programmed and codified. These tasks can be complex but in the end they consist of a number of routines. Vice versa, human workers do tasks that human workers are good at and what machines cannot do: non-routine activity and interpersonal activity. ${ }^{2}$

Technological development is characterized by a reduction in the price of machinery relative to that of human labour, and this change in relative prices causes entrepreneurs to mechanize and automate an ever larger proportion of routine tasks. As a consequence, on average workers will be required to do less routine tasks $(D$ and spend more time on non-routine activities $(b){ }^{3}$ These generally require a higher level of knowledge and skills which increases the prices of labour, thereby further strengthening technological substitution and the 'intensification' of work (Green and McIntosh 2001; Wilkinson et al. 2001; Green 2004).

When a job contains more nonroutine tasks (when there is a change in the ratio of $h$ and $h$ ), it requires more mental effort $(m)$. The reasons why non-routine work requires more mental effort, and the empirical evidence for this, were discussed in chapter 4. For non-routine work, an actor cannot make use of existing procedures, rules of behaviour, routines, heuristics and scripts but has to develop and adopt new ones.

In addition, non-routine work is characterized by an increase of interruptions of tasks by other tasks, leading to more switching of tasks and multi-tasking. ${ }^{4}$ Interruptions increase mental effort in a non-linear way, especially when it concerns complex tasks. ${ }^{5}$ This necessitates continuous optimization process of time, attention and energy, a process which in itself is time-consuming and effortful and is associated with more mental fatigue $(f)$.

\footnotetext{
${ }^{2}$ Borghans and Ter Weel (2004) find that the introduction of computers leads to skill upgrading because of a reemphasis on the non-routine job activities at the expense of routine tasks (also see Autor 1998).

${ }^{3}$ As was put forward in 2.4, there is a degree of polarization, and part of the jobs become more routinized, for example in the case of call-centres or MacDonald's. However, especially in countries with high labour costs, it can be expected that those tasks that can be substituted by technology will be, and given the limits of technology, nonroutine tasks will generally become more dominant in many jobs. In the jobs in which work is interpersonal but which are nevertheless becoming more and more routinized, this is used to achieve compression of tasks in time resulting in a (different type of) intensification of work. This effectively also increases mental effort; mental effort per task may be reduced due to standardization and routinization, but with the increase of tasks per hour the result may still be an increase in mental effort per unit time.

${ }^{4}$ From the perspective of one task, another upcoming task has a similar effect as an interruption. Kirmeyer (1988) found that coping with competing demands simultaneously caused higher workload and estimates and resulted in a higher need for coping actions. Zijlstra et al. (1999) found that more interruptions of work poses disproportionate additional demands on people's resources. Eyrolle and Cellier (2000) found that interruptions distract in the execution of primary tasks and cause a decrease in efficiency.

${ }^{5}$ Zijlstra et al 1999 show that the time and effort needed for the 'change-over' from one tasks to the other and 'resumption' of the original tasks increases as tasks become more complex. It takes longer to disengage from a complex than from a simple task, it calls for more elaborate cognitive processes from which it is less easy to disengage. People have to reorient on a task after interruption by another task, and the 'reloading' of information and cognitive schemes is to some extent also a motivational process. People may find it difficult to motivate themselves again to devote their attention to the main task again. When the number of task changes grows the level of effort rises and the resumption time, the time needed to restart the task execution, becomes disproportionally longer. This may be explained in terms of decreasing motivation and growing mental fatigue (Zijlstra et al. 1999).
} 


\subsubsection{The intensification of work and mental effort}

In addition to the composition of work, the intensity of work has increased, in terms of speed, multi-tasking and the compression of activities, resulting in higher amount of effort per unit time. ${ }^{6}$ New technology (both material and social technology, variable $\square$ in the model) has lead to speeding up of processes and a reduction of 'empty time.'. Workers not only face a compression of tasks, but also the range of tasks that a worker is expected to do has increased, due to greater flexibility in and between jobs. At the same time, the nature of tasks has become less clear-cut, and management of 'what to do when and why and how' has increasingly been decentralized to the level of the individual worker himself (as was discussed in 2.5). This increases role ambiguity, uncertainty and the need for self-regulation, and thereby again mental effort.

In addition, technology has altered the incentives of workers in a way that they are more prone to choose a higher effort level, due to the effort bias of technological change ${ }^{8}$ (as discussed in 2.6). This effect is strengthened when putting in high levels of effort becomes a social norm. ${ }^{9}$ So while technology in theory helps workers by making tasks easier or taking them over all together, in effect it often leads to a shift in the nature of tasks, a compression of tasks, and an incentive to put in more effort.

The more technology, the higher the ratio of nonroutine work $h$ to routine work $l$, and the higher the intensification of work, due to the effects of technology mentioned above. Since routine work $(\zeta$ requires no mental effort, a lower or higher proportion of this type of work can be understood as higher or lower intensity of work. Thus the ratio of $b$ and $l$ indicates more than just the proportion of nonroutine and routine tasks; it indicates the degree of intensity of work.

Technology has removed many barriers to working, and has thereby removed important temporal buffers in which a worker used to have relative rest, whether he wanted it or not. ${ }^{10}$ To illustrate, when a letter arrives no longer depends on the postal services, but on the decision of the worker, whether he managed to write an email which he can in principle do anytime in the $24 / 7$ economy. The main 'bottleneck' left determining the speed of the

\footnotetext{
${ }^{6}$ See 2.5 for empirical evidence on the intensification of work and the effort-bias of technological change.

${ }^{7}$ For example rather than waiting for something to be typed by the typist, we now type our own work; or rather than waiting for a letter to arrive by mail we receive it instantly by email.

${ }^{8}$ Another reason for the intensification of work is a change in wage inequality, which is related to the skill-bias and effort-bias of technological change. A more convex ('all-or-nothing') relationship between hours worked (or effort made) and career prospects provides a greater incentive for employees to work harder (Bell and Freeman 2001).

${ }^{9}$ As was argued in 2.6., the social norm of putting in effort in combination with the disappearing external limits to work also lead to higher effort levels. This can be understood as a form of bounded rationality called the bandwagon effect - the tendency to do (or believe) things because many other people do (or believe) the same. 10 The term 'technology' refers here to technology in the broad sense of the word, so including 'social technology'; for example, organizational innovation such as flattening hierarchies and decentralizing decision power also removes external (to the worker) drivers and barriers to work (hierarchical regulation), increasing the need to self-regulate.
} 
process, is the human worker himself, which increases the need of self-regulation ${ }^{11}$ which is effortful, as chapter 3 showed. $^{12}$

\subsubsection{Self-regulation and mental effort}

As argued in chapter 2, technology has taken away many of the external limits to effort a worker used to have, leaving it up to the workers to self-regulate their own effort. In combination with developments such as the increase in flexible work practices, multi-tasking and role ambiguity (also chapter 2), this has resulted in an increase in effortful self-regulation (chapter 3), involving monitoring of thoughts and feelings through effortful meta-cognitive activity. ${ }^{13}$

In the model, this is reflected by having the worker choose the output he wants to deliver, the aspired output $\left(y_{a}\right) \cdot{ }^{14}$ In a rapidly changing environment, fatigue accumulates more easily because there is less time to learn about sustainable production targets. The regulation capacity of workers is limited, and the increase of the intensification of work is to some extent 'hidden' since the number of working hours formally did not change. Add to this the effort bias and skill bias of this change, which increases the incentive to put in effort and to exploit skills, and the result is that workers tend to choose an aspired output level which necessitates an effort level that is not sustainable. Because regulation of oneself is in itself effortful (see chapter 3), the increased requirement to do so adds further to the mental effort a worker has to put in. Again this is to some extent a 'hidden' effort increase, in the sense that it is not expressed in more hours of work but in more effort per hour work. Together these aspects increase the chance that the worker misjudges the mental effort level he best could put in (chooses the wrong amount of $m$ ). ${ }^{15}$

The model assumes an adaptive actor, who can and has to learn. It takes the worker some costly try and error to find the right target level (or at least, to avoid the wrong level), his

\footnotetext{
11 The prefix 'self' is used not as something that happens 'by itself', thus without effort, but for something that concerns the self, such regulating oneself, which takes effort.

12 This is especially troublesome for knowledge workers; their job largely consists of processing information, which is so easily accessible these days because of ICT, that there is no natural limit and many suffer from 'information overload' (see Edmunds and Morris (2000) for a review of research literature on this phenomenon), meaning that their capacity to regulate their information intake is insufficient.

13 Metacognitive reflection refers to the appraisal, monitoring, or control of one's cognitions or mental functioning, it plays an important role in cognitive and emotional functioning (Verplanken et al. 2007)

${ }^{14}$ A model with similar variables is Yaniv (1995), which focuses on the amount of overtime that is optimal for an employer. Overtime reduces labour costs per hour worked but at the same time it raises absenteeism due to burnout. Contrary to Yaniv (1995) in the model of this chapter the focus is on the decisions made by the employee rather than the employer. The employer's decisions are captured by maximizing profit given the price of labour and the price of technology.

${ }^{15}$ For routine tasks it is relatively easy to find out what pace of work is maximally sustainable (with manual labour, for example, you will know whether you have worked too hard at the end of the day, if not sooner). For non-routine tasks, the maximally sustainable level of effort is more difficult to assess. One non-routine task may, for example, require a different kind of effort than another. Also, non-routine tasks usually do not come in well-defined portions during a working day but arrive irregularly and with varying priority. The employee has to learn what level of effort has to be made on non-routine activities in order to reach a certain target level of production.
} 
aspired output $\left(y_{a}\right){ }^{16}$ If this target is too high, the employee starts accumulating mental fatigue $(f)$ and risks a burnout $(b)$. A burnout is accompanied with a period of absence from work and in addition involves a permanent deterioration in the health of the worker, which causes a decline in his sustainable productivity. However, if the worker has some flexibility in setting his target, he can find an aspired output level that will not lead to burnout. In the model, an employee has the possibility to make only gradual changes in the target level of production. This reflects inertia in the allocation of tasks that can be found in most organisations, and the bounded rationality of the actor who persists in his aspired output for quite some time by putting in more and more effort rather than adjusting it downward.

\subsubsection{Mental effort and mental fatigue}

As was discussed in chapter 3, stress is the result of the discrepancy between the demands of work and the degree of control of the worker. ${ }^{17}$ The larger the discrepancy between demands and control, the more effort an individual will generally put in, to reduce the discrepancy. The intensification of work increases demands, and thus the stress level, and thereby the effort level. In the model, the level of effort $(m)$ an individual spends thus reflects the level of stress he is experiencing. While the level of effort goes up when stress increases, this is not necessarily the case for the level of performance. Performance goes up when stress increases at lower levels of stress, but goes down when stress increases at higher stress levels. ${ }^{18}$ However, it is effort, not performance that draws on an individual's resources. ${ }^{19}$ Thus it is possible that a worker puts in more effort, nevertheless performs less well, and gets exhausted in the process.

Individuals confronted with a high level of job demands will experience stress activating them to put in high effort, and in this process they will build up symptoms of fatigue feelings of intense tiredness, disturbed mood, impaired cognitive functioning, an increased resistance against further effort, an increased propensity towards less analytic information processing, and changes in mood (Van der Linden et al. 2003). Mental fatigue has been causally related to work demands and role conflicts (Hardy et al. 1997) and to psychological work demands, decision latitude and social support (Bültmann et al. 2001, 2002). Mental fatigue affects those control processes that are involved in the organization of actions and that play a major role in deliberate and goal-directed behaviour (Lorist 2005, 2006). Empirical research shows that fatigue is a widespread phenomenon in the labor force, ${ }^{20}$ especially in professions where work is intense, in terms working at high speed and with tight deadlines, in which tasks or not well-defined and multitasking is common. Mental fatigue $(f)$ reflects reduced capacity and willingness to act adequately, due to earlier mental effort. As a consequence, there is reduced competence and reduced willingness to develop or maintain

\footnotetext{
16 The learning assumption is similar to Hockey (1997), who makes a distinction between short-term and longterm decisions. Short-term decisions are adjusting the level of effort to a target, while long-term decisions are adjusting targets in response to unsustainable effort levels.

${ }_{17}$ See the Demands-Control model in chapter 3. Karasek and Theorell (1990) in a later publication extended the model in order to account for learning and 'accumulation of strain'.

18 See chapter 3, the inverted $U$ relationship between stress and performance.

${ }^{19}$ See chapter 4, and in particular literature on resource theory such as Hobfoll 2002.

${ }^{20}$ E.g. Paoli and Merllié (2001) in a large survey find that 33\% of workers in the EU-15 suffer from 'overall fatigue.'
} 
goal-directed behavior aimed at adequate performance. ${ }^{21}$ Fatigue calls out the need for recovery.

\subsubsection{Recovery}

Recovery $(r)$ is the process of replenishing depleted resources (Sonnentag and Zijlstra, 2006). A worker facing demands experiences stress, which activates him to put in effort, which leads to depletion of scarce mental resources; the level of depletion is reflected by the level of fatigue $(f)$. Recovery replenishes mental resources and diminishes fatigue, thereby improving an individual's performance. Recovery occurs when no further demands are put on those aspects of an individual's functioning that demands have been put on during the work process (Sonnentag and Zijlstra 2006). Recovery is thus enabled by respite, which can have the form of short breaks, days off, weekends or vacations. ${ }^{22}$ Respite experiences and recovery processes have a positive effect on individual well-being (Etzion et al. 1998) and on work engagement (Sonnentag, 2003).

The psychological mechanisms through which respite contributes to recovery are often not explicated; it is often assumed that there is a spontaneous restorative function (Westman and Eden 1997). Recovery is, ultimately, a physiological process. As McEwen (2008) describes, the stress response is a physiological process: brain regions such as hippocampus, prefrontal cortex and amygdala respond to acute and chronic stress and show changes in morphology and chemistry. These changes are in principle largely reversible due to the plasticity of the brain. ${ }^{23}$ However, regular recovery is needed, and since the stress system consists a number of complex interdependent interacting equilibrium systems which become dysregulated, recovery takes time. The level of stress hormones is elevated during work time and should decrease during off-work periods (Kuiper et al. 1998). In order to do that, other hormones have to be produced and secreted in the body, but that only happens when there are no perceived stressors anymore. This biological system determines aspect of the recovery process, such as the accumulation of need for recovery, the fact that recovery takes time, and the fact that it can only take place in times with low or no stress.

In principle, some recovery can take place during work, at low levels of demand on a worker. Routine work ( $($ ) requires low mental effort and in many ways 'gives the brain a break', since they are low-effort activities they don't draw upon mental resources and allow for the

\footnotetext{
21 Mental fatigue is a multidimensional construct (Michielsen et al. 2004). We use it here as a simple homogenous variable that increases with mental effort $m$ and influences the degree to which mental effort $m$ leads to successful performance of complex nonroutine tasks $b$ (the more fatigue $f$, the more $m$ is needed to achieve $h)$.

22 Short breaks during work are beneficial for the well-being and performance of workers, allowing them to maintain a higher level of effort; in particular suspension of self-regulation processes during task performance was found to be useful because it can help reduce resource-consumptive elements of self-regulatory processing, such as negative emotional reactions. (Kanfer et al. 1994). Vacations are found to be good for reducing stress under certain conditions, and can alleviate burnout; though often not completely and if the work situation does not change this effect is transitory (Westman and Eden 1997).

23 There is however evidence that prolonged stress for many months or years may have irreversible effects on the brain, partly also because chronic stress also leads to lifestyle changes (e.g. sleeplessness, alcohol and fat consumption) which have separate negative effects (McEwen 2008).
} 
restoration of previously taxed resources and recovery (Sonnentag and Natter, 2004). Thus the ratio of routine and nonroutine work matters for the degree of recovery that needs to and that can take place.

The worker's need for recovery is largely determined by the level of fatigue caused by work demands; the higher fatigue of a worker, the higher the need for recovery. ${ }^{24}$ Empirical evidence suggests that the more demanding and intense the working day has been, the longer it takes to recover; ${ }^{25}$ this means that the need for recovery increases with the increase of the ratio $b$ and $l$ which indicates the degree to which work is mentally demanding. Developments such as globalization (24/7 economy) and the increased use of (mobile) information and communication technology have affected the cycle of work and rest and the availability of time for recovery. This suggests that the need for recovery is also related to the technology chosen in view of the price of technology $(k)$ and labor (wages $w$ ), which determines the level of $h$.

\subsubsection{Burnout}

Recovery from work is important to protect workers' (mental) health and well-being in the long run. Lack of recovery leads to poor well-being, lower performance, and (mental) health problems (Sonnentag and Zijlstra 2006). Continuous depletion of resources in the absence of recovery leads to chronic feelings of fatigue, function loss, physical and mental impairment, and symptoms of burnout. ${ }^{26} \mathrm{~A}$ burnout due to chronic stress can permanently decrease the recovery ability of people (McEwen 2008), and thereby structurally affect their productivity.

This section has briefly described the main variables and their relationships that we need in order to find out what the optimal mix of production factors is when taking mental capital into account, on the basis of what is found in empirical research. In the next section, the model will be presented.

\subsection{The Model}

A firm produces a single good $y$ and employs one person and $k$ machines. The employee can perform both routine tasks $l$ and non-routine tasks $h$. The routine tasks $l$ can also be performed by machines but routine labour and machinery are imperfect substitutes. Nonroutine labour cannot be performed by machines and is thus complementary to both routine tasks and machines. Production takes place with constant elasticities of substitution (CES) and constant returns to scale.

\footnotetext{
${ }^{24}$ Sluiter et al. 2003; Sonnentag and Zijlstra (2006).

25 For example, Meijman et al. (1992) find that people with intensive working days had more difficulty recovering, had higher levels of adrenaline excretion at 10 p.m., reported more sleep complaints and higher levels of fatigue the next morning.

${ }^{26}$ E.g. Maslach et al. (2001); Sonnentag and Natter (2004). Burnout is a state characterized by persistent emotional exhaustion, cynicism, depersonalization (disconnecting from work), reduced competence and selfefficacy, and in the end, low or no productivity (Maslach et al. 2001).
} 
The assumption of constant returns to scale may seem unrealistic at first sight, after all workers generally learn and get better at what they do when they do more of it, which means there is increasing returns to scale. However, the essence of non-routine tasks is that the possibility to learn from one task and apply this learning to another task is limited, exactly due the non-routine character of the tasks. As to routine tasks, once tasks have become routine, it means that there is by definition not much learning possible for the worker anymore, since if that were the case it would not (yet) be a routine task.

Assuming constant elasticity of substitution may be unreasonable if variables take on extreme values. However, in general this assumption does not significantly influence the main dynamics which the model wants to show, and it enables tractable use of a nested production function.

Production can be described as the following nested production function:

$$
y=\left[h^{\phi}+\left(l^{\mu}+k^{\mu}\right)^{\frac{\phi}{\mu}}\right]^{\frac{1}{\phi}}
$$

The parameter $\phi<0$ ensures the complementarity of non-routine tasks with routine tasks and machines, the parameter $0<\mu<1$ determines the degree of substitutability between routine labour and machinery.

The entrepreneur chooses the amounts of routine and non-routine labour and machinery such that the profits of the firm are maximal. The optimization problem for given prices of output $p_{y}$ and machines $p_{k}$ and given wage rate $w$ can be stated as

$$
\max _{h, l, k}\left\{p_{y}\left[h^{\phi}+\left(l^{\mu}+k^{\mu}\right)^{\frac{\phi}{\mu}}\right]^{\frac{1}{\phi}}-w(h+l)-p_{k} k\right\} .
$$

The first part of the equation gives the revenue, the second part the costs.

It follows directly from the first order conditions that $k / l=\left(w / p_{k}\right)^{1 /(1-\mu)}$. After somewhat more elaborate manipulation, the optimal ratio of non-routine to routine labour, which is called $\kappa$, can also be expressed as a function of $w / p_{k}$.

$$
\kappa \equiv \frac{h}{l}=\left(\left(w / p_{k}\right)^{\frac{\mu}{1-\mu}}+1\right)^{\frac{\phi(1-\mu)}{\mu(\phi-1)}+1}
$$

After substitution of $l$ and $k$ in the production function (1) the output of the firm becomes a linear function of the amount of non-routine tasks, given the price of machines and the wage rate. 


$$
\begin{gathered}
y=\Gamma h \\
\Gamma \equiv\left[\left(\left(w / p_{k}\right)^{\frac{\mu}{1-\mu}}+1\right)^{\frac{\phi(1-\mu)}{\mu(\phi-1)}}+1\right]^{1 / \phi}
\end{gathered}
$$

The $\Gamma$ effectively indicates the technology that has been chosen for production. Technology is used in the broad sense of the word, so includes both material and social technology, such as that resulting from organizational innovation (see chapter 2 on organizational technology).

The employee is paid according to the amount of tasks that have been performed. Although the entrepreneur decides on the ratio of non-routine to routine tasks, the employee can choose his output level and his level of effort. It is assumed that the optimal amount of machinery is available for every number of tasks chosen by the employee. From the perspective of the employee non-routine tasks $b$ differ from routine tasks $l$ because $b$ requires 'mental effort', $m$, and leads to mental fatigue, $f$.

The quantity of non-routine tasks that are performed depends linearly on mental effort and on the level of fatigue.

$$
h=\max \{m-\alpha f, 0\}
$$

Here, $\alpha$ is a parameter that determines how much productivity is affected by fatigue.

During routine tasks the worker can 'recover' from non-routine activities, since routine tasks require no mental effort in the $\operatorname{model}^{27}$ and thus count as something resembling a 'break' from the non-routine tasks. In particular, $\rho$ hours of $m$ are compensated for during one hour of $l$. After one period of routine and non-routine activities, compensated mental effort equals

$$
m-\rho l=m-\frac{\rho}{\kappa}(m-\alpha f)=\left(1-\frac{\rho}{\kappa}\right) m+\frac{\alpha \rho}{\kappa} f .
$$

Work in real life and in the model will always by tiring to some extent, thus $\rho<\kappa$.

If $\rho$ were greater than $\kappa=b / l$ then the compensation from $/$ would be bigger than the fatigue from $m$ (caused by $h$ ), then work would be invigorating rather than tiring.

When mental effort is not fully compensated for during routine activities, it causes fatigue to accumulate.

\footnotetext{
27 Obviously, the assumption of zero fatigue from nonroutine labour is extreme. It is not necessary. What matters is that routine labour is less mentally fatiguing than nonroutine labour, and so reduces the rate at which fatigue accumulates. Making this extreme assumption reduces the parameter space of the model and does not change the fundamental results.
} 


$$
\begin{aligned}
f_{t} & =\max \left\{f_{t-1}-r_{t}+\left(1-\frac{\rho}{\kappa}\right) m_{t}+\frac{\alpha \rho}{\kappa} f_{t-1}, 0\right\} \\
& =\max \left\{\left(1+\frac{\alpha \rho}{\kappa}\right) f_{t-1}-r_{t}+\left(1-\frac{\rho}{\kappa}\right) m_{t}, 0\right\}
\end{aligned}
$$

$r$ is the 'recovery capacity' of the worker. Every period $r$ is subtracted from the fatigue accumulated in the current and previous periods. A person with a high recovery capacity is able to do a large amount of non-routine tasks without experiencing a decline in his productivity.

As a person cannot become infinitely tired there is a maximum to the fatigue a person can accumulate. If this maximum is reached the person experiences a burnout, which leads to an abrupt change in his behaviour. First of all, the employee goes on sick leave $(m=0)$ until his fatigue has disappeared $(f=0)$. Second, the recovery capacity of the person is damaged permanently, he lost some mental resilience and cannot handle as much mental effort anymore as he did in the past. A burnout causes $r$ to be reduced by the amount $\omega$. Whether a person has a burnout is signified by the dummy variable $b$, that equals one in case of a burnout and zero otherwise. The conditions for a burnout are illustrated in Figure 1.

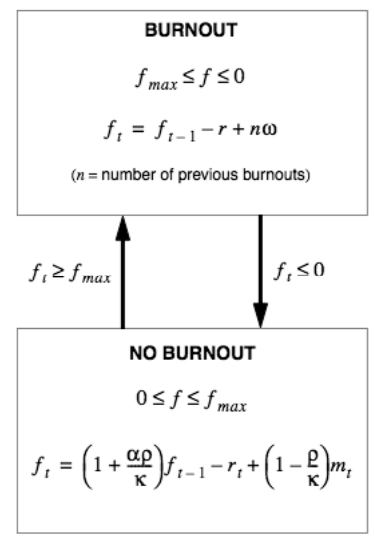

Figure 1. Conditions for burnout

Now the environment in which the employee works is specified. He can adjust to his environment by changing his mental effort and by setting his aspired level of output, $y^{a}$. The employee gradually adjusts his effort according to the rule

$$
m_{t}=\left\{\begin{array}{cc}
\max \left\{m_{t-1}+\beta\left(y_{t-1}^{a}-y_{t-1}\right), 0\right\} & \text { if } b_{t}=0 \\
0 & \text { if } b_{t}=1
\end{array}\right.
$$

where $\beta$ is a parameter. He changes his level of effort to get closer to his aspired level of output. If production in the previous period was above the aspired level then the worker will reduce his efforts, if production was too little he will work harder. 
Besides changing his effort level a worker may also alter his aspired level of production. If no fatigue is being accumulated while the aspired level of production already has been reached, the employee multiplies his desired level of production by $\eta>1$. Reversely, if fatigue accumulation does occur while the aspired level of production has not been reached, the person knows that this behaviour is likely to be unsustainable and he will start reducing his aspired level of production by dividing it by $\eta$. Furthermore, we assume that when a worker has accumulated so much fatigue that he enters a burnout, he will reduce his aspired level of production by multiplying it by $\gamma<1$, knowing that not only the previous target has been unsustainable but also that the burnout has reduced his recovery capacity.

The entrepreneur can change the technology, choosing a different mix of inputs. This will affect the production per hour worked: more technology in principle leads to more output per hour worked and vice versa. Therefore the production target should be multiplied by $\Gamma_{t} / \Gamma_{t-1}$.

The decision rules governing the aspired level of production are summarized below.

$$
y_{t}^{a}= \begin{cases}y_{t-1}^{a} \frac{\Gamma_{t}}{\Gamma_{t-1}} \gamma & \text { if } \Delta b_{t}=1 \\ y_{t-1}^{a} \frac{\Gamma_{t}}{\Gamma_{t-1}} \eta & \text { if } b_{t}=0 \text { and } y_{t-1}^{a} \leq y_{t-1} \text { and } \Delta f_{t-1} \leq 0 \\ y_{t-1}^{a} \frac{\Gamma_{t}}{\Gamma_{t-1}} \eta^{-1} & \text { if } b_{t}=0 \text { and } y_{t-1}^{a}>y_{t-1} \text { and } \Delta f_{t-1}>0 \\ y_{t-1}^{a} \frac{\Gamma_{t}}{\Gamma_{t-1}} & \text { otherwise }\end{cases}
$$

In words:

If a worker suffers a burnout, he will reduce his aspired output level by multiplying it with a factor smaller than 1 .

If a worker has had no burnout, and is not accumulating fatigue but on the contrary, he feels he can do more, he will increase his aspired output level by multiplying it with a factor larger than 1 .

If a worker has had no burnout but is accumulating fatigue, and feels he cannot go on like this, he will reduce his aspired output level by multiplying by a factor less than 1 .

If a worker works and does not have to put in more mental effort than that he can recover from, thus does not accumulate fatigue, he just remains with his aspired output level.

\subsection{Results}

The complexity of the model outlined above does not allow for a straightforward analytical solution and therefore a numerical simulation is performed for the analysis of the model. For several cases we show figures of typical time paths for output, aspiration level, mental effort, fatigue and burnouts. Following this we present a table which gives a fuller picture of the 
model. In order to get a grasp of the basic working of the model, we will start by having a fixed aspiration level for production $(\eta=\gamma=1)$. The worker is not allowed to vary his target and the entrepreneur is not allowed to change the technology of production. In this setting two events are possible. First, the aspired level of production might be feasible and sustainable given the worker's recovery capacity. In this case the worker will adjust his effort level, perhaps temporarily over- or undershoot the target level of production, reach the target, and will stick to the target with a constant level of mental effort and fatigue. Second, the worker may not be able to able to sustain or even reach the aspired level of production. This situation is illustrated by Figure 2 .

The first graph in Figure 2 plots the actual level of production $y$ (solid line) and aspired level of production (dashed line) $y_{a}$ against time. The second graph plots the level of mental effort $m$, the third the level of mental fatigue $f$, and the fourth presents the instances of $b$, the burnout dummy.28

Initially the worker is able to achieve the production target but fatigue starts to accumulate. The adverse effect of fatigue on productivity causes the worker to exert himself more and more in order to stick to his target. In period 49 fatigue has reached a maximum and the
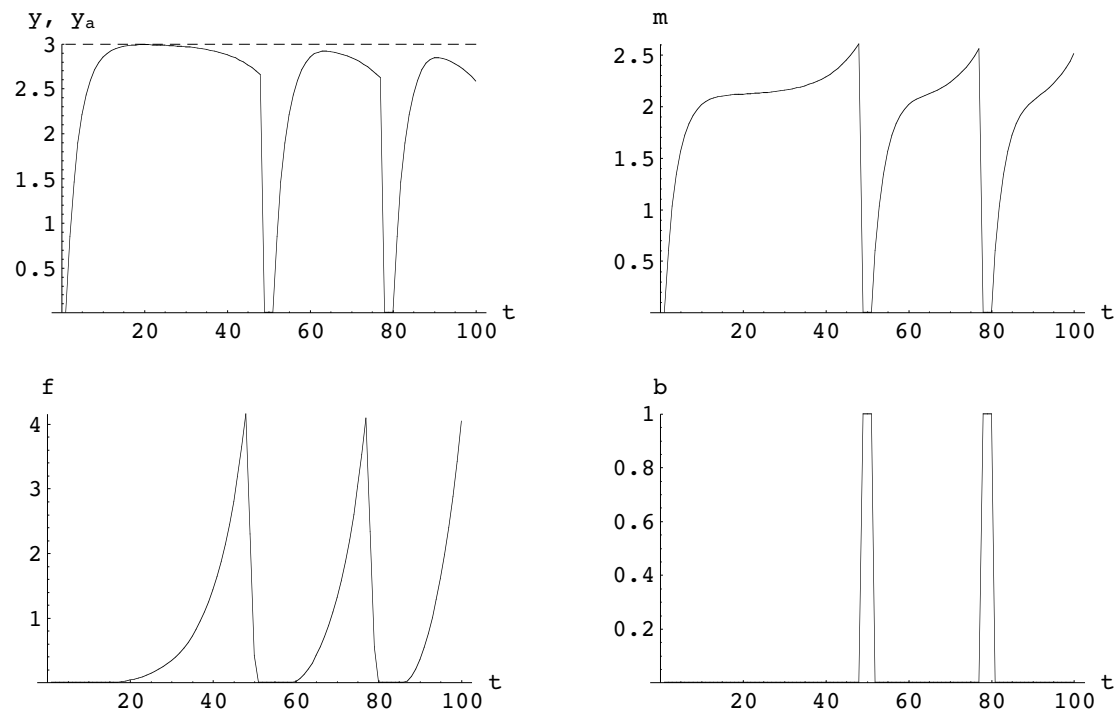

Figure 2. Fixed aspired production level

person experiences a burnout. After a few periods of rest, fatigue has disappeared and the person goes back to work. However, the burnout has lead to structural permanent damage to the recovery capacity which makes it impossible to achieve the aspired level of production again. A second burnout follows quickly.

${ }^{28}$ The other parameter settings are:

$f_{0}=0, f^{\max }=4, m_{0}=0, y^{a}=3, r=2, \alpha=0.2, \beta=0.2, \omega=0.1, \phi=2, \kappa=1, \mu=0.5, \rho=0.05$ 
Next, in contrast to the previous figure, flexibility in the aspired level of production is now allowed, while keeping technology constant. Simulation results with $\eta=1.001$ and $\gamma=0.9$ can be found in Figure 3. The other parameter settings are identical to those of the simulation of Figure 2. As soon as fatigue starts accumulating the worker begins adjusting his target downwards. Unfortunately, he is unable to reduce the target quickly enough and the burnout is postponed rather than avoided. The burnout leads the worker to drastically reduce his aspired level of production. In the situation depicted in Figure 3 the post burnout production target proves to be sustainable and a second burnout is avoided. Flexibility in the aspired level of production thus postpones the first burnout and avoids the second and third burnout completely. After the first burnout, the worker adjusts his aspired output level such
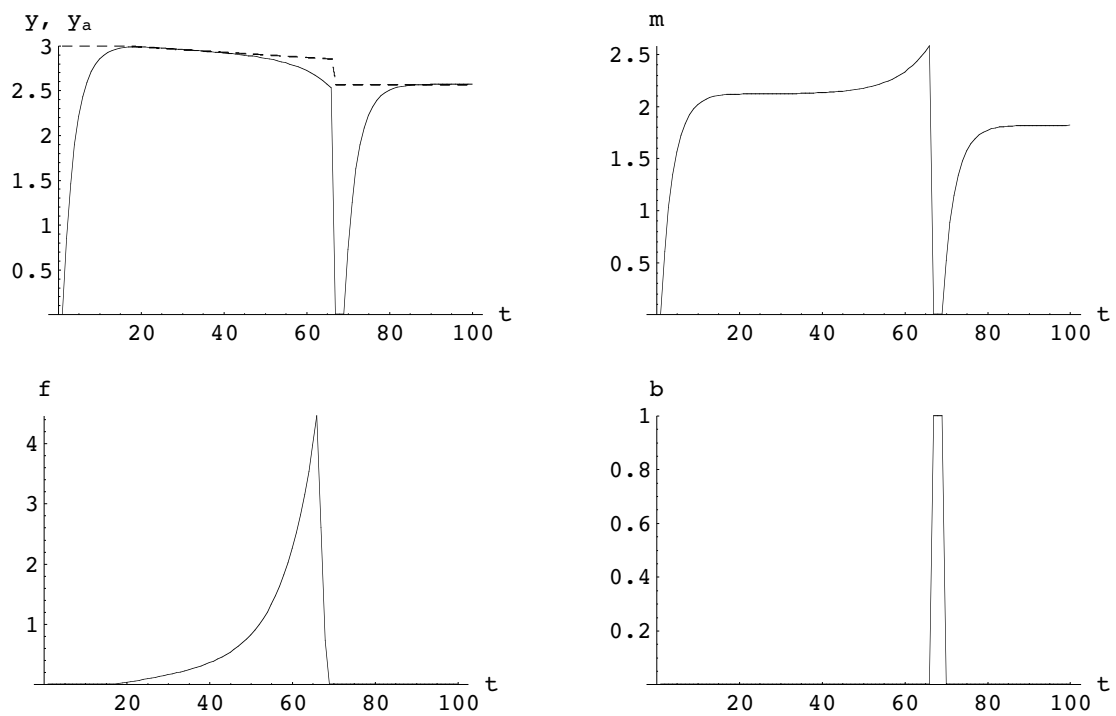

Figure 3. Flexible aspired production level.

that he does not accumulate any fatigue.

The simulation illustrated by Figure 4 allows not only for adjustment of aspiration output level, but also for gradual technological change. In particular, unskilled routine tasks are increasingly taken over by machinery - such as computers. This process of mechanization requires the worker to increase his mental effort in order to keep up with the targets set by the entrepreneur. Although the worker is able to make the same adjustments to the target as before, he is not able to postpone the burnout as long as in the situation without technological change. Thus, mechanization has an adverse effect on the worker's mental health because the worker spends a larger part of his working day on non-routine activities, which makes him more susceptible to fatigue accumulation and burnout. This describes the situation up to period 41, when he experiences his burnout. After this, he is able to modify his aspiration output level such that he never accumulates fatigue thus not experiences further burnouts. 

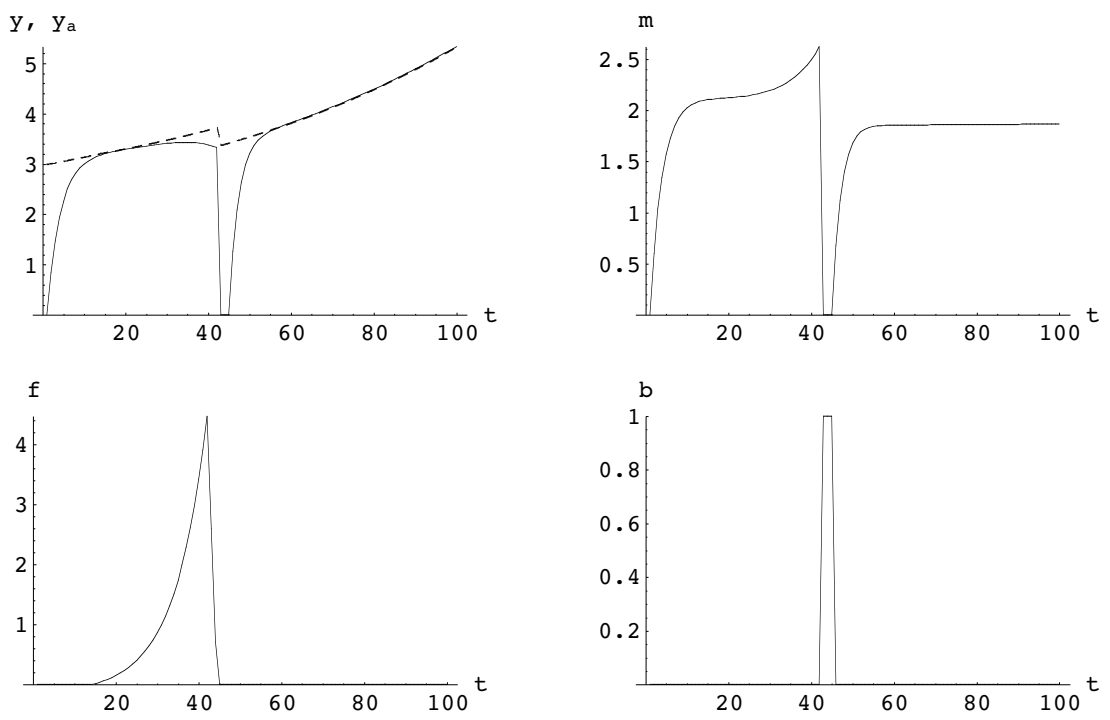

Figure 4. Technological change.

A more complete picture of the functioning of the model is provided by Table 1 , which contains simulation results for 27 parameter configurations. The configurations differ in three dimensions: recovery during routine work $(\rho)$ flexibility in the aspired level of production $(\eta)$ and the speed of mechanization $\left(\kappa_{t} / \kappa_{t-1}\right)$. The parameter $\gamma$ measuring degree of aspiration adjustment after burnout is fixed throughout at 0.9 .

The first three columns of the table show the values for $\rho, \eta$ and $\kappa_{t} / \kappa_{t-1}$, the fourth column contains the number of burnouts after 100 periods and the fifth column shows the period in which the first burnout starts. For each combination of $\rho$ and $\eta$, a higher rate of mechanization leads to more and earlier burnouts. Higher flexibility $(\eta)$ has the opposite effect. The more flexibility a worker has in choosing his target, the lower the number of burnouts will be. When routine tasks allow for recuperation from non-routine tasks (so less technology), fewer burnouts will occur. 
Table 1. Simulation results

\begin{tabular}{lllll}
$\rho$ & $\eta$ & $\kappa_{t} / \kappa_{t-1}$ & $\begin{array}{l}\text { Number } \\
\text { burnouts }\end{array}$ & $\begin{array}{l}\text { of } \\
\text { burnout }\end{array}$ \\
\hline 0 & 1 & 1 & 2 & 28 \\
0 & 1 & 1.01 & 2 & 28 \\
0 & 1 & 1.03 & 4 & 27 \\
0 & 1.001 & 1 & 1 & 29 \\
0 & 1.001 & 1.01 & 1 & 28 \\
0 & 1.001 & 1.03 & 2 & 27 \\
0 & 1.01 & 1 & 1 & 50 \\
0 & 1.01 & 1.01 & 1 & 48 \\
0 & 1.01 & 1.03 & 3 & 41 \\
0.05 & 1 & 1 & 1 & 49 \\
0.05 & 1 & 1.01 & 1 & 40 \\
0.05 & 1 & 1.03 & 1 & 33 \\
0.05 & 1.001 & 1 & 1 & 67 \\
0.05 & 1.001 & 1.01 & 1 & 43 \\
0.05 & 1.001 & 1.03 & 2 & 34 \\
0.05 & 1.01 & 1 & 0 & - \\
0.05 & 1.01 & 1.01 & 0 & - \\
0.05 & 1.01 & 1.03 & 2 & 94 \\
0.1 & 1 & 1 & 0 & - \\
0.1 & 1 & 1.01 & 1 & 90 \\
0.1 & 1 & 1.03 & 1 & 46 \\
0.1 & 1.001 & 1 & 0 & - \\
0.1 & 1.001 & 1.01 & 1 & 94 \\
0.1 & 1.001 & 1.03 & 3 & 49 \\
0.1 & 1.01 & 1 & 0 & - \\
0.1 & 1.01 & 1.01 & 0 & 94 \\
0.1 & 1.01 & 1.03 & 2 & \\
\hline & & & & \\
\hline
\end{tabular}

\subsection{Discussion}

\subsubsection{The rate of technological substitution}

The results of the model show that at higher levels of technological substitution, burnout will occur sooner and more often, due to the intensification of work in terms of mental effort. ${ }^{29}$

\footnotetext{
${ }^{29}$ This corresponds to empirical evidence linking fatigue and burnout to professions and sectors in which there is a lot of innovation (see chapter 2). Again, technology is used in an abstract sense, referring to both material and social technology (result of organizational innovation); it is the overall rationalization of the production process that increases mental effort. This is especially important in parts of the service sector, where introduction of technology generally does not "save" time but makes more efficient use of time, which effectively means intensification of work.
} 
The higher the ratio $\kappa / \kappa_{t-1}$, so if technological substitution increases over time, the sooner a burnout occurs and the more burnouts occur. Thus, on the one hand a high level of technological substitution leads to more profit due to increased efficiency and decreased costs (machines being cheaper than human labor); but on the other hand it can lead to a loss of profit due to reduced productivity (due to fatigue), absenteeism (due to burnout), reduced output levels (adjusted after burnout to accommodate structural damage of the recovery capacity). Given that at high levels of substitution the price of labor will be relatively high (because otherwise the substitution would not be as high), the reduced availability and productivity of labor is a cost factor that an entrepreneur will have to worry about. It may take away a substantial part of the profit he thought to make by increasing technological substitution. Because the negative effects of a high level of technological substitution are indirect, via the intensification of work in terms of mental effort, they are less easy to recognize than the positive effects. In addition, because it is hard to know beforehand how technology will affect job contents and thus mental effort, it is difficult for the entrepreneur to develop an optimal strategy.

\subsubsection{Decision latitude of the worker}

One option an entrepreneur has is to leave it to some extent up to the worker to choose his own aspired output level and thus his level of mental effort. After all, the worker can be expected to be more able to estimate what the right level effort is, since he has more direct information about his own fatigue levels. Indeed the model shows that when the worker is allowed to choose his aspired level of output and implicitly through this his mental effort, the first burnout occurs later, and there are less burnouts or none at all. The degree to which he adapts his output and thus effort is reflected by $\eta$; the higher $\eta$, the more adaptation by the worker takes place, and the longer it takes for a burnout to occur, if at all. ${ }^{30}$ However, even with a higher decision latitude burnouts, though later and fewer, do occur. This shows that the worker has difficulty finding the right level of output and effort, and has to learn the hard way. The worker does not have perfect foresight but has to learn and has to keep learning, because a ratio of $\kappa / \kappa_{\mathrm{t}-1}$ that is greater than 1 means continuing technological change, making the optimal level of output a moving target. Due to the increased premium for effort (because of effort-biased change) the management strategy of employers to stimulate the intrinsic motivation of their employees which makes them want to put in more effort, and the 'hidden' character of the effort intensification of work, the probability that an employee chooses an (initial) effort level that is unsustainable is high. In addition, the worker can be expected to have some degree of bounded rationality. Though it is not in the model, the degree of bounded rationality depends on his level of fatigue (fatigue clouds judgment, see 5.2.5) and if this relationship were included in the model, the worker would adjust his aspired output levels even less appropriate, thus speeding up the occurrence of a burnout, strengthening the main dynamics of the model.

\footnotetext{
30 This corresponds with empirical research findings showing that more decision latitude helps to make a better match between control and demands, and thus reduces stress, fatigue and the chance of burnout (Karasek and Theorell 1990). The need for recovery is found to an important extent to be related to people's ability to regulate their effort expenditure. When job control is low, individuals have no escape from demanding tasks and have to continue a high level of effort, increasing the need for recovery. (Sonnentag and Zijlstra 2006).
} 
More decision latitude for workers in jobs is only part of the answer. When job control is high, individuals can switch to less demanding tasks and working methods when they feel overtaxed. However the process of reorientation and learning in itself is mentally effortful. Thus to some extent high job control again adds mental effort, in the form of the need for self-management. The effect of more decision latitude in jobs depends to an important extent on the ability of the worker to self-regulate, to act on his own behalf. The extent to which individuals are successful in regulating their effort expenditure determines whether, how soon and how often a burnout will occur. Thus in an economy with high levels of technological substitution, self-agency is of more critical importance to optimize inputs and maximize profits.

The model shows that a high rate of technological change increases productivity, but at the same time reduces the mental capital of workers and thus reduces productivity - especially if they are not allowed or are unable to exercise a degree of control over their production targets. However, the conclusion that increasing job control, task autonomy or flexibility is enough to avoid burnout in a rapidly changing environment is not necessarily correct. Giving employees more control over their work (by increasing decision latitude $\eta$ ) may actually raise the amount of non-routine tasks they need to perform and may add to the problem rather than diminish it. In the model this would mean that $\eta$ in fact influences mental effort $m$, which would give rise to yet another adjustment of the optimization problem, suggesting that there is also a trade-off that $\eta$ should be optimized rather than maximized. Giving the employee too much freedom means in fact forcing him to manage himself, which is not easy.

\subsubsection{Mental capital}

In chapter 4 we identified mental health, or more specifically its close correlate, self-agency, as a form of capital, fitting the definition of capital commonly used in economics. It was proposed to characterize mental capital by the shape and position of the inverted $U$ of stress and performance; for example, at a certain level of stress a person with a taller $U$ achieves more than a person with a shorter $\mathrm{U}$, and a person with a long-stretched $\mathrm{U}$ will perform at most stress levels even the high levels. It was proposed that the tallness of the inverted $U$ is determined by the level of human capital (the more knowledge and skills, the higher the potential performance) and by the mental capital of the worker. The actual performance level at the optimum can be structurally lower than the potential performance level at the optimum level given the human capital of the worker. For example if a person is depressed and has substantial concentration problems, he will not be able to work to the full potential of his human capital.

In the model in this chapter, mental capital acts via several parameters and variables. It determines the value of $\alpha$, the parameter that determines how much productivity is affected by fatigue. It determines the value of $\rho$, because a person recovers more easily and the number of hours of $l$ needed to compensate for hours of $b$ is thus lower. Because mental capital is an indicator of the degree of bounded rationality of an actor, it determines the value

of $\beta$, the parameter that determines the extent to which a worker adjusts his effort level to 
get closer to his aspired level of output, and $\eta$, the parameter determining the extent to which aspired output is adjusted upward or downward. ${ }^{31}$

The model points out an interesting aspect of mental capital. Though the inverted $U$ can change in shape and position (for example in the case of mental illness it can shrink and shift considerably, or in the case of increasing psychological skills, it can expand), on the short term it generally is reasonably stable. However, on the short term people do seem to vary considerably in their levels of expendable mental capital. This fluctuates for example considerably over the course of a day (high in the beginning of the day, low at the end). The reason for this is biological, it has to do with the HPA-axis regulating the stress response. As soon as activities begin, stress arises to activate the person to act and deal with whatever needs to be done. This is a physiological mechanism, stress hormones make us active, alert, focused and energetic. However, as was briefly described in 5.2.7 and 5.2.8, the body has to get rid of these stress hormones before they start to affect body and brain negatively, damaging the very capacity to cope. In biology and psychology this is all studied and worked out elaborately. But how can we understand these features in terms of the concept of capital?

Similarly to other capital concepts, mental capital is not economically valuable because of itself, but because of the services it provides. To draw an analogy, a machine is valuable because of its productive services, and has a certain capacity which reflects a certain amount of services that can be provided in a certain unit of time. At the end of the day, the machine needs maintenance. If it does not get enough maintenance and gets used too much, it will start to work less well; it may get overheated from overuse, things start to break down, and its capacity decreases. Similar to a machine, the human brain provides 'mental services', in terms of processing information and knowledge, making calculations and evaluations, and taking decisions. Maintenance for recovery can only take place in periods in which few or no demands are made: during routine work, a lunch break, a night's sleep, a weekend of leisure, or a holiday. If the brain has to work more than its capacity and does not get enough maintenance, it will start to function less well (fatigue) until it gets the chance to recover. If there is no chance to sufficiently recover, it will start to break down (burnout). In the model, fatigue signifies the fluctuations in mental capital within a period of time, while the loss of recovery capacity signifies the loss of mental capital over time.

\subsection{Concluding remarks}

In this chapter a model was presented that relates a worker's mental capital to the rate of technological change. The model achieved a number of objectives. It served to organize and connect a large body of knowledge developed in different disciplines. By selecting key variables and key relationships, more control was gained over the elements discussed verbally

\footnotetext{
31 There are several types of bounded rationality that can apply here: the endowment effect - the tendency for people to value something more as soon as they own it, which is also valid for tasks at work which they don't want to delegate or give up; byperbolic discounting - the tendency for people to have a stronger preference for more immediate payoffs relative to later payoffs, the closer to the present both payoffs are; so resting now (and not achieve all you wanted) in order to protect your productivity in the future is difficult due to the time between the action and the result; the planning fallacy - the tendency to underestimate task-completion times; the self-serving bias - the tendency overestimate the chance for success and to undersestimate the chance for failure.
} 
in chapter 2, 3 and 4, and more insight was gained about the relationships of the different elements in these chapters. In addition, the model helped to get more understanding of the relative contribution potential interventions, such as limiting the speed of innovation and the intensity of work and increasing the decision latitude of workers. It is important to see possible interventions in terms of a mix that is to some extent complementary. For example, if the entrepreneur chooses not to limit the intensity of work, he will have to select potential workers more rigorously on their mental resilience, or send his current workers to training to increase their ability to regulate themselves, their self-agency (in the model: determining the value of parameter $\alpha$ and determining the effectiveness of increasing parameter $\eta$ ). If on the other hand the entrepreneur slows down the speed of innovation, by limiting the frequency of introducing social and technological innovation and by practicing good change management during innovation allowing adjustment of workers to the new situation (in the model lengthening the time for adjustment of the workers thus preventing the burnout that occurs due to failure of the worker to learn fast enough how to adjust mental effort), he can work with workers that are not perfectly mentally resilient. Since mental resilience is a scarce good and it is expensive, and since it is socially and economically undesirable to exclude people that are not perfectly mentally resilient, this is an important option.

The model can be extended in several ways. For example, it can be used to assess the impact of the type of contract between employer and employee and more generally of flexibility in the labour market on health and productivity. Clearly the employer also is suffers when an employee suffers from fatigue and burnout of an employee, because of its effects on output. However, the employee suffers quite a bit more, being fatigued constantly, having to go through burnout(s) and having to live with a reduced recovery capacity, thereby reducing his chances for promotion and (re)employment, and reducing the value of the human capital he has accumulated in terms of education. Especially in a flexible labour market in which workers can be laid off if no longer of use, the costs and benefits of technological change may be unequally distributed over employer and employee, the former having most of the benefits and the latter most of the costs. The benefits may also accrue to the consumer who gets more for less, due to the higher output which can be maintained by renewing mentally worn-out workers regularly. Nevertheless, due to mental capital effects the social outcome of the economy could be suboptimal.

Endogenizing the costs to some extent can help to reach a social optimum. This can for example be done by changing the type of contract between employer and employee. Recently in the Netherlands the law has changed, making and the employer now pay for the costs of illness and work disability of an employee for up to two years. This was especially done to deal with the above average number of people that are on sick leave or work disabled due to psychological problems. Often these problems have their origin in the work situation, and they should be solved there too, but that does not happen if both parties are not forced to do so. The employer has the obligation to try to find fitting work for the employee, and the employee has the obligation to cooperate in all possible ways to make this happen. If the employer does not do this, he will have to pay for a worker who does not work. If the employee does not cooperate, he can suffer consequences such as being fired and loosing the right to unemployment benefits. 
By giving both the employer and the employee more stakes in each others' goals and wellbeing, both can gain. Bringing the costs related to mental capital into the production function of the firm will inspire the employer to reduce fatigue and burnout, increase the quality of human resource management, and increase the agency and decision latitude of workers. Making the responsibility of employees to cooperate more explicit gives them 'coownership' of the problem of the employer and will stimulate them to cooperate in finding a solution that works for both, rather than to free ride or drop out, burdening either the employer or the tax payer unnecessarily.

Risks associated with this approach is increased 'front door selection', employers only hiring employees that seem healthy and stress resistant, leading to exclusion of part of the labor force. Also, there are costs of monitoring, arbitration and mediation to find out whether employer and employee act in good faith, and possibly costs of going to court in case of disagreement between employer and employee about a situation. On the other hand, it reduces costs that firms face related to high employee turnover and hiring and firing, since they ideally keep their workers longer aboard and if a worker leaves it will be a more clear-cut and smooth transition. Also it reduces social costs of a large part of the labour force being either on work disability or on unemployment benefits, during which they loose human capital due to lack of use, and acquire a stigma of being less useful reducing their chances to return into employment.

The model could be adapted and extended to get more grip on policy-relevant questions such has how to approach the social optimum more closely. The Dutch policy sketched above is in fact the attempt to solve a principal-agent problem in a more sophisticated way. By aligning the interests of employers and employees, with the help of a careful system of 'sticks and carrots', based on real insight in the cause of much absenteeism and work disability, all parties can win, for sure at the longer time. Adding the notion of mental capital brings this classic principal-agency problem at a deeper level. Reduction of mental capital due to stress and mental health problems means a reduction of the agency function of a person, of the ability to act as an agent. Typically principal-agent theory assumes that the main problem lies in the diverging interests of the principal and the agent. However, the problem could also lie in the ability of an agent to act as an agent in the first place. An employee can be fully willing to act in the interest of the principal in principle, but nevertheless fail to do so in practice. In addition, the system of incentives designed to make an agent act in the interest of the principal often is based on an idea of (enlightened) self-interest of the agent. However, if the agent is not able to see what is in his interest, or if he is, is not able to act in his own interest, then such systems will not have the expected and desired outcome, and sometimes even are counterproductive.

The model is a micro-level model, and up to now the discussion has been at the micro-level. However the outcome of the model has macro-economic implications. The model could be incorporated in a general equilibrium framework with endogenous technological change. In such a framework, the rate of technological change might depend on whether the costs of burnouts are carried by employers or by, for example, the government. Also it is possible to connect to human capital models. Lack of agency reduces the returns on human capital investment because it leads to suboptimal use of human capital. 
This chapter illustrates that the effects of technology on productivity and growth is not as clear-cut as it may currently seem to be to most economists. Including mental capital variables such as fatigue and burnout changes the picture about the optimal mix of inputs and the optimal rate of technological change, and shows the importance of accompanying measures such as increasing the decision latitude of workers, and increasing their mental capital so that they get less fatigued by mental effort and can better self-regulate.

\subsection{Appendix}

The Hamiltonian associated with the optimization problem is given by

$$
H=\Gamma_{t}\left(m_{t}-\alpha f^{\beta}\right) \exp [-\delta t]+\mu_{t}\left(\left(1-\frac{\rho}{\kappa_{t}}\right) m_{t}+\frac{\rho}{\kappa_{t}} \alpha f_{t}^{\beta}-r\right) .
$$

The associated first order conditions are $\partial H_{t} / \partial m_{t}=0$ and $\partial H_{t} / \partial f_{t}=-\dot{\mu}_{t}$. From the first first order condition follows a solution for $\mu$.

$$
\mu_{t}=\frac{-\Gamma_{t} \exp [-\delta t]}{1-\rho / \kappa}
$$

Differentiate with respect to time and substitute for $\dot{\mu}$ in the second first order condition to get a second solution for $\mu$.

$$
\mu_{t}=\frac{\beta \Gamma_{t} \alpha f_{t}^{\beta-1} \exp [-\delta t]}{\hat{\Gamma}_{t}-\delta-\left(\rho^{-1} \kappa_{t}-1\right)^{-1} \hat{\kappa}_{t}+\beta \alpha f_{t}^{\beta-1} \rho^{-1} \kappa_{t}}
$$

Equate both expressions for $\mu$ and solve for $f$ to get equation. 



\section{Chapter 6. A model of mental capital spillovers}

\subsection{Introduction}

In chapter 4, the concept of mental capital was introduced to capture the effect of stress and mental health on productivity. In chapter 5, a first formal application was presented, demonstrating how a classic optimization problem of getting the right production mix changes when mental capital is taken into account. The real optimum rate of technological substitution, taking into account mental capital effects, is lower than the optimum rate that would be the outcome of a traditional economic formal analysis, all things equal. The model not only organized a large body of research and demonstrated a complex dynamics, it also helped to point out conditions and options for interventions.

In the present chapter, we will present a second formal application, ${ }^{1}$ to again show how the analysis of a standard economic issue changes when including mental capital effects. We again look at the effects of mental capital on the relationship between innovation and productivity. The new element in this chapter is the addition of an important dimension of mental capital in the analysis, namely the effect of inter-agent dynamics.

As was argued in chapters 2 and 3, innovation is a source of increasing productivity, but at the same time it also is a source of stress. As of a certain level of stress, additional stress will start to actually decrease the productivity of an actor. The point at which, and the extent to which this takes place depends on the mental capital of the actor, as was explained in chapter. We are interested in the net result of innovation in terms of productivity and in terms of stress; more specifically, we are interested in how this changes when we include the fact that people interact.

This will be investigated by means of a formal model of a dyad, a pair of agents that are in a relationship The members of the dyad have certain individual characteristics that determine their stress levels (and through this their productivity). In addition, they have a relationship, which can be characterized in terms of its effects on the stress levels of the members of the dyad (and thus on the productivity of the dyad). In the model, the rate of innovation is an external factor ${ }^{2}$ generating a flow of additional stress, thereby influencing stress levels (and thus productivity, via the inverted $\mathrm{U}$ of mental capital). The variables moderating stress levels are of crucial importance for identifying the overall effects of different rates of innovation on

\footnotetext{
1 The model in this chapter is developed in cooperation with Bulat Sanditov, researcher at CEPRI, Milano, Italy.

${ }^{2}$ With innovation, both technological and organizational innovation is meant. Obviously in reality (the rate of) innovation is not completely exogenous, but to some extent endogenous. The model aims at innovation in the form of diffusion and adoption of new material and social technologies from elsewhere, and the decision about the rate of innovation (whether, what, at what speed) is not part of the model, and thus external to the model. As stated before, social technology is the result of organizational innovation, referring of new ways of doing things (e.g. organizational processes, management structures) that are more efficient and more effective.
} 
productivity. The model will show that the existence and nature of relationships of people determine the extent to which a certain rate of innovation effectively results in increasing productivity. In addition, it shows the possibility of multiple equilibria - under some parameter values both high- and low-stress steady states exist; and the dynamics exhibit hysteresis.

The chapter is organized as follows. First we will identify and discuss the different variables at stake, and their relationships (section 6.2). Next we will formalize these in a dyadic model and analyze this model, deriving results which show the significance of the dynamics associated with mental capital (section 6.3). Finally, we will do some comparative statics, to determine the influence of changes in the values of variables and in their relationships, in order to get an idea about the possibilities for interventions; we will discuss some implications and conjectures for extensions of the model; and we will reflect on how this model strengthens the case for including mental capital into economic analysis (section 6.4).

\subsection{Variables and assumptions}

\subsubsection{The variables of the model}

In the model, two agents in a spousal dyad are each subjected to stress from an external source, innovation. Innovation is exogenous in the model, meaning that the decision about the rate of innovation is not part of the model and not influenced by variables of the model.

The stress level $\mathrm{x}$ of agent $\mathrm{X}$ is determined by:

(1) the flow of stress $(S)$ from the external source, innovation $(m)$

(2) his ability to deal with it, his control or coping (variable $c$ )

(3) the extent to which he is affected by spillovers due to the stress level $y$ of his partner $Y$, which depends on the intensity of the relationship between $\mathrm{X}$ and $\mathrm{Y}$, called responsiveness (variable $r$ )

(4) his partners ability to absorb some of his stress, called buffering (variable $b$ ) which depends to some extent on responsiveness $(r)$.

The total level of stress of a dyad ( $z$ is the sum of stress level $x$ and $y$. Innovation $(m)$ increases economic growth $(G)$, so $G$ is a function of $m$. Innovation has an effect on productivity $(A)$. Innovation is intended to improve existing production processes (or enable new ones) and thereby to increase the output per worker per unit of time. There is ample evidence for this at the level of the economy, the level of firms and the level of individuals, and thus it is generally assumed that the relationship between the level of innovation $m$ and productivity $(A)$ in principle is positive. However, innovation also causes stress, and as was put forward in chapter 3 , high levels of stress reduce productivity. Thus there is a trade-off and an optimization problem.

In this section we present the findings of empirical and theoretical literature (mainly from branches from psychology) on which the assumptions presented above are based. The 
(empirical) evidence will be discussed in some detail, explaining and justifying the choices of variables and of functional forms in the model.

\subsubsection{Innovation, flow of stress and level of stress}

As was discussed in chapter 3, the stress mechanism is an activating mechanism; stress triggers physiological processes that prepare an organism for action. Life consists of a continuous stream of events or stimuli that represent (potential) demands on a person, so there is always a certain amount of stress in a person's personal and professional life. Stress is the consequence of the discrepancy between a desired and an actual state of the world, activating an actor to execute adaptive behavior to reduce the discrepancy (Selye 1956).

Innovation by definition implies means an increase in the amount of change an actor faces. Change always leads to (some) stress - regardless of whether the change is positive or negative. ${ }^{3}$ Innovation implies novelty and this reduces the extent to which an agent can rely on routines. Moreover, as was discussed in chapter 2, an important form of innovation has been to replace repetitive, routine manual tasks, and increasingly also repetitive mental tasks) by mechanization---machines take over operations that involve enough regularity. As was argued in chapter 5 , from the point of view of a labour force, if routine tasks are successfully mechanized, the ratio of non-routine to routine tasks increases. Thus innovation reduces in more than one way the extent to which an actor can rely on routines. As was discussed in chapter 3, non-routine activity is more effortful in terms of mental resources, and thus effectively means an increase in demands. ${ }^{4}$ In chapter 3, stress was identified to be the consequence of the discrepancy between (perceived) demands and (perceived) control (Karasek, 1979). It follows that when demands are increased and all other things remain equal, the discrepancy will increase, and therefore stress will increase.

Hence, innovation can justifiably be described as a source of stress. This means that in the model, the relationship between the rate of innovation $(m)$ and the flow of external stress $(S)$ is positive.

\subsubsection{Stress level and productivity}

As was described in chapter 3, a certain level of stress is needed to get an actor to deal with emerging threats and to make use of emerging opportunities. To briefly recapture the

\footnotetext{
${ }^{3}$ Change tends to increase uncertainty and unpredictability, which is experienced by actors as an increase of (potential) threat or opportunity; both are experienced as increasing demand leading to activation which is experienced as stress (e.g. Holmes and Rahe 1967; Monat et al. 1972; Rabkin and Struening 1976; Mantler et al. 2005; Rafferty and Griffin 2006). See chapter 3 for a more elaborate discussion of this.

${ }^{4}$ Routines economise on scarce information processing and decision-making capacity of agents (Simon 1947, 1955, 1977); routines are "mindsavers" (Sinclair-Desgagné and Soubeyran, 2000). Routines embody cumulative learning, they co-ordinate behaviour and bring predictability and implicit agreement on how to act (Nelson and Winter, 1982), thereby smoothing interaction, enabling efficient and effective cooperation (March and Olsen 1989) and lowering transaction costs (Langlois 1992). Novelty reduces the extent to which routines can be used and demands more effort in terms of time and (mental) resources (Alterman and Zito-Wolf 1993).
} 
discussion chapter 3, the relationship between an agent's level of "activation" or "arousal", reflected in his level of stress, and his or her performance in a given task, has generally been described as curvilinear. The most well-known finding of curvilinearity is the inverted U, which is often referred to as the "Yerkes-Dodson law"” (Yerkes and Dodson, 1908). Too little activation (low stress) implies lethargy and boredom, leading to low performance. Too much activation (high stress) implies an over-taxation of abilities, and again, underperformance. Intermediate levels of activation provide enough stimulus to alleviate boredom (and hopefully spark interest) without over-taxing the coping abilities of the actor.

In line with its intuitive appeal, an inverted U shape relationship is generally confirmed in empirical research. ${ }^{5}$ There is a biological basis for the curvilinearity; research shows that up to a certain level stress hormones are effective in preparing body and mind for action (increased heart rate, more focused attention, etc.), but at high levels they have a negative effect on the parts of the brain involved in planning, memory, reasoning and emotion regulation. ${ }^{6}$

Thus, in the model the relationship between productivity $(A)$ and the dyadic stress level $(z)$ in the model) has the shape of an inverted U.

\subsubsection{Stress level and coping}

Increasing demands increase the discrepancy between demands and control, and thereby increase stress - to deal with these demands. Stress activates behavior to cope with these increasing demands. Coping reduces stress by reducing the discrepancy between perceived demands and perceived control; the more stress, the more coping is activated. (Karasek and Theorell 1990). Coping presupposes the existence of demands (e.g. Greve and Strobl 2004); meaning that if there are no demands there will be no coping. The level of demands is represented by the level of stress, thus coping or control $(c)$ is positively related to (dyadic) stress level (z) in a linear way. ${ }^{7}$

\subsubsection{Stress level, spillover and responsiveness}

So far we have discussed variables that are located at the level of the individual. Now we will turn to the situation in which two individuals that have a (dyadic) relationship. Empirical

\footnotetext{
5 Though not universally, e.g. Neiss (1988).

${ }^{6}$ E.g. McEwen and Sapolsky (1995); Sapolsky (1996); Liston et al. (2006); Radley et al. (2006).

7 There is evidence suggesting that the relationship between coping and stress levels is not linear. More stress leads to more activation, but the resulting behavior to cope is not necessarily effective. Research suggests that the quality of coping may go down with increasing stress levels, especially at higher levels of stress. For example, Greve and Stroble (2004) point out that the "choice" of the coping reaction is in most cases not a conscious selection. Rather, it usually represents a "processual selection from a spectrum of options acknowledged by the individual or social system in a certain state". Stress affects the ability to perceive options, to process information adequately, and to control behavior, and high levels of stress diminish the ability to select the appropriate coping strategy and the quality of execution of the selected strategy by an actor (see chapter 3). However, in the model the effect of stress on the effectiveness of behavior is already captured in the curvilinear relationship between stress and productivity. In the model, the variable coping c reflects the quantity of coping; the effect of stress on the quality of coping - its effectiveness - is captured via the effects of stress on performance. Thus the relationship between the level of stress and the level of coping can be represented as linear in the model.
} 
research shows that if $X$ and $Y$ are in a relationship, the stress level $x$ of $X$ depends to some extent on the stress-level y of $Y$, because part of the stress $y$ of $Y$ will spill over and increase the stress $x$ of $X$ and vice versa, resulting in an overall increase of the dyadic stress level $\varkappa^{8}$ The extent to which this happens depends on the responsiveness $(r)$ of the members of the dyad to each other.

This phenomenon and its precise underlying mechanisms and dynamics have been extensively studied in psychological research. Since it involves the core of the contribution of this chapter, we will take some space to explain the phenomenon and to present the main empirical findings. We will discuss the main results of the two main areas of research that are relevant here: contagion and cross-over. Some alternative mechanisms and factors that may diminish or cancel out stress spillover (such as compensation and compartmentalization) are discussed in 6.2.7.

\section{Stress spillovers between domains}

The core dyad we will investigate is a spousal dyad. 'Both members of the dyad are confronted with a flow of external stress which originates at work, resulting in part from innovation. The dyad itself is located at home, so in another domain than the domain of the external stress. The stress received at work originates in the environment of work, but is attached to the person experiencing the stress - who at some point will leave work and go home, taking stress with him.

Empirical research shows that stress crosses over from one domain to another. ${ }^{10}$ Stress at home affects work, and stress at work affects home; the relationship between is bidirectional. ${ }^{11}$ Stress spillovers from work to home are generally larger when work is highskilled, when a job carries high responsibility and decision power, and when the worker is

\footnotetext{
${ }^{8}$ Clearly, there can also be positive spill-overs. Work-family positive spillover refers to the beneficial effects of one role spilling over to another role via mood, values, skills, or behaviors (Edwards and Rothbard, 2000; Rothbard 2001; Hanson et al. 2006). In the research literature, work-family facilitation (as opposed to workfamily conflict) refers to the extent to which individuals' participation in one life domain (e.g., work) is made easier by the skills, experiences, and opportunities gained by their participating in another domain (e.g., family) (Frone, 2003; Grzywacz et al. 2002). This positive spillover effect is increasingly part of the discussions of the work-family interface (Grywacz and Butler 2005). Grzywacz and Marks (2000) offer a useful ecological perspective on negative and positive spillovers between work and family.

9 The model will show a type of dynamics which is to some extent generalizable to other types of dyads, for example a dyad of colleagues.

${ }^{10}$ There is a great deal of empirical evidence about stress spillovers from work to home and vice versa (Geurts and Demerouti 2003; Story and Repetti 2006). Experiences, thoughts, and feelings in one role can spill over and color the experiences, thoughts, and feelings in another role (e.g., Bolger, DeLongis, Kessler and Wethington, 1989). Work-family spillovers flow from the effects of one role spilling over to another role via variables such as mood, values, skills or behaviors (Rothbard 2001). Stressful work experiences have been associated with greater marital conflict and lower marital satisfaction and support (Hughes and Galinsky, 1994; Story and Bradbury 2004; for a review see Perry-Jenkins et al. 2000).

11 The spillover effect is bi-directional but not symmetrical; research suggests that stress in the workplace has a greater impact on home life than vice versa (e.g. Frone et al., 1992).
} 
highly involved in his or her work. ${ }^{12}$ The extent to which stress spills over depends to some extent on predisposition and there seems to be a gender effect. ${ }^{13}$

The spillover from one domain to the other takes place through the generalized effect of stress on the multiple roles a person has in both domains (Bolger et al. 1989). There is some compartmentalization, which means that a person can to some extent isolate different parts of his or her life, but it is never complete. Thus events in one domain will have an effect in another domain. This means that even though the cause of stress may be specific to a particular domain (a difficult innovation process in the domain of work), the effect is nonspecific (stress) and can affect a variety of specific factors, in the same domain but also in other domains in which the person operates (for example, marital problems in the domain of home). The non-specificity of the stress system is at the core of the spill-over effect. ${ }^{14}$ Thus, the relationship between stress of a person in one domain and stress of the same person in another domain is positive. ${ }^{15}$ In the model it means that the external stress $S$ due to innovation rate $m$ affects the stress level of the members of the dyad when they are at home, where they have their relationship.

\section{Compensation, segmentation and growth through adversity}

In addition to spillover, Wilensky (1960) identified two otehr possible types of relationships between domains: compensation, and segmentation.

In the case of compensation, the individual attempts to compensate in one environment for what is lacking in the other. ${ }^{16}$ In the compensatory model (Wilensky, 1960), negative experiences at work (such as the uncertainty, anxiety and conflict) may lead to compensation behavior at home and vice versa. For example, individuals who have routine, socially isolated

\footnotetext{
${ }^{12}$ Higher levels of involvement and responsibility at work are found to result in more spillover to family life (e.g. Byron 2005).

13 The 'asymmetrical boundary hypothesis' argues that family factors would spillover into work more for women than men and that work factors would spillover into family more for men than women; empirical research indeed finds gender effects though other factors such as personality and attitude seem to moderate this relationship (Grywacz and Marks 2000). Although men derive an overall health benefit from marriage, women appear to be more sensitive to the differential quality of marriage which has a higher impact in terms of positive or negative effects (e.g. Kiecolt-Glaser and Newton 2001; Saxbe et al. 2008).

14 See chapter 2; stress is a set of physiological reactions in the agent's body and these do not suddenly stop when the agent goes from one domain to another. In addition spillover can take place due to scarcity of resources: if more resources have to be used in one domain due high and stressful demands, there is less left for the demands in the other domain, which can lead to stress in that other domain (Goode 1960, also see chapter 2). There is a longstanding debate about whether role accumulation has negative, stress-generating effecs (e.g. Goode 1960; Marks 1977) or positive, enriching effects (e.g. Sieber 1974).

15 See 6.2.7 for some other mechanisms that may play a moderating role, such as compensation, compartmentalization and growth through adversity.

${ }^{16}$ Compensation is a term that was put on the map by the psychologist Adler (1927). It refers to behavior that develops either consciously or unconsciously to offset a real or imagined deficiency, as in personality or physical ability. Compensation differs from direct action to restore a loss; it does not deal with the problem at stake, but with the negative feelings that the problem causes. Not being able to function in an satisfactory way can lead to inferiority feelings, which Adler describes as a "minus situation". These feelings become motivation for striving toward what he called a "plus situation", for example making up for failure in one domain by being extra good in another domain.
} 
jobs with little autonomy may choose varied and challenging nonwork activities with a high degree of social interaction, to compensate for what is lacking at work (Rousseau 1978). The worker creates positive experiences in one domain that make him feel good in order to compensate for the negative experiences in the other domain. This could imply that problems at work inspire a person to excel in his or her role at home, or with friends which would then lead to better rather than worse relationships. However, empirical findings give only limited and partial support for compensation at home to balance negative work experiences; it seems to be found predominantly in cases of impoverished routine jobs with little autonomy, and in cases of low challenge at work (Rousseau 1978).

Segmentation or compartmentalization can diminish stress spillover through cognitive organization. People select parts of self-knowledge to construct specialized working selfconcepts that enable them to function effectively in specific contexts (Markus and Nurius, 1986) and this can help to buffer stress Linville, 1987). According to the model of compartmentalization certain types of self-structures minimize the accessibility of negative self-beliefs or reduce the impact of salient negative characteristics (Showers, 1992). Although compartmentalization can be functional in reducing stress spillovers between domains and persons, it can be dysfunctional ${ }^{17}$ and too much compartmentalization is generally harmful. ${ }^{18}$

The cognitive organization of positive and negative beliefs about a relationship partner may have an impact on to what extent stress may spill over from $\mathrm{Y}$ to $\mathrm{X}$ and to what extent $\mathrm{X}$ may buffer the stress of $Y$ (and vice versa). Also, cognitive organization may determine at which stress level a relationship starts to unravel. ${ }^{19}$

Compensation and segmentation can reduce stress spillover between domains, however due to the non-specificity of stress and resource scarcity, stress spillover from one domain to another generally never fully disappears. In addition to compensation and segmentation, there is another mechanism that can reduce stress spillovers between domains: growth through adversity. The adversity in one domain may make it easier to appreciate the other domain, and may in fact increase the resilience of a person, because the adversity can be a learning experience (e.g. Linley and Joseph, 2005). However, this theory and the empirical evidence found for it seems to relate predominantly to distinct traumatic experiences not chronic flows of stress, while the empirical findings presented above about the impact of

\footnotetext{
${ }^{17}$ Integrative thinking tends to be more difficult than compartmentalization; but when negative characteristics are important and cannot be avoided, an integrative structure helps to ensure that some positive beliefs come to mind, thereby minimizing the impact of important negatives (Showers et al. 1998) While integrative thinking may often not be the best strategy of cognitive organization in normal, moderate situations, in dynamic situations with fluctuating and diverging normative information about the self. (Showers et al. 1998).

18 A related concept, which is often referred to as a symptom of mental illness, is 'splitting'. Like compartmentalization, splitting provides a mechanism for coping with negative experience and negative knowledge (by repression) (Siegel 2006). In an extreme form, strategies such as segmentation, compartmentalization and splitting are related to dissociation and multiple personality disorder in which the repression of information is so complete that it is attributed to another person al together (Schwartz 1994).

${ }^{19}$ Integrative cognitive organization also increases the probability of having a long-term relationship, unless partners in a relationship do not see each other often and have little overlap in activities; in the latter case compartmentalization works better (Showers and Kevlyn 1999).
} 
continuous cumulative distressing events on relationship quality point to the common occurrence of stress spillover. ${ }^{20}$

\section{Stress spillovers between persons}

Stress not only spills over from one domain of a person to the other domain of the same person, it also can spills over from one person to another. ${ }^{21}$ This phenomenon is investigated in psychological research under two labels: crossover and contagion; and in addition, in social information processing theory. The research shows that the relationship between the stress of one person and another person is generally positive, though moderated by a number of variables, such as responsiveness, proximity and interaction style.

\section{Crossover}

Crossover, which is sometimes called transmission (e.g. Rook, Dooley and Catalano, 1991), refers to the interpersonal process that occurs when a psychological strain experienced by one person affects the level of strain of another person in the same social environment (Westman, 2001). Crossover effects involve the spillover of emotional states from one member of a dyad to another (Westman and Etzion, 1995). Empirical research has found this to be the case for example for stress, ${ }^{22} \operatorname{mood}^{23}$ or depression. ${ }^{24}$ Westman (2002), in a review

\footnotetext{
${ }^{20}$ In addition to the factors mentioned above, the factor personality matters for the extent stress effectively spills over. For example, a person high on neuroticism may easily worry and contract more stress from his partner. In the model, differences in personality or in functional cognitive organization that reduces stress spillover between domains and between persons are not explicitly taken into account. The model does not allow for heterogeneity of actors in these respects, but takes the average person as actor, who shows some compensation and segmentation (but not much) and has some neuroticism (but not much).

${ }^{21}$ Research provides empirical evidence for crossover effects both within and between domains, and within and between persons. For example Hammer et al. (2005) find crossover effects between partners in a marital dyad, whereby the (positive or negative) effects one spouse's work-family situation on that partner cross over to the other partner, via direct empathetic relations. This was found to affect the other spouse's experience of depressive symptoms. The effect remains when controlling for common environmental factors such as shared life events.
}

${ }^{22}$ Research shows empirical evidence for stress spillover between spouses (e.g. Katz et al. 2000; Westman and Etzion, 1995; Westman and Vinokur, 1998). In addition, there are empirical findings showing stress crossover between colleagues, for example Westman and Etzion (1999) find crossover of stress between school principals and teachers.

${ }^{23}$ Kelly and Barsade (2001) find evidence for crossover of moods in small groups and work groups; Totterdell (2000) finds crossover of mood ('mood linkage') in sports teams; Williams and Alliger (1994) find crossover of mood ('mood spillover') between employed parents. Sullins (1991) found significant convergence on mood in an experimental study among participants paired with a partner.

${ }^{24}$ Individuals who interact with depressed or distressed persons are themselves at higher risk for psychological distress, through different pathways including crossover (Benazon and Coyne, 2000). Such effects have been found across a heterogenous set of relationships including roommates (Joiner, 1994), parent-child relationships (Downey and Coyne 1990; Hammen et al. 2004) and marital relationships (Coyne et al., 2002). Similarly, Howes et al. (1985) reported that participants who were assigned to live with a mildly depressed roommate became increasingly depressed over time. Hammer et al. (2005) find longitudinal effects of work-family conflict (negative spillover) and social support (positive spillover) on depressive symptoms among dual-earner couples. There is a variety of pathways for the transmission of depressive feelings. In Hammen's (1991) stress generation model, depressed people, in part, cause their own stressful experiences, which then lead to further depression. Davila et al. (1997) applied this model to depressive symptoms occurring in the context of marriage and found that this stress generation process may be mediated through dysfunctional interactions between spouses. There 
of 25 empirical studies examining crossover effects, concludes that most studies find one person's stress and distress to be significantly positively associated with his or her spouse's stress and distress.

Westman and Vinokur (1998) describe three primary mechanisms involved in the crossover process: direct crossover via empathetic reactions, common stressors experienced by both members of a dyad, and indirect crossover via interpersonal conflict. Most of the studies on crossover referred to here control for common stressors in some way or include them explicitly as part of the crossover process, enabling them to isolate the different mechanisms at work. ${ }^{25}$

Contagion

Contagion refers to the process by which one individual's mood and/or perceptions seem to "spread" to those in close proximity (Hatfield, et al. 1994; Sullins, 1991). Hatfield et al. (1994) proposed that people who share intimate relationships are especially likely to "catch" their partner's emotions and moods. Different aspects have been found to be susceptible to contagion: contagion of behavior, ${ }^{26}$ contagion of emotions, ${ }^{27}$ contagion of $\operatorname{mood},{ }^{28}$ contagion of burnout, ${ }^{29}$ contagion of stress, ${ }^{30}$ and contagion of depression. ${ }^{31}$ Contagion has been found to occur in different types of dyads: between spouses (in most cases it is then labeled as 'crossover'), between colleagues, ${ }^{32}$ and in groups. ${ }^{33}$

There are several explanations proposed and tested for this phenomenon. The theory of 'primitive emotional contagion' (Hatfield et al. 1994) suggests that contagion happens through unintentionally mimicking the emotional expression of another person. This

may be some gender asymmetry; for example the findings of Benazon and Coyne (2000) suggest that the wives of depressed men are more distressed than the husbands of depressed women.

25 This is done for example by distinguishing primary and secondary stressors. E.g. Price et al. (1998) show that the cascade of secondary stressors after job loss can present as much risk to the mental health of the job seeker as the job loss itself. Secondary stressors also appear to degrade the quality of the couple's relationship, and this in turn contributes to increased distress (Howe et al. 2004). Vinokur, Price and Caplan (1996), in a review, show that the negative impact of economic hardship is found to lead to depression and poor mental health of the job loser, but in addition may trigger and sustain a variety of destructive interaction patterns among family members, including child abuse, decreases in the mental health of the spouse, decreases in marital quality, and increases in marital and family dissolution.

26 In an early study, Wheeler (1966) found behavioral contagion in groups, depending on social norms that make up (conflicting) incentives and constraints. This type of contagion is also referred to as social contagion; for example Crandall (1988) found social contagion of binge eating (bulimia) in sororities.

${ }^{27}$ Sullins (1991) finds evidence for emotional contagion in groups, having the character of 'mood convergence', which to some extent was the result of social comparison and which varied with expressive style. Hsee et al. (1992) and Katz et al. (2000) also find empirical evidence for emotional contagion.

${ }^{28}$ E.g. Neuman and Strack (2000) found empirical evidence of mood contagion

${ }^{29}$ E.g. Bakker and Schaufeli (2000) find burnout contagion among teachers, and Bakker et al. (2001) find burnout contagion among general practitioners.

${ }^{30}$ See for example Bolger et al. (1989).

31 Joiner (1994) finds strong evidence to date that depression is contagious. Controls for baseline symptom levels and for negative life stress and use of syndromal symptom measures instead of mood checklists provided for a rigorous test of the contagion effect.

32 See Bakker and Schaufeli (2000) and Bakker et al. (2001).

33 E.g. Sy et al. (2005) find that managers transmit their moods to other group members through mood contagion. Also see Barsade (2002) and Kelly and Barsade (2001) for contagion processes in groups. 
imitation then results in a congruent mood state in the observer by a largely unconscious feedback mechanism. ${ }^{34} \mathrm{~A}$ second line of explanation is that contagion is to an important extent a consequence of social information processing, which we will briefly discuss next.

\section{Social information processing}

It is the perception of a situation, not the situation itself that determines the experience of stress. Though generally a person's perception of a situation is to some extent related to the actual situation, there is considerable room for interpretation. In the process of interpretation, people look at other people for clues about what to think and how to feel about an event or a situation. ${ }^{35}$ In accordance with Bandura's (1986) social cognitive theory, perception and appraisal of situations is not merely a consequence of certain characteristics of a person (e.g. anxious persons viewing a situation as a threat) but also to an important extent that consequence of dyadic interactions (e.g. Hubbard et al. 2001; Coie et al. 1999). Social information processing theory argues that individual perceptions, attitudes and behaviors are influenced by the perceptions, attitudes and behaviors of salient others; individuals are influenced by cues from others about what to think, what to feel and what to do. ${ }^{36}$

\section{Responsiveness}

The patterns of emotional contagion follow patterns of affiliation and the impact depends on the strength of the affiliation (Gump and Kuliks 1997). Wheeler (1966) in an early study on contagion of behavior and emotions found that behavior spreads out along sociometric and communication networks, and that norms about behavior change toward acceptance as the behavior becomes more widespread. ${ }^{37}$ Contagion has a 'ripple effect' (Barsade 2002). Spillover effects depend on the closeness or intensity of the relationship, which in the model we capture in the variable of responsiveness.

\footnotetext{
34 According to this theory, we quite generally and spontaneously mimic the facial expressions, body movements, and speech duration of affiliates. Theoretically, afferent feedback from such facial or postural mimicry or self-perception processes then create a corresponding feeling of the emotion, and emotional contagion is thereby produced (Hatfield et al. 1994).

${ }^{35}$ Newcomb (1943) was one of the first to describe social influence processes. He observed that social norms carry social sanctions with them, which inhibits people from deviating from these norms, thereby strengthening them. Schachter (1959) theorized that affiliation produces pressures to establish a common social reality; he further proposed that if affiliation exposes discrepant emotional responses to a novel situation, there will be attempts to influence others and bring them closer to one's own position. The consequence is then some degree of emotional contagion or convergence. Another classic in this area is Festinger (1950), who showed that the more important the social group, and the more central a behavior is to the group, the greater the pressure toward uniformity and the more likely that members of the group will imitate each others' behavior. Janis (1954) showed that the extent of this effect may depend on individual characteristics such as self-esteem; the lower a person's self-esteem, the more likely this person is to be open to social influence.

${ }^{36}$ E.g. see Wyer and Radvansky (1999) and Dodge (1991) on social information processing, and Fiske (1993) on social cognition.

${ }^{37}$ Another pathway through which responsiveness may decrease is through 'activated (dis)similarity' (e.g. Ruys et al. 2006); agents interacting with other agents decide during the interaction whether the other agent is similar or dissimilar and this influences their perception of (dis)similarities, which may affect the intensity of their relationship.
} 
Obviously, a dyad can be linked tighter or more loosely, and the extent to which it is linked (the intensity or strength of the relationship) matters for the extent that there will be spillover effects from one person to the other. Emotional contagion effects are more likely to occur when people pay attention to, care for, identify with, or feel responsible for others (Hatfield et al. 1994). Sullins (1991) suggested that emotional contagion is more likely when the other individual is both relevant and similar to the self. The strength and process of contagion or crossover varies, depending on whether the relationship is a fleeting contact, a more enduring, but limited, relationship (i.e., colleague), or a committed marriage (Benazon and Coyne 2000). ${ }^{38}$

As was mentioned before, an important mechanism through which stress spills over between people is social information processing. To be exposed to social information, individuals must be proximate in some way to one or more others; consequently, the stronger the relationship between persons, the higher the impact of one person on the other. ${ }^{39}$ The variable of responsiveness reflects on the intensity or strength of the relationship and on the personal characteristics of the persons in the relationship. The most important personal characteristic determining responsiveness is empathy, which is a topic of elaborate psychological research. Empathy can be defined as "sharing another's feelings by placing oneself psychologically in that person's circumstances" (Lazarus 1991, p. 287). The more ability of empathy a person has, the greater the impact of that person on the other person and vice versa. ${ }^{40}$

The level of responsiveness $(r)$ characterizes the relationship and thereby its effects. In the model, this is captured as follows: the extent to which stress spills over from one person $(X)$ to another $(Y)$ and vice versa, depends on the stress level $(x, y)$ of this person and on the degree of responsiveness $(r)$ of the other person. To some extent the degree of responsiveness may decrease rather than increase spill over of stress; to prevent unnecessary complexity in the model, this is captured in the buffering variable $b$ of the model (discussed in 6.2.6), which stands for the reduction of stress, and which is also dependent on responsiveness.

\footnotetext{
38 All the effects described in this chapter for spousal dyads (contagion, crossover, spillover, transmission, buffering) are also occurring in other dyads, for example in relationships between colleagues and between workers and their managers. The growing literature on the role of trust and social capital in organizations (and in the economy as a whole) indicates the importance of the quality of relationships in general. Since stress tends to affect social skills negatively and to emotionally distort perceptions, it can be argued that there is yet another pathway through which stress affects the economy: via its effects on trust and social capital.

39 Proximity is defined as the extent to which one could be exposed to social information (information derived from one or more other persons). In addition, the individual must value the other as a source of information, which often is confounded with the strength of proximity (people tend to have closer relationships with people that they value than with people that they do not value). For more details on social information processing (both verbal and nonverbal) and social cognition, see Wyer et al. (1999)

40 The level of empathy differs per person. Empirical evidence suggests that gender plays a role; women tend to be more empathic and tend to experiences larger spillovers from their partner than the other way around (e.g. Eisenberg and Lennon 1983). To keep the model tractable however we assume symmetry between both partners in terms of empathy and spillovers. However, for interventions purposes, more specific knowledge may be helpful, for example by making interventions gender-specific.
} 
The extent to which persons are responsive to each other is not constant; it can diminish as stress levels go up, So, responsiveness of persons to each other is a function of the stress levels of these persons, and goes down as stress levels goes up. ${ }^{41}$ Thus in the model we make responsiveness dependent on the (dyadic) stress level.

\section{Social undermining}

The interaction patterns among spouses can be described in terms of social support and social undermining (Vinokur et al. 1996). ${ }^{42}$ A person can be a source of stress spillover to another person because the second person cares for the first and therefore will be stressed by his stress (as a consequence of sympathy effects). However, another person can also simply be a stressor in a direct, active way. In addition to providing assistance, significant others may become critical, demanding, and burdensome (Liang et al. 2001). This is strengthened by the dynamics of reciprocity. ${ }^{43}$ Social undermining leads to more stress, and more stress leads to more social undermining. ${ }^{44}$ Again, responsiveness matters, because no one can hurt a person as much as someone that this person cares for.

\subsubsection{Stress level, buffering and responsiveness}

Although a relationship can function as a channel for stress spill-over and as a stressor in itself, it can also (and often will) function as a source of support, reducing the stress levels of the persons in the relationship. Being in a relationship generally absorbs stress and has important 'buffering effects' (b), which depends on the level of responsiveness $(r)$ of the members of the dyad to each others' needs. There is an extensive literature on this in psychology under the label of 'social support'. We will briefly review the main theoretical and empirical findings relevant here.

\footnotetext{
${ }^{41}$ Research has found that stressors such as financial hardship, job loss, illness and other negative life events lead to tension in relationships, marital dissatisfaction and breakdown of relationships (e.g. Conger et al. 1999, Westman et al. 2004); the more stressed a person becomes, the more maladaptive his relationship with his partner will become (e.g. Davila et al. 2003). This suggests that stress diminishes responsiveness. Some research points out that stress can increase responsiveness; e.g. Linley and Joseph (2005) report that adversity can lead to enhancement of relationships: after a traumatic experience people value their friends and family more and feel an increased compassion and altruism toward others. However these are findings for distinct traumatic events; the larger part of research in this area suggests that stress leads to erosion of the quality and intensity of relationships.

42 Social undermining is defined as behaviors directed toward the target person that display (a) negative affect (anger, dislike); (b) negative evaluation of the person in terms of his or her attributes, actions, and efforts (criticism); and (c) behaviors that hinder the attainment of instrumental goals (e.g. Vinokur and Van Rijn 1993).

${ }^{43}$ E.g. Hammer et al. (2004) studying on marital dissatisfaction find that the underlying mechanism of the direct crossover is not an empathy reaction but rather a reciprocal emotional reaction toward the other person in a close relationship. Being exposed to the marital dissatisfaction of one's partner brings out a reciprocal emotional reaction of dissatisfaction that manifests itself as a direct crossover.

44 Distress increases conflictual interactions which, in turn, augments depression and marital dissatisfaction (Vinokur et al., 1996). Westman et al. (2004) find support for direct crossover of marital dissatisfaction and an indirect crossover mediated by negative conflictual interactions, which, in turn, affect marital dissatisfaction; these direct and indirect effects are not symmetrical, but appear to be moderated by gender.
} 
In psychological research, the positive effect of one person on another is generally referred to as 'social support'. Social support has been defined as "those social interactions or relationships that provide individuals with actual assistance or that embed individuals within a social system believed to provide love, caring, or sense of attachment to a valued social group or dyad" (Hobfoll, 1988, p. 121). Social support has been conceptualized as a coping resource that affects the extent to which a situation is appraised as stressful and enables a person under stress to change the situation, to change the meaning of the situation, or to change his or her emotional reactions to the situation; it is associated with better psychological health in general and reduces the negative psychological consequences of exposure to stressful life events (Major et al. 1997). Empirical reports from a variety of samples suggest that spousal dyads are particularly important as sources of social support; marital quality or spouse support is an important buffer for job-related stress, particularly for men (Grzywacz and Marks 2000). Research shows that having a supportive partner and the opportunity to talk through difficulties at work helps individuals recover from stressful days (Repetti, 1989) and better handle the pressures associated with their jobs and, consequently, perform better at work (Barnett and Rivers, 1996; Gattiker and Larwood, 1990).

The beneficial effect of social support in terms of stress reduction also is shown in studies about the effects of (perceived) loss of social support. According to leading theories of stress (e.g. Lazarus and Folkman, 1984; Hobfoll, 1988;), the perceived loss of social support increases stress. In turn, stress influences perceptions of availability of social support, through its psychological effects (negative affect, diminished trust). This indicates that there is a certain degree of path-dependency, complicating the dynamics of the buffering effects of social support (e.g. Norris and Kaniasty 1996).

At high stress levels, generally more social support is needed and thus received, but it is the perceived social support that is psychologically most important and helps to keep stress levels in check, and while received social support can have negative effects on the feelings of selfefficacy of a person (e.g. Krause 1995; Liang et al. 2001). This adds to the plausibility of the assumption that at high levels of stress, being in a relationship gets less and less beneficial.

\section{Buffering and responsiveness}

The stress-buffering hypothesis proposes that social support attenuates the relation between negative life events and the risk for development of mental health problems because it diminishes the stress related to these life events (Cohen and Wills, 1985; Wheaton, 1985). This interactive model posits that, when faced with negative events, individuals with greater support from family and friends are less likely to become stressed and depressed than individuals with lower levels of support. Social support presumably enhances efficacy, esteem, and confidence, thereby increasing an individual's perception that he or she can cope effectively with negative life events. In addition, the tangible support provided by network members may directly facilitate the resolution of negative events. There is a general consensus in both research and clinical circles that social support reduces and/or prevents 
stress, though it is difficult to study the effect due to many interacting variables. ${ }^{45}$ As in the case of spillovers, the extent to which a relationship has buffering effects depends on the intensity of the relationship, on the responsiveness of one person to the other person. ${ }^{46}$

\subsubsection{Overview: streamlining the variety of effects and pathways}

As was discussed in chapter 3 and in 6.2.5, the stress response is non-specific: the cause of stress may be specific to a particular domain, but the resulting stress is non-specific and affects all domains.

The discussion of empirical evidence above has shown that being in a relationship has both negative and positive effects, which have a variety of forms and act via different pathways. The non-specificity of stress means that different negative and positive factors can be 'added up' together in terms of the stress they create or reduce. Stress is in this respect similar to money: a variety of products can nevertheless be added up in terms of their money value.

In the model we capture the different positive effects of being in a relationship through the variable (b), reflecting the extent to which being in a relationship reduces stress. The beneficial aspects of being in a relationship all depend on the intensity of the relationship, which together the extent to which one member of a dyad is responsive to the needs of the other. This is captured by making buffering $(b)$ dependent on responsiveness $(r)$.

In the model we capture the negative effects of being in a relationship by making the stress level of one member of the dyad dependent on the stress level of the other member and vice versa. Since the extent to which the stress of one member will affect another member depends on how much they care for each other, we make the spill over of stress dependent on responsiveness $(r)$.

The literature indicates that some effects of being in a relationship would act on stress levels by reducing or increasing the ability to cope, thus involving the variable control or coping (c). Reduced or increased coping would effectively result in more or less stress, and since we want to keep the model tractable we have routed all the effects of being in a relationship via spill-over and buffering, since it does not really change the dynamics which we want to show.

To summarise this section briefly:

- Exogenous stress levels are determined by the rate of innovation;

- Individuals can cope with some of their stress, and the degree of coping increases with the amount of stress felt;

\footnotetext{
45 Empirical evidence for the specific hypothesis of "stress-buffering" has been mixed (e.g. Burton et al. 2004), which is attributed to the difficulty to isolate factors (for a discussion on this see Krause 1995, 2005).

${ }^{46}$ To illustrate some examples are given of decreasing responsiveness and consequent decreasing social support in relationships due to stress. Repetti (1989) found that male workers were more distracted and less involved and interested in social interaction with their wives following more difficult or busy days at work. Repetti (1992) found evidence of social withdrawal as a response to daily stressors. Schulz et al. (2004) found that husbands were more withdrawn after emotionally distressing workdays, and wives were more withdrawn after more demanding and faster paced workdays. Repetti (2005) discusses evidence that mothers and fathers tend to be less behaviorally and emotionally involved with their children after stressful days at work. Saxbe et al. (2008) find that
} 
- An increase in the stress level of one member of the dyad spills over to the other member through cross-over;

- An increase in the stress level of one member can be reduced through buffering provided by the other member, and the level of buffering increases with the level of stress;

- The rate of cross-over and buffering are positively affected by responsiveness within the dyad;

- Responsiveness of an individual is itself is affected negatively by his or her stress level.

\subsection{Model}

In this section we examine the relationships between the innovation rate, the intensity of interpersonal relationships (mental capital?), and productivity growth. For that we set up and analyze a simple model that brings together the key variables and relationships identified in the previous section.

\subsubsection{Agents}

Consider a population of agents that consists of pairs of individuals engaged in a social relationship (work partners, family etc.). A typical dyad consists of two individuals, $\mathrm{X}$ and $\mathrm{Y}$. Individual $\mathrm{X}$ can be characterized by his (present) level of stress, $x_{t}$, level of self-control, the rate at which $\mathrm{X}$ can reduce his stress on his own, $c_{x}$, and the level of external stress, $S_{x}{ }^{47}$ Similarly, Y's stress level is $y_{t}$, self-control $c_{y}$, and external stress $S_{y}$.

\subsubsection{Relationship}

Social relationships play an important role in the process of contagion and absorption or buffering of stress. The degree to which the stress of one person is transmitted to the other depends on the responsiveness of the second person to the stress of the first (section 6.2.5). We characterize responsiveness of a person $i$ to the stress level of her/his partner as by the rate at which partner's stress is transmitted to this individual, $r_{i}(i=\mathrm{X}, \mathrm{Y})$. For example, when $Y$ 's stress level is $y_{t}$ then the intensity of stress crossover from $Y$ to individual $X$ is equal to $r_{i} y_{i}$.

For the sake of simplicity and tractability we assume that the relationship is symmetric:

$$
r_{x} \equiv r_{y} \equiv r .
$$

An alternative interpretation of $r$ is the intensity of the relationship. The stronger is the relationship, the more emotions partners share with each other, and the higher is the intensity of the stress crossover.

\footnotetext{
${ }^{47}$ Here and in what follows "external" means "external to the relationship", i.e. in this case all kind of stress originated outside of the relationship.
} 
Furthermore, the relationship may work as a buffer: sharing stress with one's partner reduces one's stress at the rate $b$. The efficiency of sharing $(b)$ is a function of the relationship intensity characterized by responsiveness (section 6.2.6), hence

$$
b=b(r) \text {. }
$$

We assume that with respect to responsiveness the buffering mechanism has diminishing marginal effect, i.e. function $b(r)$ is concave (Figure 1 shows a typical shape for $b(r)$ ).

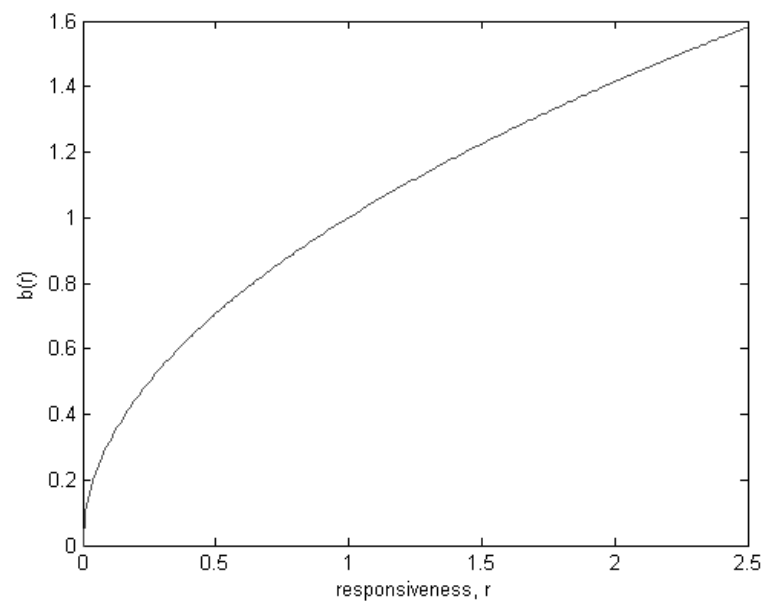

Figure 1. Buffering as a function of responsiveness $(b(r)=\sqrt{r})$.

\subsubsection{Dynamics}

We formalize dynamics with a system of (coupled) differential equations.

$$
\left\{\begin{array}{l}
\dot{x}=-c_{x} \cdot x-b(r) \cdot x+r \cdot y+S_{x}, \\
\dot{y}=-c_{y} \cdot y-b(r) \cdot y+r \cdot x+S_{y} .
\end{array}\right.
$$

According to (1) the level of $X$ 's stress is decreasing through the mechanism of self-control (at the rate $c_{x}$ ) and via sharing stress with the partner (at the rate $b(r)$, which depends on the strength of the relationship), and it is increasing with the level of the stress of the partner $y$ (at the rate $r$, that characterizes $X$ 's responsiveness). Similarly (1.2) describes the changes in Y's stress level. To simplify the analysis we will assume that the individuals are symmetric and $c_{x}=c_{y}=c$.

Summing the two equations in (1) and introducing new variable $z \equiv(x+y)$ that is the level of the total stress in the dyad, we can write the dynamics for total stress $z$ :

$$
\dot{z}=-(c+b(r)-r) z+S_{0}
$$

where $S_{0}=S_{x}+S_{y}$ (stress external to the relationship). In what follows, we leave the level of the separate individuals, and examine them as a whole, the dyad being the unit of analysis. 


\section{Dynamics of stress without a relationship}

To understand the role of the different factors in the evolution of stress let us first examine the dynamics of a system without a relationship. If there was no relationship (just two individuals not knowing each other), then equation (2) has a simple form $(r=0)$ :

$$
\dot{z}=S_{0}-c \cdot z
$$

The only steady state of equation (3) is at $z_{0}=S_{0} / c$. The steady state is stable, since at this level of stress time derivative $\dot{z}$ changes its sign from positive for $z<z_{0}$ to negative above this value. Moreover, monotonicity of the function $\dot{z}(z)$ ensures global stability of the steady state. It implies that as long as the long-run values of the parameters (external stress, $S_{0}$, and self-control, $c$ ) stay the same the system always returns to the long-term level of stress, $z_{0}$, regardless of the magnitude of the disturbance that has taken the system away from the steady state.

Let us examine how characteristics of an individual and her environment influence the longterm value of the stress, $z_{0}$. We start with the effect of coping or control $c$.

To see how $c$ affects the steady state level of stress let us fix the level of external stress, $S_{0}$, and increase $c$ (e.g. through training). To visualize the evolution of the system we can use a phase diagram that shows how $\dot{z}$ depends on $z$. In this case $\dot{z}(z)$ is a linear function and the corresponding graph is a line with vertical intercept $S_{0}$ and slope $-c$. Graphically an increase in $c$ corresponds to clock-wise rotation of $\dot{z}(z)$ as is shown in Figure 2 (cyan arrow indicates the direction of increasing $c$ ).

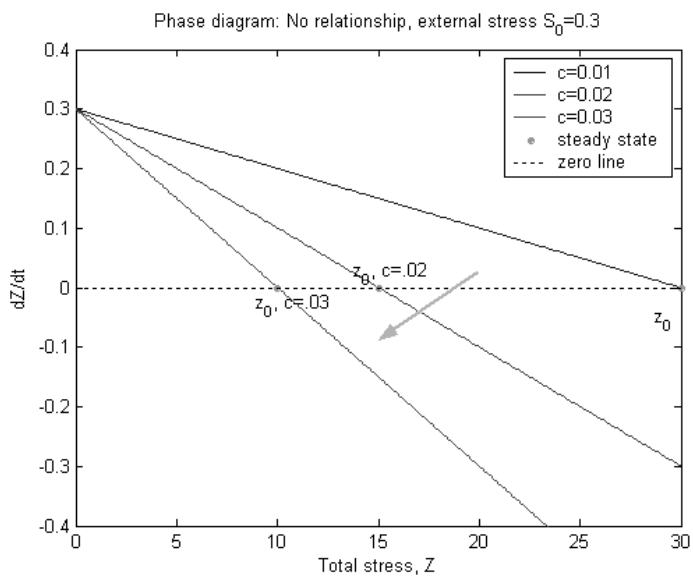

Figure 2. An effect of an increase in the efficiency of self-control. 
The steady state of the system, $z_{0}$, corresponds to the point where $\dot{z}(z)=0$, that is, where it crosses the horizontal axes. As one can see from the Figure 2, rotation of $\dot{z}(z)$ corresponding to an increase in self-control moves the steady state closer to the origin. Hence training targeting enhancing efficiency of self-control decreases the long-term level of stress.

We turn now to the effect of external stress, $S_{0}$. External stress might have a variety of sources. In this chapter we limit our attention to the effect of innovation. As was outlined in the section 6.2.2, changes associated with innovation create uncertainty and augment the amount of non-routine labour, while decrease perception of control over everyday activities. Both result in an increase of the flow of the stress an individual has to cope with.

Figure 3 gives a diagrammatic representation of an effect of an increase in $S_{0}$ for a given level of self-control, $c$.

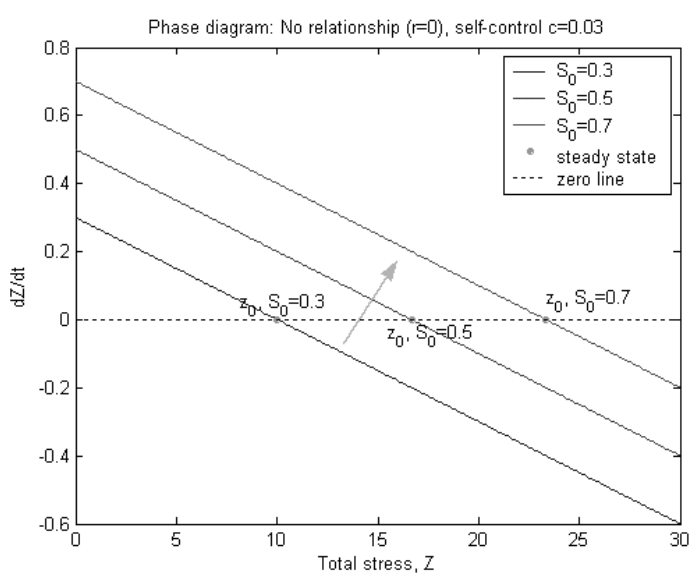

Figure 3. An effect of an increase in the efficiency of self-control.

As one can see, the steady state of stress, $z_{0}$, increases with an increase in the flow of the external stress. The change in the level of the long-term stress is proportional to the change in the intensity of external stress with the factor equal to inverse of the self-control variable, $c^{-1}$. In other words, the better one can cope with the stress on her own (via self-control), the less significant is the effect of the external stress.

Summarizing this exercise we can state that without a relationship the system has a single globally stable steady state, where the system rests most of time and to that it returns once disturbed. Policies targeting enhancing personal skills for coping with stress (increasing the efficiency of self-control) reduce the long-term level of stress, while increasing external stress tends to push this level up. 
Now we turn to the general case of dynamics of a stress for a dyad when $r>0$ (meaning that there is a relationship). According to our assumption about the diminishing marginal effect of stress-sharing (concavity of $b(r)$ ), that describes effective buffering on the level of dyad (in contrast with $b(r)$ which characterizes the effect of buffering on individual level of stress), a typical shape for the "reaction function" $\alpha(r) \equiv(c+b(r)-r y)$ is an inverse Ushape curve as shown in Figure 4. (Here we illustrate the reaction for agent $X$, and assume that Y's stress level is fixed at $y=1$.)

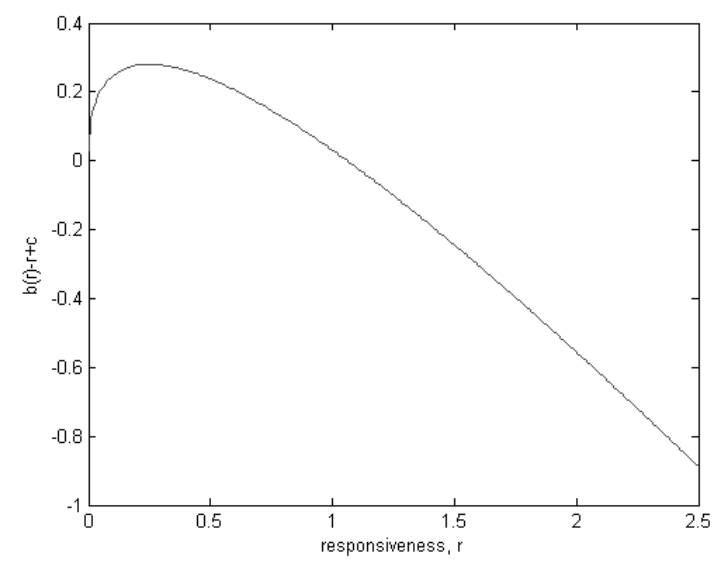

Figure 4. Dyadic buffering as a function of the relationship intensity, $r$.

At lower levels of responsiveness (strength of the relationship) the buffering capacity $b(r)$ is the dominant effect; responsiveness reduces the stress of a partner more than it increases the individuals own stress levels. However for a very intense relationship the effect of stress spillover starts to outweighs the positive effect of buffering.

We now make the strength of the relationship endogenous. The literature discussed in the section 6.2.7 suggests that a high level of stress in a relationship leads to increasing tension between the partners and tends to weaken partners' responsiveness to each other's stress. Accordingly we assume that the strength of the relationship characterized by individual responsiveness, $r$, is monotonically decreasing with increasing levels of total stress, $z$. At high levels the relationship ceases $(r=0)$. Technically, this implies that $r^{\prime}(z)<0$ and $r(z) \approx 0$, for $z>0$. Furthermore, it requires $r^{\prime \prime}(z)>0$. A monotonically decreasing convex function $r(z)$ is shown in Figure 5. 


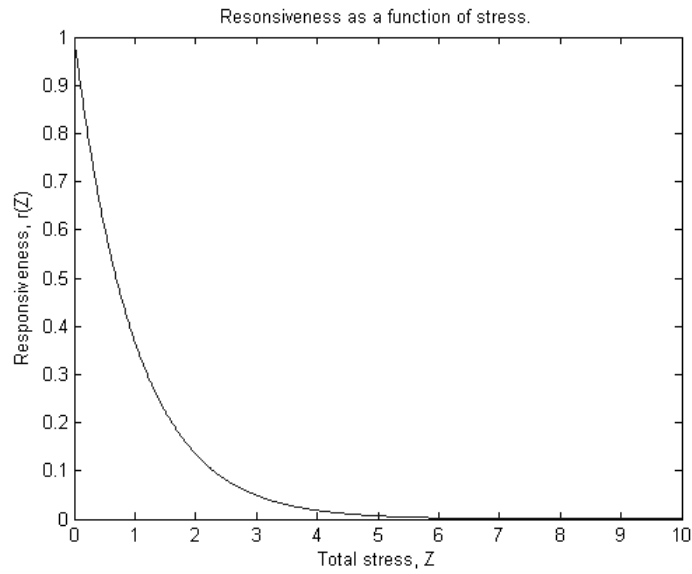

Figure 5. Relationship between responsiveness and stress.

\subsubsection{A specific example}

While many results of the model are also valid for the general model, in what follows we will examine one particular specification. It allows us keep analysis simple and intuitive, and at the same time provides a useful insight in the key results of the model. We assume that individual buffering as a function of partner's responsiveness has form

$$
b(r)=\sqrt{r},
$$

The responsiveness or the strength of the relationship as a function of total stress is

$$
r(z)=e^{-z} \text {. }
$$

Then equation (2) has the form

$$
\dot{z}=S_{0}-\left(c+e^{-\frac{z}{2}}-e^{-z}\right) \cdot z \text {. }
$$

For $c=.05$ and $S_{0}=0.6$ the phase diagram is shown in Figure 6: 


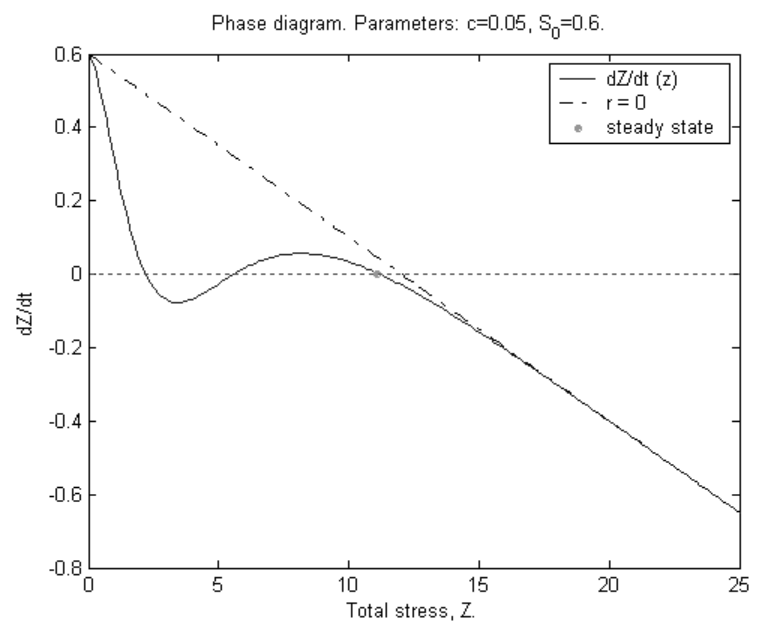

Figure 6. Phase diagram $\left(c=.05\right.$ and $\left.S_{0}=0.6\right)$.

To see the role of the social relationship, compare the curve corresponding to the reaction function $\dot{z}(z)$ (solid line) with the dash-dotted line representing the reaction function without the relationship $(r=0)$ for the same values of $c$ and $S_{0}$. The social relationship works as a stress absorber for small and intermediate values of stress. But as total stress increases, the relationship starts to fade away and can no longer absorb stress, and the reaction function approaches the no- relationship case. At this point we can say that the relationship ceases.

How is this related to innovation? The intensity of innovation (other things equal) determines the value of external stress $S_{0}$. Depending on the external stress the system may have three qualitatively different dynamics (see Figure 7).

1. Low innovation intensity (lowest curve). There is a unique steady state with relatively low stress (as compared to the situation of no relationship), the social relationship is effectively absorbing stress.

2. High innovation intensity (top curve). $S_{0}$ is large; there is single high-stress equilibrium. The social relationship is counterproductive and has become a stressor in itself. It's effect will therefore fade out (high $z$ means low $r$ ). In case of a family relationship, we may think of divorce, since the partners could not cope with the ever growing stress. If they were colleagues, they will avoid each other, or not talk to each other. Each of the partners has to rely on individual self-control mechanisms. It is in effect similar to the case of no relationship.

3. High, but not extremely high intensity of innovation (middle curve). The most interesting case: there will be a co-existence of two equilibria (the system has two stable equilibria ( $z^{*}$ and $z_{3}{ }_{3}$ ) and one unstable equilibrium $z_{2}^{*}$ ). Depending on the initial conditions, we have either a low-stress equilibrium $\left(\mathrm{z}^{*}{ }_{1}\right)$ where the social relationship is absorbing the stress (as in low innovation intensity case), or a high stress equilibrium ( $\mathrm{z}_{3}^{*}$ ) with 
(almost) no social relationships (only self-control, similar to high innovation intensity).

The latter is particularly interesting. In this case the system has "memory", e.g. suppose that there was a major temporary shock in $S_{0}$. That will shift the curve up and if the magnitude of the shock is sufficiently high, it can make the system jump over $z_{2}^{*}$ to the high stress equilibrium $z_{3}^{*}$. Now, even if the external stress returns to the initial value of $S_{0}$, the system will continue to reside in the high-stress equilibrium (corresponding to no relationship).

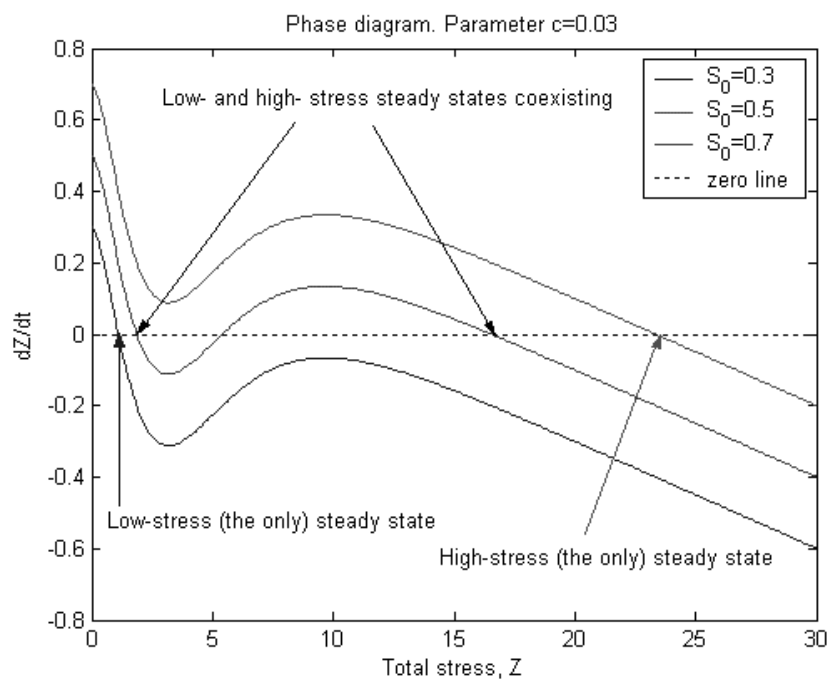

Figure 7. Effect of external stress in the presence of a social relationship.

Thus, in this case relatively small changes in external stress $S_{0}$ may lead to drastic qualitative changes in the behavior of the system. ${ }^{48}$

Historically speaking, as technological change lead to more innovation and thereby to more external stress the model suggests that increasing intensity of innovation may lead to dramatic changes in the nature of social relationships. Indeed, suppose we start with low innovation intensity, hence the single low stress equilibrium. At a certain level of external stress caused by innovation we suddenly find that second high-stress equilibrium arises, and both co-exist. If it goes on even further we risk losing the low-stress equilibrium so that at the end everybody is stressed and social relationships disappear all together.

\footnotetext{
${ }^{48}$ In terms of dynamic systems the system has a "cusp" catastrophe (see Saunders, Peter Timothy (1980) "An introduction to catastrophe theory", Cambridge: Cambridge University Press).
} 


\subsubsection{Implications for productivity and economic growth}

Now we link the dynamics of stress we have analyzed so far with productivity and economic growth. According to Y-D law (section 6.2.3) the relationship between productivity and stress is non-monotonic and has a shape of inverted U: the productivity grows with the level of stress when latter is relatively low, and it falls after the level of stress exceeds a certain threshold.

It seems to be reasonable to assume that high-stress no-relationship equilibrium of our model is located above the threshold, at the descending part of the inverted U. In other words we assume that for an individual who is stressed to the degree that (s)he is unable to support a long-term social relationship further increase in the stress tends to decrease his(her) productivity.

From the point of view of our model innovation rate has two effects on economic performance. First, there is a positive direct effect derived from the fact that innovation brings new more efficient methods of production, i.e. for the same amount and quality of labor more output can be achieved. There is also indirect effect related to the fact that innovation increases the flow of stress as it stipulate (perceived) demand, and at the same time diminish (perceived) control over the process (section 6.2.2). According to Y-D law the indirect effect can be both positive and negative depending on the initial level of stress.

We can formalize it with the same specifications of our model as have been used above. Let us make additional assumptions about relationships between innovation and external stress, stress and productivity, and innovation and output.

First, we assumed the flow of external stress caused by innovation, $S_{0}$, is proportional to the rate of innovation, $m$ :

$$
S_{0}=m \text {. }
$$

Second, we use the following specification for the relationship between productivity and stress $(\text { Y-D law })^{49}$ :

$$
A=z^{0.5} \cdot\left(\bar{z}^{0.5}-z^{0.5}\right),
$$

with $\bar{z}=25$. And, finally we assume that the rate of economic growth is a product of innovation rate, $m$ (due to increase in output per unit of labor) and productivity $A$ (that describes "quality" of labor related to worker's stress level).

$$
G=m \cdot A=m \cdot z^{0.5} \cdot\left(\bar{z}^{0.5}-z^{0.5}\right) .
$$

We are interested in how $G$ depends on $m$. For that we have to substitute $S_{0}=m$ in equation (4) and find its stable state(s) as a function of innovation rate, $z_{0}(m)$. The numerical solution, $z_{0}(m)$, is shown in Figure 8 .

\footnotetext{
${ }^{49}$ By contrast with the previous section in this expression $\mathrm{z}$ is related to individual stress. For more consistent notations it should be substituted by $z / 2$ (average stress per person).
} 


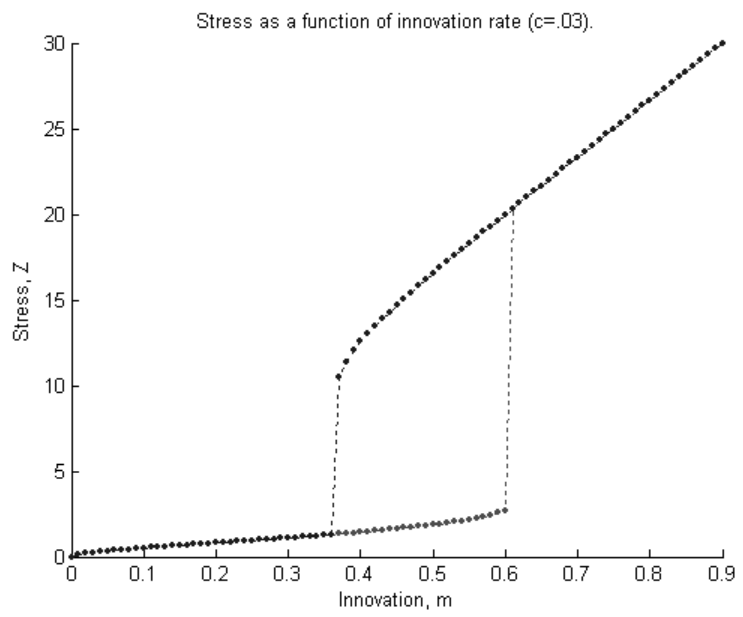

Figure 8. Stress as a function of innovation rate.

For lower innovation rate stress increases slowly (it depends on the slope of $\dot{z}(z)$ in the vicinity of the low-stress steady state), as innovation rate increases, high-stress equilibrium appears and co-exists with the low-stress equilibrium (two branches of $z_{0}(m)$ at Figure 8). At the high level of innovation only high-stress no-relationship steady state is sustainable, stress increases at rate $\sim c^{-1}$ (as in no-relationship case).

Now inserting $z_{0}(m)$ into (5) we can find how the rate of economic growth $G$ depends on the innovation rate, $m$. The function $G(m)$ is shown in Figure 9.

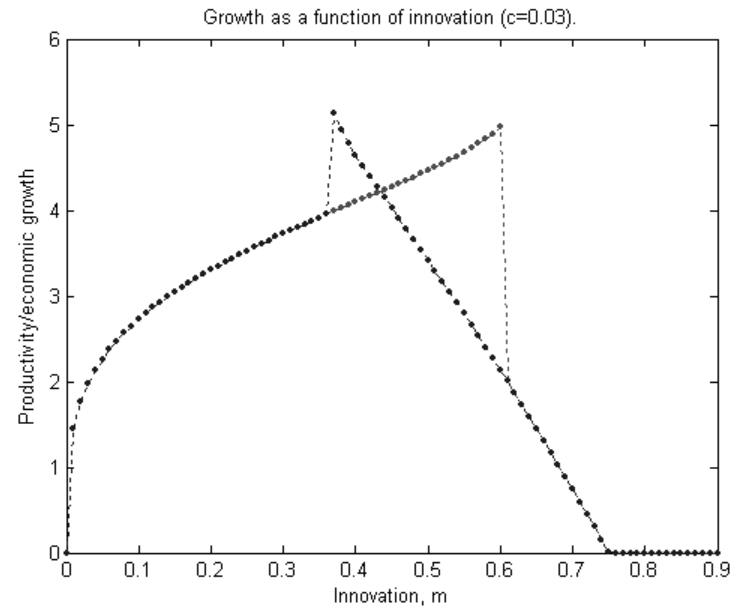

Figure 9. Economic growth as a function of innovation rate. 
Again, notice the non-monotonic relationship between innovation and economic growth. In the beginning (small $\mathrm{m}$ ) the economic growth responds rapidly to an increase in innovation rate. However, as the intensity of innovation grows further, the dark side of the innovation related to increase of the external stress and breakdown of social relationships overwhelms the positive effect of innovation and productivity suddenly drops and any further increase in innovation rate diminish the economic growth.

Co-existence of equilibria in the middle range of innovation rate makes an economy unstable with respect to small fluctuations in the flow of external stress (generally speaking not necessarily related to innovation) - small shocks may drag the system out of the low-stress equilibrium and set it on the declining branch of $G(\mathrm{~m})$. To return the system to the lowstress equilibrium we have to decrease the innovation rate much lower (so that only lowstress equilibrium exists).

In other words, not only do we find multiple steady states, in addition we find that there is hysteresis. Within a certain range of external stress flow $S$, thus within a certain range of rates of innovation, there is a double value function. If external stress $S$ increases, steady state $z$ will increase. Above a critical value of $\mathrm{S}, ₹$ tips over to the high steady state value; this has the character of a phase-change. If after crossing this threshold, $S$ is reduced again (through reducing innovation rate), nevertheless $z$ will remain in the high value segment of stress level as a function of external stress. This means that at the same level of flow of external stress $\mathrm{S}$, there can be different levels of steady state stress $z$, depending on the history of $S$ (whether $S$ was reached by going from a low to a higher $\mathrm{S}$ or by going from a high to a lower $\mathrm{S}$ ). What it means in practice is that if innovation rates become too high, thereby creating high rates of stress flow, a reduction to the (previously maintained) intermediate level of innovation and hence external stress, (because because the high stress levels are viewed as socially undesirable), we will nevertheless retain a much higher stress than before. In order to lower stress levels, we will have to lower the innovation rate considerably below the original rate which was initially associated with acceptable stress levels. This will clearly have consequences for the speed of innovation (which will be lower) and for the increase of productivity (which will also be lower). This hysteresis can imply a significant economic loss.

The explanation for the hysteresis lies in the fact that as of a certain level of external stress, relationships start to become stressors and will start to break down. ${ }^{50}$ If after relationships have broken down, the level of external stress is brought back to intermediate levels again, the buffering effects of relationships are no longer present, since relationships will only be restored again to an extent that they have beneficial impact rather than detrimental impact as of some lower rate of stress, which for quite some time will not be reached, precisely because there are not relations to help speed the reduction of stress levels.

\footnotetext{
50 The alternative is that the members of the dyad decide not to let the relationship break down, but for example quit their job and (try to) find another, less stressful job. In the model this would ether mean that the the flow of stress is reduced and thus stress levels do not get high enough to make the dyadic stress level 'flip' from the low steady state to the high steady state; or if it is too late for that and the transition to the high steady state is already made, that the members of the dyad changing or quitting jobs reduce their stress level even more in order to repair their relationship.
} 
In terms of implications this means that it is economically costly to have too high rates of innovation, even if it is only temporarily. The price is that due to the breakdown of relationships people are less able to reduce their stress levels and therefore are less able to deal with higher intermediate rates of innovation than they were before.

Innovation increases productivity, so a higher rate of innovation should increase productivity at a higher rate. However, the higher the rate of innovation, the higher the flow of stress. Since stress is related to productivity following the shape of an inverted $\mathrm{U}$, the level of stress resulting from the rate of innovation is important for understanding the real effects of innovation on productivity. As of a certain rate of innovation, a phase-change takes place, the steady state of stress switching from the low to the high steady state. When we look at the effects of this in terms of productivity, we see that at the high steady state levels of stress, productivity goes down. Moreover, as of a certain stress level, productivity gains due to innovation may be outweighed by productivity losses due to high stress levels resulting from innovation. As of that point, innovation may actually start to slow down productivity growth. So, as of a certain rate of innovation, higher rates of innovation slow down rather than speed up productivity growth. Again, the reason for this lies in the dynamics of mental capital availability and the effects of relationships on this through the effects of relationships on stress. We can conclude then that it is better to have a moderate level of innovation that, in addition, does not fluctuate too much.

\subsubsection{Comparative statics}

In this section we are interested in the consequences of changing certain variables. This will give some perspective on possible interventions ant their effects.

\section{Coping skills}

One variable that can be changed is coping. Over time people generally learn better ways of coping, by selecting more effective, more context- and problem-sensitive coping strategies (Greve and Strobl, 2004). It is possible to increase coping skills actively, for example through coaching or training. Coping skills are captured by our variable $c$. In the absence of a relationship, if $c$ is increased, a person can reduce his stress level at a higher rate. Given a certain stream of new items, he will arrive faster at a steady state stress level, and that steady state stress level is positively related to $c$.

We see a similar effect when we look at the dyad, but amplified. For higher values of $c$ stress levels are reduced faster, and the beneficial effects of having a relationship are stronger, since they depend on the level of stress through responsiveness (which is higher if stress levels are lower, hence increasing the buffering effects) and through the variable of spillover (which is lower if stress levels are lower, even though it is higher when $r$ is higher, the net effect will be positive, in the sense of less spillover). So increasing coping skills results in a lower steady state of stress, especially in the presence of a relationship. 
Coping is important in an economic sense because it determines the levels of stress at which an actor can function, and thus the level of innovation that an actor can cope with. The extent to which innovation can effectively increase productivity depends on the coping ability of agents. Most coping models ignore the potential crossover effects of coping behaviors from the individual coper to others in the coper's social group. Psychological research shows that some forms of coping represent a trade-off between managing one's own distress and contributing to a partner's distress (e.g. Coyne and Smith, 1991). Certain ways of coping have negative externalities on others (for example, dealing with stress by ignoring demands at work, which then get shifted to colleagues causing stress for them), thus increasing those types of coping may be counterproductive. Intervention directed at coping should go beyond the limited nature of an individualistic perspective, in which only the impact of coping behaviors on the individual coper is examined (O'Brien and DeLongis, 1997).

Monnier et al. (2000) demonstrated that interventions that focus on developing prosocial coping skills, such as negotiating compromises between one's own needs and those of others may produce more fruitful, long-term results. Interventions that seek to increase active coping skills without regard to the social implications of these behaviors may produce individual symptom reduction but may also cause harm to social relationships, in part, because of this differential impact of coping behaviors. Therefore, when considering increasing coping skills as an intervention to increase productivity and growth, the effect of relationships should be taken into account.

\section{Buffering}

Another variable that can be changed is the quality of the relationship, for example through developing better social skills, or by providing more insight into the dynamics of relationships through more reflection or through relationship therapy. This enters the model through buffering: $b(r)$. Since $b(r)$ is a product of a compound variable including social skills and reflection, and responsiveness $r$, then increasing social skills and reflection will shift the concave curve $b(r)$ upward, increasing the potential beneficial effects of having a relationship. Holding spillover levels constant, the net result of being in a relationship will be more positive and will remain positive longer, at higher levels of stress, than before. This implies that both the low and the high steady state of stress level $z$ are located at lower levels of stress.

\section{Responsiveness}

A third variable that could be changed is responsiveness. More responsiveness increases both the potential positive and the potential negative effects of having a relationship. On the one hand, a more responsive person will be more able to reduce the stress level of the other member of the dyad; but on the other hand, a more responsive person will suffer more from stress spillovers due to the stress level of the other member of the dyad. The precise effects of increasing or decreasing responsiveness are ambiguous. It seems generally to be the case that it will increase the beneficial effects of the relationship up to a certain level of stress, and 
above that it will increase the negative effects of the relationship, as compared to a dyad with lower levels of responsiveness. So, higher levels of responsiveness make the good parts of the relationship better, and the bad parts of the relationship worse. In terms of the phasechange discussed under the results, it implies that the area in which there is hysteresis is larger. This means that the costs of crossing the threshold rate of innovation are higher then in the case of lower levels of responsiveness. Further, dyads in which the intensity of the relationship is high are more vulnerable to fluctuations in innovation rates, and will benefit more from stable, moderate levels of innovation. Conversely, it means that in economies with high innovation rates and/or large fluctuations of the innovation rate, are better off having less intense, more superficial relationships, since that will reduce the negative effects of hysteresis.

\section{Relationships}

Both buffering and responsiveness have to do with the quality of the relationship, and how members of the dyad relate to each other. This issue is beginning to receive attention in psychology, with research on interventions that involve more than the individual expressing symptoms.

Benazon and Coyne (2000) argue that spouse burden may potentially be an important point of intervention. Instead of focusing exclusively on the reduction of the distress of an actor, attention could also perhaps be directed to the distress and burden experienced by spouses. Spouse burden is potentially modifiable by increasing relational skills (increasing buffering capacity) and increasing stress coping skills (reducing stress spillovers).

Practical implications include assessment and treatment strategies that include interpersonal processes as a focus and therapies to "inoculate" significant others against the effects of contagious emotions (Joiner 1994). For enhancement of the quality of life in individuals, interventions that target both members of a spousal pair may be most effective, as there is evidence that one partner's well-being spills over to that of the other (e.g. Bookwala and Schultz 1996; Hammer et al., 2005).

The findings of Westman et al. (2004) suggest that such interventions should focus on the reduction of social undermining, as it is found to be a powerful mediator of the adverse impact of economic hardship on marital satisfaction. Westman et al. (2004) suggest that efforts to reduce the stress and strain of employees should also target their spouses. The findings demonstrate that a distressed wife is likely to generate a process of social undermining that will have an adverse effect on the husband, and then later, through the husband, on herself. It appears that if a distressed spouse is not part of the solution, he or she is likely to become a big part of the problem. Thus, what is needed according to Westman et al. (2004) are programs that train and counsel couples in developing skills for reducing negative interactions and enhancing their relationships. The primary objective of such programs is prevention and ongoing improved functioning, achieved by focusing on techniques designed to help couples manage negative affect and handle conflict situations constructively. This understanding of interpersonal effects can be applied also to 
interventions programs designed for nonintimate relationships (e.g. coworker to coworker) (Monnier et al. 2000).

At most stress levels except for high stress levels, relationships help a person to reduce his stress faster, thereby resulting in a lower steady state of stress. This means that at least within a certain range of stress, a person without a relationship is less able to deal with innovation (external stress) as a person with a relationship at the same stress level. If we assume that stress represents disutility, and if we assume more innovation in principle is a good thing, being in a (good) relationship is in principle economically desirable. This is in line with the findings on the positive economic effects of social capital.

\subsection{Discussion}

\subsubsection{Possible extensions}

The contribution of the model presented is that, as compared to existing models on innovation and productivity, it has added two elements to the analysis. First, it included the dynamics of mental capital, by including stress in the analysis and its particular, inverted $U$ relationship to productivity. Second, it included the dynamics deriving from the fact that people are in relationships with other people, which influences the impact of mental capital through influencing stress levels.

The limits of the model are that it only looks at the dynamics of a dyad $(n=2)$, while it is clear that people have more than one relationship, with more than one other person. To see the effects of inter-agent dynamics in a populations, a network model with heterogeneous relationships would be needed, for example, a person can be a spouse of another person, while a colleague of a third person. If every person is both a spouse and a colleague, then we can find that a person can be affected by the rate of innovation that another persons faces, while neither experiencing any increase in innovation himself, nor even knowing the person that faces increased innovation. This could lead to interesting insights in negative or positive externalities arising from purely local innovation.

In addition, such a model could be used to look at the effects of changes in the proportion of the population that is stressed. One likely outcome is that if the stressed part of the population exceeds some threshold value, then stress would spread through the whole population, due to inter-agent dynamics, depending on the density of the network and the distribution of the density of the network (local high and low density vs. more evenly distributed density). In this it would reflect standard percolation theory results.

This naturally suggests that the density of the social network could be important. For example, it could become clear that there are different optimal combinations of innovativeness, network density and productivity. It could thereby offer choices in terms of how to achieve productivity growth, by aiming at different combinations of social density, and innovation rates and fluctuation, which result in the same rate of productivity growth. By including mental capital dynamics in a social welfare function, and determining a 'price' of 
stress, one could investigate which of the possible combinations scores best as far as social welfare increase is concerned.

Finally, it could offer new perspectives for forms of intervention. It may become clear that individual-oriented intervention strategies have to do much more (and therefore are relatively more costly) in order to achieve the same effect in terms of stress reduction or productivity growth than dyadic- or network-oriented forms of intervention, hence adding to the debate of 'surgical' vs. more 'ecological' intervention, and ex ante (prevention) vs. ex post intervention (cure).

\subsubsection{Mental capital}

The model presented in this chapter was intended to demonstrate how mental capital can be operationalized by including elements of mental capital (such as coping, stress resilience and cognitive and social-emotional functioning) into the economic analysis of standard economics concerns. Mental capital refers to the scarce resources that people possess to selfmanage and regulate, and through this is represents the degree of rationality and of agency of a person. Empirical research shows that mental capital as it is defined in this thesis (in terms of agency, self-efficacy) influences all the variables put forward in the model in this chapter. This has been discussed to some extent in chapter 3. Here, we will give two illustrations by considering the influence of mental capital on two key variables in the model: coping and responsiveness.

\section{Mental capital and coping}

In the model, we assumed coping to remain effective at higher levels of stress, because we captured the loss of performance at higher stress levels by means of the inverted U. However it is clear that one of the pathways by which this happens is through the diminishing quality of coping (the quantity of coping increases as stress increases, thus the linearity). Less effective coping increases stress levels, which leads to even less effective coping.

Central constructs in the 'model of coping modes' (Krohne, 1993) are approach (vigilance) and avoidance. This distinction overlaps with another important distinction, problemfocused vs. emotion-focused coping (Lazarus and Folkman 1984). Roughly speaking, if a problem can be solved by an actor, 'approach' and 'problem-focused' ways of coping are most effective; when a problem cannot be solved, 'avoidance' and 'emotion-focused' coping are generally better. Whether an actor perceives a problem as solvable depends to some extent on his self-efficacy, and thus on his mental capital (chapter 3). 'Approach' and 'problem-focused' coping generally lead to higher productivity, but they demand more selfregulating capability.

Persons with low levels of mental capital have a low self-regulation capability of their internal processes. New demands lead to increasing arousal, which increases the need for selfregulation, on which they are low. Therefore they will be primarily interested in reducing arousal and passive coping (Hock et al. 2004); they will choose avoidant coping strategies, which primarily aim at shielding the person from an increase in emotional arousal. 
Persons with high levels of mental capital have a high degree of agency and therefore high self-regulation capability of their internal processes. They can deal with higher levels of arousal. New demands will lead to increased attempts not to primarily reduce arousal but to reduce demands (and thus as a consequence also arousal) by active coping. They intensify rather than reduce their intake and processing of information to reduce uncertainty and increase control, even though this implies higher levels of arousal (Hock et al. 2004). They will choose for vigilant coping strategies, which primarily aim at decreasing actual and potential demands. While in some cases avoidant coping strategies may be best, since some demands are very hard to cope with and some demands may disappear by themselves over time; generally vigilant coping strategies are more effective. However, they require more mental capital. If a person is low on mental capital, for example due to mental health problems such as burnout, he will have no real choice but to opt for avoidant coping strategies. This is not only bad for productivity but also this will not help him to reduce demands or the resulting stress. Thus, mental capital determines coping ability and thereby stress resiliency and productivity.

\section{Mental capital and responsiveness}

When looking at comparative statics, we found that increasing responsiveness had a mixed effect: the good part of having a relationship became better, but the bad part became worse. In this, the model aligns with empirical research showing that increasing responsiveness or empathy is only useful if it happens in combination with increasing regulation capacity. Mental capital was defined as 'self-agency', the ability to act on one's own behalf, and an important element is self-regulatory ability. Empirical research suggests that actors who are unable to sufficiently regulate their emotional reactions are more likely than other people to experience distress when confronted with negative emotions of others, and to focus on their own needs, and to behave in ways that do not facilitate positive interactions in emotional social situations. In contrast, people who can regulate their emotion tend to experience sympathy and apply pro-social coping strategies when confronted with negative emotions of others. ${ }^{51}$ Thus, whether a relationship with high intensity or proximity has a net result of stress spillover or stress buffering seems to depend to an important extend on the selfregulatory ability of an actor, his self-agency.

\subsection{Conclusion}

In this chapter we have presented a simple model of induced stress. While an agent is exposed to stress from his environment, including innovations in it, the stress level he ultimately experiences is mediated by aspects of a relationship between himself and another

\footnotetext{
51 E.g. Eisenberg et al. (2000) found that individuals who are not adept at regulating their emotional states, have a tendency to become empathically overaroused and thereby stressed. Sympathy was found to be primarily associated with well-regulated individuals. Finkel et al. (2001) find that self-regulatory ability positively influences relationship quality. Derryberry and Rothbart (1988) show that people high in constructive modes of regulation are relatively high in a sympathetic disposition which is related to relationship quality.
} 
agent. Associating mental capital with the inverted-U relationship between stress and productivity permits us to take this micro-model of stress contagion and stress buffering as a basis for understanding how innovation and growth interact with mental capital. The limited ability of any agent to cope with stress, combined with spillovers from one agent to another imply that it is possible to get too much of a good thing — very high levels of innovation, if not accompanied by increases in agents' abilities to cope with their own stress, or buffer each others' stress, may be counter-productive in terms of productivity growth. In addition, the counter-productivity has an unfortunate hysteretic aspect. If innovation rates become so high that the society is tipped into the high-stress equilibrium, a simple re-establishment of the previous, lower rate will not necessarily re-establish the lower stress levels. Some overcorrection may be necessary, which can be costly. Explication of the mental capital concept, and in particular the way arousal interacts with performance, has permitted another perspective on innovation and productivity growth. Via variables such as coping and responsiveness, the level of mental capital is both a determinant of and a consequence of the quality of social relationships and their (positive or negative) effects on stress and productivity. The point has not been to argue that including mental capital shows that high rates of innovation are bad, but rather that including mental capital points out that there are complex trade-offs in the interaction between innovation, agents, stress, productivity growth, and ultimately welfare. 


\section{Chapter 7. Conclusions}

This thesis began with the observation that there is an economic dimension to mental health that needs to be explored. It argued that mental health is a new(ly found) scarcity - not because there is less supply of it, but because there is more demand for it. The increased demand results from the changed nature of work, as was described in detail in chapter 2. The supply-side is working hard to catch up; the mental health care sector is increasing the scale and effectiveness of treatment, the social welfare sector is increasingly working on improving the unfavorable social-psychological profile that characterizes many of their unemployed clients; employers are spending more and more money on human resource management and on improving the personal effectiveness of their employees; the youth care and education sector are increasingly achieving early recognition and prevention of mental health problems in youth; parents are investing more and more time and quality in parenting fewer children, and last but not least, people are working hard to help themselves, increasingly making use of the self-help industry in its many forms.

However, at the same time other forces seem to be working to erode the supply of mental health. Our dynamic, innovative, knowledge intensive service economy brings us more economic growth; but this, it seems, comes at a price. Work-related stress has become a big and costly problem, a problem which has not diminished, in spite of many efforts. There seems to be a pervasive mismatch between what is needed on the labour market and what the labour force has to offer, in terms of cognitive, social and emotional skills, mental resiliency, individual agency. Mental health problems are and have remained the number one category in terms of work-related causes for absenteeism and work disability, in spite of increased expenditure on human resource management, stress management, working conditions.

Thus, in spite of the hugely increased investment in improving (the conditions for) mental health, mental health (or rather the lack thereof) is increasingly perceived as a problem. Obviously, these developments are closely related. The supply of mental health apparently has low elasticity, and the increasing demand for it can even reduce its supply - an uncommon characteristic in economics. It shows that we are dealing with a resource which is both used and produced in the same process. As chapter 2 described, work has become more demanding, in terms of input of mental and emotional effort per hour work. In fact, chapter 2 proposes that the impressive growth of labour productivity of the past decades may to some extent be based on improved ways of extracting (mental) effort from workers; i.e., to some extent we produce more output per hour simply because we supply more (unmeasured) input per hour. In some way our mental health functions as an input in the production process. Chapter 2 also showed that work has (increasingly, it is argued) mental health consequences. Jobs provide job satisfaction, social contacts, challenges, structure, and a sense of meaning - all factors that contribute to better mental health. Jobs also can lead to job stress, work-family conflict, burnout and resulting (activated) mental health problems such as depression and anxiety. 
Chapter 2 focused on the negative psychological consequences in terms of increasing mental demands. However, in spite of this gloomy beginning, this thesis does not tell a gloomy story. It should be understood that many changes in the world of work are for the better; to name but some, most jobs have become less physically demanding, more interesting, offering more opportunity for learning and personal development. This thesis chooses to focus on the negative side of the story not in order to convince the reader that we are going down the drain, but because there is much more research done on these negative consequences, and the economic significance of mental health tends to become most clear when it is lacking.

Chapter 2 concluded that mental health is important for performance at work, more so than in the past, and that work affects mental health (for better or worse) more so than in the past. Mental health is somehow both an input and an output of the production process, but it is an uncommon resource with very specific characteristics and dynamics.

Chapter 3 assessed the widely perceived increase in mental health problems. In order to get some indication for the economic value of mental health, an overview was given of the stunningly high costs related to the lack of mental health. While the evidence for an increase in mental health problems in general is inconclusive or lacking, the evidence of an increase in work-related mental health problems suggests that this causal category has increased. In fact, it is a combination of developments: there seems to be an increase in actual mental health problems related to work, and an increase of the effects of (work-related) mental health problems on work, which together have lead to the growing salience of this issue. Thirdly, and closely related, while mental health problems in themselves may not have increased over the past decades (only the recognition and reporting of them), the costs related to mental health problems surely have. These costs are not so much the costs of mental heath care, but rather the costs related to lost productivity form the bulk of this. Mental health problems simply have more impact on performance than in the past, because performance depends more than before on factors that are determined by mental health, such as cognitive, social and emotional skills.

Chapter 3 discussed the definition and nature of mental health, and its role in the production process. In chapter 2 mental health was identified as both an output and an output of the productive process, and chapter 3 discussed the main pathway explaining the underlying mechanism: the stress response. Using stress as a sort of generic, "hub" variable, to which all other variables can be related, and through which these variables can in turn be related to each other, is highly schematic and simplifying. However, it has the advantage of converting the rich body of research in psychology - aimed at finding out very specific relationships between specific variables in specific circumstances - into something that an economist can recognize and use: a set of generalized relations that can find a home in economic analysis.

Chapter 3 provided more insight into the precise nature of the role of mental health, and argued that it is in fact not mental health, but a close correlate of mental health which is the real productive element: (self-)agency, the ability of an economic agent to act on his own behalf, to act in his best interests. Self-agency is something that is simply assumed in economics; it is a part of the set of basic assumptions, way down at the base of its 
conceptual foundation, and with the exception of behavioural economists, most economists do not think about it. For psychologists this is quite different; (lacking) agency is a central issue for research, and is studied extensively in terms of constituent elements such as 'locus of control' and 'self-efficacy'.

Agency reflects the 'intrapersonal' economy of an economic actor, the extent to which an actor is able to set scarce mental resources (such as attention, memory, empathy and motivation) productively to work. If the brain is seen as a means of production, similarly to a machine, agency reflects the sophistication and durability of this machine. As a simple metaphor, a person low on agency is like a hammer with a loose hammerhead; in principle you can hammer with the resources the hammer is made of (wood, iron), but in practice its use as a hammer will be quite limited and it will easily break down.

Mental health crucially affects agency, and mental health problems can be described in terms of different forms of lack of agency. Taking agency as the relevant economic factor rather than mental health is an important step. Different types of mental health problems have different effects on agency, and what matters from an economic perspective is not how bad a mental health problem is, but how badly the agency of an actor is affected by the mental health problem. Also, different actors have different (genetic) endowments of agency, even when no mental health problem is present. It is agency rather than mental health which is the productive factor determining performance and productivity. Mental health can be seen as a useful proxy for agency, similarly as education is taken as a proxy for human capital.

Chapter 4 investigated how agency can be conceptualized in economics. Over the course of history, the concept of capital in economic theory has been stretched, in order to enable inclusion of factors that behave like capital in the economy. This was always accompanied by intense debates about the concept of capital itself, in which the application of the term was discussed and (re)defined. Changes in the nature of the production process introduced debates about new forms of capital; the increasing value of education opened the door to human capital; recognition of the value of social and other institutions have more recently resulted in the use of the term "social capital". In chapter 4 it is argued that the capital concept is able to capture the characteristics of agency quite well: agency is a valuable generating a flow of productive services; it is involved in the production process but not used up during this process (except for the wear and tear due to overuse and neglected maintenance); it acts as a means of production which is produced itself, it is possible to invest in it with substantial returns. Based on theoretical and practical arguments, it was proposed to call this 'mental capital'.

Chapter 4 discusses why it makes sense to distinguish 'mental capital' from human capital. In principle, human capital includes health, and since mental capital is so closely correlated with mental health, it may seem most logical to simply include all the considerations with regard to self-agency and self-efficacy under the label of human capital. However, part of the existential justification of any concept is its usefulness. It is true that the concept of human capital in principle consists of any feature of a human actor that has economic value. In fact, it is in many ways a "rest category" used to explain what cannot be attributed to other economic categories. However, when it comes to the operationalization of human capital, suddenly the concept is narrowed down dramatically to some measures of education, and 
sometimes some measure of health, physical and mental health not being distinguished. Another proxy used for human capital which is less easy to measure but more promising in terms of predicting labour market success is skills. However, while the skills literature does allow for depreciation of skills (for example due to non-use), it does not allow for the type of variability of effective skill use as we can observe in real life. It was concluded that human capital as it is generally used in economic analyses today does not sufficiently capture the essence and dynamics of agency. In addition, it was argued that a label such as mental capital can be instrumental in increasing awareness of the importance of this intangible factor, and may help to open up interesting new lines of research, similarly to what happened when the term "social capital" was introduced.

Chapter 4 showed that many of the principled reservations of some economists vis-à-vis the use of the term 'social capital' also count in the case for the use of the term 'mental capital'. However, the term social capital, however ill-defined and hard to operationalize, did capture an economic element that was neglected in economics before, and it did trigger useful research on the nature and dynamics of this element. In the case of 'mental capital', the same could happen, and there is ample research (in psychology and related disciplines) on elements of mental capital already there - much more than in the case of social capital. The challenge to economists is to convert this existing valuable material into economically relevant knowledge and incorporate in their theory and models.

Chapter 4 discussed how the notion of 'mental capital' can be related to the discussions on core economic topics such as human capital, growth and bounded rationality. Research shows that agency reflects the productive capacity of a person given his stock of human capital, i.e. how well he is able to make use of his human capital. It is proposed that mental capital is related to human capital in a complementary way, similarly to the relationship between human capital and physical capital. This means that in the optimal mix of production factors, there needs to be attention for right level of mental capital in the mix, because otherwise that may be the (unobserved) bottleneck that crucially diminishes the productive effects of further investment in human capital. By discussing mental capital in the context of growth theory, some insights with regard to remaining puzzles emerge, such as possible (additional) explanations for the 'residual' in growth accounting. Furthermore, and perhaps most fruitful in terms of implications, the implications of the notion of mental capital for research on bounded rationality are discussed. When taking (different levels of) mental capital into consideration, it becomes possible to account for some of the characteristics of bounded rationality that do not get much (if any) attention in economics: heterogeneity (different economic actors have different degrees of bounded rationality), variability (the same economic actor can have different degrees of bounded rationality over time) and endogeneity (bounded rationality is itself a variable, the variables that are determined by bounded rationality (e.g., wages, employment status) are in turn determinants of bounded rationality, thus giving rise to economically relevant positive feedback mechanisms).

As was observed in the Introduction, the proof is in the eating of the pudding, and chapters 5 and 6 illustrate that (elements of) mental capital can be easily and usefully incorporated in standard economic formal analyses. In both chapters, adding elements of mental capital (in terms of variables and relationships derived from existing empirical psychological research) leads to non-conventional insights and conclusions. 
In chapter 5, we examined changes in productivity of an individual worker when the rate of innovation is increased, leading to an intensification of work. More innovation should lead to more productivity (almost by definition), but when mental capital variables and dynamics are added in the model, it becomes clear that this is not necessarily true. The model addresses the connection between effort, recovery, and burnout, illustrating pathways from one to the other, and mechanisms by which employees (and employers) deal with the risk of burnout. In this model a worker has two kinds of tasks: routine and non-routine. Nonroutine tasks have high costs in terms of mental capital depletion; routine tasks much less so, and in the extreme case we model, none. Thus the depletion of mental capital due to nonroutine work must be compensated, either outside working hours, or during routine labour (which by assumption involves no mental demands). Innovation increases the ratio of nonroutine to routine tasks, and so makes heavier demands on a worker's mental capital. Failure to compensate fully increases the worker's general fatigue level, and a vicious circle emerges. Eventually, this results in burnout, a period during which the worker is unable to work productively. Introducing this dynamic into mental capital, which is a complement to physical capital, changes the optimization problem of the firm. It now includes a trade-off in terms of short-run and long-run. It may be possible to increase productivity in the short run by driving workers harder, increasing innovation rates and thus non-routine work, but in the long run this decreases productivity, and will increase absenteeism and work-disability. Absent the possibility of continual labour turnover, this may reduce the optimal rate of innovation, and increase the optimal level of "slack" in any job.

In chapter 6, the model concerns mental capital spill-overs between people. Here we observe that most adults are involved in close relationships with one other person - they form a dyad. Members of a dyad are subject to sources of stress external to the relationship, one source of which, and which we study here, is innovation at work. Internal to the dyad, though, there are factors changing stress levels: members of the dyad increase the mental health of each other by providing social support, but at the same time they can function as a source of stress. Finally, the quality of the relationship itself is a function of stress levels: above some stress level relationships begin to deteriorate, and the spill-over effects, both positive and negative, weaken. Initially we can observe the effects of a change in the rate of innovation. Innovation implies change, an increase in non-routine work, and, as described in earlier chapters, increases here imply increases in (exogenous to the dyad) stress levels. What we find here is that when innovation rates are low, equilibrium stress levels are low, when innovation is high, stress levels are high, but for intermediate rates of innovation, multiple equilibria exist. More interesting, though, is that the intra-dyad dynamics create hysteresis in stress levels. Increasing innovation rates can push the pair from a low-stress equilibrium to the high-stress equilibrium. But an equal decrease in innovation rates will not return the pair to the low-stress state. A much bigger decrease is needed to re-establish it. It is possible to draw one further implication by introducing the Yerkes-Dodson relationship between stress and productivity. All else equal innovation increases productivity. But if innovation induces stress, then increasing the innovation rate will at some point start to have a secondary effect through stress: the increase in stress has a negative effect on productivity. Eventually the net effect is negative: innovation rates that are too high reduce productivity growth. 
The analysis in this thesis opens up new questions for research and policy. To illustrate, a few policy-relevant questions are briefly discussed here.

The question of the determinants of economic growth is an old one, but history shows that as the economy changes, this question has to be answered again. Over the past decades, the attention for the economic importance of intangibles such as knowledge, social relations, trust, has increased. Mental capital fits in this development; the term aims to capture the economic value of the intangibles associated with self-agency and self-efficacy. With the emergence of the knowledge-intensive service economy, in which jobs consist of more knowledge and emotion work than in the past, economic growth increasingly depends on intangibles. A challenge could be to study what the influence of mental capital is on economic growth. It is known that not only the quantities but also the mix of production factors determines economic growth, and that there can be important complementarities. Chapter 4 presented empirical research showing that mental capital and human capital are complements, mental capital determining the extent to which an actor can put his human capital effectively to work. Economic policy is aimed at finding and relieving bottlenecks to economic growth; perhaps mental capital is a 'bottleneck' in the mix of production factors, limiting the effects of other capital investments. More insight into the nature of mental capital may lead to new ways of achieving more economic growth, at lower psychological costs.

From an economic point of view, work stress and work-related mental problems can be considered negative externalities (comparable to environmental externalities such as pollution). Negative externalities can be 'internalized' with the help of policy, and the recent changes in the Dutch work disability law are an attempt to achieve exactly that. The expectation is that employers will put in more effort to keep the employee mentally healthy, since it is more directly in his own interest; in other words, this policy can reduce destruction of mental capital and stimulate the (preventive) investment in mental capital. However, the risk of internalising costs is an increasing 'front-door selection': a sharper selection on mental characteristics. Employers want to maximize their input of mental capital and will screen more intensively for any signal of (lack of) mental capital. Employees with less mental capital will be the last to be hired and will be the first to let go. While unemployment may have some effects on human capital of a worker (e.g. loss of skills due to non-use), it tends to have a much bigger effect on his mental capital (e.g. loss of self-esteem and selfconfidence, depressive feelings), effectively structurally reducing his employability. Due to a hysteresis effect similar to the one identified in chapter 6, it can become very costly to restore this workers employability. The challenge is to enable a flexible dynamic labour market while minimizing these mental capital effects.

The labour market shows signs of polarization, not only in terms of wages, skills, education and labour market chances, but also (and relatedly) along the lines of mental capital. Mental capital affects the ability to grab opportunities and make the most of them. Actors low on mental capital who are given opportunities will tend to fail to use them for the better. Those who end up with little mental capital for whatever reason are thus doubly disadvantaged, because they are at the bottom of the economic hierarchy, and find only themselves to blame. They will try to find other ways to achieve a sense of self-efficacy (for example in the non-legal economy), or they will remain trapped (both mentally and in reality) 
in a low steady state of being the "losers" of society. While it is important not to "blame the victim", it is equally important not to create a "victim identity" or reinforce a "patient role." The solution to lack of mental capital does not consist of "social pampering" but rather of prevention and activation. It is a balancing act, and a better understanding of mental capital and of the dynamics of its formation and destruction may inform policymakers about how to design social institutions more attuned to the characteristics of the economy of today.

Another potentially interesting line of inquiry is related to the production of mental health. The family, schools, work, and of course the mental health care sector are 'producers' of mental capital. A better insight into this 'production function' may give rise to new clues for policy. The cost-effectiveness of mental health care, both treatment and prevention, could prove to be much more favourable if all the economic effects of improving mental capital are taken into account. It could be economically very worthwhile to invest in improving parenting skills; or it could be interesting to introduce psychology as a mandatory course at high schools so that children gain basic psychological knowledge to understand themselves and others. Schools more in general could at least in theory be interesting sites for prevention policy. Firms could perhaps start to keep track of and report on the mental capital of the firm, as being an important intangible asset that they need as management information, and that shareholders may also find interesting when having to assess the future success of a firm. All these elements might provide inspiration for an innovative investment policy.

Again, this has to be done with great care. Mental capital is not a simple production factor to produce, comparable to the production of a machine. When knowledge was "discovered" as a production factor, education and research became economic assets, and on the one hand this has lead to more investment. But on the other hand it has also lead to a number of perverse incentives which are to some extent counter-effective to the production of knowledge, such as the commercialisation of universities and the erosion of the "Bildung" function of education. Mental health care, youth care and the school, being production sites of mental capital, run a similar risk. Chapter 4 presented empirical research showing that especially non-marketed relationships create most mental capital. Thus, the production of mental capital needs more attention; but first and foremost it needs more understanding.

Mental health problems may appear to be a luxury issue, relevant only to rich, developed, high-income countries. Low-income countries where half the population is infected with HIV and the other half with malaria, and where eighty percent is living below the absolute poverty line, supposedly have other things to worry about first. But, as put forward in chapter 3, epidemiological studies show that it is a mistake to see it that way. In developing countries, in spite of all their other health problems, depression is nevertheless in the top five of most common disorders and entails high costs in terms of a decreased functionality. Poverty, illness and conflict are extremely stressful and in countries where these existential threats are structurally present, depression and anxiety are widespread. The World Health Organization recently pointed out that especially child and adolescent mental health is central to the future development of low-income countries. In many poor countries, the mental health situation of AIDS orphans, war orphans, displaced populations of former child soldiers, AIDS affected and infected youth, and marginalized youth lack any economic horizon is highly worrisome - they are the labour force of the future. 
Lack of mental capital has consequences for development. There are psychological preconditions of economic development, such as a certain degree of optimism, and a substantial amount of trust in others, in oneself and in the future. These are essential for the development into a more complex economy with a high degree of division of labour, specialisation and innovation. Lack of mental capital can be an important bottleneck to economic development. The 'poverty-security trap', the vicious circle of poverty and violence in which the poorest developing countries find themselves, is partially maintained by psychological factors. Obviously, this does not mean that one should send a shipment of psychologists with bags full of antidepressants to these countries to solve the development problem. It is a more subtle message that the mental capital perspective offers. The step from subsistence thinking to investment thinking is, in the end, also a psychological step. Development strategies that take mental capital into account will prove to be more effective. For example, one of the reasons that micro-credit is so successful is the psychological effect it has on the poor: they are seen (and start to see themselves) as active, worthwhile, trustworthy entrepreneurs, and this give them the necessary self-confidence and pride that helps making their enterprise work.

For rich countries, perhaps the most fundamental issue that could gain a new dimension with the mental capital perspective is the "happiness paradox": the finding that more economic growth is not correlated with more happiness. In spite of unprecedented economic growth in the past decades, the happiness of the population in countries experiencing this growth has not increased. A number of explanations have been put forward for this, including the existence of "happiness set-points" and reference effects. This thesis proposes an additional explanation. Economic growth has a price, in terms of mental health. There may be more to enjoy, but we may become less able to enjoy it.

Mental health is crucial for "experiencing utility", i.e. for the degree to which people can actually enjoy what they have. This constitutes the basis of the ability to be happy, and it influences for example the degree to which objective wealth contributes to subjective welfare. In this sense, mental capital is perhaps the most fundamental form of value; it determines to what extent valuable matters can be experienced as having value. When GDP growth would be corrected for this, (similarly to correcting a price index for quality changes), the growth curve would look quite a bit less impressive. Having GDP growth as the main relevant indicator of progress is not very helpful, not even for economic policy itself certainly not for the richer countries. This suggests that the state of a country should be assessed and rated in other, more qualitative terms, also in comparative studies. Other existing measurements such as Human Development Index are a beginning, but they seem limited in terms of scope and impact. The apparent failure of economic growth to increase experienced well-being is not a paradox but, rather, a challenge to policymakers.

These are only some of the ways that mental capital might help to inform important debated in research and policy. Obviously, mental capital in terms of agency or self-efficacy have always been important for economic success - regardless of whether this was recognized or not - just like knowledge and social relations. However, just like knowledge and social relations it now increasingly shows up explicitly in the economic domain. One reason for this, it was argued in chapter 2 , lies in the changed nature of work more specifically the 
increased importance of psychological factors for performance. Another reason is that economists still have some important puzzles unsolved, and are looking for additional perspectives to gain more understanding of their object of research, the economy. Yet another reason is, perhaps, that in the past few decades a major jump is made in the understanding of the complexities of the human mind, how it works and develops (or not). The explosion of research in (social) psychology, psychiatry and neuroscience has created both awareness of its central importance and a knowledge base for a better understanding of the processes, mechanisms and pathways through which mental health is related to economic performance and vice versa.

This invites some further reflection on how this thesis should be understood, and its contribution could be evaluated. In order to capture "reality", we use language; with it we design categories and concepts, and when it gets more complicated, theories and models. These "conceptual tools" help us to get grasp of reality. It allows us to see certain things, but thereby it makes us less aware of others, and while it helps us to understand reality in a certain way, it gets in the way of our understanding of reality in other ways. This is nowhere clearer than in the world of research, where different disciplines investigate related or even the same phenomena, but nevertheless often fail to learn from each others' insights. By examining the role of mental health (studied in psychology and related disciplines) in the economy (studied by economics), this thesis attempts to connect these disciplines, using the notion of "mental capital" as a conceptual bridge. Conceptual innovation in this sense may be more pertinent than before, in light of the wide-spread perception that we are in some sort of "new economy" in which production and value-creation have changed significantly. As economic reality changes, the concepts used to try to capture this reality should change along.

This thesis is not a proposal for 'economization' of mental health; rather it identifies this as a trend and analyses some of the underlying mechanisms and the consequences. Introducing the term 'mental capital' can be seen as a form of economic imperialism The danger of this is an instrumentalisation of mental health and even of a 'brave new world', in which mental health is only valuable as an input into the economy. There is a chance that this thesis will contribute to this. This is a risk that has been consciously taken. Like it or not, mental health does have an important economic dimension. In practice the mental health of employees is already being put to economic use, actively, consciously and explicitly. The economization of mental health is a fact; and in order to protect mental health from the potential negative consequences of this, we need a better, more in-depth understanding of its economic role. The concept of mental capital can contribute to this important but precarious endeavour. 



\section{References}

Abbey, A., D.J. Abramis, and R.D. Caplan (1985) Effects of different sources of social support and social conflict on emotional well-being. Basic and Applied Social Psychology, 6, 111-129.

Abramovitz, M. (1956) Resource and Output Trends in the United States Since 1870. The American Economic Review, 46(2), Papers and Proceedings of the Sixty-eighth Annual Meeting of the American Economic Association (May, 1956), 5-23.

Abramowitz, M. and P.A. David(1996) Measuring performance of knowledge-based economy. In: Employment and Growth in the Knowledge-Based Economy. OECD, Paris, 35-60.

Acemoglu, D. (1998) Why Do New Technologies Complement Skills? Directed Technical Change and Wage Inequality. Quarterly Journal of Economics 113: 1055-1089.

Adler, A. (1927) Understanding Human Nature (edition of 1998, Hazelden).

Adler, D.A., T.J. McLaughlin, W.H. Rogers, H. Chang, L. Lapitsky and D. Lerner (2006) Job Performance Deficits Due to Depression. American Journal of Psychiatry 163, 1569-1576.

Agell, J. (1999) On the benefits from rigid labour markets: norms, market failures, and social insurance, The Economic Journal, 109 (453), F143-F164.

Agerbo, E., D. Gunnell, J.P. Bonde, P.B. Mortensen and M. Nordentoft (2007) Suicide and occupation: the impact of socioeconomic, demographic, and psychiatric differences. Psychological Medicine. Psychological Medicine, 37(8), 1131-1140.

Ainslie, G. (1986) Beyond microeconomics: conflict among interest in a multiple self as a determinant of value. In The Multiple Self, ed. by J. Elster, 133-175. Cambridge University Press.

Ainslie, G. (1992a) Picoeconomics: The Strategic Interaction of Successive Motivational States Within the Person. Cambridge University Press.

Ainslie, G. (1992b) Picoeconomics: A Bargaining Model of the Will and its Lapses. In Will and Economic Behavior, ed. by L. Sjoberg, R. P. Bagozzi, and D. Ingvar, 163-173. Stockholm: Economic Research Institute of the Stockholm School of Economics.

Ainslie, G. (2000) Breakdown of Will. Cambridge University Press.

Akcomak, S. and B. ter Weel (2006) Social Capital, Innovation and Growth: Evidence from Europe, UNU-MERIT Working Paper 2006-040.

Akerlof, G. (1976) The economics of caste and of the rat race and other woeful tales. Quarterly Journal of Economics, 90, 599-617.

Akerlof, G. A. (1982) Labour contracts as a partial gift exchange. Quarterly Journal of Economics, 97, 543-569.

Akerlof, G. A. (1991) Procrastination and Obedience. The American Economic Review, 81(2), Papers and Proceedings of the Hundred and Third Annual Meeting of the American Economic Association, 1-19

Akerlof, G. A. (2002) Behavioral Macroeconomics and Macroeconomic Behavior. The American Economic Review, 92(3), 411-433

Akerlof, G.A. and R.E. Kranton (2000) Economics and Identity. Quarterly Journal of Economics, MIT Press, 115(3), 715-753.

Akerlof, G.A. and R.E. Kranton (2005) Identity and the Economics of Organizations. Journal of Economic Perspectives, American Economic Association, 19(1), 9-32. 
Allen, T.D., D.E.L. Herst, C.S. Bruck, and M. Sutton (2000) Consequences associated with work-tofamily conflict: a review and agenda for future research. Journal of Occupational Health Psychology, 5(2), 278-308

Alterman, R. and R. Zito-Wolf (1993) Agents Habitats and Routine Behavior. Proceedings of the International Joint Conference on Artificial Intelligence, IJCAI 1993, 305-310.

American Psychiatric Association. (1994). Diagnostic and statistical manual of mental disorders, fourth edition. (DSM IV) Washington, DC: American Psychiatric Association.

Andlin-Sobocki, P., B. Jönsson, H.-U. Wittchen and J. Olesen (2005) Cost of disorders of the brain in Europe, European Journal of Neurology 12 (2005) (Suppl. 1), 1-27.

Antonovsky A. (1979) Health, Stress and Coping. San Francisco: Jossey-Bass Publishers.

APA (1994) Diagnostic and Statistical Manual of Mental Disorders-IV. American Psychiatric Association.

Archer, S.L. (1989) The status of identity: Reflections on the need for intervention. Journal of Adolescence, 12(4), 345-359.

Arrow, K.J. (1999) Observations on Social Capital. In Social Capital: A Multifaceted Perspective, ed. by P. Dasgupta, and I. Serageldin, 3-5. World Bank Publications Washington, DC.

Arrow, K.J., H.B. Chenery, B.S. Minhas and R.M. Solow (1961) Capital-labor substitution and economic efficiency, Review of Economics and Statistics, 43, 225-235.

Arthur, M.B. and D.M. Rousseau (1996) The boundaryless career as a new employment principle. In: M.B. Arthur and D.M. Rousseau (eds.) The boundaryless career. Oxford University Press, New York.

Auer, P. (ed.) (2001) Changing labour markets in Europe. The role of institutions and policies. Geneva: International Labour Office.

Auer, P., J. Berg, and I. Coulibaly (2005) Is a stable workforce good for productivity? International Labour Review, 144 (3), 319-343.

Autor, D.H., L. Frank and R.J. Murnane (2003) The Skill Content of Recent Technological Change: An Empirical Exploration. Quarterly Journal of Economics 118: 1279-1333.

Autor, D.H., L.F. Katz and A.B. Krueger (1998) Computing inequality: have computers changed the labor market? Quarterly Journal of Economics 113, 1169-1213

Azariadis, C., and A. Drazen (1990) Threshold Externalities in Economic Development. The Quarterly Journal of Economics, 105(2), 501-526.

Baccaro, L., and D. Rei (2005) Institutional determinants of unemployment in OECD countries: a time-series cross-section analysis (1960-98). ILO Discussion Paper 160/2005. Genève: ILO.

Badura, B., H. Schellschmidt and C. Vetter (eds.) (2004) Fehlzeiten-Report 2003. Wettbewerbsfaktor WorkLife-Balance. Betriebliche Strategien zur Vereinbarkeit von Familie, Beruf und Privatleben. Zablen, Daten, Analysen aus allen Branchen der Wirtschaft. Brosch., 2004, Springer-Verlag,

Baingana, F., I. Bannon and R. Thomas (2005) Mental Health and Conflicts. Conceptual Framework and Approaches. Health, Nutrition and Population (HNP) Discussion Paper, February 2005, Worldbank, Washington DC.

Baker, D. B. (1985) The study of stress at work, Annual Review of Public Health, 6, 367-381.

Bakker, A.B. and W.B. Schaufeli (2000). Burnout contagion process among teachers. Journal of Applied Social Psychology, 30, 2289-2308.

Bakker, A.B., W.B. Schaufeli, H.J. Sixma and W. Bosveld (2001) Burnout contagion among general practitioners. Journal of Social and Clinical Psychology, 20(1) 82-98.

Bakker, A.B., W.B. Schaufeli, H.J. Sixma, W. Bosveld and D. van Dierendonck (2000) Patient demands, lack of reciprocity, and burnout: A five-year longitudinal study among general practitioners. Journal of Organizational Behavior 21, 425-441. 
Bandura, A. (1986) Social Foundations of Thought and Action: A Social Cognitive Theory, Englewood Cliffs, NJ: Prentice Hall.

Bandura, A. (1995) Self-efficacy in changing societies, Cambridge University Press.

Bandura, A. (1997) Self-efficacy: The exercise of control. W.H. Freeman.

Bandura, A., and D. Cervone (1983) Self-evaluative and self-efficacy mechanisms governing the motivational effects of goal systems. Journal of personality and social psychology, 45(5), 1017-1028.

Bandura, A., C. B. Taylor, S. L. Williams, I. N. Mefford and J.D. Barchas (1985) Catecholamine secretion as a function of perceived coping self-efficacy. Journal of Consulting and Clinical Psychology, 53(3), 406-414.

Bandura, A., C. Pastorelli, C. Barbaranelli and G.V. Caprara (1999) Self-efficacy pathways to childhood depression. Journal of Personal Social Psychology (1999); 76 (2), 258-269.

Bargh, J.A., M. Chen and L. Burrows (1996). The Automaticity of Social Behaviour: Direct effects of trait concept and stereotype activation on action. Journal of Personality and Social Psychology, 71, 230-244.

Bar-Haim, Y., D. Lamy and L. Pergamin (2007) Threat-Related Attentional Bias in Anxious and Nonanxious Individuals: A Meta-Analytic Study. Psychological Bulletin, 133(1). 1-24.

Barker, J.R. (1993) Tightening the iron cage: Concertive control in self-managing teams. Administrative Science Quarterly, 38, 408-437.

Barling, J., E.K. Kelloway and M.R. Frone (eds.) (2004) Handbook of Work Stress. Sage.

Barnett, R.C., and C. Rivers (1996). She works, he works: How two-income families are happy, healthy, and thriving. Cambridge, MA: Harvard University Press.

Barnett, R.C., S.W. Raudenbush, R.T. Brennan, J.H. Pleck and N.L. Marshall (1995) Changes in job and marital experience and change in psychological distress: A longitudinal study of dualearner couples. Journal of Personality and Social Psychology, 69, 839-850.

Barr, P.S., J.L. Stimpert, and A.S. Huff (1992) Cognitive change, strategic action, and organizational renewal. Strategic Management Journal, 13(5), 15-36.

Barrett, B., S. Byford and M. Knapp (2005) Evidence of cost-effective treatments for depression: a systematic review. Journal of Affective Disorders, 84(1), 1-13.

Barsade, S.G. (2002) The ripple effect: Emotional contagion and its influence on group behavior. Administrative Science Quarterly, 47, 644-675.

Bartel, A., and P. Taubman (1979) Health and Labor Market Success: The role of various diseases. The Review of Economics and Statistics, LXI(1), 1-8.

Bartel, A., and P. Taubman (1986) Some Economic and Demographic Consequences of Mental Illness. Journal of Labor Economics, 4(2), 243-256.

Bartel, A.P., and F.R. Lichtenberg (1987) The Comparative Advantage of Educated Workers in Implementing New Technology. Review of Economics and Statistics, 69, 1-11.

Bartel, A.P., and F.R. Lichtenberg (1991) Technical Change, Learning and Wages. NBER Working Paper 2732, National Bureau of Economic Research, Inc.

Barton, S.B. and S. Morley (1999) Specificity of reference patterns in depressive thinking: Agency and object roles in self-representation. Journal of Abnormal Psychology, 108(4), 655-661.

Basso, M.R. and R.A. Bornstein (1999) Relative memory deficits in recurrent versus first-episode major depression on a word-list learning task. Neuropsychology, 13(4), 557-563.

Bauman, Zygmunt (1998) Work, Consumerism and the New Poor, Open University Press.

Baumeister, R. F., E. Bratslavsky, M. Muraven, and D. M. Tice (1998) Ego-depletion: Is the active self a limited resource? Journal of Personality and Social Psychology, 74, 1252-1265. 
Baumeister, R. F., M. Muraven, and D. M. Tice (2000) Ego depletion: A resource model of volition, self-regulation, and controlled processing. Social Cognition, 18, 130-150.

Baumol, W. J. (1967) Macroeconomics of Unbalanced Growth: The Anatomy of Urban Crisis. American Economic Review, LVII(3), 415-426.

Bazin, N., P. Perruchet, M. De Bonis and A. Féline (1994) The dissociation of explicit and implicit memory in depressed patients. Psychological Medicine, 24, 239-245.

Beach, S.R.H. (2001) Marital and family processes in depression. Washington, DC: American Psychological Association.

Bear, G.G., M.A. Manning and C.E. Izard (2003) Responsible behavior: The importance of social cognition and emotion. School Psychology Quarterly, 18(2), 140-157.

Beard, G.M. (1881) American Nervousness. New York: Putnam.

Beck, A.T. (1967) Depression: Causes and treatment. Philadelphia: University of Pennsylvania Press.

Beck, U. (2000) The Brave New World of Work, Polity Press: Cambridge, UK.

Becker, G.S, and N. Tomes (1986) Human Capital and the Rise and Fall of Families. Journal of Labor Economics, 4(3), S1-39.

Becker, G.S. (1992) Fertility and the Economy. Journal of Population Economics, 5(3), 185-201.

Becker, G. S. (1993) Nobel Lecture: The Economic Way of Looking at Behavior. The Journal of Political Economy, 101(3), 385-409.

Becker, G.S. (1962) Investment in Human Capital: A Theoretical Analysis. The Journal of Political Economy, Vol. 70, No. 5, Part 2: Investment in Human Beings, 9-49

Becker, G.S. (1989) On the Economics of the Family: Reply to a Skeptic, American Economic Review, American Economic Association, 79(3), 514-18.

Becker, G.S. (1993) Human Capital. University of Chicago Press, Chicago.

Beehr, T.A., S.J. Farmer and S. Glazer (2003) The enigma of social support and occupational stress: Source congruence and gender role effects. Journal of Occupational Health Psychology, 8(3), 220231.

Beidel, D.C., S.M. Turner, T.L. Morris (2000) Behavioral treatment of childhood social phobia. Journal of Consulting and Clinical Psychology, 68(6), 1072-1080.

Bekker, S., T. Wilthagen, P. Kongshøj Madsen, J. Zhou, R. Rogowski, M. Keune, and A.Tangian (2008) Flexicurity - a European Approach to Labour Market Policy. Intereconomics, 43(2), 68111.

Belger, A., and M.T. Banich (1998) Costs and benefits of integrating information between the cerebral hemispheres: a computational perspective. Neuropsychology, 12(3), 380-98.

Bell, L.A. and R.B. Freeman (2001) The incentive for working hard: explaining hours worked differences in the US and Germany. Labour Economics, 8, 181-202.

Bemporad, J.R., and S. Romano (1993) Childhood experience and adult depression: a review of studies. American Journal of Psychoanalysis, 53(4), 301-315.

Benazon, N.R. and J.C. Coyne (2000) Living with a depressed spouse, Journal of Family Psychology Vol. 14 (1), 71-79.

Benhabib, J., and M. M. Spiegel (1994) The role of human capital in economic development evidence from aggregate cross-country data. Journal of Monetary Economics, 34(2), 143-173.

Benham, L., and A. Benham (1981) Employment, Earnings and Psychiatric Diagnoses. In Economic Aspects of Health, ed. by V. Fuchs, 203-220. Chicago: University of Chicago Press.

Berndt, E.R., H.L. Bailit, M. B. Keller, J. C. Verner, and S. N. Finkelstein (2000) Health care use and at-work productivity among employees with mental disorders. Health Affairs, 19(4), 244-256. 
Berndt, E.R., S.N. Finkelstein, P.E. Greenberg, R.H. Howland, A. Keith, A.J. Rush, J. Russell and M.B. Keller (1998) Workplace performance effects from chronic depression and its treatment. Journal of Health Economics 17, 511-535.

Biddle, S.J.H., K.R. Fox and S.H. Boutcher (Eds.) (2000). Physical activity and psychological well-being. London: Taylor \& Francis.

Bijl, R.V. and A. Ravelli (2000) Psychiatric morbidity, service use, and need for care in the general population: results of The Netherlands Mental Health Survey and Incidence Study. American Journal of Public Health, 90(4): 602-607.

Birindelli, L., and E. Rustichelli (2007) The transformation of work? Work flexibility in Europe: a sectoral and occupational description of trends in work hours, part-time work, temporary work, and self-employment. WORKS project, D9.2.3, CIT3-CT-2005-006193

Birindelli, L., M. Brynin, L. Coppin, K. Geurts, N. Greenan, E. Kalugina, S. Longhi, M. Ramioul, E. Rusticelli, and E. Walkowiak (2007) The transformation of work? A quantitative evaluation of the shape of employment in Europe. WORKS project, WP9, CIT3-CT-2005-006193.

Blaney, P.H. (1986) Affect and Memory: A Review. Psychological Bulletin, 99(2) 229-246.

Blatter B., I. Houtman, S. van den Bossche, K. Kraan, and S. van den Heuvel (2005) Gezondheidsschade en kosten als gevolg van RSI en psychosociale arbeidsbelasting in Nederland. Hoofddorp: TNO Kwaliteit van Leven.

Bliss, C. J. (1975) Capital theory and the distribution of income. Amsterdam: North-Holland.

Blount, A., M. Schoenbaum, and R. Kathol (2007) The economics of behavioral health services in medical settings: A summary of the evidence. Professional Psychology: Research and Practice, 38(3), 290-229

Blustein, D. L., L. E. Devenis, and B. A. Kidney (1989) Relationship between the identity formation process and career development. Journal of Counseling Psychology, 36(2), 196-202.

Bohm-Bawerk, E. (1907) The Nature of Capital: A Rejoinder. The Quarterly Journal of Economics, 22(1), 28-47.

Bok, D. (1993) Universities in the Marketplace: The Commercialization of Higher Education. Princeton University Press.

Boksem, M.A.S., T.F. Meijman, and M.M. Lorist (2006) Mental fatigue, motivation and action monitoring. Biological Psychology, 72(2), 123-132.

Bolger, N, and J. Eckenrode (1991) Social relationships, personality, and anxiety during a major stressful event. Journal of Personality and Social Psychology, 61(3), 440-449.

Bolger, N., A. DeLongis and R.C. Kessler (1989) Effects of daily stress on negative mood. Journal of Personality and Social Psychology, 57(5), 808-818.

Bolger, N., A. DeLongis, R.C. Kessler and E. Wethington (1989) The contagion of stress across multiple roles. Journal of Marriage and the Family, 51, 175-183.

Bolino, M. C., and W. H. Turnley (2005) The Personal Costs of Citizenship Behavior: The Relationship Between Individual Initiative and Role Overload, Job Stress, and Work-Family Conflict. Journal of Applied Psychology, 90(4), 740-748.

Bookwala, J. and R. Schultz (1996) Spousal similarity in subjective well-being: the cardiovascular health study, Psychology and Aging 11 (4), 582-590.

Borghans, L. and B. ter Weel (2004) What happens when agent T gets a computer? The labor market impact of cost efficient computer adoption. Journal of Economic Behavior \& Organization, 54(2), $137-151$

Borghans, L., B. ter Weel and B.A. Weinberg (2006) "People people": Social capital and the labormarket outcomes of underrepresented groups," NBER Working Paper No. 11985. 
Bounfour, A. (2007) Organizational Capital: Modelling, Measuring and Contextualising. Routledge Studies in Innovation, Organizations and Technology.

Bourdieu, P. (1987) Distinction. A Social Critique of the Judgement of Taste. Harvard University Press.

Bower, G. H. (1981). Mood and memory. American Psychologist, 36, 129-148.

Bowles, S., and H. Gintis (1975) The Problem with Human Capital Theory--A Marxian Critique. The American Economic Review, 65(2), Papers and Proceedings of the Eighty-seventh Annual Meeting of the American Economic Association (May, 1975), 74-82.

Bradley, B.P., K. Mogg and N. Millar (1996) Implicit memory bias in clinical and non-clinical depression. Behaviour Research and Therapy, 34(11-12), 865-879.

Bradley, B.P., K. Mogg, N. Millar and J. White (1995) Selective Processing of Negative Information: Effects of Clinical Anxiety, Concurrent Depression, and Awareness. Journal of Abnormal Psychology, 104(3), 532-536.

Braverman, H. (1974) Labor and Monopoly Capital: The Degradation of Work in the Twentieth Century. New York: Monthly Review Press.

Breedveld, K., and A. van den Broek (2002) De veeleisende samenleving. De sociaal-culturele context van psychische vermoeidheid. Sociaal en Cultureel Planbureau, Den Haag.

Brehm, J.W. (1999). The intensity of emotion. Personality and Social Psychology Review, 3, 2-22.

Brenner, H.M. (1973) Mental Illness and Economy. Cambridge, MA: Harvard University Press.

Bresnahan, T.F. (1999) Computerisation and Wage Dispersion: An Analytical Reinterpretation. Economic Journal 109: F390-F415.

Bresnahan, T.F., E. Brynjolfsson, and L.M. Hitt (2002) Information Technology, Workplace Organization, and the Demand for Skilled Labor: Firm-Level Evidence. Quarterly Journal of Economics,117(1), 339-376.

Broadbridge, A. (2002) Retail managers: their work stressors and coping strategies. Journal of Retailing and Consumer Services, 9(3),173-183.

Broadhead, W.E., D.G. Blazer, L.K. George and C.K. Tse (1990) Depression, disability days, and days lost from work in a prospective epidemiologic survey. $J A M A, 264,2524-2528$.

Brouwer, W. B. F., and M.A. Koopmanschap (2005) The Friction-Cost Method: Replacement for Nothing and Leisure for Free? PharmacoEconomics, 23(2), 105-111.

Brown, S.P., R.A. Westbrook and G. Challagalla (2005) Good cope, bad cope: adaptive and maladaptive coping strategies following a critical negative work event, Journal of Applied Psychology, 90(4), 792-798.

Bruch, M.A. (2002) The relevance of mitigated and unmitigated agency and communion for depression vulnerabilities and dysphoria. Journal of Counseling Psychology, 49(4), 449-45.

Brun, E. and M. Milczarek (2007) Expert forecast on emerging psychosocial risks related to occupational safety and health (OSH), European Agency for Safety and Health at Work.

Brunstein, J.C., O.C. Schultheiss and R. Grässman (1998) Personal goals and emotional well-being: The moderating role of motive dispositions. Journal of Personality and Social Psychology, 75(2), 494-508.

Brynjolfsson, E., L.M. Hitt and S. Yang (2002) Intangible Assets: Computers and Organizational Capital. Brookings Papers on Economic Activity, 2002(1), 137-181.

Buchanan, J.M. (1975) A Contractarian Paradigm for Applying Economic Theory, The American Economic Review, 65(2), Papers and Proceedings of the Eighty-seventh Annual Meeting of the American Economic Association (May, 1975), 225-230. 
Bulger, C.A., R.A. Matthews and M.E. Hoffman (2007) Work and personal life boundary management: Boundary strength, work/personal life balance, and the segmentationintegration continuum. Journal of Occupational Health Psychology, 12(4), 365-375.

Bültmann, U, I.J. Kant, P.A. van den Brandt and S.V. Kasl (2002) Psychosocial work characteristics as risk factors for the onset of fatigue and psychological distress: prospective results from the Maastricht Cohort study. Psychol Med 32, 333-345.

Bültmann, U., I. Kant, L.G.P.M. van Amelsvoort and S.V. Kasl (2001) Differences in fatigue and psychological distress across occupations: results from the Maastricht Cohort Study of fatigue at work. JOEM 43, 976-983.

Burchell, B. J. (1989) The social psychological impact of temporary and insecure employment: An economic dream but a psychological nightmare. Warsaw: Polish Academy of Sciences.

Burchell, B.J. (1999) The unequal distribution of job insecurity. International Review of Applied Economics 13. $439-460$

Burchell, B.J., D. Lapido and F. Wilkinson (2001) Job insecurity and work intensification, Routledge: London.

Burchell, B.J. (1994) Who is affected by Unemployment? Job insecurity and Labour Market influences on Psychological Health. In Social Change and the experience of Unemployment, ed. by D. Gallie, C. Marsh, and C. Vogler. Oxford: Oxford University Press.

Burchell, B.J. (2002) The prevalence and redistribution of job security and work intensification. In Job Insecurity and Work Intensification, ed. by B. J. Burchell, D. Ladipo, and F. Wilkinson, London: Routledge.

Burchell, B.J., D. Day, M. Hudson, D. Ladipo, R. Mankelow, J. Nolan, H. Reed, I. Wichert, I. and F. Wilkinson (1999) Job Insecurity and work intensification; flexibility and the changing boundaries of work. York: York publishing

Burton, E., E. Stice, and J. R. Seeley (2004) A prospective test of the stress-buffering model of depression in adolescent girls: no support once again. Journal of Consulting and Clinical Psychology, 72(4), 689-97.

BusinessWeek (2005) The Real Reasons You're Working So Hard... and what you can do about it. BusinessWeek, October 3, 2005.

Byron, K. (2005) A meta-analytic review of work-family conflict and its antecedents. Journal of Vocational Behavior, 62, 169-198.

Camerer, C., G. Loewenstein, and D. Prelec (2005) Neuroeconomics: How neuroscience can inform economics. Journal of Economic Literature, XLIII, 9-64.

Cannon, W.B. (1915) Bodily Changes in Pain, Hunger, Fear and Rage: An Account of Recent Researches into the Function of Emotional Excitement. New York: Appleton.

Caplan, G. (1974) Social Systems and Community Mental Healtb: Lectures on Concept Development. Behavioral Publications, New York.

Cappelli, P. (1999) The New Deal at Work: Managing the Market-driven Workforce. Harvard Business School Press.

Cappelli, P. (ed.). (1997) Change at Work. Oxford University Press, Oxford

Caroli, E., and J. van Reenen (2001) Skill-Biased Organizational Change? Evidence from a Panel of British and French Establishments. Quarterly Journal of Economics, 116(4), 1449-1492.

Cartwright, S. and N. Holmes (2006) The meaning of work: The challenge of regaining employee engagement and reducing cynicism. Human Resource Management Review, 16(2), 199-208.

Carver, C.S., and T.L. White (1994) Behavioral inhibition, behavioral activation, and affective responses to impending reward and punishment: The BIS/BAS Scales. Journal of Personality and Social Psychology, 67(2), 319-333. 
Castells, M. (1996) The Information Age: economy, society and culture. Vol 1: The rise of the network society, Blackwell, Oxford.

Catalano, R. (1991) The health effects of economic insecurity. American Journal of Public Health, 81, 1148-1152.

Catalano, R., and D. Dooley (1977). Economic predictors of depressed mood and stressful life events in a metropolitan community. Journal of Health and Social Behavior, 18, 292-307.

Catalano, R., and D. Dooley (1983) Health effects of economic instability: A test of economic stress hypothesis. Journal of Health and Social Behavior, 24, 46-60.

CBS (2003) Mental problems biggest hindrance to work. CBS Web magazine.

CBS (2004) Press release 28 May 2004. The Hague.

Chabrol, H., A. Montovany, E. Ducongé, A. Kallmeyer, E. Mullet and F. Leichsenring (2004) Factor Structure of the Borderline Personality Inventory in Adolescents. European Journal of Psychological Assessment, 20(1), 59-65.

Channon, S. and P.S.S. Green (1999) Executive function in depression: the role of performance strategies in aiding depressed and non-depressed participants. Journal of Neurology, Neurosurgery and Psychiatry 66:162-171.

Chaudhuri, A. (2001) Stressed? The Guardian. Wednesday January 3, 2001.

Chen, Y. W., and S. C. Dilsaver (1996) Lifetime rates of suicide attempts among subjects with bipolar and unipolar disorders relative to subjects with other Axis I disorders. Biological Psychiatry, 39(10), 896-899.

Chiles, J.A., M.J. Lambert and A.L. Hatch (1999). The impact of psychological intervention on medical cost offset: A meta-analytic review. Clinical Psychology, 6, 204-220.

Chorpita, B. F., and D. H. Barlow (1998) The development of anxiety: The role of control in the early environment. Psychological Bulletin, 124(1), 3-21.

Clark, J. B. (1893) The Genesis of Capital, Yale Review, 2, 302-315.

Clarke, G. N., P. Rohde, P.M. Lewinsohn, H. Hops, and J.R. Seeley (1999) Cognitive-behavioral treatment of adolescent depression: Efficacy of acute group treatment and booster sessions. Journal of the American Academy of Child \& Adolescent Psychiatry, 38(3), 272-279.

Cohen, A. J., and G. C. Harcourt (2003) Retrospectives: Whatever Happened to the Cambridge Capital Theory Controversies? The Journal of Economic Perspectives, 17(1), 199-214.

Cohen, D. (2003) Our Modern Times: The New Nature of Capitalism in the Information Age, MIT Press

Cohen, S. and T.A. Wills (1985) Stress, social support, and the buffering hypothesis, Psychological Bulletin, 98(2), 310-357.

Coie, John D., A.H.N. Cillessen and K.A. Dodge (1999) It takes two to fight: A test of relational factors and a method for assessing aggressive dyads. Developmental Psychology, 35(5), 11791188.

Coleman, J.S. (1988) Social capital in the creation of human capital. American Journal of Sociology 94, pp. S95-S120

Collins, D. (1998) Organizational change. Routledge London.

Commissie Donner (2001) Werk maken van arbeidsongeschiktheid. Advies van de Adviescommissie Arbeidsongeschiktheid. Den Haag, 30 mei 2001

Conger, R.D., M.A. Rueter and G.H. Elder (1999). Couple resilience to economic pressure. Journal of Personality and Social Psychology, Vol. 76(1), 54-71.

Conlisk, J. (1996) Why Bounded Rationality? Journal of Economic Literature, 34(2), 669-700. 
Conway, N., and R. B. Briner (2005) Understanding Psychological Contracts at Work: A Critical Evaluation of Theory and Research. Oxford University Press.

Cooper, B., C. Garcia-Penalosa and P. Funk (2001) Status Effects and Negative Utility Growth, in: Economic Journal, 111(473) 642-665.

Cooper, C.L., P. Liukkonen, and S. Cartwright (1996) Stress prevention in the workplace: assessing the costs and benefits to organizations. European Foundation for the Improvement of Living and Working Conditions, Dublin.

Cooper, C.L., R.D. Cooper and L.H. Eaker (1988), Living with Stress, Penguin, London.

Cooper, W.H. (1981) Ubiquitous halo. Psychological Bulletin 90, 218-244.

Costello, E.J., D.S. Pine, C. Hammen, J.S. March, P.M. Plotsky, M.M. Weissman et al. (2002). Development and natural history of mood disorders. Biological Psychiatry, 52, 529-542.

Cowan, R. and D. Foray (1997) The economics of codification and the diffusion of knowledge. Industrial and Corporate Change 6, 595-622.

Cowan, R., P.A. David and D. Foray (2000) The explicit economics of knowledge codification and tacitness. Industrial and Corporate Change 9(2), 212-253.

Cowan, R.S. (1983) More Work for Mother: The Ironies of Household Technology from the Open Hearth to the Microwave. Basic Books.

Cox, T. (1978). Stress. London: MacMillan Education.

Coyne, J.C., and D.A. Smith, (1991) Couples coping with a myocardial infarction: A contextual perspective on wives' distress. Journal of Personality and Social Psychology, 61(3), 404-412.

Coyne, J.C. and G. Downey (1991). Social factors and psychopathology: Stress, social support and coping processes. Annual Review of Psychology, 42, 401-425.

Coyne, J.C., R. Thompson and S.C. Palmer (2002) Marital quality, coping with conflict, marital complaints, and affection in couples with a depressed wife. Journal of Family Psychology,16(1):26-37.

Coyne, J.C., R.C. Kessler, M. Tal, J. Turnbull, C.B. Wortman and J.F. Greden (1987). Living with a depressed person. Journal of Consulting and Clinical Psychology, 55, 347-352.

Crandall, C.S. (1988) Social contagion of binge eating, Journal of Personality and Social Psychology, 55(4), 588-598.

Cranwell-Ward, J. (1987) Managing Stress, Pan Macmillan.

Creed, P.A. and J. Klisch (2005) Future Outlook and Financial Strain: Testing the Personal Agency and Latent Deprivation Models of Unemployment and Well-Being. Journal of Occupational Health Psychology, 10(3), 251-260.

Crook, T., A. Raskin, and J. Eliot (1981) Parent-child relationships and adult depression. Child Development, 52(3), 950-957.

Crosby, F. (1976) A model of egoistical relative deprivation. Psychological Review, 83, 85-113.

Cukrowicz, K.C., A. Otamendi and J.V. Pinto (2006) The Impact of Insomnia and Sleep Disturbances on Depression and Suicidality. Dreaming, 16(1), 1-10.

Cummings, E. M., P. T. Davies, and S. B. Campbell (2000) Applications of developmental psychopathology: Parental depression, families, and children's development. In Developmental psychopathology and family process: Theory, research, and clinical implications, ed. by E.M. Cummings, P. T. Davies, \& S. B. Campbell, 299-340. New York: Guilford Press.

CWP (2007) Gedeeltelijk arbeidsgeschikt. Een gat in de arbeidsmarkt. Commissie Werkend Perspectief.

D'Amato, A., and F. Zijlstra (2003) Occupational Stress: A Review of the Literature Relating to Mental Health. Stress Impact Project. Guildford: University of Surrey 
Damasio, A.R. (1994) Descartes' error: emotion, reason, and the buman brain. New York: G. P. Putnam.

Dasgupta, P. (1999) Economic Progress and the Idea of Social Capital. In Social Capital: A Multifaceted Perspective, ed. by P. Dasgupta and I. Serageldin, 325-424. World Bank Publications Washington, DC.

Dasgupta, P., and I. Serageldin (eds.) (1999) Social Capital: A Multifaceted Perspective. World Bank Publications Washington, DC.

Davidson, D. (1969) How is Weakness of the Will Possible? Reprinted in Essays on Actions and Events, D. Davidson (1980), 21-42. Oxford University Press.

Davila, J., Karney, B.R. and Hall, T.W. (2003) Depressive Symptoms and Marital Satisfaction: Within-Subject Associations and the Moderating Effects of Gender and Neuroticism. Journal of Family Psychology, 17(4), 557-570.

Davila, J., T.N. Bradbury, C.L. Cohan, (1997) Marital functioning and depressive symptoms: Evidence for a stress generation model. Journal of Personality and Social Psychology, 73(4), 849861.

Davila, J., T.N. Bradbury, C. Cohan and S. Tochluk (1997) Marital functioning and depressive symptoms: Evidence for a stress generation model. Journal of Personality and Social Psychology, 73, 849-861.

De Croon, E.M., J.K. Sluiter and R.W.B. Blonk (2004) Stressful Work, Psychological Job Strain, and Turnover: A 2-Year Prospective Cohort Study of Truck Drivers. Journal of Applied Psychology, 89(3), 442-454.

Deci, E.L. and R.M. Ryan (1985) Intrinsic motivation and self-determination in human behavior. New York: Plenum.

Degl'Innocenti, A. and Å.H. Bäckman (1998) Executive deficits in major depression. Acta Psychiatr Scand 97, 182-188.

Dekker, S.W.A., and W.B. Schaufeli (1995) The effects of job insecurity on psychological health and withdrawal: A longitudinal study. Australian Psychologist, 30(1), 57-63.

DeLongis, A.M. Capreol and S. Holtzman (2004) Social Support and Social Strain Among Husbands and Wives: A Multilevel Analysis. Journal of Family Psychology, 18(3), 470-479

Demerouti, E., A.B. Bakker, F. Nachreiner and W.B. Schaufeli (2001) The Job Demands- Resources model of burnout, Journal of Applied Psychology 86, 499-512.

Demyttenaere, K., R. Bruffaerts, J. Posada-Villa, I. Gasquet, V. Kovess, J.P. Lepine et al. (2004) Prevalence, severity, and unmet need for treatment of mental disorders in the World Health Organization World Mental Health Surveys. JAMA, 2004; 291(21): 2581-2590.

Denham, S.A., K. A Blair, E. DeMulder, J. Levitas, K. Sawyer, S. Auerbach-Major, and P. Queenan (2003) Preschool Emotional Competence: Pathway to Social Competence? Child Development, 74 (1), 238-256.

Denison, E.F. (1962) United States Economic Growth. The Journal of Business, 35(2), 109-121.

Deppe, M., W. Schwindt, H. Kugel, H. Plassmann, and P. Kenning (2005) Nonlinear responses within the medial prefrontal cortex reveal when specific implicit information influences economic decision making. Journal of Neuroimaging, 15(2), 171-182.

Derryberry, D. and Rothbart, M.K. (1988) Arousal, affect, and attention as components of temperament. Journal of Personality and Social Psychology, 55(6), 958-966.

Dewan, S., M. Chung-ki (1997) The Substitution of Information Technology for Other Factors of Production: A Firm Level Analysis. Management Science 43(12) Frontier Research on Information Systems and Economics, 1660-1675. 
Dew-Becker, I., and R.J. Gordon (2008) The role of labor market changes in the slowdown of European productivity growth, NBER Working Papers 13840, National Bureau of Economic Research, Inc.

Dickerson, A., and F. Green (2004) The growth and valuation of computing and other generic skills. Oxford Economic Papers, 56(3), 371-406.

Diener, E. and F. Fujita (1995) Resources, personal strivings, and subjective well-being: A nomothetic and idiographic approach. Journal of Personality and Social Psychology, 68(5), 926-935.

Dodge, K.A. (1991) Emotion and social information processing. In The Development of Emotion Regulation and Dysregulation, ed. By J. Garber, and K. A. Dodge. Cambridge University Press.

Dodge, K.A. (1990) Developmental psychopathology in children of depressed mothers. Developmental Psychology, 26(1), 3-6.

Dollard, M.F., and A. H. Winefield (2002) Mental health: overemployment, underemployment, unemployment and healthy jobs. Australian e-Journal for the Advancement of Mental Health, 1(3).

Dooley, D. and J. A. Prause (2004) Settling down: psychological depression and underemployment. In The social costs of underemployment, D. Dooley and J.A. Prause, 134-157. Cambridge University Press.

Downey, G. and J.C. Coyne (1990) Children of depressed parents: An integrative review. Psychological Bulletin, 108(1), 50-76.

Drosopoulos, S., C. Schulze and S. Fischer (2007) Sleep's function in the spontaneous recovery and consolidation of memories. Journal of Experimental Psychology: General, 136(2), 169-183.

Drucker, P.F. (1998) The Coming of the New Organization. Harvard Business Review on Knowledge Management. Harvard Business School Press, 1-19.

Duesenberry, J.S. (1949) Income, saving, and the theory of consumer behavior. Havard Univeristy Press, Cambridge, MA.

Duffy, M., D. Ganster and M. Pagon (2002). Social undermining in the workplace. Academy of Management Journal, 45, 331-351.

Duffy, M.K., J.D. Shaw and E.M. Stark (2000) Performance and Satisfaction in Conflicted Interdependent Groups: When and How Does Self-Esteem Make a Difference? The Academy of Management Journal, 43(4), 772-782.

Duhachek, A. (2005) Coping: A multidimensional, hierarchical framework of responses to stressful consumption episodes. Journal of Consumer Research, 32(1), 41-53.

Dunn, E.W., J.C. Biesanz and L.J. Human (2007) Misunderstanding the affective consequences of everyday social interactions: The hidden benefits of putting one's best face forward. Journal of Personality and Social Psychology, 92(6), 990-1005.

Durkheim, E. (1951) Suicide. Free Press New York.

Durlauf, S.N. (2002) On The Empirics Of Social Capital. The Economic Journal, 112(483), F459-F479.

Dworkin, R.W. (2001) The medicalization of unhappiness. Public Interest.

Easterbrook, J.A. (1959) The effect of emotion on cue utilization and the organization of behavior. Psychological Review, 66(3), 183-201.

Easterlin, R.A. (2005) A puzzle for adaptive theory. Journal of Economic Behavior \& Organization, 56(4), 513-521.

EC (1999) Spice of Life - or Kiss of Death. Guidance on Work-related Stresss, Directorate-General for Employment and Social Affairs, European Commission, Brussels.

EC (1999) Proceedings of the European Conference on Promotion of Mental Health and Social Inclusion. European Commission and World Health Organization, Geneva. 
EC (2004) The State of Mental Health in the European Union, European Commission, Brussels.

EC (2005) Green paper. Improving the mental health of the population: Towards a strategy on mental health for the European Union, COM(2005)484. Directorate-General Health and Consumer Protection, European Commission, Brussels.

Eckaus, R.S. (1963) Investment in Human Capital: A Comment. The Journal of Political Economy, 71(5), 501-504.

Edmunds, A. and A. Morris (2000) The problem of information overload in business organisations: a review of the literature. International Journal of Information Management, 20(1), 17-25.

Edwards, J.R. and N.P. Rothbard (2000) Mechanisms Linking Work and Family: Clarifying the Relationship between Work and Family Constructs. The Academy of Management Review, 25(1), 178-199.

Egger, H. and V. Grossmann (2005) Non-Routine Tasks, Restructuring of Firms, and Wage Inequality Within and Between Skill-Group. Journal of Economics, 86(3), 197-228

Ehin, C. (2000) Unleashing Intellectual Capital, Butterworth-Heinemann.

Eisenberg, D.M., R.B. Davis, S.L. Ettner, S. Appel, S. Wilkey, M.V. Rompay and R.C. Kessler (1998) Trends in alternative medicine use in the United States, 1990-1997. Journal of the American Medical Association, 280, 1575-1589.

Eisenberg, N. and Lennon, R. (1983). Sex differences in empathy and related capacities. Psychological Bulletin, 94, 100-131.

Eisenberg, N., A. Cumberland, T.L. Spinrad, R.A. Fabes, S.A. Shepard, M. Reiser, B.C. Murphy, S.H Losoya and I.K Guthrie (2001) The Relations of Regulation and Emotionality to Children's Externalizing and Internalizing Problem Behavior. Child Development 72 (4), 1112-1134.

Eisenberg, P., and P. F. Lazarsfeld (1938) The psychological effects of unemployment. Psychological Bulletin, 35(6), 358-390.

Eisenhardt, K.M. (1989) Agency Theory: An Assessment and Review. The Academy of Management Review, 14(1), 57-74.

Ekman, P. (1982) Emotion in the human face. New York: Cambridge University Press

Ellis, R.P., and T,G. McGuire (1986) Cost Sharing and Patterns of Mental Health Care Utilization. The Journal of Human Resources, 21 (3) 359-379.

Elster, J. (1996) Rationality and the Emotions. The Economic Journal, 106(438), 1386-1397.

Elster, J. (1998) Emotions and Economic Theory. Journal of Economic Literature, 36(1), 47-74.

Elster, J. (1998) Emotions and Economic Theory. Journal of Economic Literature, 36(1 ), 47-74.

Engel, G.L. (1977). The need for a new medical model: A challenge to biomedicine. Science, 196, 129_ 136.

Erikson, E. (1950). Childhood and society. New York: Norton.

Erikson, E.H. (1959) Identity and the life cycle, Psychological Issues 1, 50-100.

Esping-Andersen, G., D. Gallie, A. Hemerijck, J. Myles, and J. Myers (2002) Why We Need a New Welfare State. Oxford University Press

Ettner S.L., R.G. Frank, and R.C. Kessler (1997) The impact of psychiatric disorders on labor market outcomes. Industrial and Labor Relations Review, 51, 64-81.

Ettner, S.L. (2000) The Relationship between Labour Market Outcomes and Physical and Mental Health exogenous human capital or endogenous health production. Research in Human Capital and Development 13, 1-31.

Etzion, D., Eden, D. and Lapidot, Y. (1998) Relief from job stressors and burnout: Reserve service as a respite. Journal of Applied Psychology, 83(4), 577-585. 
European Foundation (2001) Third European Survey on Working Conditions. Dublin: European Foundation.

European Foundation (2005) Work-related stress. European Foundation for the Improvement of Living and Working Conditions.

European Foundation (2006) Fifteen years of working conditions in the EU: charting the trends. European Foundation for the Improvement of Living and Working Conditions, Dublin.

European Foundation (2007) Fifteen years of working conditions in the EU: charting the trends. European Foundation for the Improvement of Living and Working Conditions, Dublin.

Evans, S. and J. Haworth (1991) Variations in personal activity, access to 'categories of experience', and psychological well-being in young adults. Leisure Studies, 10(3), 249-264.

Eyrolle, H. and J.-M. Cellier (2000) The effects of interruptions in work activity: field and laboratory results, Applied Ergonomics, 31(5), 537-543.

Ezzamel, M., and H. Willmott (1998) Accounting for Teamwork: A Critical Study of Group-based Systems of Organizational Control. Administrative Science Quarterly, Special Issue: Critical Perspectives on Organizational Control, 43(2), 358-396.

Faggio, G. and S. Nickell (2007) Patterns of work across the OECD. Economic Journal, 117 (521), F416-F440.

Fazel, S. and J. Danesh (2002) Serious mental disorders in 23000 prisoners: a systematic review of 62 surveys. The Lancet, 359, 545-550.

Feather, N.T. (1990) The Psychological Impact of Unemployment. New York: Springer-Verlag.

Feltz, D.L. (1982) Path analysis of the causal elements in Bandura's theory of self-efficacy and an anxiety-based model of avoidance behavior. Journal of Personality and Social Psychology, 42(4), 764-781.

Ferrie, J.E., M.J. Shipley, M. G. Marmot, S. Stansfeld, and G. D. Smith (1998) The health effects of major organisational change and job insecurity. Social Science and Medicine, 46(2), 243-254.

Ferrie, J.E., M.J. Shipley, M. G. Marmot, S. Stansfeld, and G.D. Smith (1995) Health effects of anticipation of job change and non-employment: longitudinal data from the Whitehall II study. British Medical Journal, 311(7015), 1264-1269.

Ferrie, J.E., M.J. Shipley, S.A. Stansfeld and M.G. Marmot (2002) Effects of chronic job insecurity and change in job security on self reported health, minor psychiatric morbidity, physiological measures, and health related behaviours in British civil servants: the Whitehall II study. Journal of Epidemiology and Community Health, 56(6), 405-406.

Festinger, L. (1950). Informal social communication. Psychological Review, 57, 271-292.

Fink, P., L. Sorensen, M. Engberg, M. Holm, and P. Munk-Jorgensen (1999) Somatization in primary care: Prevalence, health care utilization, and general practitioner recognition. Psychosomatics, 40(4), 330-338.

Finkel, E.J. and W.K. Campbell (2001) Self-control and accommodation in close relationships: An interdependence analysis. Journal of Personality and Social Psychology, 81(2), 263-277.

Fiol, C. M. (1994) Consensus, Diversity, and Learning in Organizations. Organization Science, 5(3), 403420.

Fiol, C. M. (1996) Introduction to the Special Topic Forum: Squeezing Harder Doesn't Always Work: Continuing the Search for Consistency in Innovation Research The Academy of Management Review, 21(4), 1012-1021.

Fisher, I. (1896) Appreciation and Interest. Publications of the American Economic Association, 11(4), 1-98.

Fiske, S. T. (1993) Social cognition and social perception. Annual Review of Psychology, 44, 155-94.

Fiske, S.T. and S.E. Taylor $(1984,1991)$ Social Cognition . New York, NY: Random House. 
Flavell, J.H. (1979) Metacognition and metacognitive monitoring: A new area of cognitivedevelopmental inquiry. American Psychologist, 34, 906-911.

Florian, V., M. Mikulincer and G. Hirschberger (2002) The anxiety-buffering function of close relationships: Evidence that relationship commitment acts as a terror management mechanism, Journal of Personality and Social Psychology, 82(4), 527-542.

FNV (2004) FNV: 70.000 euro voor nitgeperste werknemer. FNV Actueel, 15-10-2004.

Ford, M.T., B.A. Heinen, K.L. Langkamer (2007) Work and Family Satisfaction and Conflict: A Meta-Analysis of Cross-Domain Relations. Journal of Applied Psychology, 92(1), 57-80.

Foucault, M. (1961) History of Madness. New York: Routledge, 2006.

Fowers, B.J. and B.J. Davidov (2006) The Virtue of Multiculturalism: Personal Transformation, Character, and Openness to the Other. American Psychologist, 61(6), 581-594.

Frank, R. (1985) Choosing the Right Pond: Human Behavior and the Quest for Status, Oxford University Press, Oxford.

Frank, R.G., and Gertler, P.J. (1991) Assessment of the Management Error Bias of Estimating the Effect of Mental Distress on Income. Journal of Human Resources, 26, 154-164.

Frank, R.G. and T.G. McGuire (1999) Economics and Mental Health, NBER Working Paper No.w7052.

Franko, D.L., R.H. Striegel-Moore, and J. Bean (2005) Psychosocial and health consequences of adolescent depression in Black and White young adult women. Health Psychology, 24(6), 586593.

Frasure-Smith, N., F. Lespérance amd M. Talajic (1995) The impact of negative emotions on prognosis following myocardial infarction: Is it more than depression? Health Psychology, 14(5), 388-398.

Frayne, C.A., and J.M. Geringer (2000) Self-management training for improving job performance: a field experiment involving salespeople. Journal of Applied Psychology, 85(3), 361-372.

Freeman, C. and L. Soete (1997) The Economics of Industrial Innovation. MIT Press.

French, J.R.P., W. Rogers, and S. Cobb (1974) A model of person-environment fit - Coping and adaptation. New York: Basic Books.

Frese, M. (1985) Stress at work and psychosomatic complaints: A causal interpretation. Journal of Applied Psychology, 70, 314-328.

Frese, M., and G. Mohr (1987). Prolonged unemployment and depression in older workers: A longitudinal study of intervening variables. Social Science and Medicine, 25, 173-178.

Friedman, A., and M. C. Polson (1981) Hemispheres as independent resource systems: limitedcapacity processing and cerebral specialization. Journal of Experimental Psychology: Human Perception and Performance, 7(5), 1031-1058.

Fritz, H.L. (2000) Gender-linked personality traits predict mental health and functional status following a first coronary event. Health Psychology, 19(5), 420-428.

Fromm, E. (1942) The fear of freedom. Routledge.

Frone, M.R. (2000) Work-family conflict and employee psychiatric disorders: The national comorbidity survey. Journal of Applied Psychology, 85(6), 888-895.

Frone, M.R., M. Russell, and M.L. Cooper (1997) Relation of work-family conflict to health outcomes: A four-year longitudinal study of employed parents. Journal of Occupational and Organizational Psychology, 70, 325-335.

Frone, M.R. (2003) Work-family balance. In: J. C. Quick and L. E. Tetrick (Eds.) Handbook of occupational health psychology American Psychological Association, 143-162. 
Frone, M.R., M. Russell and M.L. Cooper (1992) Prevalence of work-family conflict: Are work and family boundaries asymmetrically permeable? Journal of Organizational Behavior, 13, 723-729.

Fryer, D. (1986) Employment deprivation and personal agency during unemployment: A critical discussion of Jahoda's explanation of the psychological effects of unemployment. Social Behaviour, 1, 3-23.

Fryer, D., and R. Payne (1984) Proactive behaviour in unemployment: findings and implications. Leisure Studies, 3(3), 273-295.

Fryer. D. (2002) Unemployment and Mental Health: Hazards and Challenges of Psychology in the Community. In: K. Isaksson, C. Hogstedt, C.Eriksson and T. Theorell (eds.) Health Effects of the New Labour Market, Springer, 11-23.

Fuchs Victor R. (1982) Economic Growth and the Rise of Service Employment. NBER Working Paper No. 486.

Fuchs, V.R. (1968) The Service Economy. N.Y.: Columbia University Press.

Fuchs, V.R. (1980) Economic Growth and the Rise of Service Employment, NBER Working Paper, No. 486.

Fuchs, V.R. (1996) Economics, Values, and Health Care Reform, The American Economic Review, 86(1), $1-24$.

Galison, P., and D. J. Stump (eds.) (1996) The Disunity of Science: Boundaries, Contexts, and Power. Stanford, CA: Stanford University Press.

Gallie, D. (2005) Work pressure in Europe 1996-2001: Trends and determinants. British Journal of Industrial Relations, 43(3), 351-75.

Ganster, D.C., M.L. Fox and D.J. Dwyer (2001) Explaining employees' health care costs: a prospective examination of stressful job demands, personal control, and physiological reactivity. Journal of Applied Psychology, 86(5), 954-964.

Gardner, F., D.S. Shaw and T.J. Dishion (2007) Randomized prevention trial for early conduct problems: Effects on proactive parenting and links to toddler disruptive behavior. Journal of Family Psychology, 21(3), 398-406.

Garud, R. and. A. Kumaraswamy (1995) Technological and Organizational Designs for Realizing Economies of Substitution Strategic Management Journal, 16, 93-109.

Gattiker, U.E., and L. Larwood (1990) Predictors for career achievement in the corporate hierarchy. Human Relations, 43, 703-726.

Gehrke, C., and C. Lager (2000) Sraffian Political Economy, Encyclopedia of Political Economy. Routledge.

Geurts, S.A.E. and E. Demerouti (2003) Work/nonwork interface: A review of theories and findings. In M.J. Schabracq, J.A.M. Winnubst and C.L. Cooper (Eds.) Handbook of work and bealth psychology, Chichester, UK: Wiley, 279-312.

Giddens, A. (1991). Modernity and self-identity: Self and society in the late modern age. Cambridge, England: Polity Press.

Gilbert, D.T, and J.G. Hixon, (1991). The trouble of thinking: Activation and application of stereotypic beliefs. Journal of Personality and Social Psychology, 60, 509-517.

Ginexi, E.M., G.W. Howe and R.D. Caplan (2000) Depression and control beliefs in relation to reemployment: What are the directions of effect? Journal of Occupational Health Psychology, 5(3), 323-336.

Gist, M.E. (1987) Self-Efficacy: Implications for Organizational Behavior and Human Resource Management. Academy of Management Review. 12(3), 472-485.

Gist, M.E. and T.R. Mitchell (1992) Self-Efficacy: A Theoretical Analysis of Its Determinants and Malleability. The Academy of Management Review, 17(2), 183-211. 
Glaeser, E.L., D. Laibson, and B. Sacerdote (2002) An Economic Approach to Social Capital. The Economic Journal, 112(483), F437-F458.

Glomb, T.M., J.D. Kammeyer-Mueller and M. Rotundo (2004) Emotional Labour Demands and Compensating Wage Differentials, Journal of Applied Psychology, 89(4), 700-714.

Goffman, E. (1959) The Presentation of Self in Everyday Life. New York: Doubleday.

GOHNET (2001) Psychosocial Factors at Work, Global Occupational Health Network Newsletter Issue no. 2, 2001.

Gold, M.R., J.E Siegel, L.B. Russell and M.C. Weinstein (1996) Cost-effectiveness in Health and Medicine. (eds.) New York: Oxford University Press.

Goldsmith, A.H., J.R. Veum, and W. Darity Jr. (1996b). The impact of labor force history on selfesteem and its component parts anxiety, alienation and depression. Journal of Economic Psychology, 17, 183-220.

Goldsmith, A.H., J.R. Veum, and W. Darity Jr. (2000) Working hard for the money? Efficiency wages and worker effort. Journal of Economic Psychology, 21(4), 351-385.

Goldsmith, A.H., J.R. Veum, and W. J. Darity (1997). The Impact of Psychological and Human Capital on Wages. Economic Inquiry, 35, 815-829.

Goleman, D. (1995) Emotional intelligence. New York: Bantam Books.

Goode, E. (2002) Antidepressants Lift Clouds, but Lose 'Miracle Drug' Label, The New York Times, 30 June 2002.

Goode, R.B. (1959) Adding to the Stock of Physical and Human Capital. The American Economic Review, 49(2), Papers and Proceedings of the Seventy-first Annual Meeting of the American Economic Association (May, 1959), 147-155.

Goode, W.J. (1960) A theory of role strain. American Sociological Review, 25, 483-496.

Goodman, W.K., L.H. Price, S.A. Rasmussen, C. Mazure, R.L. Fleischmann, C.L. Hill, G.R. Heninger and D.S. Charney (1989) The Yale-Brown Obsessive Compulsive Scale, I: development, use, and reliability. Arch Gen Psychiatry, 46, 1006-1011.

Gordon, D.M. (1994), Bosses of different stripes: a cross-national perspective on monitoring and supervision. The American Economic Review, 84(2), 375-379.

Gort, M., H. Grabowski and R. McGuckin (1985) Organizational Capital and the Choice between Specialization and Diversification. Managerial and Decision Economics, 6(1), 2-10.

Gould, E.D. (2002) Rising Wage Inequality, Comparative Advantage and the Growing Importance of General Skills in the United States. Journal of Labor Economics 20, 105-147.

Granovetter, M. (1973) The Strength of Weak Ties, American Journal of Sociology, 78, 1360-1380.

Granovetter, M. (1983) The Strength of Weak Ties: A Network Theory Revisited Sociological Theory, 1, 201-233.

Green F., and S. McIntosh (2001) The intensification of work in Europe. Labour Economics, 8(2), 291308.

Green, F. (2003) The Rise and Decline of Job Insecurity. Studies in Economics 0305, Department of Economics, University of Kent.

Green, F. (2004) Why Has Work Effort Become More Intense? Industrial Relations 43 (4), 709-741.

Green, F. (2007) Demanding Work: The Paradox of Job Quality in the Affluent Economy. Princeton University Press.

Green, F. and D. Gallie (2002) High Skills and High Anxiety: Skills, Hard Work and. Mental WellBeing? SKOPE Discussion Paper. 
Green, F. and S. McIntosh (2001) The intensification of work in Europe. Labour Economics, 8(2), 291308.

Green, F., A. Felstead, and D. Gallie (2003) Computers and the changing skill-intensity of jobs. Applied Economics, 35(14), 1561-1576.

Greenan, N., E. Kalugina, and E. Walkowiak (2007) The transformation of work? Trends in work organization. WORKS project, D9.2.2, CIT3-CT-2005-006193.

Greenberg, P.E., L.E. Stiglin, S.N. Finkelstein, E.R. Berndt. (1993a) The economic burden of depression in 1990. Journal of Clinical Psycbiatry, 54(11), 405-418.

Greenberg, P.E., L.E. Stiglin, S.N. Finkelstein and E.R. Berndt (1993b) Depression: a neglected major illness. Journal of Clinical Psychiatry, 54, 419-424.

Greenberg, P.E., R.C. Kessler, H.G. Birnbaum, S.A. Leong, S.W. Lowe, P.A. Berglund, and P.K. Corey-Lisle (2003a) The economic burden of depression in the United States: how did it change between 1990 and 2000? Journal of Clinical Psychiatry, 64(12), 1465-1475.

Greenberg, P.E., R.C. Kessler, H.G. Birnbaum, S.A. Leong, S.W. Lowe, P.A. Berglund and P.K. Corey-Lisle (2003b) The economic burden of depression in the United States: how did it change between 1990 and 2000? Journal of Clinical Psychiatry 64, 1465-1475.

Greenberg, P.E., R.C. Kessler, T.L. Nells, S.N. Finkelstein and E.R. Berndt (1996) Depression in the workplace: an economic perspective. In: J.P. Feighner, W.F. Boyer (eds.) Selective Serotonin ReUptake Inbibitors: Advances in Basic Research and Clinical Practice. New York: John Wiley \& Sons Inc, 327-363.

Greenberg, P.E., T. Sisitsky, R.C. Kessler, S.N. Finkelstein, E.R. Berndt, J.R. Davidson, J.C. Ballenger and A.J. Fryer (1999) The economic burden of anxiety disorders in the 1990s. .Journal of Clinical Psychiatry 1999; 60: 427- 435.

Greenhaus, J.H., and G.N. Powell (2006). When work and family are allies: A theory of work-family enrichment. Academy of Management Review, 31, 72-92.

Greve, W. and R. Strobl (2004) Social and individual coping with threats: Outlines of an interdisciplinary approach, Review of General Psychology Vol. 8(3), 194-207.

Griliches, Z. (1969) Capital-Skill Complementarity. The Review of Economics and Statistics, 51(4), 465468.

Grossman, M. (1972) On the Concept of Health Capital and the Demand for Health, Journal of Political Economy, 80(2), 223-55.

Grossman, M. (2003) Household Production and Health. Review of Economics of the Household, Springer, 1(4), 331-342.

Gründemann, R.W.M. and C.V. van Vuuren (1997) Preventing absenteeism at the workplace: European research report, Dublin, European Foundation for the Improvement of Living and Working Conditions.

Grzywacz, J. G., and S. L. Ettner (2000) Lost Time on the Job: The Effect of Depression Versus Physical Health Conditions. The Economics of Neuroscience, 2(6), 41-46.

Grzywacz, J. G., D. M. Almeida, and D. A. McDonald (2002) Work-Family Spillover and Daily Reports of Work and Family Stress in the Adult Labor Force. Family Relations, 51(1), 28-36.

Grzywacz, J.G. and A.B. Butler (2005) The Impact of Job Characteristics on Work-to-Family Facilitation: Testing a Theory and Distinguishing a Construct. Journal of Occupational Health Psychology, 10(2), 97-109.

Grzywacz, J.G. and N.F. Marks (2000) Reconceptualizing the work-family interface: An ecological perspective on the correlates of positive and negative spillover between work and family. Journal of Occupational Health Psychology, 5(1), 111-126. 
Gul, F., and W. Pesendorfer (2005) The Case for Mindless Economics. Working Paper, Princeton University.

Gump, B.B and J.A. Kuliks (1997) Stress, affiliation and emotional contagion, Journal of Personality and Social Psychology, 72(2), 305-319.

Gurmankin Levy, A., J. Maselko. M. Bauer (2007) Why do people with an anxiety disorder utilize more nonmental health care than those without? Health Psychology, 26(5), 545-553

Gurney, R.M. (1980) Does unemployment affect the self-esteem of school-leavers? Australian Journal of Psychology, 32(3), 175-182.

Gutteling, B. M., C. de Weerth, N. Zandbelt, E. J. H. Mulder, G. H. A. Visser, and J. K. Buitelaar (2000) Does Maternal Prenatal Stress Adversely Affect the Child's Learning and Memory at Age Six? Journal of Abnormal Child Psychology, 34(6), 787-796.

Habermas, T. and S. Bluck (2000). Getting a life: The emergence of the life story in adolescence. Psychological Bulletin, 126, 748-769.

Hagist, C. and L. Kotlikoff (2005) Who's going broke? Comparing health care costs in ten OECD countries. NBER Working Paper No. 11833

Hakanen, J.J., A.B. Bakker and W.B. Schaufeli (2006). Burnout and work engagement among teachers. Journal of School Psychology, 43, 495-513.

Halpern, D.F. (2005) Psychology at the Intersection of Work and Family: Recommendations for Employers, Working Families, and Policymakers. American Psychologist, 60(5), 397-409.

Hamilton, N.A., D. Catley and C. Karlson (2007). Sleep and the affective response to stress and pain. Health Psychology, 26(3), 288-295.

Hamilton, V.H., P. Merrigan and E. Dufresne (1997) Down and Out: Estimating the Relationship between Mental Health and Unemployment, Health Economics 6(4), 397-406.

Hammarström, A., and U. Janlert (1997) Nervous and depressive symptoms in a longitudinal study of youth unemployment-selection or exposure? Journal of Adolescence, 20(3), 293-305.

Hammen, C. (1991) Generation of stress in the course of unipolar depression. Journal of Abnormal Psychology, 100(4), 555-561.

Hammen, C., J.H. Shih and P.A. Brennan (2004) Intergenerational Transmission of Depression: Test of an Interpersonal Stress Model in a Community Sample. Journal of Consulting and Clinical Psychology, Vol 72(3), Jun 2004. pp. 511-522.

Hammer, L.B., J.C. Cullen, and M.B. Neal (2005) The Longitudinal Effects of Work-Family Conflict and Positive Spillover on Depressive Symptoms Among Dual-Earner Couples. Journal of Occupational Health Psychology, $10(2), 138-154$.

Hammer, L.B, J.C. Cullen, M.B. Neal, R.R. Sinclari and M.V. Shafiro (2005) The longitudinal effects of work-family conflict and positive spillover on depressive symptoms among dual-earner couples, Journal of Occupational Health Psychology, 10(2), 138-154.

Hammer, L.B., E. Allen and T.D. Grigsby (1997). Work-family conflict in dual-earner couples: Within-individual and crossover effects of work and family. Journal of Vocational Behavior, 50, 185-203.

Hammer, L.B., J.C. Cullen and M.B. Neal (2005) The Longitudinal Effects of Work-Family Conflict and Positive Spillover on Depressive Symptoms Among Dual-Earner Couples. Journal of Occupational Health Psychology, 10(2), 138-154.

Hammer, L.B., T. Bauer and A. Grandey (2003). Work-family conflict and work-related withdrawal behaviors. Journal of Business and Psychology, 17, 419-436.

Hammer, T.H., P.O. Saksvik, K. Nytro, H. Torvant, and M. Bayazit (2004) Expanding the Psychosocial Work Environment: Workplace Norms and Work-Family Conflict as Correlates of Stress and Health. Journal of Occupational Health Psychology, 9(1), 83-97. 
Hanson, G.C., L.B. Hammer and C.L. Colton (2006) Development and Validation of a Multidimensional Scale of Perceived Work-Family Positive Spillover. Journal of Occupational Health Psychology, 11(3), 249-265.

Hardy, G.E., D.A. Shapiro and C.S. Borrill (1997) Fatigue in the workforce of national health service trusts: levels of symptomatology and links with minor psychiatric disorder, demographic, occupational and work role factors. Journal of Psychosomatic Research 43, 83-92

Harnois, G. and P. Gabriel (2000) Mental Health and Work. Impact, Issues and Good Practices, $\mathrm{WHO} / \mathrm{MSD} / \mathrm{MPS} / 00.2$

Harnois, G., and P. Gabriel (2000) Mental Health and Work. Impact, Issues and Good Practices (WHO/ILO) WHO/MSD/MPS/00.2.

Harrison, B. (1994) Lean and Mean: The Changing Landscape of Corporate Power in the Age of Flexibility. New York: Basic Books.

Harter, J.K., F.L. Schmidt and T.L. Hayes (2002). Business-unit-level relationship between employee satisfaction, employee engagement, and business outcomes: A meta-analysis. Journal of Applied Psychology, 87, 268-279.

Hatfield, E., J.T. Cacioppo and R.L. Rapson (1994). Emotional contagion. Cambridge, England: Cambridge University Press.

Hayek, F.A. von (1936) The Mythology of Capital. The Quarterly Journal of Economics, 50(2), 199-228.

Helgeson, V.S., and H.L. Fritz (1999) Unmitigated Agency and Unmitigated Communion: Distinctions from Agency and Communion. Journal of Research in Personality, 33(2), 131158.

Hellgren, J. and M. Sverke (2003) Does job insecurity lead to impaired well-being or vice versa? Estimation of cross-lagged effects using latent variable modelling Journal of Organizational Behavior, 24(2), 215 - 236.

Hellgren, J., M. Sverke, and K. Isaksson (1999). A two-dimensional approach to job insecurity: Consequences for employee attitudes and well-being. European Journal of Work and Organizational Psychology, 8(2), 179-195.

Hemels, M. E., G. Koren, and T. R. Einarson (2002) Increased use of antidepressants in Canada: 1981-2000. The Annals of Pharmacotherapy, 36(9), 1375-1379.

Herrnstein R.J. and D. Prelec (1991) Melioration: A Theory of Distributed Choice. The Journal of Economic Perspectives, 5(3), 137-156.

Hetherington, E. M., M. Bridges and G.M. Insabella (1998) What matters? What does not? Five perspectives on the association between marital transitions and children's adjustment. American Psychologist, 53, 167-184.

Hill, R.C., and M. Levenhagen (1995) Metaphors and Mental Models: Sensemaking and Sensegiving in Innovative and Entrepreneurial Activities. Journal of Management, 1995, 21(6), 1057-1075.

Hill, T., N.D. Smith and M.F. Mann (1987) Role of efficacy expectations in predicting the decision to use advanced technologies: The case of computers. Journal of Applied Psychology, 72(2), 307313.

Hirschman, A.O. (1972) Exit, voice, and loyalty. Cambridge: Harvard University Press.

Hobfoll, S.E. (2002) Social and psychological resources and adaptation. Review of General Psychology, 6(4), 307-324.

Hobfoll, S.E. (1988) The Ecology of Stress. Washington D.C.: Hemisphere

Hobfoll, S.E. (1989). Conservation of resources: A new attempt at conceptualizing stress. American Psychologist, 44, 513-524. 
Hoch, S.J., and G.F. Loewenstein (1991) Time-Inconsistent Preferences and Consumer Self-Control. The Journal of Consumer Research, 17(4), 492-507.

Hochschild, A.R. (1997) The Time Bind: When Work Becomes Home and Home Becomes Work. New York: Metropolitan Books.

Hochschild, A.R. (1983) The Managed Heart. Commercialization of Human Feeling, University of California Press, Berkeley.

Hock, M., H. Krohne, H. Walter (2004) Coping with threat and memory for ambiguous information: testing the repressive discontinuity hypothesis, Emotion 4(1), 65-86.

Hockey, G.R.J. (1997) Compensatory control in the regulation of human performance under stress and high workload: A cognitive-energetical framework. Biological Psychology, 45, 73-93.

Hofstede, G. (1980) Culture's consequences: International differences in work-related values. Newbury Park, CA: Sage.

Hoge, D.R., E.K. Smit and S.L. Hanson (1990) School experiences predicting changes in self-esteem of sixth- and seventh-grade students. Journal of Educational Psychology, 82(1), 117-127.

Holahan, C.J., R.H. Moos and C.K. Holahan (2005) Stress Generation, Avoidance Coping, and Depressive Symptoms: A 10-Year Model. Journal of Consulting and Clinical Psychology, 73(4), 658-666.

Holm Christiansen, R. and H. Ourø Nielsen (2007) Survey highlights rise in psychosocial demands at work. European Foundation for the Improvement of Living and Working Conditions, Dublin.

Holmes, T.H. and R.H. Rahe (1967). The social readjustment rating scale. Journal of Psychosomatic Research, Vol 11(2), 213-218.

Holt, D.B. (1998) Does Cultural Capital Structure American Consumption? The Journal of Consumer Research, 25(1). 1-25.

Hooftman, W., and I. Houtman (2008) Working conditions remain stable in the Netherlands. European Foundation for the Improvement of Living and Working Conditions, Dublin.

Houtman, I. (2007) Quality in work and employment - The Netherlands. TNO Work \& Employment.

Howe, G.W., M.L. Levy and R.D. Caplan (2004) Job Loss and Depressive Symptoms in Couples: Common Stressors, Stress Transmission, or Relationship Disruption? Journal of Family Psychology, 18(4), 639-650.

Howes, M.J., J.E. Hokanson and D.A. Lowenstein (1985). Induction of depressive affect after prolonged exposure to a mildly depressed individual. Journal of Personality and Social Psychology, 49(4), 1110-1113.

Hsee, C.K., E. Hatfield and C. Chemtob (1992). Assessments of the emotional states of others: Conscious judgments versus emotional contagion. Journal of Social and Clinical Psychology, 11, 119-128.

Hu T.W. (2006) Perspectives: an international review of the national cost estimates of mental illness, 1990-2003. Journal of Mental Health Policy and Economics, 9(1), 3-13.

Hu, T.W. (2004) The economic burden of depression and reimbursement policy in the Asia Pacific region. Australas Psychiatry, 12, S11-15(1).

Hubbard, J.A., K.A. Dodge and A.H.N. Cillessen (2001) The dyadic nature of social information processing in boys' reactive and proactive aggression. Journal of Personality and Social Psychology, 80(2), 268-280.

Hughes, D.L. and E. Galinsky (1994) Work experiences and marital interactions: Elaborating the complexity of work. Journal of Organizational Behavior, 15, 423-438. 
Humphreys, M.S., and W. Revelle (1984) Personality, motivation, and performance: a theory of the relationship between individual differences and information processing. Psychological Review, 91(2), 153-84.

ILO (2000) Mental Health and Work. Impact, Issues and Good Practices. International Labour Organisation, Geneva.

ILO (2000) Mental Health in the Workplace, International Labour Organisation, Geneva.

ILO (2006) Social security for all - Investing in global social and economic development. A consultation. Issues in Social Protection; ILO Discussion Paper 16.

Irish Department of Public Health (2001) Suicide in Ireland: a national study. Departments of Public Health on Behalf of the Chief Executive Officers of the Health Board, Dublin.

Isaksson, K., C. Hogstedt, C. Eriksson and T. Theorell (2000) Health Effects of the New Labour Market. New York: Plenum.

Isen, A.M. (1993) Positive affect and decision-making. M. Lewis and J.M. Haviland (eds.) Handbook of Emotion. Guilford, New York, 261-277.

Jackson, P.R. and P.B. Warr (1984) Unemployment and psychological ill-health: The moderating role of duration and age. Psychological Medicine, 14, 605-614.

Jackson, S.E. and C. Maslach (1982). After-effects of job-related stress: Families as victims. Journal of Occupational Behavior, 3, 63-77.

Jacobson, D. (1991) Toward a theoretical distinction between the stress components of the job insecurity and job loss experiences. Research in the Sociology of Organizations, 9, 1-19.

Jahoda, M. (1982) Employment and Unemployment: A Social-Psychological Analysis. Cambridge University Press.

Janis, I.L. (1954). Personality correlates of susceptibility to persuasion. Journal of Personality, 22, 504518.

Jehoel-Gijsbers, G. (2007) (ed.) Beter aan het werk. Trendrapportage ziekteverzuim, arbeidsongeschiktheid en werkhervatting, SCP-publicatie 2007/22, Den Haag, Sociaal en Cultureel Planbureau.

Jensen P.S., and J. Cooper (eds) (2002) Attention Deficit Hyperactivity Disorder: State of the Science; Best Practices. Kingston, NJ: Civic Research Institute.

Jex, S. M., G. A. Adams, and D. G. Bachrach (2003) The impact of situational constraints, role stressors, and commitment on employee altruism. Journal of Occupational Health Psychology, 8(3), $171-180$.

Johannesson M., and G. Karlsson (1997) The friction cost method: A comment. Journal of Health Economics 16(2), 249-55.

Johnson-Laird, P. N. (1983). Mental models: Towards a cognitive science of language, inference, and consciousness. Cambridge, MA: Harvard University Press.

Joiner, T.E. (1994). Contagious depression: Existence, specificity to depressed symptoms, and the role of reassurance-seeking. Journal of Personality and Social Psychology, 67, 287-296.

Jones, E. and B. Fletcher (1993). An empirical study of occupational stress transmission in working couples. Human Relations, 46, 881-902.

Jones, J.R., C.S. Huxtable, and J.T. Hodgson (2006) Self-Reported Work-Related Illness in 2004/05: Results from the Labour Force Survey. Health \& Safety Executive, Caerphilly, UK.

Judge, T. A., C. J. Thoresen, V. Pucik, and T. M. Welbourne (1999) Managerial coping with organizational change: A dispositional perspective. Journal of Applied Psychology, 84(1), 107122.

Kahn, W.A. (1990) Psychological conditions of personal engagement and disengagement at work. Academy of Management Journal, 33, 692-724. 
Kahneman, D. (1973) Attention and effort. Prentice-Hall Englewood Cliffs, NJ.

Kahneman, D. (2000) Experienced Utility and Objective Happiness: A Moment-Based Approach, in D. Kahneman and A. Tversky (Eds.) Choices, Values and Frames, New York: Cambridge University Press and the Russell Sage Foundation, pp. 673-692.

Kahneman, D., and A. Tversky (1979) Prospect Theory: An Analysis of Decision under Risk. Econometrica, 47(2), 263-291.

Kahneman, D., and C. Varey (1991) Notes on the psychology of utility. In Interpersonal Comparisons of Well-being, ed. by J. Elster and J. E. Roemer. Cambridge University Press.

Kahneman, D., P.P. Wakker and R. Sarin (1997) Back to Bentham? Explorations of Experienced Utility. Quarterly Journal of Economics, 112(2), 375-405.

Kanfer, R., P.L. Ackerman and T.C. Murtha (1994) Goal setting, conditions of practice, and task performance: A resource allocation perspective. Journal of Applied Psychology, 79(6), 826-835

Karasek, R.A. (1979). Job demands, job decision latitude and mental strain: Implications for job redesign. Administrative Science Quarterly, 24, 285-306.

Karasek, R.A. and T. Theorell (1990) Healthy Work: Stress, Productivity and the Reconstruction of Working Life, New York, Basic Books.

Kaslow, F.W. (2001) Families and family psychology at the millennium: Intersecting crossroads, American Psychologist, 56(1), 37-46.

Kathol, R.G., D. McAlpine, Y. Kishi, R. Spies, W. Meller, T. Bernhardt, S. Eisenberg, K. Folkert and W. Gold (2005). General medical and pharmacy claims expenditures in users of behavioral health services. Journal of General Internal Medicine, 20, 160-167.

Katz, J., J. Monnier, S. Beach, J. Libet and D. Shaw (2000). Individual and crossover effects of stress on adjustment: Social support and emotional contagion in medical student marriages. Journal of Marital and Family Therapy, 26, 341-351.

Kaufman, B.E. (1999) Emotional arousal as a source of bounded rationality. Journal of Economic Behavior and Organization 38 (1999), pp. 135-144.

Kaufman, B.E. (2007) The impossibility of a perfectly competitive labour market. Cambridge Journal of Economics 31(5), 775-787.

Kavanagh, D.J., and P.H. Wilson (1989) Prediction of outcome with group cognitive therapy for depression. Behaviour Research and Therapy, 27, 333-343.

Kavanagh, D.J., and G.H. Bower (1985) Mood and self-efficacy: impact of joy and sadness on perceived capabilities. Cognitive Therapy \& Research, 9, 507-25.

Kelly, J.R. and S.G. Barsade (2001). Moods and emotions in small groups and work groups. Organizational Behavior and Human Decision Processes, 86, 99-130.

Kessler R.C., C. Barber, H.G. Birnbaum, R.G. Frank, P.E. Greenberg, R.M. Rose, G.E. Simon, and P. Wang (1999) Depression in the workplace: effects on short-term disability. Health Affairs, 18(5), 163-71.

Kessler, R.C., O. Demler, R.G. Frank, M. Olfson, H.A. Pincus, E.E. Walters, P. Wang, K.B. Wells, and A.M. Zaslavsky (2005b) Prevalence and treatment of mental disorders, 1990 to 2003. The New England Journal of Medicine, 352(24), 2515-2523.

Kessler, R.C., P.A. Berglund, C.L. Foster, W.B. Saunders, and P.E. Stang (1997) Social consequences of psychiatric disorders: II. Teenage parenthood. American Journal of Psycbiatry, 154(10), 14051411.

Kessler, R.C., P. Berglund, O. Demler, R. Jin, K.R. Merikangas, and E.E. Walters (2005a) Lifetime Prevalence and Age-of-Onset Distributions of DSM-IV Disorders in the National Comorbidity Survey Replication. Arcbives of General Psychiatry, 62(6), 593-602. 
Kessler, R.C. and R.G. Frank (1997) The impact of psychiatric disorders on work loss days. Psychogical Medicine 27, 861-873.

Kessler, R.C., J.B. Turner and J.S. House (1989) Unemployment, reemployment, and emotional functioning in a community sample. American Sociological Review, 54, 648-657.

Kessler, R.C., S. Hagop, M.D. Akiskal, M. Ames, H. Birnbaum, P. Greenberg, R.M.A. Hirschfeld, R. Jin, K R. Merikangas and Ph.S. Wang (2006) Prevalence and Effects of Mood Disorders on Work Performance in a Nationally Representative Sample of U.S. Workers. American Journal of Psychiatry 163(9), 1561-1568.

Kets de Vries, M., and K. Balazs (1997) The Downside of Downsizing. Human Relations, 50(1), 11-50.

Kiecolt-Glaser, J. and T. Newton (2001). Marriage and health: His and hers. Psychological Bulletin, 127, 472-503.

Kiesler, S., and L. Sproull (1982) Managerial response to changing environments: Perspectives on problem sensing from social cognition. Administrative Sciences Quarterly, 27, 548-570.

Kihlstrom, J.F., and L. Canter Kihlstrom (1999) Self, sickness, somatization, and systems of care. In Self, social identity, and physical health: Interdisciplinary explorations, ed. by R.J. Contrada and R.D. Ashmore, 23-42. New York: Oxford University Press.

Kiker, B.F. (1969) Von Thunen on Human Capital. Oxford Economic Papers, New Series, 21(3), 339-343.

Kim, I., C. Muntaner, Y. Khang, D. Paek and S. Cho (2006) The relationship between nonstandard working and mental health in a representative sample of the South Korean population Social Science \& Medicine, 63(3) 566-574.

Kingman, J. (ed.) (2002) A sourcebook for poverty reduction strategies, Vol. 2, Washington, DC, World Bank,

Kirmeyer, S.L. (1988) Coping with competing demands: Interruption and the Type A pattern. Journal of Applied Psychology, 73(4), 621-629.

Knoblich, G., and N. Sebanz (2005) Agency in the face of error. Trends in Cognitive Sciences, 9(6), 25961.

Kobasa, S. C. (1979) Stressful life events, personality and health: An inquiry into hardiness. Journal of Personality and Social Psychology, 42, 168-177.

Korff, M. von, J. Ormel, W. Katon, and E. H. Lin (1992) Disability and depression among high utilizers of health care. A longitudinal analysis. Archives of General Psychiatry, 49(2), 91-100.

Kouzis, A.C., and W.W. Eaton (1994) Emotional disability days: prevalence and predictors. American Journal of Public Health, 84(8), 1304-1307.

Kramer, L. and L. Bank (2005) Sibling relationship contributions to individual and family well-being: introduction to the special issue. Journal of Family Psychology, 19(4), 483-485

Krause, N. (1995) Assessing stress-buffering effects: A cautionary note. Psychology and Aging, 10(4), 518-526.

Krause, N. (2005) Exploring Age Differences in the Stress-Buffering Function of Social Support. Psychology and Aging, 20(4), Special issue: Emotion-Cognition Interactions and the Aging Mind, 714-717.

Kringelbach, M.L. and E.T. Rolls (2004) The functional neuroanatomy of the human orbitofrontal cortex: evidence from neuroimaging and neuropsychology. Progress in Neurobiology, 72(5), 341-372.

Krohne, H.W. (1993) Vigilance and cognitive avoidance as concepts in coping research. In H. W. Krohne (Ed.), Attention and avoidance: Strategies in coping with aversiveness (pp. 19-50). Seattle, WA: Hogrefe \& Huber. 
Kuhn, T.S. (1962) The Structure of Scientific Revolutions, Chicago: Univ. of Chicago Press.

Kuiper, J.I., A.J. Van der Beek, Th.F. Meijman (1998) Psychosomatic complaints and unwinding of sympathoadrenal activation after work, Stress Medicine, 14(1), 7-12.

L. Walras (1874) Elements of Pure Economics: Or the theory of social wealth. In: Walras's Progressive Theory of Capital, http: //cepa.newschool .edu/het/essays/capital/walcapit.htm.

Labbé, E., L. Murphy and C. O'Brien (1997) Psychosocial factors and prediction of headaches in college adults, Headache 37, 1-5.

Laibson, D. (1997) Golden Eggs and Hyperbolic Discounting. Quarterly Journal of Economics, 112(2), 443-477.

Laibson, D. (1997) Golden Eggs and Hyperbolic Discounting. The Quarterly Journal of Economics, In Memory of Amos Tversky (1937-1996), 112(2), 443-477.

Laibson, D., A. Repetto, J. Tobacman (1998) Self-Control and Saving for Retirement. Brookings Papers on Economic Activity, 1, 91-196.

Landers, R.M., J.B. Rebitzer, and L.J. Taylor (1996) Rat race redux: adverse selection in the determination of work hours in law firms. American Economic Review, 86, 329-348.

Lane, R.E. (2000) The Loss of Happiness in Market Democracies, Yale University Press.

Langlois, R.N. (1992) Transaction-cost economics in real time. Industrial and Corporate Change 1(1), 99127.

Lasch, C. (1979) The Culture of Narcissism. American Life in an Age of Diminishing Expectations, W.W. Norton \& Company.

Latham, G.P., and C. Frayne (1989) Self-management training for increasing job attendance: A follow-up and a replication. Journal of Applied Psychology, 74(3), 411-416.

Lavikainen, J., E. Lahtinen, and V. Lehtinen (Eds.) (2001) Proceedings of the European Conference on Promotion of Mental Health and Social Inclusion, 10-13 October 1999, Tampere, Finland. Helsinki.

Lavoie, M. (2000) Capital Reversing, Encyclopedia of Political Economy. Routledge.

Lawrence, N. S., Wooderson, S., and D. Mataix-Cols, (2006) Decision Making and Set Shifting Impairments Are Associated With Distinct Symptom Dimensions in Obsessive-Compulsive Disorder. Neuropsychology, 20(4), 409-419.

Layard, R. (2005) Happiness: Lessons from a new science, London, Allen Lane.

Lazarus, R.S. (1963) Personality and adjustment. Englewood Cliffs, N.J: Prentice-Hall.

Lazarus, R.S. (1991). Emotion and adaptation. New York: Oxford University Press.

Lazarus, R.S. (2005) Emotions and interpersonal relationships: Toward a person-centered conceptualization of emotions and coping. Journal of Personality, 74, 1-38.

Lazarus, R.S. and S. Folkman (1984) Stress, appraisal, and coping. New York: Springer.

LeDoux, J.E. (1996) The Emotional Brain. New York, Simon and Schuster.

Lepore, S.J. (1992) Social conflict, social support, and psychological distress: Evidence of crossdomain buffering effects. Journal of Personality and Social Psychology, 63(5), 857-867.

Levine, B. (2005) Brian Wilson: A Cork on the Ocean. The rise and fall of the Beach Boys leader shows how crucial the brain's executive function is to creativity. Scientific American Mind, December 2005.

Lewinsohn, S., and H. Mano (1993). Multi-attribute choice and affect: The influence of naturally occurring and manipulated moods on choice processes. Journal of Behavioral Decision Making, $6,33-51$ 
Liang, J., N.M. Krause and J.M. Bennett (2001) Social exchange and well-being: Is giving better than receiving? Psychology and Aging, 16(3), 511-523.

Liem, R. and J.H. Liem (1988) Psychological effects of unemployment on workers and their families. Journal of Social Issues, 44, 87-105.

Lindbeck, A., and D.J. Snower (2000) Multitask Learning and the Reorganization of Work: From Tayloristic to Holistic Organization. Journal of Labor Economics 18, 353-376.

Lindsley, D.H., D.J. Brass and J.B. Thomas (1995) Efficacy-Performance Spirals: A Multilevel Perspective. The Academy of Management Review, 20(3), 645-678.

Linley P.A. and S. Joseph (2005) Positive adjustment to threatening events: An organismic valuing theory of growth through adversity. Review of General Psychology 9, 262-280.

Linville, P.W. (1985). Self-complexity and affective extremity: Don't put all of your eggs in one cognitive basket. Social Cognition, 3, 94-120.

Linville, P.W. (1987) Self-complexity as a cognitive buffer against stress related illness and depression. Journal of Personality and Social Psychology, 52, 663-676.

Liston, C., M.M. Miller, J.J. Goldwater, A.B. Radley, P.R. Hof, J.H. Morrison and B.S. McEwen (2006) Repeated Stress Induces Dendritic Spine Loss in the Rat Medial Prefrontal Cortex, Journal of Neuroscience, 26, 7870-7874.

Loewenstein, G. (2000) Emotions in Economic Theory and Economic Behavior. The American Economic Review, 90(2), Papers and Proceedings of the One Hundred Twelfth Annual Meeting of the American Economic Association, 426-432.

Loewenstein, G., T. O’Donoghue and M. Rabin (2000) Projection Bias in Predicting Future Utility, Working Paper.

Lorenz, E., and A. Valeyre (2006) Organisational forms and innovative performance: a comparison of the EU-15. In How Europe's Economies Learn: Coordinating Competing Models, ed. by E. Lorenz and B. A. Lundvall. Oxford University Press.

Lorist, M.M., M.A.S. Boksem, and K.R. Ridderinkhof (2005) Impaired cognitive control and reduced cingulate activity during mental fatigue. Cognitive Brain Research, 24(2), 199-205.

Louis, M.R. and I.R. Sutton (1991) Switching cognitive gears: from habits of mind to active thinking, Human Relations 44, 55-76.

Lovibond, S.H. and P.F. Lovibond (1995). Manual for the Depression Anxiety Stress Scales. Sydney: Psychology Foundation

Lu, L., S.F. Kao, T.T. Chang, H.P. Wu, and C.L. Cooper (2008) Work/Family Demands, Work Flexibility, Work/Family Conflict, and Their Consequences at Work: A National Probability Sample in Taiwan. International Journal of Stress Management, 15(1), 1-21.

Lucas, R.E., A.E. Clark, Y. Georgellis, and E. Diener (2004) Unemployment Alters the Set Point for Life Satisfaction. Psychological Science, 15(1), 8-13.

Luce, M.F., J.R. Bettman, and J.W. Payne (1997) Choice Processing in Emotionally Difficult Decisions. Journal of Experimental Psychology: Learning, Memory, and Cognition, 23(2), 384-405.

Lundberg, U. and B. Hellström (2002) Workload and morning salivary cortisol in women, Work Stress 16 (2002), 356-363

Lundberg, U., I. Dohns, B. Melin, L. Sandsjö, G. Palmerud, R. Kadefors, M. Ekstrom and D. Parr (1999) Psychophysiological stress responses, muscle tension, and neck and shoulder pain among supermarket cashiers, Journal of Occupational Health Psychoogyl 4, 245-255.

Lupien, S.J., A. Fiocco, N. Wan, F. Maheu, C. Lord, T. Schramek and M. Thanh Tu (2005) Stress hormones and human memory function across the lifespan Psychoneuroendocrinology, 30(3), 225-242. 
Luthans, F., C.M. Youssef and B.J. Avolio (2006) Psychological Capital: Developing the Human Competitive Edge. Oxford University Press, USA.

MacArthur, R. and E.O. Wilson (1967) The Theory of Island Biogeography, Princeton University Press

Macduffie, J.P. (1995) Human Resource Bundles and Manufacturing Performance: Organizational Logic and Flexible Production Systems in the World Auto Industry. Industrial and Labor Relations Review, 48(2), 197-221.

Macrae, C.N., A.B. Milne, and G. V. Bodenhausen (1994) Stereotypes as Energy-Saving Devices: A Peek Inside the Cognitive Toolbox. Journal of Personality and Social Psychology, 66(1), 37-47.

Madelin, R. (2005) Activities of the European Commission on Mental Health. Remarks by Robert Madelin, Director General Health and Consumer Protection, European Commission. WHO European Ministerial Conference on Mental Health: Facing the Challenges, Building Solutions, Helsinki, 12-15 January 2005.

Magaro, M.M., and J.R. Weisz (2000) Perceived Control Mediates the Relation Between Parental Rejection and Youth Depression. Journal of Abnormal Child Psychology, 34(6), 863-872.

Major, B., J.M. Zubek, and M.L. Cooper (1997) Mixed messages: Implications of social conflict and social support within close relationships for adjustment to a stressful life event. Journal of Personality and Social Psychology, 72(6), 1349-1363.

Mantler, J., A. Matejicek and K. Matheson (2005) Coping with Employment Uncertainty: A Comparion of Employed and Unemployed Workers, Journal of Occupational Health Psychology, 10(3), 200-209.

Manz, C.C. (1986) Self-leadership: Toward an expanded theory of self-influence processes in organizations. Academy of Management Review, 11, 585-600.

Manz, C.C. and H.P. Sims (1987). Leading workers to lead themselves: The external leadership of self-managed work teams. Administrative Science Quarterly, 32, 106-128.

Manz, C.C. and H.P. Sims, (1980). Self-management as a substitute for leadership: A social learning theory perspective. Academy of Management Review, 5: 361-367.

March, J.G. and J.P. Olsen (1989) Rediscovering Institutions: The Organizational Basis of Politics. New York: Free Press.

Marcum, D., and S. Smith (2007) Egonomics: What Makes Ego Our Greatest Asset (or Most Expensive Liability). Fireside.

Marketdata (2005) The Market for Self Improvement Products \& Services, Marketdata Enterprise Inc., Tampa, Florida.

Marks, S.R. (1977). Multiple roles and role strain: Some notes on human energy, time and commitment. American Sociological Review, 41, 921-936.

Markus, H. and P. Nurius (1986) Possible selves. American Psychologist, 41(9), 954-969.

Marmot, M., and R.G. Wilkinson (eds.) (1999) The Social Determinants of Health. Oxford University Press, Oxford.

Marshall, R.D., R. Spitzer, and M.R. Liebowitz (1999) Review and Critique of the New DSM-IV Diagnosis of Acute Stress Disorder. American Journal of Psycbiatry, 156, 1677-1685.

Maslach, C. (1982), Burnout: The Cost of Caring, Prentice Hall, Englewood Cliffs, NJ.

Maslach, C., W.B. Schaufeli, and M.P. Leiter (2001) Job burnout. Annual Review of Psychology, 52, 397422.

Maslow, A.H. (1954) Motivation and Personality, NY: Harper.

Massman, P.J., D.C. Delis, N. Butters, R.M. Dupont and J.C. Gillin (1992) The subcortical dysfunction hypothesis of memory deficits in depression: Neuropsychological validation in a subgroup of patients. Journal of Clinical and Experimental Neuropsychology, 14, 687-706. 
Mattick, R.P., and J.C. Clarke (1998). Development and validation of measures of social phobia, scrutiny fear and social interaction anxiety. Behaviour Research and Therapy, 36, 455-470.

Mausner-Dorsch, H. and W. Eaton (2000) Psychosocial work environment and depression: epidemiologic assessment of the demand-control model, American Journal of Public Health 90, 1765-1770.

Mayer, F., P.-M. Roy, A. Emond and R. Pineault (1991) Unemployment and Mental Health: A Longitudinal Analysis. The Canadian Journal of Economics, 24(3), 551-562.

McClure, S.M., David I., Laibson, G. Loewenstein and J.D. Cohen (2004) Separate Neural Systems Value Immediate and Delayed Monetary Rewards, Science 306(5695), 503.

McEwen, B. (1998) Stress, Adaptation, and Disease: Allostasis and Allostatic Load. Annals of the New York Academy of Sciences, 840(1), 33-44.

McEwen, B.S. (2004) Protection and damage from acute and chronic stress: allostasis and allostatic overload and relevance to the pathophysiology of psychiatric disorders. Annals of the New York Academy of Science, 1032, 1-7.

McEwen, B.S. and R.M. Sapolsky (1995) Stress and cognitive function. Current Opinion in Neurobiology, 5(2), 205-216.

McGregor, I., D.P. McAdams and B.R. Little (2006) Personal projects, life stories, and happiness: On being true to traits. Journal of Research in Personality, 40(5), 551-572.

McKee-Ryan, F., Z. Song, C.R. Wanberg and A.J. Kinicki (2005) Psychological and physical wellbeing during unemployment: a meta-analytic study. Journal of Applied Psychology, 90(1), 53-76.

McLuhan, M. (1964) The Medium is the Message. Mentor, New York.

Meertens V.P. Scheepers and B. Tax (2003) Depressive symptoms in The Netherlands 1975-1996: a theoretical framework and an empirical analysis of socio-demographic characteristics, gender differences and changes over time. Sociology of Health \& Illness, 25(2), 208-231.

Mehl, M.R. (2006) The lay assessment of subclinical depression in daily life. Psychological Assessment, 18(3), 340-345.

Melchior, M., A. Caspi, B.J. Milne, A. Danese, R. Poulton and T.E. Moffitt (2007) Work stress precipitates depression and anxiety in young, working women and men. Psychological Medicine, 37(8), 1119-1129.

Mendl, M. (1999) Performing under pressure: Stress and cognitive function. Applied Animal Behaviour Science, 65(3) 221-244.

Merriam, E.P., M.E. Thase, G.L. Haas, M.S. Keshavan and J.A. Sweeney (1999) Prefrontal Cortical Dysfunction in Depression Determined by Wisconsin Card Sorting Test Performance. American Journal of Psycbiatry 156, 780-782.

Mezulis, A.H., J.S. Hyde, and L.Y. Abramson, (2006) The Developmental Origins of Cognitive Vulnerability to Depression: Temperament, Parenting, and Negative Life Events in Childhood as Contributors to Negative Cognitive Style. Developmental Psychology, 42(6), 10121025.

Michielsen, H.J., J. De Vries, J. and G.L. Van Heck (2004) Examination of the Dimensionality of Fatigue: The Construction of the Fatigue Assessment Scale (FAS). European Journal of Psychological Assessment, 20(1), 39-48.

Miller, M.A, and R.H. Rahe (1997) Life changes scaling for the 1990s. Journal of Psychosomatic Research, 43(3) 279-292.

Miller, N.E., and K. Magruder (1999) The cost-effectiveness of psychotherapy: A guide for practitioners, researchers, and policymakers. Oxford University Press, New York.

Mitchell, S.W. (1887) Wear and Tear, or Hints for the Overworked. JB Lippincott. 
Mobini, S., A. Grant, A.E. Kass and M.R. Yeomans (2007) Relationships between functional and dysfunctional impulsivity, delay discounting and cognitive distortions. Personality and Individual Differences, 43(6), 1517-1528.

Mobius, M. (2000) The Evolution of Work. MIT Working Paper, MIT, 2000.

Mobius, M., and R. Schoenle (2006) The Evolution of Work. NBER Working Paper No. W12694.

Monat, A., J.R. Averill and R.S. Lazarus (1972) Anticipatory stress and coping reactions under various condition of uncertainty, Journal of Personality and Social Psychology, 24(2), 237-253.

Monnier, J., R.P. Cameron and S.E. Hobfall (2000) Direct and crossover effects of prosocial and antisocial coping behaviors. Journal of Family Psychology, 14(4), 570-584.

Moran, M. (2004) More Workers Getting Treatment For Depression, but It's Inadequate. Psychiatric News 39(6), 9 .

Morris, J.A. and D.C. Feldman (1996) The dimensions, antecedents and consequences of emotional labour, Academy of Management Review, 21(4), 986-1010.

Morrow, L., I. Verins, and E. Willis (2002) Mental Health and Work: Issues and Perspectives. Adelaide, Auseinet: The Australian Network for Promotion, Prevention and Early Intervention for Mental Health.

Munce, S.E.P., I. Weller, E.K. Robertson Blackmore, M. Heinmaa, J. Katz and D.E. Stewart (2006) The role of work stress as a moderating variable in the chronic pain and depression association. Journal of Psychosomatic Research, 61(5), 653-660.

Münsterberg, H. (1899) Psychology and History. President's Address, American Psychological Association, New York Meeting, December, 1898, published in Psychological Review, 6, 1-31.

Muraven, M., R.F. Baumeister, and D.M. Tice (1999). Longitudinal improvement of self-regulation through practice: Building self-control strength through repeated exercise. Journal of Social Psychology, 139, 446-457.

Muraven, M., and R.F. Baumeister (2000) Self-regulation and depletion of limited resources: Does self-control resemble a muscle? Psychological Bulletin, 126(2), 247-259.

Muraven, M., D.M. Tice, and R.F. Baumeister (1998) Self-control as a limited resource: Regulatory depletion patterns. Journal of Personality and Social Psychology, 74, 774-789.

Murnane, R. J., J. B. Willett, and F. Levy (1995) The Growing Importance of Cognitive Skills in Wage Determination, The Review of Economics and Statistics, 77(2), 251-266.

Murnane, R.J., J.B. Willett, Y. Duhaldeborde, and J.H. Tyler (2000) How Important Are the Cognitive Skills of Teenagers in Predicting Subsequent Earnings? Journal of Policy Analysis and Management, 19(4), 547-568.

Murphy G.C., and J.A. Athanasou (1999) The effect of unemployment on mental health. Journal of Occupational and Organizational Psychology, 72(1), 83-99.

Murray C.J.L. and A.D. Lopez (1996) The Global Burden of Disease: A Comprehensive Assessment of Mortality and Disability From Diseases, Injuries, and Risk Factors in 1990 and Projected to 2020. Cambridge, Mass: Harvard University Press.

Muse, L.A., S.G. Harris and H.S. Field (2003). Has the inverted-U theory of stress and job performance had a fair test? Human Performance, 16, 349-364.

Nahapiet, J. and S. Ghoshal (1998) Social Capital, Intellectual Capital, and the Organizational Advantage. The Academy of Management Review, 23(2), 242-266.

Nangia, M., W. Syed, and P. M. Doraiswamy (2000) Efficacy and safety of St. John's wort for the treatment of major depression. Public Health Nutrition: 3(4A), 487-494.

Navon, D. (1984) Resources: A theoretical soup stone? Psychological Review 91, 216-234. 
Neiss, R. (1988). Reconceptualizing arousal: Psychological states in motor performance. Psychological Bulletin, 103, 345-366.

Nelson, R.R., and S.G. Winter (1982) An evolutionary theory of economic change. Cambridge, Mass.: Belknap Press of Harvard University Press.

Neubourg de, C. and M. Vendrik (1994) An extended rationality model of social norms in labour supply, Journal of Economic Psychology, 15, 93-126.

Neubourg de, C., and Weigand, C. (2000). Social policy as social risk management. Innovation: The European Journal of Social Sciences, 13(4), 401-412.

Neuman, R. and F. Strack (2000) "Mood contagion": the automatic transfer of mood between persons, Journal of Personality and Social Psychology, 79(2), 211-223.

Newcomb, T.M. (1943) Personality and social change. New York: Dryden

Newman, M. (2005) Emotional Capitalists: The New Leaders, Rochemartin Institute.

Nguyen, H.T. and A.B. Zonderman (2006) Relationship Between Age and Aspects of Depression: Consistency and Reliability Across Two Longitudinal Studies. Psychology and Aging, 21(1), 119126.

Niemi, S., S. Levoska, K. Rekola and S. Keinänen-Kiukaanniemi (1997) Neck and shoulder symptoms of high school students and associated psychosocial factors, Journal of Adolescent Health 20, 238-242.

Nigam, J.A.S., L.R. Murphy and N.G. Swanson (2003) Are Stress Management Programs Indicators of Good Places to Work? Results of a National Survey. International Journal of Stress Management, 10(4), 345-360.

NIOSH (1999) Stress at Work. NIOSH Publication No. 99-101, National Institute for Occupational Safety and Health

Nishiyama, K., and J. V. Johnson (1997) Karoshi - Death from overwork: Occupational health consequences of the Japanese production management. Sixth Draft for International Journal of Health Services, February 4, 1997.

Nolan, J. P., I. C. Wichert, and B. J. Burchell (2000) Job insecurity, psychological well-being and family life. In: E. Heery, and J. Salmon (eds.) The Insecure Work Force. Routledge Studies in Employment Relations.

Nonaka, I., and H. Takeuchi (1995) The knowledge-creating company. New York, Oxford University Press.

Norris, F.H. and Kaniasty, K. (1996) Received and perceived social support in times of stress: A test of the social support deterioration deterrence model. Journal of Personality and Social Psychology, 71(3), 498-511.

O'Brien, T., and A. DeLongis (1997). Coping with chronic stress: An interpersonal perspective. In B. H. Gottlieb (Ed.), Coping with chronic stress. New York: Plenum Publishing Corporation, 161190.

O'Donoghue, T. and M. Rabin (2001) Choice and Procrastination. The Quarterly Journal of Economics, 116(1) 121-160.

OECD (2000) The Service Economy. OECD, Paris.

O'Reilly, A., and J. Pfeffer (2000) Hidden Value: How Great Companies Achieve Extraordinary Results with Ordinary People. Harvard Business School Press.

Organ, D.W. (1988) Organizational Citizenship Behavior: The Good Soldier Syndrome, Lexington Books, Lexington, MA. 
Ostrom, E. (1999) Social Capital: A Fad or a Fundamental Concept. In Social Capital: A Multifaceted Perspective, ed. by P. Dasgupta and I. Serageldin, 172-214. World Bank Publications Washington, DC.

Ozer, E.M. and A. Bandura (1990) Mechanisms governing empowerment effects: A self-efficacy analysis. Journal of Personality and Social Psychology, 58(3), 472-486.

Paoli, P. and D. Merllie (2001) Third European Survey on Working Conditions 2000, European Foundation for the Improvement of Living and Working Conditions, Dublin.

Parent-Thirion, A., E. Fernández Macías, J. Hurley, and G. Vermeylen (2005) Fourth European Working Conditions Survey. European Foundation for the Improvement of Living and Working Conditions, Dublin.

Parker, S.K., T.D. Wall and P.R. Jackson (1997) "That's Not My Job": Developing Flexible Employee Work Orientations. The Academy of Management Journal, 40(4) 899-929.

Patten, S. N. (1889) The Fundamental Idea of Capital. The Quarterly Journal of Economics, 3(2), 188-203.

Perry-Jenkins, M., Repetti, R. L., and Crouter, A. C. (2000) Work and family in the 1990s. Journal of Marriage and the Family, 62, 981-998.

Peters, T. (1997) The Brand Called You. Fast Company Magazine, 10.

Pierce, J.L., D.G. Gardner, R.B. Dunham and L.L. Cummings (1993) Moderation by OrganizationBased Self-Esteem of Role Condition-Employee Response Relationships. The Academy of Management Journal, 36(2), 271-288.

Pilgrim, D., and A. Rogers (1999) A sociology of mental health and illness. Open University Press.

Platt, S., S. Pavis, and G. Akram (1999) Changing Labour Market Conditions and Health: a systematic literature review (1993-1998) European Foundation for the Improvement of Living and Working Conditions, Dublin.

Polder, J.J., J. Takken, W.J. Meerding, G.J. Kommer and L.J. Stokx (2002) Kosten van ziek.ten in Nederland: de zorgeuro ontrafeld. Bilthoven: RIVM.

Portes, A. (1998) Social Capital: Its Origins and Applications in Modern Sociology Annual Review of Sociology 24:1-24.

Post, R.M. (1992) Transduction of psychosocial stress into the neurobiology of recurrent affective disorder, American Journal of Psychiatry 149 (1992), 999-1010.

Potthoff, J.G., C.J. Holahan, and T.E. Joiner Jr. (1995) Reassurance seeking, stress generation, and depressive symptoms: an integrative model. Journal of Personality and Social Psychology, 68(4), 664-70.

Powell, W.W., and K. Snellman (2004) The Knowledge Economy. Annual Review of Sociology, 30(1), 199-220.

Pribram, K. H., and D. McGuinness (1992) Attention and para-attentional processing. Event-related brain potentials as tests of a model. Annals of the New York Academy of Sciences, 658, 65-92.

Price, R.H., D.S. Friedland and A.D. Vinokur (1998) Job loss: Hard times and eroded identity. In J.H. Harvey (Ed.), Perspectives on loss: A sourcebook. Death, dying, and bereavement, 303-316.

Probst, T.M. (2000) Wedded to the job: Moderating effects of job involvement on the consequences of job insecurity. Journal of Occupational Health Psychology, 5(1), 63-73.

Probst, T. M. (2005) Countering the negative effects of job insecurity through participative decision making: lessons from the demand-control model. Journal of Occupational Health Psychology, 10(4), 320-9

Pryor, F.L., and D.L. Schaffer (1999) Who is not working and why. Employment, Cognitive Skills, Wages, and the Changing US Labor Market. Cambridge, Cambridge University Press. 
Pulkkinen, L. and A. Rönkä (1994) Personal control over development, identity formation, and future orientation as components of life orientation: A developmental approach. Developmental Psychology, 30(2), 260-271.

Putnam, R., R. Leonardy, and R. Nanetti (1993). Making democracy work: Civic traditions in modern Italy. Princeton: Princeton University Press

Quick, J.C., J.D. Quick, D.L. Nelson and J.J. Hurrell Jr. (1997) Preventive stress management in organizations. Washington, DC: American Psychological Association.

Quinlan, M., C. Mayhew and P. Bohle (2001). The global expansion of precarious employment, work disorganisation, and consequences for occupational health: Placing the debate in comparative historical context. International Journal of Health Services, 31, 507-536.

Rabkin, J.G. and E.L. Struening (1976) Live events, stress and illness, Science 3, 194(4269), 1013-1020.

Radley, J.J., A.B. Rocher, M. Miller W.G.M. Janssen, C. Liston, P.R. Hof, B.S. McEwen and J.H. Morrison (2006) Repeated Stress Induces Dendritic Spine Loss in the Rat Medial Prefrontal. Cerebral Cortex, 16, 313-320.

Rafferty, A.E., M.A. Griffin (2006) Perceptions of Organizational Change: A Stress and Coping Perspective. Journal of Applied Psychology, 91(5), 1154-1162.

Raskin, R. and C.S. Hall (1981) The narcissistic personality inventory: alternate form reliability and further evidence of construct validity. Journal of Personality Assessment 45, 159-162.

Reckling, A.E., and P. Buirski (1996) Child abuse, self-development, and affect regulation. Psychoanalytic Psychology, 13(1), 81-99.

Rehm, L.P. (1977) A self-control model of depression. Behavior Therapy, 8(5) 787-804.

Reichenberg, A. and J.H. MacCabe (2007) Feeling the pressure: work stress and mental health. Psychological Medicine, 37(8), 1073-1074.

Repetti, R. (2005) A psychological perspective on the health and well-being consequences of parental employment. In S.M. Bianchi, L.M. Casper, and R.B. King (Eds.) Work, family, health and wellbeing Mahwah, NJ: Erlbaum, 245-258.

Repetti, R.L. (1989) Effects of daily workload on subsequent behavior during marital interaction: The roles of social withdrawal and spouse support. Journal of Personality and Social Psychology, 57, 651-659.

Repetti, R.L. (1992) Social withdrawal as a short-term coping response to daily stressors. In: H. S. Friedman (Ed.) Hostility, coping, and health Washington, DC: American Psychological Association, 151-165.

Repetti, R.L. and J. Wood (1997) Effects of daily stress at work on mothers' interactions with preschoolers. Journal of Family Psychology, 11(1), 90-108.

Research and Markets (2005) Impact of Generics on the Antidepressant Market. Decision Resources, Inc., Dec 2005, Research and Markets.

Rice D.P., and L.S. Miller (1998) Health economics and cost implications of anxiety and other mental disorders in the United States. British Journal of Psychiatry Supplement, 34, 4-9.

Rice D.P., S. Kelman, and L.S. Miller (1992) The economic burden of mental illness. Hospital \& Community Psychiatry. 43(12), 1227-1232.

Rice D.P., S. Kelman, L.S. Miller, and S. Dummeyer (1990) The economic costs of alcohol and drug abuse and mental illness: 1985. Rockville, MD, Alcohol, Drug Abuse and Mental Health Administration (Publication No. (ADM) 90-1694).

Rihmer, Z. (2007) Changing suicide rates in western and central Europe. European Psycbiatry. 22(1), S35. 
Ringel, J.S., S.D. Hosek, B.A. Vollaard, and S. Mahnovski (2002) The Elasticity of Demand for Health Care. A Review of the Literature and Its Application to the Military Health System. RAND publications.

Robinson S.L. (1996) Trust and Breach of the Psychological Contract, Administrative Science Quarterly, 41(4), 574-599.

Robinson, J. (1936) Disguised Unemployment, The Economic Journal, 46(182), 225-237.

Robinson, S.L. and E. Morrison (1995) Psychological contracts and OCB: the effect of unfulfilled obligations on civic virtue behavior. Journal of Organizational Behavior, 16(3), 289-98.

Rojek, C. (2004) The Consumerist Syndrome in Contemporary Society. An interview with Zygmunt Bauman. Journal of Consumer Culture, 4(3), 291-312.

Romer, P.M. (1986) Increasing Returns and Long-Run Growth. Journal of Political Economy 94, 100237.

Romer, P.M. (1989) Human Capital and Growth: Theory and Evidence. NBER Working Paper No. w3173.

Rook, K.S. (1984). The negative side of social interaction: Impact on psychological well being. Journal of Personality and Social Psychology, 46, 1097-1108.

Rook, S.K., D. Dooley and R. Catalano, R. (1991) Stress transmission: The effects of husbands' job stressors on emotional health of their wives. Journal of Marriage and the Family, 53, 165-177.

Rosenberg, C.E. (2006) Contested Boundaries: psychiatry, disease, and diagnosis, Perspectives in Biology and Medicine 49:3 (2006) 407-424.

Rosenberg, M. (1965) Society and adolescent self-image, Princeton University Press.

Roskies, E., C. Louis-Guerin, and C. Fournier (1993). Coping with job insecurity: How does personality make a difference? Journal of Organizational Behavior, 14, 617-630.

Rost, K., T.M. Kashner and G.R. Smith (1994). Effectiveness of psychiatric intervention with somatization disorder patients: Improved outcomes at reduced costs. General Hospital Psychiatry, 16, 381-387.

Rothbard, N. P. (2001). Enriching or depleting? The dynamics of engagement in work and family roles. Administrative Science Quarterly, 46, 655-684.

Rothermund, K. and J. Brändtstädter (2003) Depression in later life: Cross-sequential patterns and possible determinants. Psychology and Aging, 18, 80-90.

Rouse, B. (1995) Substance Abuse and Mental Health Statistics Sourcebook. Publication No. (SMA) 953064, Department of Health and Human Services.

Rousseau, D.M. (1978) Relationship of work to nonwork. Journal of Applied Psychology, 63(4), 513-517.

Rousseau, D.M. (1995) Psychological contracts in organizations: Understanding written and unwritten agreements, Sage, Thousand Oaks.

Rousseau, D.M. (1997) Organizational Behavior in the New Organizational Era, in: Annual Review of Psychology 48, 515-546.

Rousseau, D.M. (1998a) The 'problem' of the psychological contract reconsidered, in: Journal of Organizational Behaviour 19, 665-671.

Rousseau, D.M. (1998b) Why workers still identify with organizations, in: Journal of Organizational Behavior 19, 217-233.

Ruhm, C.J. (2000) Are Recessions good for your health? Quarterly Journal of Economics, 115(2) 617-650.

Ruys, K.I., Spears, R., Gordijn, E.H. and de Vries, N. (2006) Two Faces of (Dis)similarity in Affective Judgments of Persons: Contrast or Assimilation Effects Revealed by Morphs. Journal of Personality and Social Psychology, 90(3), 399-411. 
Salanova, M., S. Agut and J.M. Peiro (2005) Linking organizational resources and work engagement to employee performance and customer loyalty: The mediation of service climate. Journal of Applied Psychology, 90, 1217-1227.

Sapolsky, R.M. (1996) Why stress is bad for your brain, Science, Vol. 273(5276), 749-750.

Sapolsky, R.M., L.C. Krey and B.S. McEwen (1986) The neuroendocrinology of stress and aging: the glucocorticoid cascade hypothesis, Endocrine Review 7, 284-301.

Saragovi, C., J. Aube, R. Koestner and D. Zuroff (2002). Traits, motives, and depressive styles as reflections of agency and communion. Personality and Social Psychology Bulletin, 28, 563-577.

Saxbe, D.E., R.L. Repetti and A. Nishina (2008) Marital satisfaction, recovery from work, and diurnal cortisol among men and women. Health Psychology, Vol 27(1), 15-25.

Scarbrough, H. (1999) Knowledge as Work: Conflicts in the Management of Knowledge Workers. Technology Analysis and Strategic Management, 11(1), 5-16.

Schabracq, M.J., J.A.M. Winnubst, and C.L. Cooper (eds.) (2003) The Handbook of Work and Health Psychology. John Wiley \& Sons.

Schachter, S. (1959). The psychology of affiliation. Stanford, CA: Stanford University Press.

Schaufeli, W., and D. Enzman (1998) The Burnout Companion to Study and Practice. PA: Taylor and Francis.

Schaufeli, W.B. and M.A.J. Kompier (2001) Managing job stress in the Netherlands International Journal of Stress Management, 8, 15-34.

Schaufeli, W.B., and A.B. Bakker (2004) Job demands, job resources, and their relationship with burnout and engagement: A multi-sample study. Journal of Organizational Behavior, 25, 293315.

Schelling, T.C. (1978) Egonomics, or the Art of Self-Management. The American Economic Review, 68(2), Papers and Proceedings of the Ninetieth Annual Meeting of the American Economic Association (May, 1978), 290-294.

Schernhammer, E. (2005) Taking their own lives - the high rate of physician suicide. The New England Journal of Medicine, 352(24), 2473-2476.

Schettkat, R. and L. Yocarini (2006) The Shift to Services Employment: A Review of the Literature. Structural Change and Economic Dynamics, 17(2), 127-147.

Schmidt, C.W. (2007) Environmental Connections: A Deeper Look into Mental Illness. Environ Health Perspect. 115(8), A404-A410.

Schoemaker C., M.J.J.C. Poos and J. Spijker (2005) Neemt het aantal mensen met depressie toe of af? In: Volksgezondheid Toekomst Verkenning, Nationaal Kompas Volksgezondheid. Bilthoven: RIVM, www.nationaalkompas.nl, 13 december 2005.

Schoemaker, C., and M. J. J. C.Poos (2005) Neemt het aantal mensen met angststoornissen toe of af? In: Volksgezondheid Toekomst Verkenning, Nationaal Kompas Volksgezondheid. Bilthoven: RIVM,

Schönpflug, W. (1986) The trade-off between internal and external information storage. Journal of Memory and Language, 25, 657-675.

Schor, J.B. (1998) The Overspent American: Why we want what we don't need, New York: Harper Perennial.

Schuff, D., O. Turetken and J. D'Arcy (2006) A multi-attribute, multi-weight clustering approach to managing "e-mail overload". Decision Support Systems, 42(3), 1350-1365.

Schultz, T.W. (1961) Investment in Human Capital. The American Economic Review, 51(1), 1-17.

Schulz, M.S., P.A. Cowan, C.P. Cowan and R.T. Brennan (2004). Coming home upset: Gender, marital satisfaction and the daily spillover of workday experience into couple interactions. Journal of Family Psychology, 18, 250-263. 
Schuster, D.G. (2003) Neurasthenia and a Modernizing America, JAMA, 290: 2327-2328.

Schwartz, B. (2000) Self-determination. The tyranny of freedom. American Psychology, 55(1), 79-88.

Schwartz, H.L. (1994) From dissociation to negotiation: A relational psychoanalytic perspective on multiple personality disorder. Psychoanalytic Psychology, 11(2), 189-231.

Schwartz, S.H. (1999) A Theory of Cultural Values and Some Implications for Work. Applied Psychology 48 (1), 23-47.

Scitovsky, T. (1976) The Joyless Economy. New York: Oxford University Press.

Scott, S., M. Knapp, J. Henderson and B. Maughan (2001) Financial cost of social exclusion: followup study of antisocial children into adulthood. BMJ, 323, $191-194$.

Sedikides, C., E. A. Rudich, A.P. Gregg, M. Kumashiro, and C. Rusbult (2004) Are normal narcissists psychologically healthy? Self-esteem matters. Journal of Personality and Social Psychology, 87(3), 400-416.

Seibert, P.S., and H.C. Ellis (1991). Irrelevant thoughts, emotional mood states, and cognitive task performance. Memory \& Cognition, 19, 507-513.

Seligman, M.E.P., and M. Csikszentmihalyi (2000) Positive psychology: An introduction. American Psychologist, 55(1). 5-14.

Seligman, M.E.P. (1975) Helplesness: On Depression, Development and Death, San Francisco, CA: W.H. Freeman.

Selye, H. (1936) A Syndrome Produced by Diverse Nocuous Agents. Nature, 138, 32.

Selye, H. (1956) The stress of life. New York: McGraw-Hill.

Sen, A. (1993) Internal Consistency of Choice. Econometrica, 61(3), 495-521.

Sennet, R. (1998) The Corrosion of Character. The Personal Consequences of Work in the New Capitalism, W.W. Norton \& Company.

Serbin, L.A. and D.M. Stack (1998) Introduction to the special section: Studying intergenerational continuity and the transfer of risk. Developmental Psychology, 34(6), 1159-1161.

Sewell, G. (1998) The discipline of teams: the control of team-based industrial work through electronic and peer surveillance. Administrative Science Quarterly, Special Issue: Critical Perspectives on Organizational Control, 43(2), 397-428.

Shallice, T., P. Fletcher, C.D. Frith, P. Grasby, R.S. Frackowiak, and R. J. Dolan (1994) Brain regions associated with acquisition and retrieval of verbal episodic memory. Nature, 368(6472), 633635 .

Sheldon, K.M. and A.J. Elliot (1999) Goal striving, need satisfaction, and longitudinal well-being: The self-concordance model. Journal of Personality and Social Psychology, 76(3), 482-497.

Sheldon, K.M. and T. Kasser (1995) Coherence and congruence: Two aspects of personality integration. Journal of Personality and Social Psychology, 68(3), 531-543.

Showers, C. (1992) Compartmentalization of positive and negative self-knowledge: Keeping bad apples out of the bunch. Journal of Personality and Social Psychology, 62(6),1036-1049.

Showers, C.J., L.Y. Abramson, and M. E. Hogan, (1998) The dynamic self: How the content and structure of the self-concept change with mood. Journal of Personality and Social Psychology, 75(2), 478-493.

Showers, C.J. and Kevlyn, S.B. (1999) Organization of knowledge about a relationship partner: Implications for liking and loving. Journal of Personality and Social Psychology, 76(6), 958-971.

Sieber, S.D. (1974) Toward a Theory of Role Accumulation. American Sociological Review, 39(4), $567-$ 578. 
Siegel, J.P. (2006) Dyadic Splitting in Partner Relational Disorders. Journal of Family Psychology, 20(3), $418-42$.

Siegrist, J. (1996) Adverse health effects of high-efforts/low-reward conditions. Journal of Occupational Health Psychology 1, 27-41.

Simon, H.A. (1986) Rationality in Psychology and Economics, The Journal of Business, 59(4), Part 2: The Behavioral Foundations of Economic Theory, S209-S224.

Simon, H.A. (1947) Administrative Behavior. New York: Macmillan.

Simon, H.A. (1955) A Behavioral Model of Rational Choice, The Quarterly Journal of Economics, 69, 99118.

Simon, H.A. (1977) Models of discovery. Dordecht: D. Riedel.

Simon, H.A. (1982) Models of Bounded Rationality. Cambridge, MA: MIT Press.

Sims, H.P. and D.A. Goia (eds.) (1986) The Thinking Organization: The Dynamics of Organizational Social Cognition, San Francisco, Jossey-Bass.

Sinclair-Desgagné, B. and A. Soubeyran (2000) A Theory of Routines as Mindsavers, CIRANO Working Papers 2000s-52, CIRANO.

Slobbe, L.C.J., G.J. Kommer, J.M. Smit, J. Groen, W.J. Meerding and J.J. Polder (2006) Kosten van ziekten in Nederland 2003. Zorg voor euro's. RIVM rapport 270751010.

Sluiter, J.K., A.J. van der Beek and M.H.W. Frings-Dresen (2001) The relation between workinduced neuroendocrine reactivity and recovery, subjective need for recovery, and health status. Journal of Psychosomatic Research, 50, 29-37.

Sluiter, J.K., E.M. de Croon, T.F. Meijman and M.H.W. Frings-Dresen (2003) Need for recovery from work-related fatigue and its role in the development and prediction of subjective health complaints. Occupational and Environmental Medicine, 60, i62-i70.

Smit, F., and R.V. Bijl (2000) Een verkennende studie naar de kosten van de combinatie van werk en zorgtaken. Utrecht: Trimbos-instituut.

Smith, A. (1776) An Inquiry into the Nature And Causes of the Wealth of Nations. http://www.adamsmith.org/smith/won-index.htm.

Smith, G.R., R.A. Monson and D.C. Ray (1986) Patients with multiple unexplained symptoms: Their characteristics, functional health, and health care utilization. Archives of Internal Medicine, 146, 69-72.

Smith, R. (2000) On the Use of the Prisoners' Dilemma to Analyze the Relations Between Employment Security, Trust, And Effort. Review of Social Economy, 58(2) 153-175.

Smith, R.E. (1989) Effects of coping skills training on generalized self-efficacy and locus of control. Journal of Personality and Social Psychology, 56(2), 228-233.

Smith, V. (1997) New forms of work organization. Annual Review of Sociology, 23, 315-339.

Smulders, P. (ed.) (2006) Worklife in the Netherlands. TNO Kwaliteit van Leven, Hoofddorp.

Sobel, J. (2002) Can We Trust Social Capital? Journal of Economic Literature, 40(1), 139-154.

Sobocki, P., B. Jönsson, J. Angst, and C. Rehnberg (2006) Cost of depression in Europe. Journal of Mental Health Policy and Economics, 9(2), 87-98.

Sobocki, P., I. Lekander, F. Borgström, O. Ström, B. Runeson (2007) The economic burden of depression in Sweden from 1997 to 2005. European Psychiatry, 22(3), 146-152.

Sokol-Hessner, P.M. Hsu, N. Curley, M. Delgado, C. Camerer, E.A. Phelps (2007) Thinking Like A Trader: Distinct Neural Correlates of Loss Aversion and its Regulation, Society for Neuroeconomics, September 2007. 
Solow, R. (1987) Growth Theory and After, Nobel Prize Lecture, December 8, 1987. From: Nobel Lectures, Economics 1981-1990, K.G. Mäler (ed.) (1992), World Scientific Publishing Co., Singapore.

Solow, R. (1990) The Labour Market as a Social Institution. New York: Basil Blackwell.

Solow, R.M. (1956) A Contribution to the Theory of Economic Growth. The Quarterly Journal of Economics, 70(1), 65-94.

Solow, R.M. (1999) Notes on Social Capital and Economic Performance. In Social Capital: A Multifaceted Perspective, ed. by P. Dasgupta and I. Serageldin, 6-10. World Bank Publications Washington, DC.

Sonnentag, S. (2003) Recovery, work engagement, and proactive behavior: A new look at the interface between nonwork and work. Journal of Applied Psychology, 88(3), 518-528.

Sonnentag, S. and E. Natter (2004) Flight Attendants' Daily Recovery From Work: Is There No Place Like Home? International Journal of Stress Management, 11(4), 366-391.

Sonnentag, S. and F.H.R. Zijlstra (2006) Job Characteristics and Off-Job Activities as Predictors of Need for Recovery, Well-Being, and Fatigue. Journal of Applied Psychology, 91(2), 330-333.

Sonnentag, S. and F.R.H. Zijlstra (2006) Job characteristics and off-job activities as predictors of need for recovery, well-being, and fatigue, Journal of Applied Psychology 91, 330-350.

Sousa-Poza, A. and A. Ziegler (2003) Asymmetric information about workers' productivity as a cause for inefficient long working hours. Labour Economics. 10, 727-747.

Spitz, A. (2004) Are Skill Requirements in the Workplace Rising? Stylized Facts and Evidence on Skill-biased Technological Change. ZEW Discussion Paper No. 04-33.

Sroufe, J.W. (1991) Assessment of parent-adolescent relationships: Implications for adolescent development. Journal of Family Psychology, 5(1), 21-45.

Stam, R. (2007) PTSD and stress sensitisation: A tale of brain and body: Part 1: Human studies. Neuroscience \& Biobehavioral Reviews, 31(4), 530-557.

Starbuck, W.H. and F.J. Miliken (1988) 'Executives' perceptual filters: what they notice and how they make sense', in: D. Hambrick (ed.) (1988) The Executive Effect: Concepts and Methods for Studying Top Managers, Greenwich, CT, JAT.

Staudinger, U.M. (2001) Life reflection: A social-cognitive analysis of life review. Review of General Psychology, Special issue: Autobiographical memory, 5(2), 148-160.

Staw, B.M. and S.G. Barsade (1993) Affect and manegerial performance: A test of the sadder-but wiser vs. happier and smarter hypotheses, Administrative Science Quarterly 38, 304-331.

Stephens T., and N. Joubert (2001) The economic burden of mental health problems in Canada. Chronic Diseases in Canada, 22(1), 18-23.

Sternberg, R.J., and J. Kolligian (Eds.) (1990) Competence considered. Yale University Press.

Stewart, T.A. (1998) Intellectual Capital: The New Wealth of Organizations. Currency.

Stewart, W.F., J.A. Ricci, E. Chee, S. R. Hahn, and D. Morganstein (2003) Cost of Lost Productive Work Time Among US Workers With Depression. Journal of the American Medical Association, 289, 3135-3144.

Stewart, W.F., J.A. Ricci, E. Chee, S.R. Hahn and D. Morganstein (2003). Cost of lost productive work time among U.S. workers with depression. Journal of the American Medical Association, 289, 3135-3144.

Stiglitz, J.E. (1999) Formal and Informal Institutions. In Social Capital: A Multifaceted Perspective, ed. by P. Dasgupta, and I. Serageldin. World Bank Publications Washington, DC, pp. 59-68.

Storch, M., J. Gaab, Y. Küttel, A.-C. Stüssi and H. Fend (2007) Psychoneuroendocrine effects of resource-activating stress management training, Health Psychology, July 2007, 26 (4) 456-463. 
Storm, S., and C.W.M. Naastepad, (2007) Why labour market regulation may pay off: Worker motivation, co-ordination and productivity growth, Economic and Labour Market Papers 200704, International Labour Office.

Story, L.B. and Repetti, R. (2006) Daily Occupational Stressors and Marital Behavior. Journal of Family Psychology, 20(4), 690-700.

Story, L.B., and T.N. Bradbury (2004). Understanding marriage and stress: Essential questions and challenges. Clinical Psychology Review, 23, 1139-1162.

Stouthard, M.E.A., M.L. Essink-Bot, G.J. Bonsel, J. J. M. Barendregt, P. G. N. Kramers, H. P. A. van De Water, L. J. Gunning-Schepers, and P. J. van Der Maas (1997) Disability weights for diseases in the Netherlands, Inst. Sociale Geneeskunde, Amsterdam.

Straathof, S.M. and R.M. Weehuizen (2005) Technological change, job stress and burnout. In The Economics of the Digital Society, ed. by L. L. G. Soete, and B. J. ter Weel, 184-199. Edward Elgar Publishing, Cheltenham.

Strazdins, L.M., R.F. Galligan, and E.D. Scannell (1997) Gender and Depressive Symptoms: Parents' Sharing of Instrumental and Expressive Tasks When Their Children Are Young. Journal of Family Psychology, 11(2), 222-233.

Stroud, S. and C. Tappolet (eds.) Weakness of Will and Practical Irrationality, Oxford: Clarendon Press, 2003.

Sullins, E.S. (1991) Emotional contagion revisited: Effects of social comparison and expressive style on mood convergence. Personality and Social Psychology Bulletin, 17(2) 166-174.

Sullivan, S.E. (1999) The Changing Nature of Careers: A Review and Research Agenda, Journal of Management, 25(3), 457-484.

Surgeon General (1999) Mental Health: A Report of the Surgeon General. Washington, DC: U.S. Department of Health and Human Services.

Sveiby, K.E. and R. Simons (2002) Collaborative climate and effectiveness of knowledge work. Journal of Knowledge Management 6(5), 420-433.

Sverke, M., J. Hellgren and K. Näswall (2002) No security: A meta-analysis and review of job insecurity and its consequences. Journal of Occupational Health Psychology, 7(3), 242-264.

Sy, T., S. Cote and R. Saavedra (2005) The contagious leader: impact of the leader's mood on the mood of group members, group affective tone and group process, Journal of Applied Psychology 90 (2), 295-305.

Syed, J.R. (1998) An adaptive framework for knowledge work. Journal of Knowledge Management, 2(2), 59-69.

Szasz, T.S. (1961) The Myth of Mental Illness: Foundations of a Theory of Personal Conduct. New York: Hoeber.

Szasz, T.S. (1970) The Manufacture of Madness: A Comparative Study of the Inquisition and the Mental Health Movement. New York: Harper Row.

SZW (2000) Uitstroom bijstand belemmerd, Ministerie van Sociale Zaken, Nr. 2000/4.

Takeuchi, R., S. Yun and P.E. Tesluk (2002) An examination of crossover and spillover effects of spousal and expatriate cross-cultural adjustment on expatriate outcomes, Journal of Applied Psychology, 87 (4), 655-666.

Taylor, F. (1911) The Principles of Scientific Management. In Scientific Management, by F. Taylor. Routledge, 2003.

Teigen K. H. (1994) Yerkes-Dodson: A Law for all Seasons. Theory \& Psychology, 4(4), 525-547. 
Teuchmann, K., P. Totterdell and S.K. Parker (1999) Rushed, unhappy, and drained: An experience sampling study of relations between time pressure, perceived control, mood, and emotional exhaustion in a group of accountants. Journal of Occupational Health Psychology, 4(1), 37-54.

Thaler, R. (1980). Towards a positive theory of consumer choice. Journal of Economic Behavior and Organization, 1, 39-60.

Thaler, R.H. and H.M. Shefrin (1980) An Economic Theory of Self-Control. The Journal of Political Economy, 89(2), 392-406.

Thomas, C.M. and S. Morris (2003) Cost of depression among adults in England in 2000. British Journal of Psychiatry, 183, 514-519.

Thomson, K. (2000) Emotional Capital: Maximising the Intangible Assets at the Heart of Brand and Business Success, Capstone.

Tice, D.M., E. Bratslavsky and R.F. Baumeister (2001) Emotional distress regulation takes precedence over impulse control: If you feel bad, do it! Journal of Personality and Social Psychology, 80(1), 53-67.

Tomer, J.F. (1987) Organizational Capital: The Path to Higher Productivity and Well-Being, Praeger Publishers.

Totterdell, P. (2000) Catching moods and hitting runs: mood linkage and subjective performance in professional sport teams, Journal of Applied Psychology, 85(6), 848-859.

Trimbos (2001) Kosten psychische problemen zwaar onderschat. Trimbos Nieuwsflitsen, 3.

Tsutsumi, A., K. Kayaba, T. Theorell and J. Siegrist (2001) Association between job stress and depression among Japanese employees threatened by job loss in a comparison between two complementary job-stress models, Scand J Work Environ Health 27, 146-153.

Turner, J.B. (1995) Economic context and the health effects of unemployment. Journal of Health and Social Behavior, 36(3), 213-29.

Turnley, W.H., M.C. Bolino, S.W. Lester, and J.M. Bloodgood (2003) The Impact of Psychological Contract Fulfillment on the Performance of In-Role and Organizational Citizenship Behaviors. Journal of Management, 29(2), 187-206.

Tuttle, C.A. (1903) The Real Capital Concept. The Quarterly Journal of Economics, 18(1), 54-96.

Tversky, A., and D. Kahneman (1986) Rational Choice and the Framing of Decisions. The Journal of Business, 59(4), Part 2: The Behavioral Foundations of Economic Theory, S251-S278.

Tversky. A, D. Kahneman (1974) Judgment under Uncertainty: Heuristics and Biases. Science, 185(4157), 1124-1131.

Tyler, J.H., R.J. Murnane, and J. B. Willett (2000) Estimating The Labor Market Signaling Value of The GED. Quarterly Journal of Economics, 115(2), 431-468.

Van der Klink, J.J.L., R.W.B. Blonk, A.H. Schene and F.J.H. van Dijk (2001) The benefits of interventions for work-related stress. American Journal of Public Health, 91, 270-276.

Van der Linden, D., M. Frese and T.F. Meijman (2003). Mental fatigue and the control of cognitive processes: Effects on perseveration and planning. Acta Psychologica, 113, 46-65.

Van Rooy, D.L. and C. Viswesvaran (2004) Emotional intelligence: A meta-analytic investigation of predictive validity and nomological net. Journal of Vocational Behavior, 65(1), 71-95.

Van Sell, M., A. Brief and R. Schuler (1981) Role conflict and role ambiguity: integration of the literature and directions for future research, Human Relations, 34(1), 43-71.

Veblen, T. (1899) The theory of the leisure class. Reprint, New York: Viking-Penguin, 1979

Verberne, B., P. van Echtelt and S. Bunt (2007) Van school naar werk. Onderzoek naar leren, werken en werkloos zijn onder jongeren en werkgevers. Eindrapport. Een onderzoek in opdracht van de Taskforce Jeugdwerkloosheid, Research voor Beleid, B3287, Leiden 
Verkooijen, K.T., N.K. de Vries and G.A. Nielsen (2007) Youth Crowds and Substance Use: The Impact of Perceived Group Norm and Multiple Group Identification. Psychology of Addictive Behaviors, 21(1), 55-61.

Verplanken, B., Friborg, O. and Wang, C.E. (2007) Mental Habits: Metacognitive Reflection on Negative Self-Thinking. Journal of Personality and Social Psychology, 92(3), 526-541.

Vinokur, A. and M. van Ryn (1993). Social support and undermining in close relationships: Their independent effects on mental health of unemployed persons. Journal of Personality and Social Psychology, 65, 350-359.

Vinokur, A.D., Price, R.H. and Caplan, R.D. (1996) Hard times and hurtful partners: How financial strain affects depression and relationship satisfaction of unemployed persons and their spouses. Journal of Personality and Social Psychology, 71(1), 166-179.

Vogel, D.L., S.R. Wester, and L.M. Larson, (2006) An Information-Processing Model of the Decision to Seek Professional Help. Professional Psychology: Research and Practice, 37(4), 398-406.

Walker, I., and T.F. Pettigrew (1984). Relative deprivation theory: An overview and conceptual critique. British Journal of Social Psychology, 23, 303-310.

Wallis, J.J., and D.C. North (1986) Measuring the Transaction Sector in the American Economy. In Long Term Factors in American Economic Growth, ed. by S.L. Engerman, and R.E. Gallman. Chicago: University of Chicago Press.

Wanberg, C.R., T.M. Glomb, Z. Song, and S. Sorenson (2005) Job-search persistence during unemployment: a 10-wave longitudinal study. Journal of Applied Psychology, 90(3), 411-430.

Wang, P.S., A.L. Beck, P. Berglund, D.K. McKenas, N.P. Pronk, G. Simon and R.C. Kessler (2004) Effects of major depression on moment-in-time work performance. American Journal of Psychiatry, 161, 1885-1891.

Warr, P.B. (1987) Work, Unemployment and Mental Health, Oxford: Clarendon Press.

Waterman, A. S. (1982) Identity development from adolescence to adulthood: An extension of theory and a review of research. Developmental Psychology, 18(3), 341-358.

Waters, L. E., and K. A. Moore (2002a) Reducing latent deprivation during unemployment: The role of meaningful leisure activity. Journal of Occupational and Organizational Psychology, 75, 15-32.

Waters, L. E., and K. A. Moore (2002b) Self-Esteem, Appraisal and Coping: A Comparison of Unemployed and Re-Employed People. Journal of Organizational Behavior, 23(5), 593-604.

Weehuizen, R.M. (2003) Mental Capital. Working document, Algemeen Economische Politiek, Ministerie van Economische Zaken, The Hague.

Weehuizen, R.M. (2006) Mental capital. An explorative study on the psychological dimensio of economic change. Consultative Committee for Sector Councils and Advisory Council for Health Redearch, The Hague.

Wei, M., D.W. Russell, and R.A. Zakalik (2005) Adult Attachment, Social Self-Efficacy, SelfDisclosure, Loneliness, and Subsequent Depression for Freshman College Students: A Longitudinal Study. Journal of Counseling Psychology, 52(4), 602-614.

Weiland-Fiedler, P., K. Erickson, T. Waldeck, D.A. Luckenbaugh, D. Pike, O. Bonne, D.S. Charney and A. Neumeister (2004) Evidence for continuing neuropsychological impairments in depression. Journal of Affective Disorders, 82(2), 253-258.

Weisbrod, B.A. (1966) Investing in Human Capital. Journal of Human Resources, 1(1), 5-21.

Weissman, M.M., S. Wolk, R.B. Goldstein, D. Moreau, P. Adams, S. Greenwald, et al. (1999). Depressed adolescents grown up. Journal of the American Medical Association, 281, 1707-1713.

Wessely, S. and M. Hotopf (2001) Are some public-health problems better neglected? The Lancet, 357(9261), 976-978. 
Westen, D., and K. Morrison (2001). A multidimensional meta-analysis of treatments for depression, panic, and generalized anxiety disorder: An empirical examination of the status of empirically supported therapies. Journal of Consulting and Clinical Psychology, 69, 875-899.

Westman, M. (2001). Stress and strain crossover. Human Relations, 54, 717-752.

Westman, M. (2002) Crossover of stress and strain in the family and workplace. Research in Occupational Stress and Well Being, 2, 143-181.

Westman, M. and A.D. Vinokur (1998) Unraveling the relationship of distress levels within couples: Common stressors, empathic reactions, or crossover via social interaction? Human Relations, 51, 137-156.

Westman, M. and D. Eden (1997) Effects of a respite from work on burnout: Vacation relief and fade-out. Journal of Applied Psychology, 82(4), 516-527.

Westman, M. and D. Etzion (1995) Crossover of stress, strain and resources from one spouse to another. Journal of Organizational Behavior, 16, 169-181.

Westman, M. and D. Etzion (1999) The crossover of strain from school principals to teachers and vice versa. Journal of Occupational Health Psychology, 4, 269-278.

Westman, M., A.D. Vinokur, V.L. Hamilton and I. Roziner (2004) Crossover of marital dissatisfaction during military downsizing among Russian army officers and their spouses, Journal of Applied Psychology 89(5) 769-779.

Wheaton, B. (1985) Models for the stress-buffering functions of coping resources. Journal of Health \& Social Behavior, 26, 352-364.

Wheeler, L. (1966) Toward a theory of behavioral contagion. Psychological Review, 73, 179-192.

WHO (2001a) The World Health Report 2001 - Mental Health: New Understanding, New Hope. World Health Organization Geneva.

WHO (2001b) Strengthening mental health promotion, Geneva 2001 (Fact sheet no. 220).

WHO (2001c) Macroeconomics and Health, Investing in Health for Economic Development. Report of the Commission on Macroeconomics and Health, chaired by Jeffrey Sachs, World Health Organization Geneva.

WHO (2002a) The World Health Report 2002 - Reducing Risks, Promoting Healthy Life, World Health Organization, Geneva.

WHO (2002b) Nations for Mental Health. Final Report, World Health Organization Geneva.

WHO (2002c), Mental Health Global Action Programme MHGAP, World Health Organization Geneva.

Wichert, I., J. Nolan, and B. Burchell (2000) Workers on the Edge: Job Insecurity, Psychological Well-Being, and Family Life. Economic Policy Inst.

Wieren, S. van, C. Schoemaker, A. J. L. M. van Balkom (2007) Welke zorg gebruiken patiënten en wat zijn de kosten? In: Volksgezondheid Toekomst Verkenning, Nationaal Kompas Volksgezondheid. Bilthoven: RIVM.

Wilkinson, F., B. Burchell, and D. Ladipo (2001) Job insecurity and work intensification. Routledge New York.

Williams, K.J. and G.M. Alliger (1994) Role stressors, mood spillover, and perceptions of workfamily conflict in employed parents. Academy of Management Journal, 37, 837-868.

Williams, S.L., P.J. Kinney and J. Falbo (1989) Generalization of therapeutic changes in agoraphobia: The role of perceived self-efficacy. Journal of Consulting and Clinical Psychology, 57(3), 436-442.

Williamson, O.E. (1981) The economics of organization: The transaction cost approach. The American Journal of Sociology, 87(3), 548-577. 
Wilthagen, T., and F. Tros (2003) Towards "Flexicurity?": balancing flexibility and security in EU member states', Invited paper prepared for the 13th World Congress of the International Industrial Relations Association (IIRA), Berlin, September 2003.

Windle, M. (1992). A longitudinal study of stress buffering for adolescent problem behaviors. Developmental Psychology, 28, 522-530.

Windrum, P., and M. Tomlinson(1999) Knowledge-Intensive Services and International Competitiveness: A Four Country Comparison, Technology Analysis and Strategic Management, 11(3), 391-408.

Winefield, A.H. (1995). Unemployment: Its psychological costs. In International Review of Industrial and Organizational Psychology, ed. by C. L. Cooper, and I. T. Robertson, 10, 169-212. London: John Wiley \& Sons Ltd.

Winefield, A.H., B. Montgomery, U. Gault, J. Muller, J. O'Gorman, J. Reser, and D. Roland (2002) The psychology of work and unemployment in Australia today: An Australian psychological society discussion paper. Australian Psychologist, 37(1), 1-9.

Winefield, A.H., M. Tiggemann, H.R. Winefield, and R.D. Goldney, (1993) Growing up with unemployment: A longitudinal study of its psychological impact. London: Routledge.

Wood, R.E., and A. Bandura (1989). Impact of conceptions of ability on self-regulatory mechanisms and complex decision making. Journal of Personality and Social Psychology, 56, 407-415.

Wright, R.A., and J. W. Brehm (1989) Energization and goal attractiveness. In Goal concepts in personality and social psychology, ed. by L. A. Pervin. Hillsdale, NJ: Erlbaum.

Wyer, R.S. Jr. and G.A. Radvansky (1999) The comprehension and validation of social information. Psychological Review, Vol 106(1), 89-118.

Yaniv, G. (1995) Burnout, absenteeism, and the overtime decision. Journal of Economic Psychology, 16, 297-309.

Yerkes, R.M. and J.D. Dodson (1908). The relationship of stimulus to rapidity of habit formation. Journal of Comparative Neurological Psychology, 18, 459-482.

Zapf, D. (2002) Emotion work and psychological well-being: A review of the literature and some conceptual considerations. Human Resource Management Review, 12(2), 237-268.

Zheng. Y. (2001) Akrasia, Picoeconomics, and a Rational Reconstruction of Judgment Formation in Dynamic Choice. Philosophical Studies, 104(3), 227-251.

Zijlstra, F.R.H., R.A. Roe, A.B. Leonora and I. Krediet (1999) Temporal factors in mental work: Effects of interrupted activities. Journal of Occupational and Organizational Psychology, 72, 164185. 



\section{Nederlandse samenvatting}

\section{Mentaal kapitaal: de economische betekenis van geestelijke gezondheid}

In de huidige economie werken mensen steeds meer met hun hoofd in plaats van hun handen. Geestelijke gezondheid is economisch gezien dan ook belangrijker geworden, omdat deze immers bepalend is voor hoe goed mensen met hun hoofd kunnen werken. In de economische theorie speelt geestelijke gezondheid echter een zeer bescheiden rol. In dit proefschrift wordt de economische rol van geestelijke gezondheid nader onderzocht.

In de huidige kennisintensieve diensteneconomie is de aard en organisatie van werk veranderd, met name (maar zeker niet uitsluitend) aan de bovenkant van de arbeidsmarkt. De arbeidsmarkt is dynamischer geworden, banen bevatten meer kenniswerk en emotiewerk dan in het verleden, organisaties zijn flexibeler en meer gedecentraliseerd, en taakomschrijvingen zijn breder en minder duidelijk afgegrensd. Succesvol deelnemen in de huidige arbeidsmarkt vereist aanpassingsvermogen, flexibiliteit, zelf-management, en een hoog niveau van cognitieve, sociale en emotionele vaardigheden. Juist deze eigenschappen worden door geestelijke gezondheidsproblemen aangetast.

Werk produceert niet alleen een economische output (product of dienst) maar ook neveneffecten; positieve zoals arbeidssatisfactie en negatieve zoals werk stress. Deze beïnvloeden vervolgens de geestelijke gezondheid, die toeneemt of afneemt. Geestelijke gezondheid heeft een belangrijk effect op productiviteit; goede geestelijke gezondheid leidt tot hogere productiviteit, terwijl geestelijke gezondheidsproblemen tot lagere productiviteit leiden. Geestelijke gezondheid is zowel een input als een output van het productie proces: het wordt zowel geproduceerd als gebruikt tijdens werk. Het is dus een productiefactor, maar met bijzondere kenmerken.

Nadere beschouwing van de rol van geestelijke gezondheid laat zien dat het niet zozeer geestelijke gezondheid, als wel de mate van '(self)agency' van een persoon is die economisch gezien van belang is. Deze is sterk gecorreleerd met geestelijke gezondheid. 'Agency' verwijst naar het handelingsvermogen van een persoon, de mate waarin een persoon in staat is om zijn doelen te bepalen en te verwezenlijken. Dat een economische actor "actorschap" heeft wordt als vanzelfsprekend beschouwd in de economische wetenschap. Het handelingsvermogen van een persoon is echter geen gegeven maar een variabele; het verschilt tussen personen en het verschilt over de tijd. De psychologie houdt zich juist bezig met het onderzoeken van de oorzaken en gevolgen van de verschillen in handelingsvermogen. Geestelijke gezondheid bepaalt het vermogen om rationeel te handelen en daarmee de mate waarin een persoon als een economische actor optreedt. Dat is cruciaal voor bijvoorbeeld de mate waarin markten werken. Daarmee raakt geestelijke gezondheid de kern van de economie.

In het proefschrift wordt nagegaan hoe deze belangrijke economische factor conceptueel een plaats zou kunnen krijgen in de economie. Het handelingsvermogen van mensen blijkt alle kenmerken van het concept 'kapitaal' te hebben: het is een productiefactor die zelf ook geproduceerd wordt (in families, op school, op het werk, in de geestelijke gezondheidszorg), die in principe niet zelf wordt opgebruikt in het productieproces (alleen in het geval van overmatig gebruik en gebrek aan onderhoud), en waarin geïnvesteerd kan worden met duidelijke rendementen. Na een kritische discussie over het gebruik van het kapitaal concept in de afgelopen eeuwen, en de voor- en nadelen van de verbreding van dit concept, wordt 
voorgesteld om deze factor als 'mentaal kapitaal' te benoemen. Net als sociaal kapitaal verschilt mentaal kapitaal voldoende van het reeds veelvuldig gebruikte begrip menselijk kapitaal om een nieuw begrip te rechtvaardigen. Mentaal kapitaal is complementair ten opzichte van menselijk kapitaal, het bepaalt in hoeverre een persoon in staat is om zijn menselijk kapitaal effectief in te zetten. De term mentaal kapitaal kan een conceptuele brug slaan tussen de economie en de psychologie.

Het proefschrift bespreekt hoe mentaal kapitaal een rol speelt in bestaande onderzoeksgebieden in de economie, zoals economische groei en 'bounded rationality', en hoe het perspectief van mentaal kapitaal tot nieuwe inzichten kan leiden op deze gebieden. Onder meer wordt gewezen op het bestaan van 'psychological transaction costs' en 'endogenous rationality'. In twee formele modellen wordt aangetoond dat mentaal kapitaal zonder al te veel problemen kan worden meegenomen in de bestaande methodologie van de economische wetenschap, en dat het meenemen van deze factor tot nieuwe inzichten leidt aangaande kernthema's in de economie zoals productiviteit en innovatie. Tenslotte worden een aantal mogelijke implicaties voor onderzoek en beleid geschetst. 


\section{Acknowledgements}

Many people have contributed directly or indirectly to making this $\mathrm{PhD}$ thesis happen.

I thank my promotor Luc Soete for convincing me to come to Maastricht and join MERIT, for the many inspiring discussions we had, and for his personal support over the years. I am grateful that he - ignoring empirical evidence suggesting the contrary - kept believing that it is possible to do a $\mathrm{PhD}$ next to a research job; to not only work on it, but actually to finish it.

I thank the members of the reading committee, Lex Borghans, Chris de Neubourg and Nanne de Vries, for seeing through the surface flaws of my thesis and judging it on its content rather than its form.

Over the past years, a number of persons have been influential in my intellectual development, among them Frank Ankersmit and Henk te Velde of the Department of History of the Rijksuniversiteit Groningen. My study in Groningen made me aware of the tremendous importance of ideas, concepts and symbols in shaping what we think, and thereby what we do. Understanding how individual and collective perceptions emerge and evolve is crucial for any real insight in history, present and future. The fascination for the power of ideas which began in Groningen lies at the basis of this $\mathrm{PhD}$ thesis.

My time at MERIT has been dynamic and inspiring; I do not think any other such organization exists. I thank Wilma Coenegrachts for her energy and dedication to make MERIT work, and for always being there to answer any thinkable question; if you need anything, it is Wilma to whom you turn. When MERIT became UNU-MERIT in 2007, Eveline in de Braek became an additional indispensable source of support. Silvana de Sanctis provided valuable administrative support, and Ronella Wiegers helped me to keep control over the appalling number of literature references in my thesis. Over the years, many persons have made my time at MERIT pleasurable and fun, among them Bernard Krieger, Wilfred Dolfsma, Saeed Parto, Ulrika Thunstrom, Hugo Hollanders, Anthony Arundel, Bas ter Weel, Kirsten Haaland, Rebecca Schindler, Wangu Mwangi, Ezequiel Tacsir, and my room mates Rossitza Rousseva and Emmanuelle Fortune.

Special thanks go to Bas Straathof and Bulat Sanditov. It was great to cooperate with them in the construction of formal models, expressing some of the core relationships and dynamics I identified in my thesis in the language of economists: mathematics. They have been patient and understanding in the process of converting the complexity of the original material into the bare basics of the matter in a formal model. In particular Bulat Sanditov has taught me a lot about how constructing a formal analytical model helps to gain more indepth understanding of what is going on.

I thank Marten de Vries for having me at the Department of Social Psychiatry and Neuropsychology of the University Maastricht for a couple of months in 2002, and Nancy Adler for allowing me to stay at the Center for Health and Community of the University of California in San Francisco for some months in 2004.

Next to my thesis I have been working on several other projects in the past years. René Kemp and Friso den Hertog triggered my interest in the topic of innovation in the public sector, a hugely importance subject area which I hope will become more developed at 
MERIT. I enjoyed teaching at the University Maastricht in 2003-2006, with Nicolle van de Elst as a nice colleague who never seemed to run out of energy, and I enjoyed working with my master students Marie-Pauline van Voorst tot Voorst, Fidelius Kühn, and Stijn Quast. I thank Constantijn van Oranje of RAND Europe for being a great "e-colleague" over the past years, and for showing that we can be so much more than 'knowledge mercenaries.' With much pleasure I look back at the time I spent at the Dutch Advisory Council for Science and Technology Policy (AWT) in The Hague in 2006 and 2007. Babs, Paul, Rens, Peter, Veronique, Nynke and the others have provided a warm and intellectually inspiring environment. I learned a lot from them about the long and winding road of policy advice, from finding out what is, to interpreting what it means, to advising what to do, given everything.

The work on my thesis has to a great extent been enabled by the Dutch Ministry of Economic Affairs (EZ), the Advisory Council on Health Research (RGO) and especially the Consultative Committee for Sector Councils for Research (COS). I thank Stephan Raes of EZ, Rob van de Sande of the RGO, and in particular Pierre Morin of the COS, who has always kept faith in the undertaking and has been a good friend.

This thesis would not have existed without the support of my family. Josette and Michael Nauenberg have provided a warm home to me in California, as did Floske, Erik and Anna in The Hague. I thank Ad Bezemer for always challenging me to "keep it real." I owe much to my father for his intellectual sharpness and his ability to ignore 'conventional wisdom'; to my sister Floske for her understanding and refreshing pragmatism; and to my brother Marius for our many discussions over the years, helping me to give my ideas the much needed 'reality check.' And of course, I owe more than I can tell to my mother, whose concrete and direct sense of what matters has inspired important insights in my thesis and in my life, and who was always there when I needed her.

And then, my "famous last words" are dedicated to Robin, my intellectual and personal beacon in the past years. His understanding and support in so many ways have been crucial for my mental capital, without which this thesis would have been neither right, nor written. 


\section{About the author}

Rifka Maria Weehuizen was born on March 19, 1971 in Eindhoven. She studied at Randolph College, Virginia from 1989-1990 (NACEE scholarship), at the Eberhard-Karls Universität in Tübingen from 1994-1995 (Erasmus scholarship), and at the Rijksuniversiteit Groningen from 1990-1996, from where she received a Master's degree in History in 1996. From 1996-1998 she worked at the Dutch Ministry of Education, Culture and Sciences, and from 1998-2000 at the Study Centre for Technology Trends in The Hague. In 2000 she joined the Maastricht Economic Research Institute on Innovation and Technology (MERIT) as a researcher. In 2002 she spent four months at the Department for Social Psychiatry and Neuropsychology of the University of Maastricht; in 2004 she spent five months at the Centre for Health and Community of the University of California in San Francisco. In 2003 - 2005 she taught at the Faculty of Economics and Business Administration of Maastricht University, in the area of institutional economics, philosophy of science, and business ethics. In $2006-2007$ she was partially detached as scientific staff member at the Dutch Advisory Council for Science and Technology Policy (AWT) in The Hague, working in the area of innovation in the public sector. As of January 2007, MERIT became UNU-MERIT, a research and training centre of the United Nations University. At UNUMERIT she currently works on the topic of innovation for the 'bottom of the pyramid', investigating new perspectives on how knowledge and innovation can help fight poverty. A main connecting theme throughout the years is the role of perceptions in innovation. 